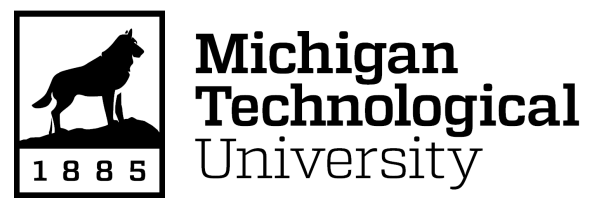

Michigan Technological University Digital Commons @ Michigan Tech

Dissertations, Master's Theses and Master's Reports

2021

\title{
COBALT, MOLYBDENUM, AND NICKEL COMPLEXES, NATURAL ZEOLITES, EPOXIDATION, AND FREE RADICAL REACTIONS
}

Nicholas K. Newberry

Michigan Technological University, nknewber@mtu.edu

Copyright 2021 Nicholas K. Newberry

\section{Recommended Citation}

Newberry, Nicholas K., "COBALT, MOLYBDENUM, AND NICKEL COMPLEXES, NATURAL ZEOLITES, EPOXIDATION, AND FREE RADICAL REACTIONS", Open Access Dissertation, Michigan Technological University, 2021.

https://doi.org/10.37099/mtu.dc.etdr/1336

Follow this and additional works at: https://digitalcommons.mtu.edu/etdr

Part of the Analytical Chemistry Commons, Environmental Chemistry Commons, Inorganic Chemistry Commons, Materials Chemistry Commons, Organic Chemistry Commons, and the Physical Chemistry Commons 


\title{
COBALT, MOLYBDENUM, AND NICKEL COMPLEXES, NATURAL ZEOLITES, EPOXIDATION, AND FREE RADICAL REACTIONS
}

By

Nicholas K. Newberry

\begin{abstract}
A DISSERTATION
Submitted in partial fulfillment of the requirements for the degree of DOCTOR OF PHILOSOPHY

In Chemistry

MICHIGAN TECHNOLOGICAL UNIVERSITY
\end{abstract}

2021

(C) 2021 Nicholas K. Newberry 
This dissertation has been approved in partial fulfillment of the requirements for the Degree of DOCTOR OF PHILOSOPHY in Chemistry.

Department of Chemistry

$\begin{aligned} \text { Dissertation Advisor: } & \text { Rudy Luck } \\ \text { Committee Member: } & \text { Tarun K. Dam } \\ \text { Committee Member: } & \text { Loredana Valenzano-Slough } \\ \text { Committee Member: } & \text { John Jaszczak } \\ \text { Department Chair } & \text { Sarah Green }\end{aligned}$




\section{Contents}

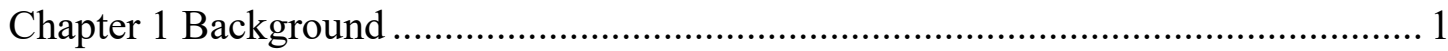

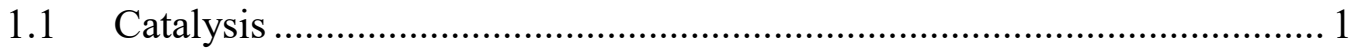

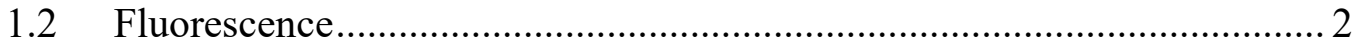

1.3 Macrocyclic Ligands/Template Synthesis ............................................ 3

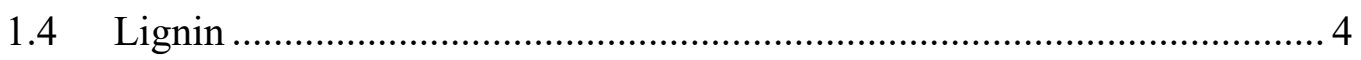

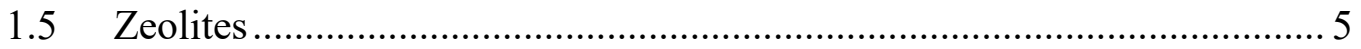

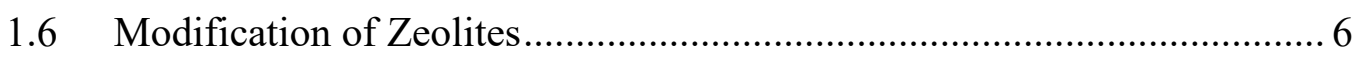

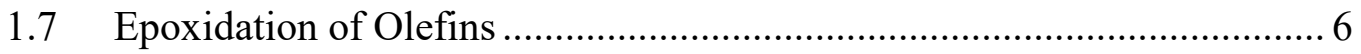

Chapter 2 Syntheses, X-ray structure, emission, and vibrational spectroscopies, DFT and thermogravimetric studies of two complexes containing the bidentate ligand ((5phenyl-1H-pyrazol-3-yl)methyl) phosphine oxide .............................................. 9

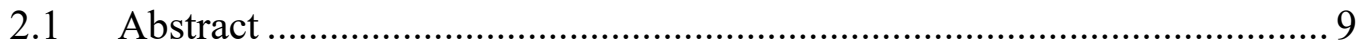

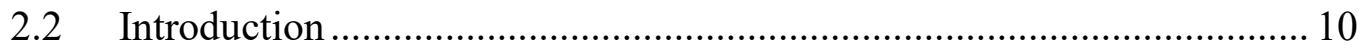

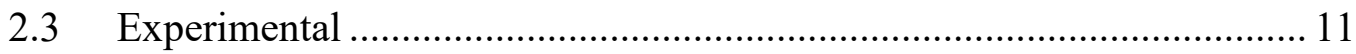

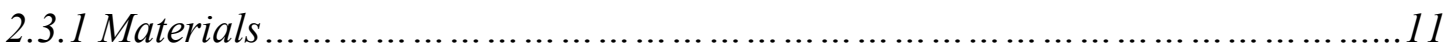

2.3.2 Synthesis of $\left[\mathrm{Co}\left(\left(\mathrm{C}_{6} \mathrm{H}_{5}\right)_{2} \mathrm{POCH}_{2}\left(\mathrm{C}_{3} \mathrm{~N}_{2} \mathrm{H}_{2}\right)\left(\mathrm{C}_{6} \mathrm{H}_{5}\right)\right)_{2}\left(\mathrm{C}_{4} \mathrm{H}_{8} \mathrm{O}\right)_{2}\right]\left[\mathrm{ClO}_{4}\right]_{2}$ (2) ........ 12

2.3.3 Synthesis of $\mathrm{Mo}_{2} \mathrm{O}_{4} \mathrm{Cl}_{2}\left(\left(\mathrm{C}_{6} \mathrm{H}_{5}\right)_{2} \mathrm{POCH}_{2}\left(\mathrm{C}_{3} \mathrm{~N}_{2} \mathrm{H}_{2}\right)\left(\mathrm{C}_{6} \mathrm{H}_{5}\right)\right)(\mathrm{THF})$ (3) ....12

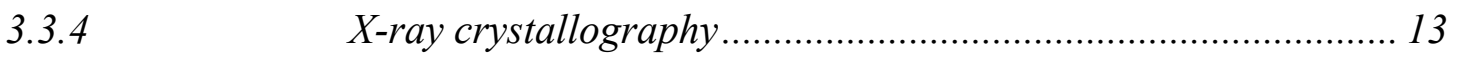

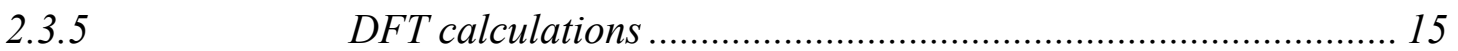

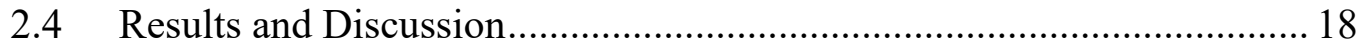

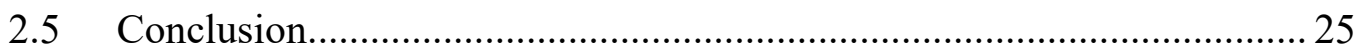

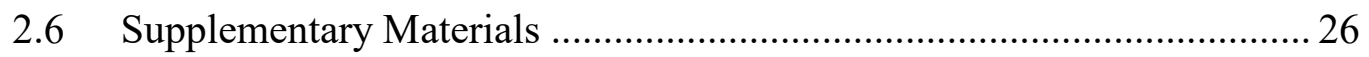

Chapter 3 Syntheses, theoretical studies, and crystal structures of $\left[\mathrm{Ni}(\mathrm{II})^{\mathrm{SSRR}} \mathrm{L}\right]\left(\mathrm{PF}_{6}\right)_{2}$ and $\left[\mathrm{Ni}(\mathrm{II})^{\mathrm{SRSR}} \mathrm{L}\right](\mathrm{Cl})\left(\mathrm{PF}_{6}\right)$ that contains anagostic interactions ...............................57

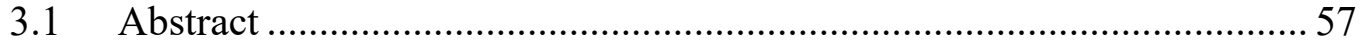

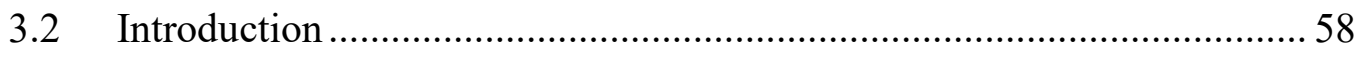

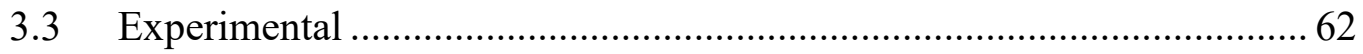

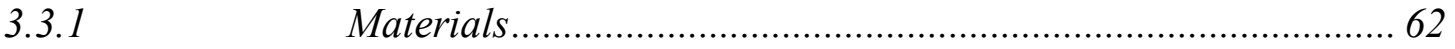


3.3.2 Synthesis of 5,5, 7,12,12,14-hexamethyl-1(S),4(S),8(R),11(R)tetraazacyclotetradecane-nickel(II) [PF6]2, [Ni(II)SSRRL](PF $)_{2}$, and 5, 5, 7, 12,12,14hexamethyl-1(S),4(R),8(S), 11(R)-tetraazacyclotetradecane-nickel(II) [Cl] [PF6], $\left[\mathrm{Ni}(\mathrm{II})^{S R S R} \mathrm{~L}\right](\mathrm{Cl})\left(\mathrm{PF}_{6}\right)$, at $\mathrm{pH} 3$.

3.3.3 Syntheses of complexes $\left[\mathrm{Ni}(\mathrm{II})^{\mathrm{SSRR}} \mathrm{L}\right]\left(\mathrm{PF}_{6}\right)_{2}$ and

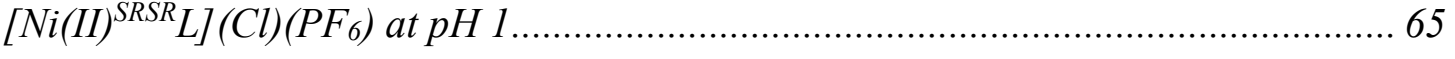

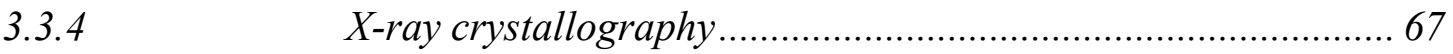

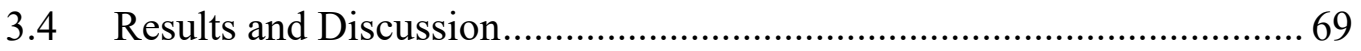

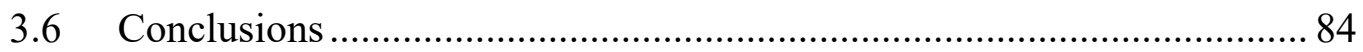

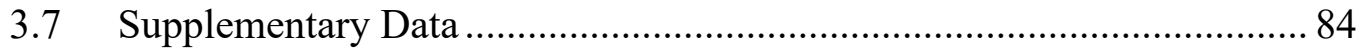

Chapter 4 Double-Shell Lignin Nanocapsules Are a Stable Vehicle for Fungicide Encapsulation and Release 109

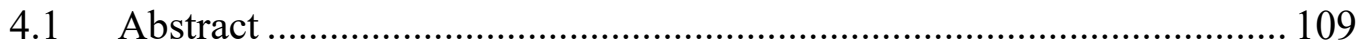

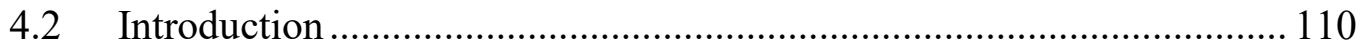

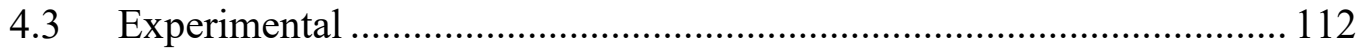

4.3.1 Materials ................................................................... 112

4.3.2 Nanocapsule Synthesis...................................................... 112

4.3.3 Nanocapsule Characterization …........................................ 113

4.3.4 Fungicide Encapsulation and Release................................. 114

4.4 Results and Discussion................................................................... 115

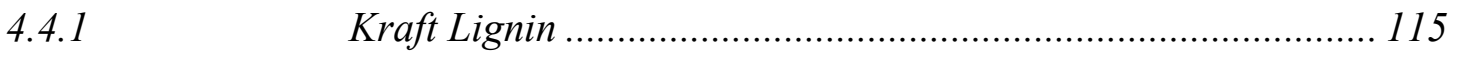

4.4.2 Double-Shell Nanocapsule................................................. 116

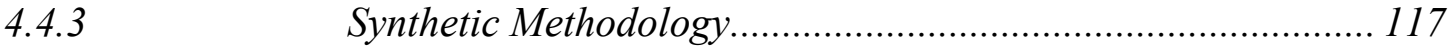

4.4.4 Nanocapsule Stability Properties ....................................... 120

4.4.5 Mechanisms of Formation ................................................... 120

4.4.6 Fungicide Encapsulation ............................................... 121

4.4.7 Mechanisms of Fungicide Encapsulation .............................. 124

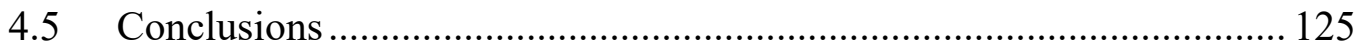

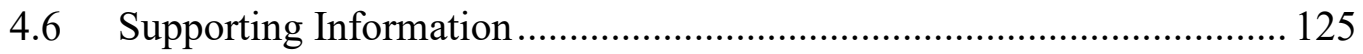

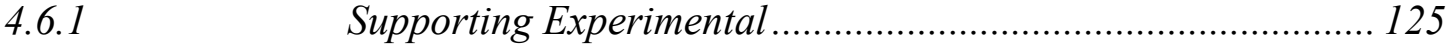


$\begin{array}{ll}4.6 .2 & 127\end{array}$

Chapter 5 Hydrochloric Acid Modification and Lead Removal Studies on Naturally Occurring Zeolites from Nevada, New Mexico, and Arizona................................... 130

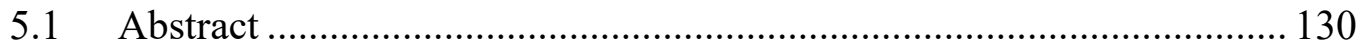

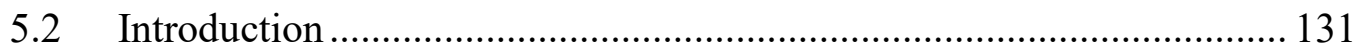

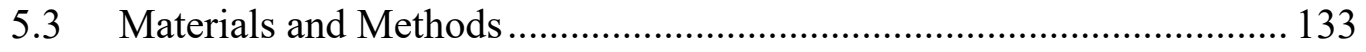

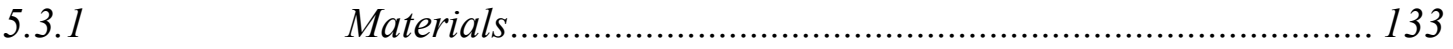

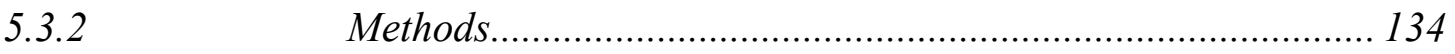

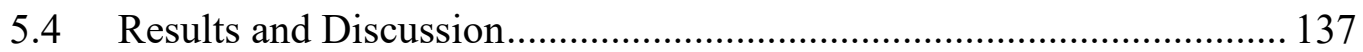

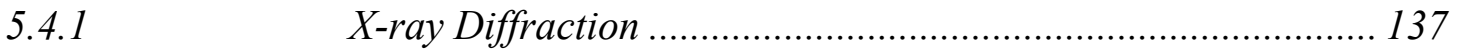

5.4.2 Surface Area Analysis....................................................... 142

5.4.3 X-ray Fluorescence/EDS ................................................... 144

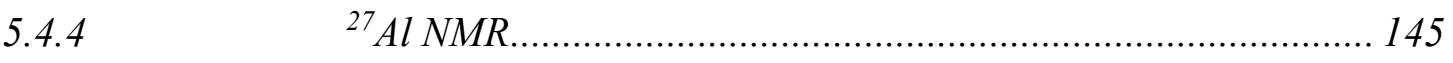

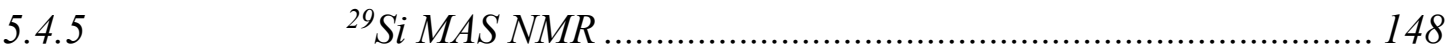

5.4.6 SEM

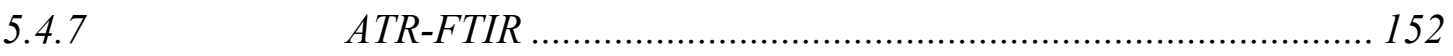

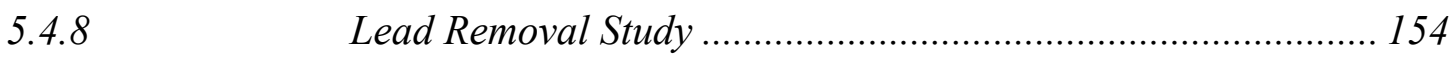

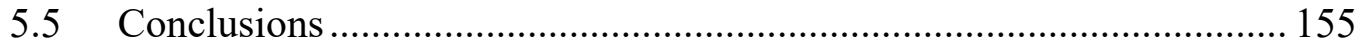

Chapter 6 Free radical catalyzed reactions with cyclohexene and cyclooctene with

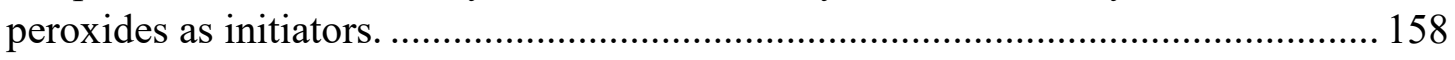

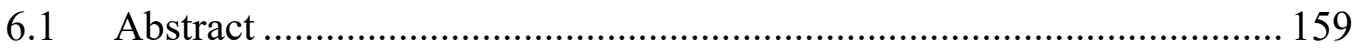

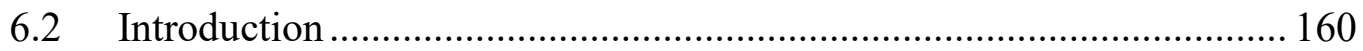

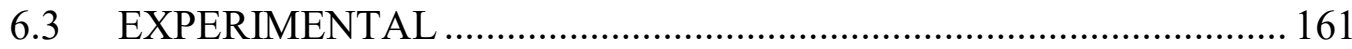

6.3.1 Materials 161

\subsubsection{Equipment 161}

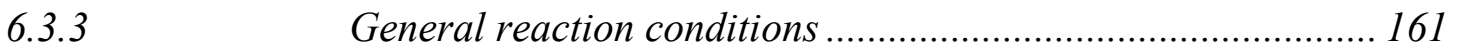

7.3.3 Reactions conducted under an Air Atmosphere or Nitrogen and

Oxygen Atmospheres with Mercury Bubbler Backpressure .................................... 162 
7.3.5 Reaction in a sealed glass container with $115 \mathrm{~mL}$ volume....... 162

7.3.6 Quantification of Reactions ................................................ 163

7.3.7 Theoretical calculations ................................................. 163

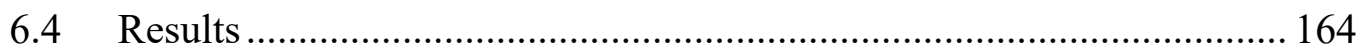

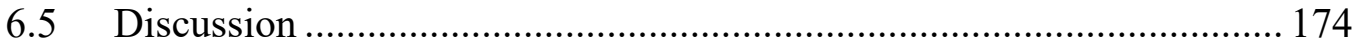

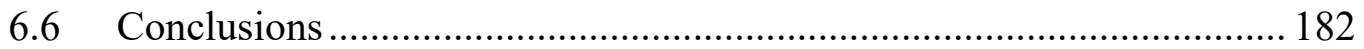

6.7 Supplementary Data for Chapter 6 ............................................... 183

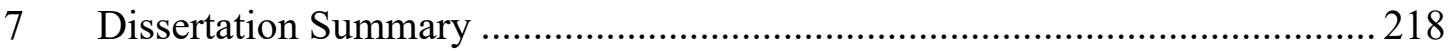

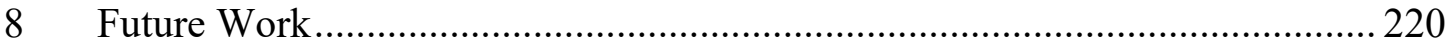

10 Reference List ............................................................................... 221

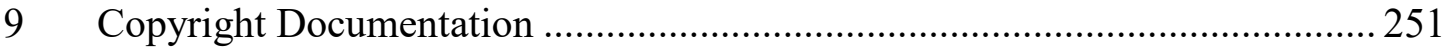

11.1 Copyright Documentation for Chapter 3 Journal of Coordination Chemistry (Taylor and Francis)

11.2 Copyright Documentation for Chapter 4 Can. J. Chem. (NRC Research Press) 252

11.3 Copyright Documentation for Chapter 5 ACS Sustainable Chem. Eng. 256

11.4 Copyright Documentation for Chapter 6 MDPI Processes ................... 257

11.5 Copyright Documentation for Chapter 7 .......................................... 257

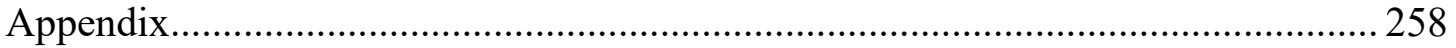

A1 Fourier Transform Infrared (FTIR) ….............................................. 258

A1.1 Theory 258

A1.2 Sampling 258

A2 Nuclear Magnetic Resonance (NMR) ..................................................... 260

A2.1 Theory 260

A2.2 Samples 261

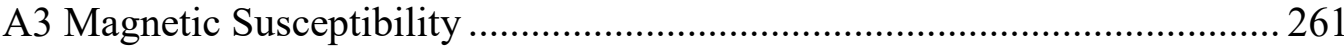

A3.1 Theory 261 
A5 Thermogravimetric Analysis (TGA) 262

A5.1 Theory 262

A6 Ultraviolet-Visible Absorbance Spectroscopy (UV-vis) .......................... 263

A6.1 Theory 263

A6.2 Samples 264

A7 Fluorescence Spectroscopy

A7.1 Theory $\quad 265$

A8 X-Ray Diffraction (Single Crystal) 266 A8.1 Theory $\quad 266$

A9 Cyclic Voltammetry. 267 A9.1 Theory 267

A10 Scanning Transmission Electron Microscope (STEM) 268 A10.1 Theory 268

A11 Brunauer-Emmett-Teller Surface Area (BET) 269 A11.1 Theory 269

A12 Confocal Fluorescence Microscopy 270 A12.1 Theory $\quad 270$

A13 X-Ray Diffraction (Powder)

A13.1 Theory 271

A14 Energy Dispersive Spectroscopy/ X-Ray Fluorescence (EDS/ERF)....... 272 A14.1 Theory 272

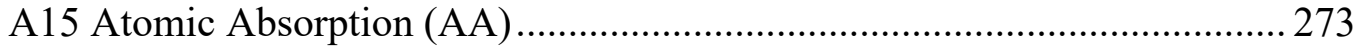

A15.1 Theory 273

A16 Scanning Electron Microscopy (SEM) ............................................... 274

A16.1 Theory 274

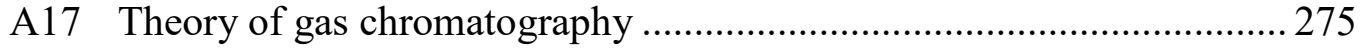

A17.1 Flame ionization Detector...................................................................... 276

A17.2 Mass Spectrometry Detector ................................................................. 276 


\section{List of Figures}

Figure 1.1 contains the catalytic cycle for the hydrogenation of terminal alkenes using Wilkinson's catalyst. ${ }^{2}$......

Figure 1.2 shows the scheme for synthesizing a macrocyclic ligand where the water ligands on the nickel (II) tetrafluoroborate hexahydrate are replaced with ethylene diamine. Then a condensation reaction between acetone and ethylene diamine forms the macrocyclic ligand while one ethylene diamine from the nickel (II) tetrafluoroborate tris-ethylenediamine is released into the solution. ${ }^{5}$

Figure 1.3 contains the structures of coniferyl, sinapyl, and p-coumaryl alcohols. ..... 5

Figure 1.4 contains ethylene oxide (left), cyclohexene oxide (middle), and cyclooctene oxide (right). Of which cyclohexene oxide and cyclooctene oxide are the epoxides of interest in Chapter 7.

Figure 1.5 shows the synthesis of ethylene oxide from ethylene using oxygen as the oxidizer and silver oxide as the catalyst. ${ }^{15}$

Figure 2.1 Platon ${ }^{30}$ rendered with PovRay ${ }^{31}$ representation of 2 with atoms represented by spheres of arbitrary sizes. The disordered orientation of the THF ligand is drawn with dashes, and only one perchlorate anion is illustrated. Symmetry code: (\#1) $-\mathrm{x}+2,-\mathrm{y},-\mathrm{z}+1$.

Figure 2.2 Unit cell packing ${ }^{37}$ of $\mathbf{2}$ viewed down the $b$ axis. Atoms are represented by spheres of arbitrary sizes using the default Mercury color scheme, and Hatoms are not illustrated.

Figure 2.3 Platon $^{30}$ rendered with PovRay ${ }^{31}$ representation of the asymmetric unit for 3 with atoms represented by spheres of arbitrary sizes. The dashed bonds represent the $\mathrm{H}$-bonded interactions between $\mathrm{N} 2$ to $\mathrm{O} 7(\mathrm{~N} 2-\mathrm{H} 2 \mathrm{~A}=0.82(2) \AA$, $\mathrm{N} 2-07=2.797(2) \AA)$ and $\mathrm{N} 4$ to $\mathrm{O} 8(\mathrm{~N} 4-\mathrm{H} 4 \mathrm{~A}=0.89(2), \mathrm{N} 4-\mathrm{O} 8=2.738(2) \AA)$. Atoms for the THF molecule inclusive of $\mathrm{O} 7$ were generated with symmetry code 1-x, 1-y, 1-z.

Figure 2.4 Mercury $^{37}$ prepared overlay of the two molecules constituting the asymmetric unit in $\mathbf{3}$. Atoms belonging to the molecule defined by $\mathrm{Mo}(1)$ are in red, and those for $\operatorname{Mo}(2)$ are in blue.

Figure 2.5 Unit cell packing ${ }^{37}$ a of $\mathbf{3}$ viewed down the $a$ axis. Atoms are represented by spheres of arbitrary sizes using the default Mercury color scheme. 23

Figure 3.1. ORTEP ${ }^{76}$ drawing (with POV-Ray ${ }^{31}$ rendering) of the cation in 65 
Figure 3.2. Mercury ${ }^{37}$ drawing of the packing arrangement in $\left[\mathbf{N i}(\mathbf{I I})^{\mathrm{SSRR}} \mathbf{L}\right]\left(\mathbf{P F}_{6}\right) \mathbf{2}$. [Colour online.]

Figure 3.3. ORTEP $^{76}$ drawing (with POV-Ray ${ }^{31}$ rendering) of the major ................. 73

Figure 3.4. Mercury ${ }^{37}$ drawing of the packing arrangement in ................................. 76

Figure 3.5. Cyclic voltammetry of complexes 1, 2, [Ni(II) $\left.{ }^{\text {SSRR }} \mathbf{L}\right]\left(\mathbf{P F}_{6}\right) 2$, and........... 77

Figure 3.6. Ring critical points (large red spheres) indicated numerically for

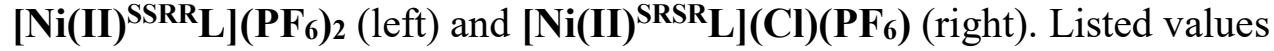
are for $\nabla^{2} \rho(r)$ in au. Bond critical points (small yellow spheres) are indicated along bond paths, with weak ones indicated by dashed lines.

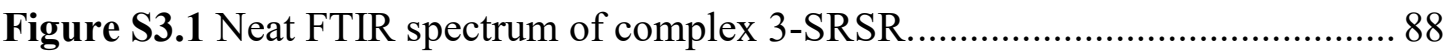

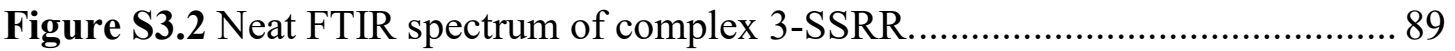

Figure S3.3 Visible spectrum of complex 3-SSRR in acetone, acetonitrile, and DMSO

Figure S3.4 Visible spectrum of complex 3-SRSR in DMSO, acetonitrile, and water.

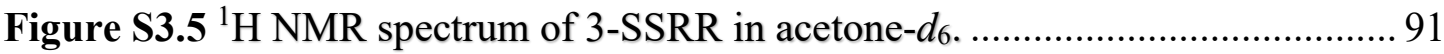

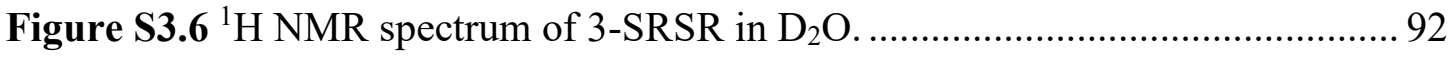

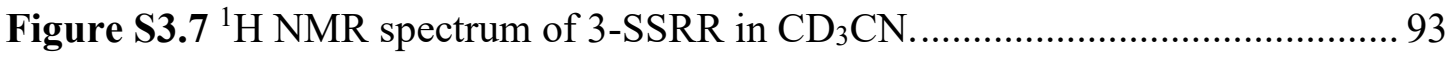

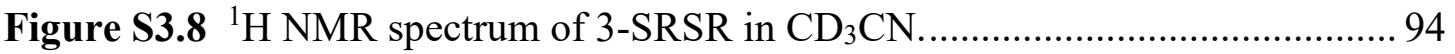

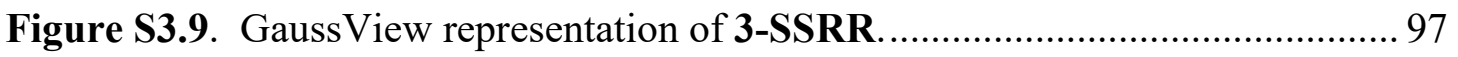

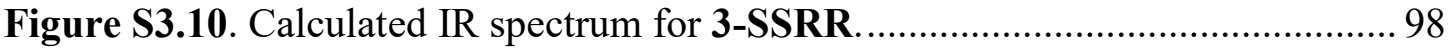

Figure S3.11. Calculated UV-Vis spectrum for 3-SSRR.................................... 98

Figure S3.12. Drawings of selected molecular orbitals listed in Table S3.5........... 100

Figure S3.13. GaussView representation of 3-SRSR ........................................ 102

Figure S3.14. Calculated IR spectrum for 3-SRSR ............................................. 104

Figure S3.15. Calculated UV-Vis spectrum for 3-SRSR.................................... 104

Figure S3.16. Expansion of the vertical scale for the Calculated UV-Vis spectrum for

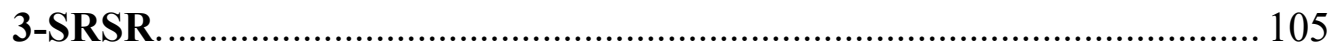

Figure S3.17. Drawings of selected molecular orbitals listed in Table S3.8........... 107 
Figure 4.1 (A) Single-shell encapsulating SDS. (B) Single-shell encapsulating CTAB. (C) Enlarged image of single-shell encapsulating CTAB. (D) Close-up of the surfactant-core single shell. (E) Surfactant-free single shell. (F) Lateral view of a surfactant-free single shell. (G) Cross-linked single shell. (H) Doubleshell nanocapsule. (I) White/black under focus-overfocus revealing the two shells at different heights. ( $\mathrm{J})$ Interior of the hollow structure of the doubleshell nanocapsule. The copper grid is the mesh-like structure in the background. The red arrows point at the two shells.

Figure 4.2 (A) Hydrodynamic size of the double-shell nanocapsule as a function of $\mathrm{pH}$ of the solvent (water). (B) $\zeta$-potential of the double-shell nanocapsules as a function of the $\mathrm{pH}$ of the solvent (water). (C) Size distribution of the doubleshell nanocapsules at a solvent (water) $\mathrm{pH}$ of 7. (D) Hydrodynamic size of the double-shell nanocapsule as a function of time in water at $\mathrm{pH} 7$ for a period of 8 months. (E) $\zeta$-potential of the double-shell nanocapsules as a function of time in water at $\mathrm{pH} 7$ for a period of 8 months. The letters represent the results from Tukey's simultaneous tests for the difference of means on the hydrodynamic size as a function of $\mathrm{pH}$. Analysis performed in Minitab. Averages that do not share a letter are statistically significantly different. ... 119

Figure 4.3 UV spectra of kraft lignin and the double-shell nanocapsule. Image edited with BioRender.com. 121

Figure 4.4 (A) Confocal fluorescence microscopic image of double-shell encapsulating propiconazole, taken six days postincubation. (B) Release profile of propiconazole from the double shell. (C) Pore thickness distribution in the single shell and double shell.

Figure 4.5 UV spectra of double-shell encapsulating propiconazole. 124

Figure S4.1. A) HAADF spectra and corresponding B) EDS plot of the single-shell. The units represent milli Counts (mCounts) and kilo Counts (kCounts). The black dashed lines show transitions from one nanoparticle domain to another. C) Elemental distribution on the surface of the single shell. D) Elemental distribution on the surface of the double-shell. 128

Figure S4.2. FTIR spectra of kraft lignin, non-crosslinked single shell, cross-linked single shell, and cross-linked double-shell nanocapsules. The spectra have been stacked vertically for clarity.

Figure 5.1 The XRD pattern of calcined AZLB-Ca. 138

Figure 5.2 The XRD pattern of calcined AZLB-Na.

Figure 5.3 (A, above) The XRD pattern of calcined NV-Na. (B, below) An expanded drawing of the XRD pattern for calcined NV-Na illustrated using QualX2 ${ }^{184}$. 
Solid vertical lines represent card [00-900-1391] clinoptilolite-Na at an FoM of 0.75 . Raw data converted with PowDLL ${ }^{185}$.

Figure 5.4 The XRD pattern of calcined NM-Ca. The AZLB-Na and AZLB-Ca zeolites lost all crystallinity when boiled in $\mathrm{HCl}$ acid for $30 \mathrm{~min}$, which is demonstrated by the loss of all sharp reflections and the spectra appearing as broad bumps (Figures 5.5 and 5.6) as a result of random scattering due to an amorphous material. In contrast, the NV-Na and NM-Ca zeolites did not lose all crystallinity during the boiling process in $\mathrm{HCl}$ acid (Figures 5.7 and 5.8, respectively). This is conclusive evidence of the instability of these chabazites subjected to $\mathrm{HCl}$ modification and the inherent stability of the clinoptilolites as evident in the $30 \mathrm{~min} \mathrm{HCl} \mathrm{NV-Na,} \mathrm{Figure} \mathrm{5.7,} \mathrm{card} \mathrm{[00-900-1393]}$ clinoptilolite- $\mathrm{Na}$ at an $\mathrm{FoM}$ of 0.66, and $30 \mathrm{~min} \mathrm{HCl} \mathrm{NM-Ca}$, Figure 5.8, card [00-901- 4410] boggsite ${ }^{192}$ of formula $\mathrm{Ca}_{3.4} \mathrm{O}_{70.76} \mathrm{Si}_{24}$ at an FoM of 0.77, both determined using QualX2 ${ }^{184}$. In particular, NM-Ca registered the least change possible because it is mostly composed of alpha quartz, Figure 5.8. 140

Figure 5.5 The XRD patterns of calcined AZLB-Ca and 30 min HCl AZLB-Ca.... 140

Figure 5.6 The XRD patterns of calcined AZLB-Na and 30 min HCl AZLB-Na. .. 141

Figure 5.7 The XRD patterns of calcined NV-Na and the $30 \mathrm{~min} \mathrm{HCl} \mathrm{NV-Na.......} 141$

Figure 5.8 The XRD patterns of calcined NM-Ca and $30 \mathrm{~min} \mathrm{HCl} \mathrm{NM-Ca............} 142$

Figure 5.9 The ${ }^{27} \mathrm{Al}$ NMR of calcined NV-Na externally referenced to $1 \mathrm{M} \mathrm{Al}\left(\mathrm{NO}_{3}\right)_{3}$ at $0.0 \mathrm{ppm}$.

Figure 5.10 The ${ }^{27} \mathrm{Al} \mathrm{NMR}$ of $30 \mathrm{~min} \mathrm{HCl} \mathrm{NV}-\mathrm{Na}$ externally referenced to $1 \mathrm{M}$ $\mathrm{Al}\left(\mathrm{NO}_{3}\right)_{3}$ at $0.0 \mathrm{ppm}$.

Figure 5.11 The ${ }^{29} \mathrm{Si}$ NMR spectrum of calcined NV-Na referenced externally to a sample of talc at $-98.1 \mathrm{ppm}$ relative to tetramethylsilane (TMS) at $0 \mathrm{ppm}$. The shaded inset depicts the obtained resonances on top and the deconvoluted components of the fit below.

Figure 5.12 The ${ }^{29} \mathrm{Si}$ NMR spectrum of $30 \mathrm{~min} \mathrm{HCl} \mathrm{NV}-\mathrm{Na}$ referenced externally to a sample of talc at $-98.1 \mathrm{ppm}$ relative to TMS at $0 \mathrm{ppm}$. The resonances on top are from the sample, and the deconvoluted components of the fit are below.

Figure 5.13 The SEM images of calcined NV-Na at a $100 \mu \mathrm{m}$ scale (a), a $10 \mu \mathrm{m}$ scale (b), and a $5 \mu \mathrm{m}$ scale (c), and that of $30 \mathrm{~min} \mathrm{HCl} \mathrm{NV-Na}$ at a $50 \mu \mathrm{m}$ scale (d), a $10 \mu \mathrm{m}$ scale (e), and a $5 \mu \mathrm{m}$ scale (f). 152

Figure 5.14 The ATR-FTIR spectra of Calcined NV-Na, 30 min $\mathrm{HCl} \mathrm{NV-Na,}$ Calcined NM-Ca, and 30 min $\mathrm{HCl}$ NM-Ca. 153 
Figure 6.1. Drawings of the LCAOs for the HOMOs for the oxo- (left) and peroxobridged (right) species depicted in Scheme 6.1.

Figure 6.2. Drawings of the LCAOs for the HOMOs for the oxo- (left) and peroxobridged (right) species depicted in Scheme 6.2 ........................................... 174

Figure A1 shows a simplified version of a typical FTIR instrument........................258

Figure A.2 shows a simplified version of an FTIR/ATR instrument. ...................... 259

Figure $\mathbf{A 3}$ shows a simplified diagram of how NMR works based on a simple ${ }^{1} \mathrm{H}$

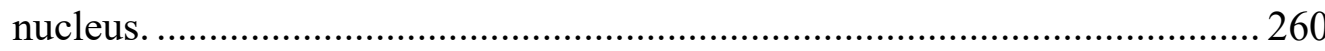

Figure A4 contains the diagram showing how a Guoy balance works to determine the magnetic susceptibility of a sample.............................................................. 262

Figure $\mathbf{A 5}$ shows a simplified version of how a TGA machine works......................263

Figure A6 shows a simplified view of a UV-Vis machine ........................................ 264

Figure A7 shows a simplified example of a fluorescence spectroscopy machine.... 265

Figure A8 shows a typical example of single-crystal x-ray diffraction. The black rectangle on the right shows a typical example of a diffraction pattern that is made by the crystal diffracting the X-ray beam. .............................................. 267

Figure A9 shows the typical setup for cyclic voltammetry.....................................2268

Figure A10 Shows an example of how a TEM machine works. To make a STEM image, the beam is scanned over an area of the sample, and the images are compiled together.

Figure A11 shows a simplified diagram to explain how BET surface area is measured.

Figure A12 shows a diagram of a confocal fluorescence microscope.

Figure A13 shows a typical setup for X-ray diffraction when using a powder sample. Only the crystals that are oriented in the proper orientation are responsible for producing the signal for the diffracted X-ray beam. The green cubes represent the crystals in the sample that are in the correct orientation for diffraction, and the blue cubes represent crystals that are not oriented correctly for diffraction.

Figure A14 shows a diagram of how an X-ray can be generated by bombarding a sample with higher-energy $\mathrm{X}$-rays..

Figure A15 shows a diagram of the typical configuration of an EDS/XRF machine.

Figure A16 shows a diagram of an Atomic Absorption Spectrometer. 


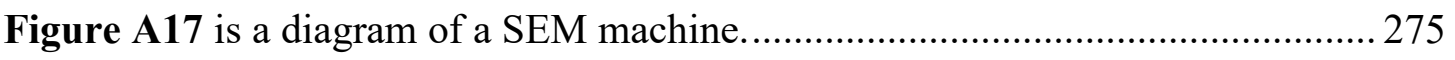

Figure A18 shows a representative setup of a gas chromatography machine. ........ 276

\section{List of Schemes}

Scheme 2.1 Synthesis of 2 and 3

Scheme 3.1. Synthesis of 5,5,7,12,12,14-hexamethyl-1,4,8,11tetraazacyclotetradecane-nickel(II $) \cdot\left(\mathrm{PF}_{6}\right)_{2}, \mathbf{3}$, and stereoviews of the cations

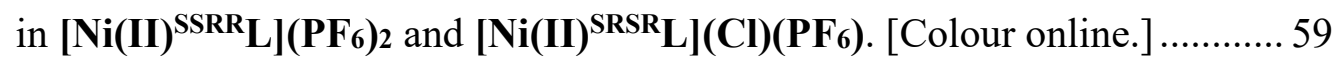

Scheme 6.1. Proposed mechanism for the free radical transformation of cyclohexene into the products observed. A potential energy plot for each transformation was calculated and the supplementary figure numbers, the activation energy and $\Delta \mathrm{H}_{\mathrm{r}}$ in $\mathrm{kcal} / \mathrm{mol}$ are indicated in that order.

Scheme 6.2. Proposed mechanism for the free radical transformation of cyclooctene into the products observed. A potential energy plot for each transformation was calculated and the supplementary figure numbers, the activation energy and $\Delta \mathrm{H}_{\mathrm{r}}$ in $\mathrm{kcal} / \mathrm{mol}$ are indicated in that order.

\section{List of tables}

Table 2.1 and Table 2.2 Crystal data and refinement details of $\mathbf{2}$ and $\mathbf{3}$, and Selected bond distances $(\AA)$ and angles $\left(^{\circ}\right)$ for 2 from X-ray and theory. ${ }^{\mathrm{a}} \ldots \ldots \ldots \ldots \ldots \ldots . . . . . . .14$

Table 2.3 Selected bond distances and angles for $\mathbf{3}$ from X-ray and theory.............. 16

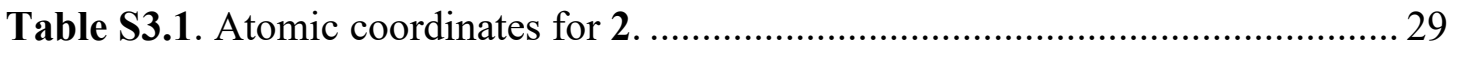

Table S3.2. Excitation energies and oscillator strength for complex 2.................... 34

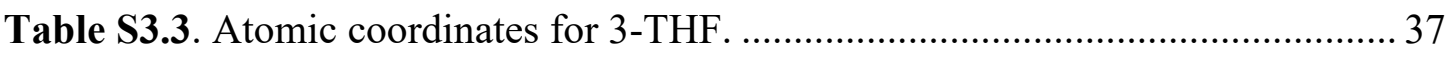

Table S3.4. Excitation Energies and Oscillator Strengths for 3-THF..................... 39

Table S3.5. Atomic coordinates for 3. .............................................................. 45

Table S3.6. Excitation Energies and Oscillator Strengths for 3 ........................... 50

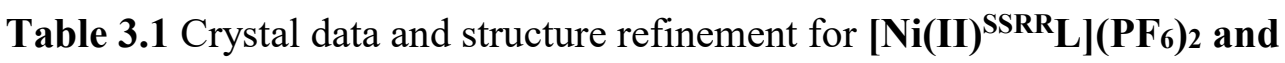

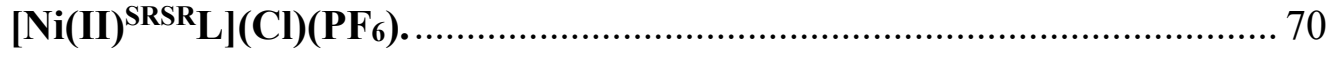

Table 3.2 Selected bond distances and angles [Colour online] ............................... 74 
Table 4.3 Chemical Properties Measured for the Kraft Lignin Utilized in This Study.

Table 4.4 Properties and Characteristics of Kraft Lignin, Single-Shell Nanocapsules, and Double-Shell Nanocapsules....

Table S4.1. Evidence of removal of surfactant using elemental concentrations of sulfur and sodium determined by EDS.

Table S4.2. Concentration changes of the elemental composition of nanocapsules at different stages of formation. Increased nitrogen concentration correlates to increased propiconazole encapsulation.

Table S4.3. Tukey pairwise comparisons of the hydrodynamic size of the nanocapsule as a function of $\mathrm{pH}$. Analysis performed in Minitab. 128

Table 5.1 The surface area analysis measurements for calcined and $\mathrm{HCl}$ etched zeolites.

Table 5.2 The average mesopore and micropore diameter.

Table 5.3 The XRF data for zeolites in mole \%

Table 5.4 The weight percentages from our calculated data and that of the manufacturer.

Table 5.5 $\mathrm{The}^{\mathrm{Pb}^{2+}}$ removal by the zeolites at a time of 5 days at $35{ }^{\circ} \mathrm{C}$. 154

Table 5.6 $\mathrm{The}^{\mathrm{Pb}^{2+}}$ removal by the $\mathrm{K}^{+}$charged zeolites at a time of 5 days at $35{ }^{\circ} \mathrm{C}$.

Figure 6.1. Drawings of the LCAOs for the HOMOs for the oxo- (left) and peroxobridged (right) species depicted in Scheme 6.1.

Figure 6.2. Drawings of the LCAOs for the HOMOs for the oxo- (left) and peroxobridged (right) species depicted in Scheme 6.2.

Table 6.1. Products from the oxidation of cyclohexene under various environments after 72 hrs. $^{\text {a }}$ 164

Table 6.2. Oxidation of cyclohexene using ${ }^{\mathrm{t}} \mathrm{BuOOH}$ or $\mathrm{H}_{2} \mathrm{O}_{2}$ after $72 \mathrm{hrs}^{\text {a }}$ 164

Table 6.3. The ratio of products in the oxidation of cyclohexene at 24,48 and $72 \mathrm{hrs}^{\text {a }}$

Table 6.4. Products from the oxidation of cyclohexene in a glass apparatus vs a Teflon apparatus. ${ }^{\mathrm{a}}$ 165

Table 6.5. The reaction of 2-cyclohexen-1-ol with and without ${ }^{t} \mathrm{BuOOH}$ and under air or nitrogen. ${ }^{\mathrm{a}}$ 166 
Table 6.6. The reaction of cyclohexene oxide with and without ${ }^{t} \mathrm{BuOOH} .{ }^{\mathrm{a}}$ 166

Table 6.7. Reactions with various alkenes. ${ }^{\mathrm{a}}$. 167

Table 6.8. Oxidation of cyclooctene at various temperatures and in various solvents. ${ }^{a}$

Table 6.9. Oxidation of cyclooctene under different atmospheres. ${ }^{a}$ 168

Table 6.10. Reactions of cyclooctene with various oxidizers. ${ }^{\mathrm{a}}$. 169

Table 6.11. The yields of products from the oxidation of cyclohexene using $\mathrm{O}_{2}$, ${ }^{t} \mathrm{BuOOH}$ or $\mathrm{H}_{2} \mathrm{O}_{2}$ as the oxidizer. See references for other conditions of the reactions. A dash indicates that the yield for that product if present was not reported.

Table 6.12. The yields of products from the oxidation of cyclooctene using $\mathrm{O}_{2}$, ${ }^{t} \mathrm{BuOOH}$ (TBO) or $\mathrm{H}_{2} \mathrm{O}_{2}$ as the oxidant. See references for other conditions of the reactions. A dash indicates that the yield for that product was not reported.

Table S6.1 contains the details of reactions from literature and this work of cyclohexene using t-butyl hydroperoxide as the oxidizer. Entries are listed in increasing order based on the yield of the 2-cyclohexen-1-one denoted as KET.

Table S6.2 contains the details of reactions from literature and this work of cyclohexene using hydrogen peroxide as the oxidizer. Entries are listed in increasing order based on the yield of the 2-cyclohexen-1-one denoted as KET. Following is the list based on the yield of cyclohexene oxide denoted as EPO.

Table S6.3 contains the details of reactions from literature and this work of cyclohexene using oxygen as the oxidizer. Entries are listed in increasing order based on the yield of the 2-cyclohexen-1-one denoted as KET. Following is the list based on the yield of cyclohexene oxide denoted as EPO.

Table S6.4 contains the details of reactions from literature and this work of cyclooctene using t-butyl hydroperoxide as the oxidizer. Entries are listed in increasing order based on the yield of the cyclooctene oxide denoted as EPO.

Table S6.5 contains the details of reactions from literature and this work of cyclooctene using hydrogen peroxide as the oxidizer. Entries are listed in increasing order based on the yield of the cyclooctene oxide denoted as EPO. 
Table S6.6 contains the details of reactions from literature and this work of cyclooctene using oxygen as the oxidizer. Entries are listed in increasing order based on the yield of the cyclooctene oxide denoted as EPO. 


\section{List of Charts}

Chart 2.1 Illustration of related molecules compound $\mathrm{A}^{19}$, compound $\mathrm{B}^{21}$, and Compound C-E ${ }^{22}$.

Chart 3.1. Representations of the stereochemistry for the nickel cations from the 79 structural results. ${ }^{61}$

61

Chart 3.1. Selected LCAOs for $\left[\mathbf{N i}(\mathrm{II})^{\mathrm{SSRR}} \mathbf{L}\right]\left(\mathbf{P F}_{6}\right)_{2}$ and $\left[\mathbf{N i}(\mathrm{II})^{\mathrm{SRSR}} \mathbf{L}\right](\mathbf{C l})\left(\mathbf{P F}_{6}\right)$ from

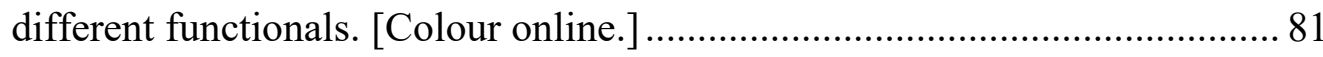




\section{Preface}

The conceptualization of the projects in Chapters 2, 3, 5, and 6 in this dissertation was from Dr. Rudy L. Luck. Conceptualization of the project in Chapter 4 was from Dr. Rebecca G. Ong.

In Chapter 2, the methodology used to conduct the experiments was made by Rudy L. Luck, John S. Maass, and Nick K. Newberry. A formal analysis of the data was performed by John S. Maass, Nick K. Newberry, and Rudy L. Luck. The investigation was performed by John S. Maass and Nick K. Newberry. Resources provided by Rudy L. Luck. Data Curation was performed by John S. Maass, Mathias Zeller, and Nick K. Newberry. Preparation of original draft by John S. Maass, Nick K. Newberry, and Rudy L. Luck. Review and editing were performed by John S. Maass, Mathias Zeller, Nick K. Newberry, and Rudy L. Luck. Visualization was performed by John S. Maass, Nick K. Newberry, and Rudy L. Luck. Supervision was performed by Rudy L. Luck. Project Administration was performed by Rudy L. Luck. John S. Maass, and Nick K. Newberry.

In Chapter 3, the methodology used to conduct the experiments was made by Rudy L. Luck and Nick K. Newberry. A formal analysis of the data was performed by Nick K. Newberry and Rudy L. Luck. The investigation was performed by Peyton C. Bainbridge and Nick K. Newberry. Resources provided by Rudy L. Luck. Data Curation was performed by Nick K. Newberry. Preparation of original draft by Peyton C. Bainbridge, Nick K. Newberry, and Rudy L. Luck. Review and editing were performed by Peyton C. Bainbridge, Nick K. Newberry, and Rudy L. Luck. Visualization was performed by Nick K. Newberry and Rudy L. Luck. Supervision was performed by Rudy L. Luck. Project Administration was performed by Rudy L. Luck and Nick K. Newberry.

In Chapter 4, Raisa C. A. Ela, Patricia A. Heiden, and Rebecca G. Ong performed the development and writing of the original draft. Raisa C. A. Ela was responsible for the design and execution of experiments, Momoko Tajiri took the UV xviii 
measurements, and Nick K. Newberry completed the surface area and porosity analysis and calculations. Raisa C. A. Ela, Patricia A. Heiden, Momoko Tajiri, Nick K. Newberry, and Rebecca G. Ong were responsible for the revision and editing of the manuscript.

In Chapter 5, the methodology used to conduct the experiments was made by Rudy L. Luck and Nick K. Newberry. A formal analysis of the data was performed by Nick K. Newberry and Rudy L. Luck. The investigation was performed by Garven M. Huntley and Nick K. Newberry. Resources provided by Rudy L. Luck. Data Curation was performed by Garven M. Huntley and Nick K. Newberry. Preparation of original draft by Nick K. Newberry and Rudy L. Luck. Review and editing were performed by Garven M. Huntley, Nick K. Newberry, Michael E. Mullins, and Rudy L. Luck. Visualization was performed by Nick K. Newberry and Rudy L. Luck. Supervision was performed by Rudy L. Luck. Project Administration was performed by Rudy L. Luck and Nick K. Newberry.

In Chapter 6, the methodology used to conduct the experiments was made by Rudy L. Luck and Nick K. Newberry. A formal analysis of the data was performed by Nick K. Newberry and Rudy L. Luck. The investigation was performed by Nick K. Newberry. Resources provided by Rudy L. Luck. Data Curation was performed by Nick K. Newberry. Preparation of original draft by Nick K. Newberry and Rudy L. Luck. Review and editing were performed by Nick K. Newberry and Rudy L. Luck. Visualization was performed by Nick K. Newberry and Rudy L. Luck. Supervision was performed by Rudy L. Luck. Project Administration was performed by Rudy L. Luck and Nick K. Newberry. 


\section{Acknowledgments}

Thank you, Dr. Rudy Luck, for your teachings and guidance through this Ph.D. Also, thank you to the Chemistry Department at Michigan Technological University for supporting me as a Graduate Teaching Assistant. I would like to thank my committee for their time and guidance Dr. Loredana Valenzano-Slough, Dr. John Jaszczak, Dr. Tarun K. Dam, and Dr. Rudy Luck. 


\section{Definitions}

AZLB-Na $=$ Natural Zeolite from Arizona Land Basin with the dominant cation being $\mathrm{Na}^{+}$

AZLB-Ca $=$ Natural Zeolite from Arizona Land Basin with the dominant cation being $\mathrm{Ca}^{2+}$

$\mathrm{NV}-\mathrm{Na}=$ Natural Zeolite from Nevada with the dominant cation of $\mathrm{Na}^{+}$

NM-Ca $=$ Natural Zeolite from New Mexico with dominant cation being $\mathrm{Ca}^{2+}$ 


\section{List of abbreviations}

XRF X-Ray Fluorescence

XRD X-Ray Diffraction

DFT Density Functional Theory

EDS Energy Dispersive Spectroscopy

NMR Nuclear Magnetic Resonance

AZLB Arizona Land Basin

NM New Mexico

NV Nevada

Py pyridine

Pyr pyrimidine

FTIR Fourier Transform Infrared

TGA Thermogravimetric Analysis

UV-Vis Ultraviolet-Visible

TEM Transmission Electron Microscopy

STEM Scanning Transmission Electron Microscopy

SEM Scanning Electron Microscopy

BET Brunauer Emmett Teller
AA Atomic Absorption
GC Gas Chromatography
FID Flame Ionization Detector 
MS Mass Spectrometry

THF Tetrahydrofuran

MSB Magnetic Susceptibility Balance

DMSO Dimethyl Sulfoxide

CSD Cambridge Structural Database

ORTEP Oak Ridge Thermal Ellipsoid Plot

PCM Polarizable Continuum Model

CTAB Cetrimonium Bromide

SDS Sodium Dodecyl Sulfate

HAADF High-Angle Annular Dark Field

$\mathrm{HCl}$ Hydrochloric Acid

MAS Magic Angle Spinning

APD Tetrahedral Aluminophosphate in a Zeolite Framework

CLI Clinoptilolite

CHA Chabazite

ERI Erionite

HOMO Highest Occupied Molecular Orbital

LUMO Lowest Unoccupied Molecular Orbital

EPO Epoxide

$\mathrm{OH}$ Alcohol

KET Ketone 
ACN Acetonitrile

DCE 1,2-dichloroethane

DCM dichloromethane

DMSO dimethylsulfoxide

TbuOOH tert-butyl hydroperoxide

$\mathrm{SiC}$ silicon carbide

BHT butylated hydroxy toluene

NMP n-methylpyrrolidinone 


\section{Abstract}

Chapter 2 is based on the synthesis and study of the compounds of the bidentate ligand ((5-phenyl-1H-pyrazol-3-yl)methyl)phosphine oxide with molybdenum and cobalt as the transition metal. The complexes were analyzed via FTIR, NMR, UVVis, Fluorescence Spectroscopy, TGA, DFT, and XRD. Chapter 3 resulted in the synthesis of the complexes $\left[\mathrm{Ni}(\mathrm{II})^{\mathrm{SSRR}} \mathrm{L}\right]\left(\mathrm{PF}_{6}\right)_{2}$ and $\left[\mathrm{Ni}(\mathrm{II})^{\mathrm{SRSR}} \mathrm{L}\right](\mathrm{Cl})\left(\mathrm{PF}_{6}\right)$ of which $\left[\mathrm{Ni}(\mathrm{II})^{\mathrm{SRSR}} \mathrm{L}\right](\mathrm{Cl})\left(\mathrm{PF}_{6}\right)$ had not been previously analyzed. Both products were analyzed via FTIR, NMR, UV-Vis, CV, DFT, and XRD. Chapter 5 contains the results of the characterization and modification of 4 natural zeolites (AZLB-Na, AZLB-Ca, NM-CA, NV-Na) from the United States in an attempt to increase the surface area of the zeolites to make them more efficient at the adsorption/absorption of lead from a simulated contaminated water source. AZLB-Na and AZLB-Ca turned into amorphous material, while NV-Na and NM-Ca retained crystallinity when treated with concentrated hydrochloric acid. NV-Na and NM-Ca untreated had surface areas of $19.0(4) \mathrm{m}^{2} / \mathrm{g}$ and $20.0(1) \mathrm{m}^{2} / \mathrm{g}$, respectively. After 30 minutes of reflux in concentrated hydrochloric acid, the surface area increased to $158(7) \mathrm{m}^{2} / \mathrm{g}$ and $111(4) \mathrm{m}^{2} / \mathrm{g}$, respectively. The study based on the uptake of lead showed NV-Na and NM-Ca removing 1.50(17)meq $/ \mathrm{g} \mathrm{Pb}^{2+}$ and $0.27(14) \mathrm{meq} / \mathrm{g} \mathrm{Pb}^{2+}$ and with the treated zeolites $30 \mathrm{~min} \mathrm{HCl} \mathrm{NV-Na}$ and $30 \mathrm{~min} \mathrm{HCl}$ NM-Ca resulting in $0.41(23) \mathrm{meq} / \mathrm{g} \mathrm{Pb}^{2+}$ and $0.09(9) \mathrm{meq} / \mathrm{g} \mathrm{Pb}^{2+}$. Chapter 6 relates to the epoxidation of olefins. In the case of cyclohexene with 5 mole percent t-butyl hydroperoxide, a yield of 2(1)\% cyclohexene oxide, $8.0(3) \%$ 2-cyclohexen-1-ol, and 23.66(1)\% 2-cyclohexen-1-one was achieved with no catalysts, and in the epoxidation of cyclooctene using 5 mole percent t-butyl hydroperoxide, a yield of 40(2)\% cyclooctene oxide, 1.18(2)\% 2-cycloocten-1-one, and $0.35(1) \% 2$-cyclooctene-1-ol was achieved with no catalysts. 


\section{Chapter 1 Background}

\subsection{Catalysis}

Catalysts are commonly used in chemical industries to increase the yield, efficiency, and even quality of the products of chemical reactions. This equates to a considerable saving of resources such as starting materials, energy used, and chemical waste. Catalysts work by promoting the chemical reaction by lowering the energy required to perform the reaction. An essential characteristic of a catalyst is that it is not used up in a chemical reaction. ${ }^{1}$ Catalysts are usually classified into two groups, homogenous and heterogeneous catalysts.

Homogenous catalysts are present in the same phase as the reactants, which typically means that the catalyst dissolves. Homogeneous catalysts usually have high selectivity towards a single product which can eliminate the issues of separation of unwanted byproducts in the reactions. However, one drawback of homogeneous catalysts is that since they dissolve in the reaction mixture, it is difficult to recover and reuse the catalyst. ${ }^{2}$

Heterogeneous catalysts are catalysts that are not in the same phase as the reaction. Usually, heterogeneous catalysts are solids, while the reactants are liquids or gasses. Heterogeneous catalysts have a couple of advantages, they are easily recovered and reused due to the ease of being able to filter the solid from the reaction, and they are usually more heat stable and can be used for higher temperature and pressure reactions. ${ }^{2}$ Figure 1.1 below contains the catalytic cycle for the hydrogenation of terminal alkenes using Wilkinson's catalyst. The importance of figure 1.1. is that the catalyst is regenerated after one cycle. 


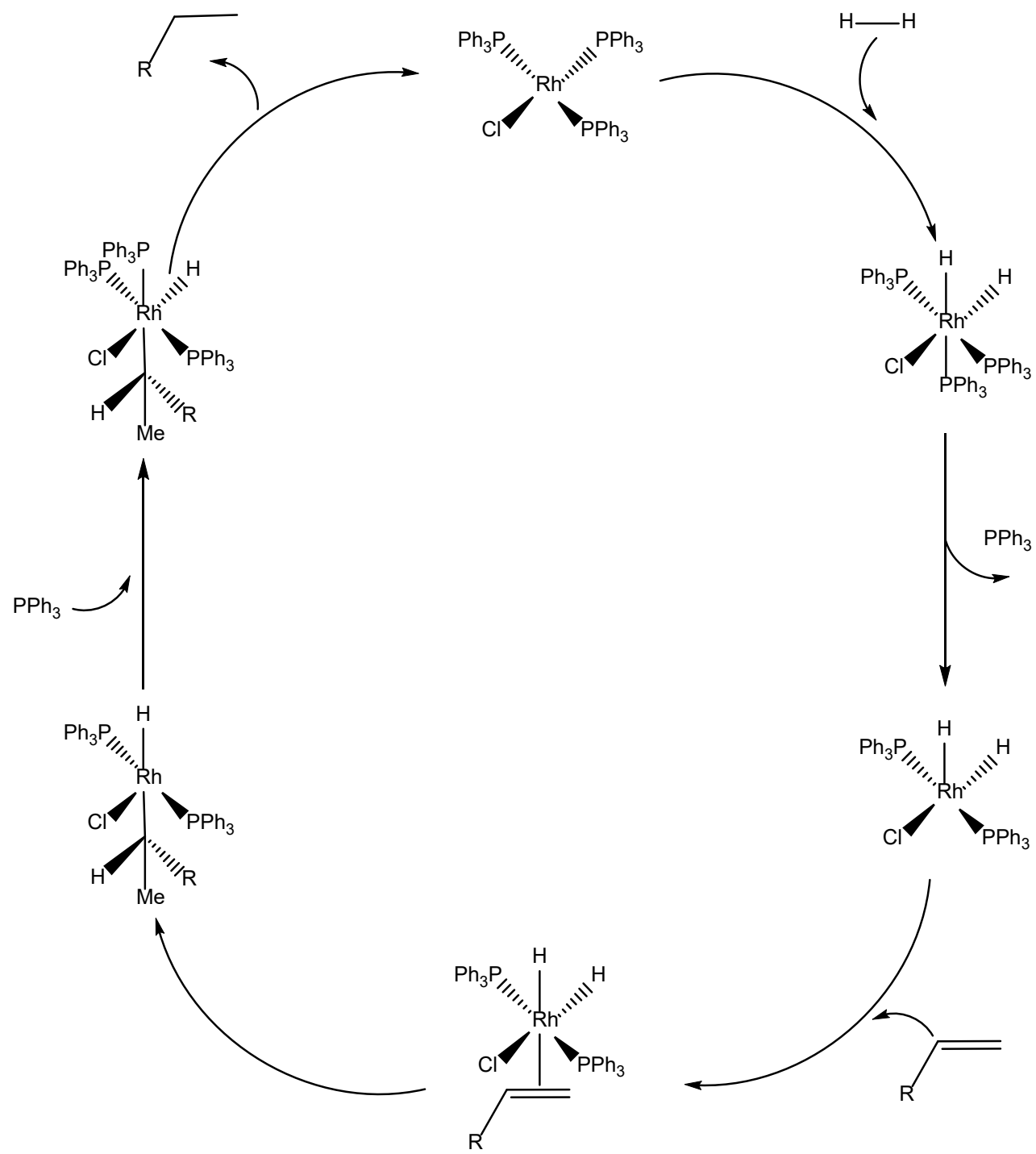

Figure 1.1 contains the catalytic cycle for the hydrogenation of terminal alkenes using Wilkinson's catalyst. ${ }^{2}$

\subsection{Fluorescence}

Ultraviolet radiation is an abundant source of energy that is naturally generated by the sun and is also easy to generate synthetically using electric lights. ${ }^{3}$ Rather than heating a reaction that could be sensitive to heat, causing many problems such as product degradation, evaporation, or polymerization, the use of ultraviolet light could 
be used to avoid these problems and also promote the desired reaction. When a molecule absorbs ultraviolet radiation, an electron gets promoted to a higher energy level which is known as an excited state. At this point, a few things could happen. If the electron quickly comes back down to the ground state, the energy emitted is in the form of molecular vibrations or movement, and no fluorescence is observed. If the electron loses a small amount of energy through vibration and then slowly comes back down to the ground state, then the energy that is emitted will be in the form of visible light at lower energy than the initial energy used to excite the molecule, which will cause the molecule to fluoresce.

\subsection{Macrocyclic Ligands/Template Synthesis}

Typically, when a metal-organic complex is synthesized, the ligand is first synthesized and then connected to the metal. Macrocycles are rings with 12 or more atoms ${ }^{4}$. When a macrocycle contains heteroatoms capable of binding to metal, the macrocycle is referred to as a macrocyclic ligand.

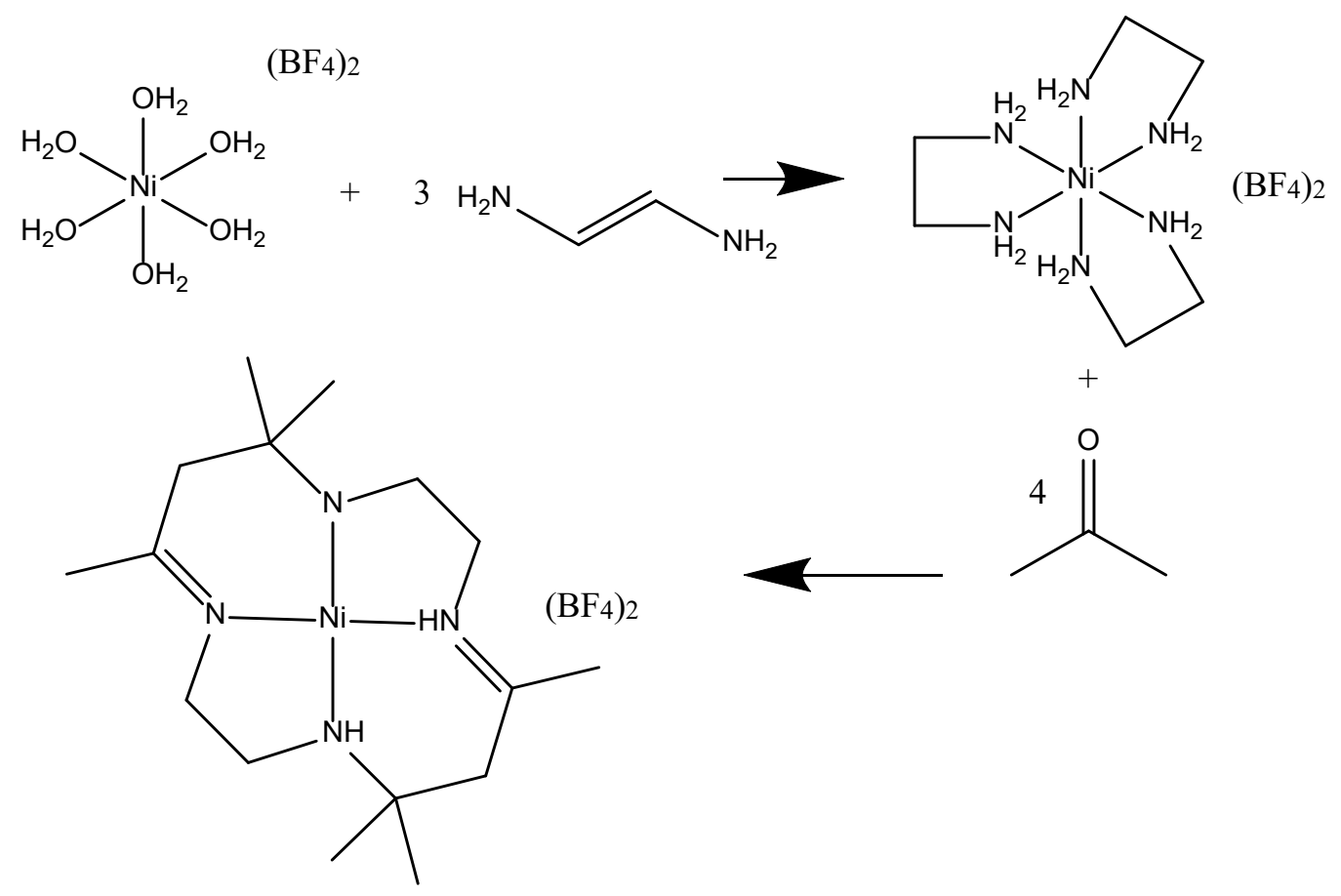


Figure 1.2 shows the scheme for synthesizing a macrocyclic ligand where the water ligands on the nickel (II) tetrafluoroborate hexahydrate are replaced with ethylene diamine. Then a condensation reaction between acetone and ethylene diamine forms the macrocyclic ligand while one ethylene diamine from the nickel (II) tetrafluoroborate tris-ethylenediamine is released into the solution. ${ }^{5}$

Template reactions are when the metal coordination sphere formed by the orbitals interacts with the pieces that will form the ligands and brings them near so they can react. ${ }^{6}$ This produces a high selectivity towards the desired reaction rather than the reaction proceeding randomly.

\section{$1.4 \quad$ Lignin}

Lignin is the second most abundant organic material on earth, with cellulose being the most abundant. Lignin is responsible for the structural integrity of plants along with the responsibility of protecting the plant from foreign invaders such as fungi and also to aid in the healing of wounds to the structure of the plant. ${ }^{7}$ Lignin also protects the plant from damage that can be caused by ultraviolet radiation. ${ }^{8}$ Lignin is a polymer comprised of 3 different groups named coniferyl, sinapyl, and pcoumaryl alcohol. ${ }^{9}$ These three structures are shown below in Figure 1.3. 


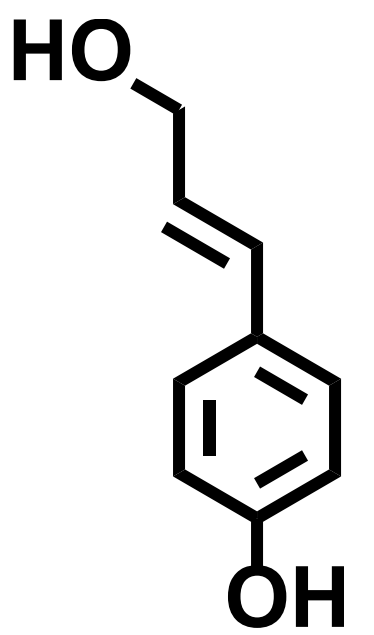

\section{p-coumaryl}

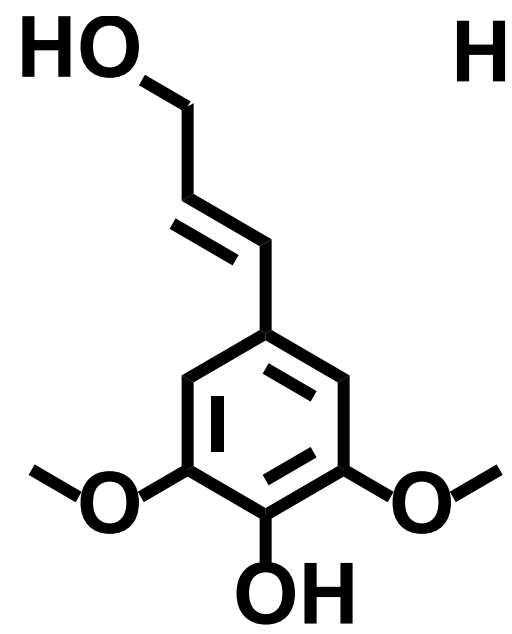

sinapyl
HO

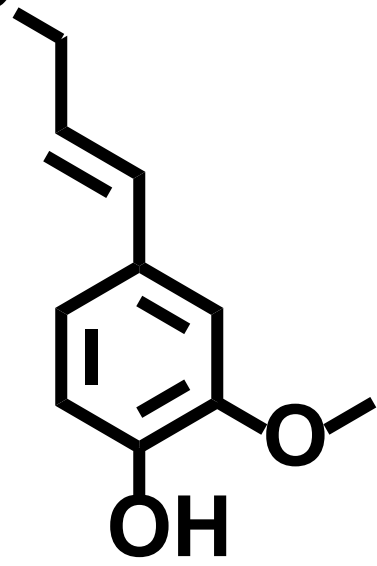

coniferyl

Figure 1.3 contains the structures of coniferyl, sinapyl, and p-coumaryl alcohols.

In 2010, 50 million tons of lignin were produced by the paper manufacturing industry, and only $2 \%$ was used for processes other than burning the lignin for its fuel value. ${ }^{10}$

\subsection{Zeolites}

Natural zeolites are a mineral formed by the alteration of volcanic glass under a wide variety of conditions such as varying temperatures and pressures in nature. Zeolites are aluminosilicate materials with a rigid framework of anionic nature that contain channels and pores. Inside these pores can be cations that can participate in ion exchanges. These pores are also known to adsorb molecules. ${ }^{11}$ The pores of zeolites can also act as a reaction site. Zeolites are commonly used in the cracking and reforming process in the petroleum industry and as adsorbents/absorbents of cations. Another common use of zeolites is as molecular sieves. Zeolites have many pores, which are usually uniform in size and can be used to selectively absorb molecules based on their size. Molecular sieves with a pore size of $3 \AA$ are commonly used to remove water from organic solvents because the water molecule can fit into the pore of the zeolite, but the organic solvent is too large to fit into the pore. Zeolites 
are crystalline materials which means they are uniform in structure and have a regular repeating pattern. However, the biggest problem is that natural zeolites are not as efficient as synthetic zeolites. This is due to the lower surface area meaning that there are not as many pores in natural zeolites as there are in synthetic zeolites.

While synthetic zeolites have proven to be very useful in a wide variety of chemical reactions, their price is quite high, and their syntheses also produces a large amount of waste. ${ }^{12}$ Synthetic zeolites are typically made by crystallizing a gel made from silica and alumina around another molecule known as a template. The template is then removed by heating the material to a high temperature in the presence of oxygen which causes the template to burn/oxidize.

\subsection{Modification of Zeolites}

An option to increase the activity and the surface area of the natural zeolites is to chemically etch more pores into the zeolites or make the current pores and channels larger by removing part of the framework that is present, making more channels and pores. Two common ways to etch the surfaces of aluminosilicates are to use either a strong base or a strong acid. A strong base such as sodium hydroxide is typically used to dissolve silicon and aluminum from the framework, and a strong acid such as nitric acid or hydrochloric acid is used to selectively dissolve the aluminum while hydrofluoric acid is used to dissolve both silicon and aluminum. ${ }^{13,14}$ While the goal is to increase the surface area of the zeolite by etching the surface and creating new pores, we do not want to destroy the crystalline structure which would collapse the zeolite into an amorphous material which is randomly ordered and would be less useful at ion exchange due to there being no more ion exchange sites in the material.

\subsection{Epoxidation of Olefins}

Epoxides are cyclic ethers forming a three-membered ring. Ethylene oxide is the most commonly used epoxide which is used as a fumigant and in the production 
of ethylene glycol, which is mainly used as antifreeze. More complex epoxides are used to make epoxy resins or glues and they are also used in organic syntheses.
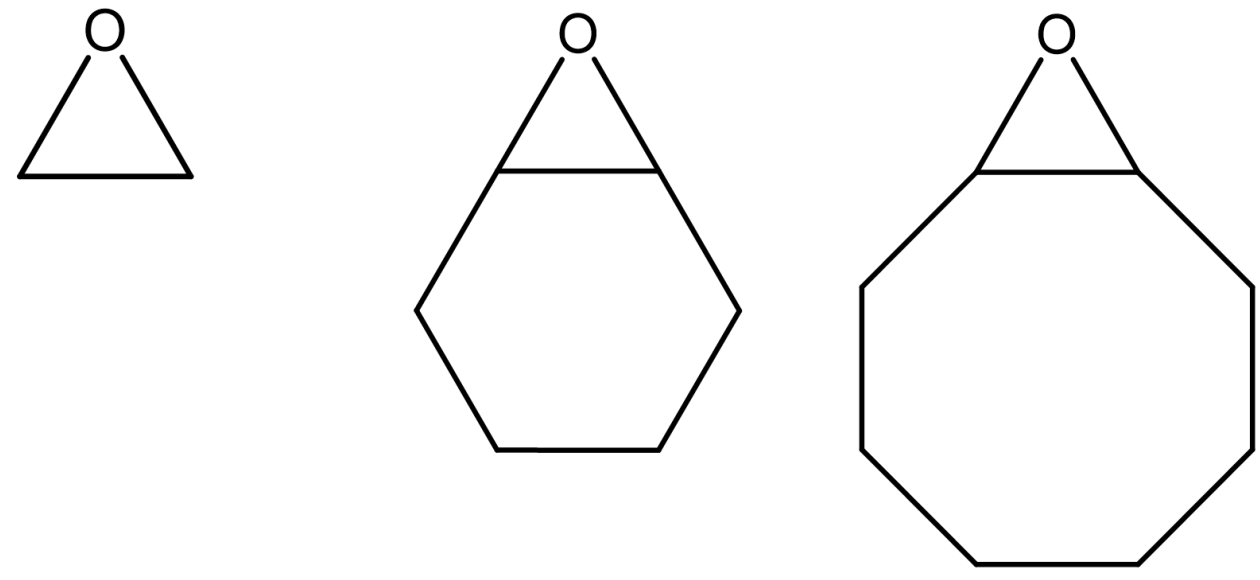

Figure 1.4 contains ethylene oxide (left), cyclohexene oxide (middle), and cyclooctene oxide (right). Of which cyclohexene oxide and cyclooctene oxide are the epoxides of interest in Chapter 7.

Epoxides are typically formed using catalysts and oxidizers or using a peroxy acid. Figure 1.5 below shows the synthesis of ethylene oxide using oxygen and silver oxide as a catalyst along with heat. Figure 1.6 below shows the synthesis of an epoxide from an olefin using the peroxy acid MCPBA.

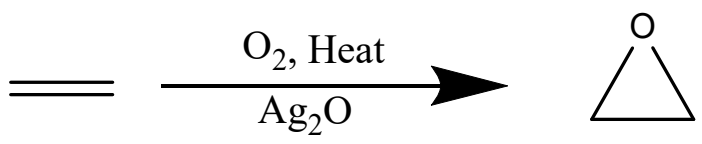

Figure 1.5 shows the synthesis of ethylene oxide from ethylene using oxygen as the oxidizer and silver oxide as the catalyst. ${ }^{15}$ 


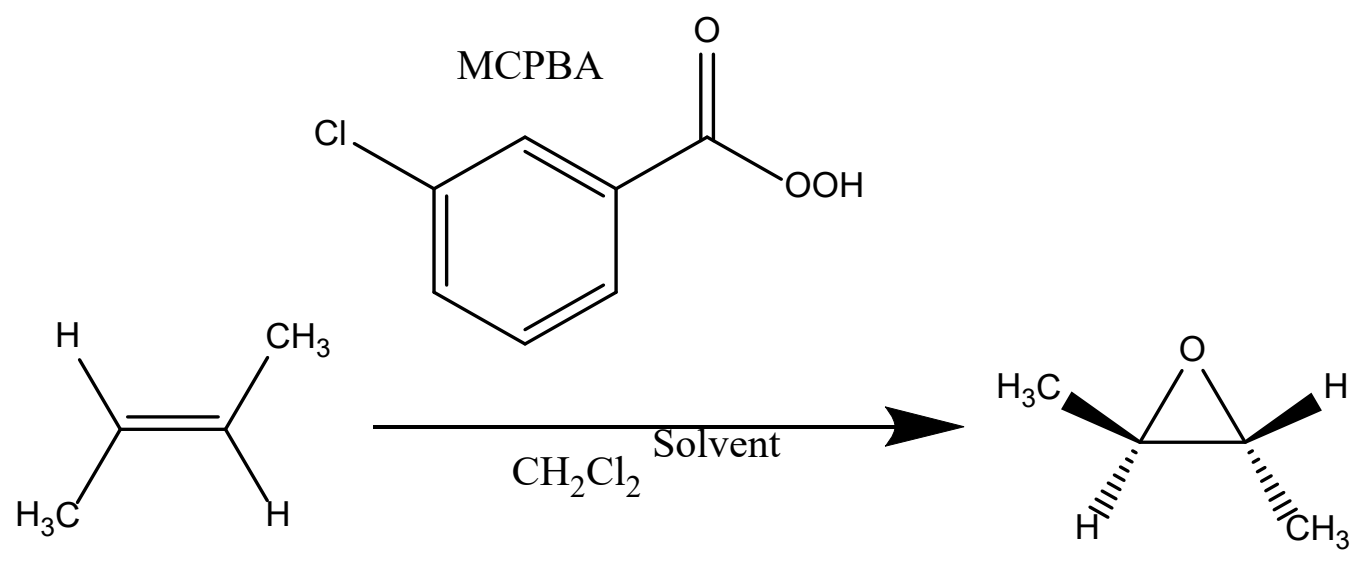

Figure 1.6 shows the synthesis of trans-2,3-dimethyloxacyclopropane from trans-2butene using MCPBA as the peroxy acid and dichloromethane as the solvent. ${ }^{16}$ 


\section{Chapter 2 Syntheses, X-ray structure, emission, and vibrational spectroscopies, DFT and thermogravimetric studies of two complexes containing the bidentate ligand ((5- phenyl-1H-pyrazol-3-yl)methyl) phosphine oxide}

Rudy L. Luck ${ }^{\mathrm{a}^{*}}$, John S. Mass ${ }^{\mathrm{a}}$, Nick K. Newberry ${ }^{\mathrm{a}}$, and Matthias Zeller ${ }^{\mathrm{b}}$

a Department of Chemistry, Michigan Technological University, Houghton, MI, USA;

${ }^{b}$ Department of Chemistry, Purdue University, West Lafayette, IN, USA

\subsection{Abstract}

The coordination chemistry of (diphenyl((5-phenyl-1H-pyrazol-3-yl)methyl)

phosphine oxide), 1, was explored. Reacting appropriate equivalents of this ligand and either cobalt perchlorate or $\mathrm{MoO}_{2} \mathrm{Cl}_{2}$ results in formation of $\left[\mathrm{Co}\left(\left(\mathrm{C}_{6} \mathrm{H}_{5}\right)_{2} \mathrm{POCH}_{2}\left(\mathrm{C}_{3} \mathrm{~N}_{2} \mathrm{H}_{2}\right)\left(\mathrm{C}_{6} \mathrm{H}_{5}\right)\right)_{2}\left(\mathrm{C}_{4} \mathrm{H}_{8} \mathrm{O}\right)_{2}\right]\left[\mathrm{ClO}_{4}\right]_{2}, \mathbf{2}$, and $\mathrm{MoO}_{2}$ $\mathrm{Cl}_{2}\left(\left(\mathrm{C}_{6} \mathrm{H}_{5}\right)_{2} \mathrm{POCH}_{2}\left(\mathrm{C}_{3} \mathrm{~N}_{2} \mathrm{H}_{2}\right)\left(\mathrm{C}_{6} \mathrm{H}_{5}\right)\right)(\mathrm{THF}), 3$. Complexes were characterized by FTIR, NMR, TGA, and elemental analyses. Single crystal X-ray spectroscopy reveals octahedral geometries for both compounds. Complex 2 consists of two trans THF ligands in axial positions and two (diphenyl((5-phenyl-1H-pyrazol-3-yl)methyl) phosphine oxide) ligands occupying equatorial positions resulting in an overall octahedral geometry. Two perchlorate counter-anions complete the structure. The Co ion resides on an inversion point. THF contains disorder with the four carbon atoms and the major orientation refined to occupancy of 86.1(9) \%. Complex 3 consists of the cis-dioxo $\mathrm{MoO}_{2}$ unit bonded with axial trans-chloride ligands and $\mathbf{1}$ in the equatorial plane completing the disordered octahedral geometry. A THF ligand is hydrogen-bonded to the $\mathrm{H}$ atom on the nitrogen of the pyrazole moiety in ligand $\mathbf{1}$. DFT calculations based on geometries obtained crystallographically were useful in assigning FTIR peaks and the UV-vis spectra. 


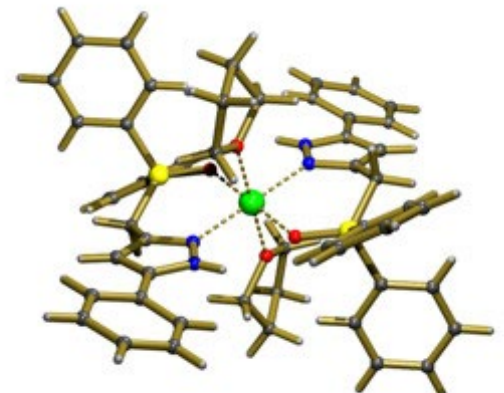

$\left[\mathrm{Co}\left(\left(\mathrm{C}_{6} \mathrm{H}_{5}\right)_{2} \mathrm{POCH}_{2}\left(\mathrm{C}_{3} \mathrm{~N}_{2} \mathrm{H}_{2}\right)\left(\mathrm{C}_{6} \mathrm{H}_{5}\right)\right)_{2}\left(\mathrm{C}_{4} \mathrm{H}_{8} \mathrm{O}\right)_{2}\right]\left[\mathrm{ClO}_{4}\right]_{2}$

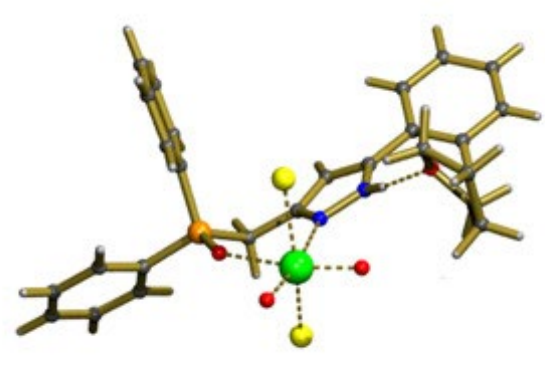

$\mathrm{MoO}_{2} \mathrm{Cl}_{2}\left(\left(\mathrm{C}_{6} \mathrm{H}_{5}\right)_{2} \mathrm{POCH}_{2}\left(\mathrm{C}_{3} \mathrm{~N}_{2} \mathrm{H}_{2}\right)\left(\mathrm{C}_{6} \mathrm{H}_{5}\right)\right)(\mathrm{THF})$

\subsection{Introduction}

We are interested in studying the coordination properties of (diphenyl( (5-phenyl-1Hpyrazol-3-yl)methyl) phosphine oxide) for its ability to capture and transfer light to a central atom, see Chart 2.1. Our prior work demonstrated the ability of this ligand to absorb UV radiation and transfer energy to $\mathrm{Sm}, \mathrm{Eu}$, and $\mathrm{Tb}$, as judged by the emission spectra ${ }^{17}$. The structures of the compounds were reported and consisted of two ligands coordinated in a bidentate manner in a cisoid configuration in the equatorial plane with three chloride ligands attached in a mer-configuration. A recent general search consisting of a phosphine oxide attached to pyrazole, i.e., ((1 H-pyrazol-3yl)methyl)dimethylphosphine oxide, in the Cambridge Data Base ${ }^{18}$ did not result in any additional hits except for the three aforementioned complexes. However, related ligands have been examined. Among these are studies on the coordination chemistry of diethyl 2-pyridylmethylphosphonate (2-pmpe) (A in Chart 2.1) with high spin cobalt(II) ${ }^{19}$ and copper(II) ${ }^{20}$ and various derivatives of a phosphinic amide ligand $\mathrm{N}$ (4-methylpyrimidin-2-yl)-P,P-diphenylphosphinic amide, (B in Chart 3.1) forming a monomeric complex with $\mathrm{Zn} 2 \mathrm{p}$ and a linear $\mathrm{Co}(\mathrm{II})$ trimer $^{21}$ and trans- $\mathrm{Cu}(\mathbf{C})_{2}\left(\mathrm{ClO}_{4}\right)_{2}$, trans- $\left[\mathrm{Co}(\mathbf{C})_{2}\left(\mathrm{CH}_{3} \mathrm{OH}\right)_{2}\right]\left(\mathrm{ClO}_{4}\right)_{2}$, trans- $\left[\mathrm{Co}(\mathbf{D})_{2}\left(\mathrm{H}_{2} \mathrm{O}\right)_{2}\right]\left(\mathrm{ClO}_{4}\right)_{2}$, cis$\left[\mathrm{Co}(\mathbf{D})_{2}\left(\mathrm{NO}_{3}\right)\right]\left(\mathrm{NO}_{3}\right)$ and polymeric $\left[\mathrm{Ag}(\mathbf{E})\left(\mathrm{NO}_{3}\right)\left(\mathrm{CH}_{3} \mathrm{CN}\right)\right]^{22}$.

Based on these reports, we decided to investigate the coordination chemistry of 1 with cobalt for comparison and also to examine the bonding with molybdenum to assess the ability of the ligand to absorb and transmit light to effect oxidation reactions. This would allow for a direct comparison with related Mo complexes 
containing phosphine oxide ligands which were previously demonstrated to be effective oxidation catalysts ${ }^{23-26}$. The two complexes synthesized were characterized by FTIR and NMR spectroscopy, and structures were determined by single-crystal Xray crystallography. Thermal decomposition was assessed gravimetrically, and DFT calculations afforded some insight into the electronic structures.

\subsection{Experimental}

\subsubsection{Materials}

Chemicals were purchased from Sigma-Aldrich Chemicals, and solvents were purified

as needed. $\mathrm{MoO}_{2} \mathrm{Cl}_{2}{ }^{27}$ and the (diphenyl((5-phenyl-1H-pyrazol-3-yl)methyl) phos-
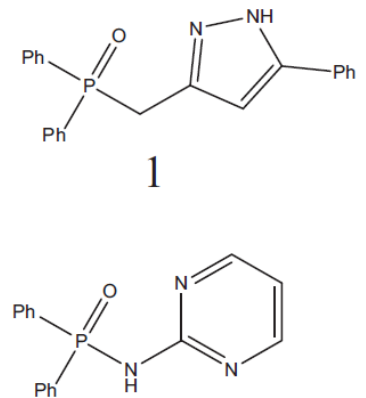

$\mathrm{C}$<smiles>O=P(O)(O)Cc1ccccn1</smiles>

A<smiles>O=P(Nc1ccccn1)(c1ccccc1)c1ccccc1</smiles>

$\mathrm{D}$<smiles>Cc1ccnc(NP(=O)(c2ccccc2)c2ccccc2)n1</smiles>

B

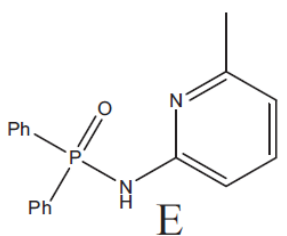

Chart 2.1 Illustration of related molecules compound $\mathrm{A}^{19}$, compound $\mathrm{B}^{21}$, and Compound C-E ${ }^{22}$.

phine oxide), $\mathbf{1}^{17}$, were synthesized as previously described. Elemental analyses were conducted by Galbraith Laboratories, Knoxville, TN. IR spectra (neat) were recorded on a Perkin Elmer Spectrum One spectrometer. ${ }^{1} \mathrm{H}$ and ${ }^{31} \mathrm{P}$ NMR data were recorded on a Varian XL-400 spectrometer referenced to $\left(\mathrm{CD}_{3}\right)_{2} \mathrm{SO}$ (i.e., the protonated impurity) and $85 \% \mathrm{H}_{3} \mathrm{PO}_{4}$, respectively. Magnetic measurements were conducted on a Johnson Matthey Auto MSB instrument. The TGA analyses were conducted on a Shimadzu 
TGA-50 analyzer under either oxygen or nitrogen gas flow of $10 \mathrm{ml} /$ minute to $800^{\circ} \mathrm{C}$ at a rate of $10^{\circ} \mathrm{C}$ per minute. Absorbance spectra were obtained using quartz cells in a Perkin Elmer Lambda 35 UV/Vis Spectrometer. Fluorescence spectra were obtained using quartz cells (solution) and glass capillaries (solid) on a Horiba (Jobin Yvon) Fluoromax-4 Spectrofluorometer.

\subsubsection{Synthesis of $\left[\mathrm{Co}\left(\left(\mathrm{C}_{6} \mathrm{H}_{5}\right)_{2} \mathrm{POCH}_{2}\left(\mathrm{C}_{3} \mathrm{~N}_{2} \mathrm{H}_{2}\right)\left(\mathrm{C}_{6} \mathrm{H}_{5}\right)\right)_{2}\left(\mathrm{C}_{4} \mathrm{H}_{8} \mathrm{O}\right)_{2}\right]\left[\mathrm{ClO}_{4}\right]_{2}(2)$}

$\mathrm{Co}\left(\mathrm{ClO}_{4}\right)_{2} * 6 \mathrm{H}_{2} \mathrm{O}(0.101 \mathrm{~g}(0.276 \mathrm{mmol}))$ was dissolved in $10 \mathrm{ml}$ of THF in a $50 \mathrm{ml}$ Erlenmeyer flask and $0.188 \mathrm{~g}(0.525 \mathrm{mmol})$ of 1 was added to the solution which was

stirred for $6 \mathrm{~h}$. Hexanes were then added until a pink oil separated. The oil was left to sit overnight and crystallized, resulting in X-ray quality pink crystals of $\left[\mathrm{Co}\left(\left(\mathrm{C}_{6} \mathrm{H}_{5}\right)_{2} \mathrm{POCH}_{2}\left(\mathrm{C}_{3} \mathrm{~N}_{2} \mathrm{H}_{2}\right)\left(\mathrm{C}_{6} \mathrm{H}_{5}\right)\right)_{2}\left(\mathrm{C}_{4} \mathrm{H}_{8} \mathrm{O}\right)_{2}\right]\left[\mathrm{ClO}_{4}\right]_{2}, 2,0.251 \mathrm{~g}(0.2318 \mathrm{mmol})$, yield $84.0 \%$. Elemental analysis: calcd. For $\mathrm{C}_{52} \mathrm{H}_{54} \mathrm{C}_{12} \mathrm{CoN}_{4} \mathrm{O}_{12} \mathrm{P}_{2}$ : C 55.83, H 4.86\%; found: C 55.85, H 5.12\%.

\subsubsection{Synthesis of $\mathrm{Mo}_{2} \mathrm{O}_{4} \mathrm{Cl}_{2}\left(\left(\mathrm{C}_{6} \mathrm{H}_{5}\right)_{2} \mathrm{POCH}_{2}\left(\mathrm{C}_{3} \mathrm{~N}_{2} \mathrm{H}_{2}\right)\left(\mathrm{C}_{6} \mathrm{H}_{5}\right)\right)(\mathrm{THF})$ (3)}

$\mathrm{MoO}_{2} \mathrm{Cl}_{2}(0.101 \mathrm{~g}(0.275 \mathrm{mmol}))$ and $0.0936 \mathrm{~g}(0.2749 \mathrm{mmol})$ of $\mathbf{1}$ were mixed together in $15 \mathrm{ml}$ of methylene chloride. The solution went from cloudy to light yellow. After six hours, hexanes were added until the solution turned cloudy, and this was allowed to sit undisturbed overnight. Subsequent filtration yielded $0.101 \mathrm{~g}$ (0.1873mmol) of $\mathrm{Mo}_{2} \mathrm{O}_{4} \mathrm{Cl}_{2}\left(\left(\mathrm{C}_{6} \mathrm{H}_{5}\right)_{2} \mathrm{POCH}_{2}\left(\mathrm{C}_{3} \mathrm{~N}_{2} \mathrm{H}_{2}\right)\left(\mathrm{C}_{6} \mathrm{H}_{5}\right)\right)$, yield 68.1\%. Crystals suitable for X-ray crystallography were grown by layering tetrahydrofuran solutions of this compound with hexanes which resulted in the formation of $\mathrm{Mo}_{2} \mathrm{O}_{4} \mathrm{Cl}_{2}\left(\left(\mathrm{C}_{6} \mathrm{H}_{5}\right)_{2} \mathrm{POCH}_{2}\left(\mathrm{C}_{3} \mathrm{~N}_{2} \mathrm{H}_{2}\right)\left(\mathrm{C}_{6} \mathrm{H}_{5}\right)\right)(\mathrm{THF}), 3$. Elemental analysis: calcd. For $\mathrm{C}_{22} \mathrm{H}_{19} \mathrm{C}_{12} \mathrm{~N}_{2} \mathrm{O}_{3} \mathrm{PMo}^{*} \mathrm{C}_{4} \mathrm{H}_{8} \mathrm{O}$ : C 49.62, H 4.32\%; found: $\mathrm{C} 49.12, \mathrm{H} 4.32 \% .{ }^{31} \mathrm{P}$ NMR (161.9MHz, (CD3)2SO): $\delta=27.75 .{ }^{1} \mathrm{H}$ NMR (400MHz, $\left.\left(\mathrm{CD}_{3}\right)_{2} \mathrm{SO}\right): \delta=3.89$ (d, 2J $\mathrm{J}_{\mathrm{HP}} 1 / 4$ $\left.12 \mathrm{~Hz}, 2 \mathrm{H}, \mathrm{CH}_{2}\right), \delta=6.20\left(\mathrm{~s}, 1 \mathrm{H}, \mathrm{CH}_{\mathrm{pz}}\right), \delta=7.02-7.90\left(\mathrm{~m}, 16 \mathrm{H}, \mathrm{NH}\right.$ and $\left.\left(\mathrm{C}_{6} \mathrm{H}_{5}\right)_{3}\right)$, see Figure S2.1 (supplementary material). 


\subsubsection{X-ray crystallography}

$\mathrm{X}$-ray quality crystals for $\mathbf{2}$ and $\mathbf{3}$ were obtained by diffusion of hexanes into THF solutions of the compounds. Diffraction data for all compounds were collected using a Bruker AXS SMART APEX CCD diffractometer using monochromatic Mo Ka radiation with the omega scan technique. Single crystals of the compounds were mounted on Mitegen micromesh supports using viscous oil flash-cooled to $100 \mathrm{~K}$.

Data were collected, unit cells determined, and the data integrated and corrected for absorption and other systematic errors using the Apex 2 suite of programs ${ }^{28}$. The structures were solved by direct methods and refined by full-matrix least-squares against $\mathrm{F}^{2}$ with all reflections using SHELXL ${ }^{29}$. Crystals of $\mathbf{2}$ contained a slight disorder with four carbons in the THF ligand and this 
Table 2.1 and Table 2.2 Crystal data and refinement details of $\mathbf{2}$ and $\mathbf{3}$, and Selected bond distances $(\AA)$ and angles $\left(^{\circ}\right)$ for 2 from X-ray and theory. ${ }^{\text {a }}$

Table 1. Crystal data and refinement details of 2 and 3.

\begin{tabular}{|c|c|c|}
\hline Compound reference & 2 & $3 \bullet$ THF \\
\hline Empirical formula & $\left(\mathrm{C}_{52} \mathrm{H}_{54} \mathrm{CoN}_{4} \mathrm{O}_{4} \mathrm{P}_{2}\right) \bullet 2\left(\mathrm{ClO}_{4}\right)$ & $\mathrm{C}_{22} \mathrm{H}_{19} \mathrm{Cl}_{2} \mathrm{MoN}_{2} \mathrm{O}_{3} \mathrm{P} \bullet \mathrm{C}_{4} \mathrm{H}_{8} \mathrm{O}$ \\
\hline Formula mass & 1118.76 & 629.31 \\
\hline Crystal system & Monoclinic & Monoclinic \\
\hline $\mathrm{a} / \AA \AA$ & $9.677(4)$ & $18.9906(8)$ \\
\hline $\mathrm{b} / \mathrm{A}$ & $12.696(5)$ & $14.8402(6)$ \\
\hline$c / \AA ̊$ & $20.642(9)$ & $20.0770(8)$ \\
\hline$\beta /^{\circ}$ & $100.788(6)$ & $108.4879(5)$ \\
\hline Unit cell volume $/ \AA^{3}$ & $2491.2(18)$ & $5366.2(4)$ \\
\hline Temperature/K & $100(2)$ & $100(2)$ \\
\hline Space group & $P 2{ }_{1} / n$ & $P 2{ }_{1} / n$ \\
\hline Z & 2 & 8 \\
\hline Density (calcd., mg/m³) & 1.491 & 1.558 \\
\hline Absorption coefficient, $\mu / \mathrm{mm}^{-1}$ & 0.585 & 0.783 \\
\hline Theta range for data collection $\left({ }^{\circ}\right)$ & $1.892-28.282$ & $1.29-28.28$ \\
\hline Reflections collected & 22664 & 42184 \\
\hline Independent reflections & $6168\left[R_{\text {int }}=0.0362\right]$ & $13316\left[R_{\text {int }}=0.0227\right]$ \\
\hline Final $R$ indices $[I>2 \sigma(l)]$ & $R_{1}=0.0345^{\mathrm{a}}{ }^{\mathrm{a}} R_{2}=0.0875^{\mathrm{b}, \mathrm{c}}$ & $R_{1}=0.0251^{\mathrm{a}}{ }^{\mathrm{a}} R_{2}=0.0596^{\mathrm{b}, \mathrm{d}}$ \\
\hline $\mathrm{R}$ indices (all data) & $R_{1}=0.0424,{ }^{\mathrm{a}} R_{2}=0.092^{\mathrm{b}, \mathrm{c}}$ & $R_{1}=0.0313^{a} R_{2}=0.0636^{\mathrm{b}, \mathrm{d}}$ \\
\hline Goodness-of-fit on $F^{2}$ & 1.068 & 1.128 \\
\hline Data / restraints / parameters & $6168 / 0 / 367$ & $13316 / 0 / 657$ \\
\hline CCDC number & 1903638 & 1903637 \\
\hline
\end{tabular}

Table 2. Selected bond distances $(\AA)$ and angles $\left(^{\circ}\right)$ for 2 from $X$-ray and theory. ${ }^{\text {a }}$

\begin{tabular}{lcc}
\hline Bond distances $(\AA ̊)$ & X-ray & Calculation \\
\hline Co(1)-O(1) & $2.0665(14)$ & 2.142 \\
Co(1)-N(11) & $2.0902(15)$ & 2.101 \\
Co(1)-O(2) & $2.1489(14)$ & 2.177 \\
$\mathrm{P}(2)-\mathrm{O}(1)$ & $1.5114(12)$ & 1.538 \\
Bond angles ( ${ }^{\circ}$ & & \\
O(1)\#1-Co(1)-O(1) & 180.0 & 179.6 \\
$\mathrm{O}(1)-\mathrm{Co}(1)-\mathrm{N}(11)$ & $91.32(5)$ & 92.6 \\
$\mathrm{O}(1)-\mathrm{Co}(1)-\mathrm{N}(11) \# 1$ & $88.68(5)$ & 87.2 \\
$\mathrm{O}(1)-\mathrm{Co}(1)-\mathrm{O}(2) \# 1$ & $90.97(5)$ & 90.0 \\
$\mathrm{O}(1)-\mathrm{Co}(1)-\mathrm{O}(2)$ & $89.03(5)$ & 89.4 \\
$\mathrm{O}(1) \# 1-\mathrm{Co}(1)-\mathrm{O}(2)$ & $90.97(5)$ & 90.6 \\
$\mathrm{~N}(11)-\mathrm{Co}(1)-\mathrm{O}(2)$ & $90.00(6)$ & 88.1 \\
$\mathrm{~N}(11) \# 1-\mathrm{Co}(1)-\mathrm{O}(2)$ & $90.00(6)$ & 92.3 \\
$\mathrm{O}(2)-\mathrm{Co}(1)-\mathrm{O}(2) \# 1$ & $180.00(5)$ & 179.3 \\
$\mathrm{~N}(11)-\mathrm{Co}(1)-\mathrm{N}(11) \# 1$ & 180.0 & 179.8 \\
$\mathrm{O}(1) \# 1-\mathrm{Co}(1)-\mathrm{N}(11)$ & $88.68(5)$ & 87.8 \\
\hline
\end{tabular}

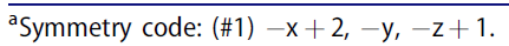

refined to $87.3(8) \%$ occupancies. One of these carbon atoms C24A was poorly behaved and modeled with isotropic parameters. Hydrogens were refined mixed with the ones attached to the pyrazole moiety discovered in difference maps and refined 
freely and the rest at calculated positions. Final figures of merit for the two structures are listed in Table 2.1, and selected bond distances and angles for $\mathbf{2}$ and $\mathbf{3}$ are in Tables 2.2 and 2.3, respectively. Ball and stick representations of the molecules are given in Figures 2.1 (for 2) and 2.3 (for 3).

\subsubsection{DFT calculations}

Superior, a high-performance computing infrastructure at Michigan Technological University, was used for the theoretical calculations presented in this publication. All 
Table 2.3 Selected bond distances and angles for $\mathbf{3}$ from X-ray and theory.

Table 3. Selected bond distances and angles for 3 from X-ray and theory.

\begin{tabular}{|c|c|c|c|c|c|}
\hline \multicolumn{6}{|c|}{ Bond distances $(\AA)$} \\
\hline & X-ray & Calculation for 3 & Calculation for 3-THF & & X-ray \\
\hline $\mathrm{Mo}(1)-\mathrm{O}(2)$ & $1.6918(12)$ & 1.715 & 1.714 & $\mathrm{Mo}(2)-\mathrm{O}(5)$ & $1.6879(12)$ \\
\hline $\mathrm{Mo}(1)-\mathrm{O}(3)$ & $1.7021(13)$ & 1.704 & 1.704 & $\mathrm{Mo}(2)-\mathrm{O}(6)$ & $1.7013(12)$ \\
\hline $\mathrm{Mo}(1)-\mathrm{O}(1)$ & $2.1799(11)$ & 2.223 & 2.221 & $\mathrm{Mo}(2)-\mathrm{O}(4)$ & $2.1675(11)$ \\
\hline $\mathrm{Mo}(1)-\mathrm{N}(1)$ & $2.3510(14)$ & 2.455 & 2.478 & $\mathrm{Mo}(2)-\mathrm{N}(3)$ & $2.3467(14)$ \\
\hline $\mathrm{Mo}(1)-\mathrm{Cl}(2)$ & $2.3676(5)$ & 2.428 & 2.427 & $\mathrm{Mo}(2)-\mathrm{Cl}(4)$ & $2.3745(5)$ \\
\hline $\mathrm{Mo}(1)-\mathrm{Cl}(1)$ & $2.4013(4)$ & 2.434 & 2.441 & $\mathrm{Mo}(2)-\mathrm{Cl}(3)$ & $2.4022(4)$ \\
\hline$O(1)-P(1)$ & $1.5145(12)$ & 1.525 & 1.526 & $O(4)-P(2)$ & $1.5146(12)$ \\
\hline $\mathrm{O}(7)-\mathrm{H}(2 \mathrm{~A})$ & $1.98(2)$ & & 1.839 & $\mathrm{O}(8)-\mathrm{H}(4 \mathrm{~A})$ & $1.85(2)$ \\
\hline \multicolumn{6}{|c|}{ Bond angles $\left({ }^{\circ}\right)$} \\
\hline $\mathrm{O}(2)-\mathrm{Mo}(1)-\mathrm{O}(3)$ & 103.79(6) & 105.0 & 104.2 & $\mathrm{O}(5)-\mathrm{Mo}(2)-\mathrm{O}(6)$ & $103.91(6)$ \\
\hline $\mathrm{O}(2)-\mathrm{Mo}(1)-\mathrm{O}(1)$ & $165.81(5)$ & 158.2 & 161.5 & $\mathrm{O}(5)-\mathrm{Mo}(2)-\mathrm{O}(4)$ & $165.00(5)$ \\
\hline $\mathrm{O}(3)-\mathrm{Mo}(1)-\mathrm{O}(1)$ & $90.25(5)$ & 96.7 & 94.3 & $\mathrm{O}(6)-\mathrm{Mo}(2)-\mathrm{O}(4)$ & $91.08(5)$ \\
\hline $\mathrm{O}(2)-\mathrm{Mo}(1)-\mathrm{N}(1)$ & $86.60(5)$ & 82.9 & 84.6 & $\mathrm{O}(5)-\mathrm{Mo}(2)-\mathrm{N}(3)$ & $85.96(5)$ \\
\hline $\mathrm{O}(3)-\mathrm{Mo}(1)-\mathrm{N}(1)$ & $169.45(6)$ & 172.1 & 171.2 & $\mathrm{O}(6)-\mathrm{Mo}(2)-\mathrm{N}(3)$ & $169.72(5)$ \\
\hline $\mathrm{O}(1)-\mathrm{Mo}(1)-\mathrm{N}(1)$ & $79.30(4)$ & 75.4 & 76.9 & $\mathrm{O}(4)-\mathrm{Mo}(2)-\mathrm{N}(3)$ & $79.04(4)$ \\
\hline $\mathrm{O}(2)-\mathrm{Mo}(1)-\mathrm{Cl}(2)$ & $95.31(5)$ & 96.9 & 95.2 & $\mathrm{O}(5)-\mathrm{Mo}(2)-\mathrm{Cl}(4)$ & $94.36(5)$ \\
\hline $\mathrm{O}(3)-\mathrm{Mo}(1)-\mathrm{Cl}(2)$ & $99.63(5)$ & 97.7 & 98.3 & $\mathrm{O}(6)-\mathrm{Mo}(2)-\mathrm{Cl}(4)$ & $98.05(5)$ \\
\hline $\mathrm{O}(1)-\mathrm{Mo}(1)-\mathrm{Cl}(2)$ & $84.19(3)$ & 82.0 & 81.9 & $\mathrm{O}(4)-\mathrm{Mo}(2)-\mathrm{Cl}(4)$ & $83.90(3)$ \\
\hline $\mathrm{N}(1)-\mathrm{Mo}(1)-\mathrm{Cl}(2)$ & $80.97(3)$ & 80.8 & 80.8 & $\mathrm{~N}(3)-\mathrm{Mo}(2)-\mathrm{Cl}(3)$ & $81.16(4)$ \\
\hline $\mathrm{O}(1)-\mathrm{Mo}(1)-\mathrm{Cl}(1)$ & $82.98(3)$ & 81.1 & 82.1 & $\mathrm{O}(4)-\mathrm{Mo}(2)-\mathrm{Cl}(3)$ & $82.78(3)$ \\
\hline $\mathrm{N}(1)-\mathrm{Mo}(1)-\mathrm{Cl}(1)$ & $81.00(3)$ & 80.8 & 81.2 & $\mathrm{~N}(3)-\mathrm{Mo}(2)-\mathrm{Cl}(4)$ & $83.83(4)$ \\
\hline $\mathrm{O}(2)-\mathrm{Mo}(1)-\mathrm{Cl}(1)$ & $93.25(4)$ & 93.4 & 95.3 & $\mathrm{O}(6)-\mathrm{Mo}(2)-\mathrm{Cl}(3)$ & $94.90(5)$ \\
\hline $\mathrm{O}(3)-\mathrm{Mo}(1)-\mathrm{Cl}(1)$ & $96.35(5)$ & 98.7 & 97.6 & $\mathrm{O}(5)-\mathrm{Mo}(2)-\mathrm{Cl}(3)$ & $95.21(5)$ \\
\hline $\mathrm{Cl}(2)-\mathrm{Mo}(1)-\mathrm{Cl}(1)$ & $159.509(16)$ & 157.6 & 158.2 & $\mathrm{Cl}(4)-\mathrm{Mo}(2)-\mathrm{Cl}(3)$ & $161.553(16)$ \\
\hline $\mathrm{P}(1)-\mathrm{O}(1)-\mathrm{Mo}(1)$ & $136.76(7)$ & 139.5 & 139.6 & $\mathrm{P}(2)-\mathrm{O}(4)-\mathrm{Mo}(2)$ & $137.52(7)$ \\
\hline $\mathrm{N}(2)-\mathrm{H}(2 \mathrm{~A})-\mathrm{O}(7)$ & $171(2)$ & & 169.5 & $\mathrm{~N}(4)-\mathrm{H}(4 \mathrm{~A})-\mathrm{O}(8)$ & $172(2)$ \\
\hline
\end{tabular}

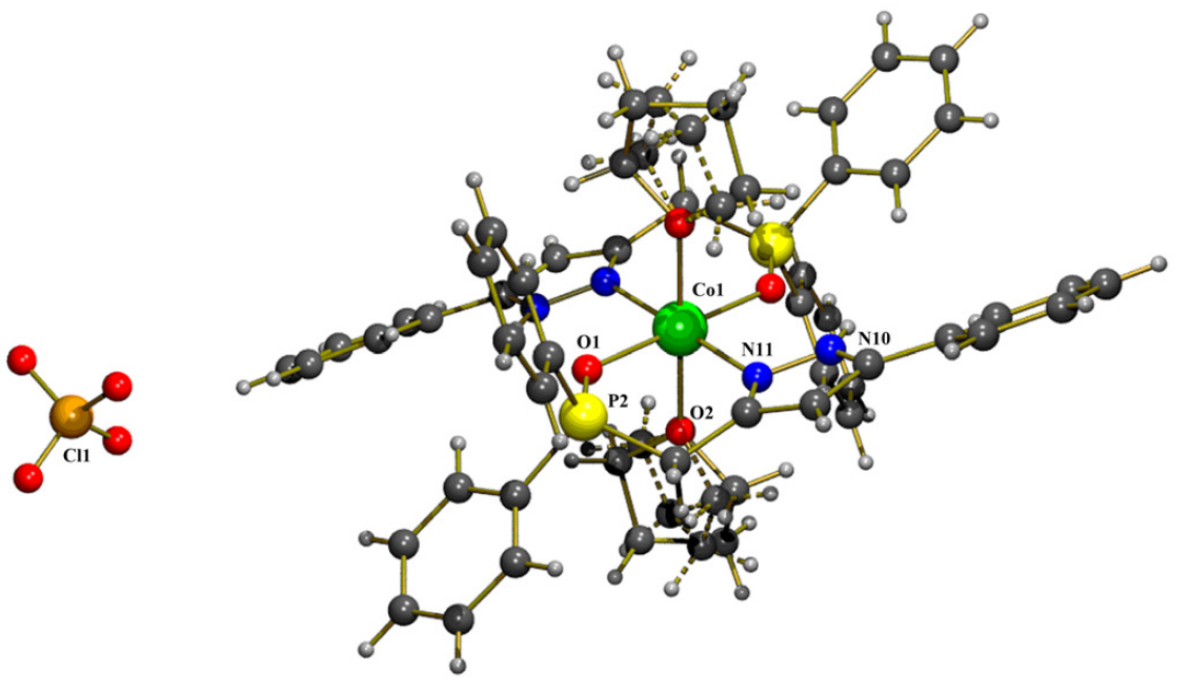

Figure 2.1 Platon ${ }^{30}$ rendered with PovRay ${ }^{31}$ representation of 2 with atoms represented by spheres of arbitrary sizes. The disordered orientation of the THF ligand is drawn with dashes, and only one perchlorate anion is illustrated. Symmetry code: $(\# 1)-x+2,-y,-z+1$. 
calculations were carried out using Gaussian 16, A03 $3^{32}$. An initial geometry for $\mathbf{1}$ was obtained using the UFF option in Avogadro ${ }^{33}$, and those for $\mathbf{2}$ and $\mathbf{3}$ were obtained from the crystal structure results. Functionals B3LYP ${ }^{34,35}$, and APFD ${ }^{36}$ combined

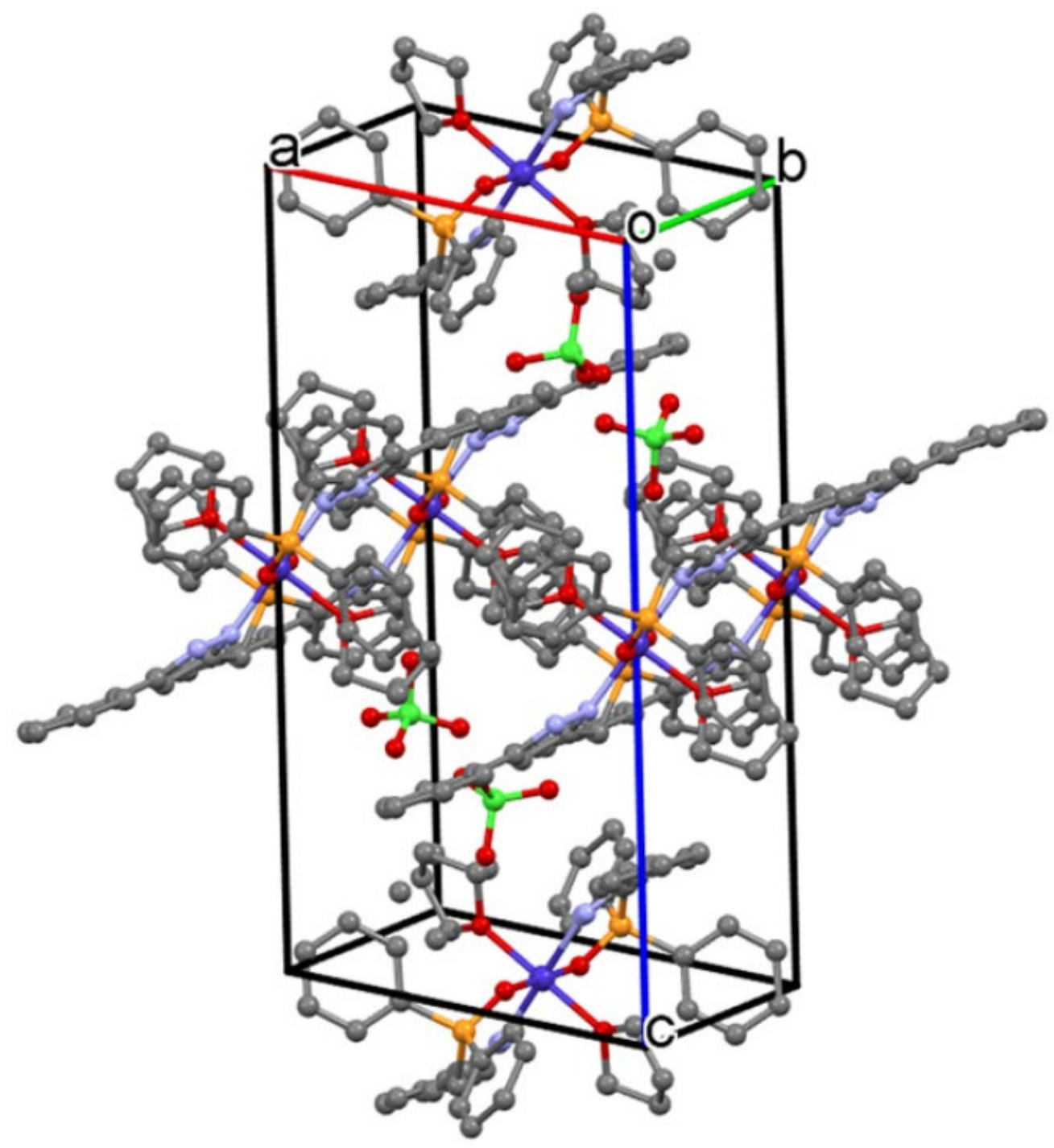

Figure 2.2 Unit cell packing ${ }^{37}$ of $\mathbf{2}$ viewed down the $b$ axis. Atoms are represented by spheres of arbitrary sizes using the default Mercury color scheme, and $\mathrm{H}$-atoms are not illustrated. 
with basis sets $6-311 \mathrm{pG}(\mathrm{d}, \mathrm{p})^{38,39}$ for $\mathbf{1}$, and the LanL2DZ ${ }^{40}$ basis set for the Mo and Co in $\mathbf{2}$ and 3, respectively, were utilized as noted. Frequency calculations were conducted for all structures, and imaginary peaks were not obtained. The program Gauss $\mathrm{Sum}^{41}$ was utilized in checking the progression of the various refinements.

\subsection{Results and Discussion}

The complexes were synthesized as shown in Scheme 2.1. Both were air-stable solids, and $\mathbf{2}$ was pink while $\mathbf{3}$ was light yellow. The results of FTIR spectroscopy (Figures S2.7 and S2.12, supplementary material) confirmed the presence of the ligand in both cases. In $\mathbf{2}$ and $\mathbf{3}$, bending and stretching absorptions for the $\mathrm{P}=\mathrm{O}$ bond were observed at $1081,1026 \mathrm{~cm}^{-1}$ and $1123,1087 \mathrm{~cm}^{-1}$, respectively, compared to $1170 \mathrm{~cm}^{-1}$ for the free ligand ${ }^{17}$. These assignments were based on results from the theoretical calculations described below. A large absorption at 695 and $689 \mathrm{~cm}^{-1}$ for $\mathbf{2}$ and $\mathbf{3}$, respectively, could be assigned to a bending mode involving the $\mathrm{P}=\mathrm{O}$ bond. For $\mathbf{2}$, an absorption at $3417 \mathrm{~cm}^{-1}$ was ascribed to a $v_{(\mathrm{NH})}$ stretch, but a band in this area was not observed for $\mathbf{3}$, possibly due to the formation of a hydrogen bond between the H-atom and an O-atom from the THF solvate (as determined by single-crystal X-ray determination).

Decomposition upon thermal analysis of $\mathbf{2}$ and $\mathbf{3}$ was carried out using TGA, and the traces are given in the Supplementary Information (Figures S2.2-S2.5, supplementary material). The figures contain speculative molecular fragments which may have been produced with the weights of these indicated for comparison. Under a mostly 
$\mathrm{Co}\left(\mathrm{ClO}_{4}\right)_{2} 6 \mathrm{H}_{2} \mathrm{O}$

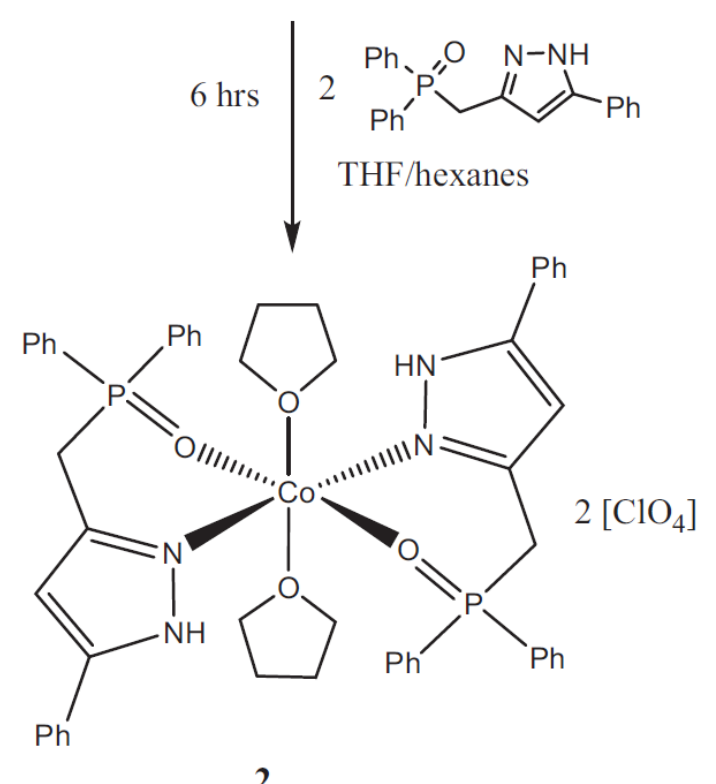

$\mathrm{Mo}_{2} \mathrm{O}_{4} \mathrm{Cl}_{2}$

$\left.6 \mathrm{hrs}\right|_{\mathrm{CH}_{2} \mathrm{Cl}_{2} / \text { hexanes }} ^{\mathrm{Ph}}$

$\downarrow$ THF/hexanes

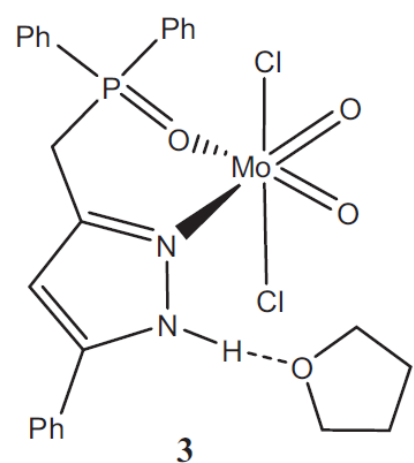

Scheme 2.1 Synthesis of 2 and 3

nitrogen atmosphere, 2 may have lost THF at $266^{\circ} \mathrm{C}$, and then the organic matter is consumed by the perchlorate anions from $360^{\circ} \mathrm{C}$ to $538^{\circ} \mathrm{C}$ resulting in a black powder that was not identified (Figure S2.2, supplementary material). Interestingly, a completely different decomposition pathway is obtained if the heating is conducted under oxygen, as evident in Figure S2.3. Here an abrupt decomposition occurs at $269^{\circ} \mathrm{C}$ with a $72 \%$ mass loss, eventually resulting in $\mathrm{CoO} \cdot \mathrm{Co}_{2} \mathrm{O}_{3}$. The decomposition of $\mathrm{Co}\left(\mathrm{ClO}_{4}\right)_{2} \cdot 6 \mathrm{H}_{2} \mathrm{O}$ was assessed under mostly nitrogen for comparison (Figure S2.4, supplementary material), and this appears to lose three water molecules at $140^{\circ} \mathrm{C}$ and then collapse to $\mathrm{CoO} . \mathrm{Co}_{2} \mathrm{O}_{3}$ over the temperature range of $227-260^{\circ} \mathrm{C}$ is based on the final weight produced. This mixed oxidation state species was also suggested to be produced in the TGA analysis of a cobalt-containing polymer ${ }^{42}$; suggesting that this mixed oxide species may also be produced in the decomposition of $\mathbf{2}$ when conducted under an oxygen atmosphere. Our apparatus is not completely sealed and is not capable of preventing some oxygen from getting into the reaction chamber. In a TGA measurement on lanthanide triflates and perchlorates with N,N,N,N'- 
tetramethylsuccinamide, no weight loss was observed up to $220^{\circ} \mathrm{C}$, but at higher temperatures, ejection of sample from the reaction pan was observed, which resulted in variable and unreliable results ${ }^{43}$. The TGA for $\mathbf{3}$ was conducted under mostly nitrogen and demonstrated the loss of the H-bonded THF molecule at $150^{\circ} \mathrm{C}$ and then a slow decomposition from 280 to $580^{\circ} \mathrm{C}$ ending up in the form of a dark grey brittle substance, possibly $\mathrm{MoO}_{2} \mathrm{Cl}_{2}$, based on the weight at the end (Figure S2.5, supplementary material).

Ball and stick representations of $\mathbf{2}$ and $\mathbf{3}$ are given in Figures 2.1 and 2.3, respectively. Comparisons of selected bond angles and distances are given in Tables 2.2 and 2.3 for $\mathbf{2}$ and $\mathbf{3}$ and their respective theoretically calculated structures. Complex 2 features the Co ion situated on an inversion point with the two ligands arranged trans on the equatorial plane with two THF molecules (disordered) bonded axially, resulting in an octahedral geometry. The fact that the cobalt to ligand atom distances are not that different (i.e., the largest difference is $0.08 \AA$, Table 2.2) would suggest a high spin $\mathrm{d}^{7}$ configuration on the Co. This was confirmed by a mass susceptibility measurement on $\mathbf{2}$, which resulted in a somewhat high value of 5.350 BM (usually 4.7 to $5.2 \mathrm{BM}^{44}$ ), suggesting that orbital coupling pertains as is normally the case with the $\mathrm{d}^{7}$ configuration of $\mathrm{Co}(\mathrm{II})$. A trans-arrangement of the ligand was also reported for similar octahedral cobalt complexes featuring ligands A-E in Chart 2.1. One interesting aspect of the coordination is the fact that the Co-N distance for 2 at 2.0902(15) $\AA$ is significantly shorter than those reported for $\left[\mathrm{Co}(\mathbf{A})_{2}\left(\mathrm{H}_{2} \mathrm{O}\right)_{2}\right]\left(\mathrm{ClO}_{4}\right)_{2}$ at 2.1947(16) and 2.2104(16) $\AA^{19}$, that involved the center atom in a trimer structure with $\mathbf{B}, 2.192(3) \AA^{21}$, trans- $\left[\mathrm{Co}(\mathbf{C})_{2}\left(\mathrm{CH}_{3} \mathrm{OH}\right)_{2}\right]\left(\mathrm{ClO}_{4}\right)_{2}$ at 2.241(2) $\AA$, and trans$\left[\mathrm{Co}(\mathbf{D})_{2}\left(\mathrm{H}_{2} \mathrm{O}\right)_{2}\right]\left(\mathrm{ClO}_{4}\right)_{2}$ at 2.170(2) and 2.189(2) $\AA^{22}$. This would suggest that the substituted pyrazole (pz) $\mathrm{N}$ atom in 1 is a better $\mathrm{r}$-donor of electron density than that of the substituted pyridine (py) and pyrimidine (pyr) ligands in the aforementioned complexes. One ranking of the basicity of these nitrogen heterocycles would be the $\mathrm{pKa}$ values for their protonated states which is for $\mathrm{pyH}, 5.17>\mathrm{pzH}, 2.61>\mathrm{pyrH}, 1.3^{45}$. On this basis, pz would appear to be a better donor of electron density than pyr, but py 
would rank higher than both, and this is ascribed to the inductive withdrawing effect of the second nitrogen atom. However, it should be noted that $\mathbf{2}$ has two hydrogen bonds between adjacent ligands involving $\mathrm{H}$ atoms on the pz moiety and $\mathrm{O}$ atoms attached to P (distance of 2.33(2) $\AA$ ), and this may result in a stronger interaction between $\mathrm{Co}$ and $\mathrm{N}$. It was also discovered in a series of $[\mathrm{MeHgL}]\left(\mathrm{NO}_{3}\right)$ complexes and as assessed by the magnitude of the $2 \mathrm{~J}(1 \mathrm{H}-199 \mathrm{Hg})$ coupling constants, that $\mathrm{N}-$ substituted imidazole and pyrazole ligands were better r-donors than pyridines ${ }^{46}$. The metal to ligand bond distances calculated (DFT) for $\mathbf{2}$ are all slightly longer than those measured by diffraction, but the bond angles are in good agreement (Table 2.2).

The unit cell packing of $\mathbf{2}$ is illustrated in Figure 3.2 and features alternating planes of cobalt complex cations and perchlorate anions as illustrated looking down the $b$ axis. One set of adjacent phenyl groups, each attached to different cobalt complex cations, are in a planar arrangement to each other but skewed so that only the outer edges of the rings approach a distance of $3.462 \AA$. The close approach of the $\mathrm{H}$ atoms bonded to the disordered THF ligand to the perchlorate anions of $2.452 \AA$ would suggest that this proximity may be responsible for the disordered arrangement.

Complex 3, as depicted in Figure 2.3, consists of two distorted octahedral molecules (i.e., labeled as Mo1 and Mo2) in the asymmetric unit. The two oxo ligands have similar O-Mo-O angles of 103.79(6) for O(2)-Mo(1)-O(3) and 103.91(6) ${ }^{\circ}$ for $\mathrm{O}(5)-\mathrm{Mo}(2)-\mathrm{O}(6)$, Table 2.3 . There is a very small but significant difference in the bidentate coordination angles for 1, comparing the $\mathrm{O}(1)-\mathrm{Mo}(1)-\mathrm{N}(1)$ angle of $79.30(4)^{\circ}$ to $\mathrm{O}(4)-\mathrm{Mo}(2)-\mathrm{N}(3)$ of $79.04(4)^{\circ}$ that together with the two oxo ligands constitute the equatorial plane for the molecules. The two chlorides occupy axial positions and contain significantly different $\mathrm{Cl}-\mathrm{Mo}-\mathrm{Cl}$ angles of $159.509(16)^{\circ}$ for $\mathrm{Cl}(2)-\mathrm{Mo}(1)-\mathrm{Cl}(1)$ and $161.553(16)^{\circ}$ for $\mathrm{Cl}(4)-\mathrm{Mo}(2)-\mathrm{Cl}(3)$ and these ligands are bent away from the multiply bonded oxo groups 


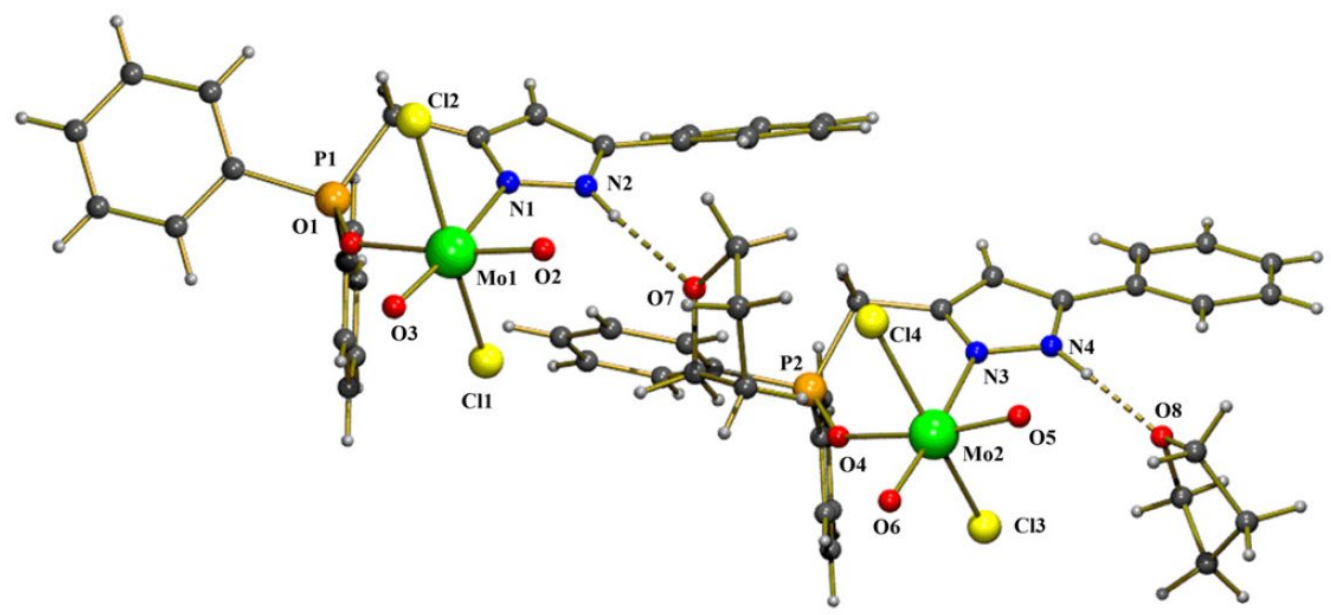

Figure 2.3 Platon ${ }^{30}$ rendered with PovRay ${ }^{31}$ representation of the asymmetric unit for 3 with atoms represented by spheres of arbitrary sizes. The dashed bonds represent the H-bonded interactions between $\mathrm{N} 2$ to $\mathrm{O} 7(\mathrm{~N} 2-\mathrm{H} 2 \mathrm{~A}=0.82(2) \AA, \mathrm{N} 2-07=2.797(2) \AA)$ and $\mathrm{N} 4$ to $\mathrm{O} 8(\mathrm{~N} 4-\mathrm{H} 4 \mathrm{~A}=0.89(2), \mathrm{N} 4-\mathrm{O} 8=2.738(2) \AA)$. Atoms for the THF molecule inclusive of $\mathrm{O} 7$ were generated with symmetry code 1-x, 1-y, 1-z.

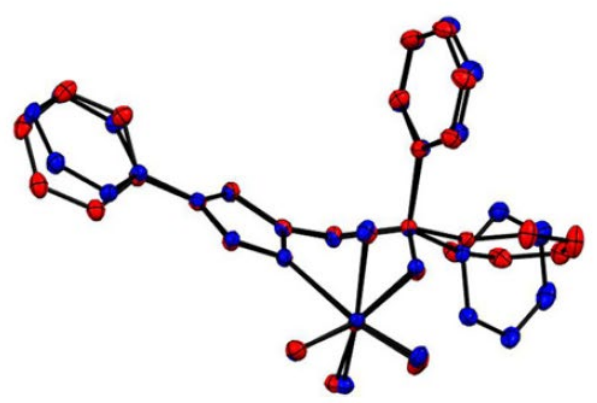

Figure 2.4 Mercury ${ }^{37}$ prepared overlay of the two molecules constituting the asymmetric unit in $\mathbf{3}$. Atoms belonging to the molecule defined by $\operatorname{Mo}(1)$ are in red, and those for $\operatorname{Mo}(2)$ are in blue.

towards $\mathbf{1}$. THF molecules are $\mathrm{H}$-bonded to the $\mathrm{H}$ atom on the pyrazole moiety in both molecules, as shown in Figure 2.3. The four short Mo-Ooxo distances ranging from 1.6879(12) to 1.7021(13) $\AA$ are indicative of multiple bonds, whereas the equatorial 
Mo-O of 2.1799(11) $\AA$ for Mo(1)-O(1) and 2.1675(11) for Mo(2)-O(4) would suggest a single bond. The Mo-N atom bond distances of 2.3510(14) $\AA$ for $\mathrm{Mo}(1)-\mathrm{N}(1)$ and 2.3467(14) $\AA$ for $\mathrm{Mo}(2)-\mathrm{N}(3)$ would suggest a very long bond between these atoms in the two compounds. This appears because the $\mathrm{H}$ atoms attached to $\mathrm{N}(2)$ and $\mathrm{N}(4)$ are H-bonded to a THF molecule (Figure 2.2), and the resulting steric crowding may affect the ability of $\mathrm{N}(1)$ and $\mathrm{N}(2)$ to more effectively bond with Mo. The two Hbonded distances are significantly different, with $\mathrm{O}(7)-\mathrm{H}(2 \mathrm{~A})$ at 1.98(2) $\AA$ and $\mathrm{O}(8)-$ $\mathrm{H}(4 \mathrm{~A})$ at $1.85(2) \AA$. An overlay of the two complexes reveals that the major difference in the conformers is in one of the phenyl rings attached to $\mathrm{P}$, as seen on the right side of the illustration in Figure 2.4. The THF ligands dissociate readily in DMSO, as evident in the ${ }^{1} \mathrm{H}$ NMR spectrum of $\mathbf{3}$ (Figure S2.1). The chemical shift of the THF H-atoms at 1.76 and 3.60 are identical to those reported for THF in $\mathrm{DMSO}^{47}$, suggesting that these THF molecules are

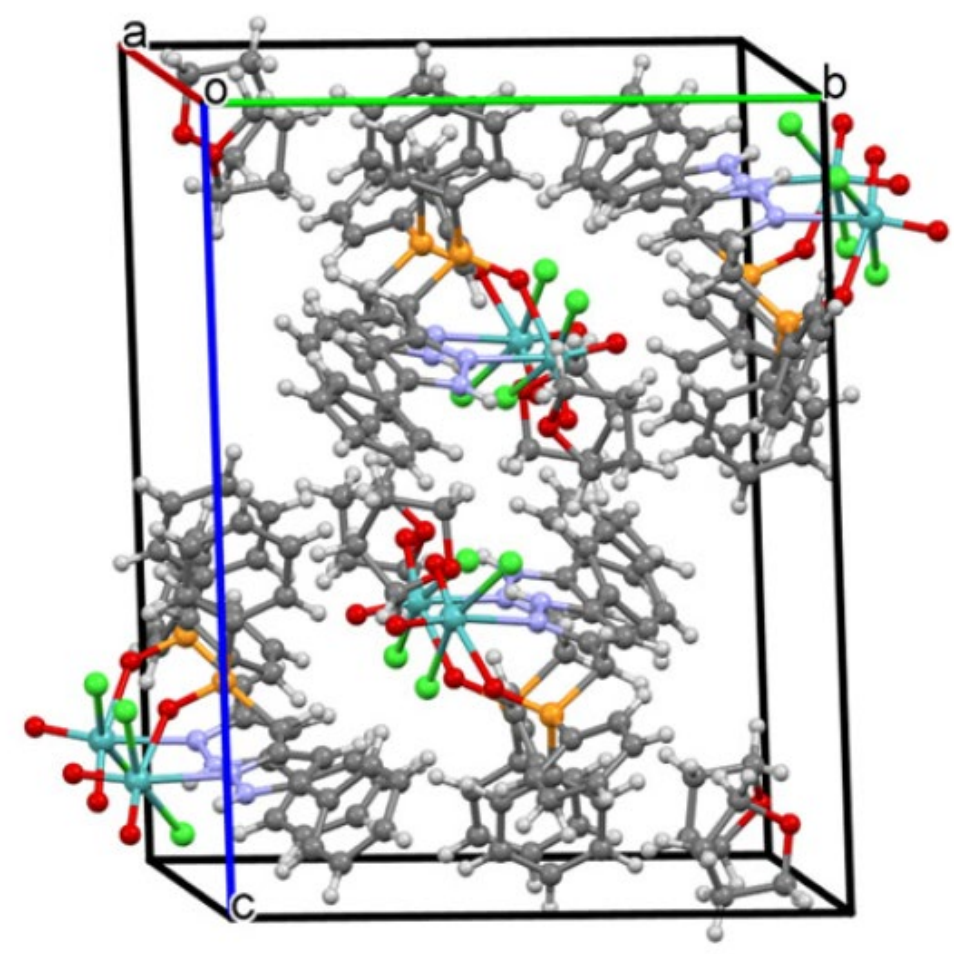

Figure 2.5 Unit cell packing ${ }^{37} \mathrm{a}$ of $\mathbf{3}$ viewed down the $a$ axis. Atoms are represented by spheres of arbitrary sizes using the default Mercury color scheme. 
no longer H-bonded to 3. For the DFT calculation of 3, models with and without THF were utilized. The bond distances listed in Table 2.3 are slightly longer than those obtained crystallographically. The data do show an increase in the Mo(1)-N(1) bond distance of 2.455 to 2.478 (without and with THF, respectively), perhaps as a result of an increased steric hindrance as noted above. There is reasonable agreement between most of the bond angles, but some do differ substantially (Table 2.3).

The unit cell packing for $\mathbf{3}$ is illustrated in Figure 2.5. Molecules are held together by weak H-bonds between the $\mathrm{H}$ atoms on the attached THF ligand on one molecule and the terminal $\mathrm{Cl}$ on an adjacent molecule with the shortest interaction at $2.876 \AA$. The packing arrangement also allows for contacts between $\mathrm{Cl}$ on adjacent molecules of 4.1958(5) $\AA$, but as distances of $4 \AA$ were assessed as contributing only 2 kcals of stability ${ }^{48}$, these contacts within $\mathbf{3}$ are probably not that significant and most likely result in a serendipitous consequence of crystal packing.

The light absorption properties of 1 were previously described and consist of an absorption at $253 \mathrm{~nm}$ and emissions at 309 and $611 \mathrm{~nm}^{17}$. The emission at a higher wavelength was ascribed to Rayleigh second-order scattering ${ }^{49}$. As this ligand was capable of absorbing light and then transmitting this to lanthanide elements $\mathrm{Sm}, \mathrm{Eu}$ and $\mathrm{Tb}^{17}$ based on emission spectra measurements, it was of interest to measure the electronic properties of $\mathbf{2}$ and $\mathbf{3}$. Solutions of $\mathbf{2}$ and $\mathbf{3}$ in $\mathrm{CH}_{2} \mathrm{Cl}_{2}$ absorb at 256 and 255nm as evidenced in Figures S2.9 and S2.18 (supplementary material), respectively. The TD-DFT ${ }^{50}$ calculated values are 355 and $340 \mathrm{~nm}$ for $\mathbf{2}$ (Figure S2.8, supplementary material) and $\mathbf{3}$ (Figure S2.17, supplementary material), respectively, but $300 \mathrm{~nm}$ for 3 without the H-bonded THF ligand (Figure S2.14, supplementary material), in reasonable agreement with the experimentally obtained results ${ }^{51}$. The emission spectra (Figure S2.10 for $\mathbf{2}$ and Figure S2.19 for 3, supplementary material) indicate substantially weakened fluorescence from the bonded ligand, much reduced in comparison to the free ligand, and no fluorescence from either metal center. In the emission spectra peaks 
the large bumps at 365 and 607 emanated either from the $\mathrm{CH}_{2} \mathrm{Cl}_{2}$ solvent (including the large narrow band at $500 \mathrm{~nm}$ ), Figure S2.20 (supplementary material), or from some other intractable impurity as evidenced in Figure S2.20 (supplementary material) which features the emission spectrum of the $\mathrm{CH}_{2} \mathrm{Cl}_{2}$ utilized. Attempts to increase the emission intensity by increasing the concentration of $\mathbf{2}$ was not successful as the intensity of the emission decreased. Excited-state results from the TD-DFT calculations are listed in tables S2.2 and S2.6, and all of these transitions contained very low $f$ values. A difference density diagram featuring the highest $f$ value (i.e., the oscillator strength where a value of 0 indicates a forbidden transition) for $\mathbf{2}$, Figure S2.11 (supplementary material, excited-state 9 with $\mathrm{f}=0.0658$ ), reveals that this transition arose from the p-orbitals on $\mathbf{1}$ and was not transferred to the metal center but distributed among ligand orbitals. For $\mathbf{3}$, calculations at the indicated level of sophistication were able to identify the HOMO to be based primarily on the phenyl pyrazole part of 1, but, as the difference density diagram in Figure S2.21 (supplementary material) for excited state 1 shows, the transfer ends up on an LCAO involving the metal-based orbitals. This is with an $\mathrm{f}$ value of 0.0150 , suggesting a transition that would be very weak. All of the 20 excited states calculated for 3 listed in Table S2.4 contained very low f values, and none had a LUMO, which had contribution from $\pi^{*}$ orbitals on 1 . In conclusion, the experimentally obtained absorption and emission data suggest that, in contrast to the report with lanthanide elements where transfer of electron density occurred from the ligand to the metal, no such transfer takes place in $\mathbf{2}$ and $\mathbf{3}$.

\subsection{Conclusion}

The binding ability of 1 formed coordination complexes with cobalt, i.e., $\mathbf{2}$ and molybdenum, i.e., 3. The complexes were characterized by FTIR, ${ }^{1} \mathrm{H}$ NMR for $\mathbf{3}$, TGA, UV-vis, and single-crystal X-ray diffraction. Electronic transitions were determined experimentally to be primarily ligand-based. DFT calculation with basis sets $6-311 \mathrm{pG}(\mathrm{d}, \mathrm{p})$ for $\mathbf{1}$ and the LanL2DZ basis set for Mo and Co were conducted, and these generated fairly reasonable bond distances and angles for the geometries 
compared to the data obtained crystallographically and allowed for the assignment of the FTIR data.

\subsection{Supplementary Materials}

MoO2C12PN2-d6DMSO-1H

Standard $\mathrm{H}-1$ Observe

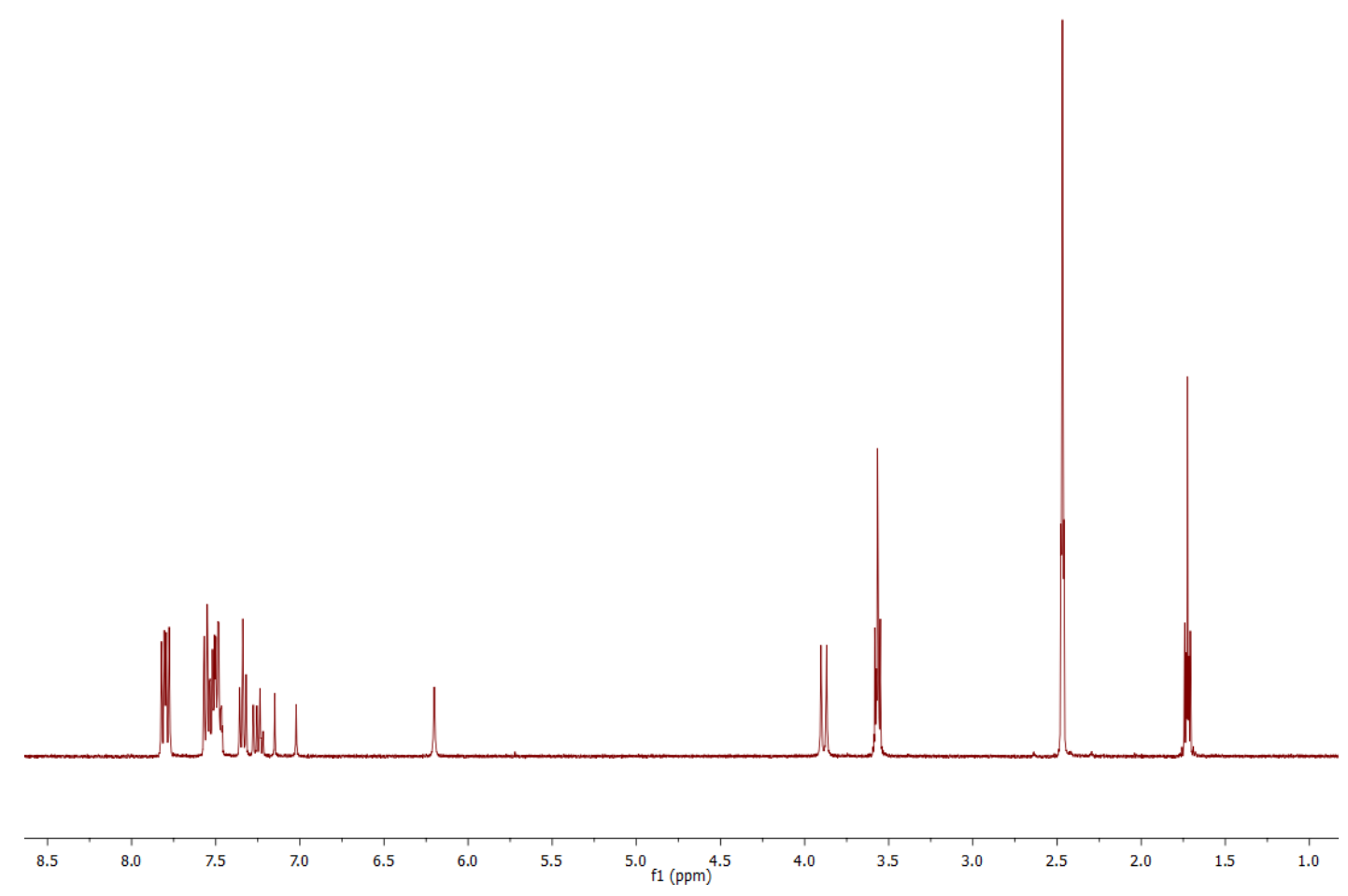

Figure S2.1 ${ }^{1} \mathrm{H}$ NMR spectrum of complex 3 in $\left(\mathrm{CD}_{3}\right)_{2} \mathrm{SO}$. 


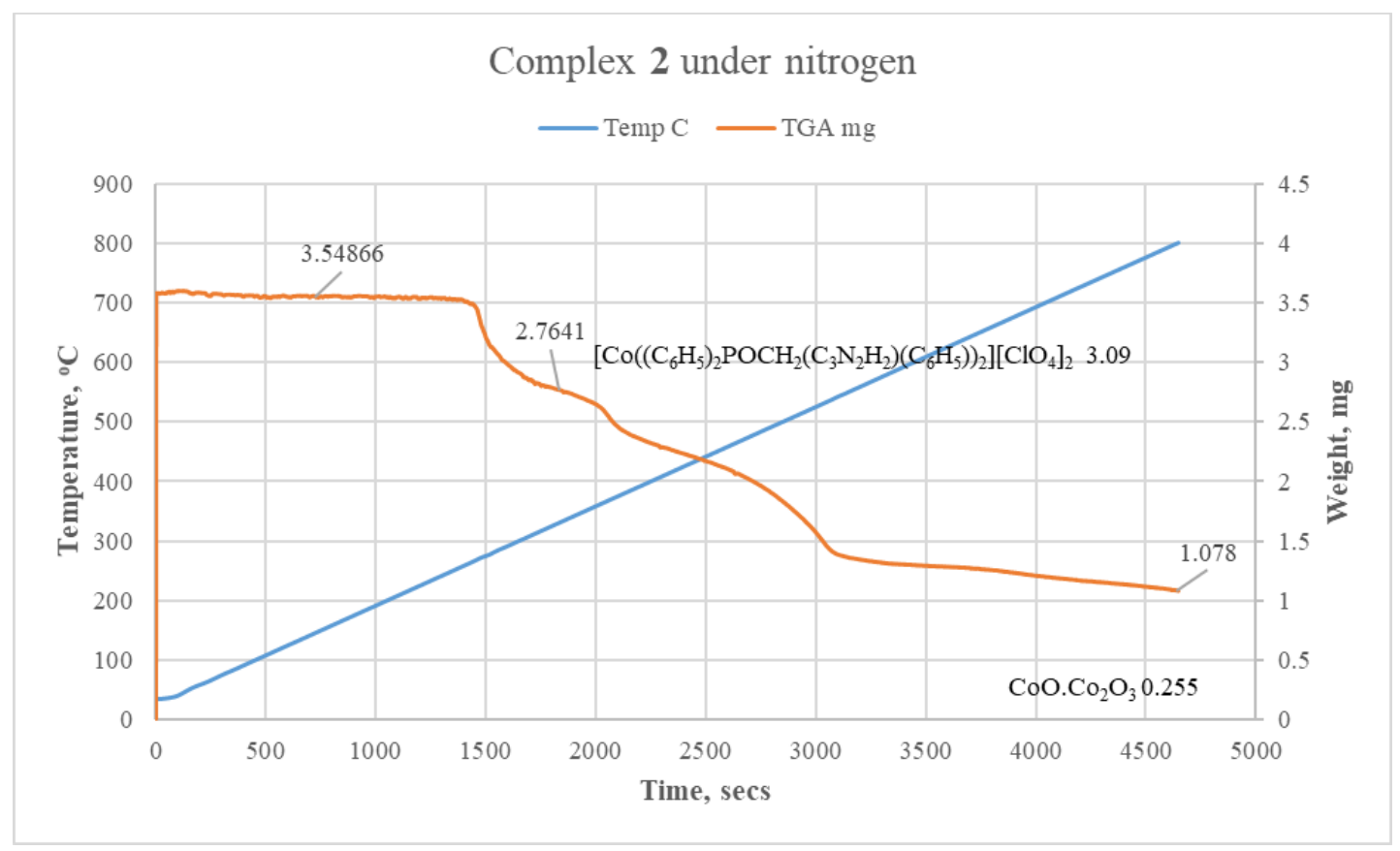

Figure S2.2. TGA for Complex 2 under nitrogen.

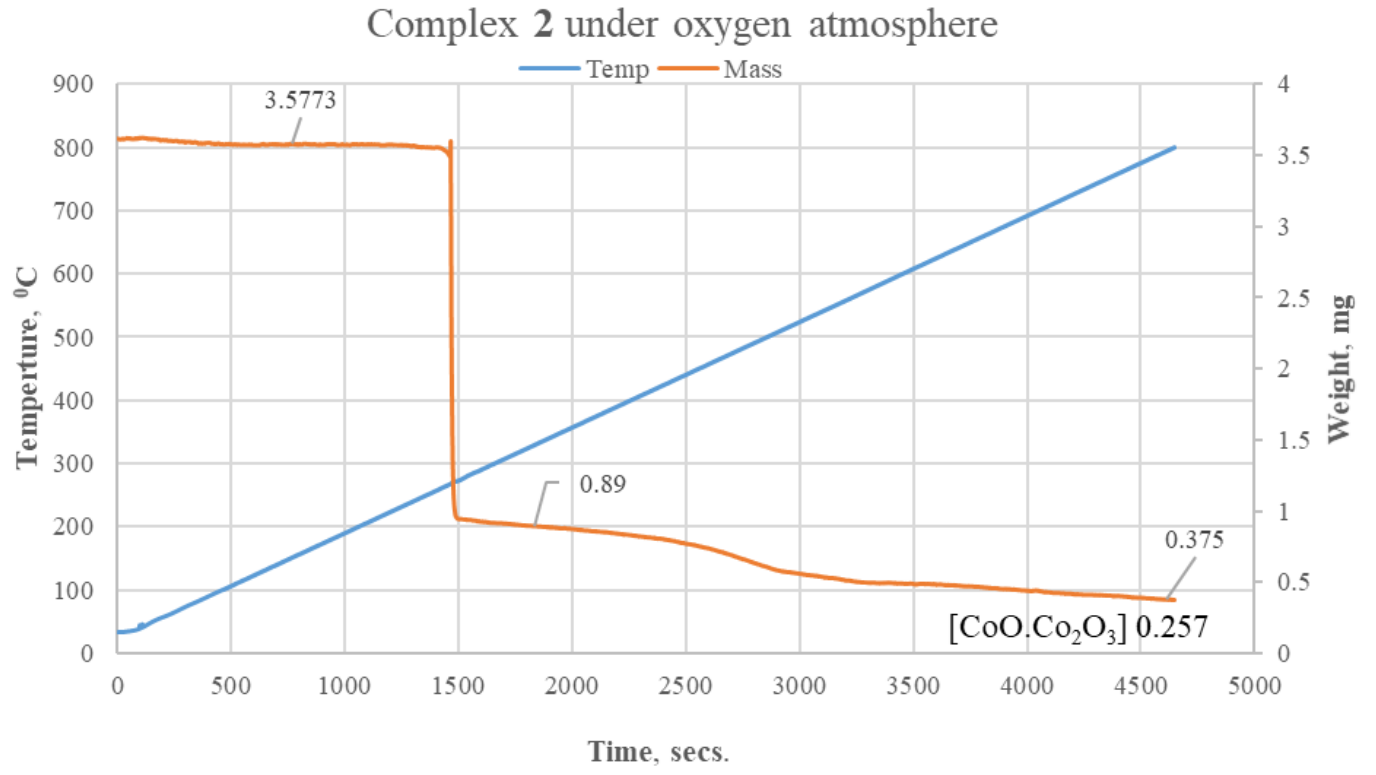

Figure S2.3. TGA for complex 2 under oxygen. 


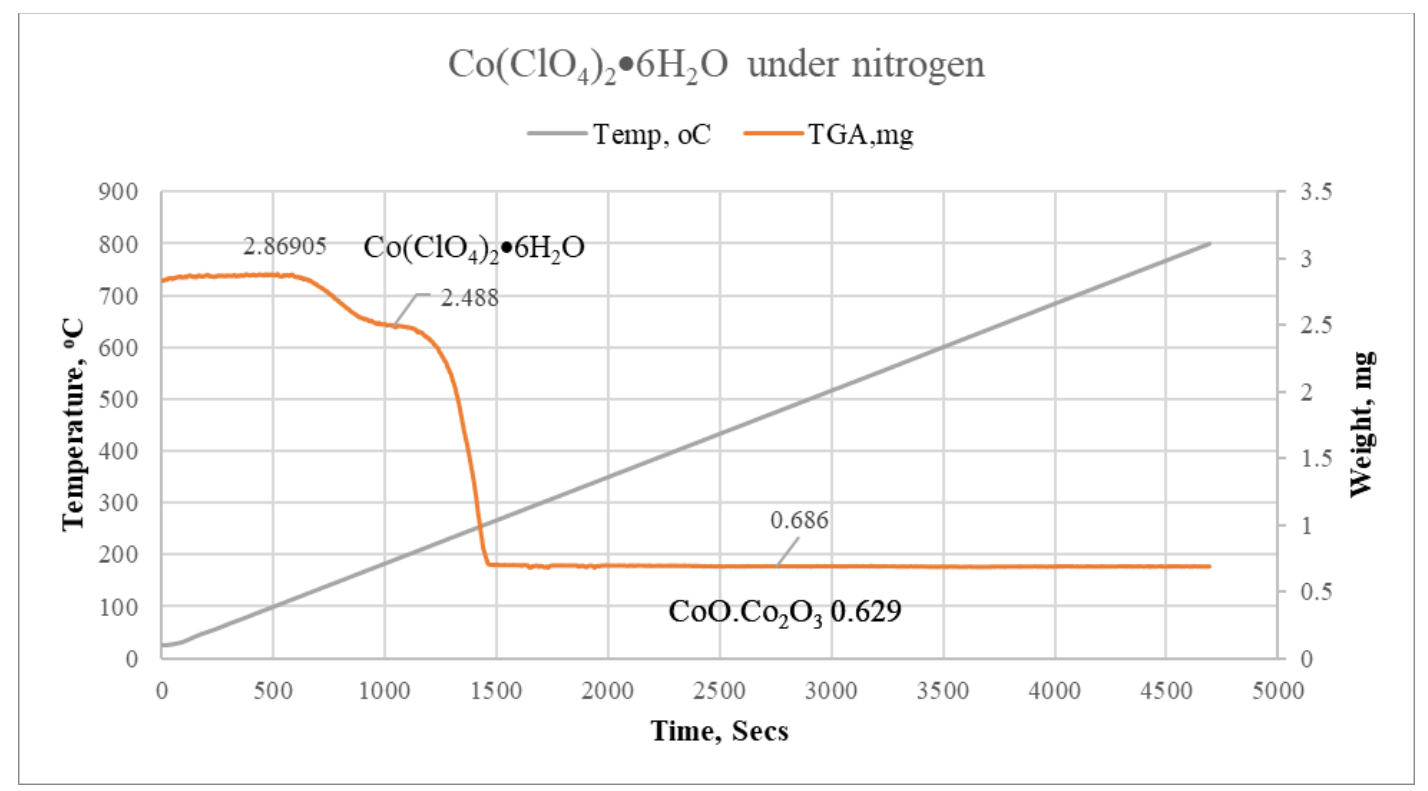

Figure S2.4. TGA for $\mathrm{Co}\left(\mathrm{ClO}_{4}\right)_{2} * 6 \mathrm{H}_{2} \mathrm{O}$ under nitrogen.

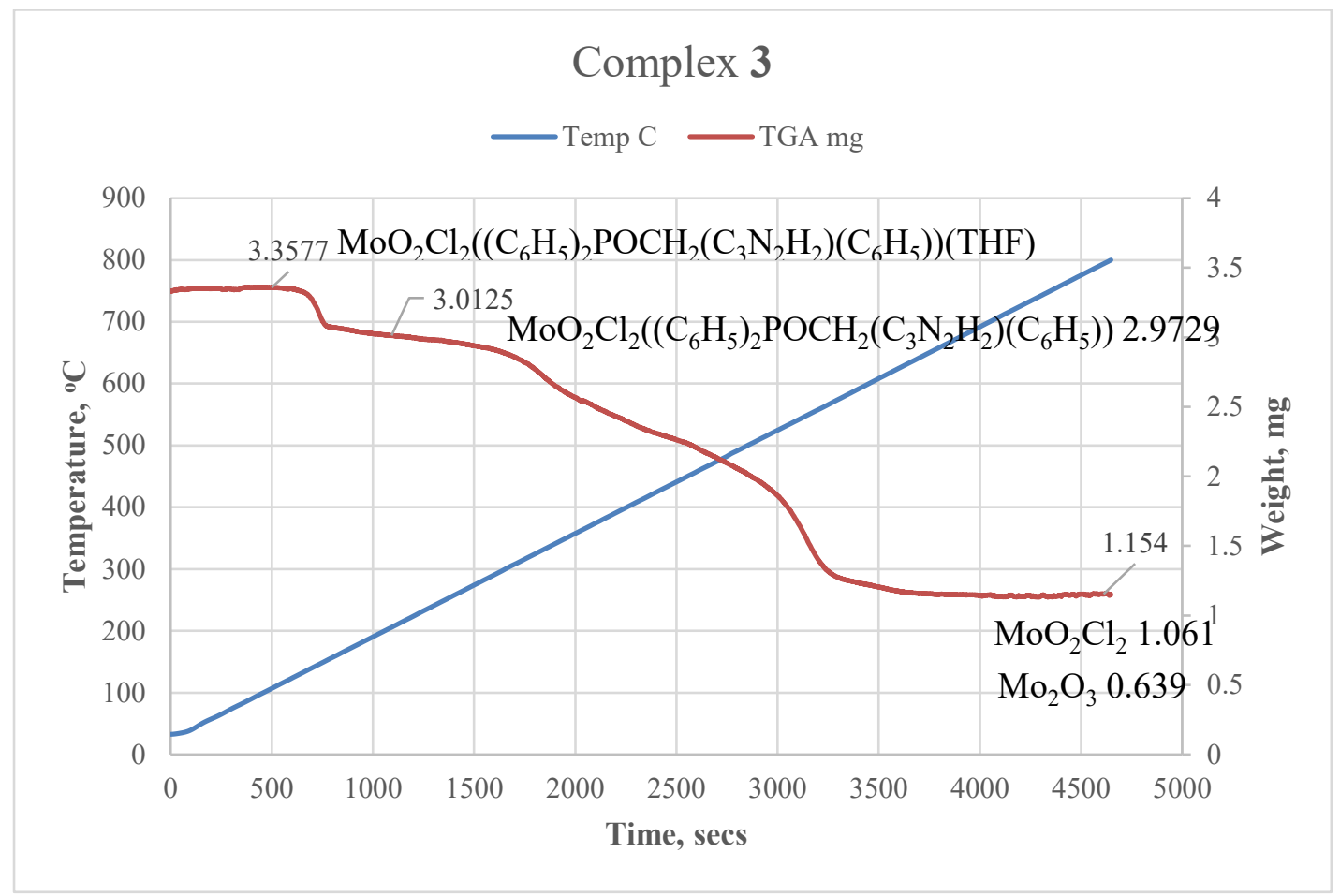

Figure S2.5. TGA for Complex 3 under nitrogen. 
Theoretical Calculations.

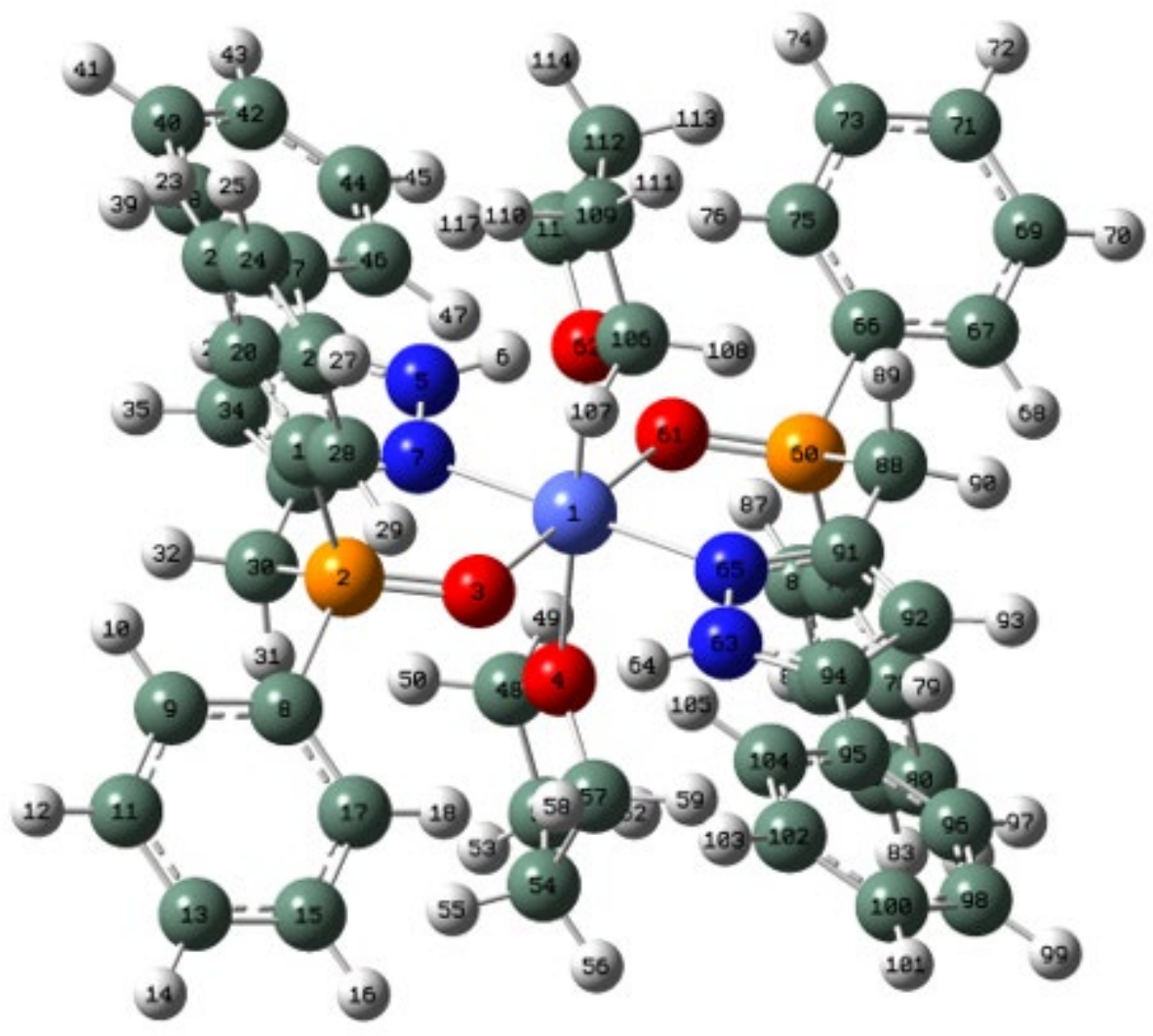

Figure S2.6. Drawing of compound 2 with atoms represented as spheres of arbitrary size (H-white, C-grey, N-blue, and O-red) using the GaussView ${ }^{52}$ program.

Table S2.1. Atomic coordinates for $\mathbf{2}$.

$\begin{array}{llllllllll}\text { Row } & \text { Symbol } & \mathbf{X} & \mathbf{Y} & \mathbf{Z} & 10 & \mathrm{H} & 4.260932 & 4.342892 & 1.184861 \\ 1 & \mathrm{Co} & -0.01866 & -0.00152 & -0.01933 & 11 & \mathrm{C} & 5.787088 & 3.450705 & 2.396672 \\ 2 & \mathrm{P} & 2.381864 & 2.171229 & 0.512861 & 12 & \mathrm{H} & 6.316373 & 4.38533 & 2.537954 \\ 3 & \mathrm{O} & 1.986164 & 0.717375 & 0.2047 & 13 & \mathrm{C} & 6.276182 & 2.275248 & 2.966651 \\ 4 & \mathrm{O} & 0.011928 & -0.66317 & 2.057006 & 14 & \mathrm{H} & 7.186542 & 2.297669 & 3.554063 \\ 5 & \mathrm{~N} & -2.1621 & 2.054374 & 0.533009 & 15 & \mathrm{C} & 5.599555 & 1.071947 & 2.777926 \\ 6 & \mathrm{H} & -2.74216 & 1.309899 & 0.163748 & 16 & \mathrm{H} & 5.981672 & 0.157333 & 3.215399 \\ 7 & \mathrm{~N} & -0.84452 & 1.806112 & 0.659961 & 17 & \mathrm{C} & 4.428693 & 1.040827 & 2.023916 \\ 8 & \mathrm{C} & 3.935363 & 2.218087 & 1.450366 & 18 & \mathrm{H} & 3.905391 & 0.105355 & 1.873887 \\ 9 & \mathrm{C} & 4.621876 & 3.425973 & 1.636572 & 19 & \mathrm{C} & 2.628094 & 3.190312 & -0.97049\end{array}$




\begin{tabular}{|c|c|c|c|c|c|c|c|c|c|}
\hline 20 & $\mathrm{C}$ & 1.775218 & 4.250399 & -1.30051 & 60 & $\mathrm{P}$ & -2.39702 & -2.20216 & -0.49823 \\
\hline 21 & $\mathrm{H}$ & 0.930355 & 4.50056 & -0.67163 & 61 & $\mathrm{O}$ & -2.01673 & -0.73334 & -0.24694 \\
\hline 22 & $\mathrm{C}$ & 2.009165 & 5.000372 & -2.45164 & 62 & $\mathrm{O}$ & -0.03362 & 0.681489 & -2.08609 \\
\hline 23 & $\mathrm{H}$ & 1.349096 & 5.823128 & -2.69873 & 63 & $\mathrm{~N}$ & 2.139024 & -2.02907 & -0.59196 \\
\hline 24 & $\mathrm{C}$ & 3.08853 & 4.695417 & -3.27759 & 64 & $\mathrm{H}$ & 2.70917 & -1.26722 & -0.24051 \\
\hline 25 & $\mathrm{H}$ & 3.270578 & 5.283023 & -4.16965 & 65 & $\mathrm{~N}$ & 0.814193 & -1.80802 & -0.69511 \\
\hline 26 & $\mathrm{C}$ & 3.93879 & 3.636766 & -2.95593 & 66 & $\mathrm{C}$ & -3.96584 & -2.30522 & -1.40587 \\
\hline 27 & $\mathrm{H}$ & 4.780779 & 3.400946 & -3.59552 & 67 & $\mathrm{C}$ & -4.63511 & -3.52966 & -1.54019 \\
\hline 28 & $\mathrm{C}$ & 3.71326 & 2.886848 & -1.80672 & 68 & $\mathrm{H}$ & -4.25128 & -4.42558 & -1.06582 \\
\hline 29 & $\mathrm{H}$ & 4.387823 & 2.075585 & -1.55707 & 69 & $\mathrm{C}$ & -5.81258 & -3.5983 & -2.27836 \\
\hline 30 & $\mathrm{C}$ & 1.134653 & 2.982646 & 1.599922 & 70 & $\mathrm{H}$ & -6.32833 & -4.54561 & -2.37956 \\
\hline 31 & $\mathrm{H}$ & 1.259548 & 2.477734 & 2.564059 & 71 & $\mathrm{C}$ & -6.33093 & -2.45048 & -2.87807 \\
\hline 32 & $\mathrm{H}$ & 1.43478 & 4.020441 & 1.756076 & 72 & $\mathrm{H}$ & -7.25078 & -2.5072 & -3.44815 \\
\hline 33 & $\mathrm{C}$ & -0.30621 & 2.915235 & 1.182171 & 73 & $\mathrm{C}$ & -5.67094 & -1.23104 & -2.7417 \\
\hline 34 & $\mathrm{C}$ & -1.30187 & 3.886736 & 1.372098 & 74 & $\mathrm{H}$ & -6.07518 & -0.33787 & -3.20299 \\
\hline 35 & $\mathrm{H}$ & -1.17929 & 4.867952 & 1.799388 & 75 & $\mathrm{C}$ & -4.48807 & -1.1563 & -2.00967 \\
\hline 36 & $\mathrm{C}$ & -2.49444 & 3.299084 & 0.951205 & 76 & $\mathrm{H}$ & -3.97662 & -0.20894 & -1.90095 \\
\hline 37 & $\mathrm{C}$ & -3.86892 & 3.811051 & 0.934979 & 77 & $\mathrm{C}$ & -2.60381 & -3.17531 & 1.022278 \\
\hline 38 & $\mathrm{C}$ & -4.09979 & 5.187253 & 0.794401 & 78 & $\mathrm{C}$ & -1.73651 & -4.21922 & 1.366302 \\
\hline 39 & $\mathrm{H}$ & -3.26232 & 5.864772 & 0.678505 & 79 & $\mathrm{H}$ & -0.90043 & -4.48088 & 0.730406 \\
\hline 40 & $\mathrm{C}$ & -5.39853 & 5.684903 & 0.782175 & 80 & $\mathrm{C}$ & -1.94574 & -4.9412 & 2.539913 \\
\hline 41 & $\mathrm{H}$ & -5.56337 & 6.749999 & 0.670057 & 81 & $\mathrm{H}$ & -1.27473 & -5.75196 & 2.796988 \\
\hline 42 & $\mathrm{C}$ & -6.48395 & 4.818225 & 0.906261 & 82 & $\mathrm{C}$ & -3.01441 & -4.62431 & 3.375096 \\
\hline 43 & $\mathrm{H}$ & -7.49496 & 5.207955 & 0.895522 & 83 & $\mathrm{H}$ & -3.17743 & -5.1906 & 4.284469 \\
\hline 44 & $\mathrm{C}$ & -6.26382 & 3.448942 & 1.048234 & 84 & $\mathrm{C}$ & -3.87867 & -3.58138 & 3.039879 \\
\hline 45 & $\mathrm{H}$ & -7.10259 & 2.771342 & 1.155668 & 85 & $\mathrm{H}$ & -4.71284 & -3.33623 & 3.686203 \\
\hline 46 & $\mathrm{C}$ & -4.96637 & 2.946853 & 1.066578 & 86 & $\mathrm{C}$ & -3.67824 & -2.85987 & 1.867982 \\
\hline 47 & $\mathrm{H}$ & -4.81063 & 1.883914 & 1.21187 & 87 & $\mathrm{H}$ & -4.36639 & -2.06341 & 1.608374 \\
\hline 48 & $\mathrm{C}$ & -0.97879 & -0.28059 & 3.057246 & 88 & $\mathrm{C}$ & -1.16064 & -3.03636 & -1.58037 \\
\hline 49 & $\mathrm{H}$ & -1.96228 & -0.36587 & 2.599071 & 89 & $\mathrm{H}$ & -1.31387 & -2.57161 & -2.56043 \\
\hline 50 & $\mathrm{H}$ & -0.79935 & 0.760532 & 3.339207 & 90 & $\mathrm{H}$ & -1.44865 & -4.08384 & -1.68992 \\
\hline 51 & $\mathrm{C}$ & -0.7488 & -1.22888 & 4.226916 & 91 & $\mathrm{C}$ & 0.287647 & -2.9323 & -1.19675 \\
\hline 52 & $\mathrm{H}$ & -1.29235 & -2.16361 & 4.072885 & 92 & $\mathrm{C}$ & 1.298495 & -3.88532 & -1.39838 \\
\hline 53 & $\mathrm{H}$ & -1.07107 & -0.79389 & 5.173798 & 93 & $\mathrm{H}$ & 1.186895 & -4.87287 & -1.81395 \\
\hline 54 & $\mathrm{C}$ & 0.766053 & -1.46902 & 4.15899 & 94 & $\mathrm{C}$ & 2.487134 & -3.2709 & -1.00553 \\
\hline 55 & $\mathrm{H}$ & 1.306859 & -0.63206 & 4.608596 & 95 & $\mathrm{C}$ & 3.870371 & -3.75901 & -1.00941 \\
\hline 56 & $\mathrm{H}$ & 1.078089 & -2.386 & 4.660063 & 96 & $\mathrm{C}$ & 4.126232 & -5.13085 & -0.86878 \\
\hline 57 & $\mathrm{C}$ & 1.022505 & -1.52586 & 2.656175 & 97 & $\mathrm{H}$ & 3.302014 & -5.82193 & -0.73861 \\
\hline 58 & $\mathrm{H}$ & 2.000308 & -1.14526 & 2.365876 & 98 & $\mathrm{C}$ & 5.43304 & -5.60702 & -0.87445 \\
\hline 59 & $\mathrm{H}$ & 0.88877 & -2.53342 & 2.255457 & 99 & $\mathrm{H}$ & 5.617035 & -6.66893 & -0.76199 \\
\hline
\end{tabular}




$\begin{array}{llllllllll}100 & \mathrm{C} & 6.502057 & -4.72292 & -1.01678 & 109 & \mathrm{C} & 0.771569 & 1.291491 & -4.22685 \\ 101 & \mathrm{H} & 7.519446 & -5.09585 & -1.01987 & 110 & \mathrm{H} & 1.27414 & 2.244561 & -4.04697 \\ 102 & \mathrm{C} & 6.257114 & -3.3579 & -1.15901 & 111 & \mathrm{H} & 1.140611 & 0.878474 & -5.16646 \\ 103 & \mathrm{H} & 7.082841 & -2.66677 & -1.28047 & 112 & \mathrm{C} & -0.75291 & 1.472411 & -4.20624 \\ 104 & \mathrm{C} & 4.95139 & -2.87735 & -1.15944 & 113 & \mathrm{H} & -1.24534 & 0.618712 & -4.67945 \\ 105 & \mathrm{H} & 4.776167 & -1.81762 & -1.30486 & 114 & \mathrm{H} & -1.08457 & 2.380728 & -4.71046 \\ 106 & \mathrm{C} & 0.999495 & 0.341431 & -3.05852 & 115 & \mathrm{C} & -1.06003 & 1.506144 & -2.71191 \\ 107 & \mathrm{H} & 1.96453 & 0.457088 & -2.56918 & 116 & \mathrm{H} & -2.03081 & 1.08394 & -2.45645 \\ 108 & \mathrm{H} & 0.864684 & -0.70255 & -3.35339 & 117 & \mathrm{H} & -0.98204 & 2.515643 & -2.30107\end{array}$
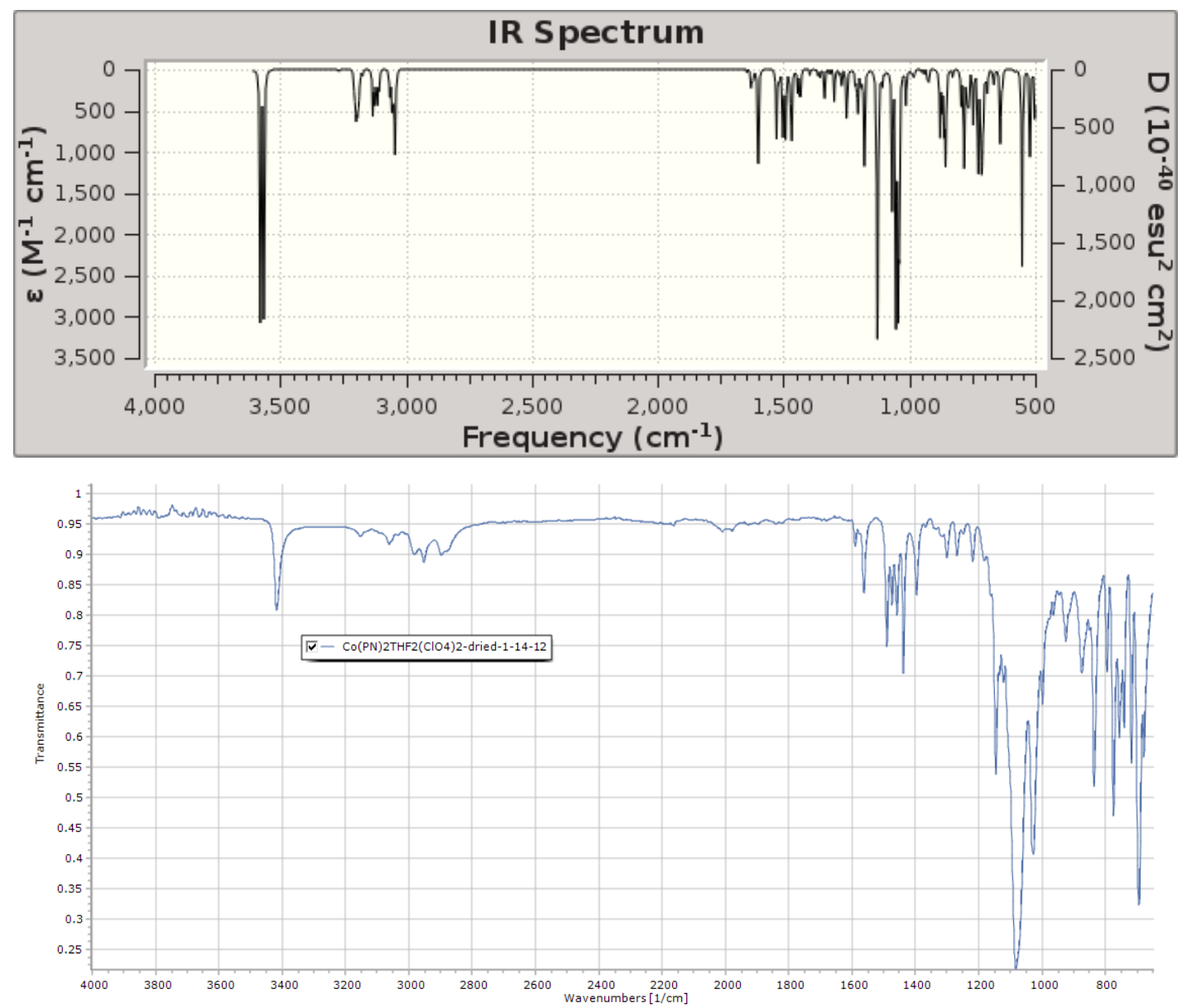

Figure S2.7. Uncorrected calculated FTIR (top) and experimental (neat) spectrum of compound 2. 


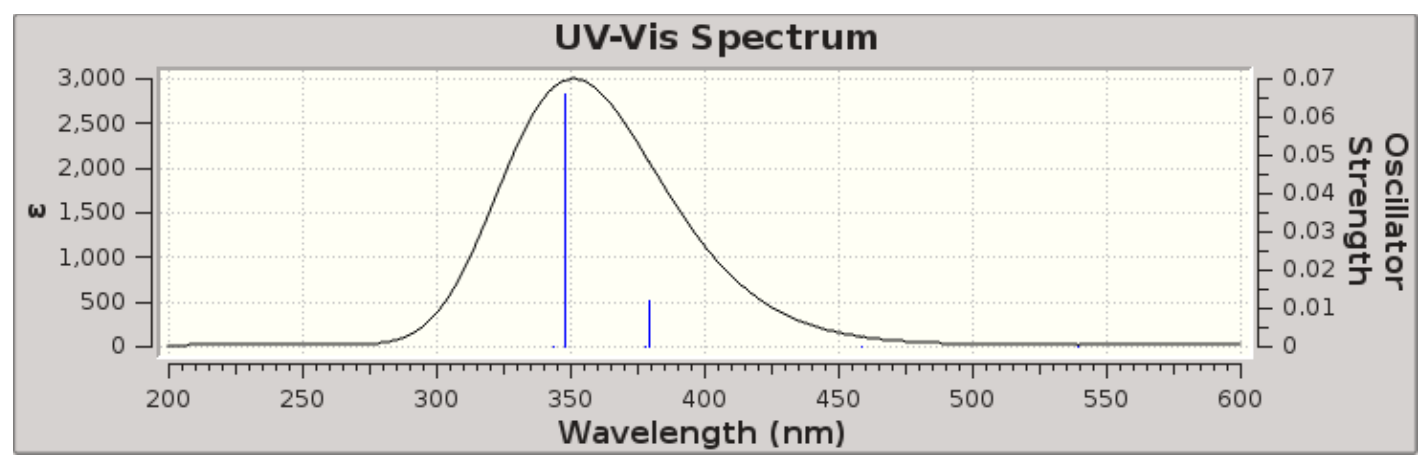

Figure S2.8. Calculated UV-Vis spectrum for 2.

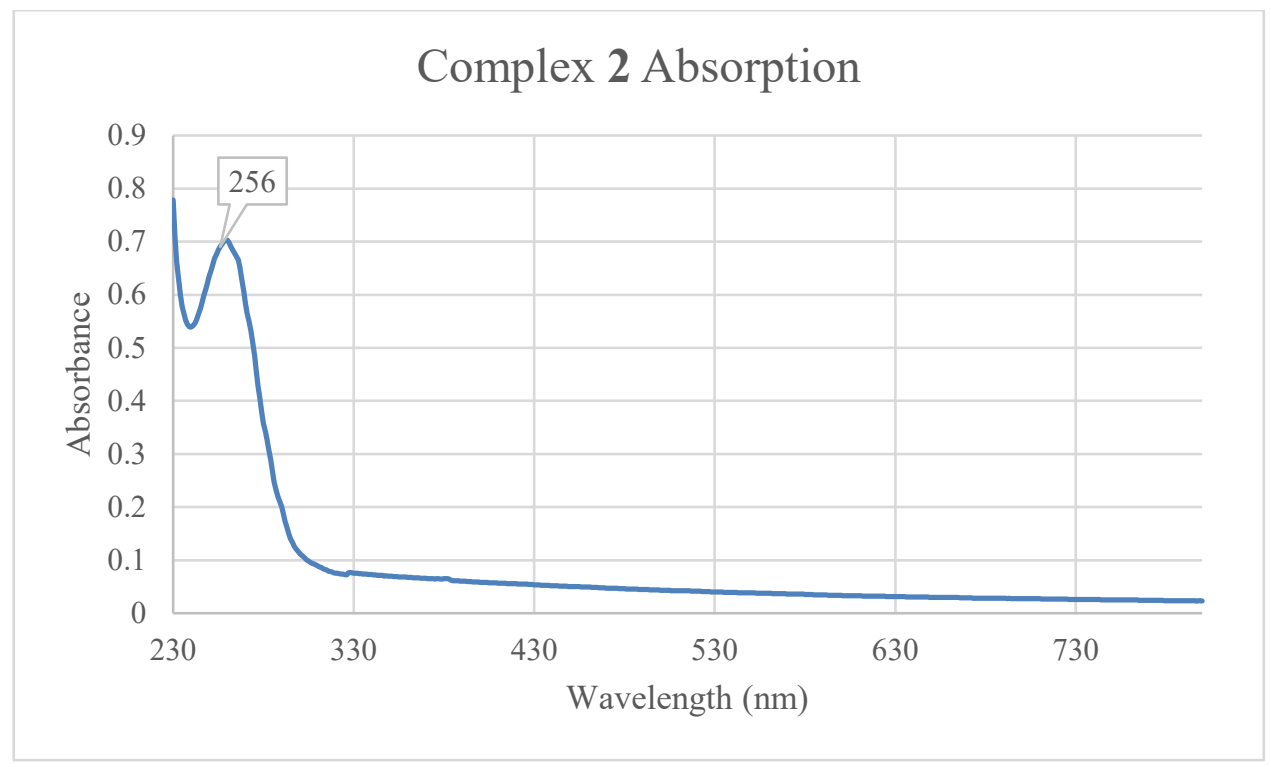

Figure S2.9. UV-vis absorption spectrum of 2 in $\mathrm{CH}_{2} \mathrm{Cl}_{2}$. 


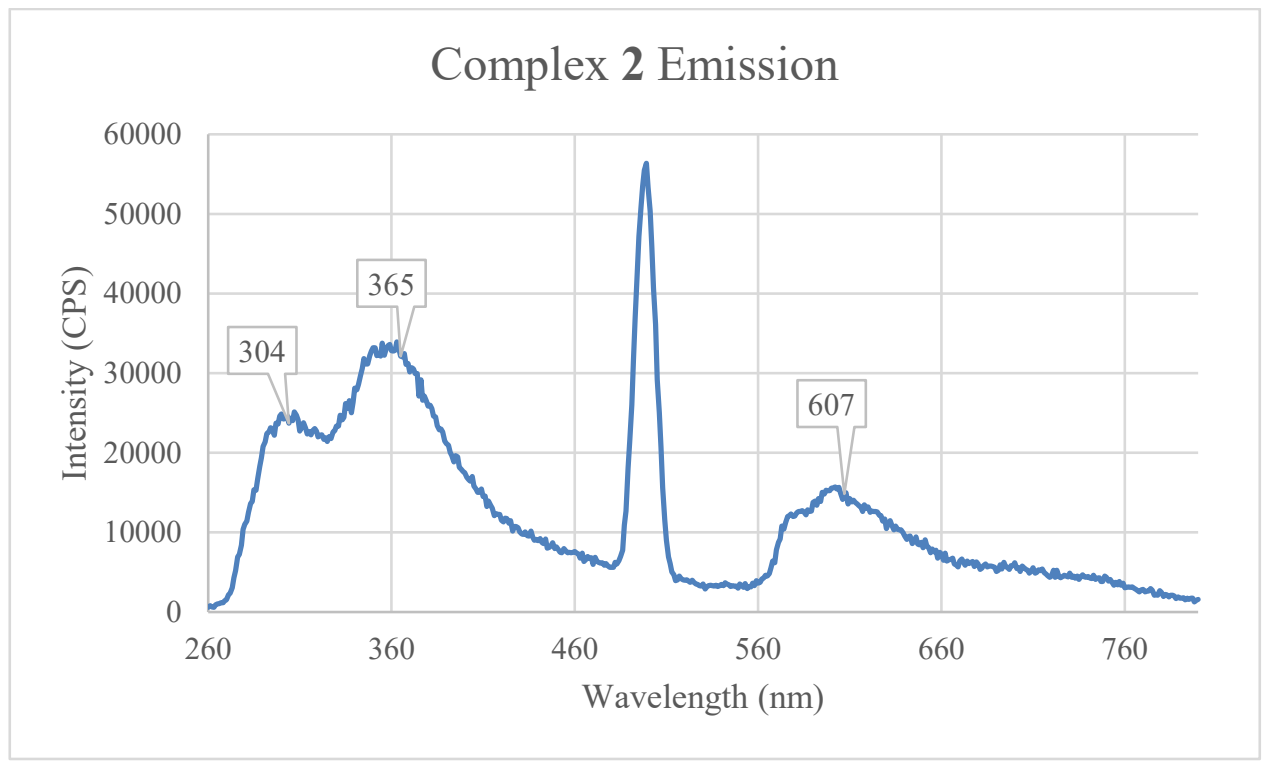

Figure S2.10. Emission spectrum of 2 in $\mathrm{CH}_{2} \mathrm{Cl}_{2}$. 


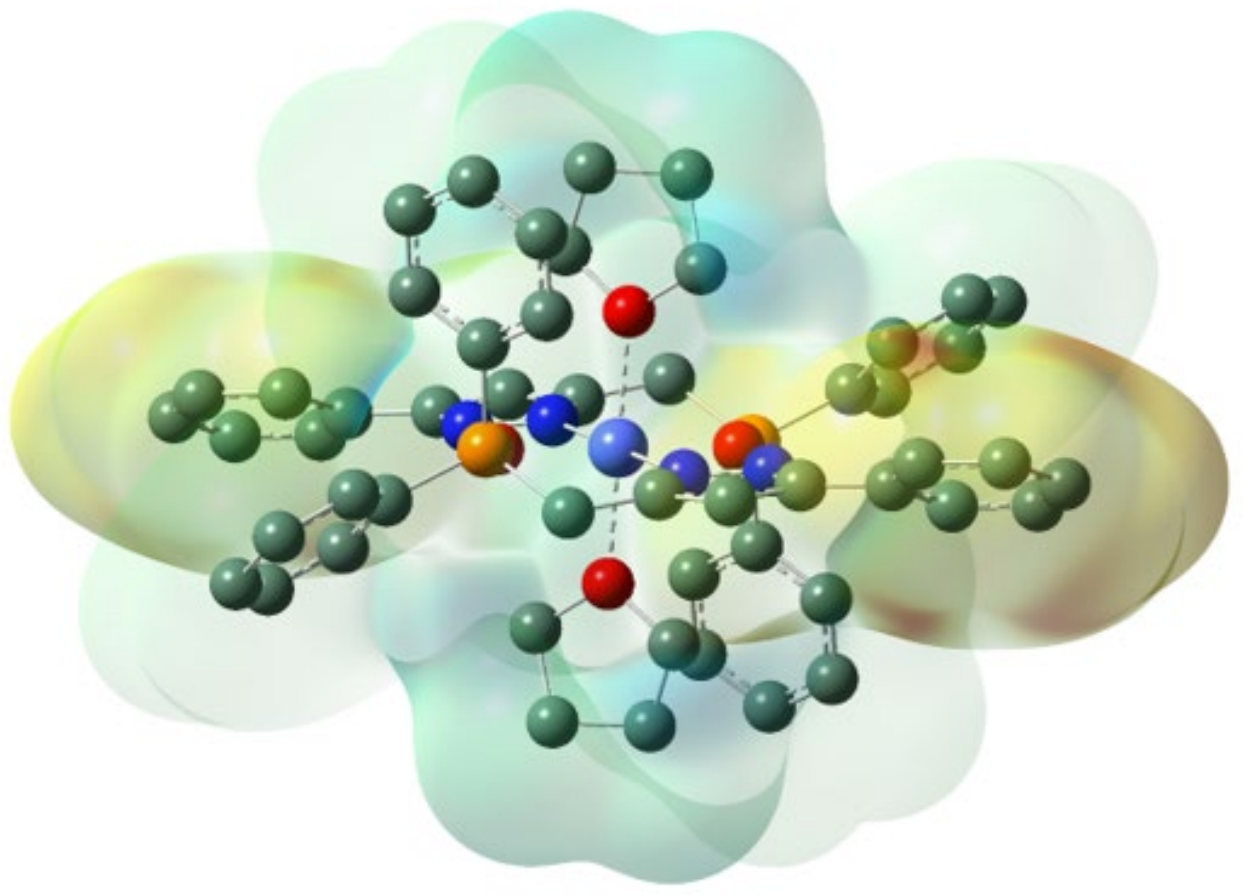

Figure S2.11. Difference density illustrations as iso-surfaces of complex 2 featuring excited state 9. Red areas indicate values for the different densities of $-4.575 \mathrm{e}^{-5}$, and blue are for $4.575 \mathrm{e}^{+5}$; see the scale on top of the illustration.

Table S2.2. Excitation energies and oscillator strength for complex 2

Of the 10 Excited States calculated, numbers 1-6 all had $\mathrm{f}=0$ and are not listed.

Excited State 7: $3.2699 \mathrm{eV} 379.17 \mathrm{~nm} \mathrm{f}=0.0120<\mathrm{S}^{* *} 2>=5.360$

$$
\begin{array}{ll}
235 \mathrm{~A} \rightarrow 249 \mathrm{~A} & 0.12356 \\
236 \mathrm{~A} \rightarrow>239 \mathrm{~A} & 0.32756 \\
236 \mathrm{~A} \rightarrow 241 \mathrm{~A} & 0.16219
\end{array}
$$




$$
\begin{array}{lr}
237 \mathrm{~A}->238 \mathrm{~A} & 0.38446 \\
232 \mathrm{~B}->249 \mathrm{~B} & -0.12313 \\
233 \mathrm{~B}->235 \mathrm{~B} & 0.51914 \\
233 \mathrm{~B}->240 \mathrm{~B} & -0.32932 \\
234 \mathrm{~B}->237 \mathrm{~B} & 0.39114
\end{array}
$$

Excited-state symmetry could not be determined.

Excited State 8: $3.2827 \mathrm{eV} 377.69 \mathrm{~nm} \mathrm{f}=0.0002<\mathrm{S} * * 2>=5.472$

$$
\begin{array}{lr}
234 \mathrm{~A}->248 \mathrm{~A} & -0.12997 \\
235 \mathrm{~A}->249 \mathrm{~A} & -0.10160 \\
236 \mathrm{~A}->238 \mathrm{~A} & -0.40323 \\
237 \mathrm{~A}->239 \mathrm{~A} & -0.35297 \\
237 \mathrm{~A}->241 \mathrm{~A} & -0.17487 \\
231 \mathrm{~B}->248 \mathrm{~B} & 0.12869 \\
231 \mathrm{~B}->249 \mathrm{~B} & -0.10172 \\
232 \mathrm{~B}->249 \mathrm{~B} & 0.10051 \\
233 \mathrm{~B}->237 \mathrm{~B} & 0.40190 \\
234 \mathrm{~B}->235 \mathrm{~B} & 0.42470 \\
234 \mathrm{~B}->240 \mathrm{~B} & -0.35126
\end{array}
$$

Excited-state symmetry could not be determined.

Excited State 9: $3.5607 \mathrm{eV} 348.21 \mathrm{~nm} \mathrm{f}=0.0658<\mathrm{S} * * 2>=4.224$

$$
\begin{array}{ll}
236 \mathrm{~A}->239 \mathrm{~A} & -0.20267 \\
236 \mathrm{~A}->241 \mathrm{~A} & -0.10347 \\
237 \mathrm{~A}->238 \mathrm{~A} & -0.23598 \\
216 \mathrm{~B}->235 \mathrm{~B} & 0.13146 \\
233 \mathrm{~B}->235 \mathrm{~B} & 0.82444 \\
233 \mathrm{~B}->240 \mathrm{~B} & 0.24223 \\
234 \mathrm{~B}->237 \mathrm{~B} & -0.20855
\end{array}
$$


Excited-state symmetry could not be determined.

Excited State 10: $3.6123 \mathrm{eV} 343.22 \mathrm{~nm} \mathrm{f}=0.0002<\mathrm{S} * * 2>=4.116$

$$
\begin{array}{lr}
236 \mathrm{~A}->238 \mathrm{~A} & 0.19182 \\
237 \mathrm{~A}->239 \mathrm{~A} & 0.16812 \\
215 \mathrm{~B}->235 \mathrm{~B} & -0.17587 \\
218 \mathrm{~B}->235 \mathrm{~B} & -0.18954 \\
222 \mathrm{~B}->235 \mathrm{~B} & 0.11160 \\
224 \mathrm{~B}->235 \mathrm{~B} & -0.13338 \\
233 \mathrm{~B}->237 \mathrm{~B} & -0.18662 \\
234 \mathrm{~B}->235 \mathrm{~B} & 0.79749 \\
234 \mathrm{~B}->240 \mathrm{~B} & 0.20793
\end{array}
$$

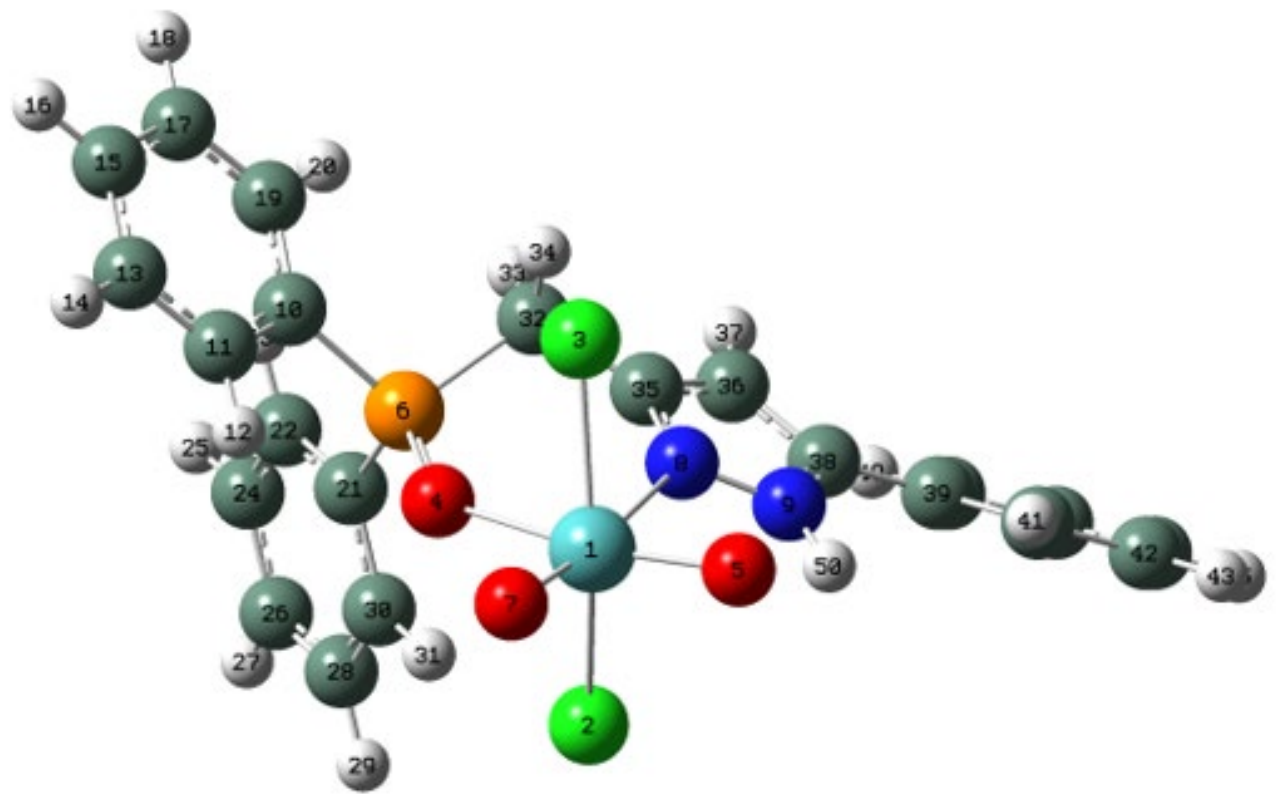

Figure S2.12. Drawing of complex 3-THF with atoms represented as spheres of arbitrary size (H-white, C-grey, N-blue, and O-red) using the GaussView ${ }^{52}$ program. 
Table S2.3. Atomic coordinates for 3-THF.

\begin{tabular}{lllll} 
Row & Symbol & $\mathbf{X}$ & $\mathbf{Y}$ & $\mathbf{Z}$ \\
1 & $\mathrm{Mo}$ & 0.086855 & -2.30858 & 0.749534 \\
2 & $\mathrm{Cl}$ & -0.77129 & -1.06986 & 2.660818 \\
3 & $\mathrm{Cl}$ & 0.971937 & -2.65984 & -1.48426 \\
4 & $\mathrm{O}$ & 1.476902 & -0.57469 & 0.69014 \\
5 & $\mathrm{O}$ & -1.36859 & -3.19089 & 0.536603 \\
6 & $\mathrm{P}$ & 1.781997 & 0.63781 & -0.1834 \\
7 & $\mathrm{O}$ & 1.130298 & -3.37055 & 1.578721 \\
8 & $\mathrm{~N}$ & -1.15585 & -0.55977 & -0.4446 \\
9 & $\mathrm{~N}$ & -2.4906 & -0.54362 & -0.31526 \\
10 & $\mathrm{C}$ & 3.426765 & 0.493876 & -0.93756 \\
11 & $\mathrm{C}$ & 4.338673 & -0.37616 & -0.32931 \\
12 & $\mathrm{H}$ & 4.033419 & -0.95171 & 0.536218 \\
13 & $\mathrm{C}$ & 5.620017 & -0.51439 & -0.85613 \\
14 & $\mathrm{H}$ & 6.321668 & -1.19413 & -0.38702 \\
15 & $\mathrm{C}$ & 5.993871 & 0.206246 & -1.98897 \\
16 & $\mathrm{H}$ & 6.990652 & 0.091935 & -2.39944 \\
17 & $\mathrm{C}$ & 5.083847 & 1.065308 & -2.60355 \\
18 & $\mathrm{H}$ & 5.368842 & 1.615338 & -3.49295 \\
19 & $\mathrm{C}$ & 3.800717 & 1.209403 & -2.08193 \\
20 & $\mathrm{H}$ & 3.099119 & 1.868075 & -2.58196 \\
21 & $\mathrm{C}$ & 1.711533 & 2.153055 & 0.818682 \\
22 & $\mathrm{C}$ & 2.291672 & 3.353573 & 0.387931 \\
23 & $\mathrm{H}$ & 2.842074 & 3.399855 & -0.54497 \\
\hline $\mathrm{H}$ & $\mathrm{H}$ & 2.640074 & 5.423406 & 0.841189
\end{tabular}

\begin{tabular}{lllll}
26 & $\mathrm{C}$ & 1.506905 & 4.446295 & 2.391865 \\
27 & $\mathrm{H}$ & 1.430113 & 5.337354 & 3.004791 \\
28 & $\mathrm{C}$ & 0.937251 & 3.25125 & 2.824644 \\
29 & $\mathrm{H}$ & 0.41661 & 3.207104 & 3.774244 \\
30 & $\mathrm{C}$ & 1.036863 & 2.100867 & 2.043656 \\
31 & $\mathrm{H}$ & 0.601837 & 1.167419 & 2.380784 \\
32 & $\mathrm{C}$ & 0.568747 & 0.803422 & -1.56353 \\
33 & $\mathrm{H}$ & 0.652718 & 1.802773 & -1.99488 \\
34 & $\mathrm{H}$ & 0.871544 & 0.067799 & -2.31414 \\
35 & $\mathrm{C}$ & -0.84245 & 0.540717 & -1.13383 \\
36 & $\mathrm{C}$ & -2.00426 & 1.278845 & -1.42361 \\
37 & $\mathrm{H}$ & -2.07454 & 2.192261 & -1.99057 \\
38 & $\mathrm{C}$ & -3.05887 & 0.54873 & -0.88138 \\
39 & $\mathrm{C}$ & -4.50553 & 0.786606 & -0.87866 \\
40 & $\mathrm{C}$ & -5.41462 & -0.28136 & -0.85299 \\
41 & $\mathrm{H}$ & -5.05418 & -1.30405 & -0.86649 \\
42 & $\mathrm{C}$ & -6.78535 & -0.04144 & -0.84558 \\
43 & $\mathrm{H}$ & -7.47513 & -0.87728 & -0.82832 \\
44 & $\mathrm{C}$ & -7.26955 & 1.265251 & -0.87302 \\
45 & $\mathrm{H}$ & -8.33746 & 1.450271 & -0.86976 \\
46 & $\mathrm{C}$ & -6.37328 & 2.333077 & -0.90622 \\
48 & $\mathrm{H}$ & -6.74268 & 3.35207 & -0.92253 \\
50 & $\mathrm{H}$ & -5.00246 & 2.097529 & -0.90515 \\
& & -2.92089 & -1.27791 & 0.23152 \\
\hline 39 & & & \\
\hline 3 & $\mathrm{H}$ & -4.31124 & 2.932288 & -0.9047 \\
\hline 3 & & &
\end{tabular}



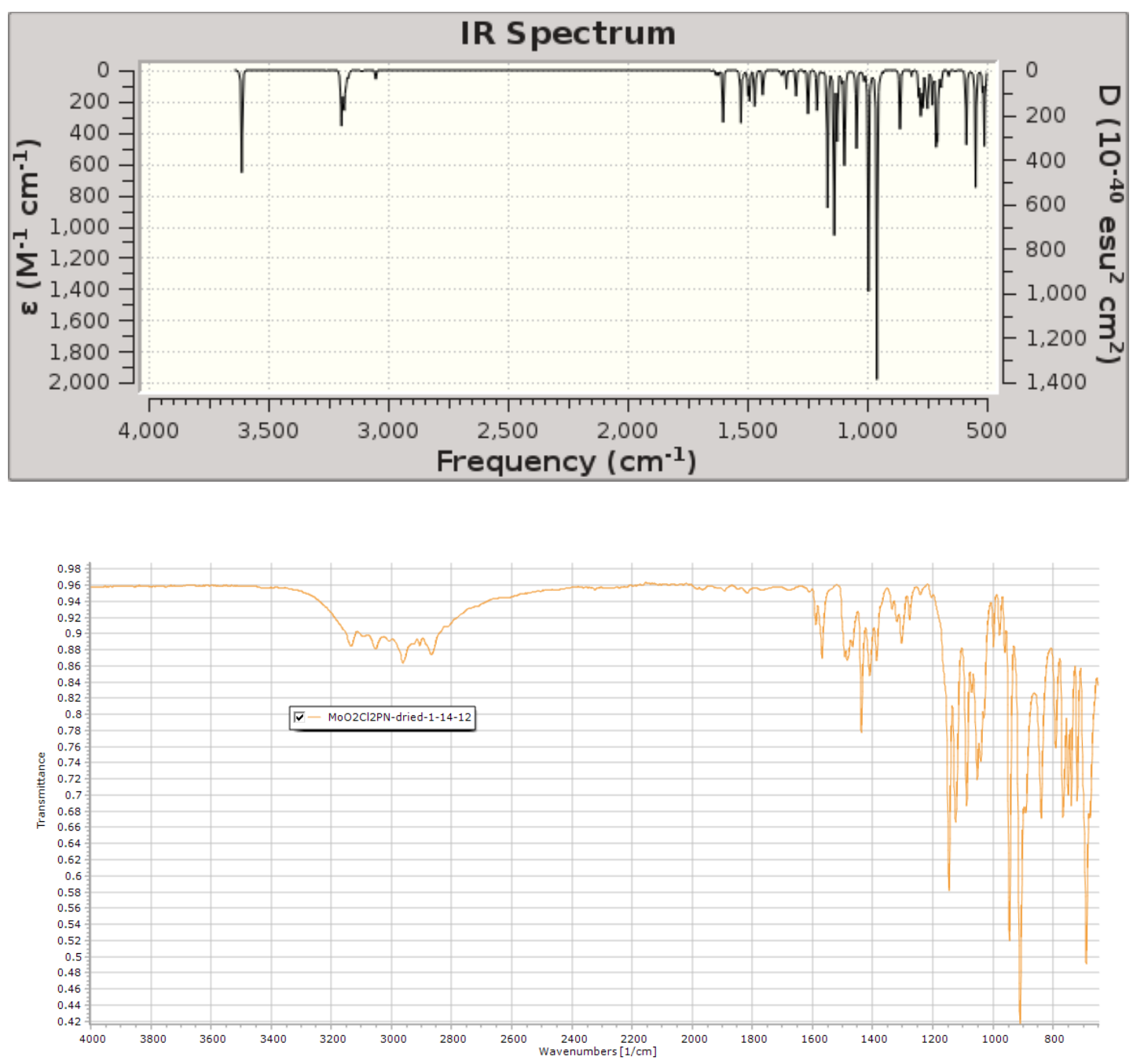

Figure S2.13. Uncorrected calculated FTIR (top) and experimental (neat) spectrum of compound 3-THF. 


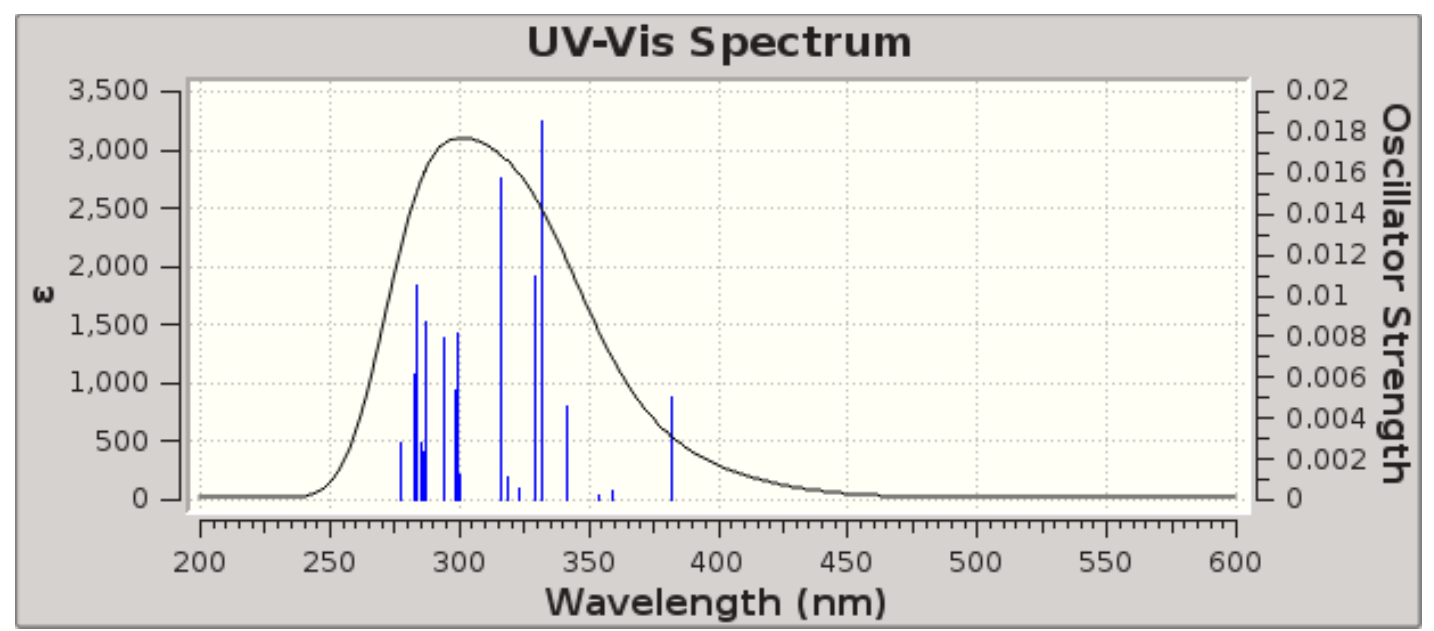

Figure S2.14. Calculated UV-Vis spectrum for 3-THF.

Table S2.4. Excitation Energies and Oscillator Strengths for 3-THF.

Excited State 1: $\quad$ Singlet-A $\quad 3.2471 \mathrm{eV} \quad 381.84 \mathrm{~nm} \mathrm{f}=0.0050<\mathrm{S} * * 2>=0.000$

$$
\begin{array}{ll}
123->127 & 0.12167 \\
124->127 & -0.16728 \\
125->127 & 0.16951 \\
126->127 & 0.63847
\end{array}
$$

This state is for optimization and/or second-order correction.

Total Energy, E(TD-HF/TD-DFT) = -2513.41919938

Copying the excited state density for this state as the 1-particle RhoCI density.

Excited State 2: $\quad$ Singlet-A $\quad 3.4514 \mathrm{eV} 359.23 \mathrm{~nm} \mathrm{f}=0.0004<\mathrm{S} * * 2>=0.000$

$$
\begin{array}{ll}
125->127 & 0.64720 \\
125->128 & -0.12494 \\
126->127 & -0.17906
\end{array}
$$

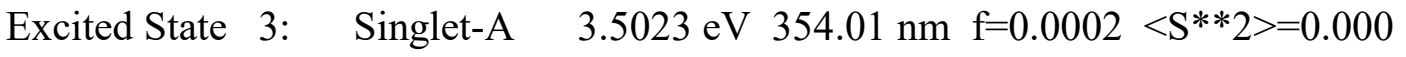
$115->127 \quad-0.32597$ 


$$
\begin{array}{ll}
117->127 & 0.28114 \\
118->127 & -0.12711 \\
120->127 & 0.12828 \\
122->127 & 0.24040 \\
123->127 & 0.32876 \\
124->127 & 0.30449
\end{array}
$$

Excited State 4: $\quad$ Singlet-A $\quad 3.6306 \mathrm{eV} \quad 341.50 \mathrm{~nm} \mathrm{f}=0.0046<\mathrm{S} * * 2>=0.000$

$$
\begin{array}{ll}
115->127 & 0.13256 \\
121->127 & -0.17799 \\
123->127 & -0.33523 \\
124->127 & 0.49530 \\
126->127 & 0.19683
\end{array}
$$

Excited State 5: $\quad$ Singlet-A $\quad 3.7328 \mathrm{eV} \quad 332.15 \mathrm{~nm} \mathrm{f}=0.0186<\mathrm{S} * * 2>=0.000$

$$
\begin{array}{ll}
115->128 & 0.10084 \\
120->127 & 0.12487 \\
124->127 & 0.10330 \\
126->128 & 0.63474
\end{array}
$$

Excited State 6: $\quad$ Singlet-A $\quad 3.7609 \mathrm{eV} \quad 329.67 \mathrm{~nm} \mathrm{f}=0.0110<\mathrm{S} * * 2>=0.000$

$$
\begin{array}{ll}
115->127 & 0.24921 \\
120->127 & 0.41889 \\
121->127 & 0.37316 \\
125->128 & 0.11490 \\
126->128 & -0.14380
\end{array}
$$

Excited State 7: $\quad$ Singlet-A $\quad 3.8384 \mathrm{eV} 323.01 \mathrm{~nm} \mathrm{f}=0.0006<\mathrm{S} * * 2>=0.000$ $115->127 \quad 0.43593$ 


$\begin{array}{ll}115->128 & 0.25707 \\ 117->128 & -0.15314 \\ 122->127 & 0.13802 \\ 122->128 & -0.11521 \\ 123->127 & 0.27149 \\ 123->128 & -0.17953 \\ 124->128 & -0.11762\end{array}$

Excited State 8: $\quad$ Singlet-A $\quad 3.8950 \mathrm{eV} \quad 318.32 \mathrm{~nm} \mathrm{f}=0.0011<\mathrm{S} * * 2>=0.000$ $115->127-0.17057$

$115->128 \quad 0.18463$

$123->127-0.10403$

$123->128 \quad-0.20541$

$125->128 \quad 0.57423$

Excited State 9: $\quad$ Singlet-A $\quad 3.9266 \mathrm{eV} \quad 315.75 \mathrm{~nm} \mathrm{f}=0.0157<\mathrm{S} * * 2>=0.000$
$115->127-0.19034$
$115->128 \quad 0.36534$
$117->128 \quad-0.17443$
$120->127 \quad 0.18451$
$121->127 \quad 0.16534$
$123->127-0.15981$
$123->128 \quad-0.13077$
$124->128 \quad-0.11009$
$125->128 \quad-0.29745$
$126->128 \quad-0.11307$

Excited State 10: Singlet-A $\quad 4.1260 \mathrm{eV} \quad 300.49 \mathrm{~nm} \mathrm{f}=0.0012<\mathrm{S} * * 2>=0.000$ $116->127-0.19279$ 


$$
\begin{array}{ll}
117->127 & 0.41534 \\
119->127 & 0.20407 \\
120->127 & 0.27589 \\
121->127 & -0.18972 \\
123->127 & -0.17126 \\
124->127 & -0.25896
\end{array}
$$

Excited State 11: $\quad$ Singlet-A $\quad 4.1473 \mathrm{eV} 298.95 \mathrm{~nm} \mathrm{f}=0.0082<\mathrm{S} * * 2>=0.000$

$$
\begin{array}{ll}
114->127 & -0.10820 \\
119->128 & -0.12282 \\
120->128 & 0.43022 \\
121->128 & 0.27652 \\
123->128 & -0.23999 \\
124->128 & 0.27854
\end{array}
$$

Excited State 12: $\quad$ Singlet-A $\quad 4.1569 \mathrm{eV} 298.26 \mathrm{~nm} \mathrm{f}=0.0054<\mathrm{S} * * 2>=0.000$

$$
\begin{array}{ll}
114->127 & -0.21378 \\
116->127 & 0.11526 \\
120->128 & -0.18988 \\
121->128 & -0.35946 \\
123->128 & -0.16387 \\
124->128 & 0.40779 \\
126->128 & 0.11369
\end{array}
$$

Excited State 13: $\quad$ Singlet-A $\quad 4.2136 \mathrm{eV} \quad 294.24 \mathrm{~nm} \mathrm{f}=0.0079<\mathrm{S} * * 2>=0.000$

$$
\begin{array}{ll}
123->129 & 0.13524 \\
124->129 & -0.14728 \\
125->129 & 0.10231 \\
126->129 & 0.64243
\end{array}
$$


Excited State 14: Singlet-A $\quad 4.3175 \mathrm{eV} \quad 287.17 \mathrm{~nm} \mathrm{f}=0.0087<\mathrm{S} * * 2>=0.000$
$114->127 \quad 0.11022$
$115->128 \quad 0.38021$
$116->127 \quad-0.10648$
$121->127 \quad-0.17473$
$122->128 \quad 0.19209$
$123->128 \quad 0.29609$
$124->128 \quad 0.23612$
$125->129 \quad-0.23803$

Excited State 15: $\quad$ Singlet-A $\quad 4.3318 \mathrm{eV} \quad 286.22 \mathrm{~nm} \mathrm{f}=0.0024<\mathrm{S}^{* *} 2>=0.000$
$114->127 \quad-0.12438$
$116->127 \quad 0.11857$
$119->127 \quad 0.58812$
$121->127 \quad 0.18587$
$123->128 \quad 0.10847$

Excited State 16: Singlet-A $\quad 4.3527 \mathrm{eV} \quad 284.84 \mathrm{~nm} \mathrm{f}=0.0028<\mathrm{S}^{* *} 2>=0.000$
$117->127 \quad-0.26979$
$118->127 \quad 0.14080$
$119->127 \quad 0.16146$
$120->127 \quad 0.27534$
$121->127 \quad-0.34060$
$123->127 \quad 0.19035$
$125->129 \quad 0.34391$

Excited State 17: $\quad$ Singlet-A $\quad 4.3664 \mathrm{eV} \quad 283.95 \mathrm{~nm} \mathrm{f}=0.0033<\mathrm{S} * * 2>=0.000$ $119->127 \quad-0.10206$ 


$$
\begin{array}{ll}
120->127 & -0.22383 \\
122->127 & 0.46846 \\
123->127 & -0.22261 \\
125->129 & 0.34356
\end{array}
$$

Excited State 18: $\quad$ Singlet-A $\quad 4.3727 \mathrm{eV} \quad 283.54 \mathrm{~nm} \mathrm{f}=0.0105<\mathrm{S} * * 2>=0.000$

$$
\begin{array}{ll}
115->128 & -0.13048 \\
117->127 & -0.24402 \\
118->127 & 0.17097 \\
122->127 & 0.39881 \\
123->128 & -0.17797 \\
125->129 & -0.36097
\end{array}
$$

Excited State 19: Singlet-A $\quad 4.3880 \mathrm{eV} \quad 282.55 \mathrm{~nm} \mathrm{f}=0.0061<\mathrm{S} * * 2>=0.000$

$$
\begin{array}{ll}
113->127 & -0.11385 \\
114->127 & 0.27748 \\
116->127 & -0.31403 \\
118->127 & 0.32745 \\
119->127 & 0.21072 \\
120->127 & -0.13321 \\
121->127 & 0.19691 \\
123->127 & 0.10987 \\
123->128 & -0.10029 \\
124->128 & 0.12495
\end{array}
$$

Excited State 20: $\quad$ Singlet-A $\quad 4.4726 \mathrm{eV} \quad 277.21 \mathrm{~nm} \mathrm{f}=0.0028<\mathrm{S} * * 2>=0.000$

$$
\begin{array}{ll}
114->127 & -0.21094 \\
116->127 & 0.24946 \\
117->127 & 0.24978
\end{array}
$$




$$
118->127 \quad 0.53318
$$

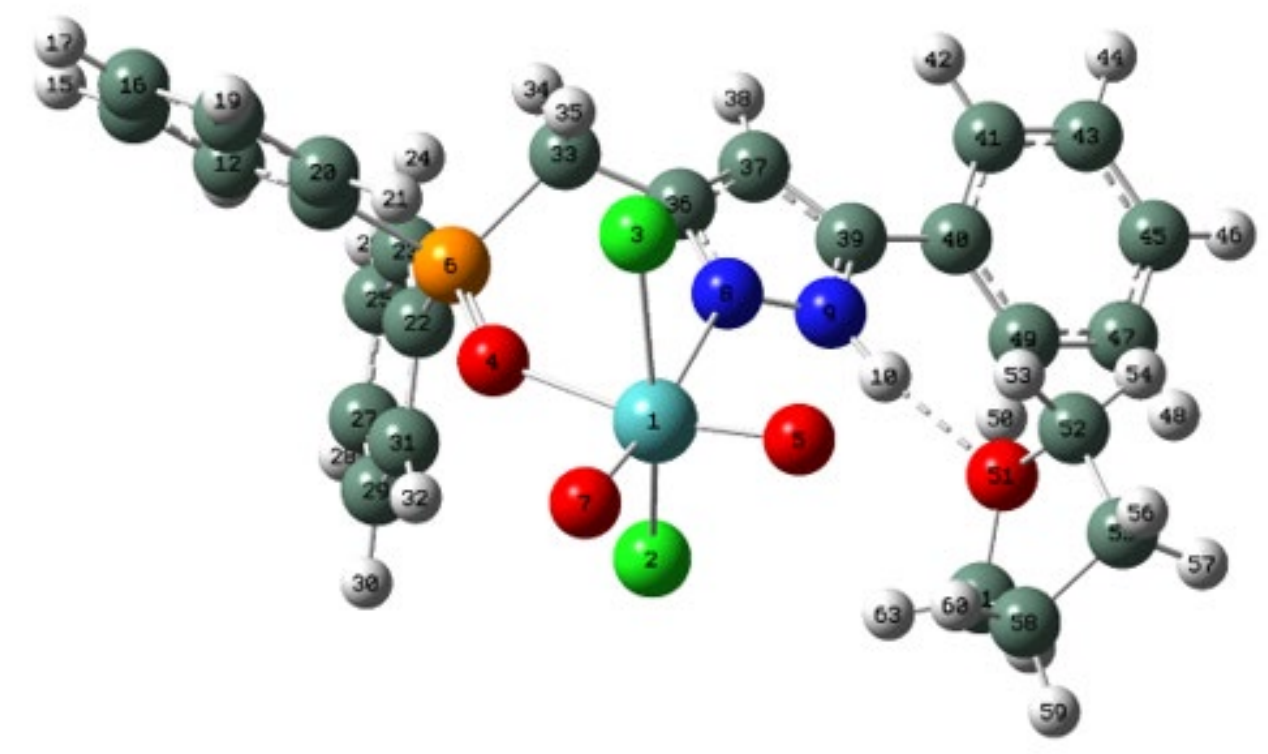

Figure S2.15. Drawing of complex 3 with atoms represented as spheres of arbitrary

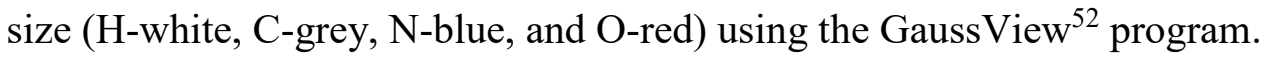

Table S2.5. Atomic coordinates for 3 .

$\begin{array}{lllll}\text { Row } & \text { Symbol } & \mathbf{X} & \mathbf{Y} & \mathbf{Z} \\ 1 & \mathrm{Mo} & 0.103201 & -2.11335 & 0.260193 \\ 2 & \mathrm{Cl} & -0.43066 & -1.00032 & 2.349646 \\ 3 & \mathrm{Cl} & 0.902324 & -2.36761 & -2.03236 \\ 4 & \mathrm{O} & 1.944797 & -0.88518 & 0.442124 \\ 5 & \mathrm{O} & -1.50865 & -2.58572 & -0.08158 \\ 6 & \mathrm{P} & 2.534305 & 0.412901 & -0.10215 \\ 7 & \mathrm{O} & 0.821416 & -3.51643 & 0.906753 \\ 8 & \mathrm{~N} & -0.60145 & 0.088514 & -0.63169 \\ 9 & \mathrm{~N} & -1.87649 & 0.510649 & -0.5193 \\ 10 & \mathrm{H} & -2.59628 & -0.12392 & -0.14073 \\ 11 & \mathrm{C} & 4.221174 & 0.125515 & -0.71609 \\ 12 & \mathrm{C} & 5.271273 & 1.024325 & -0.49616\end{array}$

$\begin{array}{lllll}13 & \mathrm{H} & 5.111051 & 1.926499 & 0.081444 \\ 14 & \mathrm{C} & 6.539307 & 0.74925 & -1.00411 \\ 15 & \mathrm{H} & 7.351608 & 1.444835 & -0.82721 \\ 16 & \mathrm{C} & 6.764044 & -0.42156 & -1.72557 \\ 17 & \mathrm{H} & 7.752778 & -0.63529 & -2.11569 \\ 18 & \mathrm{C} & 5.721796 & -1.32381 & -1.93662 \\ 19 & \mathrm{H} & 5.897458 & -2.24082 & -2.48698 \\ 20 & \mathrm{C} & 4.45169 & -1.0575 & -1.43353 \\ 21 & \mathrm{H} & 3.645726 & -1.76694 & -1.58396 \\ 22 & \mathrm{C} & 2.567005 & 1.709308 & 1.167332 \\ 23 & \mathrm{C} & 2.740337 & 3.0634 & 0.850313 \\ 24 & \mathrm{H} & 2.84718 & 3.383698 & -0.18034 \\ 25 & \mathrm{C} & 2.770062 & 4.017047 & 1.863842\end{array}$




$\begin{array}{lllll}26 & \mathrm{H} & 2.900253 & 5.064101 & 1.615613 \\ 27 & \mathrm{C} & 2.624316 & 3.624272 & 3.19442 \\ 28 & \mathrm{H} & 2.643155 & 4.369007 & 3.982094 \\ 29 & \mathrm{C} & 2.443068 & 2.279777 & 3.510954 \\ 30 & \mathrm{H} & 2.313993 & 1.975275 & 4.54295 \\ 31 & \mathrm{C} & 2.41317 & 1.319373 & 2.50226 \\ 32 & \mathrm{H} & 2.243047 & 0.276727 & 2.73901 \\ 33 & \mathrm{C} & 1.529979 & 1.003049 & -1.52123 \\ 34 & \mathrm{H} & 1.910685 & 1.966097 & -1.86646 \\ 35 & \mathrm{H} & 1.698218 & 0.268547 & -2.31448 \\ 36 & \mathrm{C} & 0.071574 & 1.101046 & -1.1942 \\ 37 & \mathrm{C} & -0.78696 & 2.18226 & -1.43409 \\ 38 & \mathrm{H} & -0.52719 & 3.139664 & -1.85385 \\ 39 & \mathrm{C} & -2.04189 & 1.771091 & -0.99092 \\ 40 & \mathrm{C} & -3.31817 & 2.497826 & -0.99322 \\ 41 & \mathrm{C} & -3.51317 & 3.546954 & -1.90531 \\ 42 & \mathrm{H} & -2.738 & 3.783661 & -2.62469 \\ 43 & \mathrm{C} & -4.69937 & 4.272815 & -1.91131 \\ 44 & \mathrm{H} & -4.83288 & 5.077263 & -2.62578 \\ 45 & \mathrm{C} & -5.71661 & 3.960674 & -1.01002 \\ 46 & \mathrm{H} & -6.64221 & 4.524934 & -1.01508\end{array}$

\begin{tabular}{|c|c|c|c|c|}
\hline 47 & $\mathrm{C}$ & -5.53559 & 2.916159 & -0.10533 \\
\hline 48 & $\mathrm{H}$ & -6.32076 & 2.665855 & 0.599162 \\
\hline 49 & $\mathrm{C}$ & -4.34794 & 2.190066 & -0.09229 \\
\hline 50 & $\mathrm{H}$ & -4.2271 & 1.378563 & 0.613091 \\
\hline 51 & $\mathrm{O}$ & -4.09726 & -1.04951 & 0.382264 \\
\hline 52 & $\mathrm{C}$ & -4.65038 & -1.85642 & -0.6859 \\
\hline 53 & $\mathrm{H}$ & -3.82642 & -2.21206 & -1.31165 \\
\hline 54 & $\mathrm{H}$ & -5.31145 & -1.22132 & -1.28004 \\
\hline 55 & $\mathrm{C}$ & -5.36827 & -3.01779 & 0.000846 \\
\hline 56 & $\mathrm{H}$ & -5.41181 & -3.90606 & -0.63204 \\
\hline 57 & $\mathrm{H}$ & -6.39237 & -2.73526 & 0.264321 \\
\hline 58 & $\mathrm{C}$ & -4.51869 & -3.21804 & 1.265388 \\
\hline 59 & $\mathrm{H}$ & -5.05774 & -3.72262 & 2.069632 \\
\hline 60 & $\mathrm{H}$ & -3.61982 & -3.79186 & 1.032319 \\
\hline 61 & $\mathrm{C}$ & -4.14039 & -1.78407 & 1.634348 \\
\hline 62 & $\mathrm{H}$ & -4.89874 & -1.31727 & 2.274187 \\
\hline 63 & $\mathrm{H}$ & -3.16484 & -1.69923 & 2.113033 \\
\hline
\end{tabular}



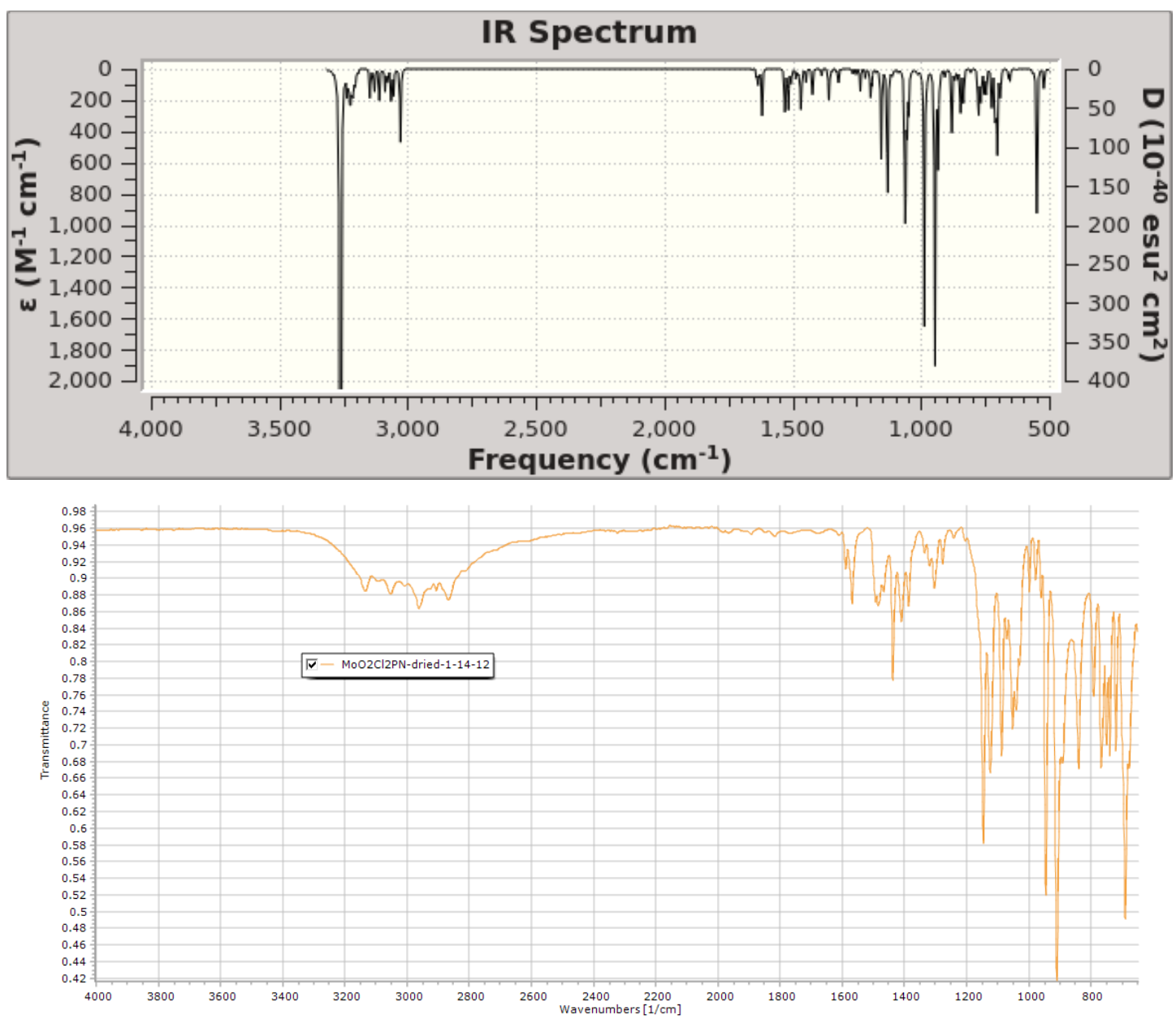

Figure S2.16. Uncorrected calculated FTIR (top) and experimental (neat) spectrum of compound $\mathbf{3}$. 


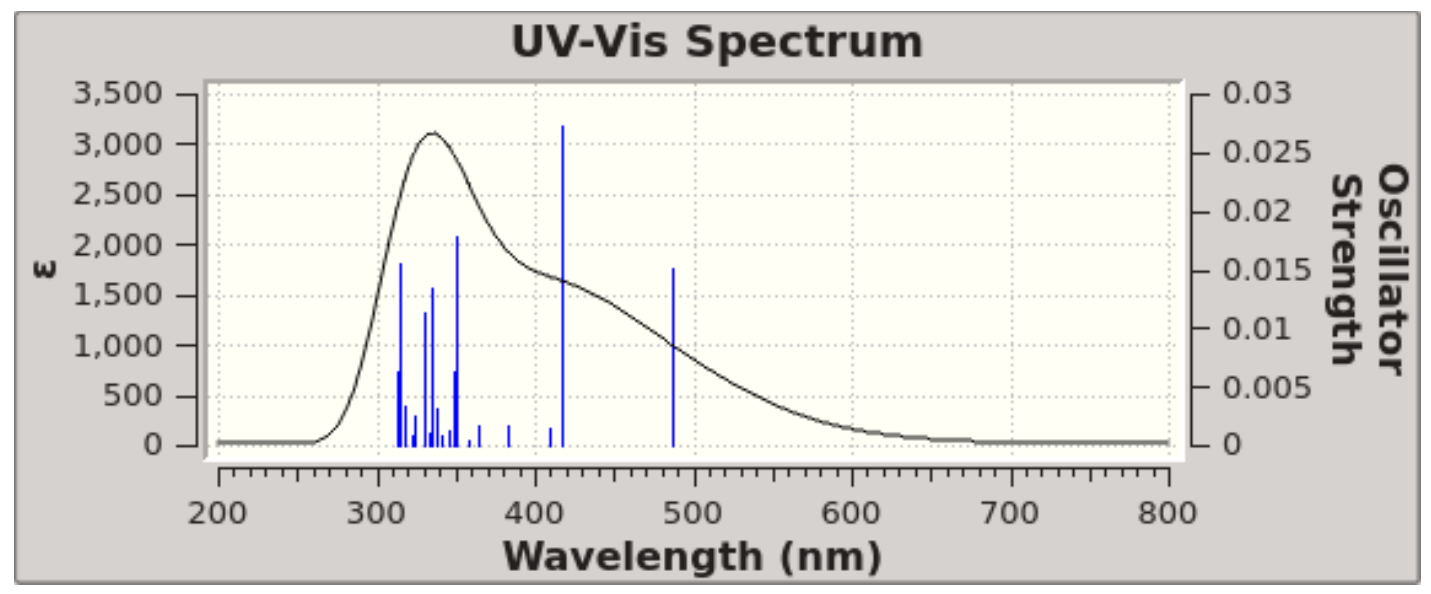

Figure S2.17. Calculated UV-Vis spectrum for 3.

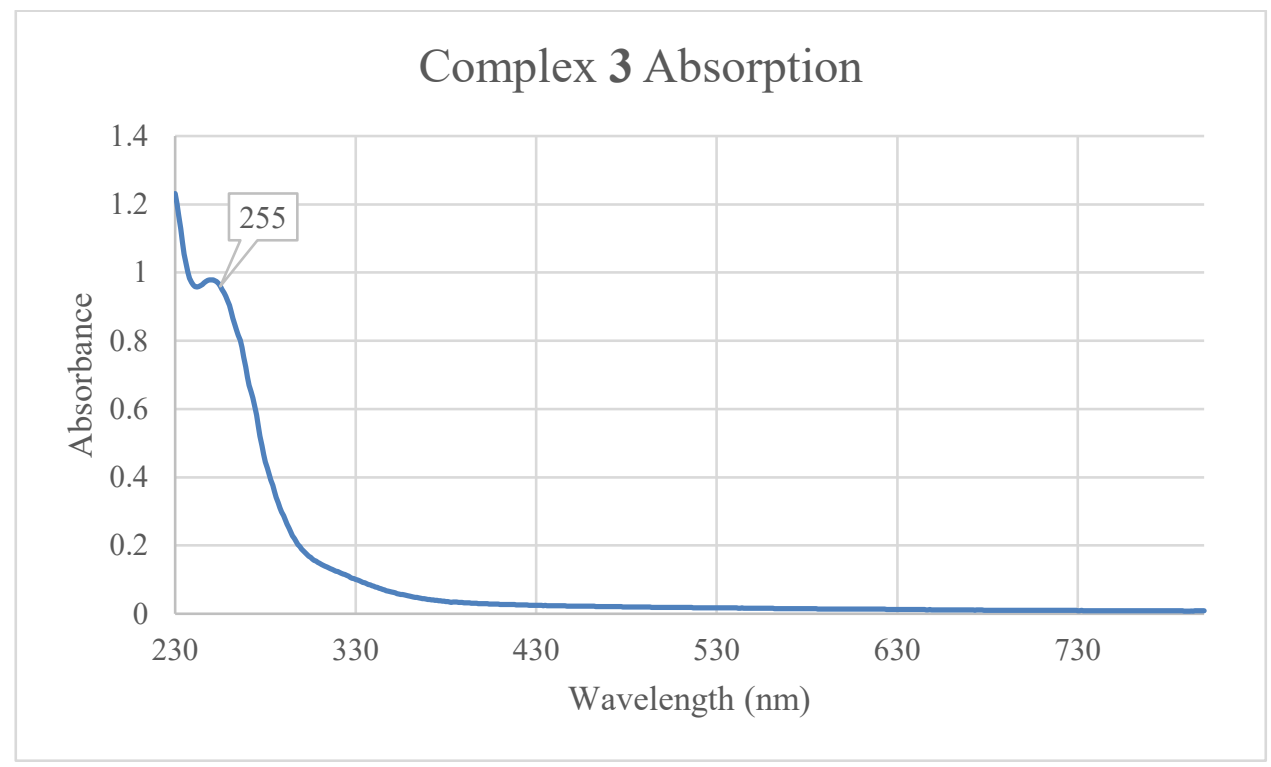

Figure S2.18. UV-vis absorption spectrum of $\mathbf{3}$ in $\mathrm{CH}_{2} \mathrm{Cl}_{2}$. 


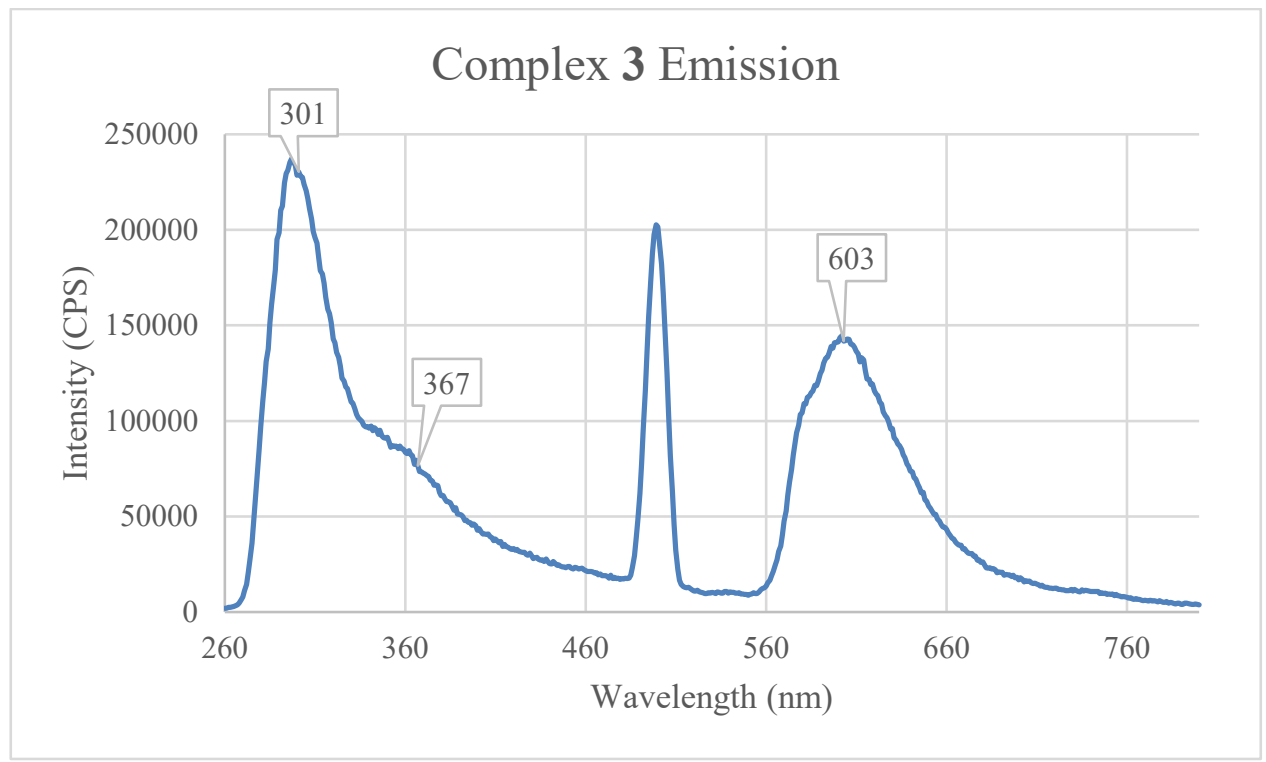

Figure S2.19. Emission spectrum of 3 in $\mathrm{CH}_{2} \mathrm{Cl}_{2}$.

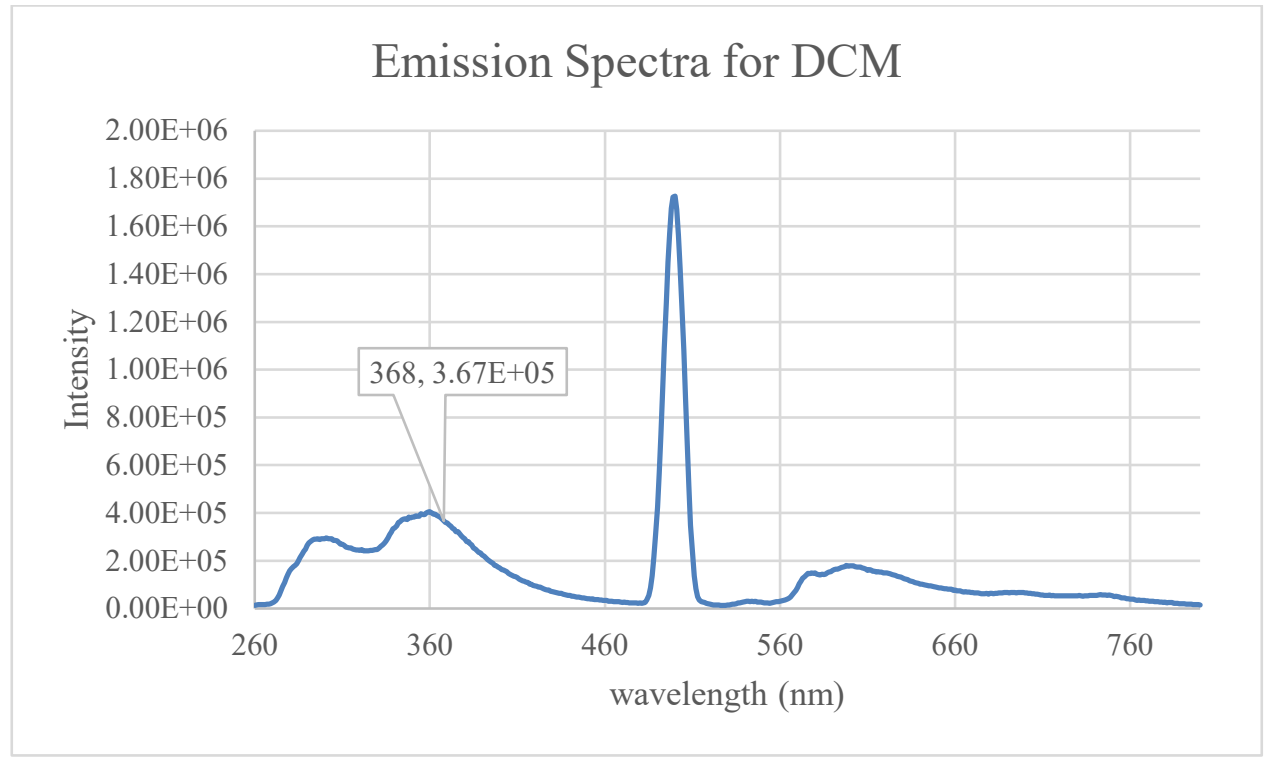

Figure S2.20. Emission spectrum of solvent $\mathrm{CH}_{2} \mathrm{Cl}_{2}$. 


\begin{tabular}{|l|l|l|l|l|}
\hline$-1.630 \mathrm{e}-4$ & $1.630 \mathrm{e}-4$ \\
\hline
\end{tabular}

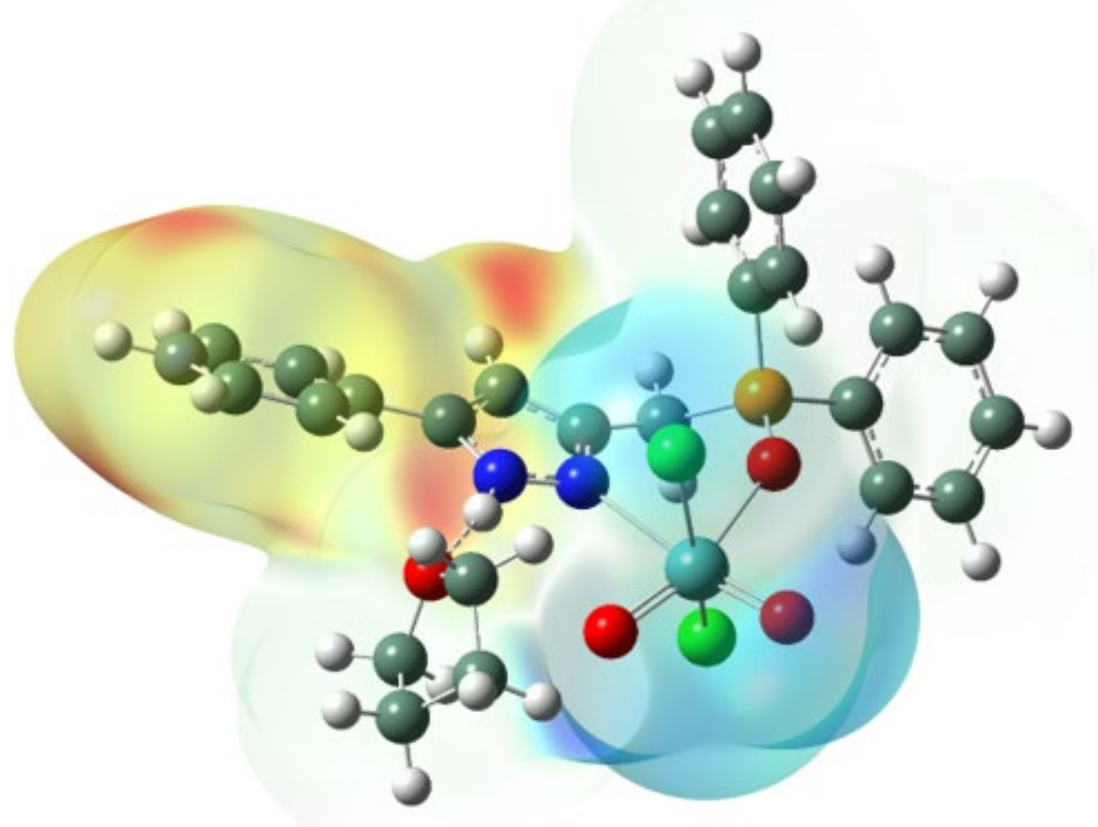

Figure S2.21. Difference density illustrations as iso-surfaces of complex $\mathbf{3}$ featuring excited state 1 . Red areas indicate values for the different densities of $-1.630 \mathrm{e}^{-4}$, and blue are for $1.630 \mathrm{e}^{+4}$; see the scale on top of the illustration.

Table S2.6. Excitation Energies and Oscillator Strengths for 3.

Excited State 1: $\quad$ Singlet-A $\quad 2.5491 \mathrm{eV} \quad 486.38 \mathrm{~nm} \mathrm{f}=0.0150<\mathrm{S} * * 2>=0.000$

$$
146->147 \quad 0.69782
$$

This state is for optimization and/or second-order correction.

Total Energy, E(TD-HF/TD-DFT) = -2745.81946723

Copying the excited state density for this state as the 1-particle RhoCI density. 


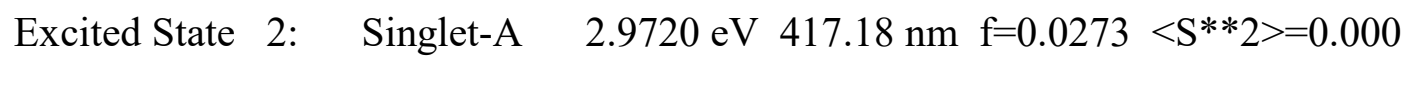
$146->148 \quad 0.69826$

Excited State 3: $\quad$ Singlet-A $\quad 3.0269 \mathrm{eV} \quad 409.60 \mathrm{~nm} \mathrm{f}=0.0014<\mathrm{S}^{* *} 2>=0.000$

$$
\begin{array}{ll}
144->147 & 0.10857 \\
145->147 & 0.68291
\end{array}
$$

Excited State 4: Singlet-A $3.2438 \mathrm{eV} 382.22 \mathrm{~nm} \mathrm{f}=0.0016<\mathrm{S}^{* *} 2>=0.000$

$$
\begin{array}{ll}
139->147 & 0.10870 \\
143->147 & 0.57198 \\
144->147 & 0.36299
\end{array}
$$

Excited State 5: $\quad$ Singlet-A $\quad 3.3987 \mathrm{eV} \quad 364.80 \mathrm{~nm} \mathrm{f}=0.0018<\mathrm{S}^{* *} 2>=0.000$

$$
\begin{array}{ll}
138->147 & 0.43782 \\
138->148 & 0.10518 \\
139->147 & -0.11074 \\
140->147 & 0.10225 \\
141->147 & 0.24170 \\
142->147 & 0.18035 \\
145->148 & -0.39444
\end{array}
$$

Excited State 6: $\quad$ Singlet-A $\quad 3.4649 \mathrm{eV} \quad 357.83 \mathrm{~nm} \mathrm{f}=0.0003<\mathrm{S} * * 2>=0.000$

$$
\begin{array}{ll}
138->147 & 0.28953 \\
141->147 & 0.17741 \\
142->147 & 0.11876 \\
145->147 & 0.14031 \\
145->148 & 0.54863
\end{array}
$$

Excited State 7: $\quad$ Singlet-A $\quad 3.5307 \mathrm{eV} \quad 351.16 \mathrm{~nm} \mathrm{f}=0.0177<\mathrm{S} * * 2>=0.000$ 


$$
\begin{array}{ll}
143->147 & -0.12292 \\
144->147 & 0.20200 \\
146->149 & 0.65613
\end{array}
$$

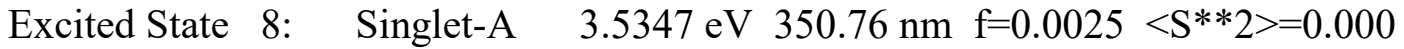

$$
\begin{array}{ll}
143->147 & -0.31811 \\
144->147 & 0.54582 \\
146->149 & -0.23116
\end{array}
$$

Excited State 9: $\quad$ Singlet-A $\quad 3.5599 \mathrm{eV} \quad 348.28 \mathrm{~nm} \mathrm{f}=0.0062<\mathrm{S} * * 2>=0.000$

$$
\begin{array}{ll}
134->147 & -0.25364 \\
137->147 & 0.35126 \\
138->147 & -0.18130 \\
139->147 & 0.16234 \\
142->147 & 0.47008
\end{array}
$$

Excited State 10: $\quad$ Singlet-A $\quad 3.5883 \mathrm{eV} \quad 345.52 \mathrm{~nm} \mathrm{f}=0.0012<\mathrm{S} * * 2>=0.000$

$$
\begin{array}{ll}
130->147 & -0.11303 \\
131->147 & 0.25360 \\
132->147 & -0.25513 \\
133->147 & -0.18508 \\
134->147 & 0.18465 \\
135->147 & 0.35829 \\
136->147 & 0.27870 \\
139->147 & 0.12867 \\
143->147 & -0.13991
\end{array}
$$

Excited State 11: $\quad$ Singlet-A $\quad 3.6339 \mathrm{eV} \quad 341.19 \mathrm{~nm} \mathrm{f}=0.0008<\mathrm{S} * * 2>=0.000$ $134->147-0.15779$ 


$$
\begin{array}{ll}
137->147 & 0.27830 \\
141->147 & 0.43667 \\
142->147 & -0.41895
\end{array}
$$

Excited State 12: $\quad$ Singlet-A $\quad 3.6619 \mathrm{eV} \quad 338.58 \mathrm{~nm} \mathrm{f}=0.0031<\mathrm{S} * * 2>=0.000$

$$
\begin{array}{ll}
135->148 & 0.10235 \\
136->147 & -0.12966 \\
137->147 & 0.11875 \\
138->148 & 0.11659 \\
140->147 & -0.11182 \\
143->148 & 0.52579 \\
144->148 & 0.33012
\end{array}
$$

Excited State 13: $\quad$ Singlet-A $\quad 3.6944 \mathrm{eV} 335.60 \mathrm{~nm} \mathrm{f}=0.0135<\mathrm{S} * * 2>=0.000$

$$
\begin{array}{lr}
135->147 & -0.17235 \\
136->147 & 0.26236 \\
137->147 & -0.21965 \\
138->147 & -0.30606 \\
139->147 & -0.10450 \\
140->147 & 0.30958 \\
141->147 & 0.25667 \\
143->147 & 0.11266 \\
143->148 & 0.14856 \\
144->148 & 0.10547
\end{array}
$$

Excited State 14: Singlet-A $\quad 3.7167 \mathrm{eV} \quad 333.59 \mathrm{~nm} \mathrm{f}=0.0010<\mathrm{S} * * 2>=0.000$

$$
\begin{array}{ll}
137->147 & 0.19953 \\
138->147 & 0.12748 \\
140->147 & 0.52823
\end{array}
$$




$$
\begin{array}{ll}
141->147 & -0.33481 \\
142->147 & -0.14809
\end{array}
$$

Excited State 15: Singlet-A $\quad 3.7512 \mathrm{eV} \quad 330.52 \mathrm{~nm} \mathrm{f}=0.0113<\mathrm{S} * * 2>=0.000$

$$
\begin{array}{ll}
131->147 & -0.20081 \\
132->147 & 0.23213 \\
133->147 & 0.11226 \\
134->147 & -0.12937 \\
136->147 & 0.52577 \\
138->147 & 0.12342 \\
140->147 & -0.14386
\end{array}
$$

Excited State 16: Singlet-A $\quad 3.8175 \mathrm{eV} \quad 324.78 \mathrm{~nm} \mathrm{f}=0.0025<\mathrm{S} * * 2>=0.000$

$$
\begin{array}{ll}
132->147 & 0.10794 \\
137->147 & -0.21114 \\
139->147 & 0.60557 \\
140->147 & 0.12864
\end{array}
$$

Excited State 17: Singlet-A $\quad 3.8500 \mathrm{eV} \quad 322.03 \mathrm{~nm} \mathrm{f}=0.0009<\mathrm{S} * * 2>=0.000$

$$
\begin{array}{ll}
134->148 & -0.12562 \\
137->148 & 0.18299 \\
138->148 & 0.41386 \\
140->148 & 0.12445 \\
141->148 & 0.30993 \\
142->148 & 0.27591 \\
144->148 & -0.11529 \\
145->148 & 0.11033
\end{array}
$$

Excited State 18: $\quad$ Singlet-A $\quad 3.8980 \mathrm{eV} \quad 318.07 \mathrm{~nm} \mathrm{f}=0.0033<\mathrm{S} * * 2>=0.000$ 


$\begin{array}{ll}131->148 & 0.20817 \\ 132->147 & 0.12888 \\ 132->148 & -0.20030 \\ 133->148 & -0.13580 \\ 134->148 & 0.14031 \\ 135->147 & 0.36139 \\ 135->148 & 0.19463 \\ 136->148 & 0.13848 \\ 139->147 & -0.13754 \\ 140->147 & 0.17768 \\ 144->148 & -0.18004\end{array}$

Excited State 19: $\quad$ Singlet-A $\quad 3.9421 \mathrm{eV} \quad 314.51 \mathrm{~nm} \mathrm{f}=0.0155<\mathrm{S} * * 2>=0.000$
$131->147-0.17530$
$131->148 \quad-0.20522$
$132->147 \quad 0.11042$
$132->148 \quad 0.14978$
$133->148 \quad 0.11496$
$134->148 \quad-0.10728$
$135->147 \quad 0.33580$
$135->148 \quad-0.15446$
$136->147-0.13084$
$143->148-0.13205$
$144->148 \quad 0.33881$

Excited State 20: Singlet-A $\quad 3.9547 \mathrm{eV} \quad 313.51 \mathrm{~nm} \mathrm{f}=0.0063<\mathrm{S} * * 2>=0.000$
$131->147$
0.10568
$131->148$
0.15468
$132->148 \quad-0.13121$ 


$$
\begin{array}{ll}
133->148 & -0.10736 \\
135->147 & -0.15277 \\
142->148 & 0.13066 \\
143->148 & -0.35212 \\
144->148 & 0.44168
\end{array}
$$




\section{Chapter 3 Syntheses, theoretical studies, and crystal structures of $\left[\mathrm{Ni}(\mathrm{II})^{\mathrm{SSRR}} \mathrm{L}\right]\left(\mathrm{PF}_{6}\right)_{2}$ and $\left[\mathrm{Ni}(\mathrm{III})^{\mathrm{SRSR}} \mathrm{L}\right](\mathrm{Cl})\left(\mathrm{PF}_{6}\right)$ that contains anagostic interactions}

Peyton C. Bainbridge, Rudy L. Luck, and Nick K. Newberry

\subsection{Abstract}

The syntheses of two square-planar nickel complexes containing the condensation and subsequently reduced products obtained by reacting $\left[\mathrm{Ni}(\mathrm{en})_{3}\right]\left(\mathrm{BF}_{4}\right)_{2}$ and acetone are reported. The complexes5,5,7,12,12,14-hexamethyl 1(S),4(S),8(R),11(R)tetraazacyclotetradecane-nickel(II) $\left[\mathrm{PF}_{6}\right]_{2}$ and 5,5,7,12,12,14-hexamethyl$1(S), 4(R), 8(S), 11(R)$-tetraazacyclotetradecane-nickel(II)[Cl][PF 6$]$ labelled as $\left[\mathbf{N i}(\mathrm{II})^{\mathrm{SSRR}} \mathbf{L}\right]\left(\mathbf{P F}_{6}\right)_{2}$ and $\left[\mathbf{N i}(\mathrm{II})^{\mathrm{SRSR}} \mathbf{L}\right](\mathbf{C l})\left(\mathbf{P F}_{6}\right)$, respectively, were found to have slightly different solubilities that allowed for their purification. The complexes were characterized by FTIR, 1H NMR, and UV-vis spectra. Redox potentials, determined by cyclic voltammetry, established that $\left[\mathbf{N i ( I I )}{ }^{\mathbf{S S R R}} \mathbf{L}\right]\left(\mathbf{P F}_{6}\right)_{2}$ exhibits a reversible oxidation $(E 1 / 2(\mathrm{ox})=0.85 \mathrm{~V})$ and reduction $(E 1 / 2(\mathrm{red})=-1.59 \mathrm{~V})$, whereas $\left[\mathbf{N i}(\mathbf{I I})^{\mathbf{S R S R}} \mathbf{L}\right](\mathbf{C l})\left(\mathbf{P F}_{6}\right)$ displays an irreversible oxidation $(E \mathrm{pa}(\mathrm{ox})=1.37 \mathrm{~V})$ and reversible reduction $(E 1 / 2(\mathrm{red})=-1.62 \mathrm{~V})$ relative to the ferrocene couple at $0.0 \mathrm{~V}$. Single-crystal X-ray determinations established that one of the compounds, $\left[\mathbf{N i}(\mathrm{II})^{\mathrm{SSRR}} \mathbf{L}\right]\left(\mathbf{P F}_{6}\right)_{2}$, contained two $\mathrm{PF}_{6}$-anions, whereas the other compound, $\left[\mathbf{N i}(\mathrm{II})^{\mathrm{SRSR}} \mathbf{L}\right](\mathbf{C l})\left(\mathbf{P F}_{6}\right)$, contained one $\mathrm{Cl}^{-}$and one $\mathrm{PF}_{6}{ }^{-}$anion. In the solid-state,

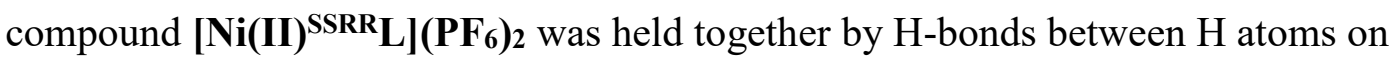
the $\mathrm{Ni}$ containing dictation and $\mathrm{F}$ atoms in the $\mathrm{PF}_{6}{ }^{-}$anion. Compound $\mathbf{N i}(\mathrm{II})^{\mathrm{SRSR}} \mathbf{L} \mathbf{(}\left(\mathrm{Cl}_{)}\left(\mathbf{P F}_{6}\right)\right.$ crystallized in the form of dimers held together by interactions between $\mathrm{H}$ atoms attached to $\mathrm{N}$ atoms on adjacent cations binding to two $\mathrm{Cl}^{-}$anions in the middle with these dimers held together by further $\mathrm{H}$-bonding to interstitial $\mathrm{PF}_{6}$

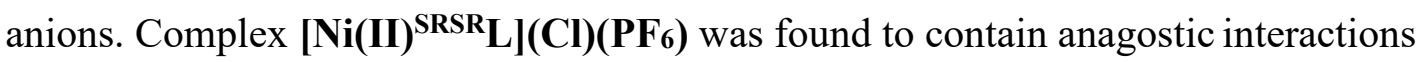


on the bases of NMR (downfield shift in $\mathrm{C}-\mathrm{H}$ protons) and structural data $\left(2.3<d_{(\mathrm{H}-}\right.$ $\mathrm{Ni})<2.9 \AA$ ), as well as theoretical calculations.

\subsection{Introduction}

The syntheses and structures of macrocyclic Schiff base-amine complexes of nickel(II) ${ }^{53}$ were comprehensively described and characterized by Curtis ${ }^{5,54-56}$ and consisted of a novel template approach, as shown in Scheme 3.1. Following a seminal structural publication $^{57}$, at least 43 crystal structure reports ${ }^{58}$ featuring the nickel cationic complex in $\mathbf{2}$ have been reported. ${ }^{59}$ The cation in $\mathbf{3}$, produced by sodium borohydride reduction ${ }^{60}$ of $\mathbf{2}$, has also been examined crystallographically as evidenced by at least 79 structural reports ${ }^{61}$ (based on a non-selective search for all isomeric forms of the Ni-ligand complex, Supplementary Table S3.1) in the Cambridge Structural Database (CSD) ${ }^{59}$ however, none with the 
Scheme 3.1. Synthesis of 5,5,7,12,12,14-hexamethyl-1,4,8,11tetraazacyclotetradecane-nickel(II $) \cdot\left(\mathrm{PF}_{6}\right)_{2}, \mathbf{3}$, and stereoviews of the cations in $\left[\mathbf{N i}(\mathrm{II})^{\mathrm{SSRR}} \mathbf{L}\right]\left(\mathbf{P F}_{6}\right)_{2}$ and $\left[\mathbf{N i}(\mathrm{II})^{\mathrm{SRSR}} \mathbf{L}\right]\left(\mathrm{Cl}_{)}\left(\mathrm{PF}_{6}\right)\right.$. [Colour online.]
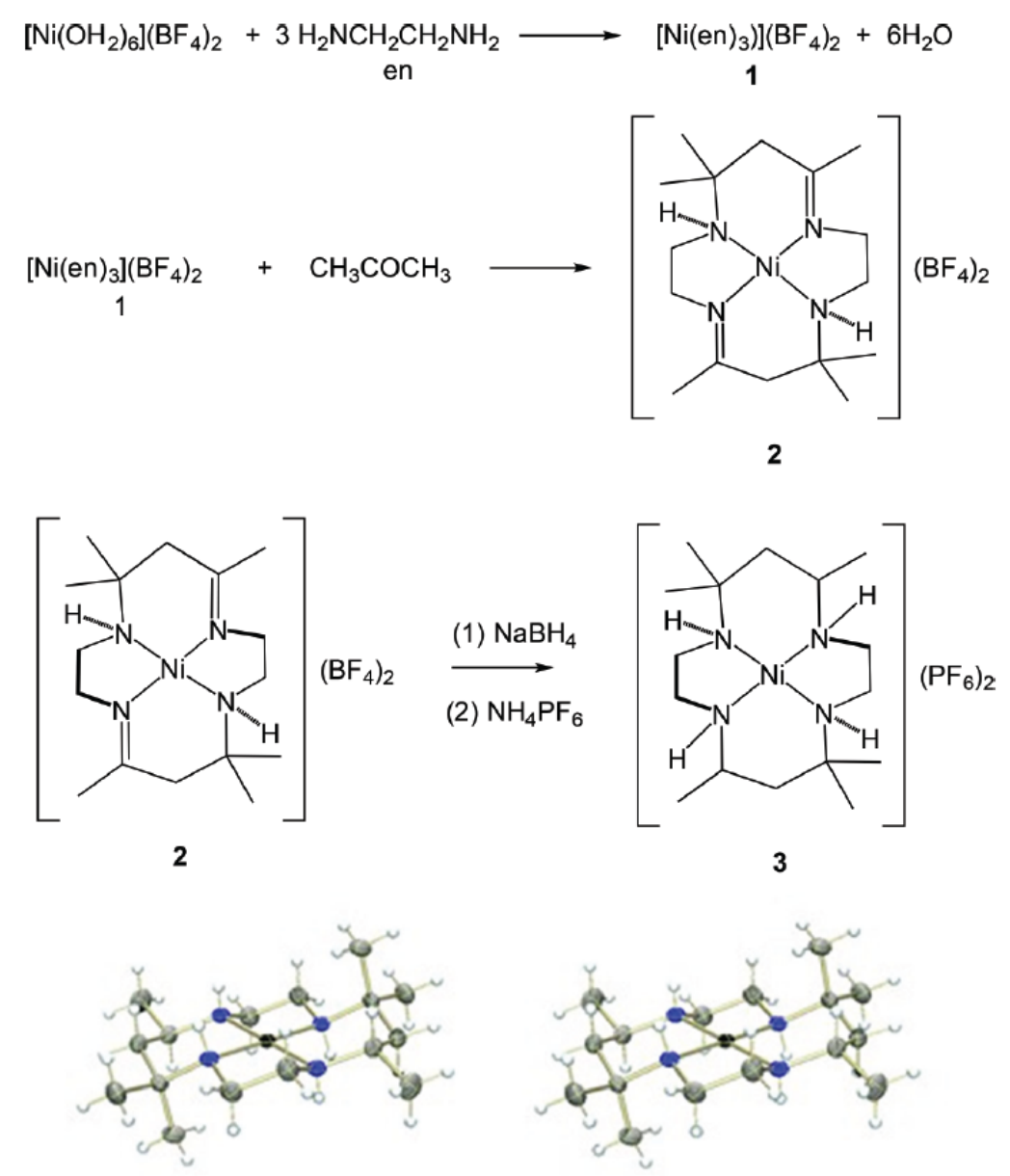

$$
\left[\mathrm{Ni}(\mathrm{II})^{\mathrm{SSRR}} \mathbf{L}\right]\left(\mathbf{P F}_{6}\right)_{2}
$$
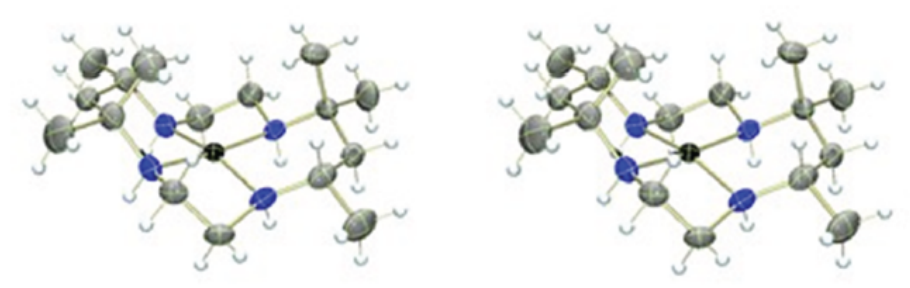

$$
\left[\mathbf{N i}(\mathrm{II})^{\mathrm{SRSR}} \mathbf{L}\right](\mathrm{Cl})\left(\mathrm{PF}_{6}\right)
$$


$\mathrm{PF}_{6}{ }^{-}$counterion have been reported. The various conformational forms of this ligand have been previously described, ${ }^{60,62}$, the totals for each of the forms for which crystal structures have been reported are listed in Chart 3.1. The four $\mathrm{N}$ atoms and the two pseudotertiary $\mathrm{C}$ atoms in the six-membered rings are all chiral. Additionally, the two ethyl moieties can each exist in $\delta$ or $\lambda$ conformations, and these arrangements are commonly found in crystal structure analyses in the form of disorder. The sixmembered ring inclusive of the $\mathrm{Ni}$, two $\mathrm{N}$ atoms, and a $-\mathrm{C}\left(\mathrm{CH}_{3}\right) \mathrm{CH}_{2} \mathrm{C}\left(\mathrm{CH}_{3}\right)_{2}-$ section occurs most commonly in a chair conformation, though in some cases twisted conformations are observed. Interestingly, forms $\mathbf{A}$ and $\mathbf{B}$, which feature $\operatorname{SSRR}(\operatorname{SR}) \delta \lambda$ and $S S R R(S R) \delta \lambda-R_{2} S_{9}$ conformations, respectively (considering the bottom left $\mathrm{N}$ atom in each illustrated arrangement in Chart 3.1 as number 1 and going anticlockwise around the ring for the $\mathrm{N}$ atoms, the conformation of the pseudo-tertiary $\mathrm{C}$ atoms in the six-membered rings in brackets, followed by the conformations of the ethylene group and, in some cases, methyl groups attached to the ethylenic moiety), are found in 56 structures. Form $\mathbf{C}$ contains disorder between the propane-1,2diamine ligand (also chiral) and opposite ethylenediamine moiety, but all forms exhibit the $S R S S(R S) \lambda \delta-R_{2}$ 
Chart 3.1. Representations of the stereochemistry for the nickel cations from the 79 structural results. ${ }^{61}$

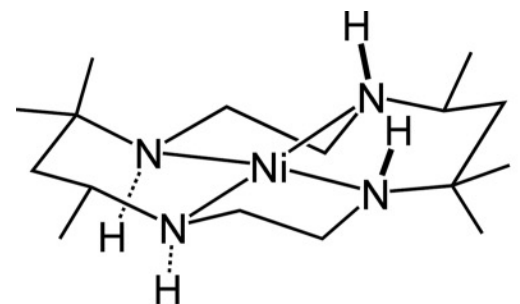

A, 37, SSRR(SR) $\delta \lambda$

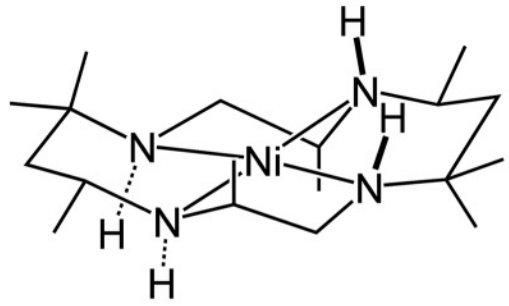

$\mathrm{B}, 19, \operatorname{SSRR}(S R) \delta \lambda-R_{2} S_{9}$

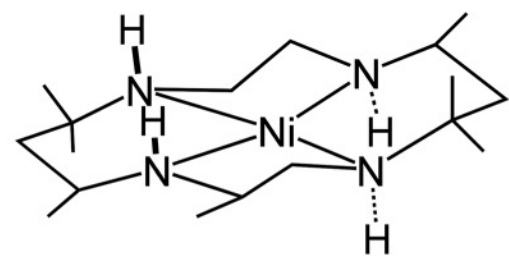

C, 3, SRSS(RS) $\lambda \delta-R_{2}$

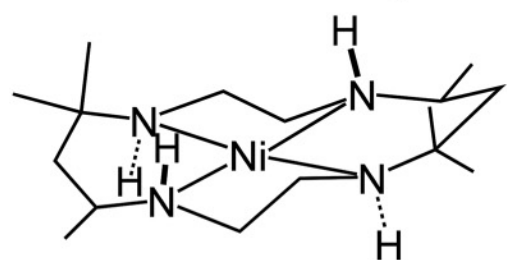

D, 6, RRRR(SS) $\lambda \lambda$

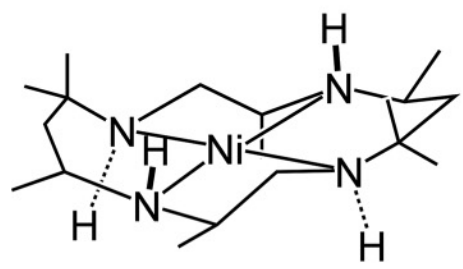

$E, 1, \operatorname{SRSR}(S S) \lambda \lambda-R_{2} S_{9}$

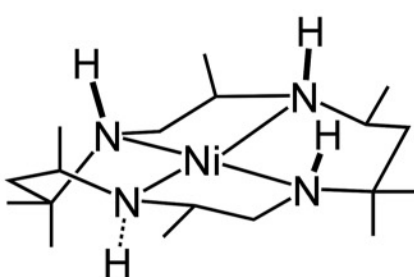

$\mathrm{F}, 1, \operatorname{RSSS}(\mathrm{SS}) \delta \delta-S_{2} R_{9}$

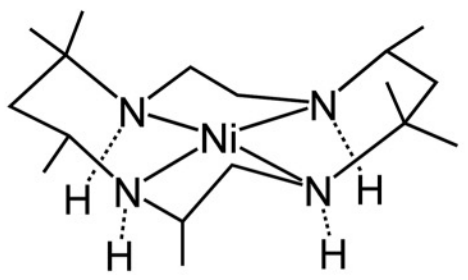

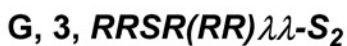

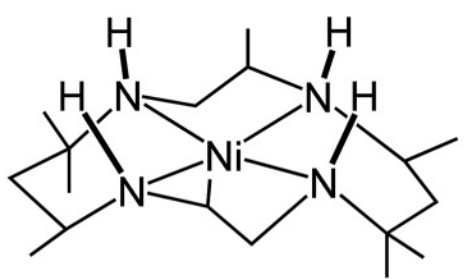

$\mathrm{H}, 5, \operatorname{SSSS}(\mathrm{SS}) \delta \delta-R_{2} R_{9}$

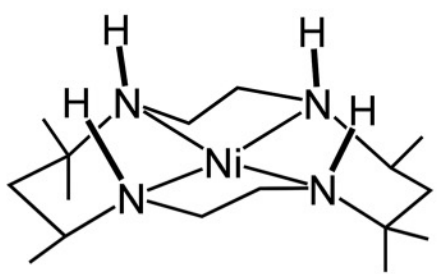

I, 2, RSRS(SS) $\lambda \delta$

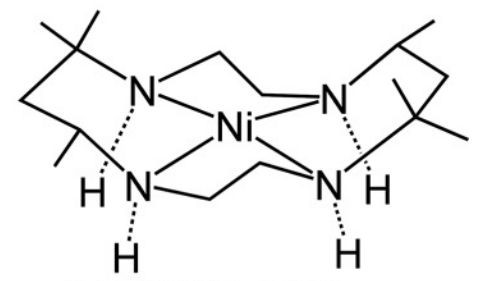

$\mathrm{J}, 2, \operatorname{SRSR}(R R) \lambda \lambda$

conformation. The six structures representing form $\mathbf{D}$ have a different arrangement of the $\mathrm{N}-\mathrm{H}$ groups and feature the $R R R R(S S) \lambda \lambda$ conformation. One structure each was 
reported for forms $\mathbf{E}^{63}$ and $\mathbf{F}^{64}$ featuring $S R S R(S S) \lambda \lambda-R_{2} S_{9}$ and $R S S S(S S) \delta \delta-S_{2} R_{9}$ conformations, respectively. Forms $\mathbf{G}-\mathbf{J}$ have all the $\mathrm{H}$ atoms bonded to the $\mathrm{N}$ atoms pointing in the same direction from the nickel coordination equatorial plane but feature different chiral representations due to the presence of the additional methyl groups in forms $\mathbf{G}$ and $\mathbf{H}$. All forms of $\mathbf{G}\left(R R S R(R R) \_-S 2\right)$ either contain disorder with the methyl group on the propane-1,2-diamine fragment as mentioned above or contain mixtures of molecules containing this ligand and those containing only the ethylenediamine moiety. ${ }^{62} \mathrm{An}$ example of form $\mathbf{H}\left(\operatorname{SSSS}(S S) \delta \delta-R_{2} R 9\right)$ was earlier published as the perchlorate salt, then as three polymorphs, ${ }^{63,65}$, and then with the counteranion $\left[\mathrm{ZnCl}_{4}\right]^{2-63}$. The final two forms, $\mathbf{I}$ and $\mathbf{J}$, differ in the arrangement of

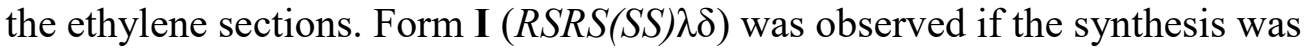
conducted under acidic conditions, which hinders inversion at the $\mathrm{N}$ atoms. ${ }^{60} \mathrm{~A}$ structure of form I, co-crystallized with a large vanadium cluster, was more recently reported ${ }^{66}$ Form $\mathbf{J}, \operatorname{SRSR}(R R)$ _, was reported as a perchlorate salt ${ }^{67}$ and then with a mixture of anions consisting of perchlorate, chromate, and water molecules in the crystal with one form of the cation exhibiting disorder.$^{68}$ Structures that crystallized in centrosymmetric space groups contain the mirror images of the structural forms displayed in Chart 3.1, but some were chiral. ${ }^{60,64,69-72}$ Herein, we report slightly revised syntheses for forms $\mathbf{A}, \mathbf{I}$, and $\mathbf{J}$ and show how they could be differentiated based on their ${ }^{1} \mathrm{H}$ NMR spectra (i.e., $\mathbf{A}$ from $\mathbf{I}$ and $\mathbf{J}$ ). The structures of these complexes were also determined crystallographically, and the electronic properties were assessed via theoretical calculations and redox potentials. The results confirm the existence of anagostic interactions ${ }^{73,74}$ in the complexes exhibiting forms $\mathbf{I}$ and $\mathbf{J}$.

\subsection{Experimental}

\subsubsection{Materials}

Chemicals were purchased from Fisher Scientific $\left(\left[\mathrm{Ni}\left(\mathrm{H}_{2} \mathrm{O}\right)_{6}\right]\left[\mathrm{BF}_{4}\right]_{2}\right.$, Strem Chemicals, Inc. $\left(\mathrm{NH}_{4} \mathrm{PF}_{6}\right)$, and Sigma-Aldrich Chemicals (solvents). Solvents were reagent grade and used as received. Complex 2 was synthesized as previously 
described for the borohydride salt. ${ }^{75}$ The elemental analysis was conducted by Galbraith Laboratories, Knoxville, TN. IR spectra were recorded on a PerkinElmer Spectrum One (neat) spectrometer with a Perkin Elmer Universal ATR Sampling Accessory. 1H NMR data were recorded on a Varian XL-400 spectrometer referenced to $\mathrm{D}_{2} \mathrm{O}$ or acetone- $d_{6}$. Magnetic measurements were conducted on a Johnson Matthey Auto MSB instrument. Absorbance spectra were obtained using quartz cells in a Perkin Elmer Lambda 35 UV/Vis Spectrometer. Cyclic voltammograms were recorded in a $0.2 \mathrm{~mol} / \mathrm{L}(\mathrm{nBu})_{4} \mathrm{NPF}_{6}$ acetonitrile solution under nitrogen using a $\mathrm{CH}$ Instruments Electrochemical Analyzer. The working electrode used was glassy carbon, the counter electrode was platinum wire, and the reference electrode consisted of a silver wire in $10 \mathrm{mmol} / \mathrm{L}$ silver nitrate dissolved in acetonitrile sealed with a vycor plug. Ferrocene was added as an internal reference, and spectra are normalized to the $\mathrm{Fc} / \mathrm{Fc}+$ couple set to $0.00 \mathrm{~V}$.

\subsubsection{Synthesis of 5,5,7,12,12,14-hexamethyl-1(S),4(S),8(R),11(R)- tetraazacyclotetradecane-nickel(II)[PF6]2, [Ni(II)SSRRL](PF6)2, and}

\section{$5,5,7,12,12,14-h e x a m e t h y l-1(S), 4(R), 8(S), 11(R)$-tetraazacyclotetradecane- nickel(II)[Cl][PF 6 , [ $\left.\mathrm{Ni}(\mathrm{II})^{\mathrm{SRSR}} \mathrm{L}\right](\mathrm{Cl})\left(\mathrm{PF}_{6}\right)$, at $\mathrm{pH} 3$}

Complex $2(194 \mathrm{mg})$ was added to $5 \mathrm{~mL}$ of water and heated to $80^{\circ} \mathrm{C}$. Sodium borohydride (126 mg) was added slowly with rapid stirring. The yellow solution turned dark brown-black, and purple foam was observed above the solution. The mixture was heated for an additional $30 \mathrm{~min}$ and then allowed to cool for $10 \mathrm{~min}$ before adjusting to $\mathrm{pH} 3$ using $6 \mathrm{M}$ hydrochloric acid. Ammonium hexafluorophosphate $(207 \mathrm{mg}$ ) was dissolved in $1 \mathrm{~mL}$ of water and then added to the reaction mixture. An orange precipitate formed immediately and was filtered off and washed with cold ethanol and diethyl ether; this orange precipitate is a mixture of the two forms. The filtrate was allowed to evaporate slowly for 1 week, which resulted in a mixture of orange powder, red crystals, and white crystals. Any remaining liquid was removed via vacuum filtration, and acetone was added to the 
mixture. The solution was filtered, resulting in the separation of the red and white crystals from the orange crystals, which remained in solution. The red crystals were separated from the white crystals by dissolving them into methanol and collecting the

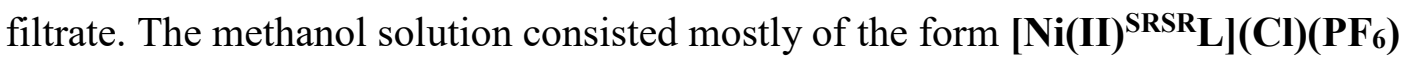

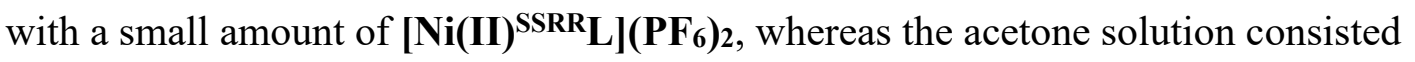

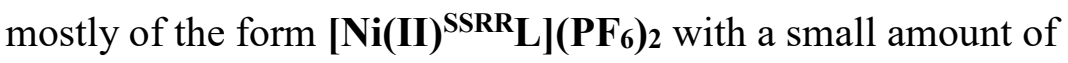

$\left[\mathbf{N i}(\mathrm{II})^{\mathrm{SRSR}} \mathbf{L}\right](\mathbf{C l})\left(\mathbf{P F}_{6}\right)$. Both solutions were allowed to evaporate to dryness. To

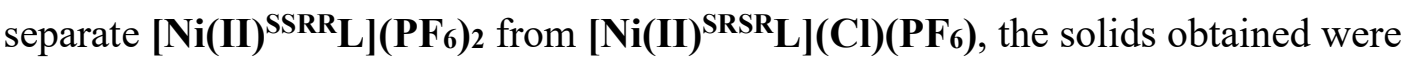
stirred in a small amount of water. The water fraction contains product

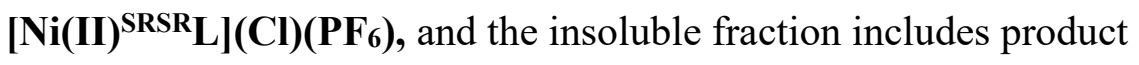
$\left[\mathbf{N i}(\mathrm{II})^{\mathrm{SSRR}} \mathbf{L}\right]\left(\mathbf{P F}_{6}\right)_{2}$. Complex [Ni(II) $\left.{ }^{\text {SRSR }} \mathbf{L}\right](\mathbf{C l})\left(\mathbf{P F}_{6}\right)$ was recrystallized by dissolving in hot ethanol and then slowly adding diethyl ether until cloudiness barely persisted, and then the solution was cooled. The product was collected by filtration and washed with cold ethanol and diethyl ether. Complex [Ni(II) $\left.{ }^{\mathrm{SSRR}} \mathbf{L}\right]\left(\mathbf{P F}_{6}\right)_{2}$ was recrystallized by dissolving the solid in hot water and then allowed to cool to effect crystallization. The product was obtained via filtration and washed with cold ethanol and diethyl ether. The yield of product [Ni(II) $\left.{ }^{\mathrm{SSRR}} \mathbf{L}\right]\left(\mathbf{P F}_{6}\right)_{2}$ was $223 \mathrm{mg}$ (93.3\%), and

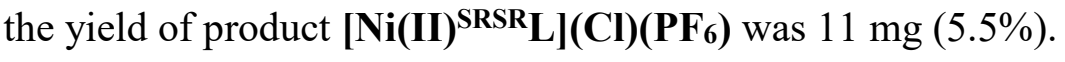


Figure 3.1. ORTEP ${ }^{76}$ drawing (with POV-Ray ${ }^{31}$ rendering) of the cation in [Ni(II) $\left.{ }^{\text {SSRR }} \mathbf{L}\right]\left(\mathbf{P F}_{6}\right)_{2}$. Thermal ellipsoids are drawn at the 50\% probability level, and $\mathrm{H}$ atoms are represented by spheres of arbitrary radii. [Colour online.]

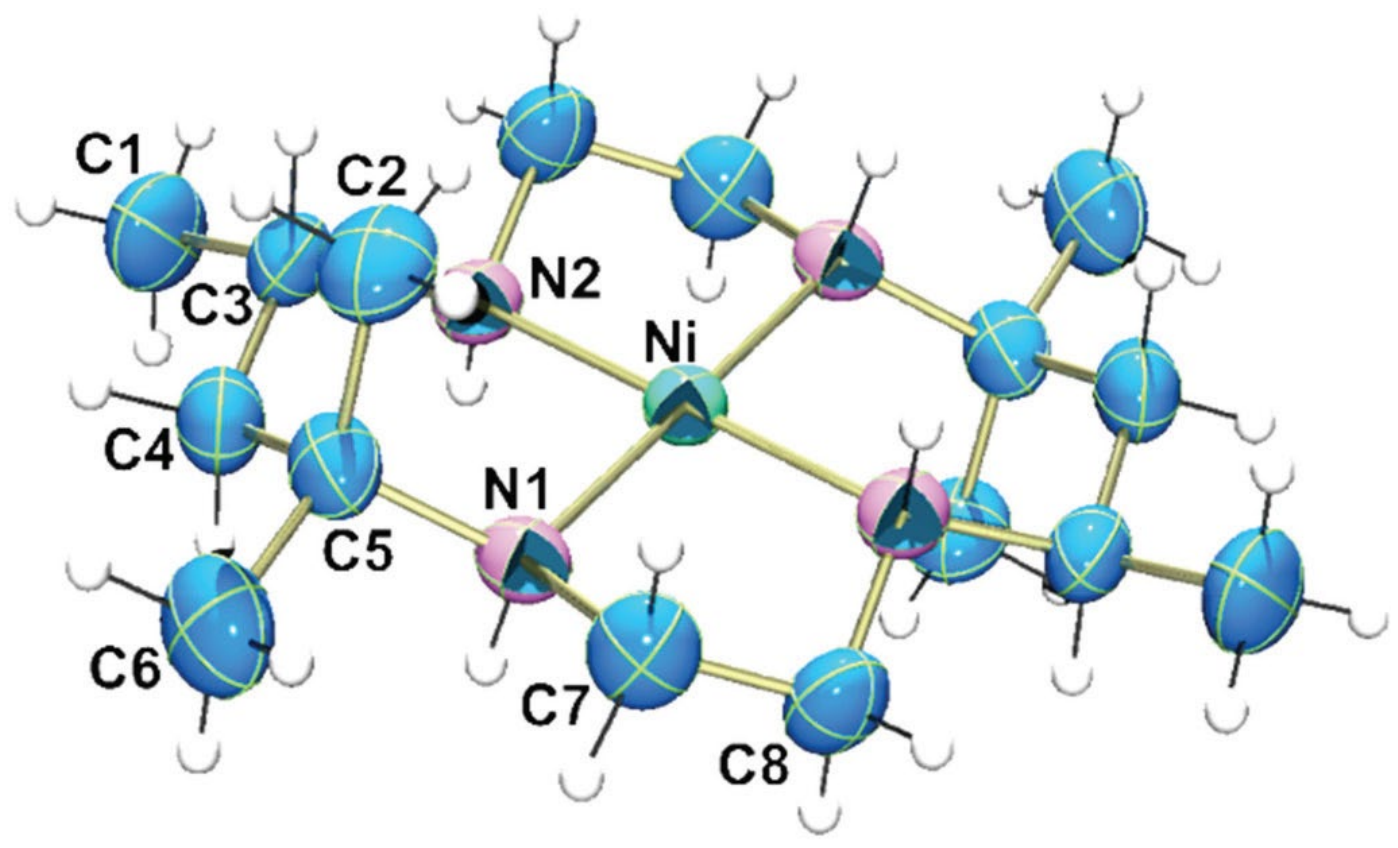

\subsubsection{Syntheses of complexes $\left[\mathrm{Ni}(\mathrm{II})^{\mathrm{SSRR}} \mathrm{L}\right]\left(\mathrm{PF}_{6}\right)_{2}$ and $\left[\mathrm{Ni}(\mathrm{II})^{\mathrm{SRSR}} \mathrm{L}\right](\mathrm{Cl})\left(\mathrm{PF}_{6}\right)$ at} pH 1

Complex 2 (201 mg) was dissolved in $5 \mathrm{~mL}$ of water and heated to $80{ }^{\circ} \mathrm{C}$. Sodium borohydride (130 mg) was added slowly for $20 \mathrm{~min}$. The solution darkened, and a purple foam was observed. The mixture was then heated for an additional $30 \mathrm{~min}$, allowed to cool for $10 \mathrm{~min}$, and the solution was adjusted to $\mathrm{pH} 1 \mathrm{using} 6 \mathrm{M}$ hydrochloric acid. Ammonium hexafluorophosphate $(206 \mathrm{mg})$ was dissolved in $1 \mathrm{~mL}$ of water and added to the solution. An orange precipitate formed immediately. This was filtered off and washed with cold ethanol and diethyl ether. The solution was allowed to evaporate slowly over 1 week, resulting in a mixture of orange powder and red and white crystals (possibly a hexafluorophosphate salt). One of these red crystals was suitable for single crystal diffractometry. Any remaining liquid was removed via vacuum filtration, and the precipitate was washed with acetone, which dissolves and separates the orange powder from the mixture. The red crystals were separated from 
the white crystals by washings with methanol and subsequent filtration. The methanol solution consisted mostly of the form $\left[\mathbf{N i}(\mathbf{I I})^{\mathbf{S R S R}} \mathbf{L}\right](\mathbf{C I})\left(\mathbf{P F}_{6}\right)$ with a small amount of [Ni(II) $\left.{ }^{\text {SSRR }} \mathbf{L}\right]\left(\mathbf{P F}_{6}\right)_{2}$, whereas the acetone solution consisted mostly of the form

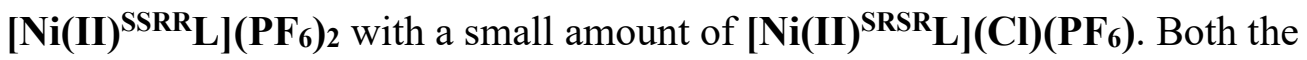
methanol and acetone fractions were allowed to evaporate to dryness. The compounds were separated using the procedures described above. The yield of the orange powder (product [Ni(II) $\left.\left.{ }^{\text {SSRR }} \mathbf{L}\right]\left(\mathbf{P F}_{6}\right)_{2}\right)$ was $102 \mathrm{mg}(41.1 \%$ ), and the yield of product [Ni(II) $\left.{ }^{\text {SRSR }} \mathbf{L}\right](\mathbf{C l})\left(\mathbf{P F}_{6}\right)$ was $46 \mathrm{mg}(22.4 \%)$. Crystals of complex [Ni(II) $\left.{ }^{\text {SSRR }} \mathbf{L}\right]\left(\mathbf{P F}_{6}\right)_{2}$ were grown by diffusion of solutions consisting of $102 \mathrm{mg}$ of ammonium hexafluorophosphate in $0.5 \mathrm{~mL}$ of water on the bottom, pure water, and a top layer of $30 \mathrm{mg}$ of complex [Ni(II) $\left.)^{\mathbf{S S R R}} \mathbf{L}\right]\left(\mathbf{P F}_{\mathbf{6}}\right)_{\mathbf{2}}$ in $2 \mathrm{~mL}$ of acetone. This was capped and left to stand for about 1-week, forming crystals at the interface of the layers. Crystals of $\left[\mathbf{N i}(\mathbf{I I})^{\mathbf{S R S R}} \mathbf{L}\right](\mathbf{C l})\left(\mathbf{P F}_{6}\right)$ were obtained accidentally during a preparation where the reaction mixture was left undisturbed for 1 week. In retrospect, given the stability of these cations, ion exchange chromatography may also be capable of effecting a separation, but this was not investigated. Elemental analysis on the bulk product corresponded to a $1.7\left(\mathrm{PF}_{6^{-}}\right)+0.3(\mathrm{Cl}-)$ counter ion formation: calcd. For $\mathrm{C}_{16} \mathrm{H}_{36} \mathrm{C}_{10.3} \mathrm{~F}_{10.2} \mathrm{~N}_{4} \mathrm{NiP}_{1.7}$ : C 32.00\%, H 6.04\%; found: C 32.46\%, H 6.00\%. ${ }^{1} \mathrm{H}$ NMR

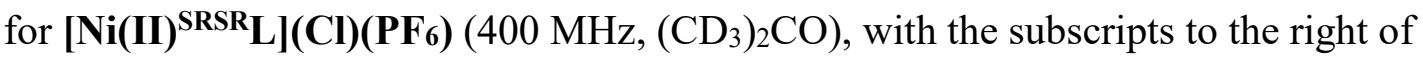
the $\mathrm{C}$ atom identifying which $\mathrm{C}$ atoms the $\mathrm{H}$ atoms are bonded to, see Figure 3.1: = $1.205\left(\mathrm{~d}, 3 J_{\mathrm{HH}}=4 \mathrm{~Hz}, 6 \mathrm{H}, \mathrm{C}_{1} H_{3}\right), \delta=1.250\left(\mathrm{~s}, 6 \mathrm{H}, \mathrm{C}_{6} H_{3}\right), \delta=1.380(\mathrm{dd}, 2 J \mathrm{HH}=16$ $\mathrm{Hz}, 3 J \mathrm{HH}=12 \mathrm{~Hz}, 2 \mathrm{H}, \mathrm{C}_{4} H$ trans to $\mathrm{H}_{3}$ on $\left.\mathrm{C}_{3}\right), \delta=1.757(\mathrm{~d}, 2 J \mathrm{HH}=16,2 \mathrm{H}$, $\mathrm{C}_{4} H$ perpendicular to $\mathrm{H}$ on $\left.\mathrm{C}_{3}\right), \delta=1.895\left(\mathrm{~s}, 6 \mathrm{H}, \mathrm{C}_{2} H_{3}\right), \delta=2.530\left(\mathrm{~s}, 4 \mathrm{H}, \mathrm{C}_{7} H_{\mathrm{eq}}, \mathrm{C}_{8} H_{\mathrm{eq}}\right)$, $\delta=2.92\left(\mathrm{br}, 2 \mathrm{H}, \mathrm{C}_{3} H\right), \delta=3.085\left(\mathrm{~s}, 4 \mathrm{H}, \mathrm{C}_{7} H_{\mathrm{ax}}, \mathrm{C}_{8} H_{\mathrm{ax}}\right)$,

Figure 3.2. Mercury ${ }^{37}$ drawing of the packing arrangement in $\left[\mathbf{N i}(\mathbf{I I})^{\mathrm{SSRR}} \mathbf{L}\right]\left(\mathbf{P F}_{6}\right) 2$. [Colour online.] 


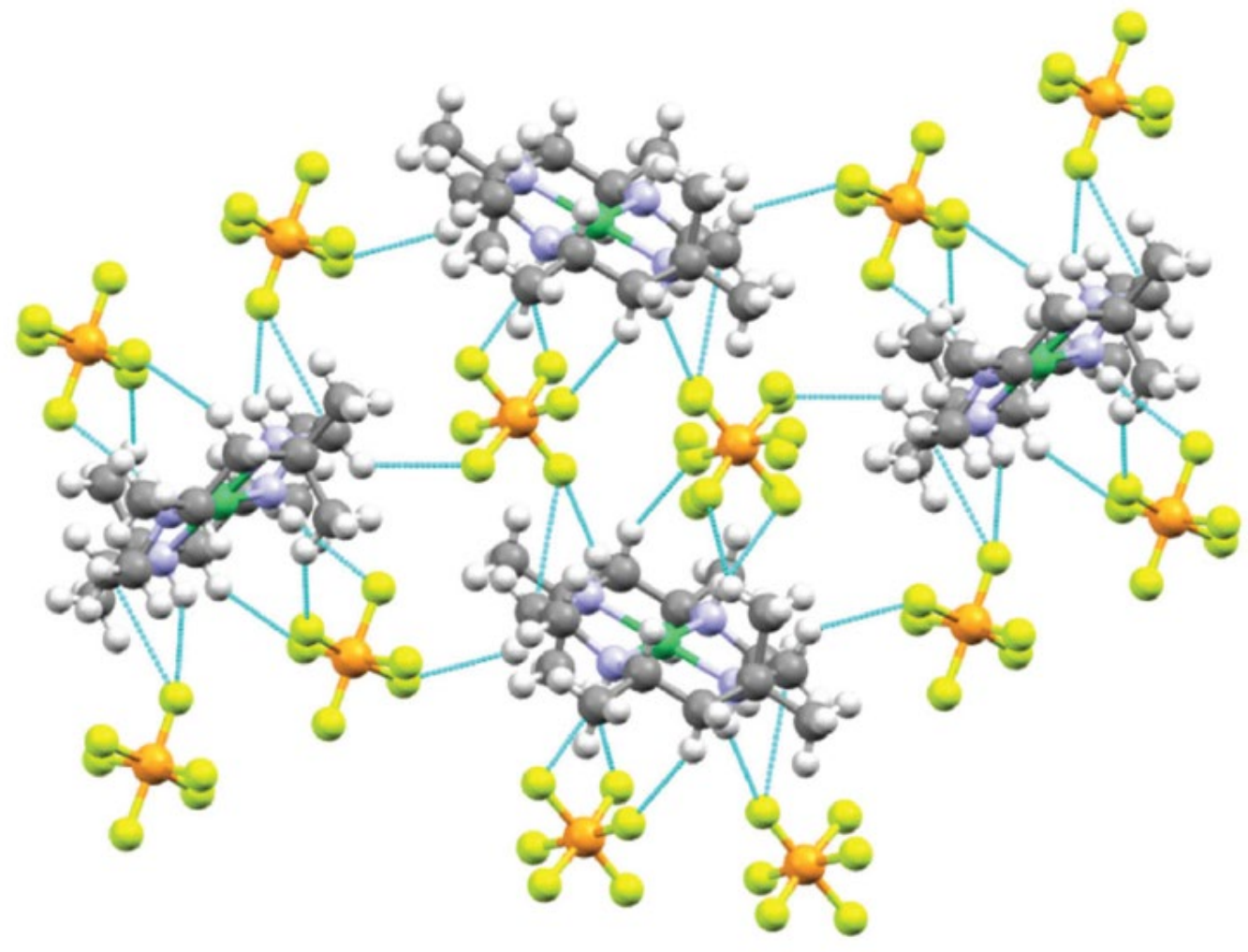

$\delta=3.175\left(\mathrm{~s}, 2 \mathrm{H}, \mathrm{N}_{2} H\right)$, and $\delta=3.550\left(\mathrm{~s}, 2 \mathrm{H}, \mathrm{N}_{1} H\right)$; see Supplementary Figure S4.5. The singlet at $\delta=2.998$ may be due to $\mathrm{H}_{2} \mathrm{O}$ but the other singlet, at $\delta=2.965$, is unknown. ${ }^{1} \mathrm{H}$ NMR for [Ni(II)SSRRL](PF6)2 $\left(400 \mathrm{MHz}, \mathrm{D}_{2} \mathrm{O}\right)$, the subscripts to the right of the $\mathrm{C}$ atom identifies which $\mathrm{C}$ atoms the $\mathrm{H}$ atoms are bonded to, see Figure 4.2: $\delta=0.96\left(\mathrm{~d}, 3 J_{\mathrm{HH}}=8 \mathrm{~Hz}, 6 \mathrm{H}, \mathrm{C}_{6} H_{3}, \mathrm{C}_{14} H_{3}\right), \delta=1.07\left(\mathrm{~s}, 6 \mathrm{H}, \mathrm{C}_{3} H_{3}, \mathrm{C}_{10} H_{3}\right), \delta=1.12$ $\left(\mathrm{m}, 2 \mathrm{H}, \mathrm{C}_{4} H\right.$ trans to $\mathrm{H}$ on $\mathrm{C}_{5}, \mathrm{C}_{12} H$ trans to $\mathrm{H}$ on $\left.\mathrm{C}_{13}\right), \delta=1.72\left(\mathrm{~m}, 2 J_{\mathrm{HH}}=16,2 \mathrm{H}\right.$, $\mathrm{C}_{4} H$ perpendicular to $\mathrm{H}$ on $\mathrm{C}_{5}, \mathrm{C}_{12} H$ perpendicular to $\mathrm{H}$ on $\left.\mathrm{C}_{13}\right), \delta=2.10\left(\mathrm{~s}, 6 \mathrm{H}, \mathrm{C}_{2} \mathrm{H}_{3}\right.$, $\left.\mathrm{C}_{11} H_{3}\right), \delta=2.39,2.49,2.58\left(\mathrm{~m}, 8 \mathrm{H}, \mathrm{C}_{7} H_{2}, \mathrm{C}_{8} H_{2}, \mathrm{C}_{15} H_{2}, \mathrm{C}_{16} H 2\right), \delta=3.37$ (br, $2 \mathrm{H}, \mathrm{C}_{5} H$, $\left.\mathrm{C}_{13} H\right), \delta=3.54\left(\mathrm{br}, 2 \mathrm{H}, \mathrm{N}_{1} H, \mathrm{~N}_{3} H\right)$, and $\delta=3.87(\mathrm{br}, 2 \mathrm{H}, \mathrm{N} 2 H, \mathrm{~N} 4 H)$; see

Supplementary Figure S3.6.

\subsubsection{X-ray crystallography}

In both cases, suitable crystals were cut to an appropriate size and fixed onto the head of thin glass fibers with epoxy resin, which were anchored in goniometer mounting 
pins. The pin-mounted crystal was then inserted into the goniometer head of the Enraf Nonius Turbo CAD-4 diffractometer and centered in the beam path. Standard CAD4 centering, indexing, and data collection programs were utilized. ${ }^{77}$ Data were reduced, corrected for decay, and then for absorption using psi-scans, ${ }^{78}$ and then solved using the program SIR2018, ${ }^{79}$, which afforded nearly complete solutions for the non- $\mathrm{H}$ atoms in all cases. These programs were utilized using the WinGX interface ${ }^{80}$ The models were then refined using SHELXL-2018/3 ${ }^{29}$ first with isotropic and then anisotropic thermal parameters to convergence. For complex $\left[\mathbf{N i}(\mathbf{I I})^{\mathbf{S R S R}} \mathbf{L}\right](\mathbf{C l})\left(\mathbf{P F}_{6}\right)$, it was apparent that one of the ethylene moieties and the anion were disordered. The ethylene disorder was modeled by refining the occupancies of the disordered atoms with their sum constrained to unity and resulted in a $61(2): 39(2) \%$ ratio for the occupancies. The six fluorine atoms in the anion were modeled in three orientations and restrained with SAME/SADI options resulting in 71(1):16(1):13(1)\% occupancies. The fluorine atoms in the anion in complex $\left[\mathbf{N i}(\mathbf{I I})^{\mathrm{SSRR}} \mathbf{L}\right]\left(\mathbf{P F}_{6}\right)_{2}$ was accounted for in two orientations resulting in 60(3):40(3)\% occupancies. In both cases, $\mathrm{H}$ atoms attached to $\mathrm{C}$ atoms were accounted for with thermal parameters constrained to ride on the $\mathrm{C}$ atom on which they were bonded and set to 1.5 times the isotropic equivalent of the atoms they were attached to. The $\mathrm{H}$ atoms attached to the $\mathrm{N}$ atoms were located in difference maps and freely refined. Crystal and data collection parameters are summarized in Table 3.1.

\subsubsection{DFT calculations}

All calculations were carried out using Gaussian 16, A03. ${ }^{81}$ Atomic positions from the single-crystal determinations provided the starting coordinates. The $\mathrm{APFD}^{36}$ functional combined with basis sets $6-311+\mathrm{G}(\mathrm{d})^{40}$ for the non-metal atoms and the LanL2DZ ${ }^{40}$ basis set for the $\mathrm{Ni}$ atoms were utilized. Frequency calculations were conducted for all structures, and imaginary peaks were not obtained. Calculations were also conducted using the mPW1PW91/genecp functionality, Ni with the effective core potential $\mathrm{SDD}^{82,83}$ basis set, and with the $\mathrm{H}$ and $\mathrm{C}$ atoms involved in 
the close interaction defined with $6-311++\mathrm{G}(2 \mathrm{~d}, 2 \mathrm{p})$ basis sets and the rest at the 6$31 \mathrm{G}(\mathrm{d})$ level. Ten excited states were assessed using TD-DFT optimizations ${ }^{84}$ in a polarizable continuum model (PCM) in acetone. Coordinates of all optimized structures, calculated IR and UV-vis spectra, listings of the 10 calculated excited states, and drawings of selected molecular orbitals are presented in the Supplementary data.

\subsection{Results and Discussion}

The various isomeric forms of complex $\mathbf{3}$ have their origins in the fact that compound 2 in Scheme 3.1 has two chiral $\mathrm{N}$ atoms, which result in two non-enantiomeric configurations, SR and SS. Subsequent reduction of these species with preservation of initial configurations results in the cations present in complexes $\left[\mathbf{N i ( I I )}{ }^{\mathbf{S S R R}} \mathbf{L}\right]\left(\mathbf{P F}_{6}\right)_{2}$ and $\left[\mathbf{N i}(\mathbf{I I})^{\text {SRSR }} \mathbf{L}\right](\mathbf{C l})\left(\mathbf{P F}_{6}\right)$. Maintaining configuration at the $\mathrm{N}$ atoms (i.e., reducing inversion) and formation of metastable structures was noted previously to be possible under acidic conditions. ${ }^{60}$ The complexes can be separated and isolated due to their differing solubilities with complex $\left[\mathbf{N i}(\mathbf{I I})^{\mathbf{S R S R}} \mathbf{L}\right](\mathbf{C l})\left(\mathbf{P F}_{6}\right)$ being more soluble in room temperature water and methanol, whereas complex $\left[\mathbf{N i}(\mathbf{I I})^{\mathbf{S S R R}} \mathbf{L}\right]\left(\mathbf{P F}_{6}\right)_{2}$ is more soluble in acetone and hot water. Complex $\left[\mathbf{N i}(\mathbf{I I})^{\mathbf{S R S R}} \mathbf{L}\right](\mathbf{C l})\left(\mathbf{P F}_{6}\right)$ melted in the range $302-316^{\circ} \mathrm{C}$ with the orange powder transforming into a dark red liquid, which quickly decomposed to brown. In contrast, complex $\left[\mathbf{N i}(\mathbf{I I})^{\mathrm{SSRR}} \mathbf{L}\right]\left(\mathbf{P F}_{6}\right)_{2}$ melted in the range $187-200{ }^{\circ} \mathrm{C}$ with a gas evolving at $235^{\circ} \mathrm{C}$ and the liquid turning dark brown at $251{ }^{\circ} \mathrm{C}$. The complexes display very different IR spectra due to the different conformations of the ligand and also the fact that $\left[\mathbf{N i}(\mathbf{I I})^{\mathrm{SRSR}} \mathbf{L}\right](\mathbf{C l})\left(\mathbf{P F}_{6}\right)$ (Supplementary Figure S3.2) has $\mathrm{Cl}^{-}$and $\mathrm{PF}_{6}{ }^{-}$as counterions. Thus, a reduced

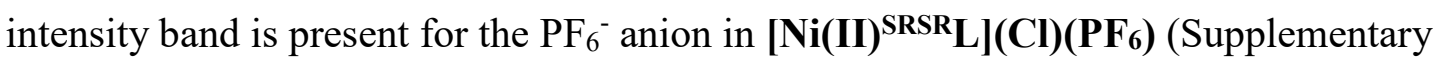
Figure S3.2) in comparison with [Ni(II) $\left.{ }^{\text {SSRR }} \mathbf{L}\right]\left(\mathbf{P F}_{6}\right)_{2}$ (Supplementary Figure S3.1) at $838 \mathrm{~cm}^{-1}$. Additionally, a broad absorption from $1170-925 \mathrm{~cm}^{-1}$ due to $\mathrm{C}-\mathrm{C}, \mathrm{C}-\mathrm{H}$, and $\mathrm{C}-\mathrm{N}$ bending modes is present in $\left[\mathbf{N i}(\mathbf{I I})^{\mathbf{S R S R}} \mathbf{L}\right](\mathbf{C l})\left(\mathbf{P F}_{6}\right)$ in contrast to more sharply defined medium intensity absorptions at 1190, 1173, 1147, 1100, and 1022

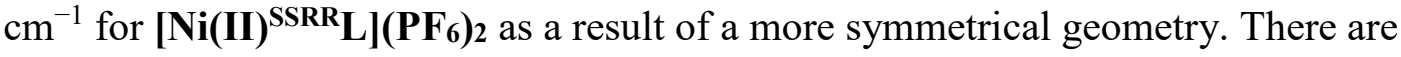


also absorption bands centered around $2975 \mathrm{~cm}^{-1}$ due to $\mathrm{C}-\mathrm{H}$ stretching and bands at 3221 and $3216 \mathrm{~cm}^{-1}$ due to $\mathrm{N}-\mathrm{H}$ stretching for $\left[\mathbf{N i}(\mathbf{I I})^{\mathbf{S S R R}} \mathbf{L}\right]\left(\mathbf{P F}_{\mathbf{6}}\right)_{2}$ and

[Ni(II) $\left.{ }^{\text {SRSR }} \mathbf{L}\right](\mathbf{C l})\left(\mathbf{P F}_{6}\right)$, respectively. In addition, a small absorption at $3095 \mathrm{~cm}^{-1}$ is present in the spectrum for $\left[\mathbf{N i}(\mathbf{I I})^{\mathbf{S R S R}} \mathbf{L}\right](\mathbf{C l})\left(\mathbf{P F}_{6}\right)$, which may be due to the $\mathrm{N}-\mathrm{H}$ to $\mathrm{Cl}$ interactions (see structural results below). The visible spectra for the complexes consist of a broad transition that only changes slightly in different solvents. Complex [Ni(II) $\left.)^{\text {SSRR }} \mathbf{L}\right]\left(\mathbf{P F}_{6}\right)_{2}$ displays a small broad absorption centered at $462 \mathrm{~nm}$ (acetone), 456 (acetonitrile), and 466 nm (DMSO) (Supplementary Figure S3.3), whereas complex [Ni(II) $\left.{ }^{\text {SRSR }} \mathbf{L}\right](\mathbf{C l})\left(\mathbf{P F}_{6}\right)$ absorbs at $451 \mathrm{~nm}$ (DMSO), $456 \mathrm{~nm}$ (acetonitrile), and $453 \mathrm{~nm}$ (water) (Supplementary Figure S3.4). These complexes also display interesting ${ }^{1} \mathrm{H}$ NMR spectra, as shown in Supplementary Figure. S3.5-S3.8. Due to their differing solubilities, the ${ }^{1} \mathrm{H}$ NMR spectra were initially obtained in different solvents, acetone- $d 6$ for $\left[\mathbf{N i}(\mathbf{I I})^{\mathbf{S S R R}} \mathbf{L}\right]\left(\mathbf{P F}_{6}\right)_{2}$ (Supplementary Figure S3.5) and $\mathrm{D}_{2} \mathrm{O}$ for $\left[\mathbf{N i}(\mathbf{I I})^{\text {SRSR }} \mathbf{L}\right](\mathbf{C l})\left(\mathbf{P F}_{6}\right)$ (Supplementary Figure S3.6). Previous assignments of the ${ }^{1} \mathrm{H}$ NMR spectra illustrated the formation of different isomeric forms of complex 2 in Scheme $3.1,{ }^{85}$, and thus, if mixtures were initially prepared, these would add to the complexities present in the spectra reported here. The resonances from the methyl groups for $\left[\mathbf{N i}(\mathbf{I I})^{\mathbf{S S R R}} \mathbf{L}\right]\left(\mathbf{P F}_{\mathbf{6}}\right)_{2}$ consist of a doublet at $\delta 1.205(J=4 \mathrm{~Hz})$ and two singlets that are at $\delta 1.250$ and 1.895 for

Table 3.1 Crystal data and structure refinement for $\left[\mathbf{N i}(\mathbf{I I})^{\mathrm{SSRR}} \mathbf{L}\right]\left(\mathbf{P F}_{6}\right)_{2}$ and $\left[\mathrm{Ni}(\mathrm{II})^{\mathrm{SRSR}} \mathbf{L}\right](\mathrm{Cl})\left(\mathrm{PF}_{6}\right)$. 
Table 1. Crystal data and structure refinement for $\left[\mathrm{Ni}(\mathrm{II})^{\operatorname{ssk}} \mathrm{L}\right]\left(\mathrm{PF}_{\epsilon}\right)_{2}$ and $\left[\mathrm{Ni}(\mathrm{II})^{s k s k} \mathrm{~L}\right]\left(\mathrm{CI}_{1}\left(\mathrm{PF}_{6}\right)\right.$.

\begin{tabular}{|c|c|c|}
\hline Identification code & 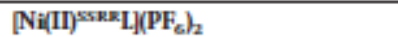 & {$\left[\mathrm{Ni}(\mathrm{II})^{\text {SESR }} \mathrm{L}\right](\mathrm{CI})\left(\mathrm{PF}_{\mathrm{f}}\right)$} \\
\hline Empirical formula & $\mathrm{C}_{26} \mathrm{H}_{36} \mathrm{~F}_{12} \mathrm{~N}_{4} \mathrm{NiP}_{2}$ & $\mathrm{C}_{16} \mathrm{H}_{36} \mathrm{ClF}_{6} \mathrm{~N}_{4} \mathrm{NiP}$ \\
\hline Formula mass & 633.12 & 523.83 \\
\hline Colour, habit & Orange, plate & Red, block \\
\hline Crystal dimensions (mm) & $0.50 \times 0.20 \times 0.10$ & $0.30 \times 0.20 \times 0.15$ \\
\hline Crystal system & Monoclinic & Triclinic \\
\hline Space group & $\mathrm{P}_{2}$ /n (no. 14) & $P \overline{1}$ (no. 2) \\
\hline $\mathrm{Z}$ & 4 & 2 \\
\hline$a(\AA)$ & $10.767(2)$ & $9.773(2)$ \\
\hline$b(\hat{A})$ & $9.162(3)$ & $10.382(2)$ \\
\hline$c(\AA)$ & $12.979(5)$ & $12.774(5)$ \\
\hline$\alpha\left(n^{\circ}\right)$ & 90 & $100.27(2)$ \\
\hline$\beta\left(n^{*}\right)$ & $97.67(2)$ & $103.67(2)$ \\
\hline$\gamma\left({ }^{\circ}\right)$ & 90 & $105.81(2)$ \\
\hline Collection ranges & $-1 \leq h \leq 12,-1 \leq k \leq 10,-15 \leq \ell \leq 15$ & $-11 \leq h \leq 0,-11 \leq k \leq 12,-14 \leq \ell \leq 15$ \\
\hline Temperature $(\mathrm{K})$ & $293(2)$ & $570(2)$ \\
\hline Volume $(\hat{A}(3))$ & $1268.9(7)$ & $170.2(6)$ \\
\hline$D_{\text {calcal }}\left(\mathrm{Mg} / \mathrm{m}^{3}\right)$ & 1.657 & 1.486 \\
\hline Radiation & Mo $\operatorname{Ko}(\lambda=0.71073 \AA)$ & Mo $\mathrm{K} \alpha(\lambda=0.71073 \AA)$ \\
\hline Absorption coefficient $(\mu)\left(\mathrm{mm}^{-1}\right)$ & 0.992 & 1.069 \\
\hline Absorption correction & Psi-scan & Psi-scan \\
\hline Maximum and minimum transmissions & 0.9998 and 0.9093 & 0.9982 and 0.927 \\
\hline$F(000)$ & 652 & 548 \\
\hline$\theta$ range for data collection $\left({ }^{\circ}\right)$ & $2.312-24.967$ & $1699-24.973$ \\
\hline Reflections collected & 2723 & 4375 \\
\hline Independent reflections & $2232\left(R_{1 n t}=0.0336\right)$ & $4112\left(R_{\text {Int }}=0.0322\right)$ \\
\hline Completeness to $\theta=24.967^{\circ}(\%)$ & 100.0 & 100.0 \\
\hline Data/restraints/parameters & $2232 / 15 / 223$ & $4112 / 46 / 348$ \\
\hline Maximum shift/error & 0.00 & 0.00 \\
\hline Refinement method & Full-matrix least-squares on $\mathrm{F}^{2}$ & Full-matrix least-squares on $\mathrm{F}^{2}$ \\
\hline Goodness of fit on $F^{2}$ & 1.082 & 1.029 \\
\hline$R_{1},{ }^{a} w R_{2}[I>2 \sigma(I)]^{b}$ & $0.0442,0.1043^{c}$ & $0.0415,0.1003^{4}$ \\
\hline$R_{1}$, wR $R_{2}$ (all data) & $0.0715,0.1148$ & $0.0627,0.1105$ \\
\hline Extinction coefficient & NIA & N/A \\
\hline Largest diff. peak and hole (e $\hat{A}^{-\lambda}$ ) & 0.628 and -0.464 & 0.501 and -0.252 \\
\hline
\end{tabular}

$-R_{1}=2 F_{0}|-| F_{d} \mid \sum F_{0}$.

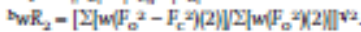

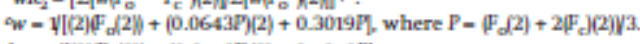

$u_{w}=1\left[(2)\left(F_{d}(2]\right)+(0.05) 6 P(2)+0.7959 P\right]$.

the $\mathrm{H}$ atoms attached to $\mathrm{C} 1, \mathrm{C} 6$, and $\mathrm{C} 2$, respectively (Figure 3.1; Supplementary Figure S3.5). This downfield shift for the signal for the $\mathrm{H}$ atoms bonded to $\mathrm{C} 2$ as opposed to $\mathrm{C} 6$ is probably due to the closer proximity to the tetragonal axis on the nickel atom, as noted previously. ${ }^{60} 9$ The two $\mathrm{H}$ atoms on $\mathrm{C} 4$ appear to resonate at $\delta 1.380(\mathrm{dd})$ and $1.757(\mathrm{~d})$, an assignment also confirmed based on integration. Here, we employ the Karplus observation ${ }^{86}$ to differentiate between these two protons on $\mathrm{C} 4$ based on the dihedral angle between the $\mathrm{H}$ atoms on the vicinal $\mathrm{C} 3$ and $\mathrm{C} 4$ atoms (Figure 3.1) and the expected coupling. The $\mathrm{H}$ atom that has a $179.8^{\circ}$ dihedral angle to the $\mathrm{H}$ atom on $\mathrm{C} 3$ appears as the doublet of doublets, whereas the other $\mathrm{H}$ atom on $\mathrm{C} 4$ at $64.3^{\circ}$ appears as the doublet. Interestingly the $\mathrm{H}$ atom on $\mathrm{C} 3$ is assigned as coming downfield at $\delta 2.92$. Based on intensities, the ethylenic $\mathrm{H}$ atoms may be differentiated based on axial and equatorial arrangements. Thus, the broad resonance 
at $\delta 2.530$ may be due to the equatorial $\mathrm{H}$ atoms, and that at $\delta 3.085$ may be due to the axially located resonances on the $\mathrm{C} 7$ and $\mathrm{C} 8$ atoms. The proximity to the $\mathrm{Ni}$ atom was used for possible identification of the $\mathrm{H}$ atoms bonded to the $\mathrm{N}$ atoms, with closer proximity resulting in a downfield shift. Thus, $\mathrm{H}$ atoms on N2 $(\mathrm{H} 12-\mathrm{Ni}=2.326 \AA)$ resonate at $\delta 3.175$, and those on $\mathrm{N} 1(\mathrm{H} 11-\mathrm{Ni}=2.217 \mathrm{~A})$ resonate at $\delta 3.550$. The $1 \mathrm{H}$ NMR spectrum of [Ni(II) $\left.{ }^{\text {SRSR }} \mathbf{L}\right](\mathbf{C l})\left(\mathbf{P F}_{6}\right)$ contains a similar pattern for the methyl resonances, except that those $\mathrm{H}$ atoms on $\mathrm{C} 2$ and $\mathrm{C} 11$ are shifted further downfield, appearing at $\delta 2.10$ compared with the $\delta 1.895$ obtained for the equivalent groups in [Ni(II) $\left.{ }^{\mathbf{S S R R}} \mathbf{L}\right]\left(\mathbf{P F}_{6}\right)_{2}$ (Figure 3.3; Supplementary Figure S3.6). This downfield shift is one of the main aspects of an anagostic interaction 
Figure 3.3. ORTEP $^{76}$ drawing (with POV-Ray ${ }^{31}$ rendering) of the major orientation of the cation in $\left[\mathbf{N i}(\mathbf{I I})^{\mathbf{S R S R}} \mathbf{L}\right](\mathbf{C l})\left(\mathbf{P F}_{6}\right)$. Thermal ellipsoids are drawn at the $50 \%$ probability level, and $\mathrm{H}$ atoms are represented by spheres of arbitrary radii. [Colour online.]

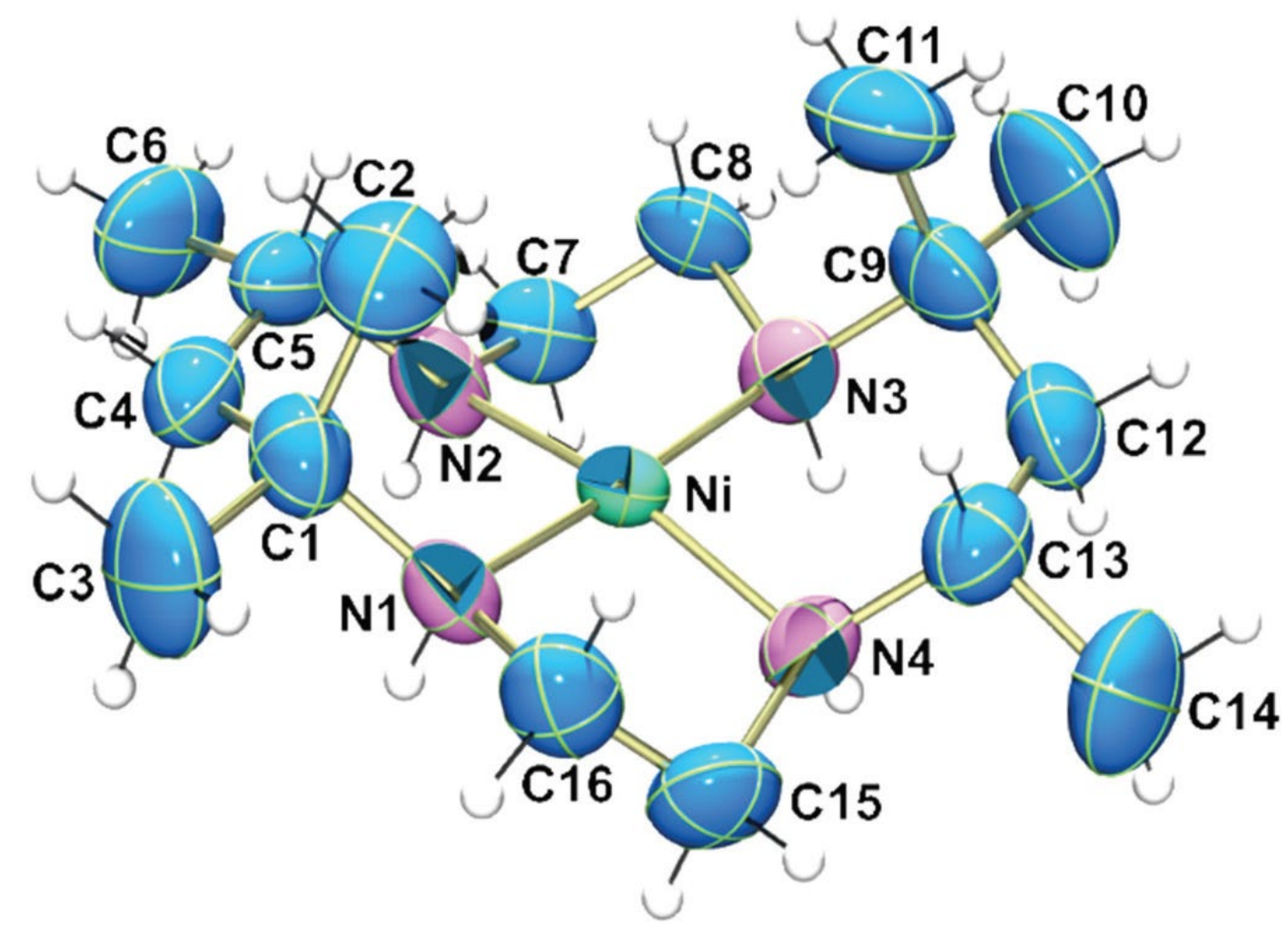

(i.e., largely electrostatic) as opposed to an agostic one (i.e., a 3-center, 2-electron bond) where upfield shifts are observed. ${ }^{73}$ The ethylenic $\mathrm{H}$ atoms resonate in the form of a 2:1:1 pattern at $\delta 2.39,2.49$, and 2.58 , based on intensities. However, as the crystal struc- 
Table 3.2 Selected bond distances and angles [Colour online]

\begin{tabular}{|c|c|c|c|c|c|c|}
\hline & {$\left[\mathrm{Ni}(\mathrm{II})^{\sin }\right.$} & & & {$\left[\mathrm{Ni}(\mathrm{II})^{\mathrm{seSBR}}\right.$} & $\frac{1}{10}$ & \\
\hline & \multirow[b]{2}{*}{$\mathrm{X}$-ray } & \multicolumn{2}{|c|}{ Calculations } & \multirow[b]{2}{*}{ X-ray } & \multicolumn{2}{|c|}{ Calculations } \\
\hline & & $\overline{\mathrm{APFD}}$ & mPW1Pw91 & & $\overline{\text { APFD }}$ & mPW1Pw91 \\
\hline \multicolumn{7}{|c|}{ Bond distance $(\AA \tilde{)})$} \\
\hline $\mathrm{N} 1-\mathrm{Ni}$ & $1.955(3)$ & 2.041 & 1.978 & $1.931(3)$ & 1.926 & 1.948 \\
\hline $\mathrm{N} 2-\mathrm{Ni}$ & $1.954(3)$ & 1.931 & 1.970 & $1.921(3)$ & 1.917 & 1.944 \\
\hline N3-Ni & & & & $1.921(3)$ & 1.925 & 1.948 \\
\hline $\mathrm{N} 4-\mathrm{Ni}$ & & & & $1.913(3)$ & 1.917 & 1.944 \\
\hline N1-H11 & $0.77(4)$ & 1.02 & 1.03 & & & \\
\hline $\mathrm{N} 2-\mathrm{H} 12$ & $0.91(4)$ & 1.02 & 1.02 & & & \\
\hline N1-H101 & & & & $0.85(3)$ & 1.02 & 1.02 \\
\hline $\mathrm{N} 2-\mathrm{H}_{102}$ & & & & $0.81(4)$ & 1.02 & 1.02 \\
\hline N3-H103 & & & & $0.96(4)$ & 1.02 & 1.02 \\
\hline N4-H104 & & & & $0.81(4)$ & 1.02 & 1.02 \\
\hline $\mathrm{H} 2 \mathrm{~B}-\mathrm{Ni}$ & 2.948 & 2.53 & 2.87 & 2.893 & 2.675 & 2.819 \\
\hline $\mathrm{H} n \mathrm{~B}-\mathrm{Ni}$ & & & & 2.729 & 2.675 & 2.819 \\
\hline \multicolumn{7}{|c|}{ Bond angle (") } \\
\hline $\mathrm{N} 1-\mathrm{Ni}-\mathrm{N1}{ }^{\prime}$ & 180 & 180 & 180 & & & \\
\hline $\mathrm{N} 2-\mathrm{Ni}-\mathrm{N} 2{ }^{\prime}$ & 180 & 180 & 180 & & & \\
\hline $\mathrm{N} 1-\mathrm{Ni} 1-\mathrm{N2}{ }^{\prime}$ & $93.38(12)$ & 93.41 & 93.52 & & & \\
\hline $\mathrm{N} 1-\mathrm{Ni}-\mathrm{N} 2$ & $86.62(12)$ & 86.59 & 86.47 & $92.66(13)$ & 91.41 & 92.37 \\
\hline N1-Ni-N3 & & & & $174.35(14)$ & 53.74 & 171.12 \\
\hline N1-Ni-N4 & & & & $88.67(14)$ & 89.51 & 88.78 \\
\hline $\mathrm{N} 2-\mathrm{Ni}-\mathrm{N} 3$ & & & & $88.86(14)$ & 89.51 & 92.37 \\
\hline $\mathrm{N} 2-\mathrm{Ni}-\mathrm{N} 4$ & & & & $166.26(16)$ & 163.05 & 165.08 \\
\hline $\mathrm{N} 3-\mathrm{Ni}-\mathrm{N} 4$ & & & & $91.14(14)$ & 89.51 & 88.78 \\
\hline
\end{tabular}

ture (see below) contained disorder in the ethylene moieties, definitive assignments are not possible. The $\mathrm{H}$ atoms on the $\mathrm{N}$ atoms are identified as broad singlets at $\delta 3.54$ (for those on N1 and N3) and 3.87 (for those on N2 and N4) based on closer proximity to the $\mathrm{Ni}$ center resulting in a downfield shift. The remaining three $\mathrm{H}$ atoms in the six-membered ring are harder to discern due to complexities in the respective regions (based on comparison with the spectrum for $\left.\left[\mathbf{N i}(\mathbf{I I})^{\mathrm{SSRR}} \mathbf{L}\right]\left(\mathbf{P F}_{6}\right)_{2}\right)$ but tentatively assigned as indicated in the Experimental section. It is noteworthy that the equivalent $\mathrm{H}$ atoms bonded to $\mathrm{C} 5$ and $\mathrm{C} 13$ in $\left[\mathbf{N i}(\mathrm{II})^{\mathrm{SRSR}} \mathbf{L}\right](\mathbf{C l})\left(\mathbf{P F}_{6}\right)$ resonate further

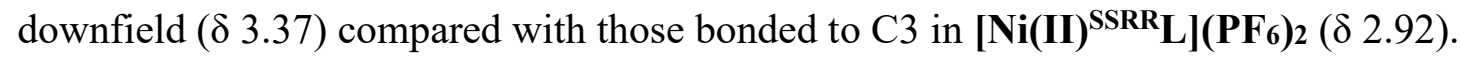
This is also evidence of anagostic interactions. Compound $\left[\mathbf{N i}(\mathbf{I I})^{\mathrm{SSRR}} \mathbf{L}\right]\left(\mathbf{P F}_{6}\right)_{2}$ either 
forms a square pyramidal complex with one apically bound $\mathrm{CD}_{3} \mathrm{CN}$ or an octahedral arrangement with two axial $\mathrm{CD}_{3} \mathrm{CN}$ ligands as the spectrum in $\mathrm{CD}_{3} \mathrm{CN}$ consisted of very broad resonances indicating paramagnetism at $\delta 0.5,5.25$, and 7.25 (Supplementary Figure S3.7). In contrast, the spectrum of $\left[\mathbf{N i}(\mathbf{I I})^{\mathbf{S R S R}} \mathbf{L}\right](\mathbf{C l})\left(\mathbf{P F}_{6}\right)$ in $\mathrm{CD}_{3} \mathrm{CN}$ (Supplementary Figure S3.8) was similar to that obtained when $\left[\mathbf{N i}(\mathbf{I I})^{\text {SRSR }} \mathbf{L}\right](\mathbf{C l})\left(\mathbf{P F}_{6}\right)$ was dissolved in $\mathrm{D}_{2} \mathrm{O}$ (Supplementary Figure S3.6), suggesting that a square planar geometry is maintained with presumably steric hindrance blocking coordination of acetonitrile. ORTEP representations of $\left[\mathbf{N i}(\mathbf{I I})^{\mathbf{S S R R}} \mathbf{L}\right]\left(\mathbf{P F}_{\mathbf{6}}\right)_{2}$ and $\left[\mathbf{N i}(\mathbf{I I})^{\mathbf{S R S R}} \mathbf{L}\right](\mathbf{C l})\left(\mathbf{P F}_{6}\right)$ are displayed in Figures. 3.1 and 3.3, respectively, stereoviews of the cations are in Scheme 3.1, and selected bond distances are given in Table 3.2. With [Ni(II) $\left.{ }^{\mathbf{S S R R}} \mathbf{L}\right]\left(\mathbf{P F}_{\mathbf{6}}\right)_{2}$, the Ni atom is situated on an inversion point, and the conformation of this arrangement is $\boldsymbol{S S R R}(\boldsymbol{S R}) \delta \lambda$ (point group $\mathrm{Ci}$ ), which corresponds to structure $\mathbf{A}$ in Chart 3.1, i.e., the most common arrangement. The coordination sphere of the asymmetric unit consists of the $\mathrm{Ni}$ and two $\mathrm{N}$ atoms with similar distances for $\mathrm{Ni}-\mathrm{N} 1$ and $\mathrm{Ni}-\mathrm{N} 2$ at 1.955(3) and 1.954(3) A, respectively (Table 3.2). In both structures, $\mathrm{H}$ atoms attached to $\mathrm{N}$ atoms were refined freely, whereas those attached to $\mathrm{C}$ atoms were inserted at calculated positions and refined with thermal parameters constrained to the riding atom. The coordination sphere in $\left[\mathbf{N i}(\mathbf{I I})^{\mathbf{S S R R}} \mathbf{L}\right]\left(\mathbf{P F}_{6}\right)_{2}$ is thus square planar with adjacent angles close to $90^{\circ}$ with $\mathrm{N} 1-\mathrm{Ni}-\mathrm{N} 2{ }^{\prime}=93.38(12)^{\circ}$ and N1-Ni-N2 $=86.62(12)^{\circ}$. The overall geometry consists of two five-membered rings arising from the coordination of ethylenediamine and two six-membered ones from the condensation of four acetone molecules. The five-membered rings are in a $\delta \lambda$ configuration, and the two six-membered rings are in almost flattened chair conformations caused by the $\mathrm{H}$ atoms attached to the $\mathrm{N}$-atoms in each ring being on opposite sides of the equatorial plane (Figure 3.1). The structure is held together by a series of $\mathrm{H}$-bonded arrangements with two $\mathrm{PF}_{6}{ }^{-}$anions bridging two cations forming extended chains, which are also held together by H-bonds (involving $\mathrm{F}$ atoms and $\mathrm{H}$ atoms bonded to the $\mathrm{N} 1, \mathrm{~N} 2, \mathrm{C} 4, \mathrm{C} 6$, and $\mathrm{C} 8$ atoms; 
Supplementary Table S4.2) between the anions and adjacent cations as depicted in Figure 3.2.

Figure 3.4. Mercury ${ }^{37}$ drawing of the packing arrangement in $\left[\mathrm{Ni}(\mathrm{II})^{\mathrm{SRSR}} \mathrm{L}\right](\mathrm{Cl})\left(\mathrm{PF}_{6}\right)$. [Colour online.]

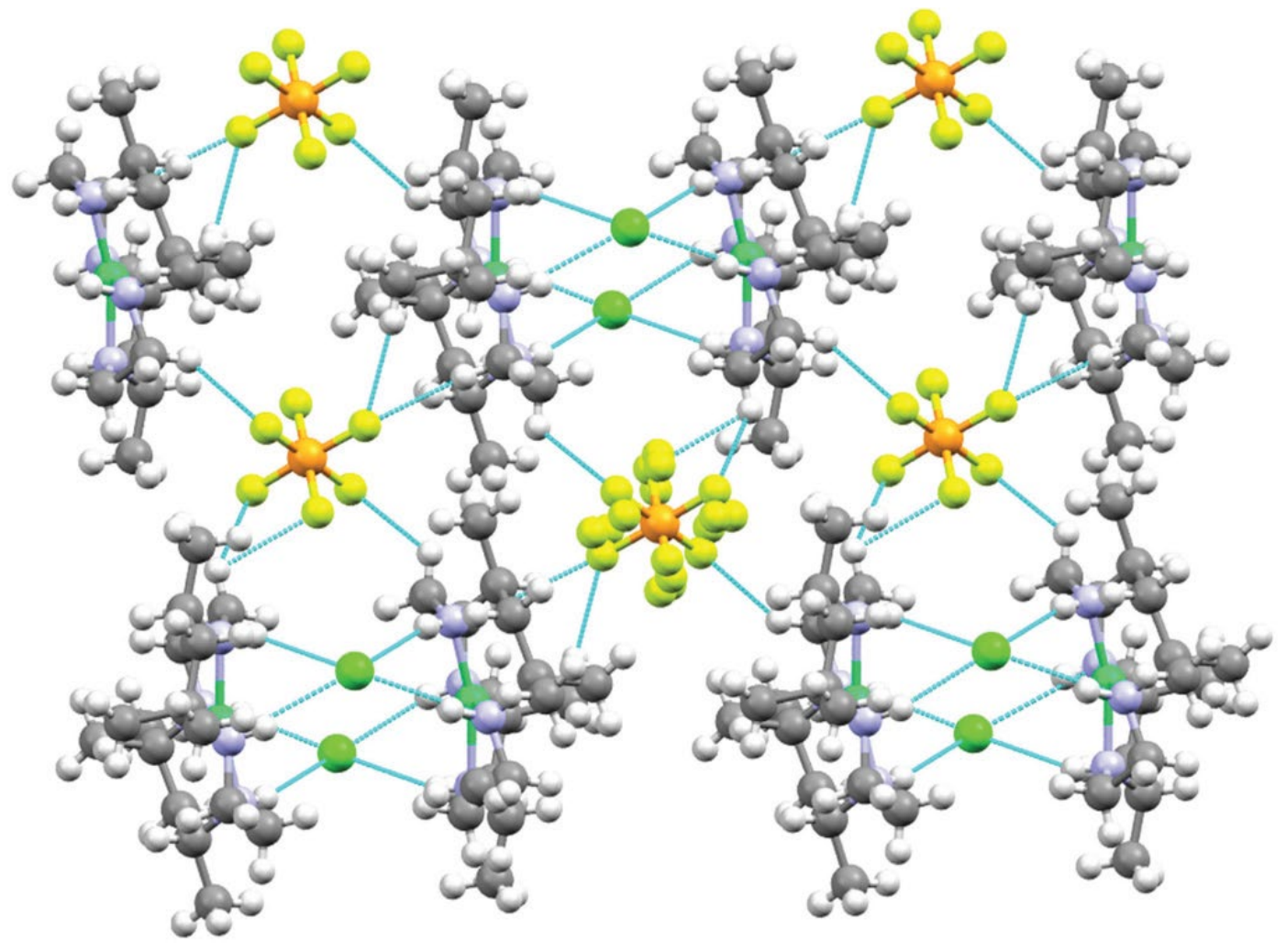


Figure 3.5. Cyclic voltammetry of complexes 1, 2, [Ni(II) $\left.{ }^{\mathrm{SSRR}} \mathbf{L}\right]\left(\mathbf{P F}_{6}\right)_{2}$, and

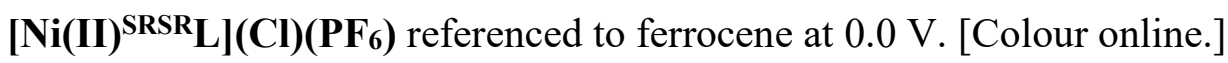

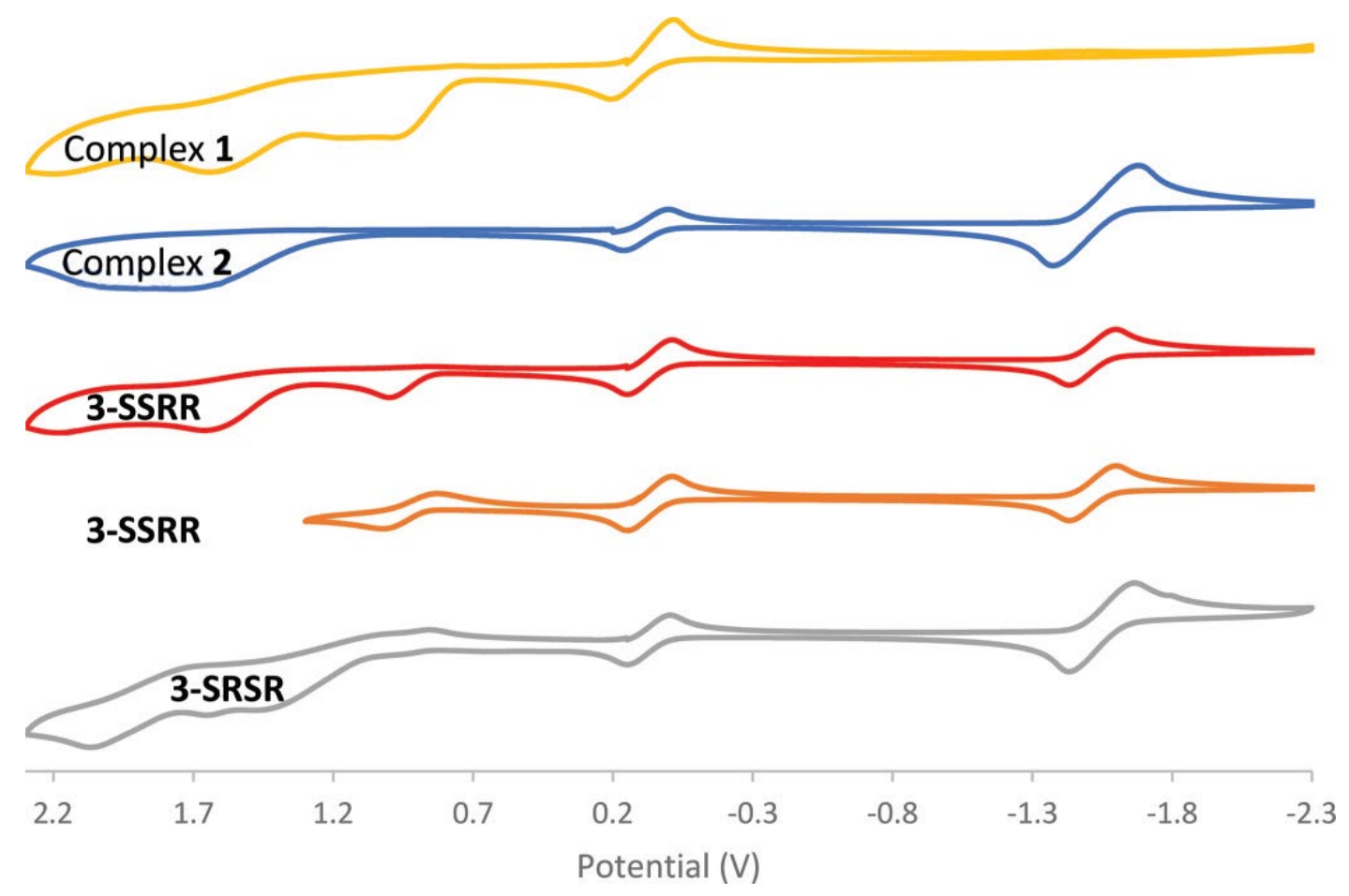

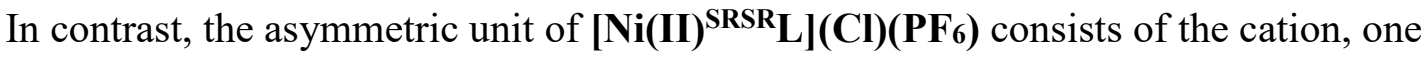
$\mathrm{Cl}-$ anion, and one $\mathrm{PF}_{6}{ }^{-}$anion. There is a 61(2):39(2)\% disorder in one of the ethylene groups, and this structure corresponds to a similar ratio of forms $\mathbf{J}$ and $\mathbf{I}$, respectively, in Chart 4.1. The coordination sphere around the Ni atom is distorted square planar with distances Ni-N1 = 1.931(3), Ni-N2 = 1.921(3), Ni-N3 = 1.921(3), and Ni-N4= 1.913(3) A and trans angles deviate significantly from linearity at $\mathrm{Ni}-\mathrm{Ni}-\mathrm{N} 3=$ $174.25(14)^{\circ}$ and $\mathrm{N} 2-\mathrm{Ni}-\mathrm{N} 4=166.26(16)^{\circ}$. As shown in Figure 4.3, the ethylene chains are in $\lambda \lambda$ configurations with a puckered-up arrangement in the two sixmembered rings resulting in close contacts between the $\mathrm{Ni}$ atom and $\mathrm{H}$ atoms at distances of $\mathrm{Ni}-\mathrm{H} 2 \mathrm{~B}=2.893$ and $\mathrm{Ni}-\mathrm{H} 11 \mathrm{~B}=2.729 \AA$. These distances are shorter than the equivalent one, i.e., $\mathrm{NiH} 2 \mathrm{~B}=2.948 \AA$ in $\left[\mathbf{N i}(\mathbf{I I})^{\mathbf{S S R R}} \mathbf{L}\right]\left(\mathbf{P F}_{6}\right)_{2}$ (Table 4.2), and this puckered-up arrangement results in the four $\mathrm{H}$ atoms bonded to $\mathrm{N}$ atoms being on the same side of the coordination equatorial plane (point group C2). Overall, the 
structure is held together by $\mathrm{H}$-bonds to the $\mathrm{Cl}^{-}$and $\mathrm{PF}_{6}{ }^{-}$anions. Two cations are bonded together by $\mathrm{H}$-bonds to two $\mathrm{Cl}-$ anions that are each situated in the middle and slightly about a plane described by $\mathrm{H}$ atoms attached to the $\mathrm{N}$ atoms from two adjacent cations. These dimers of cations and $\mathrm{Cl}-$ anions are then situated in a staggered adjacent arrangement (i.e., with respect to the $\mathrm{Cl}^{-}$anions) held together with $\mathrm{H}$-bonds to the $\mathrm{F}$ atoms on the $\mathrm{PF}_{6}{ }^{-}$anions (Figure 3.4; Supplementary Table S3.3).

Table 3.3. Potentials (V) for complexes 1, 2, [Ni(II) $\left.{ }^{\mathrm{SSRR}} \mathbf{L}\right]\left(\mathbf{P F}_{6}\right)_{2}$, and $\left[\mathrm{Ni}(\mathrm{II})^{\mathrm{SRSR}} \mathbf{L}\right](\mathrm{Cl})\left(\mathrm{PF}_{6}\right)$.

\begin{tabular}{lllll}
\hline Complex & $E_{\mathrm{pa}^{\prime}}(\mathrm{ox})$ & $E_{\mathrm{pa}}(\mathrm{ox})$ & $E_{1 / 2}(\mathrm{ox})$ & $E_{1 / 2}(\mathrm{red})$ \\
\hline $\mathbf{1}$ & 1.54 & 0.89 & & \\
$\mathbf{2}$ & 1.63 & & & -1.59 \\
{$\left[\mathrm{Ni}(\mathrm{II})^{\mathrm{SSRR}} \mathrm{L}\right]\left(\mathrm{PF}_{6}\right)_{2}$} & 1.58 & 0.93 & 0.85 & -1.59 \\
{$\left[\mathrm{Ni}(\mathrm{II})^{\mathrm{SRSR}} \mathrm{L}\right](\mathrm{Cl})\left(\mathrm{PF}_{6}\right)$} & 1.58 & 1.37 & & -1.62 \\
\hline
\end{tabular}

Cyclic voltammograms and listing of potentials of complexes 1, 2, $\left[\mathbf{N i}(\mathbf{I I})^{\text {SSRR }} \mathbf{L}\right]\left(\mathbf{P F}_{6}\right) 2$, and $\left[\mathbf{N i}(\mathbf{I I})^{\text {SRSR }} \mathbf{L}\right](\mathbf{C l})\left(\mathbf{P F}_{6}\right)$ are displayed in Figure 3.5 and Table 3.3, respectively. Complex 1 displays two irreversible oxidations at $0.89 \mathrm{~V}$ (NiII/III) and $1.54 \mathrm{~V}(\mathrm{NiIII} / \mathrm{IV})$ but does not display a reduction. In contrast, complexes 2, [Ni(II) $\left.{ }^{\mathbf{S S R R}} \mathbf{L}\right]\left(\mathbf{P F}_{6}\right) 2$, and [Ni(II) $\left.{ }^{\mathbf{S R S R}} \mathbf{L}\right](\mathbf{C l})\left(\mathbf{P F}_{6}\right)$ display reversible one electron $(\mathrm{NiII} / \mathrm{I})$ reductions at $-1.59,-1.59$, and $-1.62 \mathrm{~V}$, respectively. Only complex $\left[\mathbf{N i}(\mathbf{I I})^{\mathbf{S S R R}} \mathbf{L}\right]\left(\mathbf{P F}_{6}\right)_{2}$ displays a reversible (NiII/III) oxidation at $0.85 \mathrm{~V}$. If the voltammogram trace for complex $\left[\mathbf{N i}(\mathbf{I I})^{\mathbf{S S R R}} \mathbf{L}\right]\left(\mathbf{P F}_{6}\right)_{2}$ is allowed to reverse at $2.2 \mathrm{~V}$, then only two irreversible oxidations at 0.93 and $1.58 \mathrm{~V}$ are observed (Figure 3.5). Presumably, not enough of $\left[\mathbf{N i}(\mathbf{I I})^{\mathbf{S S R R}} \mathbf{L}\right]\left(\mathbf{P F}_{6}\right)_{2}{ }^{+}$is present to be reduced on the return trace. Interestingly, complex $\left[\mathbf{N i}(\mathbf{I I})^{\mathbf{S R S R}} \mathbf{L}\right](\mathbf{C l})\left(\mathbf{P F}_{6}\right)$ does not show a reversible oxidation, and only an irreversible oxidation at $1.37 \mathrm{~V}$ is observed. Given the unique arrangement of the nitrogen bonded $\mathrm{H}$-atoms, it is likely that reductive elimination of dihydrogen occurs with $\mathrm{Ni}(\mathrm{III})$, resulting in an irreversible oxidation, as recently 
noted for a thiolate-bound $\mathrm{Ni}$ (III) hydride complex. ${ }^{87}$ The magnitudes of the oxidation and reduction potentials obtained are comparable with those obtained for a series of square pyramidal Ni complexes containing a tetraazacyclotetradecane ring in the equatorial plane with derivatized acetylides at the apex, except, in that case, only irreversible oxidation and reduction potentials were obtained. ${ }^{88}$ Theoretical calculations on the cations in $\left[\mathbf{N i}(\mathbf{I I})^{\mathbf{S S R R}} \mathbf{L}\right]\left(\mathbf{P F}_{6}\right)_{2}$, $\left[\mathbf{N i}(\mathbf{I I})^{\mathbf{S R S R}} \mathbf{L}\right](\mathbf{C I})\left(\mathbf{P F}_{6}\right)(\lambda \lambda)$, and

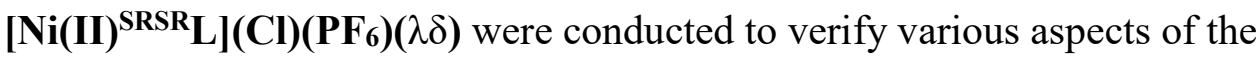
complexes pertaining to thermodynamic stabilities, electronic transitions, and assessment of anagostic interactions. Surprisingly, for calculations conducted with the APFD/6-311+G(d)- LanL2DZ functional/basis set combination (Supplementary Table S3.4), complex [Ni(II) $\left.{ }^{\mathbf{S S R R}} \mathbf{L}\right]\left(\mathbf{P F}_{6}\right)_{2}$ with a total electronic energy of -1019.0631 Ha is only very slightly more stable than $\left[\mathbf{N i}(\mathbf{I I})^{\mathbf{S R S R}} \mathbf{L}\right](\mathbf{C l})\left(\mathbf{P F}_{6}\right)(\lambda \lambda)(-1019.0619 \mathrm{Ha})$ and equivalent to $\left[\mathbf{N i}(\mathbf{I I})^{\mathbf{S R S R}} \mathbf{L}\right](\mathbf{C l})\left(\mathbf{P F}_{6}\right)(\lambda \delta)(-1019.0638 \mathrm{Ha})$. [Ni(II) $\left.{ }^{\mathbf{S S R R}} \mathbf{L}\right]\left(\mathbf{P F}_{6}\right)_{2}$ was assessed a dipole moment of $0 \mathrm{D}$ in contrast to $\left[\mathbf{N i}(\mathbf{I I})^{\mathbf{S R S R}} \mathbf{L}\right](\mathbf{C I})\left(\mathbf{P F}_{\mathbf{6}}\right)(\lambda \lambda)$ and

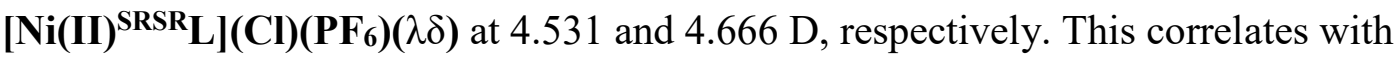
the differences in solubility noted for $\left[\mathbf{N i}(\mathbf{I I})^{\mathbf{S R S R}} \mathbf{L}\right](\mathbf{C I})\left(\mathbf{P F}_{6}\right)$ in methanol as opposed

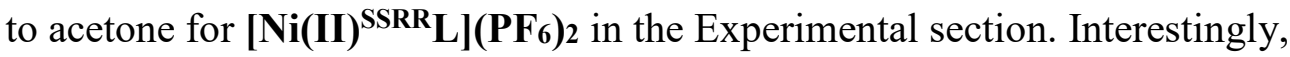

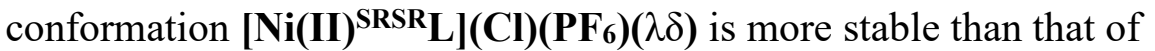

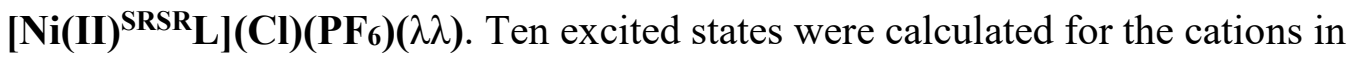
[Ni(II) $\left.{ }^{\text {SSRR }} \mathbf{L}\right]$ (PF6)2 (Supplementary Table S3.6), and [Ni(II) $\left.{ }^{\text {SRSR }} \mathbf{L}\right](\mathbf{C l})\left(\mathbf{P F}_{6}\right)(\lambda \lambda)$ (Supplementary Table S3.9), with selected LCAOs for the orbitals depicted in Supplementary Figures S3.12 and S3.17, respectively. For [Ni(II) $\left.{ }^{\text {SSRR }} \mathbf{L}\right]\left(\mathbf{P F}_{6}\right)_{2}$, only the transitions in the UV range, i.e., Supplementary Table S3.6, excited states 5 and 6, which correspond to ligand to metal charge transfer, have nonzero oscillator strengths. The experimentally observed transition at $462 \mathrm{~nm}$ in acetone (Supplementary Figure S3.3), which may correspond to excited states 2 and (or) 3, has an oscillator strength of 0 , most likely due to this transition being forbidden (mostly $d \rightarrow d$ ). ${ }^{84}$ In contrast, with [Ni(II) $\left.{ }^{\text {SRSR }} \mathbf{L}\right](\mathbf{C l})\left(\mathbf{P F}_{6}\right)$, we observed an absorption band with a very weak oscillator strength of 0.0022 for excited state 2 centered at $506.25 \mathrm{~nm}$ (Supplementary 
Table S3.9 and Figure S3.16), which may arise from vibronic coupling corresponding to that observed experimentally at $451 \mathrm{~nm}$ in DMSO and possibly from the asymmetry in this conformation. 
Chart 3.1. Selected LCAOs for $\left[\mathbf{N i}(\mathrm{II})^{\mathrm{SSRR}} \mathbf{L}\right]\left(\mathbf{P F}_{6}\right)_{2}$ and $\left[\mathrm{Ni}(\mathrm{II})^{\mathrm{SRSR}} \mathbf{L}\right](\mathrm{Cl})\left(\mathrm{PF}_{6}\right)$ from different functionals. [Colour online.]

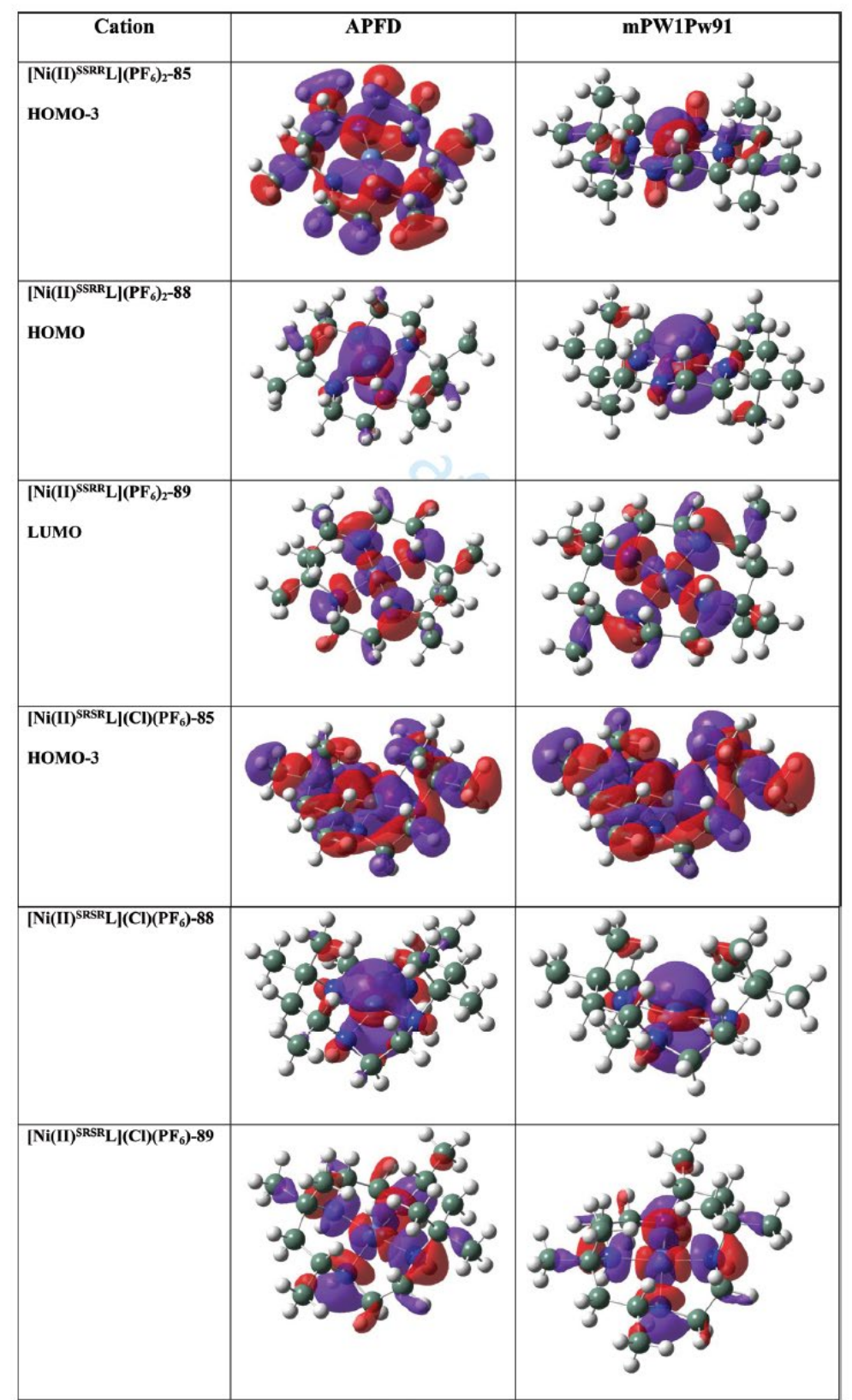

Interestingly, in a study of $\mathrm{M} \cdot \cdot \cdot \mathrm{H}-\mathrm{C} \mathrm{d}^{8}$ square planar complexes, ${ }^{89}$ calculations with the mPW1PW91/SDD ${ }^{82}$ method were found to give the best-optimized structures out of other "effective core potential basis sets (LanL2DZ, CEP31G, CEP-121G, and 
SDD)" ${ }^{90}$ On that basis, we also conducted calculations using the APFD $/ 6-311+\mathrm{G}(\mathrm{d})-$ LanL2DZ and the mPW1PW91/SDD34 methods and drawings of selected orbitals are displayed in Chart 3.2. Suitable coordinates for the cations were obtained from the crystal structure results, and these were then optimized to produce the comparable distances and angles listed in Table 3.2. Additionally, the LCAOs depicted in Chart 3.2 calculated with the two functionals are quite similar. In both cases, the HOMO and the LUMO appeared to be mostly comprised of the $\mathrm{dz}^{2}$ and $\mathrm{dx}^{2}-\mathrm{y}^{2}$ orbitals,

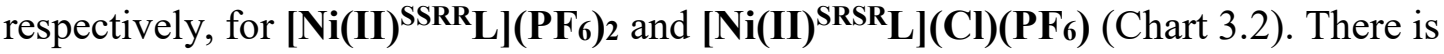
no evidence of a direct bonding interaction in the LCAOs between the $\mathrm{Ni}$ atom and the closest $\mathrm{H}$ atom bonded to atom $\mathrm{C} 2$ (Chart 3.2; Supplementary Figure S3.12) for [Ni(II) $\left.{ }^{\text {SSRR }} \mathbf{L}\right]\left(\mathbf{P F}_{6}\right)_{2}$ with either functional. However, for the $\mathrm{H}$ atoms on $\mathrm{C} 2$ and $\mathrm{C} 11$ (Figure 3.3), there is evidence of positive overlap between a Ni dxz/yz orbital and the $\mathrm{C}-\mathrm{H}$ * orbital (based on phase similarity) as seen for [Ni(II) $\left.{ }^{\mathrm{SRSR}} \mathbf{L}\right](\mathbf{C l})\left(\mathbf{P F}_{6}\right)-85$ (i.e., HOMO-3 in Chart 3.2). A similar interaction involving a HOMO-3 molecular orbital was noted for Pt square planar complexes, ${ }^{89}$, and this was deemed preagostic (i.e., anagostic). Additionally, various non-bonded interactions were 
Figure 3.6. Ring critical points (large red spheres) indicated numerically for

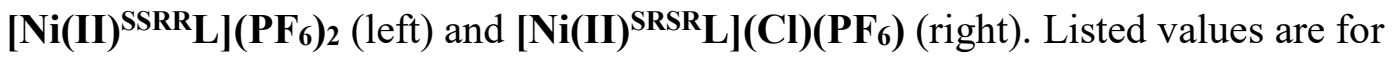
$\nabla^{2} \rho(\mathrm{r})$ in au. Bond critical points (small yellow spheres) are indicated along bond paths, with weak ones indicated by dashed lines.

[Colour online.]
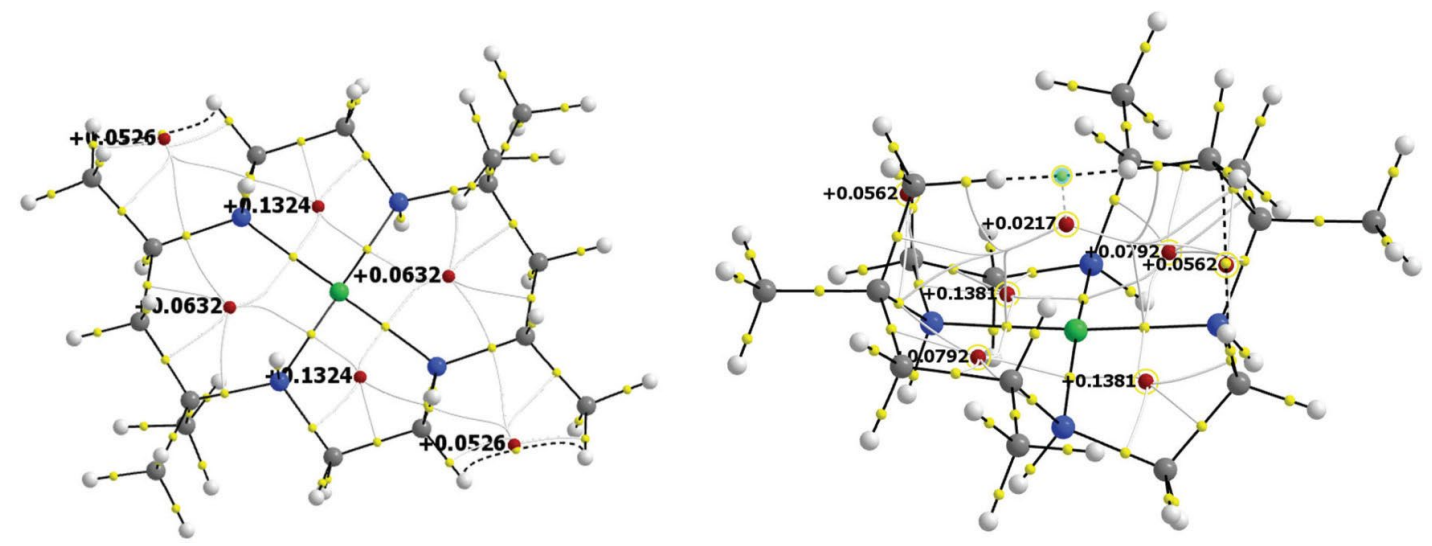

investigated using atoms in molecule (AIM) theory ${ }^{91-93}$ as applied to bond ${ }^{89}$ and ring critical point $^{94}$ (BCP and RCP) determinations. We do not observe RCPs in [Ni(II) $\left.{ }^{\mathbf{S S R R}} \mathbf{L}\right]\left(\mathbf{P F}_{6}\right) \mathbf{2}$ for the $\mathrm{H}$ atom bonded to $\mathrm{C} 2$ (Figure 3.1), but there is one present for the equivalent $\mathrm{H}$ atoms in $\left[\mathbf{N i}(\mathbf{I I})^{\mathbf{S R S R}} \mathbf{L}\right](\mathbf{C l})\left(\mathbf{P F}_{\mathbf{6}}\right)$, i.e., those bonded to $\mathrm{C} 2$ and C11 (Figure 3.3), as shown in Figure 3.6. This constitutes a $(3,+1)^{93}$ type of critical point, i.e., where the electron density (i.e., the Hessian) decreases in one direction and rises in two other perpendicular orientations, a situation found in rings, as evidenced by the presence of other RCPs displayed in Figure 3.6 for both $\left[\mathbf{N i}(\mathbf{I I})^{\text {SRSR }} \mathbf{L}\right](\mathbf{C l})\left(\mathbf{P F}_{6}\right)$ and $\left[\mathbf{N i}(\mathrm{II})^{\text {SSRR }} \mathbf{L}\right]\left(\mathbf{P F}_{6}\right) 2$. The RCP value for $\nabla^{2} \rho(\mathrm{r})$ of 0.022 au is very small compared with those reported for the BCPs for complexes 1-4 at 0.067, 0.072, 0.031, and 0.059 au, respectively. ${ }^{89}$ Interestingly, a BCP was measured between the two $\mathrm{H}$ atoms involved with the anagostic interaction, and this had a p2_(r) of 0.052, comparable with those reported. ${ }^{89}$ However, the presence of the BCP and RCP in [Ni(II) $\left.{ }^{\text {SRSR }} \mathbf{L}\right](\mathbf{C l})\left(\mathbf{P F}_{6}\right)$ for these two $\mathrm{H}$ atoms suggests that weak nonbonded interactions (anagostic) are present. 


\subsection{Conclusions}

We have reported modifications to existing synthetic pathways to produce and isolate

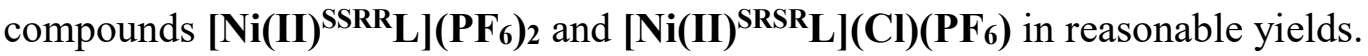
Complex [Ni(II) $\left.{ }^{\mathbf{S S R R}} \mathbf{L}\right]\left(\mathbf{P F}_{6}\right)_{2}$ is described as having an overall configuration of $\operatorname{SSRR}(S R) \delta \lambda$, whereas complex $\left[\mathbf{N i}(\mathbf{I I})^{\mathbf{S R S R}} \mathbf{L}\right](\mathbf{C l})\left(\mathbf{P F}_{\mathbf{6}}\right)$ is composed of a mixture of $61(2) \% \operatorname{SRSR}(R R) \lambda \lambda$ and $39(2) \% R S R S(S S) \lambda \delta$. On the basis of stated criteria for anagostic interactions and in comparison with the NMR, structural, and theoretical properties obtained for $\left[\mathbf{N i}(\mathbf{I I})^{\mathbf{S S R R}} \mathbf{L}\right]\left(\mathbf{P F}_{6}\right) \mathbf{2}$, complex [Ni(II) $\left.{ }^{\text {SRSR }} \mathbf{L}\right](\mathbf{C l})\left(\mathbf{P F}_{6}\right)$ was assessed as having anagostic interactions between the $\mathrm{H}$ atoms on two methyl groups and the $\mathrm{Ni}$ atom.

\subsection{Supplementary Data}

Table S3.1. Listing of conformational forms and corresponding REFL codes in the CSD. ${ }^{59}$

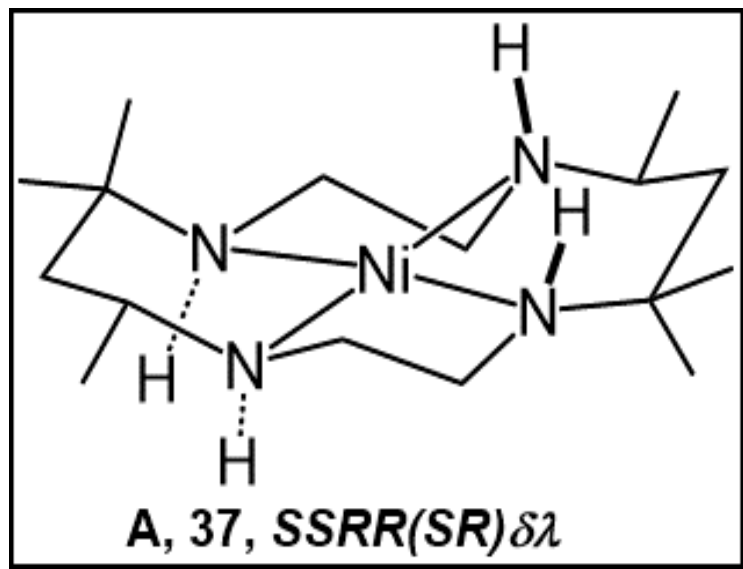

JIVBAU

AJITOE

AJITOE01
$\operatorname{BADSAA}(\mathrm{Et})$

BADSAA10(Et)

BADSEE(Et) 


$\begin{array}{ll}\text { BIYZIT } & \text { OBOPEC } \\ \text { BUSBIC } & \text { OCAREP } \\ \text { BUSBIC01 } & \text { PIMHAU } \\ \text { CAPVUL } & \text { QQQFMG } \\ \text { FIBHED } & \text { QQQFMJ } \\ \text { IDIKOY } & \text { QUBCAS } \\ \text { IVUYON } & \text { RAJLOE } \\ \text { KOHSUX } & \text { UDUPOY } \\ \text { MAZNIA } & \text { UQOREY } \\ \text { MEAZNI } & \text { WACKUJ } \\ \text { MEAZNI01 } & \text { WACLAQ } \\ \text { MEAZNI02 } & \text { WUFQOF } \\ \text { MONKUW } & \text { XEHKEB } \\ \text { MUVYIL } & \text { YOWNON } \\ \text { NIGTET } & \text { NOLHAA (phenylethylene) } \\ \text { NIGTET01 } & \end{array}$

Table S3.1 (contd.). Listing of conformational forms and corresponding REFL codes in the CSD. ${ }^{59}$

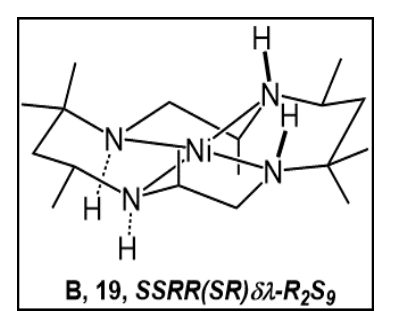

ANEMUD
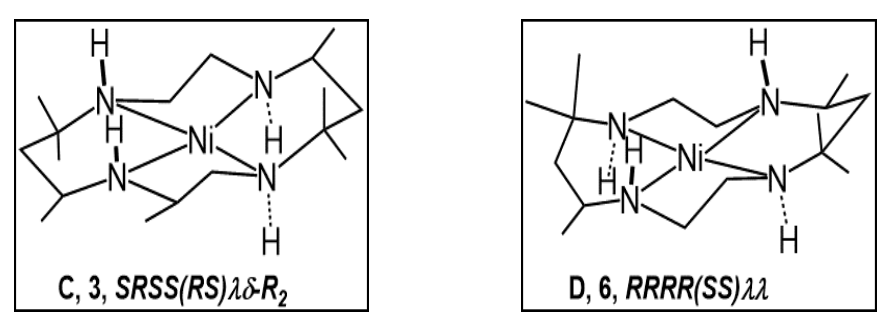

BURZUL (first two packing NIATET 
disorder)

ANEMUD01

BUSBOI

NIATET01

ANENAK

BUSBUO (ordered)

NIATET02

ANENAK01

NIATET03

ANENEO

RABWIC

ANENEO01

RABWOI

ANENIS

ANENIS01

CERVIF (disorder with a $(\mathrm{N}-$

$\mathrm{Me})$ )

EBAJOJ01

EBAKUQ

EBAKUQ01

OCMENH

OCMENH01

OCMENH02

OCMENH03

OCMENH04

QAFVIF

XALQUZ 
Table S3.1 (contd.). Listing of conformational forms and corresponding REFL codes in the CSD. ${ }^{59}$

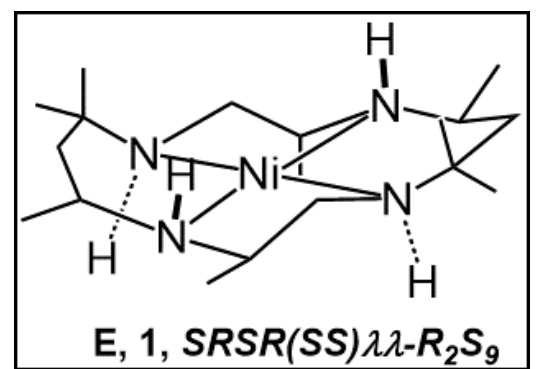

EBAJOJ

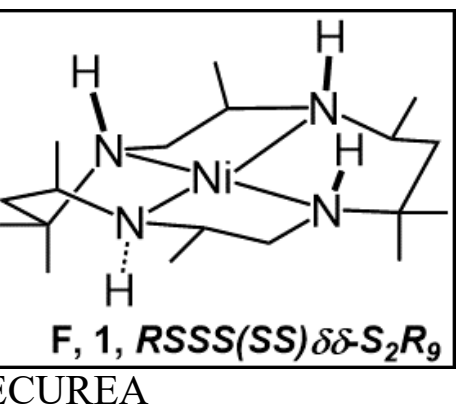

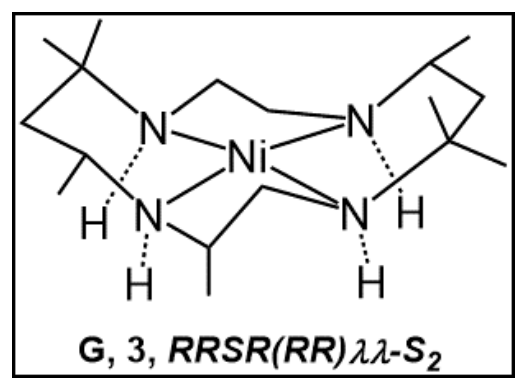

AJITUK (partial Me dis CoCrystal with en)

AJIVAS (partial Me dis CoCrystal with en)

AJIVEW (Me disorder) 


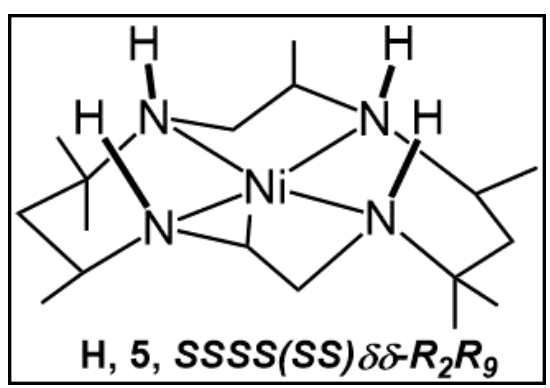

OCMENI

QADSIA

QADSIA01

QADSIA02

QADSOG

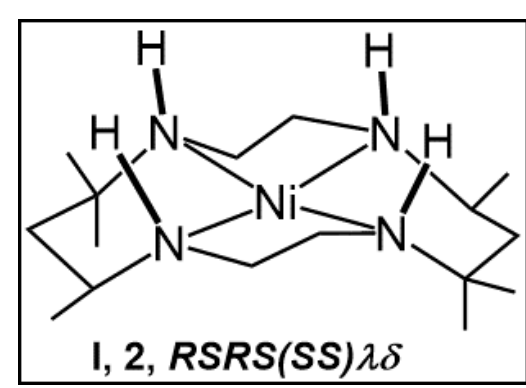

LIFYEG (massive counterion) NIBTET

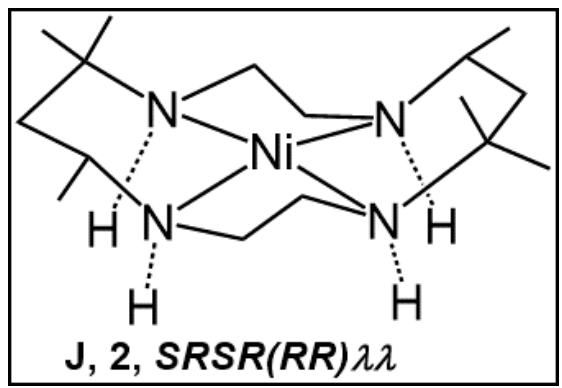

RAPXOW

VURRAC

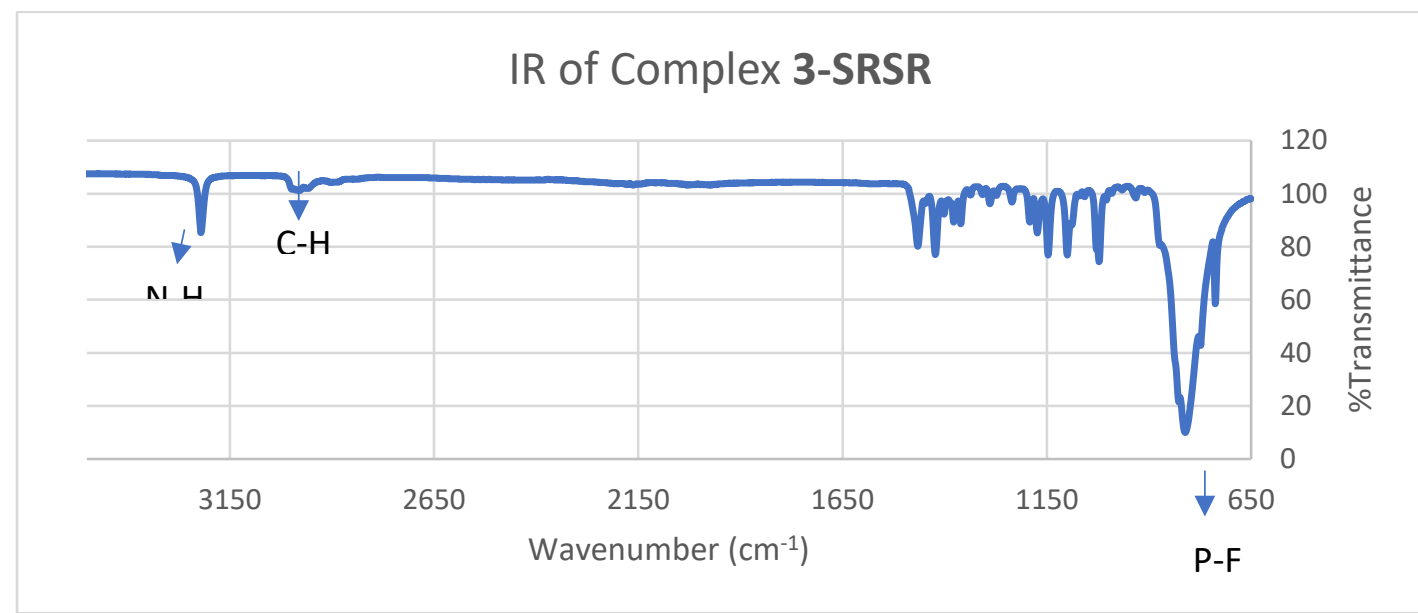

Figure S3.1 Neat FTIR spectrum of complex 3-SRSR. 


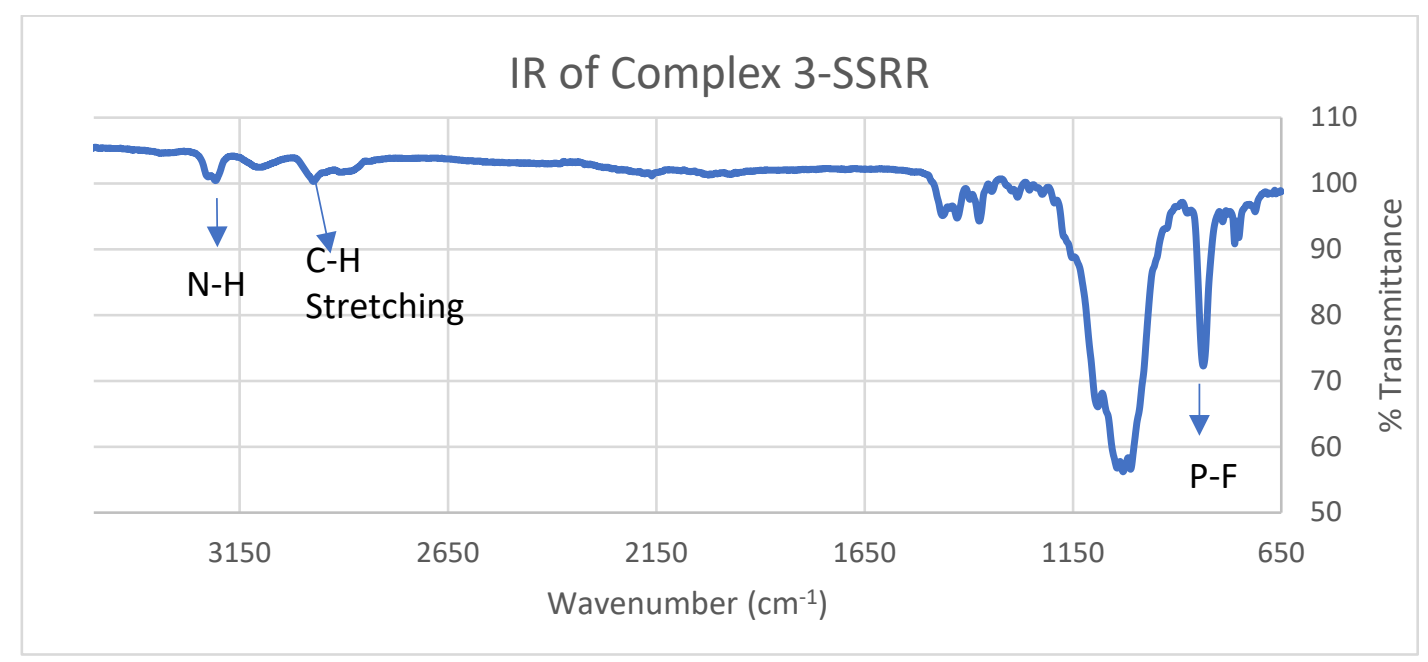

Figure S3.2 Neat FTIR spectrum of complex 3-SSRR.

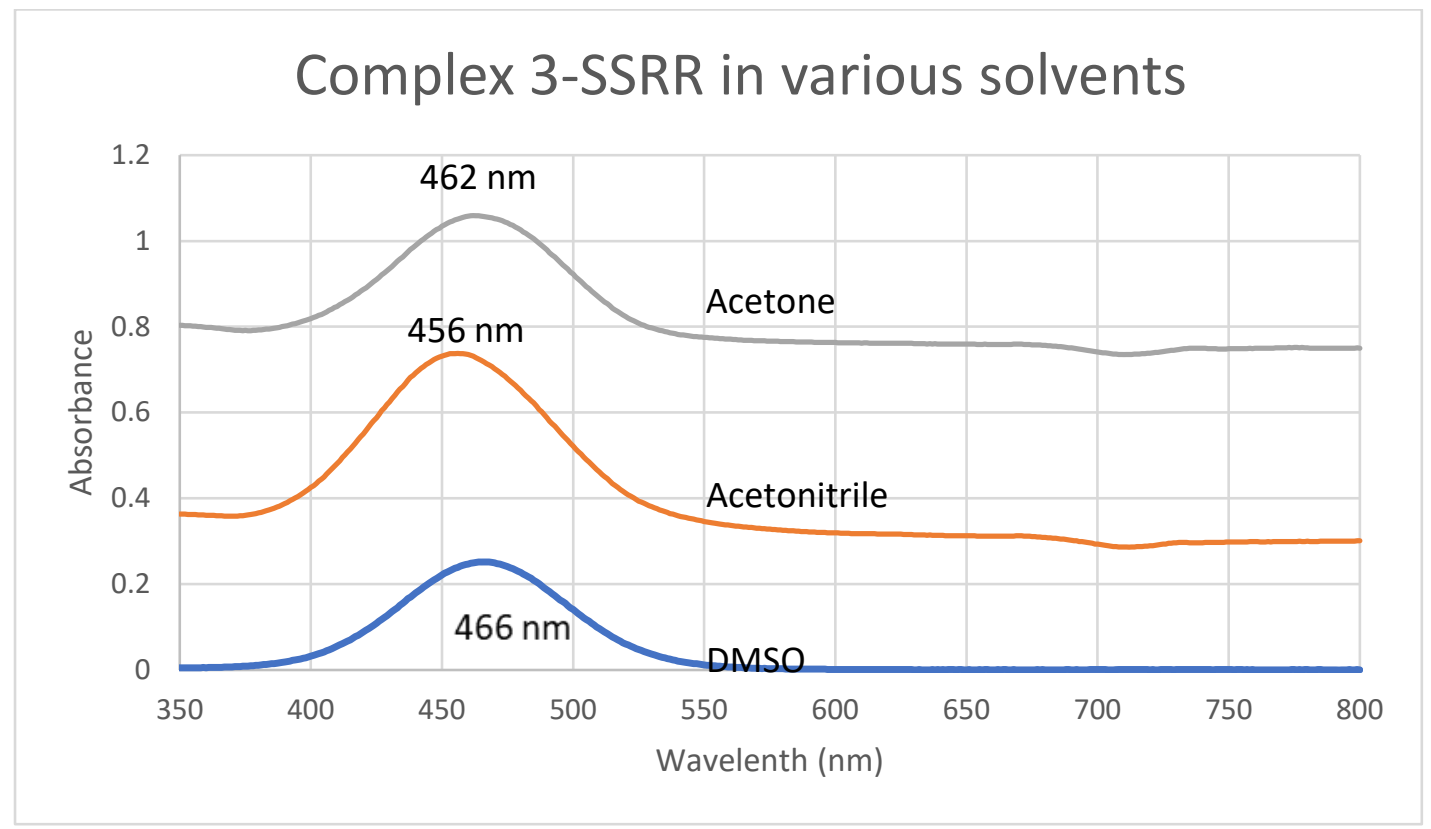


Figure S3.3 Visible spectrum of complex 3-SSRR in acetone, acetonitrile, and DMSO.

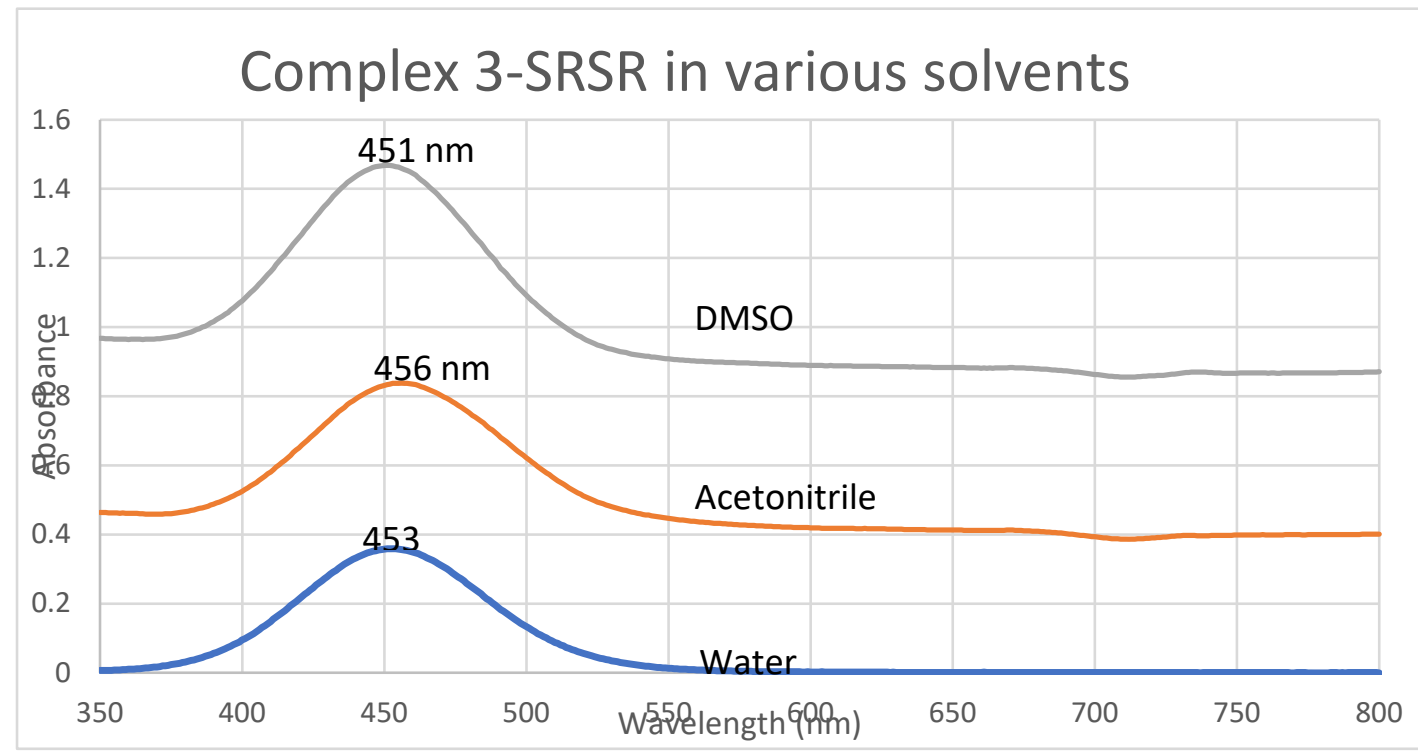

Figure S3.4 Visible spectrum of complex 3-SRSR in DMSO, acetonitrile, and water. 


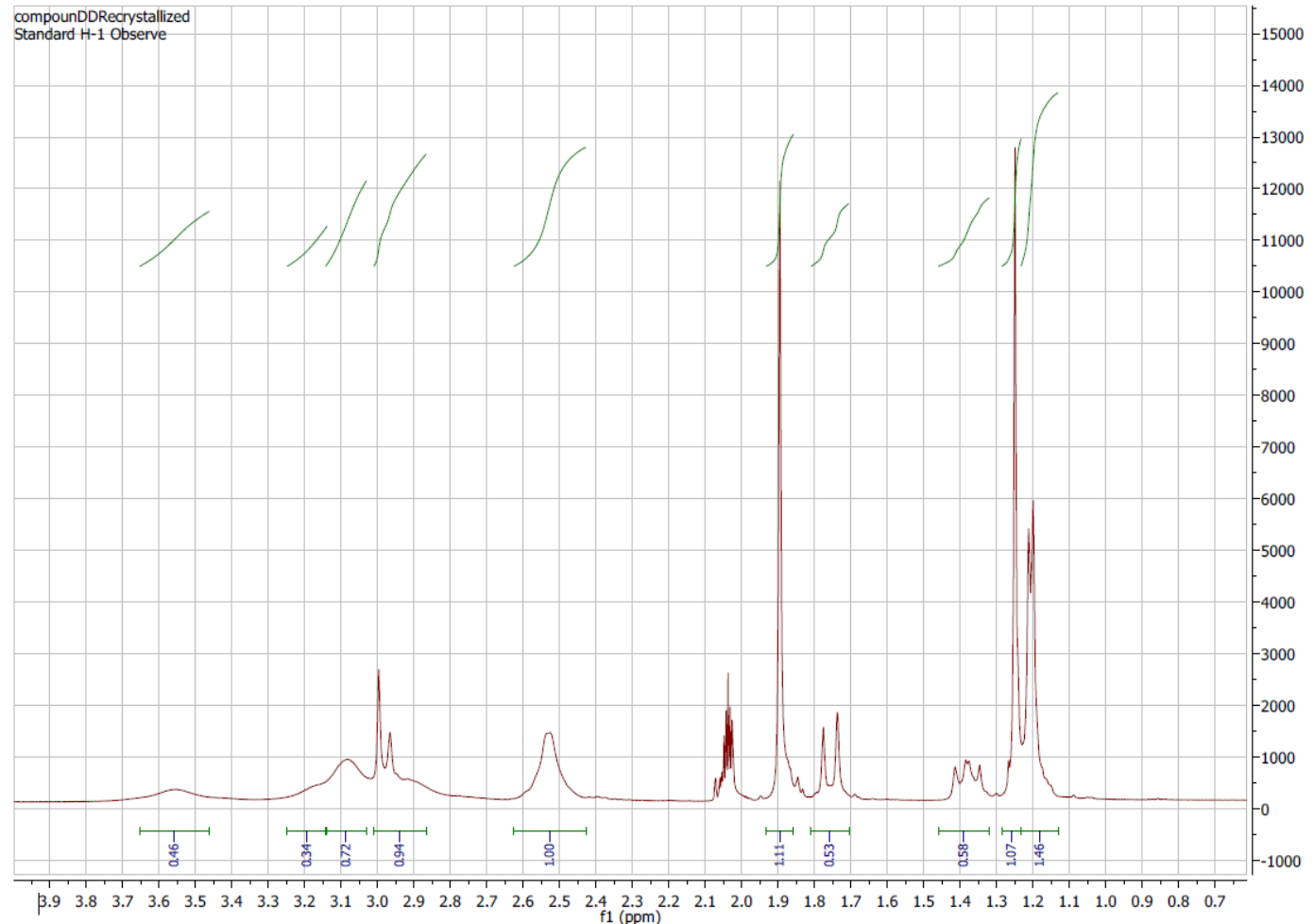

Figure S3.5 ${ }^{1} \mathrm{H}$ NMR spectrum of 3-SSRR in acetone- $d 6$. 


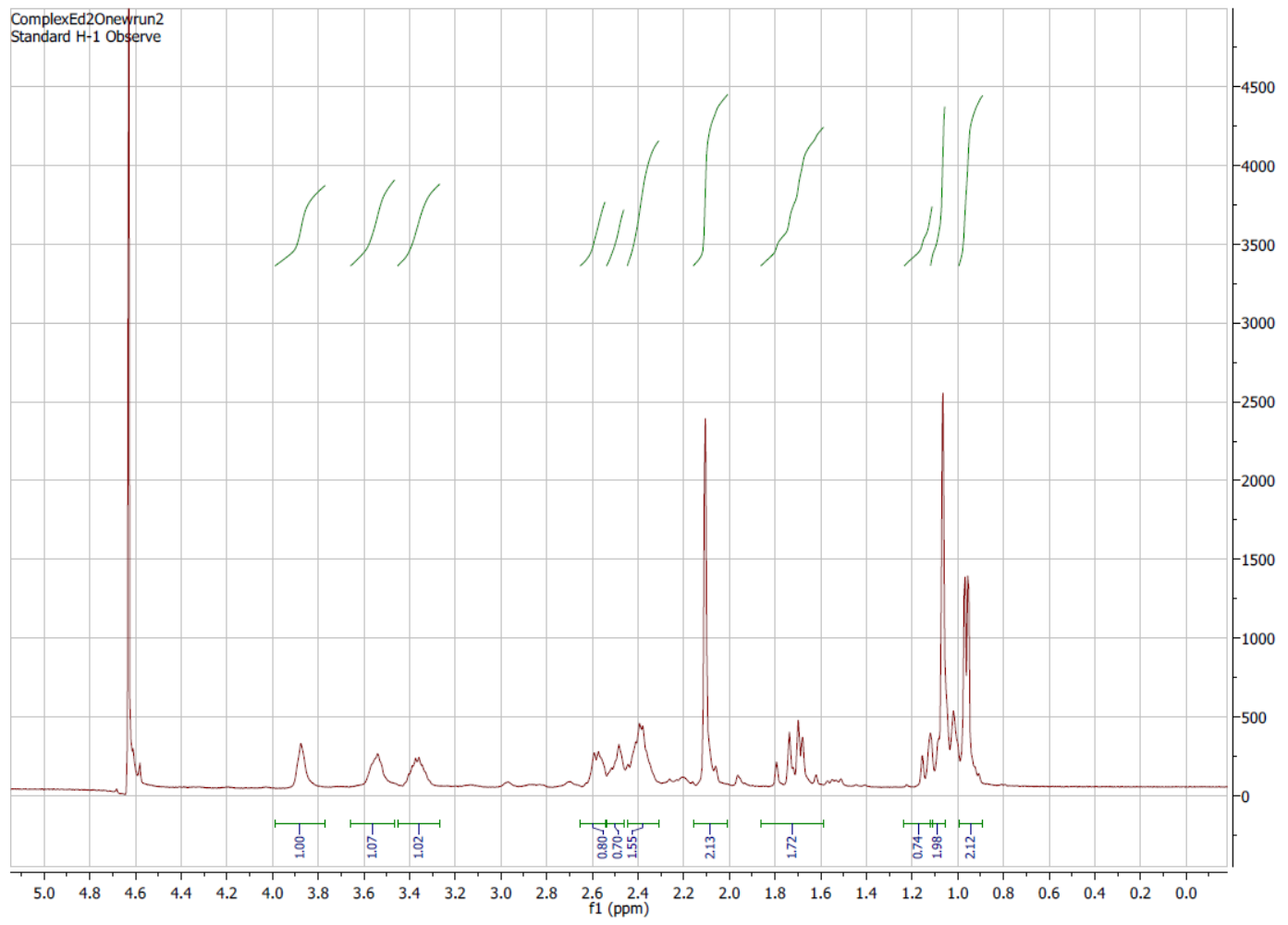

Figure S3.6 ${ }^{1} \mathrm{H}$ NMR spectrum of 3-SRSR in $\mathrm{D}_{2} \mathrm{O}$. 


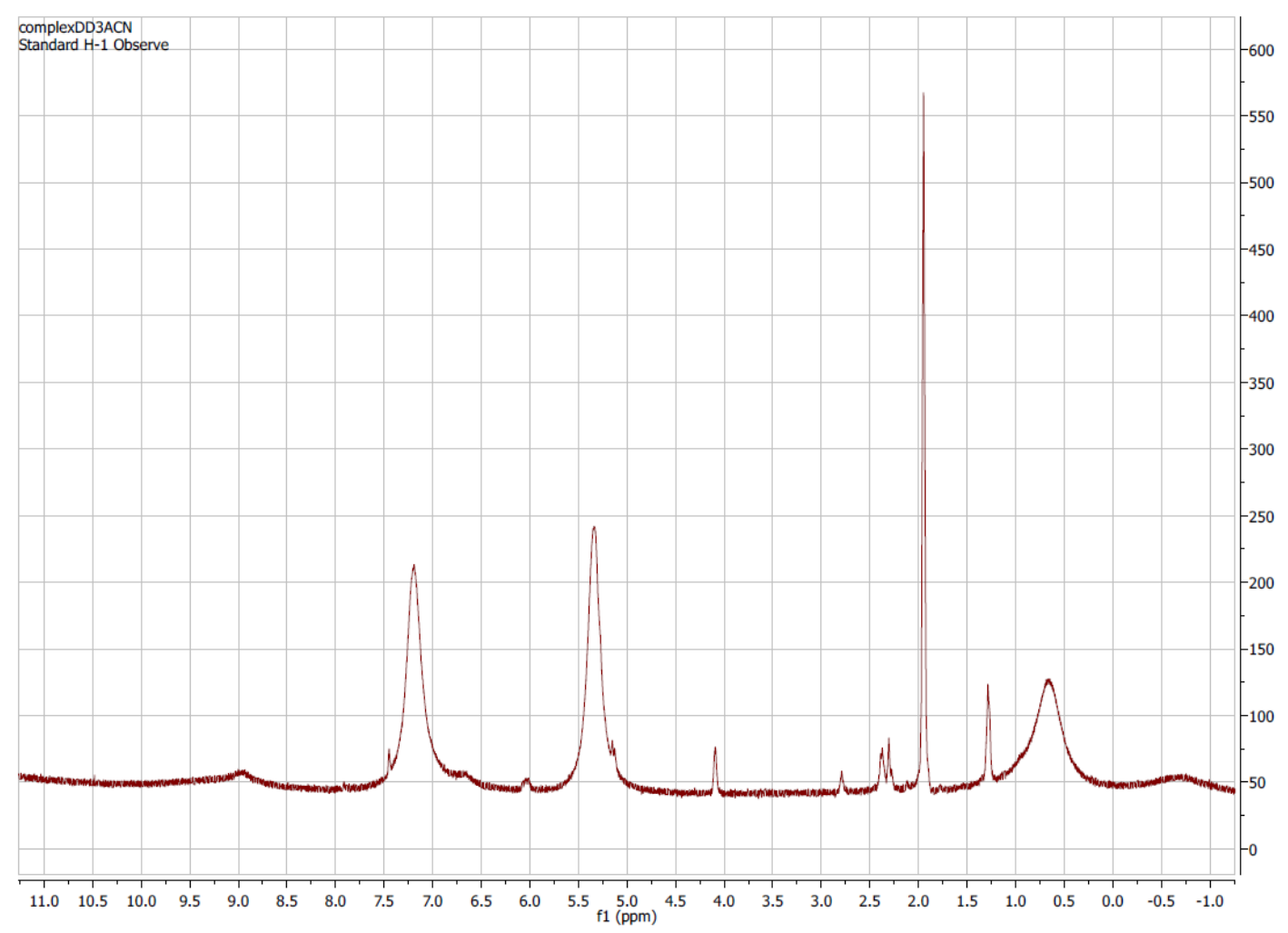

Figure S3.7 ${ }^{1} \mathrm{H}$ NMR spectrum of 3-SSRR in $\mathrm{CD}_{3} \mathrm{CN}$. 


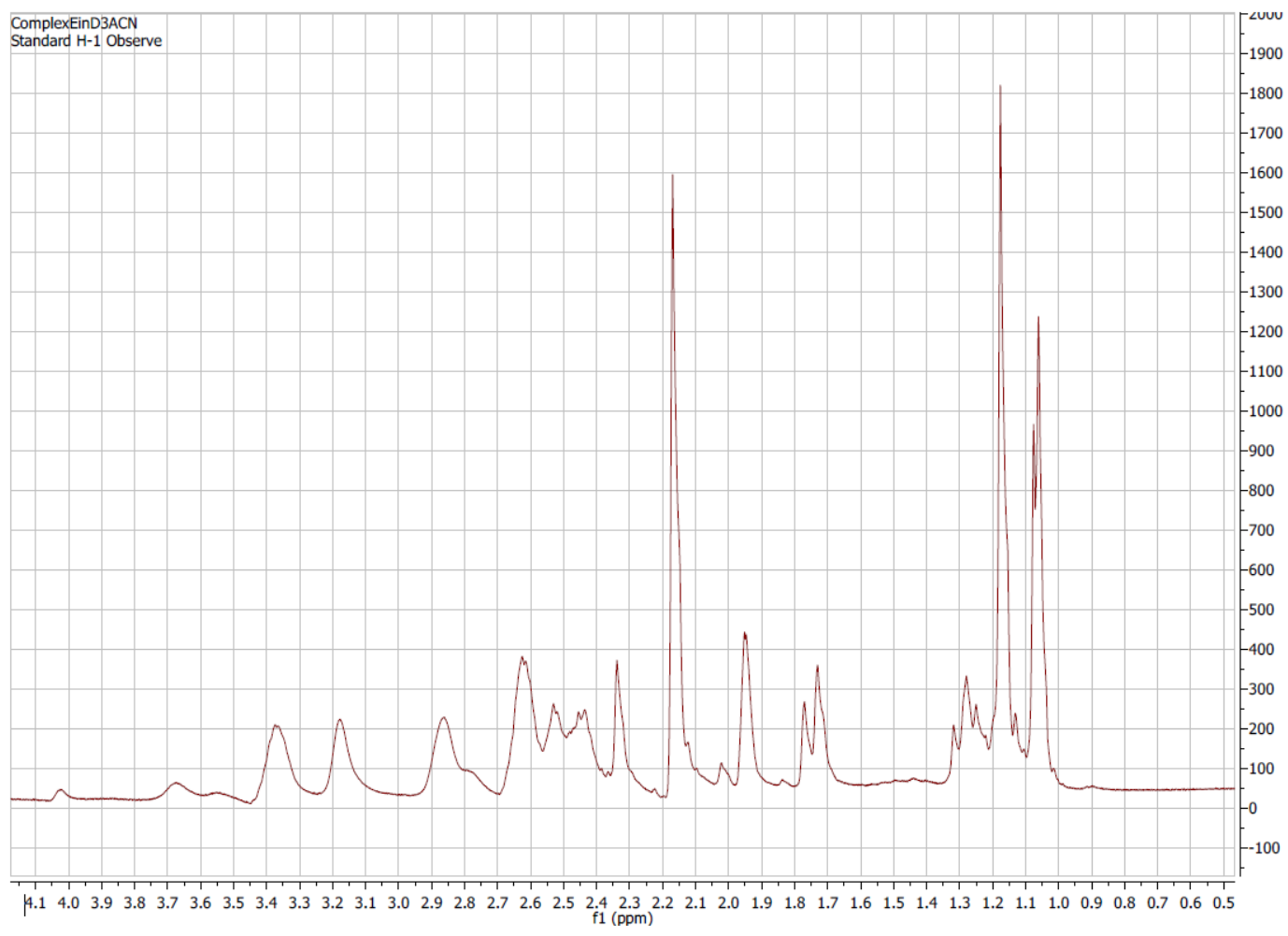

Figure S3.8 ${ }^{1} \mathrm{H}$ NMR spectrum of 3-SRSR in $\mathrm{CD}_{3} \mathrm{CN}$.

Table S3.2. Listing of hydrogen bonds in 3-SSRR.

D-H d(D-H) d(H..A) $<$ DHA d(D..A) A

$\begin{array}{lllllll}\text { N1-H11 } & 0.772 & 2.392 & 167.31 & 3.151 & \mathrm{~F} 4^{\wedge} \mathrm{a}[\mathrm{x}-1 / 2,-\mathrm{y}+1 / 2, \mathrm{z}+1 / 2] \\ \mathrm{N} 1-\mathrm{H} 11 & 0.772 & 2.536 & 138.36 & 3.155 & \mathrm{~F} 11^{\wedge} \mathrm{b}[\mathrm{x}-1 / 2,-\mathrm{y}+1 / 2, \mathrm{z}+1 / 2] \\ \mathrm{N} 1-\mathrm{H} 11 & 0.772 & 2.406 & 168.06 & 3.166 & \mathrm{~F} 14^{\wedge} \mathrm{b}[\mathrm{x}-1 / 2,-\mathrm{y}+1 / 2, \mathrm{z}+1 / 2] \\ \mathrm{N} 2-\mathrm{H} 12 & 0.907 & 2.343 & 138.97 & 3.085 & \mathrm{~F} 2^{\wedge} \mathrm{a}[\mathrm{x}-1 / 2,-\mathrm{y}+3 / 2, \mathrm{z}+1 / 2] \\ \mathrm{N} 2-\mathrm{H} 12 & 0.907 & 2.561 & 132.98 & 3.248 & \mathrm{~F} 11^{\wedge} \mathrm{b}[-\mathrm{x}+1 / 2, \mathrm{y}+1 / 2,-\mathrm{z}+1 / 2] \\ \mathrm{N} 2-\mathrm{H} 12 & 0.907 & 2.285 & 144.66 & 3.069 & \mathrm{~F} 12^{\wedge} \mathrm{b}[\mathrm{x}-1 / 2,-\mathrm{y}+3 / 2, \mathrm{z}+1 / 2] \\ \mathrm{C} 4-\mathrm{H} 4 \mathrm{~A} & 0.970 & 2.375 & 153.95 & 3.275 & \mathrm{~F} 5^{\wedge} \mathrm{a}[\mathrm{x}-1 / 2,-\mathrm{y}+1 / 2, \mathrm{z}+1 / 2] \\ \text { C4-H4A } & 0.970 & 2.635 & 161.40 & 3.567 & \mathrm{~F} 15^{\wedge} \mathrm{b}[\mathrm{x}-1 / 2,-\mathrm{y}+1 / 2, \mathrm{z}+1 / 2]\end{array}$


C6-H6A $\quad 0.960 \quad 2.614 \quad 130.63 \quad 3.320 \quad \mathrm{~F} 15^{\wedge} \mathrm{b}[-\mathrm{x}+1,-\mathrm{y}+1,-\mathrm{z}+1]$

C8-H8A $\quad 0.970 \quad 2.565 \quad 134.08 \quad 3.314 \quad \mathrm{~F}^{\wedge} \mathrm{a}[-\mathrm{x},-\mathrm{y}+1,-\mathrm{z}+1]$

C8-H8A $\quad 0.970 \quad 2.558 \quad 137.93 \quad 3.341 \quad F 16^{\wedge} b\left[-x,-y+1,-z^{+} 1\right]$

Table S3.3.Listing of hydrogen bonds in 3-SRSR.

D-H d(D-H) d(H..A) <DHA d(D..A) A

$\begin{array}{llllll}\mathrm{C} 2-\mathrm{H} 2 \mathrm{C} & 0.960 & 2.577 & 155.90 & 3.476 & \mathrm{~F} 2{ }^{\wedge} \mathrm{a}\end{array}$

$\begin{array}{llllll}\mathrm{C} 3-\mathrm{H} 3 \mathrm{~A} & 0.960 & 2.436 & 127.40 & 3.114 & \mathrm{~F} 4 \mathrm{~A}^{\wedge} \mathrm{b}[\mathrm{x}, \mathrm{y}-1, \mathrm{z}]\end{array}$

$\begin{array}{llllll}\mathrm{C} 4-\mathrm{H} 4 \mathrm{~A} & 0.970 & 2.975 & 134.94 & 3.724 & \mathrm{Cl} 1\end{array}$

C6-H6A $\quad 0.960 \quad 2.617 \quad 127.62 \quad 3.292 \quad \mathrm{~F}^{\prime} \mathrm{B}^{\wedge} \mathrm{c}[-\mathrm{x}+1,-\mathrm{y}+2,-\mathrm{z}+1]$

${\mathrm{C} 7{ }^{\wedge} \mathrm{a}-\mathrm{H} 7 \mathrm{~B}^{\wedge} \mathrm{a}}^{0} 0.970 \quad 2.544 \quad 129.14 \quad 3.245 \quad \mathrm{~F} 1^{\wedge} \mathrm{a}[\mathrm{x}-1, \mathrm{y}-1, \mathrm{z}]$

$\mathrm{C} 8^{\wedge} \mathrm{a}-\mathrm{H} 8 \mathrm{~B}^{\wedge} \mathrm{a} \quad 0.970 \quad 2.498 \quad 125.84 \quad 3.165 \quad \mathrm{~F}^{\wedge} \mathrm{a}[-\mathrm{x}+1,-\mathrm{y}+2,-\mathrm{z}+1]$

$\mathrm{C} 11-\mathrm{H} 11 \mathrm{C} \quad 0.960 \quad 2.532 \quad 167.88 \quad 3.476 \quad \mathrm{~F}^{\wedge} \mathrm{A}^{\wedge} \mathrm{b}[-\mathrm{x}+1,-\mathrm{y}+2,-\mathrm{z}+1]$

$\mathrm{C} 11-\mathrm{H} 11 \mathrm{C} \quad 0.960 \quad 2.469 \quad 160.11 \quad 3.387 \quad \mathrm{~F}^{\circ} \mathrm{B}^{\wedge} \mathrm{c}[-\mathrm{x}+1,-\mathrm{y}+2,-\mathrm{z}+1]$

$\begin{array}{llllll}\mathrm{C} 13-\mathrm{H} 13 & 0.980 & 2.430 & 145.98 & 3.289 & \mathrm{~F}^{2} \mathrm{~A}^{\wedge} \mathrm{b}\end{array}$

$\begin{array}{llllll}\mathrm{C} 13-\mathrm{H} 13 & 0.980 & 2.545 & 134.95 & 3.310 & \mathrm{~F} 4 \mathrm{~B}^{\wedge} \mathrm{c}\end{array}$

$\begin{array}{llllll}\mathrm{C} 15-\mathrm{H} 15 \mathrm{~A} & 0.970 & 2.539 & 117.29 & 3.106 & \mathrm{~F} \mathrm{~B}^{\wedge} \mathrm{c}[-\mathrm{x}+1,-\mathrm{y}+2,-\mathrm{z}]\end{array}$

C15-H15B $\quad 0.970 \quad 2.611 \quad 120.99 \quad 3.219 \quad \mathrm{~F} 4 \wedge \mathrm{a}[-\mathrm{x}+1,-\mathrm{y}+2,-\mathrm{z}]$

$\begin{array}{lllllll}\mathrm{C} 16-\mathrm{H} 16 \mathrm{~A} & 0.970 & 2.502 & 172.76 & 3.467 & \mathrm{~F} 2^{\wedge} \mathrm{a}\end{array}$

N1-H101 $\quad 0.852 \quad 2.433 \quad 158.60 \quad 3.242 \quad$ Cl1

N2-H102 $\quad 0.807 \quad 2.624 \quad 155.56 \quad 3.375 \quad$ Cl1

N3-H103 $\quad 0.961 \quad 2.352 \quad 160.47 \quad 3.273 \quad$ Cl1 [ -x, -y+1, -z $]$ 
N4-H104 $0.806 \quad 2.535 \quad 165.48 \quad 3.322 \quad$ Cl1 $[-x,-y+1,-z]$

Theoretical Calculations

Table S3.4. Comparison of selected thermodynamic data for the cations in 3-SSRR, 3-SRSR( $\lambda \lambda$ ), and 3-SRSR( $(\lambda \delta)$ computed under identical conditions.

\begin{tabular}{|c|c|c|c|}
\hline Factor & 3-SSRR & $3-\operatorname{SRSR}(\lambda \lambda)$ & $3-\operatorname{SRSR}(\lambda \delta)$ \\
\hline E (RAPFD) (Hartrees) & -1019.0631 & -1019.0619 & -1019.0638 \\
\hline $\begin{array}{l}\text { (kJ/mol) compared to } \\
\text { 3- SSRR }\end{array}$ & 0 & 3.1506 & -1.8378 \\
\hline Dipole moment (Debye) & 0 & 4.5308 & 4.6659899 \\
\hline $\begin{array}{l}\text { EE }=\text { Zero=point } \\
\text { Energy (Hartrees) }\end{array}$ & -1018.5241 & -1018.5221 & -1018.5252 \\
\hline $\begin{array}{l}\Delta \text { (kJ/mol) compared to } \\
\text { 3- SSRR }\end{array}$ & 0 & -5.251 & 8.13905 \\
\hline $\begin{array}{l}\text { EE + Thermal Energy } \\
\text { Correction (Hartrees) }\end{array}$ & -1018.5025 & -1018.5007 & -1018.5034 \\
\hline $\begin{array}{l}\Delta(\mathrm{kJ} / \mathrm{mol}) \text { compared to } \\
\text { 3- SSRR }\end{array}$ & 0 & -4.7259 & 2.36295 \\
\hline $\begin{array}{l}\text { EE + Thermal Enthalpy } \\
\text { Correction (Hartrees) }\end{array}$ & -1018.5016 & -1018.4997 & -1018.5025 \\
\hline $\begin{array}{l}\Delta \text { (kJ/mol) compared to } \\
\text { 3-SSRR }\end{array}$ & 0 & -4.98845 & 2.36295 \\
\hline $\begin{array}{l}\text { EE + Thermal Free } \\
\text { Energy Correction } \\
\text { (Hartrees) }\end{array}$ & -1018.571 & -1018.5686 & -1018.5716 \\
\hline $\begin{array}{l}\Delta(\mathrm{kJ} / \mathrm{mol}) \text { compared to } \\
\text { 3- SSRR }\end{array}$ & 0 & -6.3012 & 1.5753 \\
\hline $\mathrm{E}$ (thermal) (kcal/mol & 351.774 & 352.171 & 351.644 \\
\hline
\end{tabular}

Results for 3-SSRR based on AFPD/GENECP with Ni at LanL2DZ and H, C, N at 6$311+\mathrm{G}(\mathrm{d})$ basis sets. 


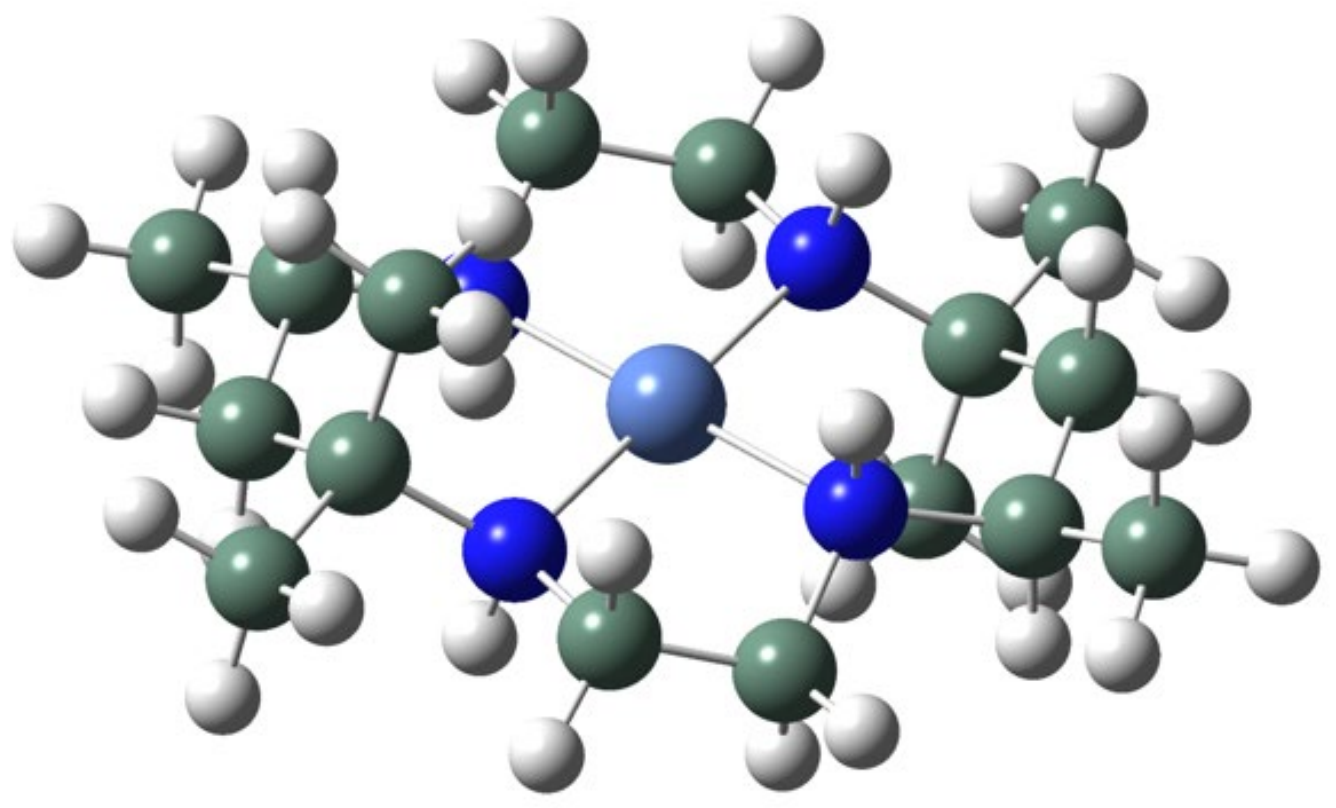

Figure S3.9. Gauss View representation of 3-SSRR.

Table S3.5. Calculated atomic coordinates for 3-SSRR.

\begin{tabular}{ccccccccccc} 
Ro & Symb & $\mathbf{X}$ & $\mathbf{Y}$ & $\mathbf{Z}$ & \multicolumn{2}{c}{ Ro } & Symb & $\mathbf{X}$ & $\mathbf{Y}$ & $\mathbf{Z}$ \\
1 & $\mathrm{Ni}$ & $-9 \mathrm{E}-07$ & $-1.4 \mathrm{E}-$ & $4.1 \mathrm{E}-06$ & 20 & $\mathrm{C}$ & 3.510344 & - & -0.57884 \\
2 & $\mathrm{~N}$ & 1.301236 & - & -0.15669 & 21 & $\mathrm{H}$ & 4.576647 & - & -0.35539 \\
3 & $\mathrm{H}$ & 1.148505 & - & -1.13128 & 22 & $\mathrm{H}$ & 3.174086 & - & -0.21936 \\
4 & $\mathrm{~N}$ & -1.3268 & - & 0.51735 & 23 & $\mathrm{H}$ & 3.396374 & - & -1.66731 \\
5 & $\mathrm{H}$ & -1.46484 & - & 1.51087 & 24 & $\mathrm{C}$ & 0.699922 & - & 0.71576 \\
6 & $\mathrm{C}$ & 3.5711 & 2.3156 & -0.12671 & 25 & $\mathrm{H}$ & 0.851429 & - & 1.74982 \\
7 & $\mathrm{H}$ & 3.189436 & 3.2565 & 0.27320 & 26 & $\mathrm{H}$ & 1.179357 & -3.5583 & 0.59086 \\
8 & $\mathrm{H}$ & 4.540862 & 2.1390 & 0.34276 & 27 & $\mathrm{C}$ & -0.75638 & - & 0.38313 \\
9 & $\mathrm{H}$ & 3.737227 & 2.4359 & -1.20156 & 28 & $\mathrm{H}$ & -0.88739 & - & -0.64848 \\
10 & $\mathrm{C}$ & 2.395589 & 1.0120 & 1.66645 & 29 & $\mathrm{H}$ & -1.27542 & - & 1.02985 \\
11 & $\mathrm{H}$ & 2.047118 & 1.9540 & 2.09443 & 30 & $\mathrm{~N}$ & -1.30124 & 1.5652 & 0.15669 \\
12 & $\mathrm{H}$ & 1.644683 & 0.2492 & 1.89377 & 31 & $\mathrm{H}$ & -1.14851 & 1.8255 & 1.13129 \\
13 & $\mathrm{H}$ & 3.320305 & 0.7461 & 2.18323 & 32 & $\mathrm{~N}$ & 1.326792 & 1.3044 & -0.51735 \\
14 & $\mathrm{C}$ & 2.646321 & 1.1321 & 0.16780 & 33 & $\mathrm{H}$ & 1.464828 & 1.1245 & -1.51087 \\
15 & $\mathrm{C}$ & 3.298262 & - & -0.41503 & 34 & $\mathrm{C}$ & -3.57111 & - & 0.12667 \\
16 & $\mathrm{H}$ & 3.261615 & - & -1.51193 & 35 & $\mathrm{H}$ & -3.18946 & - & -0.27327 \\
17 & $\mathrm{H}$ & 4.361551 & - & -0.16077 & 36 & $\mathrm{H}$ & -4.54087 & -2.139 & -0.34279 \\
18 & $\mathrm{C}$ & 2.758107 & - & 0.07337 & 37 & $\mathrm{H}$ & -3.73723 & - & 1.20151 \\
19 & $\mathrm{H}$ & 2.892397 & - & 1.15699 & 38 & $\mathrm{C}$ & -2.39556 & - & -1.66646
\end{tabular}




\begin{tabular}{|c|c|c|c|c|c|c|c|c|c|}
\hline Ro & Symb & $\mathbf{X}$ & $\mathbf{Y}$ & $\mathbf{Z}$ & Ro & Symb & $\mathbf{X}$ & $\mathbf{Y}$ & $\mathbf{Z}$ \\
\hline 39 & $\mathrm{H}$ & -2.04713 & - & -2.09445 & 49 & $\mathrm{H}$ & -4.57665 & 2.5217 & 0.35537 \\
\hline 40 & $\mathrm{H}$ & -1.64462 & - & -1.89375 & 50 & $\mathrm{H}$ & -3.1741 & 3.5740 & 0.21936 \\
\hline 41 & $\mathrm{H}$ & -3.32026 & - & -2.18324 & 51 & $\mathrm{H}$ & -3.39639 & 2.5756 & 1.66730 \\
\hline 42 & $\mathrm{C}$ & -2.64632 & - & -0.16781 & 52 & $\mathrm{C}$ & -0.69992 & 2.5840 & -0.71574 \\
\hline 43 & $\mathrm{C}$ & -3.29826 & 0.1196 & 0.41502 & 53 & $\mathrm{H}$ & -0.85143 & 2.2646 & -1.7498 \\
\hline 44 & $\mathrm{H}$ & -3.26162 & 0.0735 & 1.51192 & 54 & $\mathrm{H}$ & -1.17935 & 3.5583 & -0.59084 \\
\hline 45 & $\mathrm{H}$ & -4.36155 & 0.0974 & 0.16075 & 55 & $\mathrm{C}$ & 0.756376 & 2.6586 & -0.38312 \\
\hline 46 & $\mathrm{C}$ & -2.75811 & 1.4450 & -0.07337 & 56 & $\mathrm{H}$ & 0.887392 & 2.9882 & 0.64850 \\
\hline 47 & $\mathrm{H}$ & -2.89239 & 1.4996 & -1.157 & 57 & $\mathrm{H}$ & 1.275422 & 3.3682 & -1.02983 \\
\hline 48 & $\mathrm{C}$ & -3.51035 & 2.5998 & 0.57884 & & & & & \\
\hline
\end{tabular}

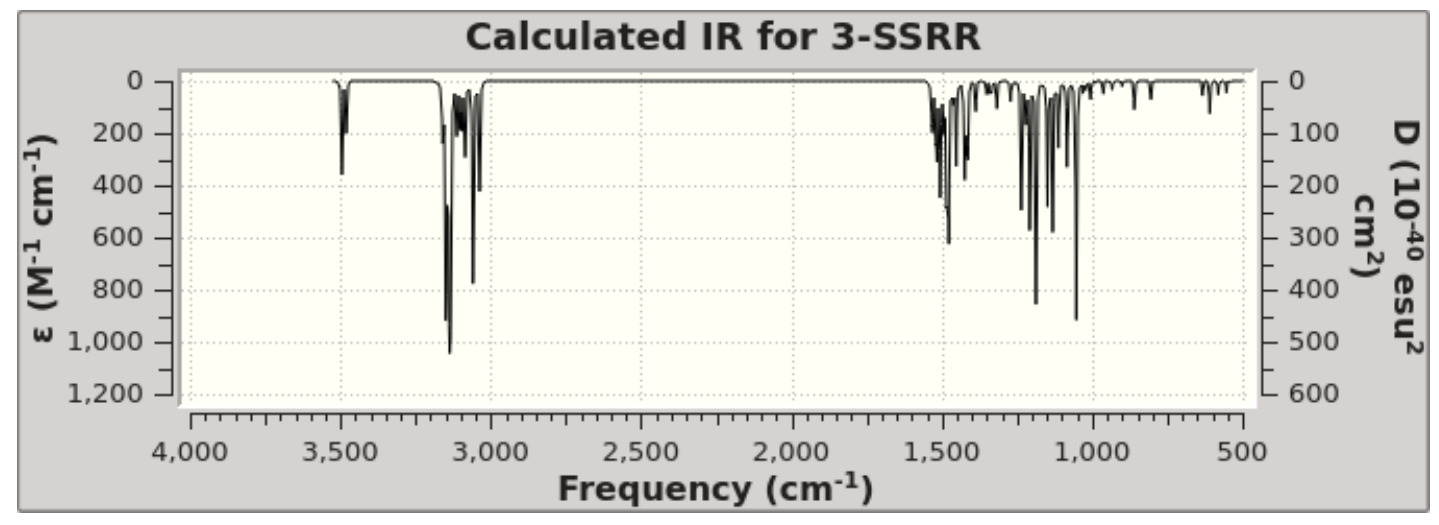

Figure S3.10. Calculated IR spectrum for 3-SSRR.

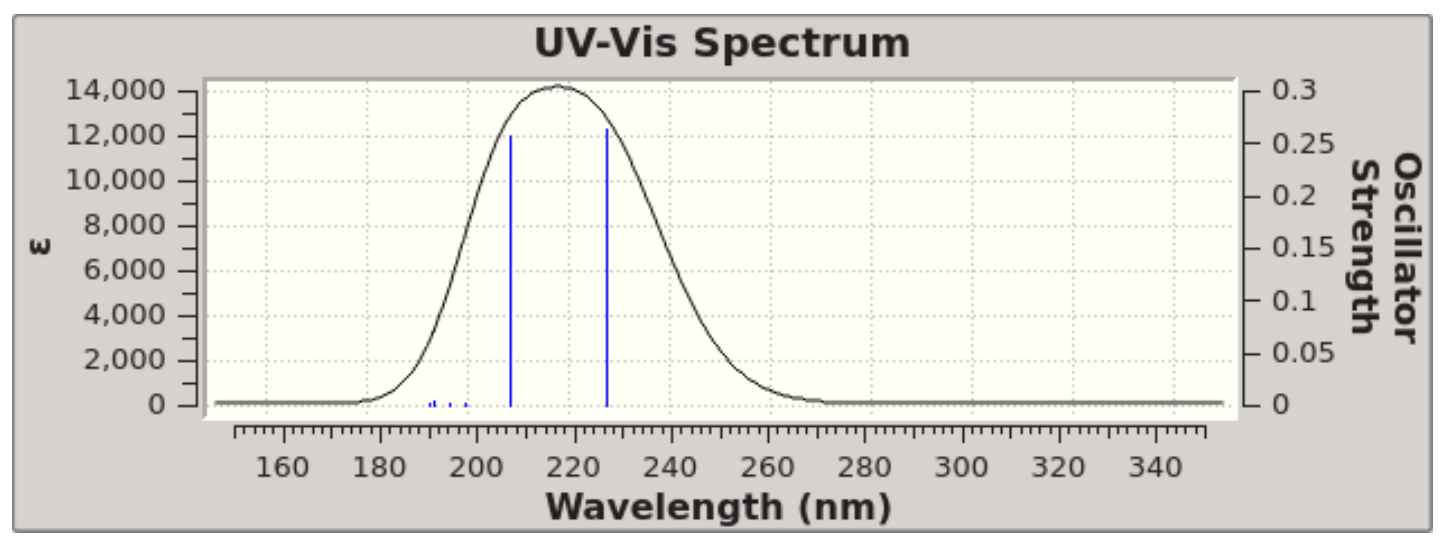

Figure S3.11. Calculated UV-Vis spectrum for 3-SSRR. 
Table S3.6. Excitation energies and oscillator strengths listing for 3-SSRR.

\begin{tabular}{|c|c|c|c|c|c|c|}
\hline $\begin{array}{l}\text { Excited } \\
\text { State }\end{array}$ & Nature & $E(e V)$ & $\lambda(\mathrm{nm})$ & $f$ & $\begin{array}{l}\text { Orbital } \\
\text { transitions }\end{array}$ & $\begin{array}{l}\text { Normalized } \\
\text { coefficient }\end{array}$ \\
\hline $1:$ & A & 1.6615 & 746.21 & 0.0000 & $\begin{array}{l}88->89 \\
88<-89\end{array}$ & $\begin{array}{r}0.71252 \\
-0.15346\end{array}$ \\
\hline 2: & A & 2.1112 & 587.28 & 0.0000 & $\begin{array}{l}87->89 \\
87<-89\end{array}$ & $\begin{array}{r}0.70829 \\
-0.10627\end{array}$ \\
\hline 3: & A & 2.2018 & 563.11 & 0.0000 & $86->89$ & 0.70614 \\
\hline 4: & A & 2.5628 & 483.77 & 0.0000 & $\begin{array}{c}78->89 \\
80->89 \\
82->89 \\
83->89\end{array}$ & $\begin{array}{r}-0.18200 \\
0.23756 \\
0.61428 \\
-0.11924\end{array}$ \\
\hline 5: & A & 5.1041 & 242.91 & 0.3607 & $85->89$ & 0.69764 \\
\hline $6:$ & A & 5.5083 & 225.09 & 0.3231 & $84->89$ & 0.69567 \\
\hline 7: & A & 5.8095 & 213.42 & 0.0000 & $\begin{array}{l}78->89 \\
80->89 \\
83->89\end{array}$ & $\begin{array}{c}-0.17908 \\
0.22258 \\
0.61590\end{array}$ \\
\hline 8: & A & 5.9872 & 207.08 & 0.0000 & $\begin{array}{l}77->89 \\
78->89 \\
80->89 \\
82->89 \\
83->89\end{array}$ & $\begin{array}{r}0.18672 \\
-0.20454 \\
0.50672 \\
-0.31175 \\
-0.23220\end{array}$ \\
\hline 9: & A & 6.0726 & 204.17 & 0.0195 & $81->89$ & 0.69738 \\
\hline 10: & A & 6.1938 & 200.18 & 0.0056 & $79->89$ & 0.69881 \\
\hline
\end{tabular}




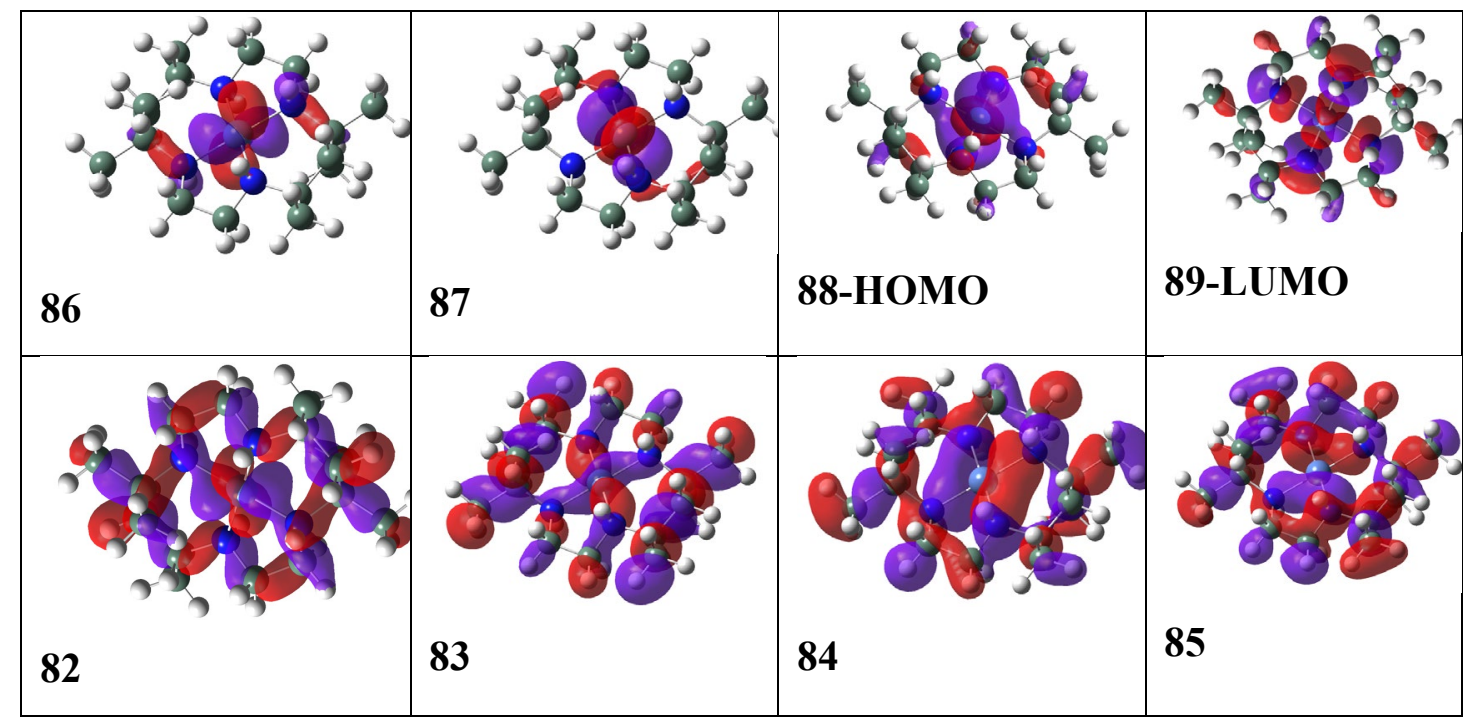

Figure S3.12. Drawings of selected molecular orbitals listed in Table S3.5.

Results for 3-SSRR based on mPW1PW91/GENECP with Ni at SDD and all H, C, N at $6-31 \mathrm{G}(\mathrm{d})$ basis sets except for the $\mathrm{C}$ and $\mathrm{H}$ atoms $(\# 10,12,38,40)$ involved in the anagostic interaction which were at the $6-311++\mathrm{G}(2 \mathrm{~d}, 2 \mathrm{p})$ basis set level.

Table S3.7. Calculated atomic coordinates for 3-SSRR based on mPW1PW91/GENECP.

$\begin{array}{rlrrr}\text { Ro } & & & & \\ \mathbf{w} & \text { Symbol } & \mathbf{X} & \mathbf{Y} & \mathbf{Z} \\ 1 & \mathrm{Ni} & -2 \mathrm{E}-06 & 9.2 \mathrm{E}-06 & 2.5 \mathrm{E}-06 \\ 2 & \mathrm{~N} & 1.15496 & -1.59598 & -0.17173 \\ 3 & \mathrm{H} & 1.066193 & -1.82384 & -1.1677 \\ 4 & \mathrm{~N} & -1.45651 & -1.25161 & 0.441266 \\ 5 & \mathrm{H} & -1.55442 & -1.14395 & 1.455307 \\ 6 & \mathrm{C} & 3.814704 & 2.071926 & -0.379 \\ 7 & \mathrm{H} & 3.583511 & 3.064283 & 0.013615 \\ 8 & \mathrm{H} & 4.824758 & 1.827606 & -0.0413 \\ 9 & \mathrm{H} & 3.839824 & 2.122042 & -1.47324 \\ 10 & \mathrm{C} & 2.785597 & 1.001763 & 1.643612 \\ 11 & \mathrm{H} & 2.650477 & 2.006042 & 2.051609 \\ 12 & \mathrm{H} & 1.987712 & 0.369547 & 2.033827\end{array}$

$\begin{array}{clccc}\text { Ro } & & & & \\ \mathbf{w} & \text { Symbol } & \mathbf{X} & \mathbf{Y} & \mathbf{Z} \\ 13 & \mathrm{H} & 3.730509 & 0.630597 & 2.049417 \\ 14 & \mathrm{C} & 2.841456 & 0.997675 & 0.120668 \\ 15 & \mathrm{C} & 3.304844 & -0.35051 & -0.43414 \\ 16 & \mathrm{H} & 3.238826 & -0.34165 & -1.5326 \\ 17 & \mathrm{H} & 4.372028 & -0.44523 & -0.21421 \\ 18 & \mathrm{C} & 2.631231 & -1.59456 & 0.116759 \\ 19 & \mathrm{H} & 2.716617 & -1.59671 & 1.207332 \\ 20 & \mathrm{C} & 3.307549 & -2.84544 & -0.44399 \\ 21 & \mathrm{H} & 4.380132 & -2.79926 & -0.24086 \\ 22 & \mathrm{H} & 2.946538 & -3.77136 & 0.006463 \\ 23 & \mathrm{H} & 3.185601 & -2.91269 & -1.53103 \\ 24 & \mathrm{C} & 0.477355 & -2.68469 & 0.576735\end{array}$




$\begin{array}{clccc}\text { Ro } & & & & \\ \mathbf{w} & \text { Symbol } & \mathbf{X} & \mathbf{Y} & \mathbf{Z} \\ 25 & \mathrm{H} & 0.637305 & -2.50318 & 1.644213 \\ 26 & \mathrm{H} & 0.901657 & -3.66163 & 0.336778 \\ 27 & \mathrm{C} & -0.98077 & -2.64092 & 0.224884 \\ 28 & \mathrm{H} & -1.12957 & -2.89691 & -0.82651 \\ 29 & \mathrm{H} & -1.54836 & -3.35313 & 0.827364 \\ 30 & \mathrm{~N} & -1.15497 & 1.595996 & 0.171721 \\ 31 & \mathrm{H} & -1.06622 & 1.823856 & 1.167697 \\ 32 & \mathrm{~N} & 1.456509 & 1.25163 & -0.44125 \\ 33 & \mathrm{H} & 1.554415 & 1.143969 & -1.45529 \\ 34 & \mathrm{C} & -3.81465 & -2.07196 & 0.379037 \\ 35 & \mathrm{H} & -3.58333 & -3.06434 & -0.01344 \\ 36 & \mathrm{H} & -4.8247 & -1.82776 & 0.041226 \\ 37 & \mathrm{H} & -3.83986 & -2.12196 & 1.473287 \\ 38 & \mathrm{C} & -2.78557 & -1.00182 & -1.6436 \\ 39 & \mathrm{H} & -2.65037 & -2.00611 & -2.05155 \\ 40 & \mathrm{H} & -1.98773 & -0.36956 & -2.03383 \\ 41 & \mathrm{H} & -3.73051 & -0.63074 & -2.04943\end{array}$

$\begin{array}{clccc}\text { Ro } & & & & \\ \mathbf{w} & \text { Symbol } & \mathbf{X} & \mathbf{Y} & \mathbf{Z} \\ 42 & \mathrm{C} & -2.84145 & -0.99768 & -0.12066 \\ 43 & \mathrm{C} & -3.30486 & 0.350513 & 0.43412 \\ 44 & \mathrm{H} & -3.23885 & 0.341672 & 1.53258 \\ 45 & \mathrm{H} & -4.37204 & 0.44523 & 0.214175 \\ 46 & \mathrm{C} & -2.63124 & 1.594564 & -0.11678 \\ 47 & \mathrm{H} & -2.71661 & 1.596698 & -1.20736 \\ 48 & \mathrm{C} & -3.30757 & 2.845448 & 0.443937 \\ 49 & \mathrm{H} & -4.38015 & 2.799263 & 0.240799 \\ 50 & \mathrm{H} & -2.94656 & 3.771367 & -0.00652 \\ 51 & \mathrm{H} & -3.18564 & 2.912709 & 1.530987 \\ 52 & \mathrm{C} & -0.47737 & 2.684705 & -0.57674 \\ 53 & \mathrm{H} & -0.63731 & 2.503186 & -1.64421 \\ 54 & \mathrm{H} & -0.90168 & 3.661639 & -0.33678 \\ 55 & \mathrm{C} & 0.980757 & 2.640936 & -0.22488 \\ 56 & \mathrm{H} & 1.129543 & 2.896935 & 0.826521 \\ 57 & \mathrm{H} & 1.548336 & 3.353157 & -0.82736\end{array}$

Results for 3-SRSR based on AFPD/GENECP with Ni at LanL2DZ and H, C, N at 6$311+\mathrm{G}(\mathrm{d})$ basis sets. 


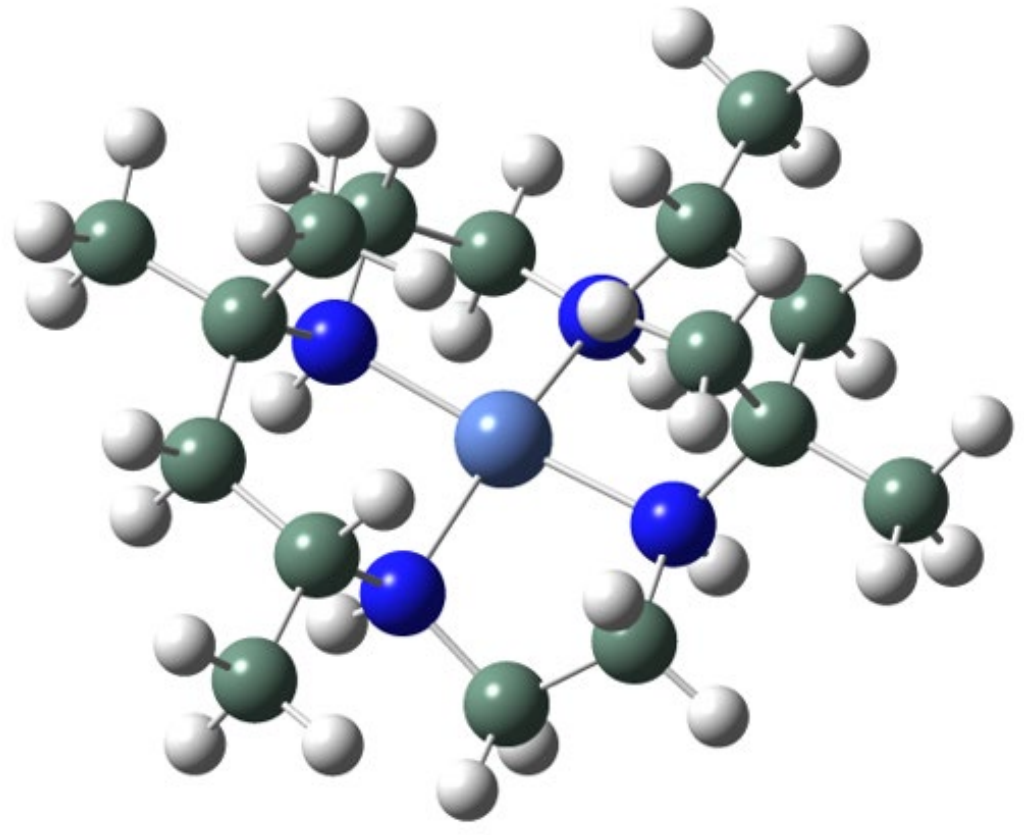

Figure S3.13. GaussView representation of 3-SRSR. 
Table S3.8. Calculated atomic coordinates for 3-SRSR.

\begin{tabular}{ccccc} 
Row & Symbol & $\mathbf{X}$ & $\mathbf{Y}$ & $\mathbf{Z}$ \\
1 & $\mathrm{C}$ & 0.601671 & -2.69523 & -0.28284 \\
2 & $\mathrm{H}$ & 1.230412 & -3.54844 & -0.54812 \\
3 & $\mathrm{H}$ & 0.312581 & -2.80161 & 0.763496 \\
4 & $\mathrm{C}$ & -0.61615 & -2.62265 & -1.16732 \\
5 & $\mathrm{H}$ & -1.24649 & -3.5067 & -1.06185 \\
6 & $\mathrm{H}$ & -0.32013 & -2.56052 & -2.21927 \\
7 & $\mathrm{C}$ & -2.40016 & -1.44475 & 0.236132 \\
8 & $\mathrm{H}$ & -1.87122 & -1.56915 & 1.186058 \\
9 & $\mathrm{C}$ & -3.36798 & -2.60903 & 0.041126 \\
10 & $\mathrm{H}$ & -2.89465 & -3.58452 & 0.167544 \\
11 & $\mathrm{H}$ & -4.15891 & -2.55007 & 0.792706 \\
12 & $\mathrm{H}$ & -3.84679 & -2.57646 & -0.94349 \\
13 & $\mathrm{C}$ & -3.16654 & -0.12149 & 0.225699 \\
14 & $\mathrm{H}$ & -3.64399 & 0.002455 & -0.75894 \\
15 & $\mathrm{H}$ & -3.99666 & -0.21847 & 0.930762 \\
16 & $\mathrm{C}$ & -2.42288 & 1.170107 & 0.599041 \\
17 & $\mathrm{C}$ & -1.80681 & 1.058532 & 1.987691 \\
18 & $\mathrm{H}$ & -2.57065 & 0.73387 & 2.698967 \\
19 & $\mathrm{H}$ & -0.99702 & 0.331548 & 2.026963 \\
20 & $\mathrm{H}$ & -1.42752 & 2.013038 & 2.358786 \\
21 & $\mathrm{C}$ & -3.42805 & 2.325597 & 0.556595 \\
23 & $\mathrm{H}$ & -4.25367 & 2.119997 & 1.24246 \\
23 & $\mathrm{H}$ & -2.98339 & 3.272636 & 0.870774 \\
\hline $\mathrm{H}$ & $\mathrm{H}$ & -1.23044 & 3.548451 & -0.54799 \\
\hline $\mathrm{H}$ & -3.85781 & 2.453923 & -0.44304 \\
\hline 25 & -0.616091 & 2.622673 & -1.16729 \\
\hline 2 & & -246438 & 3.506722 & -1.06184
\end{tabular}

\begin{tabular}{ccccc} 
Row & Symbol & $\mathbf{X}$ & $\mathbf{Y}$ & $\mathbf{Z}$ \\
30 & $\mathrm{H}$ & 0.320031 & 2.560564 & -2.21923 \\
31 & $\mathrm{C}$ & 2.400178 & 1.444746 & 0.236044 \\
32 & $\mathrm{H}$ & 1.871282 & 1.569129 & 1.185999 \\
33 & $\mathrm{C}$ & 3.367991 & 2.609031 & 0.041009 \\
34 & $\mathrm{H}$ & 4.158959 & 2.550048 & 0.792549 \\
35 & $\mathrm{H}$ & 3.846746 & 2.576472 & -0.94363 \\
36 & $\mathrm{H}$ & 2.894664 & 3.58452 & 0.167466 \\
37 & $\mathrm{C}$ & 3.166547 & 0.121482 & 0.225553 \\
38 & $\mathrm{H}$ & 3.643952 & -0.00244 & -0.75911 \\
39 & $\mathrm{H}$ & 3.996704 & 0.218452 & 0.93058 \\
40 & $\mathrm{C}$ & 2.422905 & -1.17012 & 0.598907 \\
41 & $\mathrm{C}$ & 1.8069 & -1.05857 & 1.987585 \\
42 & $\mathrm{H}$ & 2.57077 & -0.73392 & 2.698834 \\
43 & $\mathrm{H}$ & 0.997108 & -0.33158 & 2.026906 \\
44 & $\mathrm{H}$ & 1.427615 & -2.01308 & 2.358679 \\
45 & $\mathrm{C}$ & 3.428072 & -2.32561 & 0.556396 \\
46 & $\mathrm{H}$ & 4.253724 & -2.12002 & 1.242229 \\
47 & $\mathrm{H}$ & 2.983428 & -3.27265 & 0.870579 \\
48 & $\mathrm{H}$ & 3.857783 & -2.45392 & -0.44326 \\
59 & $\mathrm{~N}$ & 1.336843 & -1.40854 & -0.43859 \\
50 & $\mathrm{~N}$ & -1.35525 & -1.37032 & -0.84167 \\
51 & $\mathrm{~N}$ & -1.33686 & 1.408551 & -0.4385 \\
53 & $\mathrm{~N}$ & 1.355212 & 1.370341 & -0.84171 \\
54 & $\mathrm{Hi}$ & $-1.3 \mathrm{E}-05$ & $5.5 \mathrm{E}-06$ & -0.58939 \\
\hline 5 & -1.82474 & 1.466397 & -1.33652 \\
\hline $\mathrm{H}$ & 1.866096 & 1.110427 & -1.68811 \\
\hline 3 & 1.82468 & -1.46637 & -1.33663 \\
\hline 3 & -1.86618 & -1.11039 & -1.68805
\end{tabular}




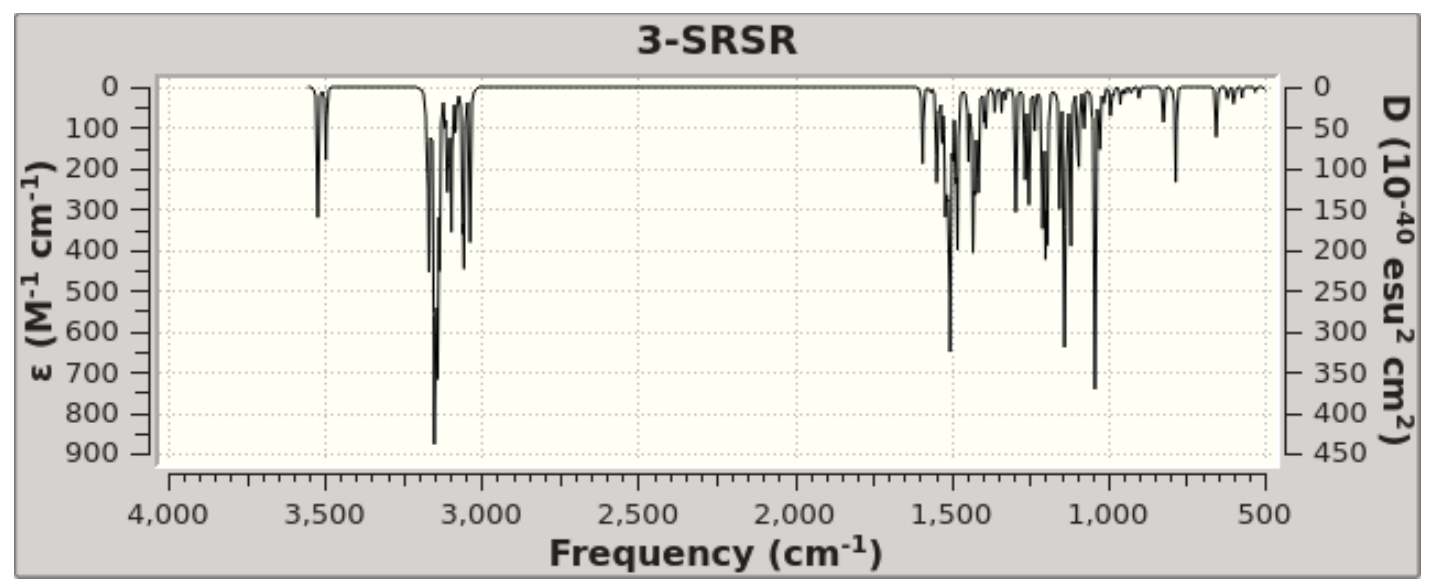

Figure S3.14. Calculated IR spectrum for 3-SRSR.

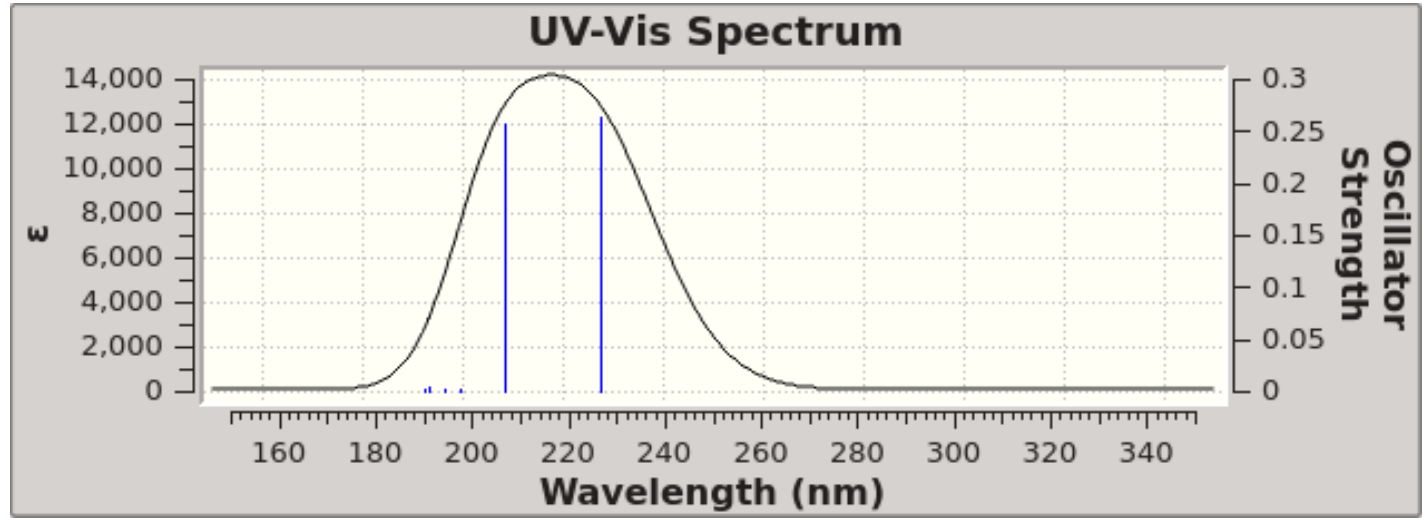

Figure S3.15. Calculated UV-Vis spectrum for 3-SRSR. 


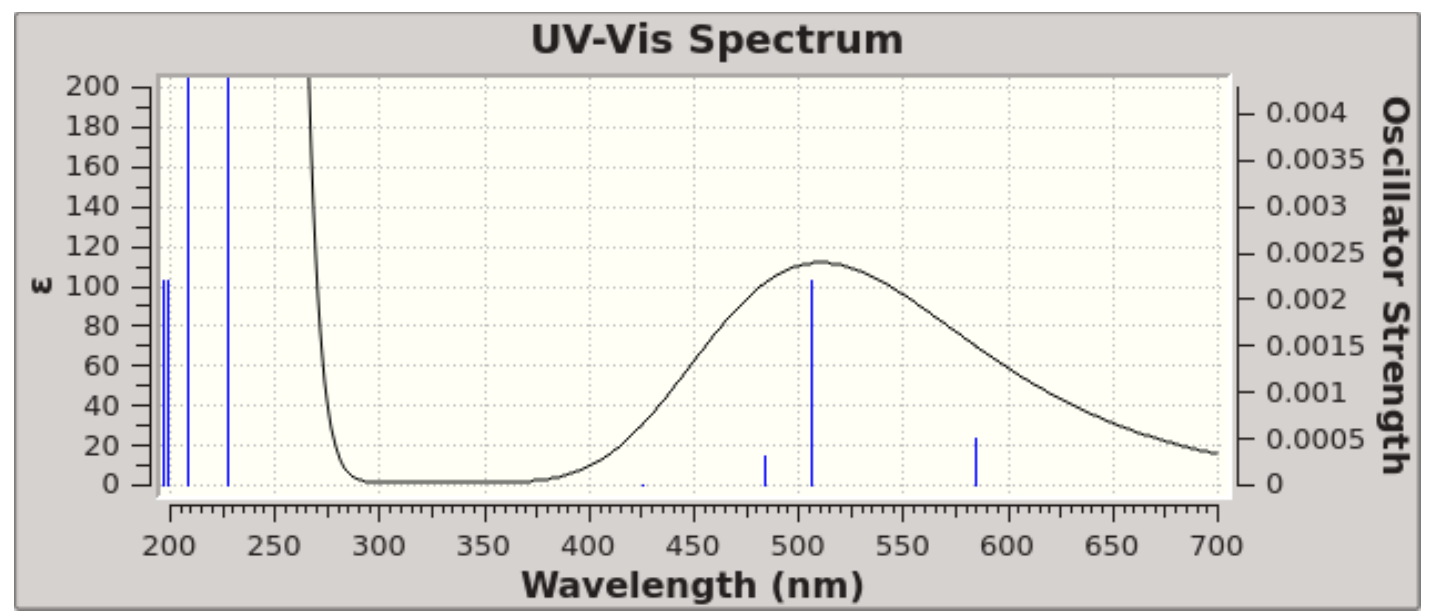

Figure S3.16. Expansion of the vertical scale for the Calculated UV-Vis spectrum for 3-SRSR. 
Table S3.9. Excitation energies and oscillator strengths listing for 3-SRSR.

\begin{tabular}{|c|c|c|c|c|c|c|}
\hline $\begin{array}{l}\text { Excited } \\
\text { State }\end{array}$ & Nature & $E(e V)$ & $\lambda(\mathrm{nm})$ & $f$ & $\begin{array}{l}\text { Orbital } \\
\text { transitions }\end{array}$ & $\begin{array}{l}\text { Normalized } \\
\text { coefficient }\end{array}$ \\
\hline 1: & A & 2.1195 & 584.98 & 0.0005 & $\begin{array}{c}88->89 \\
88<-89\end{array}$ & $\begin{array}{c}0.70628 \\
-0.11994\end{array}$ \\
\hline 2: & A & 2.4491 & 506.25 & 0.0022 & $\begin{array}{l}84->89 \\
85->89 \\
86->89 \\
87->89\end{array}$ & $\begin{array}{r}0.16437 \\
0.20628 \\
-0.11605 \\
0.64293\end{array}$ \\
\hline 3: & A & 2.5634 & 483.67 & 0.0003 & $\begin{array}{l}84->89 \\
86->89 \\
87->89\end{array}$ & $\begin{array}{l}0.12272 \\
0.67965 \\
0.12258\end{array}$ \\
\hline 4: & A & 2.9146 & 425.39 & 0.0000 & $\begin{array}{l}77->89 \\
80->89 \\
82->89 \\
83->89\end{array}$ & $\begin{array}{r}0.13056 \\
-0.18904 \\
0.45944 \\
0.47112\end{array}$ \\
\hline 5: & A & 5.4465 & 227.64 & 0.2635 & $\begin{array}{l}84->89 \\
85->89 \\
86->89 \\
87->89\end{array}$ & $\begin{array}{r}0.10399 \\
0.64660 \\
0.11288 \\
-0.21999\end{array}$ \\
\hline 6: & A & 5.9555 & 208.18 & 0.2575 & $\begin{array}{l}84->89 \\
85->89 \\
86->89 \\
87->89\end{array}$ & $\begin{array}{r}0.65665 \\
-0.14290 \\
-0.11501 \\
-0.15107\end{array}$ \\
\hline 7: & A & 6.2220 & 199.27 & 0.0022 & $\begin{array}{l}82->89 \\
83->89 \\
88->90\end{array}$ & $\begin{array}{c}0.44321 \\
-0.42446 \\
-0.32626\end{array}$ \\
\hline 8: & A & 6.3101 & 196.49 & 0.0022 & $\begin{array}{l}77->89 \\
80->89 \\
82->89 \\
83->89\end{array}$ & $\begin{array}{c}-0.27174 \\
0.59667 \\
0.13105 \\
0.18197\end{array}$ \\
\hline 9: & A & 6.4155 & 193.26 & 0.0050 & $\begin{array}{l}78->89 \\
82->89 \\
83->89 \\
88->90\end{array}$ & $\begin{array}{r}0.14387 \\
0.23447 \\
-0.19341 \\
0.59529\end{array}$ \\
\hline
\end{tabular}




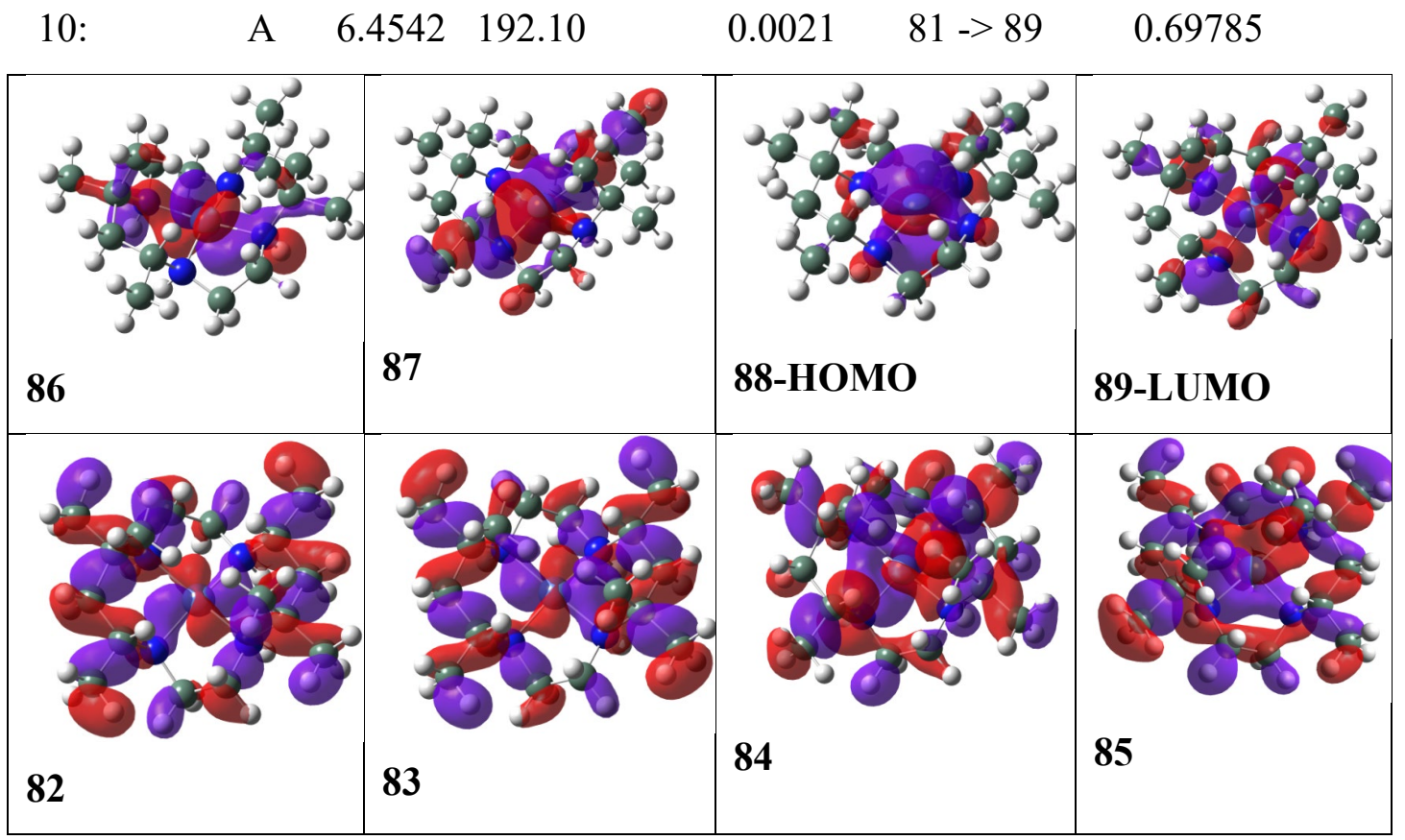

Figure S3.17. Drawings of selected molecular orbitals listed in Table S3.8.

Results for 3-SRSR based on mPW1PW91/GENECP with Ni at SDD and all H, C, N at 6-31G(d) basis sets except for the $\mathrm{C}$ and $\mathrm{H}$ atoms $(\# 10,12,38,40)$ involved in the anagostic interaction which were at the $6-311++\mathrm{G}(2 \mathrm{~d}, 2 \mathrm{p})$ basis set level.

Table S3.10. Calculated atomic coordinates for 3-SSRR.

$\begin{array}{clcccccccc} & \text { Symbol } & \mathbf{X} & \mathbf{Y} & \mathbf{Z} & & \text { Symbol } & \mathbf{X} & \mathbf{Y} & \mathbf{Z} \\ 1 & \mathrm{C} & 0.601671 & -2.69523 & -0.28284 & 12 & \mathrm{H} & -3.84679 & -2.57646 & -0.94349 \\ 2 & \mathrm{H} & 1.230412 & -3.54844 & -0.54812 & 13 & \mathrm{C} & -3.16654 & -0.12149 & 0.225699 \\ 3 & \mathrm{H} & 0.312581 & -2.80161 & 0.763496 & 14 & \mathrm{H} & -3.64399 & 0.002455 & -0.75894 \\ 4 & \mathrm{C} & -0.61615 & -2.62265 & -1.16732 & 15 & \mathrm{H} & -3.99666 & -0.21847 & 0.930762 \\ 5 & \mathrm{H} & -1.24649 & -3.5067 & -1.06185 & 16 & \mathrm{C} & -2.42288 & 1.170107 & 0.599041 \\ 6 & \mathrm{H} & -0.32013 & -2.56052 & -2.21927 & 17 & \mathrm{C} & -1.80681 & 1.058532 & 1.987691 \\ 7 & \mathrm{C} & -2.40016 & -1.44475 & 0.236132 & 18 & \mathrm{H} & -2.57065 & 0.73387 & 2.698967 \\ 8 & \mathrm{H} & -1.87122 & -1.56915 & 1.186058 & 19 & \mathrm{H} & -0.99702 & 0.331548 & 2.026963 \\ 9 & \mathrm{C} & -3.36798 & -2.60903 & 0.041126 & 20 & \mathrm{H} & -1.42752 & 2.013038 & 2.358786 \\ 10 & \mathrm{H} & -2.89465 & -3.58452 & 0.167544 & 21 & \mathrm{C} & -3.42805 & 2.325597 & 0.556595 \\ 11 & \mathrm{H} & -4.15891 & -2.55007 & 0.792706 & 22 & \mathrm{H} & -4.25367 & 2.119997 & 1.24246\end{array}$




$\begin{array}{llccc} & \text { Symbol } & \mathbf{X} & \mathbf{Y} & \mathbf{Z} \\ 23 & \mathrm{H} & -2.98339 & 3.272636 & 0.870774 \\ 24 & \mathrm{H} & -3.85781 & 2.453923 & -0.44304 \\ 25 & \mathrm{C} & -0.60168 & 2.695236 & -0.28275 \\ 26 & \mathrm{H} & -0.31254 & 2.801595 & 0.763569 \\ 27 & \mathrm{H} & -1.23044 & 3.548451 & -0.54799 \\ 28 & \mathrm{C} & 0.616091 & 2.622673 & -1.16729 \\ 29 & \mathrm{H} & 1.246438 & 3.506722 & -1.06184 \\ 30 & \mathrm{H} & 0.320031 & 2.560564 & -2.21923 \\ 31 & \mathrm{C} & 2.400178 & 1.444746 & 0.236044 \\ 32 & \mathrm{H} & 1.871282 & 1.569129 & 1.185999 \\ 33 & \mathrm{C} & 3.367991 & 2.609031 & 0.041009 \\ 34 & \mathrm{H} & 4.158959 & 2.550048 & 0.792549 \\ 35 & \mathrm{H} & 3.846746 & 2.576472 & -0.94363 \\ 36 & \mathrm{H} & 2.894664 & 3.58452 & 0.167466 \\ 37 & \mathrm{C} & 3.166547 & 0.121482 & 0.225553 \\ 38 & \mathrm{H} & 3.643952 & -0.00244 & -0.75911 \\ 39 & \mathrm{H} & 3.996704 & 0.218452 & 0.93058 \\ 40 & \mathrm{C} & 2.422905 & -1.17012 & 0.598907\end{array}$

$\begin{array}{llrrc} & \text { Symbol } & \mathbf{X} & \mathbf{Y} & \mathbf{Z} \\ 41 & \mathrm{C} & 1.8069 & -1.05857 & 1.987585 \\ 42 & \mathrm{H} & 2.57077 & -0.73392 & 2.698834 \\ 43 & \mathrm{H} & 0.997108 & -0.33158 & 2.026906 \\ 44 & \mathrm{H} & 1.427615 & -2.01308 & 2.358679 \\ 45 & \mathrm{C} & 3.428072 & -2.32561 & 0.556396 \\ 46 & \mathrm{H} & 4.253724 & -2.12002 & 1.242229 \\ 47 & \mathrm{H} & 2.983428 & -3.27265 & 0.870579 \\ 48 & \mathrm{H} & 3.857783 & -2.45392 & -0.44326 \\ 49 & \mathrm{~N} & 1.336843 & -1.40854 & -0.43859 \\ 50 & \mathrm{~N} & -1.35525 & -1.37032 & -0.84167 \\ 51 & \mathrm{~N} & -1.33686 & 1.408551 & -0.4385 \\ 52 & \mathrm{~N} & 1.355212 & 1.370341 & -0.84171 \\ 53 & \mathrm{Ni} & -1.3 \mathrm{E}-05 & 5.5 \mathrm{E}-06 & -0.58939 \\ 54 & \mathrm{H} & -1.82474 & 1.466397 & -1.33652 \\ 55 & \mathrm{H} & 1.866096 & 1.110427 & -1.68811 \\ 56 & \mathrm{H} & 1.82468 & -1.46637 & -1.33663 \\ 57 & \mathrm{H} & -1.86618 & -1.11039 & -1.68805\end{array}$




\title{
Chapter 4 Double-Shell Lignin Nanocapsules Are a Stable Vehicle for Fungicide Encapsulation and Release
}

\author{
Raisa Carmen Andeme Ela,* Momoko Tajiri, Nick K. Newberry, Patricia A. Heiden, \\ and Rebecca G. Ong
}

\subsection{Abstract}

Industry is increasingly turning to biobased and environmentally benign materials for use in high-value applications. Kraft lignin's low cost and inherent properties, such as its easily tunable amphiphilic nature, adsorption capacity, and natural

cross-linking tendency, make it suitable for use as a raw material for high-value nanomaterials. To support that need, this paper describes the synthesis of innovative, double-shelled lignin nanocapsules from hardwood kraft lignin, their performance towards encapsulating a fungicide, and effectiveness at controlling its release. The recovered lignin was dissolved without further modification in tetrahydrofuran and inserted dropwise into a water/ethanol solution containing sacrificial surfactant templates. Monodispersed, hollow, double-shell nanocapsules were produced via a two-step self-assembly. The water/ethanol solution acted as a nonsolvent while simultaneously providing strategic sites for controlled-size production. The shells of the nanocapsules were cross-linked with biodegradable maleic anhydride to bolster the structural stability. The average hydrodynamic diameter of the particles was $241.8 \pm$ $33.3 \mathrm{~nm}$, and these structures were stable in water for eight months. The specific surface area of kraft lignin increased by 4-fold in the double-shell nanocapsule form. The nanocapsules were loaded with propiconazole at an entrapment efficiency of $56.1 \%$. This system could represent an effective method to enable the biologically activated, controlled release of fungicides.

KEYWORDS: Kraft lignin, Nanocapsule, Double shell, Drug vehicle, Release studies 109 


\subsection{Introduction}

Sustainable and biologically, and environmentally friendly materials are essential components to achieving ecological balance. ${ }^{95}$ Lignin is the second most abundant biopolymer in the biosphere, representing $30 \%$ of nonfossil carbon. It is comprised of polymerized coniferyl, sinapyl, and p-coumaryl monomers that are largely linked together by $\beta$-O-4 ether bonds. ${ }^{96}$ In the cell walls of vascular plants, lignin provides antioxidant and antimicrobial properties and resistance to ultraviolet light, ${ }^{97}$ and there are many potential applications for lignin that could benefit from these inherent characteristics. The main industrial source of lignin is the kraft pulping process, and kraft lignin is an attractive renewable precursor with high valorization potential. ${ }^{96}$ The kraft process produces approximately 53 million metric tons of lignin per year, and of this, only $\sim 2 \%$ is utilized in advanced applications, with the remainder being combusted for energy and chemical recovery. ${ }^{98}$ Various high-value products have been proposed for lignin, of which the major advances have been focused on carbon fiber technology, ${ }^{99}$ hydrogels, ${ }^{100}$, and nanoparticles. ${ }^{101-103}$ Lignin nanoparticles have applications in biomedical, environmental, electronic, and personal care products and thermoplastics. ${ }^{101-104}$ However, one property of lignin that has hindered its use industrially is its inherent hydrophobicity, which causes it to sediment in aqueous systems. Lignin nanoparticles are able to overcome this challenge by forming nanoparticles in water that are stabilized by electrostatic repulsions between the ionized surface hydroxyl groups. ${ }^{105,106}$ However, the physical and chemical properties of the final particle depend on the type of lignin precursor, synthesis route, and post-synthesis modifications. Hollow lignin spheres have been produced from unmodified kraft lignin through a solvent exchange process. ${ }^{107}$ This is a significant advancement, as most methods have relied on copolymerization and unsustainable approaches to chemically modify the lignin precursor prior to nanoparticle synthesis. ${ }^{105,106}$ The production of hollow particles from unmodified kraft lignin was achieved by dissolving lignin in tetrahydrofuran and slowly inserting water into the system. The particles ranged in size, $200-600 \mathrm{~nm}$, and they were reported to be stable for 45 days. ${ }^{107}$ Nonetheless, the 
specific mechanism responsible for the formation of the hollow structure was not described sufficiently, as solid spheres have also been produced from kraft lignin using the same approach. ${ }^{101,105}$ All papers have attributed the nanoparticle formation mechanism primarily to $\pi-\pi$ stacking between the aromatic rings. Thus, a deeper understanding of the phenomenon that promotes cavity formation is needed. Li et al. reported perforated kraft lignin nanocapsules ${ }^{108}$ that were obtained by adding water to a lignin in ethanol solution. This method produced fine particles. The core of some particles fused together upon ethanol removal, and the particles were reported to flatten upon drying. Various studies have studied the suitability of lignin nanoparticles for drug delivery; ${ }^{109}$; however, only Zhou et al. ${ }^{110}$ investigated the mechanisms driving encapsulation and release, in this case of a hydrophilic drug, from lignin nanoparticles. As such, there is significant room for additional research. Producing uniform and stable hollow structures from unmodified kraft lignin could pave the way toward its commercial utilization in drug-delivery applications. One way to achieve a high yield of regular structures is by employing surfactant templates. ${ }^{111} \mathrm{Li}$ et al. ${ }^{112}$ prepared an alkali lignin-anionic surfactant nanoparticle complex and reported it to be effective for the encapsulation of a hydrophobic compound, but released it at a fast rate. Yiamawas et al. ${ }^{113}$ used a nonionic surfactant to envelope a kraft lignin-based nanoparticle encapsulating a UV-active cargo. Both methods modified the lignin precursor to promote the molecular assembly. In this work, an inventive mesoporous, uniform, doubleshelled, hollow particle was produced from unmodified kraft lignin. The mechanisms inducing particle morphology and stability in water were studied. For this study, we encapsulated the common foliar fungicide, propiconazole, which has modest solubility in water into the mesoporous double-shell nanocapsule, with the expectation that the amphiphilic nature of lignin would enhance the uptake and retention of the propiconazole within the nanocapsules. The drug encapsulation and retention mechanisms for this system were also investigated. 


\subsection{Experimental}

\subsubsection{Materials}

The kraft lignin utilized in this study was precipitated from a mixed-hardwood black liquor obtained from Verso (Quinnesec, MI) through the LignoBoost process to a final $\mathrm{pH}$ of 4.2 at $70^{\circ} \mathrm{C}$. The lignin was vacuum freeze-dried (FreeZone 4.5L, 77500/77510, Labconco) for $18 \mathrm{~h}$ at a temperature of $-40{ }^{\circ} \mathrm{C} .{ }^{114}$ The characterization methodology can be found in the supplemental document. All reagents were utilized as purchased. The ethanol (EtOH) utilized was 95\% concentration, and the water ultrapure.

\subsubsection{Nanocapsule Synthesis}

Kraft lignin was dissolved in tetrahydrofuran (THF) (1.2 g: $35 \mathrm{~mL})$ under continuous stirring for $2 \mathrm{~h}$ at room temperature. A total of $\sim 0.15 \mathrm{~g}$ remained undissolved and was separated from the liquid by decanting. A water/EtOH solution $(2: 1, \mathrm{v} / \mathrm{v})$ was prepared, and $200 \mathrm{~mL}$ of this solution was stirred at medium-low speed and heated to $67 \pm 3{ }^{\circ} \mathrm{C}$. To this solution, $0.8 \mathrm{~g}$ of either the cationic surfactant cetrimonium bromide (CTAB) or anionic surfactant sodium dodecyl sulfate (SDS) was added. The surfactant was allowed to disperse for $20 \mathrm{~min}$, and then $20 \mathrm{~mL}$ of the lignin/THF solution was added dropwise with a $1 \mathrm{~mL}$ pipet within an interval of $20 \mathrm{~min}$. The self-assembly was allowed to proceed under stirring for $30 \mathrm{~min}$; then, the dispersion was centrifuged (5810R, Eppendorf) for $1 \mathrm{~h}$ at $5{ }^{\circ} \mathrm{C}$ and $1200 \mathrm{rpm}$. The supernatant was discarded, and the pellet was sonicated in a warm bath at $69^{\circ} \mathrm{C}(\mathrm{M} 1800 \mathrm{H}$, Branson) for 30 min with a 5\% (v/v) EtOH water solution containing 1\% (v/v) sulfuric acid at $\mathrm{pH} 6$ to remove the surfactant. ${ }^{111}$ This washing step was repeated twice. The nanocapsules were subsequently cross-linked in a dilute aqueous mixture containing $20 \mathrm{mg}$ of maleic anhydride and $200 \mu \mathrm{L}$ of dibutyl tin dilaurate as a catalyst. The esterification was allowed to proceed for $15 \mathrm{~min}$ at room temperature. Then, the nanocapsules were washed once with $\mathrm{EtOH}$ and twice with water to remove all traces of the reagents utilizing centrifugation and resuspension through sonication. To create the second 
shell, the process was repeated on the single-shell particles with a $15 \mathrm{~mL}$ lignin/THF solution. The nanocapsules were kept suspended in distilled water at a $\mathrm{pH}$ of 7 .

\subsubsection{Nanocapsule Characterization}

The morphologies of the nanostructures were studied using transmission electron microscopy (FEI $200 \mathrm{kV}$ Titan Themis) operating at $60 \mathrm{kV}$. The sample preparation was done by dripping $10 \mu \mathrm{L}$ of the aqueous nanocapsule suspension onto a copper grid, and the drop was allowed to disperse out for $2 \mathrm{~min}$; the excess water was removed by absorbing it from the sides of the grid using filter paper, and the grids were left to dry in a desiccator for 4 days. The particles were not stained. Images collected and shown are representative after observing different areas throughout the grid. The mean hydrodynamic particle size and zeta $(\zeta)$-potential of the nanocapsules were measured at $25^{\circ} \mathrm{C}$ by a zetasizer (Malvern Nano- ZS) at a refractive index of $1.61 .{ }^{115}$ The spatial distribution and relative proportions of the elements were studied by energy dispersive X-ray spectrometry (EDS) and high angle annular dark-field (HAADF) imaging techniques (STEM, FEI $200 \mathrm{kV}$ Titan Themis). The samples (precipitated kraft lignin and the nanocapsules) were oven-dried at $105^{\circ} \mathrm{C}$ for $3.5 \mathrm{~h}$ prior to surface area measurement. These were utilized to determine the specific surface area and the porosity of each. The dried samples were degassed (at $100{ }^{\circ} \mathrm{C}, 1 \mathrm{~mm}$ mercury $(\mathrm{Hg})$ for $4 \mathrm{~h}$ ), and the measurements were performed by nitrogen (N2) and helium (He) sorption, respectively, through the 5- point Brunauer-Emmett-Teller (BET) method (ASAP 2020, Micrometrics). The functional groups of the oven-dried recovered kraft lignin, the empty single shell before cross-linking, the cross-linked single shell, and the final double-shell nanocapsules were evaluated using Fourier transform infrared spectroscopy with 65 scans on a MIRacle A Diamond prizm-ZnSe support element (SHIMADZU, IRTracer-100). 
The average number of molecules assembled per particle (Nass) was computed from eq 1 ,

$$
\begin{gathered}
N_{a s s}=\frac{M_{w_{p}}}{M_{w_{m}}} \\
\rho=\frac{M_{n_{p}}}{N_{A} 4 \pi\left(\frac{R_{h}^{3}}{3}\right)}
\end{gathered}
$$

(2) where Mwp represents the molecular weight of the particle estimated from the shell hydrodynamic radius, Mwm represents the molecular weight of KL, and the particle density $(\rho)$ is from eq 2, ${ }^{108}$ where NA represents Avogadro's number and Rh the hydrodynamic radius of the shell.

\subsubsection{Fungicide Encapsulation and Release}

The nanocapsules were loaded according to a published method with some modifications. ${ }^{110,116}$ Briefly, the lignin nanocapsules were incubated in a parafilmsealed $500 \mathrm{~mL}$ glass beaker with a $0.01 \%(\mathrm{v} / \mathrm{v})$ propiconazole solution in water, at a ratio of 10:1 (w/w) nanocapsules to propiconazole on a mass basis. The tube was kept in the dark for $20 \mathrm{~h}$ on an orbital shaker at ambient conditions. The mixture was centrifuged and the loaded nanocapsule pellet was washed once and redispersed in water at a concentration of $20 \mathrm{mg} / \mathrm{mL}$. The percentage of the mass attributed to the drug per nanocapsule could be determined by eq 3 , and eq 4 permitted the total entrapment efficiency of propiconazole in the total nanocapsule mass. The maximum absorbance for propiconazole was taken at a wavelength of $223 \mathrm{~nm}$. Measurements were conducted through UV spectrophotometry using a $1 \mathrm{~cm}$ quartz cuvette, and the calculation was performed by a calibration curve (UV-vis-NIR spectrophotometer, Shimadzu UV-3600 Plus). 


$$
\begin{gathered}
\text { Drug Loading }(\%)=\frac{\text { weight of drug in nanocapsules }}{\text { weight of nanocapsules }} \times 100 \\
\text { Entrapment Efficiency }(\%)=\frac{\text { weight of drug in nanocapsules }}{\text { weight of drug fed initially }} \times 100 \text { (4) }
\end{gathered}
$$

The drug release studies were performed by placing the loaded drug dispersion in a 6-8 $\mathrm{kDa}$ dialysis tube and placing it in a parafilm-sealed $500 \mathrm{~mL}$ glass beaker containing $150 \mathrm{~mL}$ of water rotating on an orbital shaker at ambient conditions. A redfluorescence label (Cy5) was added to propiconazole via a click reaction. The details are given in the supplemental document. The specific location of Cy5-labeled propiconazole within the nanocapsule was visualized by confocal fluorescence microscopy at an excitation of $488 \mathrm{~nm}$ for lignin and $635 \mathrm{~nm}$ for propiconazole at a single confocal point. The objective lens numerical aperture was 0.9 , and the magnification was 40× (Olympus FluoView, FV1000). The sample preparation was done by simply dripping the loaded nanocapsule solution on a microscope dish.

\subsection{Results and Discussion}

\subsubsection{Kraft Lignin}

The first objective of this work was to make sure that the key properties of the kraft lignin isolated and used here were comparable to those reported in the literature. The number-averaged molecular weight $(\mathrm{Mw})$ of the kraft lignin is relatively high (Table 4.1); as such, the chains are not expected

Table 4.3 Chemical Properties Measured for the Kraft Lignin Utilized in This

\begin{tabular}{|c|c|}
\hline property & value \\
\hline$M_{\mathrm{w}}(\mathrm{kDa})$ & $2.47 \pm 0.06$ \\
\hline polydispersity (Đ) & $4.63 \pm 0.13$ \\
\hline aliphatic $\mathrm{OH}$ (mmol/g lignin) & $3.61 \pm 0.11$ \\
\hline
\end{tabular}
Study 


$\begin{array}{lc}\text { sinapyl OH (mmol/g lignin) } & 1.91 \pm 0.77 \\ \text { coniferyl OH (mmol/g lignin) } & 1.03 \pm 0.06 \\ p \text {-comaryl OH (mmol/g lignin) } & 0.25 \pm 0.03 \\ \text { carboxyl OH (mmol/g lignin) } & 0.56 \pm 0.16 \\ \text { ash (\%) } & 4.72 \pm 0.34 \\ \mathrm{C}: \mathrm{O}(\%) & 2.90 \pm 0.07 \\ \mathrm{Na}(\mathrm{g} / \mathrm{kg}) & 52.5 \pm 3.13 \\ \text { hemicelluloses (\%) } & 1.68 \pm 0.16 \\ \text { xylose } & 1.34 \pm 0.05 \\ \text { glucose } & 0.082 \pm 0.002 \\ \text { galactose } & 0.048 \pm 0.004 \\ \text { mannose } & 0.13 \pm 0.01\end{array}$

to solubilize in ethanol, which would act as an antisolvent. ${ }^{108,117}$ Moreover, the presence of hydroxyl groups in the lignin precursor will induce a charge on the surface of the nanocapsule (Figure 4.2B), thus stabilizing the structures through electrostatic repulsions. ${ }^{105,106}$ Similarly, the significant presence of the sodium ion $(\mathrm{Na}+)(\mathrm{Table}$ 4.1 ) could contribute to the particle stability by promoting ion $-\pi$ interactions. ${ }^{118}$ The aliphatic and phenolic hydroxyl content agrees with what has been previously reported for kraft lignin (1.65-3.28 mmol/g and 1.58-3.58 mmol/g, respectively). ${ }^{103,119,120}$ Similarly, the ratio of carbon to oxygen atoms $(\mathrm{C}: \mathrm{O})$ coincides with previous reports (2.4-3.1). ${ }^{121,122}$ The physical and chemical properties tested support that the methods used to isolate the lignin did not alter it so its performance should not differ from that of the other kraft lignins.

\subsubsection{Double-Shell Nanocapsule.}

The nanocapsule synthesis method reported herein yielded monodispersed, doubleshelled particles, which were stable in water in the $\mathrm{pH}$ range 4-7 (Figure 4.1, Figure 4.2A, B). These particles are considered fine particles with an average hydrodynamic size of $242 \pm 33 \mathrm{~nm}$ at pH 7 (Figure 4.2). The self-assembly of the kraft lignin molecules occurred in a solvent evaporation process. It was hypothesized that at $65{ }^{\circ} \mathrm{C}$, the THF would evaporate from the system. It is well-known that ethanol and water are 
mutually soluble; nonetheless, previous work on kraft lignin nanoparticles proved that, in a water-ethanol system, a considerable portion of ethanol was entrapped in the hydrophobic core of the nanocapsules. ${ }^{108,123,124}$ Moreover, ethanol has been reported to enhance the homogeneity of the resultant nanoparticles. ${ }^{123}$ This leads us to a hypothesis that, in a water-ethanol system, the ethanol provides specific sites for hydrophobic segregation, thus producing globules of uniform size and shape at an optimum precursor concentration. Amphiphilic molecules adopt the conformation (selfassembly) that costs them less energy with respect to the system conditions, ${ }^{125}$ in this system, both the surfactant and kraft lignin assembled into a spherical shape (Figure 4.1A-D).

\subsubsection{Synthetic Methodology}

The sacrificial surfactant sodium dodecyl sulfate (SDS) produced nanocapsules of a wide size range (Figure 4.1A), which could be due to the negative head of the surfactant electrostatically repulsing the negatively ionized lignin molecules. The sulfur content in the nanocapsules produced by SDS was monitored through energy dispersive spectroscopy (EDS), and this was utilized to assess the effectiveness of the surfactant removal method (Table S4.1). On the other hand, the cetrimonium bromide (CTAB) surfactant, which has a positively charged headgroup, yielded monodispersed nanocapsules (Figure 4.1B-C). It was observed that when the lignin precursor concentration was increased from $0.03 \mathrm{~g} / \mathrm{mL}$ to $0.05 \mathrm{~g} / \mathrm{mL}$, under the same experimental conditions, the average hydrodynamic diameter of the double-shelled nanocapsule increased as well, from $242 \pm 33 \mathrm{~nm}$ to $489 \pm 25 \mathrm{~nm}$. This occurs as a result of the enhanced nucleation-growth mechanism of the particles due to excess lignin molecules. ${ }^{105}$ After successful removal of the surfactant (Table S4.1), the particles were cross-linked (Figure 4.1G) with maleic anhydride, which forms ester cross-links between aliphatic hydroxyl groups. ${ }^{126}$ Cross-linking with maleic anhydride preserves the antiradical and antioxidative properties of lignin, which stem primarily from the phenolic hydroxyl groups, ${ }^{127}$ and enhances cargo retention for drug-delivery 
applications. ${ }^{128}$ Moreover, making the particles less hydrophilic while remaining dispersed in water. Cross-linking typically results in some volume reduction due to loss of chain ends, and this could partially contribute to the shrinking of the particles after acetylation and addition of the second shell (Figure 4.1G, H). The shrinking could also occur as a result of adding additional weight to a coreless shell; as such, the second shell may also contribute to the observed shrinkage. The shrinking phenomenon as a result of acetylation was also observed by Chen et al. ${ }^{129}$ Cross-linking enhances the structural integrity and assists in generating a second shell by modestly increasing the hydrophobicity of the first shell. This is observed from a slight reduction in the $\zeta$ potential after cross-linking (Figure 4.1F, G). The increased hydrophobicity
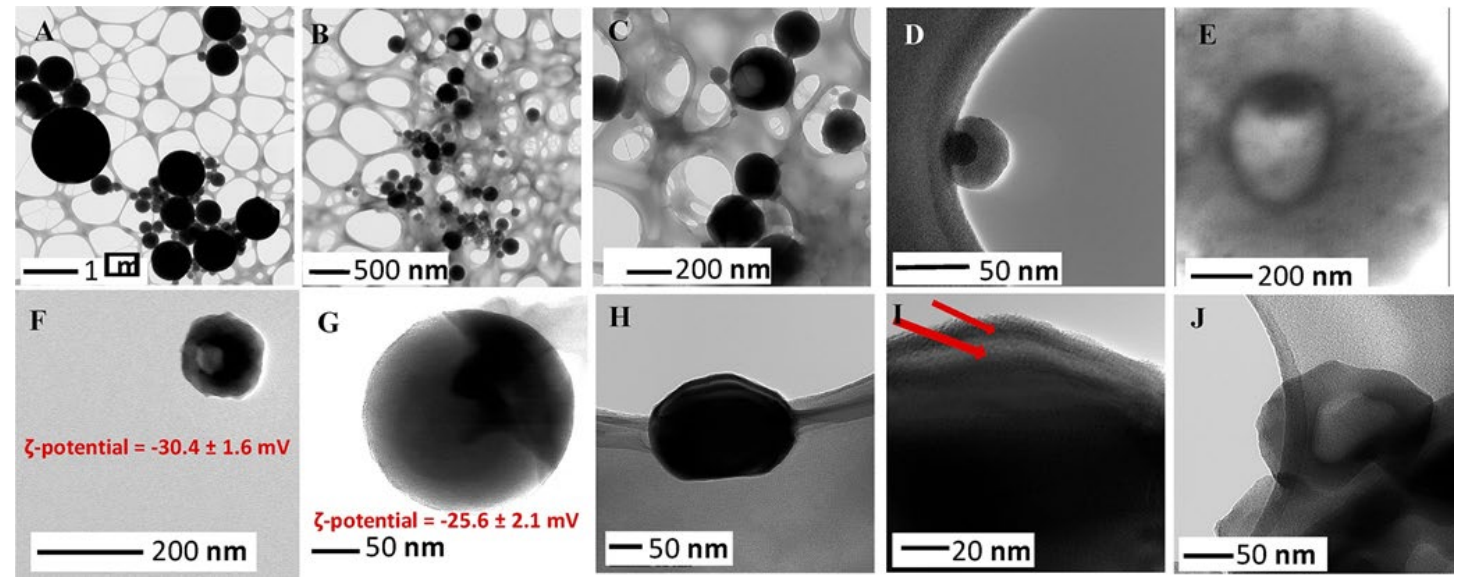

Figure 4.1 (A) Single-shell encapsulating SDS. (B) Single-shell encapsulating CTAB.

(C) Enlarged image of single-shell encapsulating CTAB. (D) Close-up of the surfactant-core single shell. (E) Surfactant-free single shell. (F) Lateral view of a surfactant-free single shell. (G) Cross-linked single shell. (H) Double-shell nanocapsule. (I) White/black under focus-overfocus revealing the two shells at different heights. (J) Interior of the hollow structure of the double-shell nanocapsule. The copper grid is the mesh-like structure in the background. The red arrows point at the two shells. 

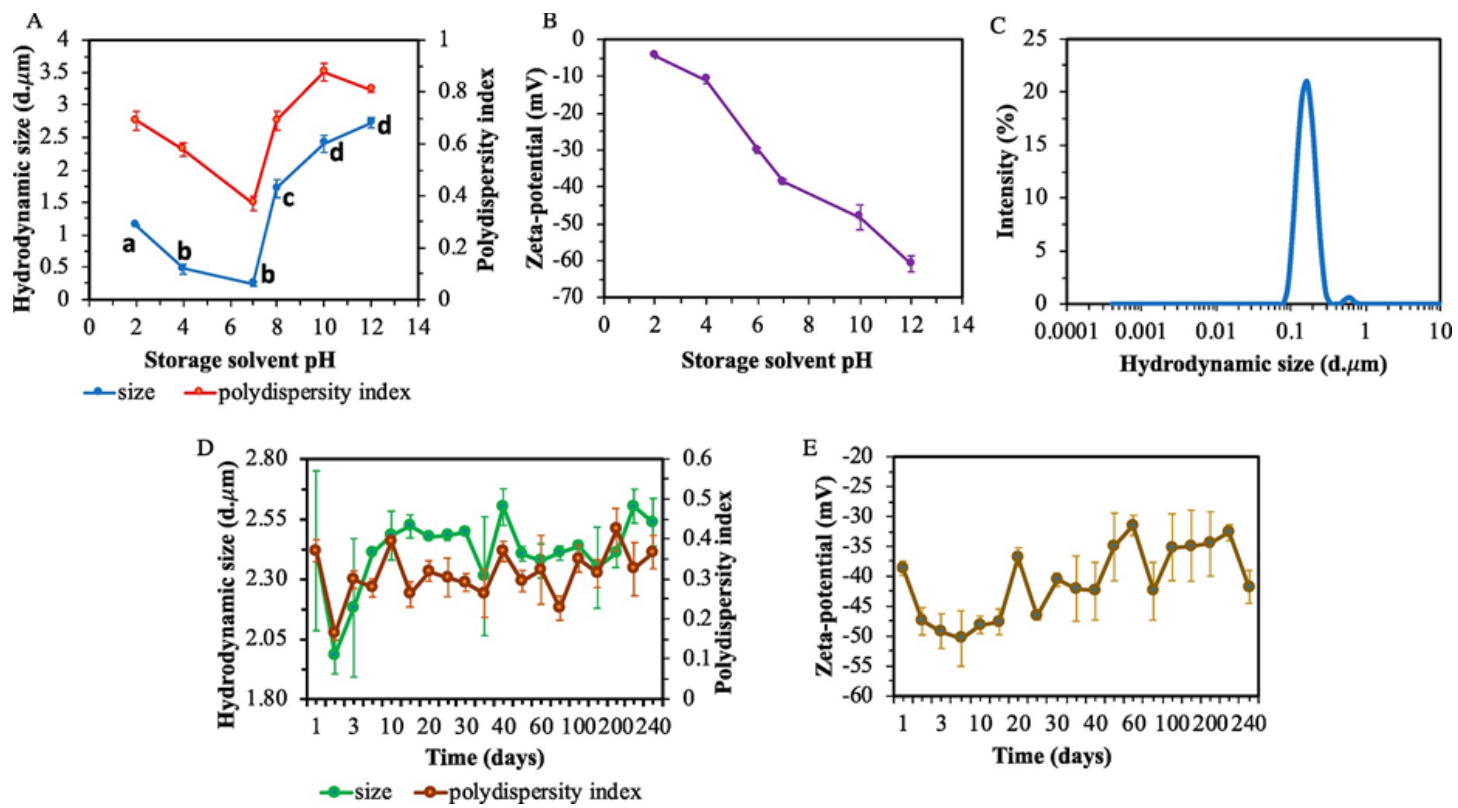

Figure 4.2 (A) Hydrodynamic size of the double-shell nanocapsule as a function of $\mathrm{pH}$ of the solvent (water). (B) $\zeta$-potential of the double-shell nanocapsules as a function of the $\mathrm{pH}$ of the solvent (water). (C) Size distribution of the double-shell nanocapsules at a solvent (water) $\mathrm{pH}$ of 7. (D) Hydrodynamic size of the double-shell nanocapsule as a function of time in water at $\mathrm{pH} 7$ for a period of 8 months. (E) $\zeta$-potential of the double-shell nanocapsules as a function of time in water at $\mathrm{pH} 7$ for a period of 8 months. The letters represent the results from Tukey's simultaneous tests for the difference of means on the hydrodynamic size as a function of $\mathrm{pH}$. Analysis performed in Minitab. Averages that do not share a letter are statistically significantly different.

would promote surfactant attachment to the existing shell and facilitate the generation of a second hollow shell. ${ }^{129,130}$ The two shells were successfully produced (Figure $4.1 \mathrm{H}-\mathrm{J})$, and the white-black under-focus/overfocus microscope technique revealed that the two detected shells are at different heights (Figure 4.1I). Moreover, Figure 4.1H suggests that both the first (lower) shell and the second shell have a thickness of $\sim 7 \mathrm{~nm}$. 


\subsubsection{Nanocapsule Stability Properties}

For $\zeta$-potentials between $-10 \mathrm{mV}$ and $10 \mathrm{mV}$, particles are considered neutral. ${ }^{131}$ The double-shell nanocapsules become neutrally charged below $\mathrm{pH} 4$, and they aggregate as a result of hydrophobic interactions (Figure 4.2A, B). Above $\mathrm{pH} 7$, the molecules become significantly ionized, and the nanocapsules start expanding (Figure 4.2A, B). Furthermore, at elevated $\mathrm{pH}$, ester bonds can undergo hydrolysis, and this could also contribute to the nanocapsule expansion. The nanocapsules have a unimodal size distribution, with a minute peak of $0.2 \%$ intensity between 0.5 and $0.8 \mu \mathrm{m}$ (Figure 4.2C). The sizes reported by TEM are lower than the hydrodynamic sizes. This discrepancy results as the hydrodynamic size includes the water molecules that interact at the electric double layer. The particles were observed to be stable in water at $\mathrm{pH} 7$ for a period of eight months (Figure 4.2D, E). Nonetheless, the $\zeta$-potential trend reveals the particles become slightly protonated over time. This could be because even though the nanocapsules are well-dispersed, they may experience flocculation at high concentrations. $^{132}$

\subsubsection{Mechanisms of Formation}

To study the nanocapsule formation mechanisms, the spatial distribution of the elements on the surface of the particles and their mutual orientations were analyzed by EDS and HAADF. Changes in the functional groups and their conformations were evaluated by FTIR and UV spectra. The results showed that the ratio of carbon to oxygen $(\mathrm{C}: \mathrm{O})$ is higher at the periphery of the hollow space across the surface of the first shell (Figure S4.1A, B). This suggests a more hydrophobic core for the first shell. The potassium ion $(\mathrm{K}+), \mathrm{Na}+$, and sulfur $(\mathrm{S} 2-)$ appear to be randomly distributed. Moreover, the presence of $\mathrm{Na}+$ in the surface of the second shell (Figure S4.1D) could contribute to ion $-\pi$ interactions. The ultraviolet spectrum of kraft lignin and the double-shell nanocapsules revealed a bathochromic (red) shift in the nanocapsule curve (Figure 4.3). This shift is typical of a J- 


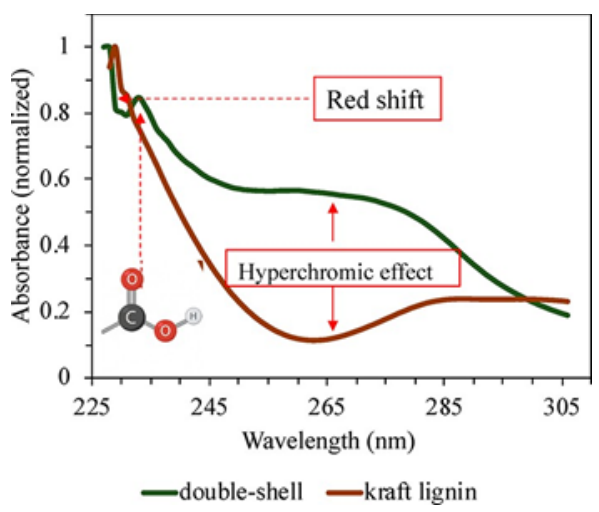

Figure 4.3 UV spectra of kraft lignin and the double-shell nanocapsule. Image edited with BioRender.com.

aggregation, and it has been interpreted as revealing $\pi-\pi$ interactions between benzene rings. ${ }^{107} \mathrm{~J}$-aggregation is a head to- tail orientation between interacting rings. The hyperchromic shift and the adsorption peak at $232 \mathrm{~nm}$ in the double-shell spectrum could be attributed to the increased presence of carboxyl groups from the esterification, thus increasing the absorptivity. ${ }^{133,134}$

\subsubsection{Fungicide Encapsulation}

Lignin nanostructures can be employed in applications that exploit the inherent properties of lignin, such as UV protection. ${ }^{97,} 135$ In this work, the inherent ability of lignin to act as a radical scavenger is being exploited. ${ }^{136}$ This property is enhanced in nanomaterials compared to the raw molecule. ${ }^{137}$ In this work, this property is used for the purpose of creating a dual-action antifungal system. Nanomaterials possess the quality of high surface area to volume ratio, ${ }^{111}$ an interesting trait for optimum cargo loading. The surface area provides available space that cargo may occupy. The specific surface area (SAp) of kraft lignin increased by 2.5 times in the single-shell and 4.2 times in the double-shell (Table 4.2). Similarly, the average pore dimensions also increased from the raw molecule to the double-shelled nanocapsule; however, the average pore volume $(\mathrm{Vp})$ of the single-shell is $16.9 \%$ higher than that of the doubleshell, and the average pore width (Wp) was $12.95 \mathrm{~nm}$ larger in the single-shell. There 
is a reported trade-off between SAp and Vp; moreover, a wider pore distribution in the second shell, as well as cross-linking, may have aided in the reduction of $\mathrm{Wp}$. The surface area is the primary factor aiding cargo loading; as such, the entrapment efficiency of the fungicide propiconazole in the double-shell is $21.4 \%$ higher than in the single-shell, and the drug loading of the double-shell was calculated to be $5.6 \%$. Moreover, the larger pore width (Wp) in the single shell may have deterred cargo entrapment by encouraging cargo diffusion into the storage medium. ${ }^{129}$ Moreover, the double-shell possesses a double barrier which would reduce diffusion. Propiconazole has modest solubility in water. This nature would permit for a preference to settle in the less hydrophilic core of the nanocapsule in an aqueous medium. The density ( $\rho$ ) of the double-shelled nanocapsule is less than that of water; as such, the particles are expected to float in the storage media. The number of molecules (Nass) forming the double-shelled nanocapsule is $\sim 2.6 \times$ larger than the number of molecules forming the single-shelled nanocapsule. This could also contribute to the elongation of the doubleshell (Figure 4.1H). According to the FTIR spectra, the hydroxyl peak is broader in nanocapsule conformations (Figure S4.2). This could be due to the stacking of the molecules in the nanocapsule form promoting inter and intramolecular hydrogen bonding. ${ }^{138}$ All the nanocapsule spectra show the presence of intermolecular hydrogen bonding, which is inferred from the broad hydroxyl stretch in the region 3350-3200 $\mathrm{cm}^{-1}$, and this could contribute to particle stability in water. The FTIR spectra reveal that cross-linking increases the concentration of carbonyl hydroxyl, carbonyl $(\mathrm{C}=\mathrm{O})$, alkene $(\mathrm{C}=\mathrm{C})$, and ester $(\mathrm{C}-\mathrm{O})$ groups, indicating that the esterification has taken place. THF absorption peaks are seen at $3125-3165 \mathrm{~cm}-1$, none of our spectra have additional peaks in this region, so this confirms the absence of THF in the particles. ${ }^{106}$ Based on confocal imaging, UV spectroscopy, and the increased nanocapsule nitrogen content, the double-shell nanocapsules successfully encapsulated propiconazole (Figure 4.4A, Table 4.2, Table $\mathrm{S} 4.2$ ); as a result, the hydrodynamic radius 
Table 4.4 Properties and Characteristics of Kraft Lignin, Single-Shell Nanocapsules, and Double-Shell Nanocapsules

\begin{tabular}{|c|c|c|c|c|c|c|c|}
\hline & $\begin{array}{l}\quad \text { specific } \\
\text { surface } \\
\text { area }\left[\mathrm{SA}_{\mathrm{p}}\right] \\
\left(\mathrm{cm}^{2} / \mathrm{g}\right)\end{array}$ & $\begin{array}{c}\text { average } \\
\text { pore } \\
\text { volume } \\
{\left[V_{\mathrm{p}}\right]} \\
\left(\mathrm{mm}^{3} / \mathrm{g}\right)\end{array}$ & $\begin{array}{c}\text { average } \\
\text { pore } \\
\text { width } \\
{\left[W_{\mathrm{p}}\right]} \\
(\mathrm{nm})\end{array}$ & $\begin{array}{l}\text { entrapment } \\
\text { efficiency } \\
(\%)\end{array}$ & $\begin{array}{l}\text { average number of } \\
\text { lignin molecules } \\
\text { assembled }\left[N_{\text {ass }}\right]\end{array}$ & $\begin{array}{c}\text { nanocapsule } \\
\text { density }[\rho] \\
\left(\mathrm{g} / \mathrm{cm}^{3}\right)\end{array}$ & $\begin{array}{l}\text { hydrodynamic } \\
\text { radius }\left[R_{\mathrm{h}}\right] \\
(\mathrm{nm})\end{array}$ \\
\hline $\begin{array}{l}\text { kraft } \\
\text { lignin }\end{array}$ & 650 & 0.1 & 7.1 & - & - & - & - \\
\hline $\begin{array}{r}\text { single } \\
\text { shell }\end{array}$ & 1590 & 1.0 & 26.2 & $34.7 \pm 0.9$ & $\begin{array}{c}54.5 \\
\times \\
10^{3}\end{array}$ & 0.8 & $41.9 \pm 0.9$ \\
\hline $\begin{array}{r}\text { double } \\
\text { shell }\end{array}$ & 2700 & 0.9 & 13.2 & $56.1 \pm 2.1$ & $\begin{array}{c}14.4 \\
\times \\
10^{4}\end{array}$ & 0.8 & $58.1 \pm 7.9$ \\
\hline
\end{tabular}
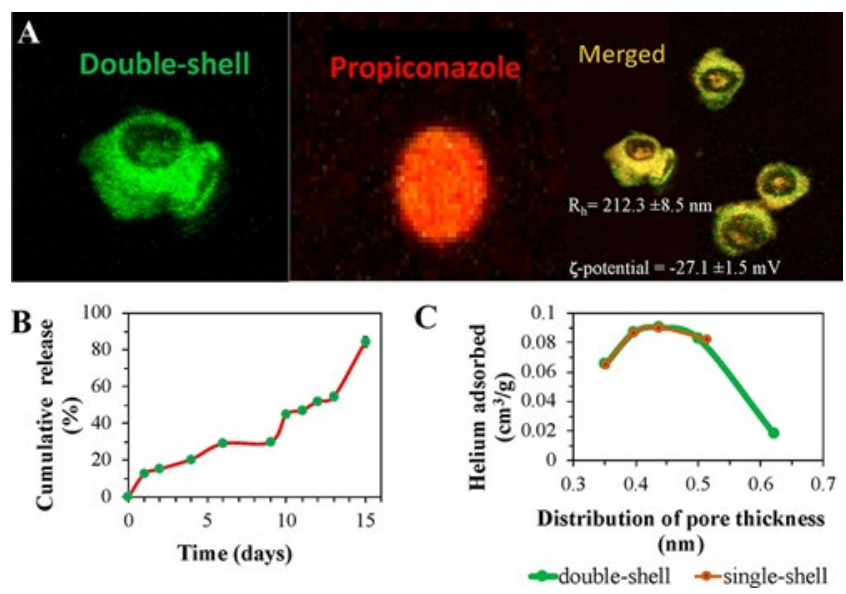

Figure 4.4 (A) Confocal fluorescence microscopic image of double-shell encapsulating propiconazole, taken six days postincubation. (B) Release profile of propiconazole from the double shell. (C) Pore thickness distribution in the single shell and double shell.

$(\mathrm{Rh})$ of the double-shell increased from $120.9 \pm 16.65 \mathrm{~nm}$ to $212.3 \pm 8.5 \mathrm{~nm}$ (both values include hollow region), but the $\zeta$ - potential decreased slightly from $-38.65 \pm$ $0.64 \mathrm{mV}$ to $-27.1 \pm 1.5 \mathrm{mV}$. The double-shell nanocapsules displayed a slow release of propiconazole (Figure 4.4B), retaining $15.7 \%$ of the initially loaded drug by the end of the second week. This sustained release of active cargo could prolong the active effect 
of the fungicide. Furthermore, the size and polydispersity of a particle contribute to the stability of the cargo release, and the double-shell particles are considered monodispersed (polydispersity less than 0.7), ${ }^{139}$ and fall within the nanoparticle-fine particle range. The single-shell and double-shell nanocapsules possessed similar pore thicknesses $(0.35$ to $\sim 0.5 \mathrm{~nm})$, while the double-shell had an extra pore thickness dimension at $0.61 \mathrm{~nm}$, which could be attributed to the thickness of the second shell (Figure 4.4C).

\subsubsection{Mechanisms of Fungicide Encapsulation}

The mechanisms of propiconazole encapsulation into the double-shell nanocapsules were investigated by UV spectroscopy (Figure 4.5).

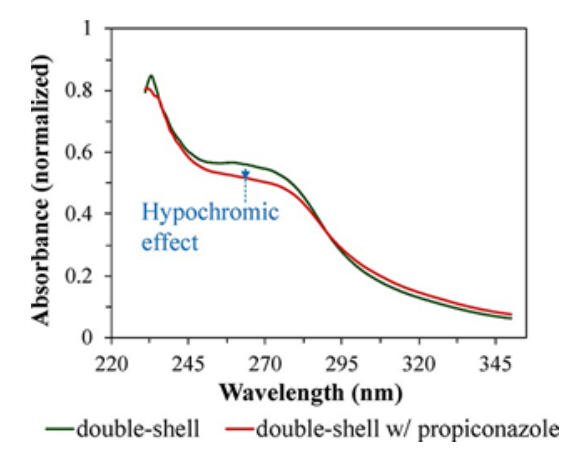

Figure 4.5 UV spectra of double-shell encapsulating propiconazole.

It is expected that the propiconazole molecules settling in the pores of the nanocapsule will sterically hinder intermolecular hydrogen bonding. ${ }^{140}$ This would result in a slight decrease in electrostatic stability (Figure 4.4A). The UV spectra reveal a hypochromic shift from the empty to the loaded double-shell nanocapsule. This could be due to molecular stacking between propiconazole and the double-shell or due to submerged hydroxyl groups in the double shell, and thus, a slight decrease in absorptivity. This phenomenon could also be responsible for the decreased electrostatic stability of 
double-shell nanocapsules upon loading propiconazole. As such, it can be concluded that diffusion and hydrophobic interactions drive the encapsulation process.

\subsection{Conclusions}

We have synthesized unprecedented double-compartment nanocapsules from unmodified kraft lignin. These structures are monodispersed and stable for periods of up to 8 months in water at neutral $\mathrm{pH}$, as indicated by stable hydrodynamic size. Similarly, the $\zeta$-potential remained strongly negative for the same duration. The increased carbon to oxygen ratio at the periphery of the central hollow cavity reveals the hydrophobic nature of the hollow cores. The mechanisms driving the nanocapsule formation have been determined to be hydrophobic interactions, nucleation-growth, $\pi-\pi$ stackings of benzene rings, plausibly ion $-\pi$ stackings, and intermolecular and intramolecular hydrogen bonding. Upon successful encapsulation of propiconazole into the double-shell nanocapsule by diffusion and hydrophobic interactions, the nanocapsules displayed slow release kinetics preserving $\sim 16 \%$ of the initially loaded drug at the end of 2 weeks. This novel synthetic methodology will support designing diverse lignin nanoparticles for different uses.

\subsection{Supporting Information}

\subsubsection{Supporting Experimental}

\subsubsection{Kraft Lignin Characterization}

Oven-dried kraft lignin was acetylated by reacting a $100 \mathrm{mg}$ sample with $5 \mathrm{~mL}$ of a pyridine/acetic anhydride solution $(1: 1, \mathrm{v} / \mathrm{v})$ for 18 hours. The reaction was quenched with a $50 \%$ aqueous methanol solution, and the pellet washed sequentially with $99.5 \%$ methanol, distilled water, and 95\% ethanol. ${ }^{141}$ The relative molecular weight of the acetylated kraft lignin was determined from size exclusion chromatography (Malvern OMNISEC), with tetrahydrofuran as the mobile phase, and the analysis was performed 
by polystyrene standards with an exclusion limit of $400 \mathrm{kDa}$. The hydroxyl content was analyzed via 31P-NMR (Unity Inova, Varian, $400 \mathrm{MHz}$ ) at $25^{\circ} \mathrm{C}$. The sample was prepared by dissolving $\sim 40 \mathrm{mg}$ of oven-dried lignin in $500 \mu \mathrm{l}$ of an anhydrous pyridine/deuterated chloroform solution (1.6:1, v/v). To this, $100 \mu 1$ of cyclohexanol, $50 \mu \mathrm{l}$ of chromium (III) acetylacetone, and $100 \mu \mathrm{l}$ of 2-chloro-4,4,5,5-tetramethyl1,3,2-dioxaphospholane were added. The reaction proceeded for 25 minutes, and 600 $\mu l$ of the mixture was transferred to an NMR tube for analysis with a relaxation delay of $5 \mathrm{~s}$ and through 512 scans. Cyclohexanol was taken as the internal standard, and the different hydroxyl group contents were calculated based on the ratio of the integrated area peaks. The following spectral regions were considered: aliphatic hydroxyls (149.1145.4 ppm), cyclohexanol (145.3-144.9 ppm), syringyl phenolic hydroxyls (143.3142.0 ppm), guaiacyl phenolic hydroxyls (140.5-138.6 ppm), p-hydroxyphenyl

hydroxyls (138.5-137.3 ppm), and carboxyl hydroxyls (135.9-134 ppm). ${ }^{142}$ The atomic concentration of carbon and oxygen was analyzed by X-ray photoelectron spectrometer (PHI 5800) using a magnesium (Mg) beam. Analysis was performed using the XPS Casa software. Sodium content was measured by X-ray fluorescence spectrometer (Xenemetrix EX-6600 EDS) and analyzed from calibration standards. The residual sugars in kraft lignin were hydrolyzed ${ }^{143}$, and the hydrolysate was analyzed by highperformance liquid chromatography (HPLC) (1100 series, RID, and DAD, Agilent Technologies) in a HPX-87 P-Column $(300 \times 7.8 \mathrm{~mm})$ with ultra-filtered water as the mobile phase. The analysis was performed by calibration standards for the sugar moieties, glucose, xylose, mannose, arabinose, and galactose.

\subsubsection{Red fluorescence label addition to propiconazole}

In a typical experiment, $10 \mathrm{mg}$ of propiconazole was dissolved in $100 \mathrm{~mL}$ ultra-filtered water. To it, $5 \mathrm{mg}$ of ammonium tetrachlorocuprate (II) dihydrate, $1 \mathrm{mg}$ of 95\% Cy5alkyne, and $0.1 \mathrm{~mL}$ of a sodium acetylide suspension in xylene were added. The reaction was conducted at ambient conditions. The reaction pathway was developed based on an idea obtained from Lumiprobe life sciences solutions' website. ${ }^{144}$ 


\subsubsection{Supporting Results and Discussion}

Table S4.1. Evidence of removal of surfactant using elemental concentrations of sulfur and sodium determined by EDS.

\begin{tabular}{|c|c|c|}
\hline \multirow{2}{*}{} & \multicolumn{2}{|c|}{ Atomic fraction (\%) } \\
\cline { 2 - 3 } & $\mathrm{S}$ & $\mathrm{Na}$ \\
\hline Kraft lignin & $0.5 \pm 0.2$ & $1.8 \pm 0.7$ \\
\hline Single shell + SDS & $1.1 \pm 0.4$ & $0.2 \pm 0.1$ \\
\hline Single shell & $0.2 \pm 0.1$ & $0.2 \pm 0.1$ \\
\hline Double shell + SDS & $1.3 \pm 0.5$ & $0.8 \pm 0.3$ \\
\hline Double shell & $0.5 \pm 0.1$ & $0.1 \pm 0.0$ \\
\hline
\end{tabular}

Table S4.2. Concentration changes of the elemental composition of nanocapsules at different stages of formation. Increased nitrogen concentration correlates to increased propiconazole encapsulation.

\begin{tabular}{|c|c|c|c|c|c|}
\hline & \multicolumn{5}{|c|}{ Atomic fraction (\%) } \\
\cline { 2 - 6 } & $\mathrm{C}$ & $\mathrm{O}$ & $\mathrm{N}$ & $\mathrm{S}$ & $\mathrm{Na}$ \\
\hline Kraft lignin & $93.1 \pm 2.2$ & $4.1 \pm 1.4$ & 0 & $0.5 \pm 0.2$ & $1.8 \pm 0.7$ \\
\hline Single shell & $94.1 \pm 2.0$ & $4.5 \pm 0.1$ & 0 & $0.2 \pm 0.1$ & $0.4 \pm 0.2$ \\
\hline Double shell & $93.3 \pm 0.4$ & $5.5 \pm 1.1$ & $0.7 \pm 0.2$ & $0.5 \pm 0.1$ & $0.1 \pm 0.0$ \\
\hline $\begin{array}{c}\text { Double shell } \\
+ \\
\text { propiconazole }\end{array}$ & $91.2 \pm 2.7$ & $5.6 \pm 1.1$ & $2.5 \pm 0.5$ & $0.3 \pm 0.1$ & $0.4 \pm 0.1$ \\
& & & & & \\
\hline
\end{tabular}


Table S4.3. Tukey pairwise comparisons of the hydrodynamic size of the nanocapsule as a function of $\mathrm{pH}$. Analysis performed in Minitab.

\begin{tabular}{|c|c|c|c|}
\hline Solution $\mathrm{pH}$ & $\begin{array}{c}\text { Average } \\
\text { hydrodynamic } \\
\text { size (nm) }\end{array}$ & $\begin{array}{c}\text { Standard } \\
\text { deviation }(\mathrm{nm})\end{array}$ & Grouping $^{\mathrm{s}}$ \\
\hline 2 & 1139.5 & 12.0 & $\mathrm{~A}$ \\
\hline 4 & 468.5 & 74.1 & $\mathrm{~B}$ \\
\hline 7 & 241.8 & 33.3 & $\mathrm{~B}$ \\
\hline 8 & 1711.0 & 140.0 & $\mathrm{D}$ \\
\hline 10 & 2401.5 & 132.2 & $\mathrm{D}$ \\
\hline 12 & 2725.2 & 78.9 & \\
\hline \multicolumn{2}{|c|}{ S Samples that do not share a letter are statistically different. } \\
\hline
\end{tabular}

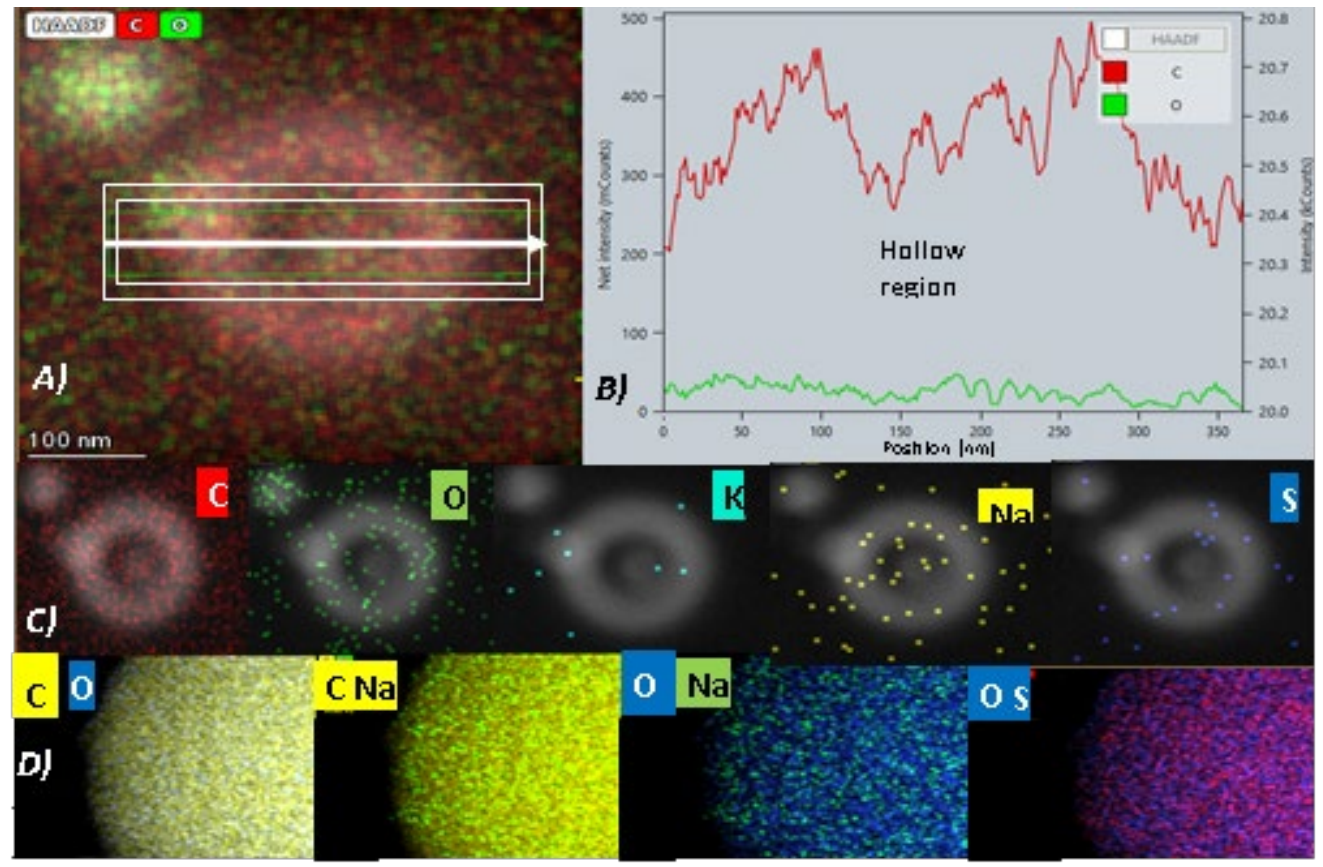

Figure S4.1. A) HAADF spectra and corresponding B) EDS plot of the single-shell. The units represent milli Counts (mCounts) and kilo Counts (kCounts). The black dashed lines show transitions from one nanoparticle domain to another. C) Elemental 
distribution on the surface of the single shell. D) Elemental distribution on the surface of the double-shell.

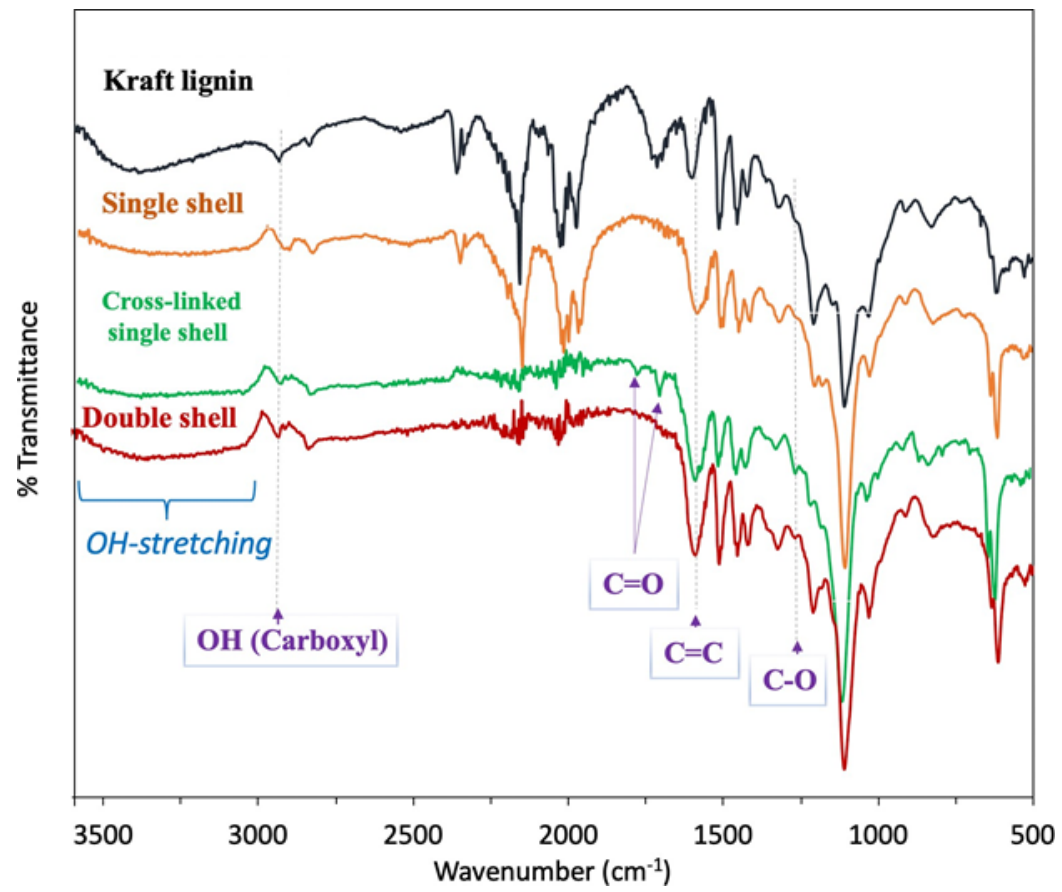

Figure S4.2. FTIR spectra of kraft lignin, non-crosslinked single shell, cross-linked single shell, and cross-linked double-shell nanocapsules. The spectra have been stacked vertically for clarity. 


\title{
Chapter 5 Hydrochloric Acid Modification and Lead Removal Studies on Naturally Occurring Zeolites from Nevada, New Mexico, and Arizona
}

\author{
Garven M. Huntley ${ }^{1}$, Rudy L. Luck ${ }^{1,}{ }^{*}$, Michael E. Mullins ${ }^{2}$ and Nick K. Newberry ${ }^{1}$ \\ ${ }^{1}$ Department of Chemistry, Michigan Technological University, 1400 Townsend \\ Drive, Houghton, MI 49931, USA; gmhuntle@mtu.edu (G.M.H.); \\ Nknewber@mtu.edu(N.K.N.) \\ ${ }^{2}$ Department of Chemical Engineering, Michigan Technological University, 1400 \\ Townsend Drive, Houghton, MI 49931, USA; memullin@mtu.edu \\ *Correspondence: rluck@mtu.edu; Tel.: +1-906-487-7137; Fax: +1-906-487-2061
}

\subsection{Abstract}

Four naturally occurring zeolites were examined to verify their assignments as chabazites AZLB-Ca and AZLB-Na (Bowie, Arizona) and clinoptilolites NM-Ca (Winston, New Mexico) and NV-Na (Ash Meadows, Nevada). Based on powder X-ray diffraction, NM-Ca was discovered to be mostly quartz with some clinoptilolite residues. Treatment with concentrated $\mathrm{HCl}(12.1 \mathrm{M})$ acid resulted in AZLB-Ca and AZLB-Na, the chabazite-like species, becoming amorphous, as confirmed by powder X-ray diffraction. In contrast, NM-Ca and NV-Na, which are clinoptilolite-like species, withstood boiling in concentrated $\mathrm{HCl}$ acid. This treatment removes calcium, magnesium, sodium, potassium, aluminum, and iron atoms or ions from the framework while leaving the silicon framework intact as confirmed via X-ray fluorescence and diffraction. SEM images on calcined and $\mathrm{HCl}$ treated NV-Na were obtained. BET surface area analysis confirmed an increase in surface area for the two zeolites after treatment, NM-Ca 20.0(1) to $111(4) \mathrm{m}^{2} / \mathrm{g}$ and NV-Na 19.0(4) to $158(7) \mathrm{m}^{2} / \mathrm{g} .{ }^{29} \mathrm{Si}$ and ${ }^{27}$ Al MAS NMR were performed on the natural and treated NV-Na zeolite, and the data 
for the natural NV-Na zeolite suggested a $\mathrm{Si}$ : Al ratio of 4.33 similar to that determined by X-Ray fluorescence of 4.55. Removal of lead ions from solution decreased from the native NM-Ca, 0.27(14), NV-Na, 1.50(17) meq/g compared to the modified zeolites, $30 \mathrm{~min} \mathrm{HCl}$ treated NM-Ca 0.06(9) and NV-Na, 0.41(23) meq/g, and also decreased upon $\mathrm{K}^{+}$ion pretreatment in the $\mathrm{HCl}$ modified zeolites.

Keywords: clinoptilolites; acid modification; heavy metals; toxic substances; purification; lead removal.

\subsection{Introduction}

Natural zeolites, which are composed of hydrated aluminosilicates containing group I and II metals ${ }^{145}$, are an abundant resource ${ }^{146}$, with desirable chemical properties for many different applications, such as in construction ${ }^{147}$, slow release of fertilizer ${ }^{148-154}$, $\operatorname{cosmetics}^{155}$, reduction of lactate or ammonia in mammalian blood ${ }^{156}$, removal of Fe and $\mathrm{Mn}$ from water ${ }^{157}$, catalysis and ion exchange ${ }^{158}$, and in environmental protection $^{159}$. Zeolites have a crystalline structure with small voids, commonly called pores, that act as a site for the zeolite to capture or stabilize different cations or molecules. These compounds have been utilized to remove salinity/sodicity ${ }^{160}$, copper $^{161}, \mathrm{Cr}^{6+162}, \mathrm{Mn}^{2+163}$, heavy metals ${ }^{164}$, ammonia ${ }^{165}$, phosphorus ${ }^{166}$, purify urine ${ }^{167}$, zinc ${ }^{168}$ from wastewater, and also anions such as $\mathrm{Cl}^{-}$and $\mathrm{CO}_{3}{ }^{2-169}$. Zeolites contain cations to stabilize the negative charge in their structure, with $\mathrm{Na}^{+}, \mathrm{K}^{+}, \mathrm{Ca}^{2+}$, and $\mathrm{Mg}^{2+}$ being the four most common with others possible ${ }^{170}$. While it is possible to synthesize a single phase of clinoptilolite ${ }^{171}$, as much as $4.75 \mathrm{mg} \mathrm{Fe} / \mathrm{g}$ of Mexican natural zeolite consisting of clinoptilolite, mordenite, and feldspar phases was reported $^{172}$. During the ion exchange process, zeolites adsorb toxic metal ions dissolved in solutions into their pores while releasing the other cations present in the structure into the solutions. Thus, water contaminated with $\mathrm{Pb}^{2+}$ ions, which are toxic to humans, could be made safe by stirring with a zeolite to remove the $\mathrm{Pb}^{2+}$ ions from the solution. The $\mathrm{Pb}^{2+}$ ions would be contained inside the zeolite and could be easily filtered off, and the $\mathrm{Na}^{+}$ion that was previously in the zeolite would now be dissolved in the water, 
rendering it safer for human consumption ${ }^{173}$. In this report, four naturally occurring zeolites that were reported to be of the chabazite and clinoptilolite (based on $\mathrm{Si}: \mathrm{Al} \geq$ $4.0^{174}$ ) varieties were examined ${ }^{175}$. The chabazite form has been explored for its unusually high-sodium composition ${ }^{176}$ and chemical upgrading ${ }^{177}$, and the clinoptilolite zeolite has been studied for various membrane applications ${ }^{178-180}$. Additionally, both chabazite and clinoptilolite were previously subjected to treatment with base and applied for $\mathrm{Pb}^{2+}$ and $\mathrm{Cd}^{2+}$ removal ${ }^{181}$. It was of some interest to determine if modifications under acidic conditions while maintaining structural integrity were possible and what impact this would have on their properties and potential use in remediation, an idea prompted by a publication on chemical etching on a glass surface using $\mathrm{HCl}^{182}$. A report dealing with the treatment of naturally occurring clinoptilolites in Cuba using $0.6 \mathrm{M} \mathrm{HCl}$ discovered that milder forms of acid treatment were required as higher concentrations led to the decomposition of the zeolites. Another report found that the basic clinoptilolite structure remained after acid leaching and heating to 600 ${ }^{\circ} \mathrm{C}$. In the present study, the integrity of the samples, i.e., their purity and classification as chabazite and clinoptilolite, was assessed as evident by powder X-ray diffraction. Additionally, treatment with concentrated $\mathrm{HCl}$ removes metal ions from the pores leaving the silicon framework intact with the clinoptilolite variety, whereas the chabazite ones became amorphous. A variety of analytical techniques were employed to assess the nature and composition of the natural and acid-modified zeolites, including solid-state ${ }^{29} \mathrm{Si}$ and ${ }^{27} \mathrm{Al}$ NMR, BET measurements ${ }^{183}$, SEM images, and powder X-ray fluorescence and diffraction. Lead removal studies on the clinoptilolite samples suggested differing capacities between the two samples after calcination and deterioration of $\mathrm{Pb}^{2+}$ storage capacity upon modification.

The following abbreviations are used. APD-AlPO4-D, a tetrahedrally coordinated aluminophosphate zeolite framework ATR - FTIR-Attenuated Total ReflectanceFourier Transformed Infrared spectroscopy BET-Brunauer Emmett Teller CHAchabazite CLI—clinoptilolite EDS/XRF—energy dispersive X-ray spectroscopy/X-ray 
fluorescence $\mathrm{ERI}$ — erionite $\mathrm{HCl}$ —-hydrochloric acid MAS—magic angle spinning NMR - nuclear magnetic resonance SEM—scanning electron microscope.

\subsection{Materials and Methods}

\subsubsection{Materials}

The zeolites were generously donated from the St. Cloud Mining Company and consisted of St. Cloud Mining Bowie chabazite (AZLB-Na, -325 mesh), St. Cloud Mining Bowie chabazite (AZLB-Ca, -325 mesh), St. Cloud Winston clinoptilolite (NM-Ca, -325 mesh), and St. Cloud Mining Ash Meadows clinoptilolite (NV-Na, -325 mesh), where AZLB = Arizona Land Basin, NM = New Mexico, NV = Nevada, $\mathrm{Na}$ is the dominant cation, and $\mathrm{Ca}$ is the dominant cation. $\mathrm{HCl}(12.1 \mathrm{M})$ and $\mathrm{HNO} 3$ $(15.6 \mathrm{M})$ acids were obtained from Fisher. Lead nitrate was obtained from Mallinckrodt Chemical Works.

\subsubsection{Zeolite Modifications}

\subsection{Calcined Zeolites}

The calcined zeolite samples were obtained by heating the zeolites at $550{ }^{\circ} \mathrm{C}$ for $5 \mathrm{~h}$ under air. After cooling the zeolite, the samples were stored in a desiccator to prevent the absorption of water.

\subsection{Hydrochloric Acid Treated Zeolites}

The $\mathrm{HCl}$ acid-treated samples were prepared by heating at $85^{\circ} \mathrm{C}$ a solution of the acid and zeolite at a ratio of $10 \mathrm{~mL}$ of concentrated $\mathrm{HCl}(12.1 \mathrm{M})$ per gram of zeolite. This was based on a procedural modification from the literature ${ }^{182}$, and the samples were placed in an oil bath for 10,20,30, or $40 \mathrm{~min}$ and, upon removal, allowed to cool for $20 \mathrm{~min}$. The zeolite was quickly filtered off after cooling and washed with water three times at a ratio of $5 \mathrm{~mL}$ per gram of zeolite initially used. The final rinse was clear as 
assessed with $\mathrm{pH}$ paper, and when added to solutions of $\mathrm{AgNO}_{3}$, did not result in a white (i.e., $\mathrm{AgCl}$ ) precipitate. The zeolite was dried overnight in an oven at $70^{\circ} \mathrm{C}$ and then calcined at $550{ }^{\circ} \mathrm{C}$ in a flow of air for $5 \mathrm{~h}$. After cooling, the zeolite was stored in a desiccator to prevent the absorption of water.

\subsubsection{Methods}

\subsubsection{X-ray Diffraction}

X-ray diffraction spectra of the zeolites were collected using a Scintag XDS 2000 Diffractometer (Scintag Inc., Division of Thermo, Dearborn, MI, US) using a copper target to generate X-rays and a graphite monochromator with a scan range of 5-60 $2 \theta$, a step size of $0.020^{\circ}$, a count time of $0.600 \mathrm{~s}$, and a step scan rate of $2.0 \mathrm{deg} / \mathrm{min}$. The samples were packed into an aluminum sample plate of dimensions of $30 \mathrm{~mm}$ wide by $90 \mathrm{~mm}$ long by $8 \mathrm{~mm}$ depth. The data were analyzed using the program DMSNT v 1.37 (1994-1998) Scintag Inc. (Division of Thermo, Dearborn, MI, US). The spectra were background-subtracted using a manual spline curve fit. Sample phase identification was conducted using QualX2 ${ }^{184}$ after the raw data was transformed using PowDLL ${ }^{185}$.

\subsubsection{Surface Area Analysis}

Surface area analysis was performed using an ASAP 2020 machine made by Micrometrics (Norcross, GA, USA). The program used for the analysis was the "5point BET Analysis" program supplied by the manufacturer. Some modifications were required and consisted of adding parameters from the standard micropore analysis program (from the manufacturer) to the 5 Point BET Program. The samples were degassed at $350{ }^{\circ} \mathrm{C}$ at $1 \mathrm{~mm} \mathrm{Hg}$ for $4 \mathrm{~h}$ and backfilled with nitrogen gas. The BET analysis was performed using nitrogen gas, and the micropore analysis was performed using helium gas. Calibration of the machine was checked by running a standard supplied by Micrometrics. 


\subsubsection{Energy Dispersive Specroscopy/X-ray Fluorescence EDS/XRF}

Energy Dispersive Spectroscopy EDS/XRF was performed to obtain an elemental composition of the zeolites using a Xenemetrix EX-6600 EDS machine (Migdal HaEmek, Israel) with a rhodium target to generate the X-rays. Samples were prepared by mixing the zeolite with corn starch at a ratio of $4: 1$ weight zeolite: corn starch. The mixture was added to an aluminum cup with a diameter of $3 \mathrm{~cm}$ and a depth of 0.75 $\mathrm{cm}$. Once packed by hand pressure, the cup was loaded into a hydraulic press and pressure applied for $1 \mathrm{~min}$ up to $700 \mathrm{psi}$; once reached, the sample was held for $1 \mathrm{~min}$ at $700 \mathrm{psi}$, and then for $1 \mathrm{~min}$, the pressure was released.

\subsubsection{NMR Study of Zeolite}

${ }^{27} \mathrm{Al}$ MAS and ${ }^{29} \mathrm{Si}$ MAS NMR analyses of calcined NV-Na and 30 min HCl NV-Na were performed at ambient temperature on a Varian Infinity-Plus NMR spectrometer equipped with a $6 \mathrm{~mm}$ MAS broadband probe operating at $79.41 \mathrm{MHz}$ for ${ }^{29} \mathrm{Si}, 104.2$ $\mathrm{MHz}$ for ${ }^{27} \mathrm{Al}$, and $399.75 \mathrm{MHz}$ for $1 \mathrm{H}$. Samples were spun at the magic angle at 4 kHz. A standard one-pulse was used for all experiments. The 29Si pulse width was 4 $\mu \mathrm{s}$, the pulse delay was $120 \mathrm{~s}$, the acquisition length was $20.5 \mathrm{~ms}$, and between 650 and 700 scans were collected. Exponential multiplication of $100 \mathrm{~Hz}$ was used before the Fourier transform. Chemical shifts were referenced against an external sample of talc at $-98.1 \mathrm{ppm}$ relative to TMS (tetramethylsilane) at $0 \mathrm{ppm}$. The ${ }^{27} \mathrm{Al}$ pulse width was 1 $\mu \mathrm{s}$, the pulse delay was $0.2 \mathrm{~s}$, the acquisition length was $2.1 \mathrm{~ms}$, and between 8000 and 10,000 scans were collected. Exponential multiplication of $100 \mathrm{~Hz}$ was used prior to the Fourier transform. Chemical shifts were referenced against an external sample of $1 \mathrm{M} \mathrm{Al}\left(\mathrm{NO}_{3}\right)_{3}$ at $0.0 \mathrm{ppm}$.

\subsubsection{Scanning Electron Microscopy}

SEMs were performed on uncoated samples (loaded onto double-sided carbon tape followed by air removal of unstuck material) using a Hitachi S4700 scanning electron microscope at a voltage of $15-20 \mathrm{kV}$ and $10-20 \mu \mathrm{A}$. 


\subsubsection{ATR-FTIR}

ATR-FTIR spectroscopy was performed on pure material using calcined and modified pulverized samples on a PerkinElmer Spectrum one with a Perkin Elmer universal ATR sampling attachment.

\subsubsection{Lead Removal Studies}

An analysis of the amount of lead absorbed or adsorbed by the zeolite was performed using a Buck Scientific Model 200 A atomic absorption spectrometer. A Fisher hollow cathode tube for lead analysis was used at an operating current of $10 \mathrm{~mA}$. The detector was set to a wavelength of $283.3 \mathrm{~nm}$ with a slit width of $0.7 \mathrm{~nm}$. A $335 \mathrm{mg} / \mathrm{L}$ concentrated lead nitrate solution was made using water with a $\mathrm{pH}$ of 4.5 , which was adjusted using $\mathrm{HNO}_{3}$ acid. A total of $0.250 \mathrm{~g}$ of previously dried zeolite was added to $150 \mathrm{~mL}$ of the $335 \mathrm{ppm}$ lead nitrate solution and stirred for 5 days at room temperature as detailed previously ${ }^{186}$. After 5 days, the solution was centrifuged, the sample was diluted, and analysis was performed on the AAS. 


\subsubsection{Flow Chart of Techniques}

The techniques utilized in this paper are illustrated in Scheme 1.

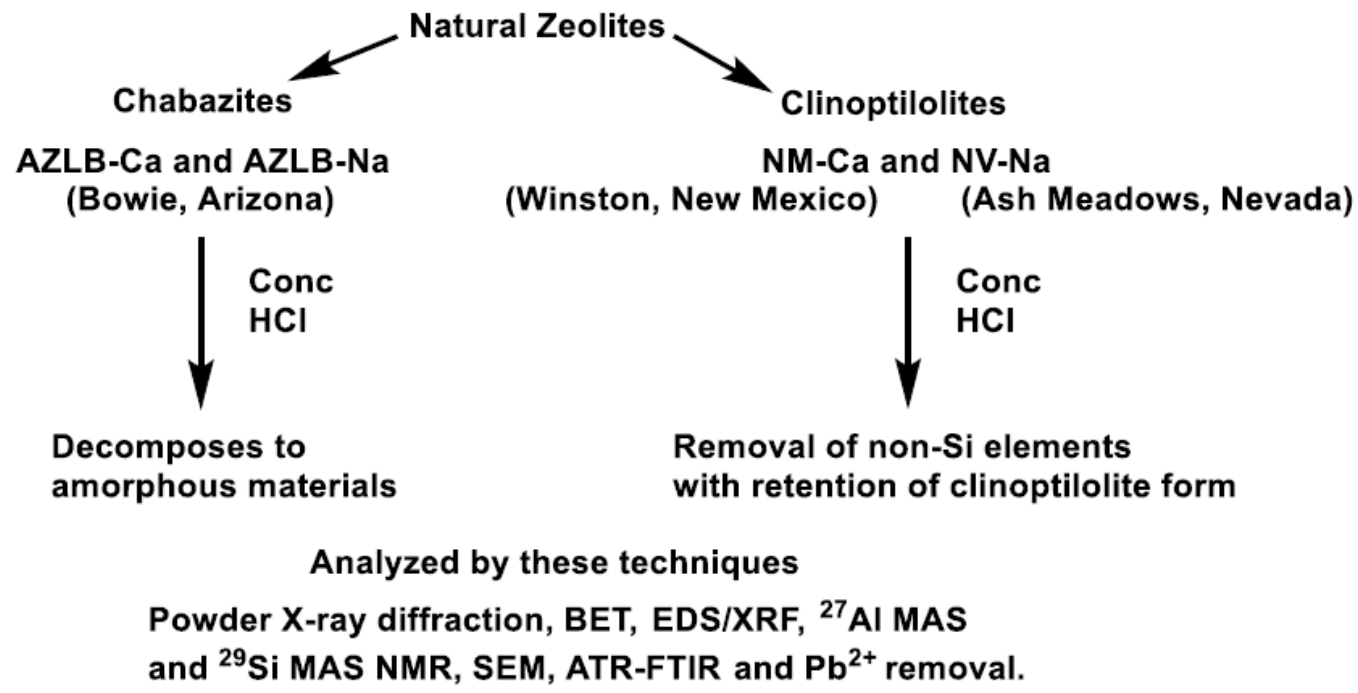

Scheme 5.1 Flow chart summarizing results and listing utilized analytical techniques.

\subsection{Results and Discussion}

\subsubsection{X-ray Diffraction}

Initial Phase Assignment The spectra obtained for AZLB-Ca, Figure 5.1, and AZLB$\mathrm{Na}$, Figure 5.2, suggests the presence of chabazite if one compares the patterns to that obtained from simulations ${ }^{187}$ of single-crystal X-ray data ${ }^{165}$. In particular, present were intense reflections for Miller indices ( $\left(\begin{array}{lll}0 & 0\end{array}\right)$ and (3 11 ) at $2 \theta$ of 9.40 and $30.40^{\circ}$, respectively, which are ascribed to chabazite ${ }^{187}$. These suggest that the samples were dominantly chabazite; however, differing ratios of erionite and AlPO4-D were also evident in the samples ${ }^{187}, 188$. Interestingly, no phases indicative of clinoptilolite, heulandite, or alpha quartz were observed in either sample AZLB-Ca or AZLB-Na, Figures 5.1 and 5.2, respectively. The X-ray powder spectra for the clinoptilolite samples, NV-Na Figure 5.3 and NM-Ca Figure 5.4, also contained large differences. 
Evidence for clinoptilolites is in the presence of reflections at 9.88, 11.19, and $22.49^{\circ}$ in $2 \theta$ ascribable to the (0 20 ), (2 00 ), and (3 30 ) Miller indices respectively ${ }^{187,189,190 .}$ In the case of the calcined NV-Na sample (Figure 5.3a), signals for these peaks are quite intense, and the sample appears to be quite pure. There was a match for clinoptilolite-Na (card [00-900-1391]) at an FoM of 0.75 determined using QualX2 (Figure 5.3b). Raw data from the diffractometer were converted with PowDLL ${ }^{185}$ for use with the QualX2 ${ }^{184}$ program. In the case of NM-Ca (Figure 5.4), the most intense peak is located at about a $2 \theta$ of $26.6^{\circ}$, and the program QualX2 could not find a match to clinoptilolite. This is probably because this calcined NM-Ca sample is mostly alpha quartz, which has its most intense reflection at a $2 \theta$ of $26.65^{\circ}$ due to the $\left(\begin{array}{lll}1 & 0 & 1\end{array}\right)$ Miller phase $^{191}$. There is some evidence of clinoptilolite in the sample judging by small peaks at the $2 \theta$ angles mentioned above, but it is clearly not the dominant constituent. No chabazite or erionite species were observed in either sample NV-Na or NM-Ca.

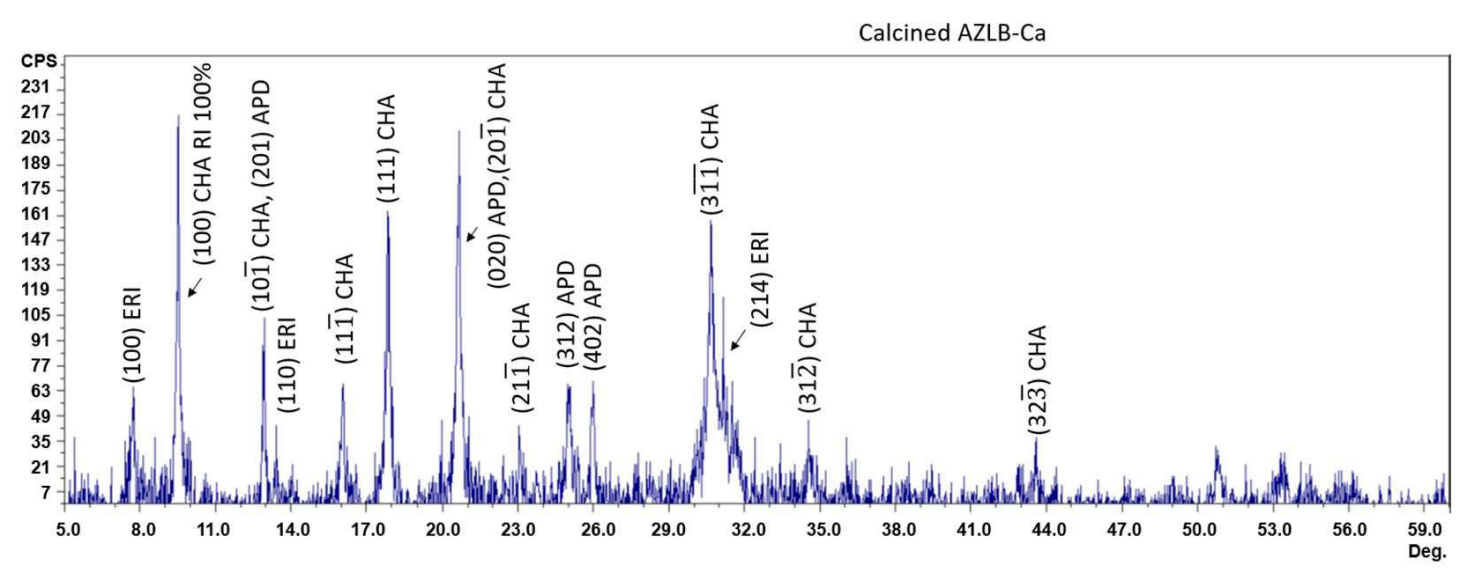

Figure 5.1 The XRD pattern of calcined AZLB-Ca. 


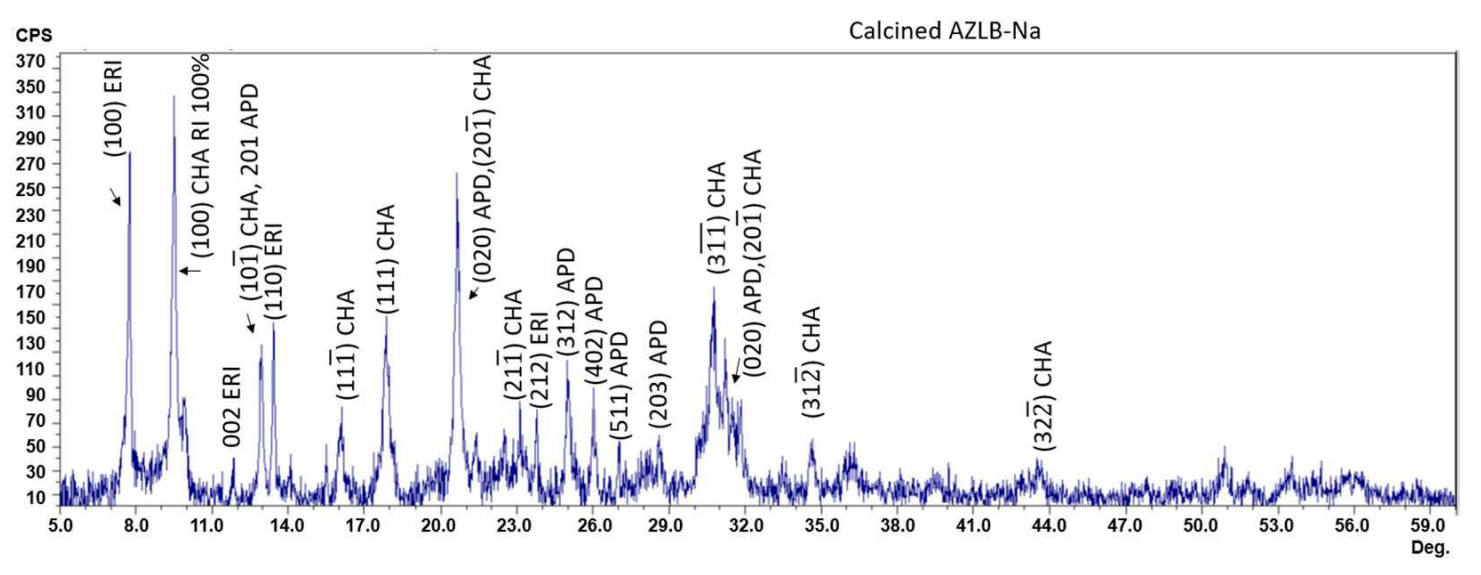

Figure 5.2 The XRD pattern of calcined AZLB-Na.

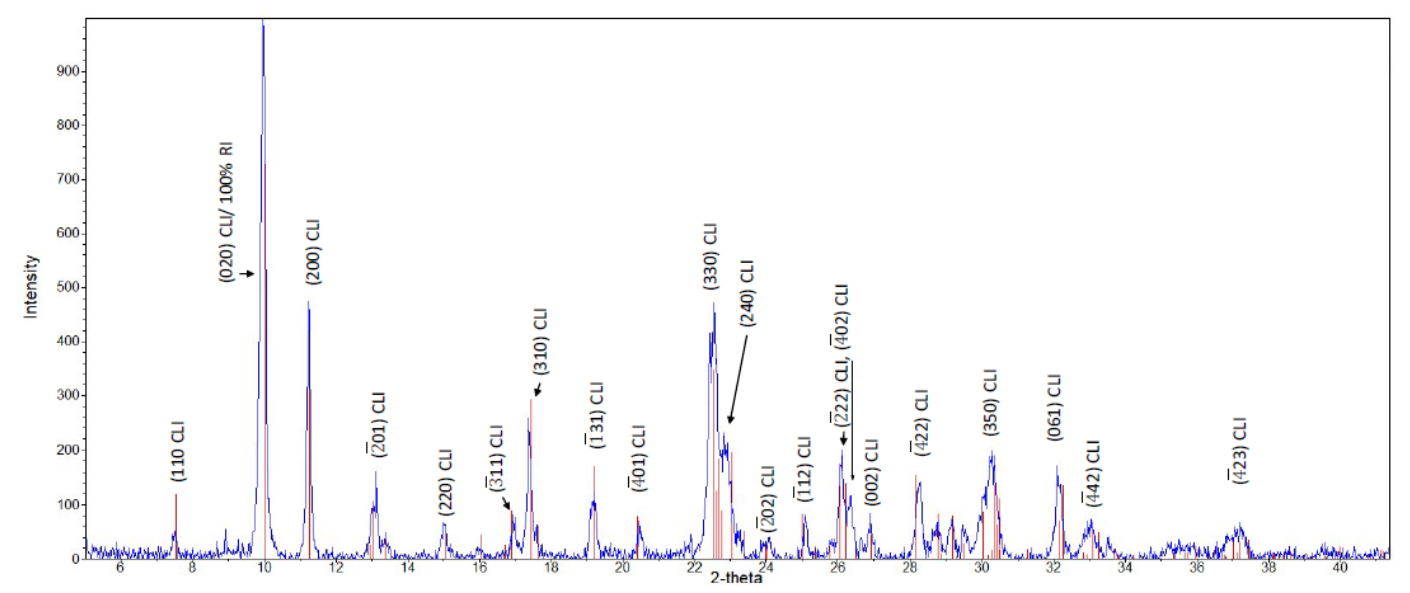

Figure 5.3 (A, above) The XRD pattern of calcined NV-Na. (B, below) An expanded drawing of the XRD pattern for calcined NV-Na illustrated using QualX2 ${ }^{184}$. Solid vertical lines represent card [00-900-1391] clinoptilolite-Na at an FoM of 0.75. Raw data converted with PowDLL ${ }^{185}$. 


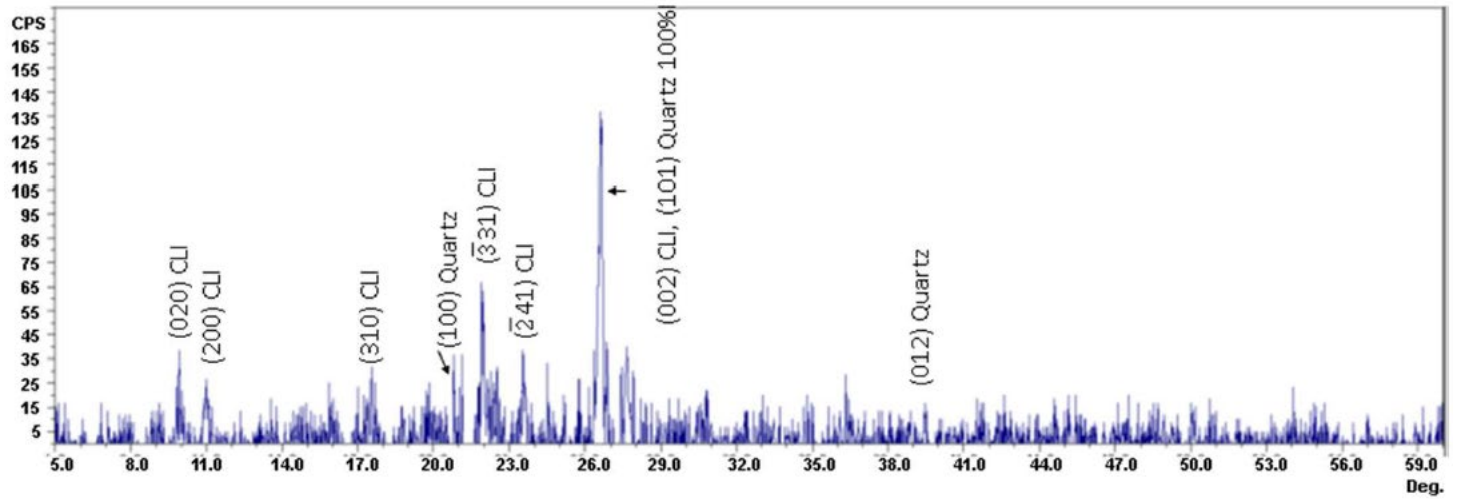

Figure 5.4 The XRD pattern of calcined NM-Ca. The AZLB-Na and AZLB-Ca zeolites lost all crystallinity when boiled in $\mathrm{HCl}$ acid for $30 \mathrm{~min}$, which is demonstrated by the loss of all sharp reflections and the spectra appearing as broad bumps (Figures 5.5 and 5.6) as a result of random scattering due to an amorphous material. In contrast, the NV-Na and NM-Ca zeolites did not lose all crystallinity during the boiling process in $\mathrm{HCl}$ acid (Figures 5.7 and 5.8, respectively). This is conclusive evidence of the instability of these chabazites subjected to $\mathrm{HCl}$ modification and the inherent stability of the clinoptilolites as evident in the $30 \mathrm{~min} \mathrm{HCl}$ NV-Na, Figure 5.7, card [00-9001393] clinoptilolite-Na at an FoM of 0.66, and $30 \mathrm{~min} \mathrm{HCl} \mathrm{NM-Ca,} \mathrm{Figure} \mathrm{5.8,} \mathrm{card}$ [00-901-4410] boggsite ${ }^{192}$ of formula $\mathrm{Ca}_{3.4} \mathrm{O}_{70.76} \mathrm{Si}_{24}$ at an FoM of 0.77 , both determined using QualX2 ${ }^{184}$. In particular, NM-Ca registered the least change possible because it is mostly composed of alpha quartz, Figure 5.8.

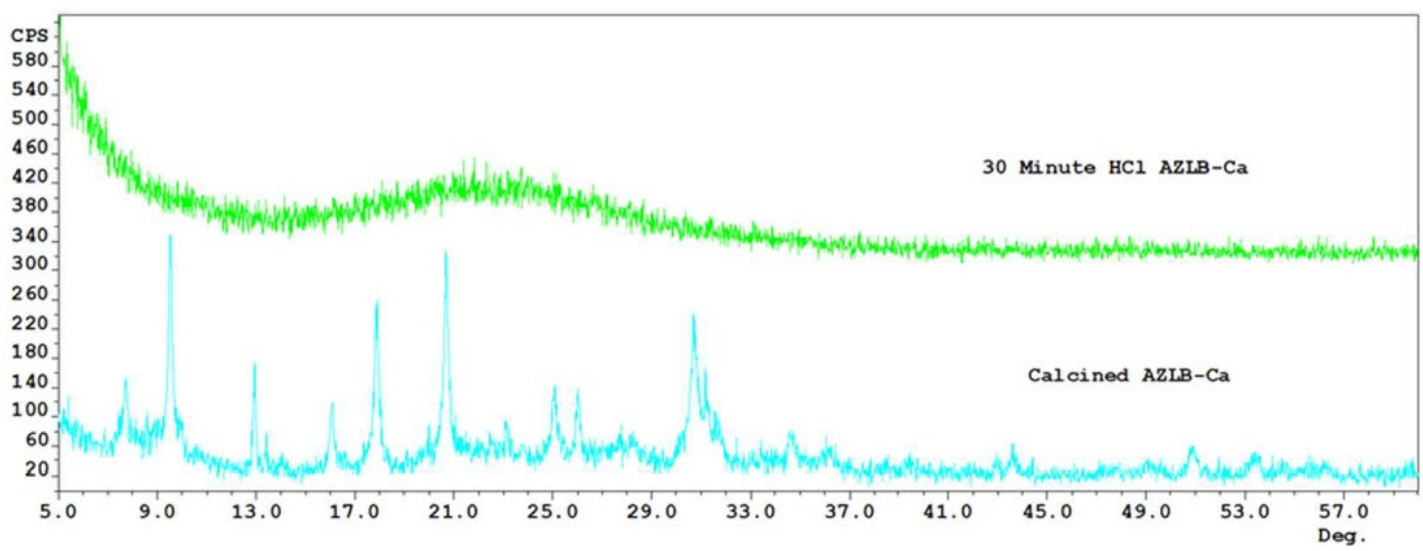

Figure 5.5 The XRD patterns of calcined AZLB-Ca and 30 min HCl AZLB-Ca. 


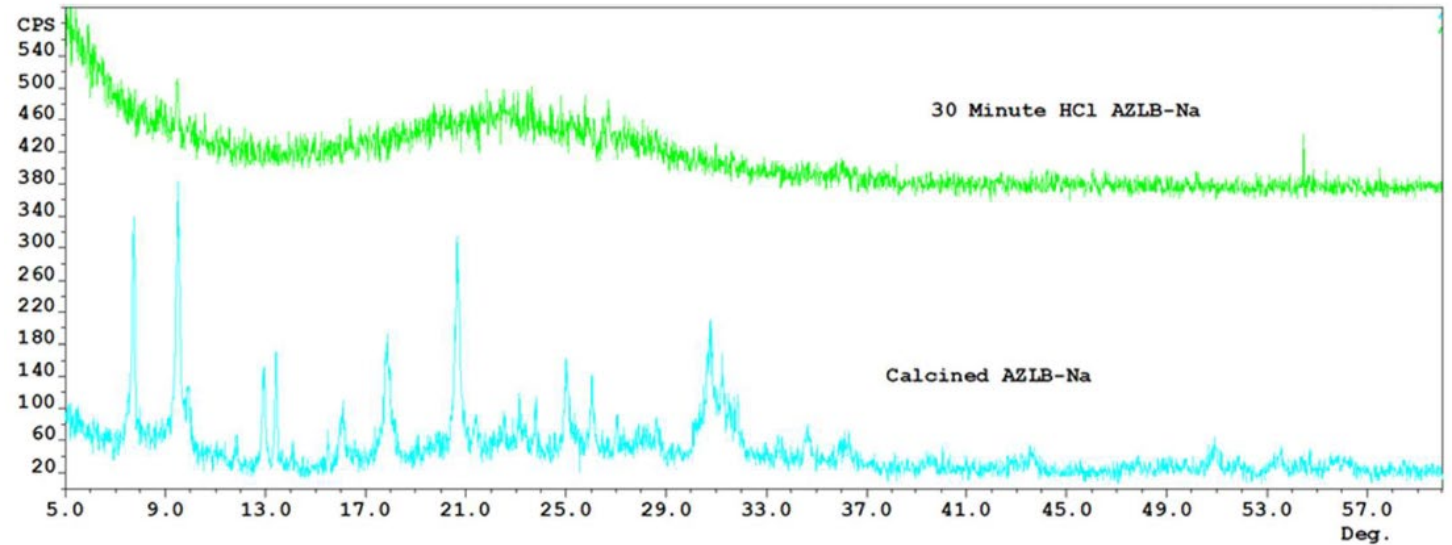

Figure 5.6 The XRD patterns of calcined AZLB-Na and 30 min HCl AZLB-Na.

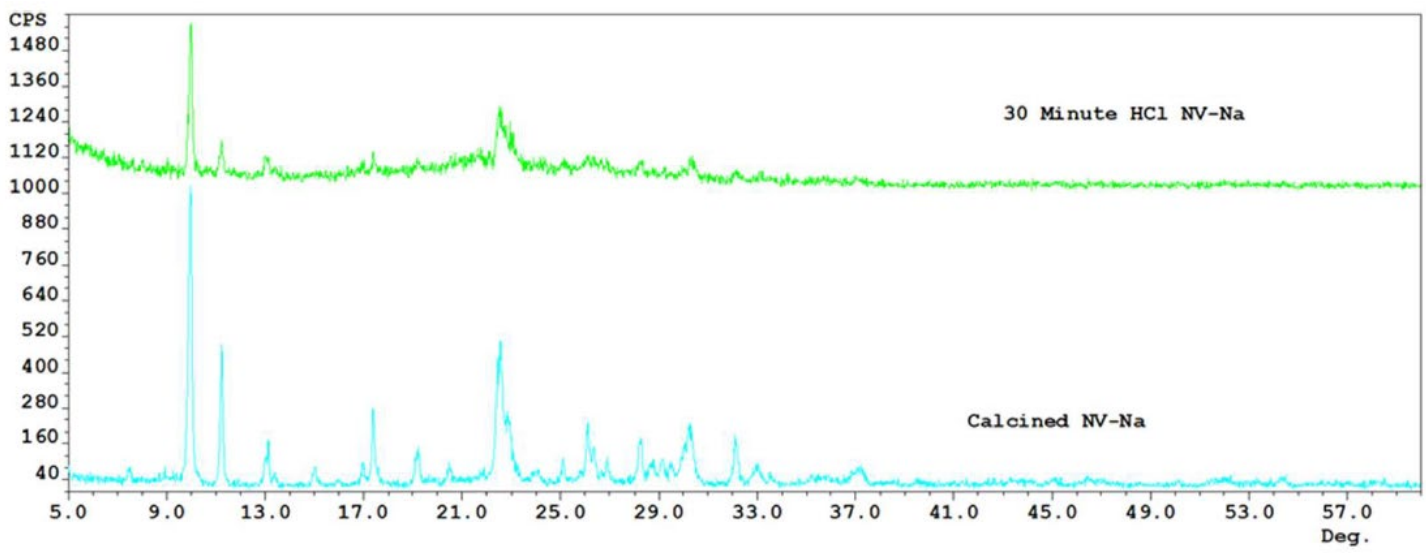

Figure 5.7 The XRD patterns of calcined NV-Na and the 30 min $\mathrm{HCl} \mathrm{NV-Na.}$ 


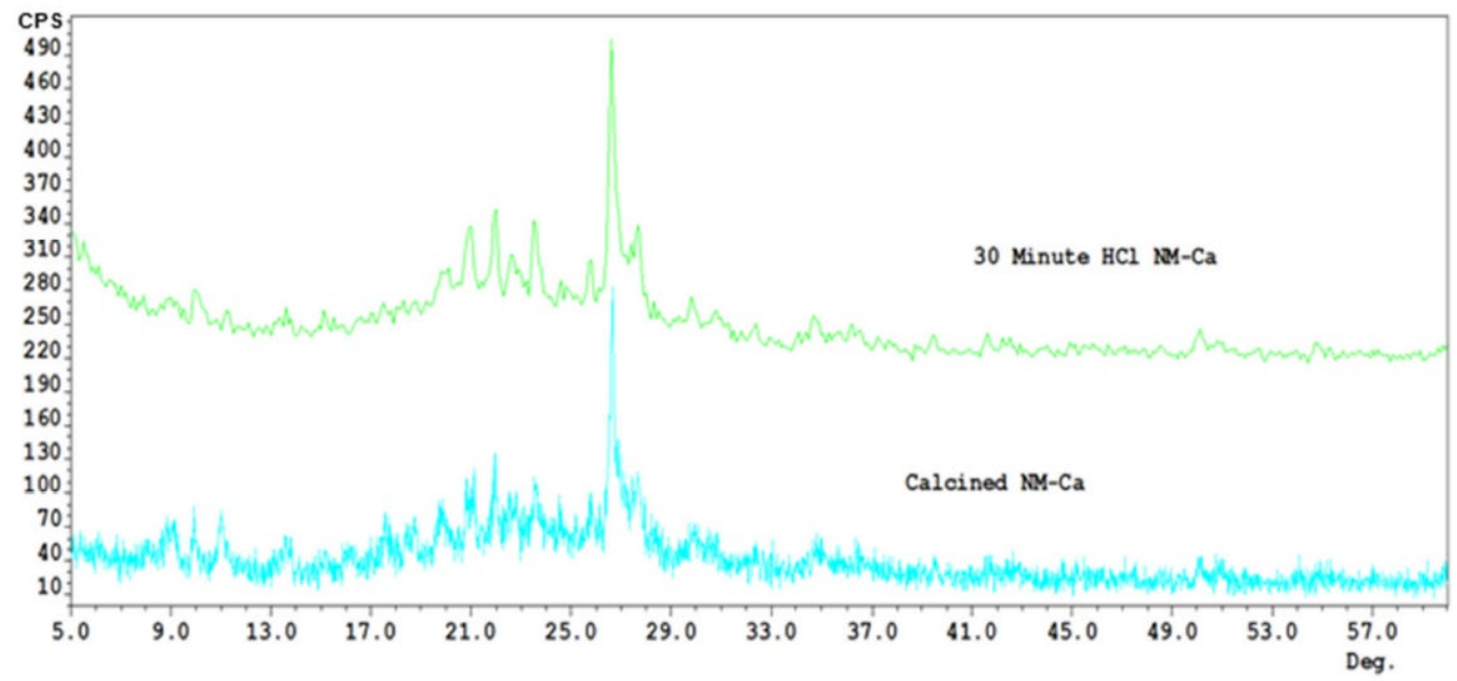

Figure 5.8 The XRD patterns of calcined NM-Ca and 30 min HCl NM-Ca.

\subsubsection{Surface Area Analysis}

Based on the fact that the chabazite samples lost crystallinity upon treatment with conc. $\mathrm{HCl}$, only surface area analyses on the clinoptilolite samples were conducted. Thus $\mathrm{NM}-\mathrm{Ca}$ and NV-Na were both subjected to boiling concentrated $\mathrm{HCl}$ acid for a varying amount of time from 10 to $40 \mathrm{~min}$, as listed with the surface area analysis results (Table 5.1). This indicated that 30 min etching of the zeolite produced the highest surface area, with 40 min etching resulting in a decrease in the surface area, which is likely due to the acid collapsing some of the crystalline structures. Therefore, in this case, the optimum time for boiling the clinoptilolite zeolite in $\mathrm{HCl}$ acid is $30 \mathrm{~min}$. In the case of NV-Na, the surface area increased from 19 to $158 \mathrm{~m}^{2} / \mathrm{g}$, and the pore volume increased from 0.04 to $0.12 \mathrm{~cm}^{3} / \mathrm{g}$. The NM-Ca increased in surface area from 20 to $111 \mathrm{~m}^{2} / \mathrm{g}$, and the pore volume increased from 0.04 to $0.10 \mathrm{~cm}^{3} / \mathrm{g}$. The values for the micropore, mesopore, and external surface areas provide valuable insight into what is happening during the etching process, Tables 5.1 and 5.2. There is a dramatic increase in micropore area of the $\mathrm{HCl}$ acid-etched zeolites, 4.800 to $94.99 \mathrm{~m}^{2} / \mathrm{g}$ for calcined NV-Na to $30 \mathrm{~min} \mathrm{HCl} \mathrm{NV}-\mathrm{Na}$, and 2.730 to $55.15 \mathrm{~m}^{2} / \mathrm{g}$ for calcined NM-Ca to $30 \mathrm{~min}$ HCL NM-Ca, suggesting that either new micropores are forming and/or the 
existing micropores are being deepened, increasing their surface area. In the case of the calcined NM-Ca sample versus the $10 \mathrm{~min} \mathrm{HCl}$ NM-Ca sample, Table 5.2, the $10 \mathrm{~min}$ $\mathrm{HCl}$ NM-Ca sample has a smaller average micropore diameter going from 4.584 to $4.388 \AA$, and this likely represents new micropores being formed, thus lowering the average value for the micropore diameter. The $30 \mathrm{~min} \mathrm{HCl}$ NM-Ca sample seems to reach a maximum average micropore diameter of $4.597 \AA$ before declining in the 40 min $\mathrm{HCl}$ NM-Ca sample to $4.588 \AA$, which is probably due to the crystallinity of the zeolite collapsing based on the loss of surface area of the sample, see Table 5.1. In contrast, $\mathrm{NV}-\mathrm{Na}$ appears less stable to $\mathrm{HCl}$ treatment, and the average micropore diameter increases from 4.586 to $4.600 \AA$ for calcined NV-Na to $30 \mathrm{~min} \mathrm{HCl} \mathrm{NV}-\mathrm{Na}$, respectively. In the case of mesopores, calcined NV-Na has a value of $91.00 \AA$, which decreases to $31.06 \AA$ in the $10 \mathrm{~min} \mathrm{HCl} \mathrm{NV}-\mathrm{Na}$ sample. This is attributable to the formation of new mesopores, thus lowering the average diameter of mesopores. The same trend is observed with the calcined NM-Ca sample, which has an initial average mesopore diameter of $93.71 \AA$ (calcined NM-Ca), and changes to $40.31 \AA(10 \mathrm{~min} \mathrm{HCl}$ NM-Ca sample). In the case of the NM-Ca zeolite, the average mesopore diameter continues to become lower with longer treatment in $\mathrm{HCl}$ acid. However, the $\mathrm{NV}-\mathrm{Na}$ zeolite reaches equilibrium around a $32 \AA$ average mesopore diameter (Table 5.2).

Table 5.1 The surface area analysis measurements for calcined and $\mathrm{HCl}$ etched zeolites.

\begin{tabular}{|c|c|c|c|c|c|}
\hline Sample & 5 Point BET Surface & Pore Volume & Micropore Volume & Micropore & External Surface \\
\hline & Area $\left(\mathrm{m}^{2} / \mathrm{g}\right)$ & $\left(\mathrm{cm}^{3} / \mathrm{g}\right)$ & $\left(\mathrm{cm}^{3} / \mathrm{g}\right)$ & Area $\left(\mathrm{m}^{2} / \mathrm{g}\right)$ & Area $\left(\mathrm{m}^{2} / \mathrm{g}\right)$ \\
\hline NV-Na calcined & $19.0(4)$ & 0.04 & 0.002 & 4.8 & 14.23 \\
\hline $20 \mathrm{~min} \mathrm{HCl} N \mathrm{NV}-\mathrm{Na}$ & 141(6) & 0.11 & 0.043 & 81.43 & 59.87 \\
\hline $30 \mathrm{~min} \mathrm{HCl} \mathrm{NV}-\mathrm{Na}$ & $158(7)$ & 0.12 & 0.051 & 94.99 & 63.15 \\
\hline $40 \mathrm{~min} \mathrm{HCl} \mathrm{NV}-\mathrm{Na}$ & $138(6)$ & 0.11 & 0.041 & 75.06 & 63.49 \\
\hline NM-Ca calcined & $20.0(1)$ & 0.04 & 0.001 & 2.73 & 17.27 \\
\hline $30 \mathrm{~min} \mathrm{HCl} \mathrm{NM}-\mathrm{Ca}$ & $111(4)$ & 0.1 & 0.029 & 55.15 & 56.22 \\
\hline $40 \mathrm{~min} \mathrm{HCl} \mathrm{NM}-\mathrm{Ca}$ & 101(4) & 0.08 & 0.028 & 53.53 & 48.28 \\
\hline
\end{tabular}


Table 5.2 The average mesopore and micropore diameter.

\begin{tabular}{ccc}
\hline Sample & Average Micropore & Average Mesopore \\
\hline NV-Na calcined & Diameter $(\AA)$ & Diameter $(\AA)$ \\
10 min HCl NV-Na & 4.586 & 91.00 \\
20 min HCl NV-Na & 4.597 & 31.06 \\
30 min HCl NV-Na & 4.591 & 32.44 \\
40 min HCl NV-Na & 4.600 & 31.72 \\
NM-Ca calcined & 4.598 & 32.95 \\
10 min HCl NM-Ca & 4.584 & 93.71 \\
20 min HCl NM-Ca & 4.388 & 40.31 \\
30 min HCl NM-Ca & 4.584 & 39.62 \\
40 min HCl NM-Ca & 4.597 & 36.36 \\
\hline
\end{tabular}

\subsubsection{X-ray Fluorescence/EDS}

The NM-Ca zeolite has a much greater mole percentage concentration of $\mathrm{Ca}(6.31 \%)$ compared to that for NV-Na (1.14\%) while containing less $\mathrm{Na}$ ( 0.10 to 0.25 , respectively), clearly justifying the label, Table 5.3. There is also more Fe in NM-Ca compared to NV-Na (2.67 to $0.79 \%$, respectively) and correspondingly less $\mathrm{Si}$ (76.26 to $84.36 \%$, respectively). The X-ray fluorescence data results in Table 5.3 show, by way of the reduction in molar percentage concentrations, that etching the zeolites in concentrated $\mathrm{HCl}$ acid effectively removes sodium, calcium, potassium, magnesium, iron, and aluminum, while the silicon concentration increases proportionally. Table 5.4 lists the weight percentage data supplied by the manufacturer ${ }^{175}$ and that obtained by converting the molar percentages in Table 5.3 to weight percentages. This requires the assumption that only the ions listed in Table 5.3 were present and are also present in the zeolite in the oxide form indicated in the table. Additionally, XRF is not good at determining very low concentrations. However, there are large differences in the weight percentages between our determinations and those determined by the manufacturer. This may well be due to natural variation in the samples used in the studies. Our determinations of the concentrations of $\mathrm{Al}_{2} \mathrm{O}_{3}$ would appear to be much lower, whereas those for $\mathrm{SiO}_{2}$ are higher compared to those listed by the manufacturer. 
However, this does correlate with the X-ray powder diffraction pattern where quartz was found in NM-Ca, Figure 5.8. On this basis, NV-Na is composed mostly of $\mathrm{K}_{2} \mathrm{O}$, $\mathrm{Al}_{2} \mathrm{O}_{3}$, and $\mathrm{SiO}_{2}$, in contrast to NM-Ca, where $\mathrm{CaO}, \mathrm{K}_{2} \mathrm{O}, \mathrm{Fe}_{2} \mathrm{O}_{3}, \mathrm{Al}_{2} \mathrm{O}_{3}$, and $\mathrm{SiO}_{2}$ are the major contributors. This calculation allows for a stoichiometric formula for $\mathrm{NV}-\mathrm{Na}$ of $\left[\mathrm{Na}_{2} \mathrm{O}\right]_{0.01}[\mathrm{CaO}]_{0.11}\left[\mathrm{~K}_{2} \mathrm{O}\right]_{0.27}[\mathrm{MgO}]_{0.02}\left[\mathrm{Fe}_{2} \mathrm{O}_{3}\right]_{0.11}\left[\mathrm{P}_{2} \mathrm{O}_{5}\right]_{0.05}\left[\mathrm{Al}_{2} \mathrm{O}_{3}\right]_{0.80}\left[\mathrm{SiO}_{2}\right]_{8.63}$ and NM-Ca of $[\mathrm{CaO}]_{0.60}\left[\mathrm{~K}_{2} \mathrm{O}\right]_{0.34}[\mathrm{MgO}]_{0.04}\left[\mathrm{Fe}_{2} \mathrm{O}_{3}\right]_{0.36}\left[\mathrm{Al}_{2} \mathrm{O}_{3}\right]_{0.83}\left[\mathrm{SiO}_{2}\right]_{7.79}$.

Table 5.3 The XRF data for zeolites in mole $\%$.

\begin{tabular}{|c|c|c|c|c|c|c|c|c|c|}
\hline $\begin{array}{l}\text { Experimental } \\
\text { Run }\end{array}$ & $\mathrm{Na}$ & $\mathrm{Ca}$ & K & $\mathrm{Mg}$ & $\mathrm{Fe}$ & $\mathrm{Al}$ & $\mathrm{Si}$ & $\mathrm{P}$ & $\begin{array}{c}\text { Si: } \\
\mathrm{Al}_{2} \text { Ratio }\end{array}$ \\
\hline $\mathrm{NV}-\mathrm{Na}$ & $0.25 \pm 0.08$ & $1.14 \pm 0.04$ & $3.34 \pm 0.08$ & $0.30 \pm 0.08$ & $0.79 \pm 0.01$ & $9.27 \pm 0.24$ & $84.36 \pm 0.70$ & $0.442 \pm 0.08$ & 4.55 \\
\hline $\begin{array}{l}30 \mathrm{~min} \\
\mathrm{NV}-\mathrm{Na}\end{array}$ & $0.02 \pm 0.04$ & $0.05 \pm 0.01$ & $0.30 \pm 0.02$ & $0.16 \pm 0.04$ & $0.04 \pm 0.002$ & $4.16 \pm 0.11$ & $95.04 \pm 0.49$ & $0.17 \pm 0.03$ & 11.42 \\
\hline NM-Ca & $0.10 \pm 0.04$ & $6.31 \pm 0.11$ & $4.29 \pm 0.10$ & $0.52 \pm 0.05$ & $2.67 \pm 0.04$ & $9.51 \pm 0.17$ & $76.26 \pm 0.46$ & $0.27 \pm 0.04$ & 4.01 \\
\hline $\begin{array}{l}30 \mathrm{~min} \\
\mathrm{NM}-\mathrm{Ca}\end{array}$ & $0.04 \pm 0.04$ & $0.42 \pm 0.04$ & $2.54 \pm 0.08$ & $0.17 \pm 0.05$ & $0.07 \pm 0.002$ & $4.71 \pm 0.13$ & $91.83 \pm 0.56$ & $0.17 \pm 0.04$ & 9.75 \\
\hline
\end{tabular}

Table 5.4 The weight percentages from our calculated data and that of the manufacturer.

\begin{tabular}{|c|c|c|c|c|c|c|}
\hline \multirow[b]{2}{*}{ Experimental } & \multicolumn{4}{|c|}{$\mathrm{NV}-\mathrm{Na}$} & \multicolumn{2}{|c|}{ NM-Ca } \\
\hline & Mole \% & Formula & Calculated & Manufacturer & Calculated & Manufacturer \\
\hline Run & & & $\mathrm{Wt} \%$ & $\mathrm{Wt} \%{ }^{\mathrm{a}}$ & $\mathrm{Wt} \%$ & $\mathbf{W t} \%^{a}$ \\
\hline $\mathrm{Na}$ & 0.10 & $\mathrm{Na}_{2} \mathrm{O}$ & 0.13 & 3.5 & 0.05 & 0.3 \\
\hline $\mathrm{Ca}$ & 6.31 & $\mathrm{CaO}$ & 1.09 & 0.8 & 6.02 & 3.4 \\
\hline K & 4.29 & $\mathrm{~K}_{2} \mathrm{O}$ & 2.68 & 3.8 & 3.44 & 3.2 \\
\hline $\mathrm{Mg}$ & 0.52 & $\mathrm{MgO}$ & 0.21 & 0.4 & 0.36 & 1.4 \\
\hline $\mathrm{Fe}$ & 2.67 & $\mathrm{Fe}_{2} \mathrm{O}_{3}$ & 1.07 & 0.7 & 3.63 & 1.6 \\
\hline $\mathrm{Al}$ & 9.51 & $\mathrm{Al}_{2} \mathrm{O}_{3}$ & 8.04 & 11.9 & 8.25 & 11.9 \\
\hline $\mathrm{Si}$ & 76.26 & $\mathrm{SiO}_{2}$ & 86.25 & 69.1 & 77.94 & 64.9 \\
\hline \multirow[t]{3}{*}{$\mathrm{P}$} & 0.27 & $\mathrm{P}_{2} \mathrm{O}_{5}$ & 0.53 & & 0.33 & $>0.05$ \\
\hline & & $\mathrm{MnO}$ & & 0.02 & & \\
\hline & & $\mathrm{TiO}_{2}$ & & 0.1 & & \\
\hline Total & & & 100 & 90.32 & 100 & 86.7 \\
\hline
\end{tabular}

${ }^{\text {a }}$ Reference ${ }^{175}$

\subsection{4 $\quad{ }^{27}$ Al NMR}

Aluminum NMR is very sensitive to the geometry with 6-coordinate species resonating around 4-11 ppm and 4-coordinate downfield in the range 55-66 ppm depending on the nature of the aluminosilicate species ${ }^{193}$. Only one signal at $55 \mathrm{ppm}$ belonging to 
tetrahedral aluminum species was evident in the ${ }^{27} \mathrm{Al}$ spectrum of a clinoptilolite found in $\mathrm{Cuba}^{194}$. As is evident in Figure 5.9, which displays the ${ }^{27} \mathrm{Al}$ NMR of the calcined $\mathrm{NV}$-Na sample, the $\mathrm{Al}$ in that sample is composed mainly of 4-coordinate $\mathrm{Al}$ species, as the spectrum consists mainly of a single large resonance at $54.49 \mathrm{ppm}$. A much smaller quantity is in the octahedral conformation that corresponds to the peak at 2.60 ppm. Applying a framework equation ${ }^{193}$, which equates the position of the $27 \mathrm{Al}$ isotropic chemical shift to the angles on the $\mathrm{Al}$ (i.e., $\delta \mathrm{Al}=132-(0.5 \cdot \angle \mathrm{Al}-\mathrm{O}-\mathrm{Si})$ ), would suggest a mean $\angle \mathrm{Al}-\mathrm{O}-\mathrm{Si}$ of $155^{\circ}$. However, this derivation is not valid for zeolites with a high percentage of $\mathrm{Si}$, as other factors also pertain ${ }^{195}$. Subjecting the zeolite to $\mathrm{HCl}$ resulted in changes in the ${ }^{27} \mathrm{Al}$ NMR spectrum, as evident in Figure 5.10. The peak for the 4-coordinate species in calcined NV-Na shifts from 54.99 to a broad peak with peaks at 53.96 and $59.64 \mathrm{ppm}$ for the $30 \mathrm{~min} \mathrm{HCl} \mathrm{NV-Na.} \mathrm{Additionally,}$ there is a slight shift in the octahedral resonance from 2.60 to $2.03 \mathrm{ppm}$. This indicates that the ratio of tetrahedral to octahedral aluminum has changed; however, it is unknown whether this is due to conversion or the dissolution of one of the forms following $\mathrm{HCl}$ treatment ${ }^{176}$. 


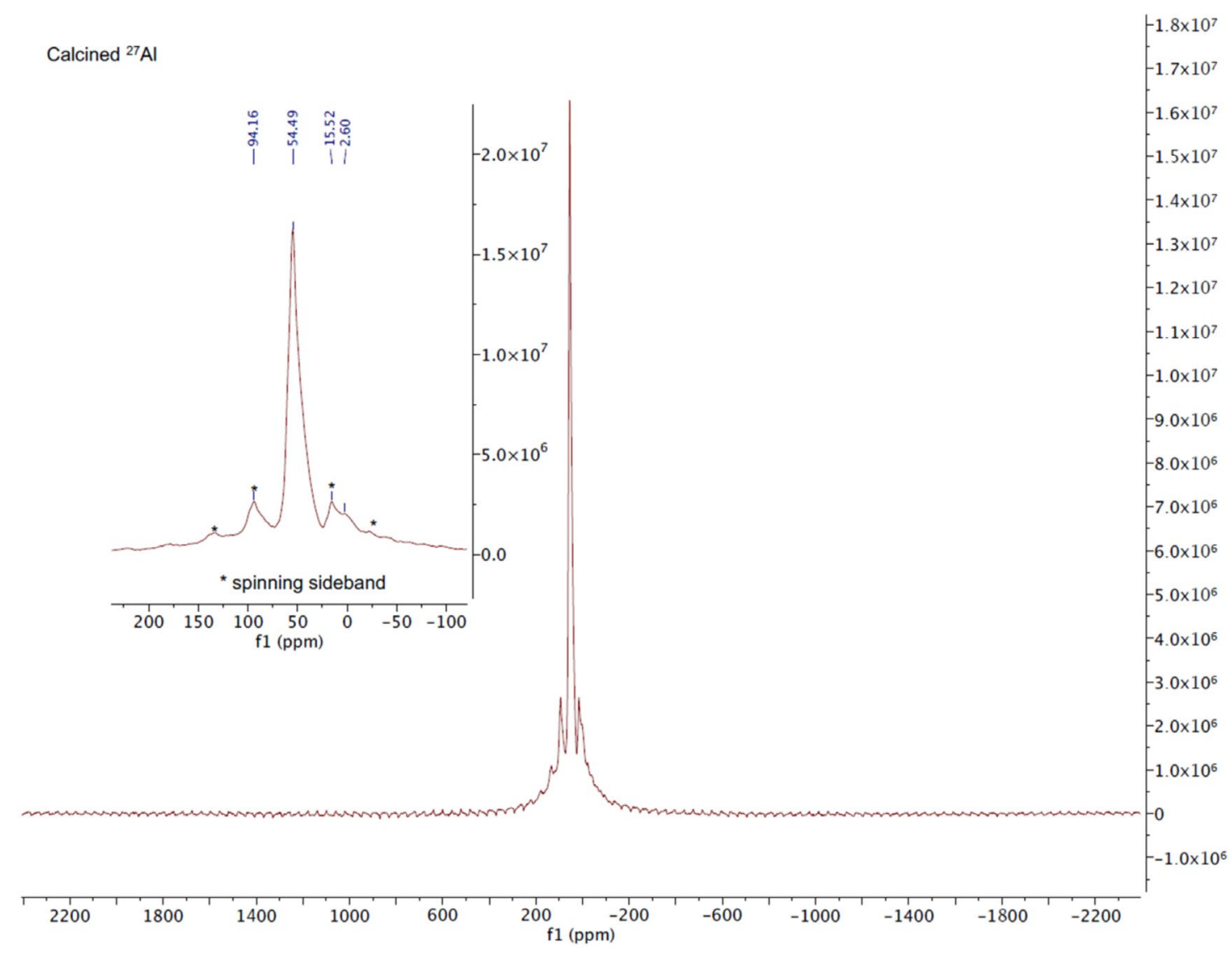

Figure 5.9 The ${ }^{27} \mathrm{Al} \mathrm{NMR}$ of calcined $\mathrm{NV}-\mathrm{Na}$ externally referenced to $1 \mathrm{M} \mathrm{Al}\left(\mathrm{NO}_{3}\right)_{3}$ at $0.0 \mathrm{ppm}$. 


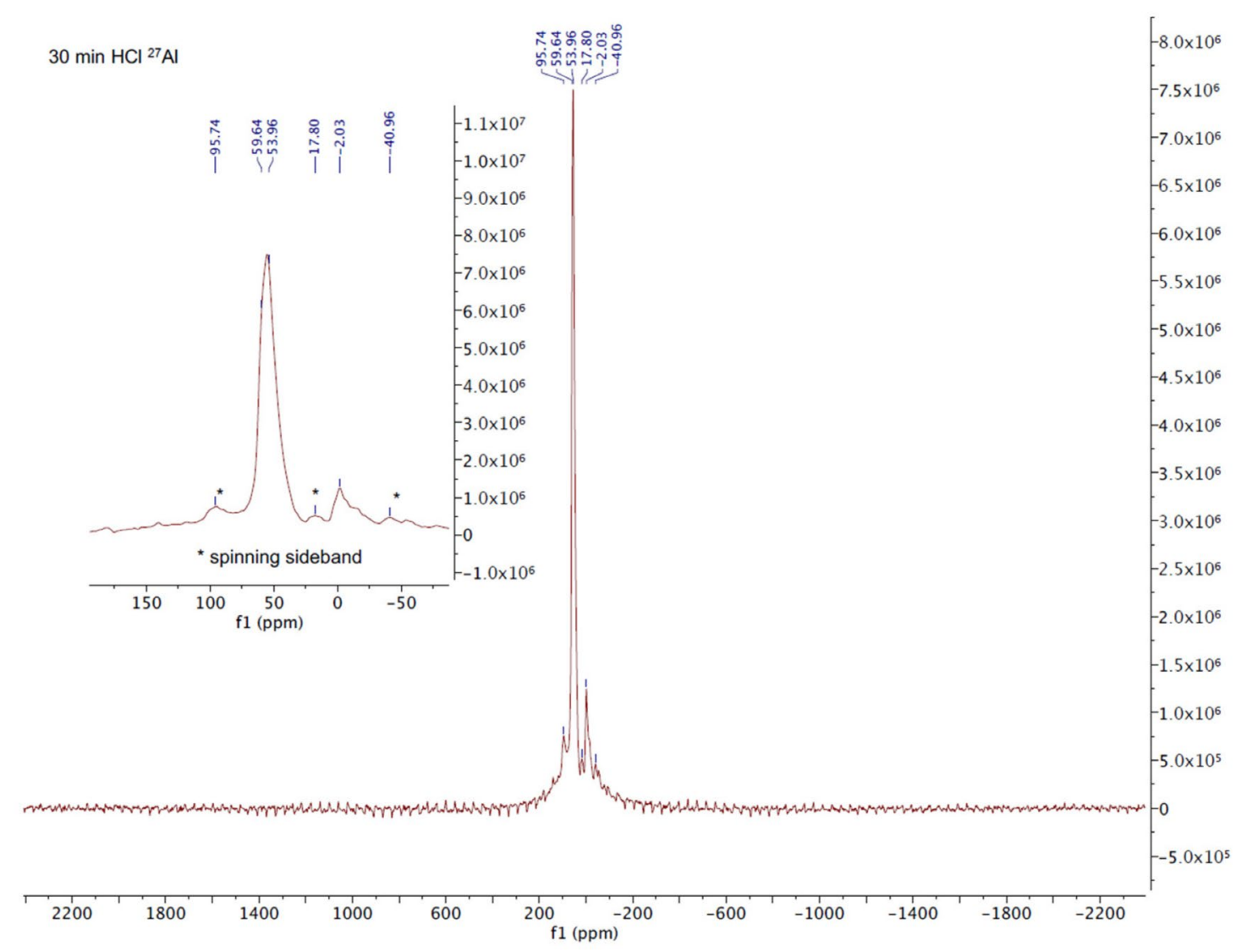

Figure 5.10 The ${ }^{27} \mathrm{Al} \mathrm{NMR}$ of $30 \mathrm{~min} \mathrm{HCl} \mathrm{NV}-\mathrm{Na}$ externally referenced to $1 \mathrm{M}$ $\mathrm{Al}\left(\mathrm{NO}_{3}\right)_{3}$ at $0.0 \mathrm{ppm}$.

\subsection{5 ${ }^{29}$ Si MAS NMR}

\subsubsection{Calcined $\mathrm{NV}-\mathrm{Na}$}

The ${ }^{29} \mathrm{Si}$ NMR spectrum of clinoptilolite has been reported to consist of peaks at $112.8,-106.9$, and $-100.6 \mathrm{ppm}$, with the peak at $-106.9 \mathrm{ppm}$ having the highest intensity ${ }^{196}$. The spectrum for calcined NV-Na contains many signals, as listed in Figure 6.11 , but the one with the most area occurs at $-106.02 \mathrm{ppm}(27.12 \%)$. Peaks at $-112.14(13.46 \%)$ and $-100.1(23.43 \%)$ ppm are also obtained, and these are probably from the clinoptilolite regions within calcined NV-Na. Peaks at -95.99 (19.56\%), $-101.11(2.48 \%)$, and $-108.58(13.90 \%)$ ppm are also evident in the deconvoluted 
analysis, Figure 5.10. The peak at $-95.99 \mathrm{ppm}$ may be either due to $\mathrm{SiOH}$ and $\mathrm{Si}(\mathrm{OH}) 2$ groups, as Si resonances for these groups lie in this range ${ }^{196}$, or related to the presence of $\mathrm{Fe}^{3+}$ complexes rather than $\mathrm{Al}^{3+194}$. Studies on a natural clinoptilolite from Cuba reported peaks and area percentages of $-94.90(5.7 \%),-97.8(2.3 \%),-100.90(34 \%)$, $-106.90(45.3 \%)$, and $-112.70(13.7 \%)^{194}$. These peaks are very close in position and area to that ascribed to a heulandite zeolite that has the following peaks and areas, 93.44 (4.25\%), -98.44 (31.26\%), $-104.63(56.11 \%)$, and $-111.41(8.37 \%)^{197}$. However, in our NV-Na sample, the peaks at $-101.11(2.48 \%)$ and $-108.58(13.90 \%)$ are probably due to impurities, with the one at $-108.58 \mathrm{ppm}$ possibly due to regions of pure $\left(\mathrm{SiO}_{2}\right) \mathrm{n}^{198}$. The $\mathrm{Si}$ : Al ratio was calculated from the ${ }^{29} \mathrm{Si}$ MAS NMR data using Equation (1) ${ }^{196}$.

$$
\frac{S i}{A l}=\frac{\sum_{0}^{4} I_{S i(n A l)}}{\sum_{0}^{4} 0.25 * n I_{S i(n A l)}}
$$

In this equation, $\mathrm{n}$ represents the number of aluminum atoms connected to silicon through an oxygen bridge, and a value of 4.34 for the $\mathrm{Si}$ : Al ratio pertains to justify a mostly clinoptilolite designation. 


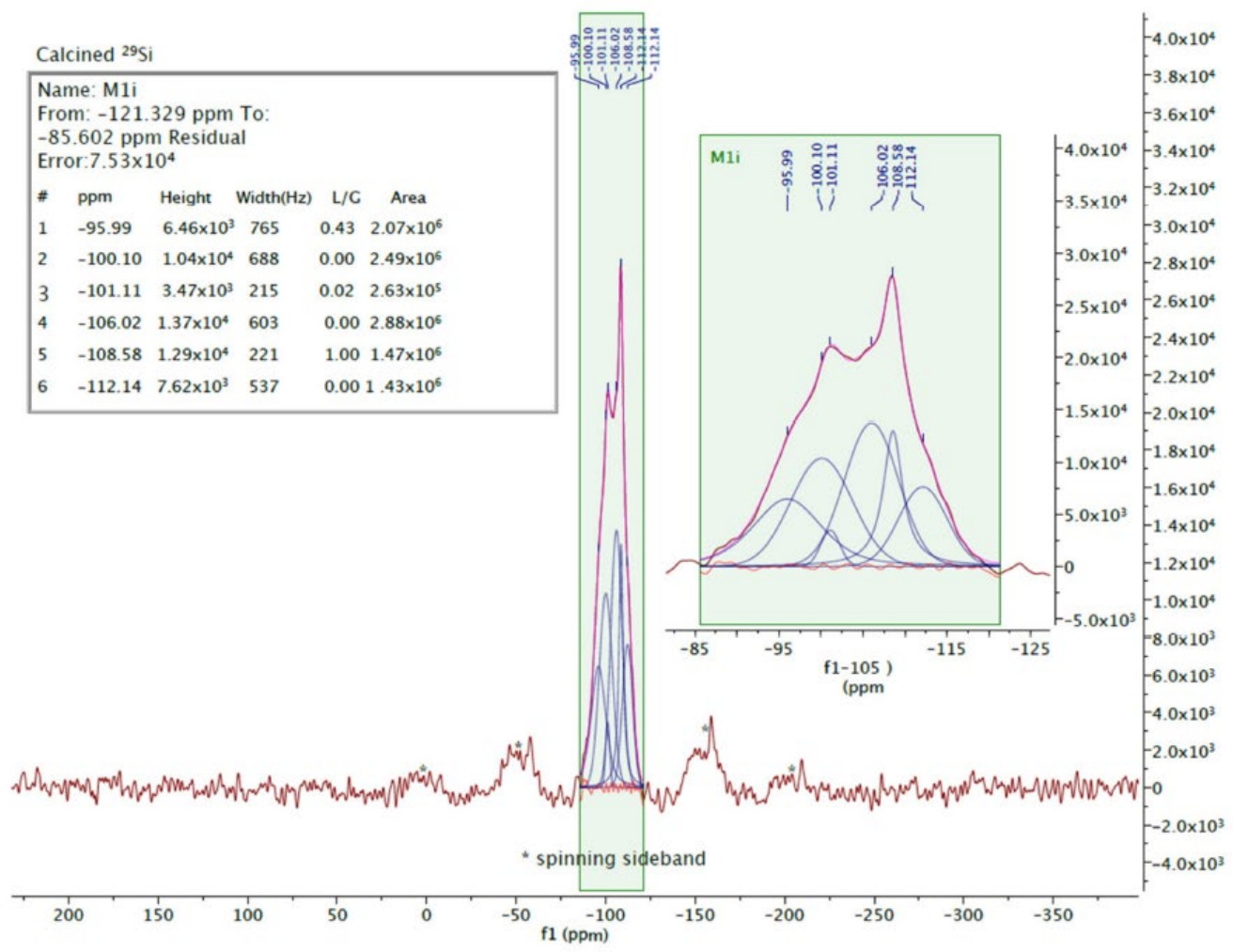

Figure 5.11 The ${ }^{29} \mathrm{Si}$ NMR spectrum of calcined NV-Na referenced externally to a sample of talc at $-98.1 \mathrm{ppm}$ relative to tetramethylsilane (TMS) at $0 \mathrm{ppm}$. The shaded inset depicts the obtained resonances on top and the deconvoluted components of the fit below.

\subsubsection{2 $30 \mathrm{~min} \mathrm{HCl} \mathrm{NV-Na}$}

There are dramatic changes to the ${ }^{29} \mathrm{Si}$ NMR spectrum of the $30 \mathrm{~min} \mathrm{HCl} \mathrm{NV}-\mathrm{Na}$, Figure 5.12, compared to NV-Na, Figure 5.11. A peak (ppm) and area percentage profile of $-91.13(1.83 \%),-94.01$ (1.97\%), -97.51 (9.25\%), -102.81 (22.40\%), $-108.37(39.36 \%)$ and $-112.33(25.19 \%)$ is obtained. The intense clinoptilolite peak at -106.02 present in NV-Na is no longer present, and an increase in the peak at -108.37 , which was ascribed above to $\left(\mathrm{SiO}_{2}\right)$ n entities, is observed. The peaks at -91.13 and $-94.01 \mathrm{ppm}$ may be due to $\mathrm{SiOH}$ and $\mathrm{Si}(\mathrm{OH})_{2}$ groups, and the peaks at -97.51 and $-102.81 \mathrm{ppm}$ correspond to silicon being connected to either one or two aluminum 
atoms via oxygen atom bridges ${ }^{196}$. As the nature of this modified zeolite is not known precisely, the $\mathrm{Si}$ : Al ratio cannot be assessed.

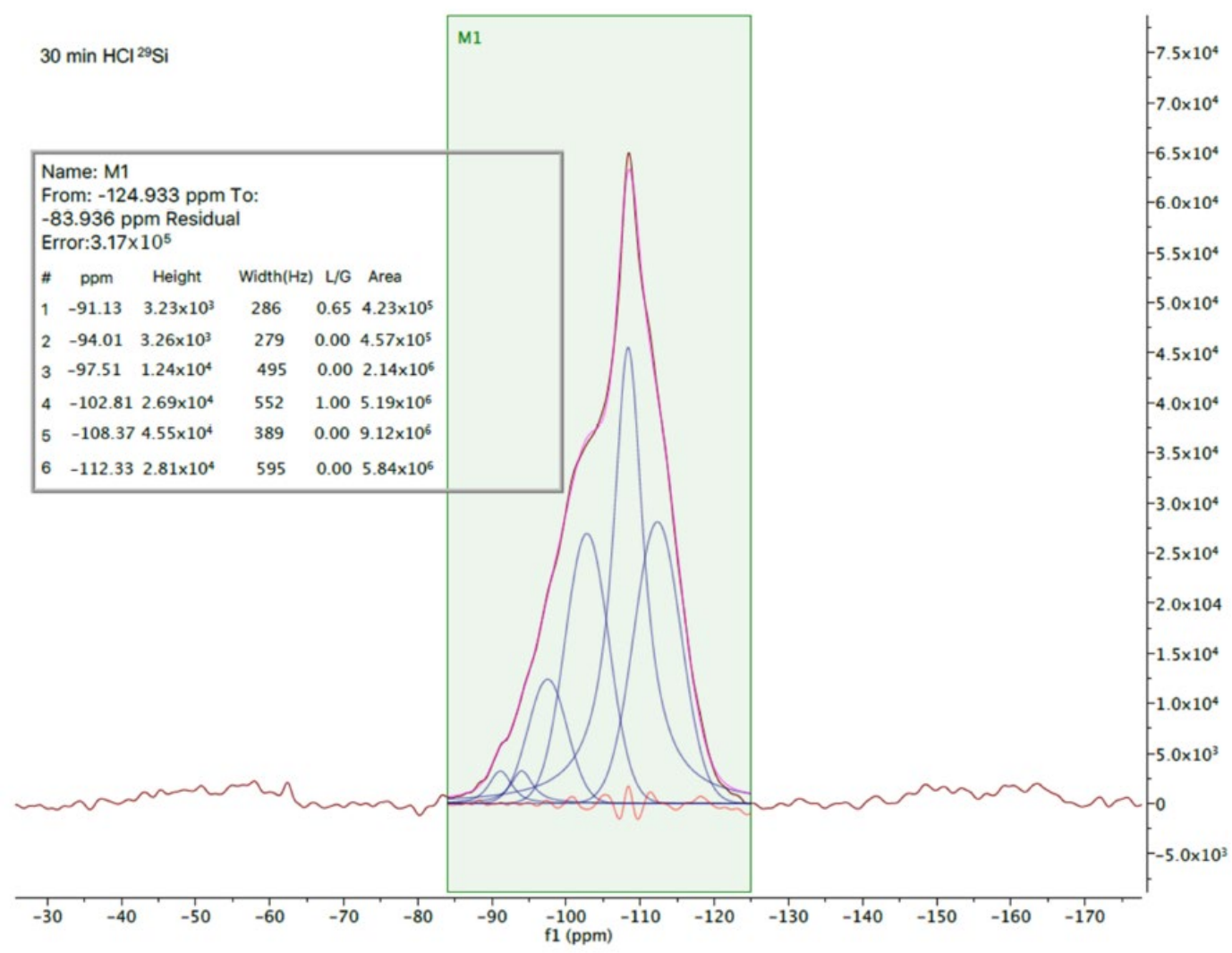

Figure 5.12 The ${ }^{29} \mathrm{Si}$ NMR spectrum of $30 \mathrm{~min} \mathrm{HCl}$ NV-Na referenced externally to a sample of talc at $-98.1 \mathrm{ppm}$ relative to TMS at $0 \mathrm{ppm}$. The resonances on top are from the sample, and the deconvoluted components of the fit are below.

\subsubsection{SEM}

Scanning electron micrographs of calcined NV-Na and 30 min $\mathrm{HCl} \mathrm{NV-Na} \mathrm{were}$ obtained as presented in Figure 5.13. The overall morphology of calcined NV-Na looks smoother than those published at an equal magnification (i.e., $10 \mu \mathrm{m}$ ) and somewhat larger, approx. $20 \mu \mathrm{m}$ compared to $5 \mu \mathrm{m}^{199}$. $\mathrm{HCl}$ treatment results in a much less "smooth" surface comparing the images in Figure 5.13b for calcined NV-Na and (e) for 30 min HCL NV-Na, and there appear to be many more voids, which correlates 
positively with the increase in surface area measurements from the BET calculations. The $5 \mu \mathrm{m}$ images for the samples consist of smooth surfaces, albeit with smaller particle sizes for the $30 \mathrm{~min} \mathrm{HCl} \mathrm{NV-Na.}$
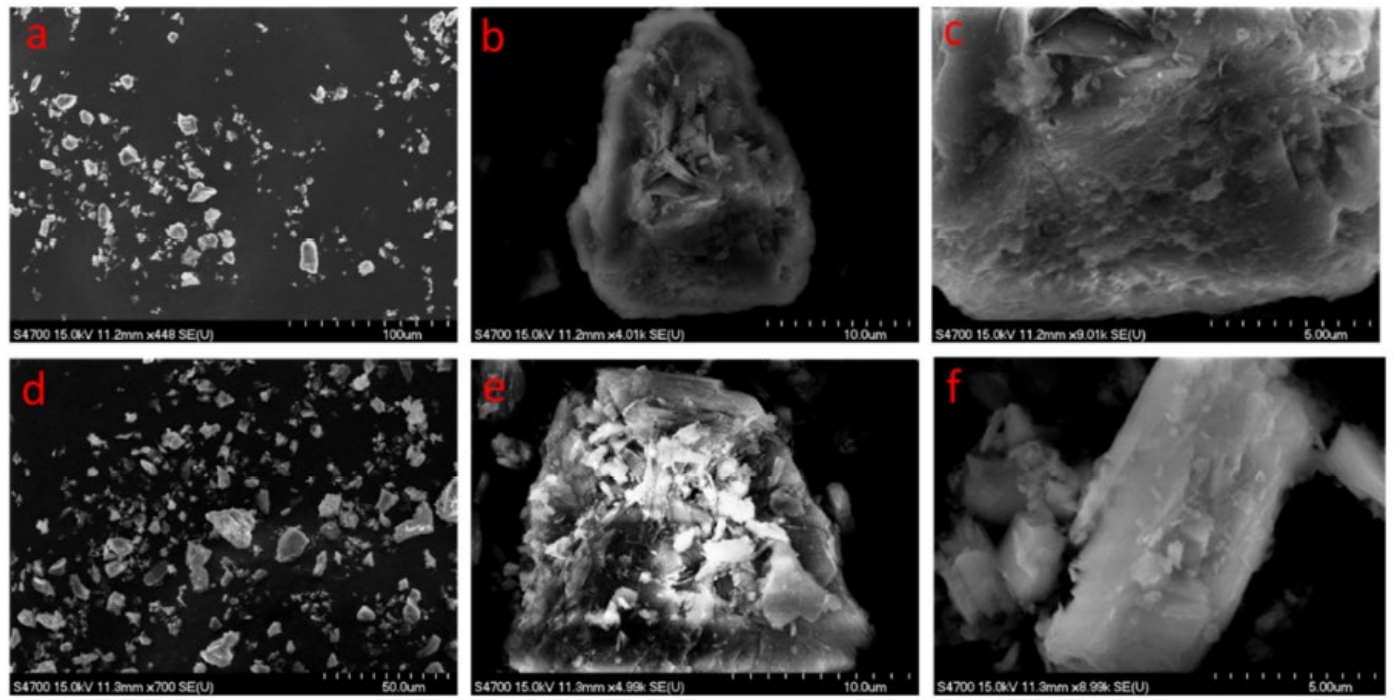

Figure 5.13 The SEM images of calcined NV-Na at a $100 \mu \mathrm{m}$ scale (a), a $10 \mu \mathrm{m}$ scale (b), and a $5 \mu \mathrm{m}$ scale (c), and that of $30 \mathrm{~min} \mathrm{HCl} \mathrm{NV-Na}$ at a $50 \mu \mathrm{m}$ scale (d), a $10 \mu \mathrm{m}$ scale (e), and a $5 \mu \mathrm{m}$ scale (f).

\subsubsection{ATR-FTIR}

The ATR-FTIR spectra for the calcined and HCl-modified clinoptilolites are displayed in Figure 5.14. All contain a small absorption around $1650 \mathrm{~cm}^{-1}$, which has been ascribed to a deformation vibration of residual water bound up inside of the zeolite ${ }^{200}$. The very large broad absorption is due to stretches of the Si-O or Al-O bonds of a tetrahedral nature in the zeolite. It is noteworthy that the center of this absorption shifts from 1024 to $1071 \mathrm{~cm}^{-1}$ for the calcined NV-Na to $30 \mathrm{~min} \mathrm{HCl} \mathrm{NV-Na.} \mathrm{Quartz} \mathrm{is}$ known to have a large absorption around $1088 \mathrm{~cm}^{-1201}$, and the fact that this peak for the $30 \mathrm{~min} \mathrm{HCl} \mathrm{NV-Na} \mathrm{occurs} \mathrm{at} 1071 \mathrm{~cm}^{-1}$ would suggest that most of the non-Si elements were removed in the $\mathrm{HCl}$ treatment, leaving behind essentially porous quartz. The peaks around $795 \mathrm{~cm}^{-1}$ are due to the symmetric stretch of Si-O or Al-O bonds of 
a tetrahedral nature of the zeolite ${ }^{202}$. Finally, the peak that appears in calcined NV-Na at $672 \mathrm{~cm}^{-1}$ is indicative of an octahedral species, most likely aluminum or iron ${ }^{200}$.

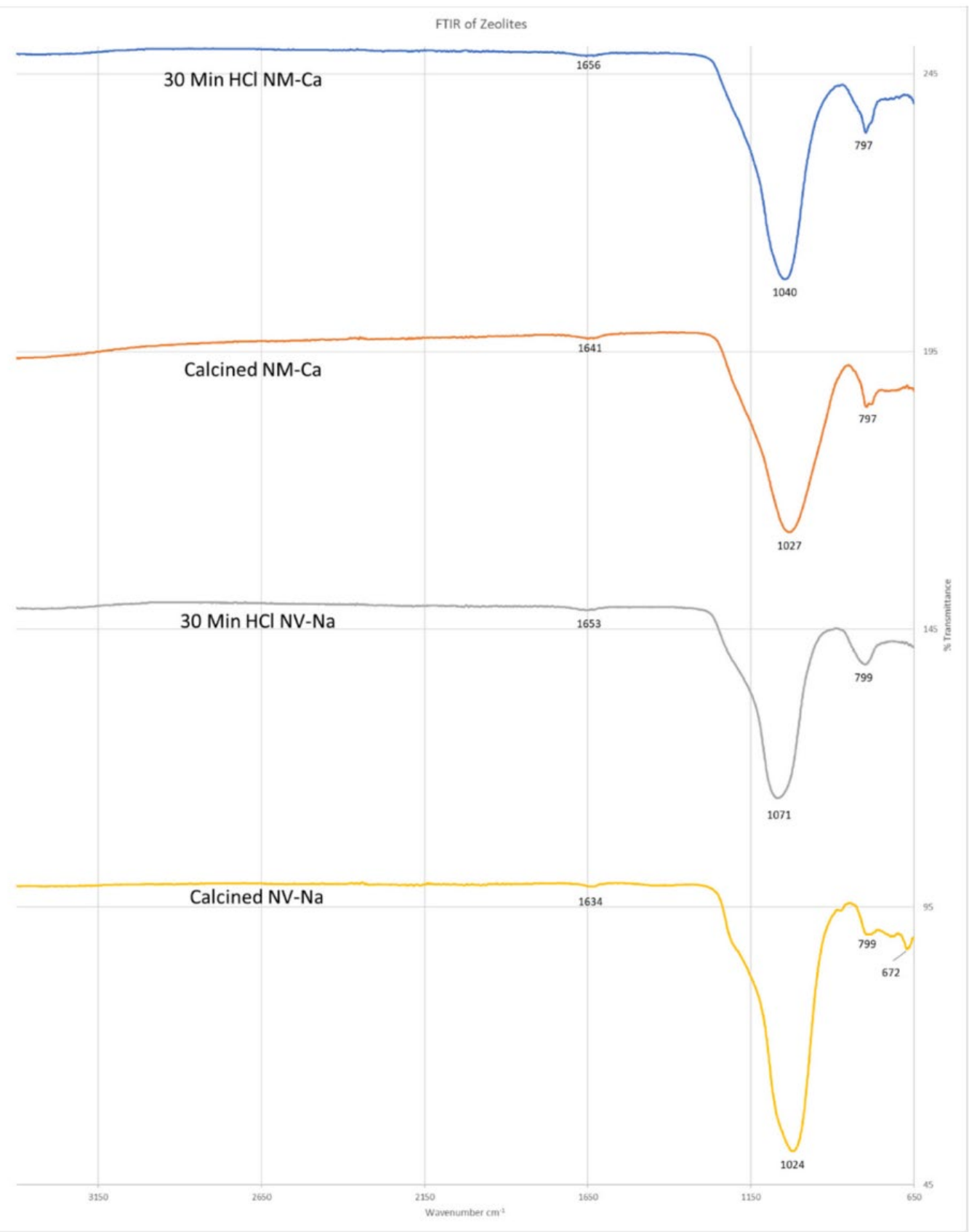

Figure 5.14 The ATR-FTIR spectra of Calcined NV-Na, 30 min HCl NV-Na, Calcined NM-Ca, and 30 min $\mathrm{HCl}$ NM-Ca. 


\subsubsection{Lead Removal Study}

It was of interest to compare the lead absorption and/or adsorption capacities between the calcined material and the $30 \mathrm{~min} \mathrm{HCl}$ modified clinoptilolites, which had more micropores and a larger surface area. First, AZLB-Na and AZLB-Ca removed 2.05(27) and 2.00(11) meq $/ \mathrm{g}$ of $\mathrm{Pb}^{2+}$, and this was slightly more than the removal with the clinoptilolites, as evident in Table 5.5. This difference, i.e., better removal with chabazites than clinoptilolites, was previously noted ${ }^{181}$. Two other natural clinoptilolites report an ion exchange of $0.730 \mathrm{meq} / \mathrm{g} \mathrm{Pb}^{2+203}$ and $0.433 \mathrm{meq} / \mathrm{g} \mathrm{Pb}^{2+204}$. $\mathrm{NV}-\mathrm{Na}$ calcined is significantly better at the ion exchange of $\mathrm{Pb}^{2+}$ than these natural clinoptilolites at 1.50(17) meq/g, Table 5.5. NM-Ca, $30 \mathrm{~min} \mathrm{HCl} \mathrm{NV-Na,} \mathrm{and} 30 \mathrm{~min}$ $\mathrm{HCl} \mathrm{NM-Ca} \mathrm{are} \mathrm{not} \mathrm{as} \mathrm{efficient} \mathrm{for} \mathrm{ion} \mathrm{exchange} \mathrm{of} \mathrm{Pb}^{2+}$ with values of $0.27(14)$, $0.41(23)$, and $0.06(9) \mathrm{meq} / \mathrm{g}$, respectively, Table 5.5 . The results of this lead removal study prove that treating the zeolite in $\mathrm{HCl}$ acid decreases the ability of the zeolite to remove lead ions from the solution. Theoretically, if the removal of lead was based on ion exchange, the $\mathrm{Pb}^{2+}$ ion would likely exchange with $\mathrm{K}^{+}$due to the radius of $\mathrm{Pb}^{2+}$ being $133 \mathrm{pm}$ versus $\mathrm{K}^{+}$having a radius of $137 \mathrm{pm}^{205}$. However, if lead ions are exchanged solely with $\mathrm{K}^{+}$ions, NM-Ca should have a higher rate of removal than NV$\mathrm{Na}$. The increase in uptake by NV-Na may be attributed to the fact that it contains less quartz than NM-Ca. Thus a more clinoptilolite structure, as was evident in the X-ray powder diffraction spectra, Figures 5.3 and 5.4.

Table 5.5 $\mathrm{The}^{\mathrm{Pb}^{2+}}$ removal by the zeolites at a time of 5 days at $35^{\circ} \mathrm{C}$.

\begin{tabular}{cc}
\hline Sample & Meq/g of $\mathrm{Pb}^{2+}$ (3 Samples) \\
\hline AZLB-Na & $2.05(27)$ \\
AZLB-Ca & $2.00(11)$ \\
NV-Na calcined & $1.50(17)$ \\
NM-Ca calcined & $0.27(14)$ \\
30 min HCl NV-Na & $0.41(23)$ \\
30 min HCl NM-Ca & $0.06(9)$ \\
\hline
\end{tabular}

In order to increase the lead ion uptake, the zeolites (natural and modified NV-Na and NM-Ca) were stirred in a $1 \mathrm{M} \mathrm{KCl}$ solution at $25{ }^{\circ} \mathrm{C}$ for 5 days, Table 5.6. The 
solutions were then filtered and washed with water until the filtrate was clear of chloride ions, which were monitored by tests with silver nitrate solution ${ }^{206}$. After drying and calcining at $550{ }^{\circ} \mathrm{C}$ for $5 \mathrm{~h}$, these treated zeolites were tested similarly for their ability to remove lead ions from polluted water.

Table 5.6 $\mathrm{The}^{\mathrm{Pb}^{2+}}$ removal by the $\mathrm{K}^{+}$charged zeolites at a time of 5 days at $35^{\circ} \mathrm{C}$.

\begin{tabular}{cc}
\hline Sample & Meq/g of $\mathrm{Pb}^{2+}$ (3 Samples) \\
\hline $\mathrm{K}^{+}$charged NV-Na & $0.84(5)$ \\
$\mathrm{K}^{+}$charged NM-Ca & $0.34(3)$ \\
$\mathrm{K}^{+}$charged 30 min HCl NV-Na & $0.22(5)$ \\
$\mathrm{K}^{+}$charged 30 min HCl NM-Ca & $0.07(9)$ \\
\hline
\end{tabular}

The results listed in Table 5.6 show that charging NV-Na with $\mathrm{KCl}$ decreased its ability to remove lead, as there was a significant decrease in the quantities removed, 1.50(17) for $\mathrm{NV}-\mathrm{Na}$ calcined to $0.84(5) \mathrm{meq} / \mathrm{g}$ for the $\mathrm{K}^{+}$charged sample. There were no significant differences with the other zeolites, as this method did not have high enough precision, as is evident in the data in Tables 5.5 and 5.6. However, charging these zeolites with potassium ions by stirring in a potassium chloride solution was ineffective at increasing the zeolite's ability to remove $\mathrm{Pb}^{2+}$ ions from the solution. It is also possible, given the high percentage concentration of Si in the two zeolites, removal of the $\mathrm{Fe}^{3+}$ and $\mathrm{Al}^{3+}$ ions results in a more electrically neutral species, thus reducing the capacity for ion exchange.

\subsection{Conclusions}

The assignment of four natural zeolites, labeled AZLB-Ca, AZLB-Na, NV-Na, and NM-Ca, as containing chabazite and clinoptilolite forms were examined by X-ray powder diffraction. One of these, NM-Ca, turned out to be mostly quartz, namely NMCa. The two chabazites (AZLB-Na and AZLB-Ca) lost structural integrity after boiling in concentrated $\mathrm{HCl}$ acid, as is evident by the amorphous pattern generated in the powder X-ray diffraction patterns. Zeolites NV-Na and NM-Ca, which are clinoptilolites, withstood boiling in concentrated $\mathrm{HCl}$ acid, as can be seen by the 
remaining sharp peaks in their powder X-ray diffraction spectra. Results from X-ray fluorescence measurements confirmed that concentrated $\mathrm{HCl}$ acid was effective at removing aluminum, calcium, magnesium, sodium, potassium, and iron from the framework. These two results suggested that NM-Ca had a higher concentration of quartz impurities than NV-Na. The increase in pore size/or increase in the number of pores by removing atoms from the structure was confirmed via BET surface area analysis with NM-Ca 20.0(1) to $111(4) \mathrm{m}^{2} / \mathrm{g}$ and NV-Na $19.0(4)$ to $158(7) \mathrm{m}^{2} / \mathrm{g} .{ }^{29} \mathrm{Si}$ and ${ }^{27} \mathrm{Al}$ MAS NMR were performed on the natural and treated NV-Na zeolite, and the data for the natural NV-Na zeolite suggested a $\mathrm{Si}$ : Al ratio of 4.33 similar to that determined by X-Ray fluorescence of 4.55. A lead removal study performed to determine whether the increase in pore size/or increase in the number of pores after the acid treatment would result in increased capturing of lead ions found that the acid treatment decreased the ability of the zeolite to remove lead ions from the solution. Unmodified NM-Ca removed 0.27(14), NV-Na, 1.50(17) meq/g compared to the modified zeolites, $30 \mathrm{~min} \mathrm{HCl}$ treated NM-Ca 0.06(9) and NV-Na, 0.41(23) meq/g, and also decreased upon $\mathrm{K}^{+}$ion pretreatment in the $\mathrm{HCl}$ modified zeolites. Thus, increasing the surface area of the natural zeolites with concentrated HCL acid treatment was not useful at increasing cation removal or ion exchange capabilities. However, it is also possible that the removal of acid in the acid-treated zeolites was not thorough, and thus, lead removal was compromised with the acid-treated samples species. These results suggest that clinoptilolites modified with this $12.1 \mathrm{M} \mathrm{HCl}$ concentrated treatment, which results in substantially larger pore sizes, may be better suited for removing neutral contaminants from solution or as 3-dimensional hollow structures to allow for slow release of fertilizers in soil treatment.

All authors have read and agreed to the published version of the manuscript. Funding: This research received no external funding. Institutional Review Board Statement: Not applicable. Informed Consent Statement: Not applicable. Acknowledgments: Special thanks to Jared Edwards for obtaining the SEM images, Edward Laitila for assistance with the XRF measurements, and Daniel Holmes of the Max T. Rogers NMR Facility 
at Michigan State University for the solid-state NMR spectra. The zeolites were generously donated by the St. Cloud Mining Company. Michigan Technological University is acknowledged for its support. Insightful comments from reviewers are acknowledged. Conflicts of Interest: The authors declare no conflict of interest. 


\section{Chapter 6 Free radical catalyzed reactions with cyclohexene and cyclooctene with peroxides as initiators.}

Rudy L. Luck* and Nick K. Newberry

Department of Chemistry, Michigan Technological University, 1400 Townsend Drive, Houghton, MI USA 49931.

Correspondence: rluck@mtu.edu; Tel.: +1-906-487-7137; Fax: +1-906-487-2061 


\subsection{Abstract}

The free radical oxidation reaction of cyclohexene is accomplished at $80^{\circ} \mathrm{C}$ in a $10: 1$ 1,2-dichloroethane:acetonitrile mixture under an air atmosphere using 0.05 molar equivalents of either ${ }^{\mathrm{t}} \mathrm{BuOOH}$ or $\mathrm{H}_{2} \mathrm{O}_{2}$ and results in a $33.7 \%$ conversion yielding $23.7 \%$ 2-cyclohexen-1-one, $8.0 \%$ 2-cyclohexen-1-ol and 2.0\% cyclohexene oxide. In contrast, with cyclooctene under similar conditions, a $42.3 \%$ conversion is obtained, $40.3 \%$ epoxide, $0.35 \%$ of 1,2 -cyclooctanediol, and $1.18 \%$ of 2 -cycloocten-1-one. The reaction is not catalyzed by a glass reaction flask, works best at $80^{\circ} \mathrm{C}$, has the highest yield of products in a 10:1 DCE:ACN solvent mixture, and the overall yield and composition of the products in the case of cyclooctene is dependent on the concentration of reactants in solution. The reaction is dependent on oxygen as reduced yields are obtain under a nitrogen atmosphere, is initiated best with $\mathrm{H}_{2} \mathrm{O}_{2}$ and ${ }^{\mathrm{t}} \mathrm{BuOOH}$ and does not work with ammonium persulfate as a radical initiator. This free radical reaction was not useful for three other alkenes tested as under similar reaction conditions, many products formed with styrene, 2 -indanone (7(2)\% conversion rate) with indene and there was no reaction with pentene. Transition states and activation energies were calculated using Gaussian for possible reaction pathways involving radicals produced from the homolysis of the peroxide $\mathrm{O}-\mathrm{O}$ bond which abstract an alkyl $\mathrm{H}$ atom adjacent to the double bond forming a cyclic alkene radical. This can react rapidly with oxygen forming a cyclic-alkene peroxide radical. This intermediate may result in ketone products via a unimolecular pathway whereas the formation of epoxides requires a bimolecular route. A comparison of oxidation reactions on cyclohexene and cyclooctene from the literature reveals yields of products similar to those reported here suggesting that these reactions may have occurred via a similar free radical mechanism and not via catalysis. 


\subsection{Introduction}

It was noted some decades ago ${ }^{207}$ that if a wide range of oxidized products are produced in reactions involving the epoxidation of an alkene, then autoxidation processes may be operative. More recently, there have been many reports recently which assert the utility of various metal complexes and supports as catalysts in which oxidation of cyclohexene occurs and where a wide variety of products are obtained. ${ }^{208}$ For example, with cyclohexene, a range of products were obtained using as the catalyst $\mathrm{Cu}$ deposited onto a zeolite and $\mathrm{H}_{2} \mathrm{O}_{2}$ affording the products shown below. ${ }^{209}$

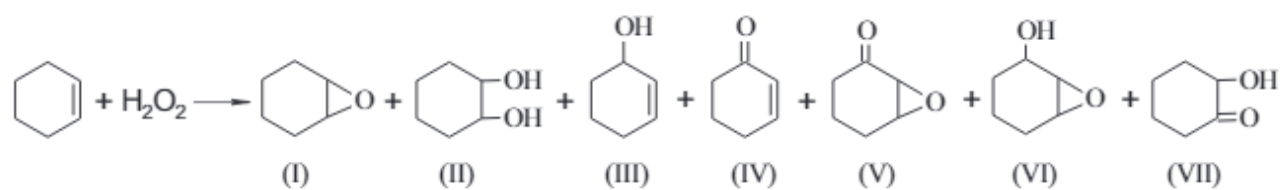

In fact, differing quantities of products are obtained in experiments involving the oxidation of either cyclohexene or cyclooctene. Tables S6.1-S6.6 list the results of oxidation reactions obtained with different oxidant concentrations employing either ${ }^{t} \mathrm{BuOOH}, \mathrm{H}_{2} \mathrm{O}_{2}$ or $\mathrm{O}_{2}$, and catalysts. Herein, the extent of free radical oxidation with cyclohexene and cyclooctene using a relative concentration of $5 \%$ of ${ }^{t} \mathrm{BuOOH}$ or $\mathrm{H}_{2} \mathrm{O}_{2}$ as radical initiators is determined. We find that reactions with cyclohexene result in a $33.7 \%$ conversion producing $23.7 \%$ 2-cyclohexen-1-one, $8.0 \% 2$-cyclohexen-1-ol and $2.0 \%$ cyclohexene oxide. In contrast, with cyclooctene under similar conditions, $42.3 \%$ conversion is obtained, $40.3 \%$ epoxide, $0.35 \%$ of 1,2 -cyclooctanediol, and $1.18 \%$ of 2 cycloocten-1-one. These experiments were conducted under a variety of experimental conditions and theory is utilized to suggest mechanisms by which these different products are obtained. ${ }^{210}$ The results suggest that free radical chemistry may be contributing to some reports of catalysis (Tables S6.1-S6.6) in the oxidation of cyclohexene and cyclooctene. 


\subsection{EXPERIMENTAL}

\subsubsection{Materials}

Z-cyclooctene $95 \%$, cyclooctene oxide $99 \%$, cyclooctane diol $99 \%$, cyclohexene 99\%, 2-cyclohexen-1-one 95\%, cyclohexene oxide 98\%, 2-cyclohexen-1ol 95\%, 2-indanone 98\%, 1,2-dichloroethane (DCE) 99\%, and styrene 99\% were all purchased from Sigma Aldrich and used as received. Tert-butyl hydroperoxide 70\% in water was purchased from Acros Organics and was titrated using KI and sodium thiosulfate confirming an oxidizer concentration of about $69 \%$. 1-hexene $98 \%$ was obtained from Fluka. Hydrogen peroxide 30\% in water was obtained from Macron and was titrated using $\mathrm{KI}$ and sodium thiosulfate resulting in an oxidizer concentration of about $31 \%$. Acetonitrile $(\mathrm{ACN})$ was obtained from J.T. Baker and was distilled over calcium hydride before use. Dichloromethane, 1,1,1-trichloroethane, and chloroform were obtained from Fisher and used as received. Dimethyl sulfoxide was obtained from Fisher and was dried with molecular sieves before use. Chlorobenzene $99 \%$ was from Mallincrockdt. Decane 99\% was used as the internal standard.

\subsubsection{Equipment}

Reactions were analyzed using a Shimadzu 2010 Gas chromatograph with a flame ionization detector. The GC was equipped with a DB- 5 column made by J\&W Scientific $\mathrm{L}=30$, $\mathrm{ID}=0.25$, Film $=0.25$ microns.

\subsubsection{General reaction conditions}

Reactions were typically done as follows, $4.6 \mathrm{mmol}$ of alkene, $5 \mathrm{~mL}$ of solvent, $0.5 \mathrm{~mL}$ of co-solvent ( $5.5 \mathrm{~mL}$ of solvent when cosolvent not used), $5 \mathrm{~mol} \%$ of oxidizer (i.e., $0.23 \mathrm{mmol}$ ), $0.300 \mathrm{~mL}$ of decane as the internal standard. In some cases, the amounts of oxidizers, type of solvent, temperature, and type of atmospheres varied and will be indicated as such. Samples were taken from the reaction at $72 \mathrm{hrs}$. 


\subsubsection{Reactions conducted under an Air Atmosphere or Nitrogen and Oxygen Atmospheres with Mercury Bubbler Backpressure}

Reactions under air were conducted in a 2 neck round bottom glass flask with a stir bar and a condenser attached. The other neck of the flask was plugged with a stopper and served as a place to easily sample the reaction. The top of the condenser was open to the atmosphere. The flask was lowered into an oil bath that was set at the reaction temperature of $80^{\circ} \mathrm{C}$. In the experiments conducted under $\mathrm{N}_{2}$ or $\mathrm{O}_{2}$, the top of the condenser had a gas inlet adapter attached which was connected to a mercury bubbler to provide back pressure through a Schlenk line. The reaction system was evacuated and then backfilled with the respective gas for the reaction. The flask was lowered into an oil bath that was set at the reaction temperature.

\subsubsection{Reactions in a Teflon container}

Reactions in a Teflon container was conducted by placing reactants inside a sealed Teflon autoclave with a volume of about $120 \mathrm{~mL}$. The autoclave was heated in an oven at $80^{\circ} \mathrm{C}$. The autoclave was removed and allowed to cool and opened to refresh the air in the autoclave every $24 \mathrm{hrs}$.

\subsubsection{Reaction in a sealed glass container with $115 \mathrm{~mL}$ volume.}

The reaction was conducted in a 2 neck round bottom flask $(100 \mathrm{~mL})$ with a stir bar and a condenser attached. The total volume of the condenser was $15 \mathrm{~mL}$ resulting in $115 \mathrm{~mL}$ of volume for the whole apparatus. The top of the condenser was fitted with a gas adapter and attached to a mercury bubbler to provide back pressure through a Schlenk line. The reaction was heated to $80^{\circ} \mathrm{C}$ and then the gas adapter was closed to approximate conditions in the Teflon container. The flask was also opened every 24 hours to refresh the air in the reaction similar to the conditions used with the Teflon apparatus. 


\subsubsection{Quantification of Reactions}

Quantification graphs were made by making 4 samples of varying concentrations of the products with the internal standard and running the samples on the GCFID machine. The concentration was graphed vs the ratio of area of product divided by the area of decane. The graphs were checked with a calibration sample before running each reaction sample to ensure the machine was working correctly by analyzing a sample with a known amount of product.

\subsubsection{Theoretical calculations}

Models for the different compounds were generated using previously published procedures. $^{211}$ Energy was minimized using the MM2 functionality in Chem3D, ${ }^{212}$ then force field (UFF) calculations in Avogadro ${ }^{33}$ were utilized. Density functional theory (DFT), using the APFD functional ${ }^{36}$ and electron basis sets initially at the 6$31 \mathrm{~g}(\mathrm{~d})$ level led to convergence of the atomic positions in Gaussian 16, Revision A.03. ${ }^{213}$ The results from this level were refined in a Polarizable Continuum Model $(\mathrm{PCM})^{214}$ of 1,2-dichloroethane with $6-311 \mathrm{~g}+(\mathrm{d})$ basis sets and frequency calculations conducted. One imaginary frequency was observed for the transition state species obtained via QST2 or QST3 calculations. Results for all data and figures were interpreted using either GaussView $6^{215}$ or GoodVibes ${ }^{216}$ and some presented as Supporting Information. 


\subsection{Results}

The total conversion of cyclohexene to oxidized products does not vary much whether the atmosphere is pure air or oxygen at 33.7 and $31.1 \%$ respectively, see Table 6.1. However, there is some difference in selectivity for when the environment is pure oxygen, selectivity towards the epoxide is slightly increased $6(1) \%$ under oxygen compared to $2(1) \%$ under air.

Table 6.1. Products from the oxidation of cyclohexene under various environments after 72 hrs. $^{\text {a }}$

\begin{tabular}{|c|c|c|c|c|}
\hline Atmosphere & $\begin{array}{c}\text { cyclohexene } \\
\text { oxide (\%) }\end{array}$ & $\begin{array}{c}\text { 2-cyclohexen-1-ol } \\
\mathbf{( \% )}\end{array}$ & $\begin{array}{c}\text { 2-cyclohexen-1- } \\
\text { one (\%) }\end{array}$ & $\begin{array}{c}\text { Total } \\
\text { Conversion } \\
\mathbf{( \% )}\end{array}$ \\
\hline Air & $2(1)$ & $8.0(3)$ & $23.66(1)$ & 33.7 \\
\hline Oxygen & $6(1)$ & $8.1(1)$ & $17.0(1)$ & 31.1 \\
\hline
\end{tabular}

${ }^{\mathrm{a} C o n d i t i o n s: ~} 4.6 \mathrm{mmol}$ cyclohexene, 10:1 DCE:ACN, $0.3 \mathrm{~mL}$ decane (internal standard), 5 mole $\% 70 \%{ }^{\mathrm{t}} \mathrm{BuOOH}, 80^{\circ} \mathrm{C}$.

The results in Table 6.2 show that using hydrogen peroxide or tert-butyl hydroperoxide as the initiator of the free radical reaction does not result in significant differences either in total conversion or selectivity of products.

Table 6.2. Oxidation of cyclohexene using ${ }^{\mathrm{t}} \mathrm{BuOOH}$ or $\mathrm{H}_{2} \mathrm{O}_{2}$ after $72 \mathrm{hrs}^{\mathrm{a}}$

\begin{tabular}{|c|c|c|c|c|}
\hline Oxidizer & $\begin{array}{c}\text { cyclohexene } \\
\text { oxide (\%) }\end{array}$ & $\begin{array}{c}\text { 2-cyclohexen- } \\
\mathbf{1 - o l}(\%)\end{array}$ & $\begin{array}{c}\text { 2-cyclohexen- } \\
\mathbf{1 - o n e}(\%)\end{array}$ & $\begin{array}{c}\text { Total } \\
\text { Conversion } \\
\text { (\%) }\end{array}$ \\
\hline $\begin{array}{c}0.05 \mathrm{eq} 70 \% \\
{ }^{\mathrm{BuOOH}}\end{array}$ & $2(1)$ & $8.0(3)$ & $23.66(1)$ & 33.68 \\
\hline $\begin{array}{c}0.05 \mathrm{eq} 30 \% \\
\mathrm{H}_{2} \mathrm{O}_{2}\end{array}$ & $2(1)$ & $9.4(2)$ & $23.5(1)$ & 35.16 \\
\hline
\end{tabular}

${ }^{a}$ Conditions: $4.6 \mathrm{mmol}$ cyclohexene, 10:1 DCE:ACN, 0.3 mL decane (internal standard), 5 mole $\%$ oxidizer, $80^{\circ} \mathrm{C}$, air atmosphere.

The composition of the products changes with length of reaction time as the amount of the alcohol and ketone increase compared to yield of epoxide, Table 6.3. 
Table 6.3. The ratio of products in the oxidation of cyclohexene at 24,48 and $72 \mathrm{hrs}^{\text {a }}$

\begin{tabular}{|c|c|c|c|}
\hline Substrate & $\begin{array}{c}\text { Ratio } \\
\text { Epoxide:Alcohol:Ke } \\
\text { tone at 24 hrs }\end{array}$ & $\begin{array}{c}\text { Ratio } \\
\text { Epoxide:Alcohol:Ke } \\
\text { tone at 48 hrs }\end{array}$ & $\begin{array}{c}\text { Ratio } \\
\text { Epoxide:Alcohol:Ke } \\
\text { tone at 72 hrs }\end{array}$ \\
\hline $\begin{array}{c}\text { Cyclohexe } \\
\text { ne }\end{array}$ & $1: 1.93: 9.86$ & $1: 1.68: 8.40$ & $1: 3.99: 11.77$ \\
\hline
\end{tabular}

${ }^{a}$ Conditions: $4.6 \mathrm{mmol}$ cyclohexene, 10:1 DCE:ACN, $0.3 \mathrm{~mL}$ decane (internal standard), 5 mole $\% 70 \%{ }^{t} \mathrm{BuOOH}, 80^{\circ} \mathrm{C}$, air atmosphere.

The difference in the reaction of the oxidation of cyclohexene when using a glass apparatus versus using a Teflon apparatus was also evaluated, Table 6.4.

Reactions conducted in glass under an air atmosphere resulted in $33.66 \%$ total conversion compared with that conducted in the sealed Teflon container with a $22.15 \%$ total conversion. However, when the experiment was conducted in glass under sealed conditions with approximately the same volume of air, a closer value of $25.7 \%$ was obtained. Therefore, the large difference in yield between the two reactions with the reaction under air versus the sealed Teflon container is due to the supply of air to the reactions and there does not appear to be catalysis from the surface of the glass container.

Table 6.4. Products from the oxidation of cyclohexene in a glass apparatus vs a Teflon apparatus. $^{\text {a }}$

\begin{tabular}{|c|c|c|c|c|}
\hline $\begin{array}{c}\text { Reaction } \\
\text { container }\end{array}$ & $\begin{array}{c}\text { cyclohexene } \\
\text { oxide (\%) }\end{array}$ & $\begin{array}{c}\text { 2-cyclohexen- } \\
\mathbf{1 - o l}(\mathbf{\%})\end{array}$ & $\begin{array}{c}\text { 2-cyclohexen-1- } \\
\text { one (\%) }\end{array}$ & $\begin{array}{c}\text { Total } \\
\text { Conversion } \\
\mathbf{( \% )}\end{array}$ \\
\hline $\begin{array}{c}\text { Glass (under } \\
\text { air) }\end{array}$ & $2(1)$ & $8.0(3)$ & $23.66(1)$ & 33.66 \\
\hline $\begin{array}{c}\text { Teflon } \\
\text { Autoclave }\end{array}$ & $2(1)$ & $9.9(3)$ & $10.25(1)$ & 22.15 \\
\hline Glass (sealed) & $2(1)$ & $12(1)$ & $11.7(2)$ & 25.7 \\
\hline
\end{tabular}

${ }^{\mathrm{a} C}$ Conditions: $4.6 \mathrm{mmol}$ cyclohexene, 10:1 DCE:ACN, $0.3 \mathrm{~mL}$ decane (internal Standard), 5 mole $\% 70 \%{ }^{\mathrm{t}} \mathrm{BuOOH}, 80^{\circ} \mathrm{C}, 72 \mathrm{hrs}$, air atmosphere.

Experiments to probe the reactivity of 2-cyclohexen-1-ol were also conducted and the results are listed in Table 6.5. The results indicate that under air and without the presence of a peroxide, 2-cyclohexen-1-ol does not transform into 2-cyclohexen-1one in the solvent mixture 10:1 DCE:ACN at $80{ }^{\circ} \mathrm{C}$. However, with added ${ }^{t} \mathrm{BuOOH}$ 
and under an air atmosphere, a transformation resulting in a 38.93(8)\% yield (based on a $100 \%$ conversion of the alcohol) of the ketone is observed. Under nitrogen with similar reactant conditions, some decomposition of the 2-cyclohexen-1-ol is observed but there is not the same extent of conversion to 2-cyclohexen-1-one suggesting that oxygen is required for this transformation.

Table 6.5. The reaction of 2-cyclohexen-1-ol with and without ${ }^{t} \mathrm{BuOOH}$ and under air or nitrogen. ${ }^{\mathrm{a}}$

\begin{tabular}{|c|c|c|c|}
\hline Oxidizer & Atmosphere & 2-cyclohexen-1-ol & 2-cyclohexen-1-one \\
\hline None $^{\mathrm{b}}$ & Air & $100(3)$ & $4.3(2)$ \\
\hline $0.030 \mathrm{~mL}{ }^{\mathrm{t}} \mathrm{BuOOH}$ & Air & $48.3(5)$ & $38.93(8)$ \\
\hline $0.030 \mathrm{~mL}{ }^{\mathrm{t}} \mathrm{BuOOH}$ & Nitrogen & $86.4(3)$ & $5.8(2)$ \\
\hline
\end{tabular}

${ }^{\mathrm{a} C}$ Conditions: $451 \mu \mathrm{L}$ 2-cyclohexen-1-ol, 10:1 DCE:ACN, 0.3 mL decane (internal Standard), $80^{\circ} \mathrm{C}, 72 \mathrm{hrs}$. ${ }^{\mathrm{b}}$ The bottle of 2-cyclohexen-1-ol was tested for purity via GCFID and consisted of 94(1)\% alcohol and 3.1(1)\% ketone.

Cyclohexene oxide was demonstrated to be stable under the conditions of the experiment as the data in Table 6.6 shows as there appears to be no significant changes in the concentration of the oxide and the alcohol that were in the original solution obtained.

Table 6.6. The reaction of cyclohexene oxide with and without ${ }^{t} \mathrm{BuOOH} .{ }^{\mathrm{a}}$

\begin{tabular}{|c|c|c|c|}
\hline Oxidizer & cyclohexene oxide & 2-cyclohexen-1-ol & 2-cyclohexen-1-one \\
\hline None $^{\mathrm{b}}$ & $93(1)$ & $0.38(6)$ & 0 \\
\hline $0.030 \mathrm{~mL}^{\mathrm{t}} \mathrm{BuOOH}$ & $96(2)$ & $0.28(8)$ & 0 \\
\hline
\end{tabular}

${ }^{\mathrm{a} C}$ Conditions: $465 \mu \mathrm{L}$ cyclohexene oxide, 10:1 DCE:CAN $5.5 \mathrm{~mL}, 0.3 \mathrm{~mL}$ decane (internal Standard), $80^{\circ} \mathrm{C}, 72 \mathrm{hrs} .{ }^{\mathrm{b}} \mathrm{The}$ bottle of cyclohexene oxide was tested for purity via GCFID and consisted of $95(2) \%$ oxide and $0.26(8) \%$ of the alcohol.

Under similar reaction conditions and in contrast to reactions with cyclohexene and cyclooctene, oxidized products were not obtained with 1-pentene, indene had a 7\% yield of 2-indanone and styrene resulted in many different products, Table 6.7. 
Table 6.7. Reactions with various alkenes. ${ }^{a}$

\begin{tabular}{|c|c|c|c|}
\hline Substrate & $\mathbf{7 2 h}$ Yield epoxide (\%) & $\begin{array}{c}\mathbf{7 2 h} \text { Yield Alcohol } \\
\mathbf{( \% )}\end{array}$ & $\begin{array}{c}\mathbf{7 2 h} \text { Yield Ketone } \\
\mathbf{( \% )}\end{array}$ \\
\hline $\begin{array}{c}\text { Cyclohexen } \\
\text { e }\end{array}$ & 2(1) Cyclohexene oxide & $\begin{array}{c}8.0(3) 2- \\
\text { cyclohexen-1-ol }\end{array}$ & $\begin{array}{c}23.66(1) 2- \\
\text { cyclohexen-1-one }\end{array}$ \\
\hline $\begin{array}{c}\text { Z- } \\
\text { Cycloocten } \\
\text { e }\end{array}$ & $\begin{array}{c}\text { Cyclooctene oxide } \\
\text { cyclooctene-1-one }\end{array}$ & $\begin{array}{c}0.35(1) 2- \\
\text { cyclooctene-1-ol }\end{array}$ \\
\hline 1-Pentene & 0.00 & & \\
\hline Styrene & $\begin{array}{c}\text { Oxidized Internal } \\
\text { Standard, 40+ products }\end{array}$ & 0 & $7(2)$ 2-indanone \\
\hline Indene & 0 & &
\end{tabular}

${ }^{a}$ Conditions: $4.6 \mathrm{mmol}$ substrate, $5 \mathrm{~mL}$ DCE, $0.5 \mathrm{~mL}$ ACN, $0.3 \mathrm{~mL}$ Decane (internal Standard), $0.030 \mathrm{~mL} 70 \%{ }^{\mathrm{t}} \mathrm{BuOOH}, 80^{\circ} \mathrm{C}$ air atmosphere.

Table 6.8 illustrates the dependance of the yield of cyclooctene epoxide upon temperature and solvent. A 10:1 mixture of DCE: ACN at $80^{\circ} \mathrm{C}$ afforded the highest yield of epoxide at 40(2)\%, though pure DCE at 37.0(2) \% was similar. Very low yields of epoxide $(0.73(1) \%)$ were obtained in the presence of the radical trap butylated hydroxytoluene (BHT). Interesting the more polar solvents such as $\mathrm{NaCl}$ in $\mathrm{H}_{2} \mathrm{O}:{ }^{\mathrm{t}} \mathrm{BuOH}$ at $80{ }^{\circ} \mathrm{C}$ and $\mathrm{DMSO}$ at $100{ }^{\circ} \mathrm{C}$ had much lower yields at 9.1(2) and 6.0(9) $\%$ whereas a temperature of $50{ }^{\circ} \mathrm{C}$ in a DCM:ACN mixture was also not constructive with a yield of $1.79(1) \%$. Reactions at $25^{\circ} \mathrm{C}$ did not yield measurable quantities of epoxide and initiation at $80{ }^{\circ} \mathrm{C}$ followed by reaction at room temperature resulted in the very low yield of epoxide at $0.63(2) \%$.

Table 6.8. Oxidation of cyclooctene at various temperatures and in various solvents. ${ }^{\text {a }}$

\begin{tabular}{|l|l|l|}
\hline Solvent & Temperature $\left({ }^{\circ} \mathbf{C}\right)$ & 72h Yield epoxide $(\%)$ \\
\hline $10: 1 \mathrm{DCE}: \mathrm{ACN}$ & 80 & $40(2)$ \\
\hline $10: 1 \mathrm{DCE}: \mathrm{ACN}^{\mathrm{b}}$ & 80 & $0.73(1)$ \\
\hline $2: 13 \% \mathrm{NaCl}$ in $\mathrm{H}_{2} \mathrm{O}:{ }^{\mathrm{t}} \mathrm{BuOH}$ & 80 & $9.1(2)$ \\
\hline $\mathrm{DMSO}$ & 100 & $6.0(9)$ \\
\hline
\end{tabular}




\begin{tabular}{|l|l|l|}
\hline 10:1 DCM: ACN & 50 & $1.79(1)$ \\
\hline $10: 1$ Chlorobenzene:ACN & 80 & $15.0(2)$ \\
\hline $\begin{array}{l}10: 11,1,1- \\
\text { trichloroethane:ACN }\end{array}$ & 80 & $17.5(2)$ \\
\hline ACN & 80 & $28.9(5)$ \\
\hline DCE & 80 & $37.0(2)$ \\
\hline $10: 1$ DCE: ACN & 25 & 0.00 \\
\hline $10: 1$ DCE: ACN & $\begin{array}{l}\text { Heat at } 80 \text { for } 30 \text { minutes } \\
\text { then cool to room temp }\end{array}$ & $0.63(2)$ \\
\hline 10:1 DCE: ACN $(11 \mathrm{~mL})$ & 80 & $9.22(9)^{\mathrm{c}}$ \\
\hline
\end{tabular}

${ }^{\mathrm{a} C o n d i t i o n s: ~} 4.6 \mathrm{mmol} \mathrm{Z}$-cyclooctene, $5.5 \mathrm{~mL}$ solvent total, varying temp $\left(50-100^{\circ} \mathrm{C}\right)$ see above, $0.030 \mathrm{~mL} 70 \%{ }^{\mathrm{t}} \mathrm{BuOOH}, 72 \mathrm{hrs}$, air atmosphere. ${ }^{\mathrm{b}}$ Reaction contained 551 $\mathrm{mg}$ of BHT. ${ }^{\mathrm{c}}$ Also produced $0.42(2) \%$ ketone and $0.315(4) \%$ diol.

Experiments were also conducted under different atmospheres where the concentration of oxygen varied from 0 to $100 \%$, Table 6.9. Reactions under $100 \%$ oxygen afforded the highest yield of epoxide, 49.1(7)\% compared to under air at $40(2) \%$, whereas those under nitrogen or in a sealed glass tube where the oxygen supply was restricted, had very low yields of epoxide probably resulting from the direct reaction of the added ${ }^{\mathrm{t}} \mathrm{BuOOH}$ and cyclooctene. An experiment with one equivalent of ${ }^{t} \mathrm{BuOOH}$ per cyclooctene conducted under nitrogen resulted in $14.1(1) \%$ of the epoxide, 5.3(2)\% of 2-cycloocten-1-one and 5.1(4)\% 1,2-cyclooctanediol.

Table 6.9. Oxidation of cyclooctene under different atmospheres. ${ }^{a}$

\begin{tabular}{|l|c|}
\hline Atmosphere & 72h Yield epoxide (\%) \\
\hline Air & $40(2)$ \\
\hline Oxygen Oil Bubbler Backpressure & $49.1(7)$ \\
\hline Nitrogen Oil Bubbler Backpressure & $1.76(2)$ \\
\hline Sealed Glass Tube & $2.7(1)$ \\
\hline Nitrogen with $100 \%$ equiv ${ }^{\mathrm{t}} \mathrm{BuOOH}$ & $14.1(1)^{\mathrm{b}}$ \\
\hline
\end{tabular}

${ }^{a}$ Conditions: $4.6 \mathrm{mmol}$ Z-cyclooctene, $5 \mathrm{~mL}$ DCE, $0.5 \mathrm{~mL} \mathrm{ACN}, 0.3 \mathrm{~mL}$ Decane (internal Standard), $0.030 \mathrm{~mL} 70 \%{ }^{\mathrm{t}} \mathrm{BuOOH}, 80^{\circ} \mathrm{C}, 72 \mathrm{hrs}$. b $502 \mathrm{mg}$ Z-Cyclooctene, $0.610 \mathrm{~mL} \mathrm{70 \%}{ }^{\mathrm{t}} \mathrm{BuOOH}$, also produces $5.3(2) \%$ 2-cycloocten-1-one and 5.1(4)\% 1,2cyclooctanediol. 
Table 6.10 shows the reactions of cyclooctene with various oxidizers. The amount of 0.05 eq $70 \%{ }^{t} \mathrm{BuOOH}$ produced the highest yield of epoxide at $40.2(2)$ equal to that when one equivalent was used.

Table 6.10. Reactions of cyclooctene with various oxidizers. ${ }^{\mathrm{a}}$

\begin{tabular}{|l|c|}
\hline Oxidizer & 72h Yield epoxide (\%) \\
\hline 0.05 eq $70 \%{ }^{\mathrm{t}} \mathrm{BuOOH}$ & $40(2)$ \\
\hline None & 0 \\
\hline $\begin{array}{l}0.05 \mathrm{eq} 70 \%{ }^{\mathrm{t}} \mathrm{BuOOH} \text { added at start then } 24 \mathrm{~h} \\
\text { and } 48 \mathrm{~h}\end{array}$ & $41(2)$ \\
\hline $0.05 \mathrm{eq} 30 \% \mathrm{H}_{2} \mathrm{O}_{2}$ & $31(2)$ \\
\hline $0.05 \mathrm{eq} \mathrm{Cyclooctene}$ oxide & $3.9(1)$ \\
\hline 0.9 eq $\mathrm{Ammonium}$ persulfate & 0 \\
\hline 1 eq $70 \%{ }^{\mathrm{t}} \mathrm{BuOOH}$ & $40(2)$ \\
\hline
\end{tabular}

${ }^{a}$ Conditions: $4.6 \mathrm{mmol}$ Z-cyclooctene, $5 \mathrm{~mL}$ DCE, $0.5 \mathrm{~mL}$ ACN, $0.3 \mathrm{~mL}$ Decane (internal Standard), Varying oxidizers, $80^{\circ} \mathrm{C}$ Air atmosphere

\section{Mechanistic and theoretical calculations}

The direct reaction between ${ }^{t} \mathrm{BuOOH}$ and either cyclohexene or cyclooctene is accomplished with an activation energy calculated to be 33.15 or $30.05 \mathrm{kcal} / \mathrm{mol}$, respectively, and is exothermic with $\Delta \mathrm{H}_{\text {react }}=-49.87$ and $-52.94 \mathrm{kcal} / \mathrm{mol}$ respectively, see Figs. S1 and S2. This activation energy is comparable to that required to break the peroxide $\mathrm{O}-\mathrm{O}$ bond which was calculated to be $33.12 \mathrm{kcal} / \mathrm{mol}$, Fig. S3, but the binuclear reaction also requires a collision to occur whereas the bond rupture is unimolecular and presumably occurs at $80^{\circ} \mathrm{C}$. This value of $33.12 \mathrm{kcal} / \mathrm{mol}$ is similar to that from other low level calculations (around $34 \mathrm{kcal} / \mathrm{mol}$ ) though higher level calculations in the case of ${ }^{\mathrm{t}} \mathrm{BuOOH}$ puts the $\mathrm{O}-\mathrm{O}$ bond homolysis at $41 \mathrm{kcal} / \mathrm{mol}^{217}$

Proposed mechanisms for the formation of the products observed from the reactions between ${ }^{t} \mathrm{BuOOH}$ and cyclohexene or cyclooctene are displayed in Schemes 6.1 and 6.2 respectively. It is necessary to invoke a free radical mechanism as the yield of products far 


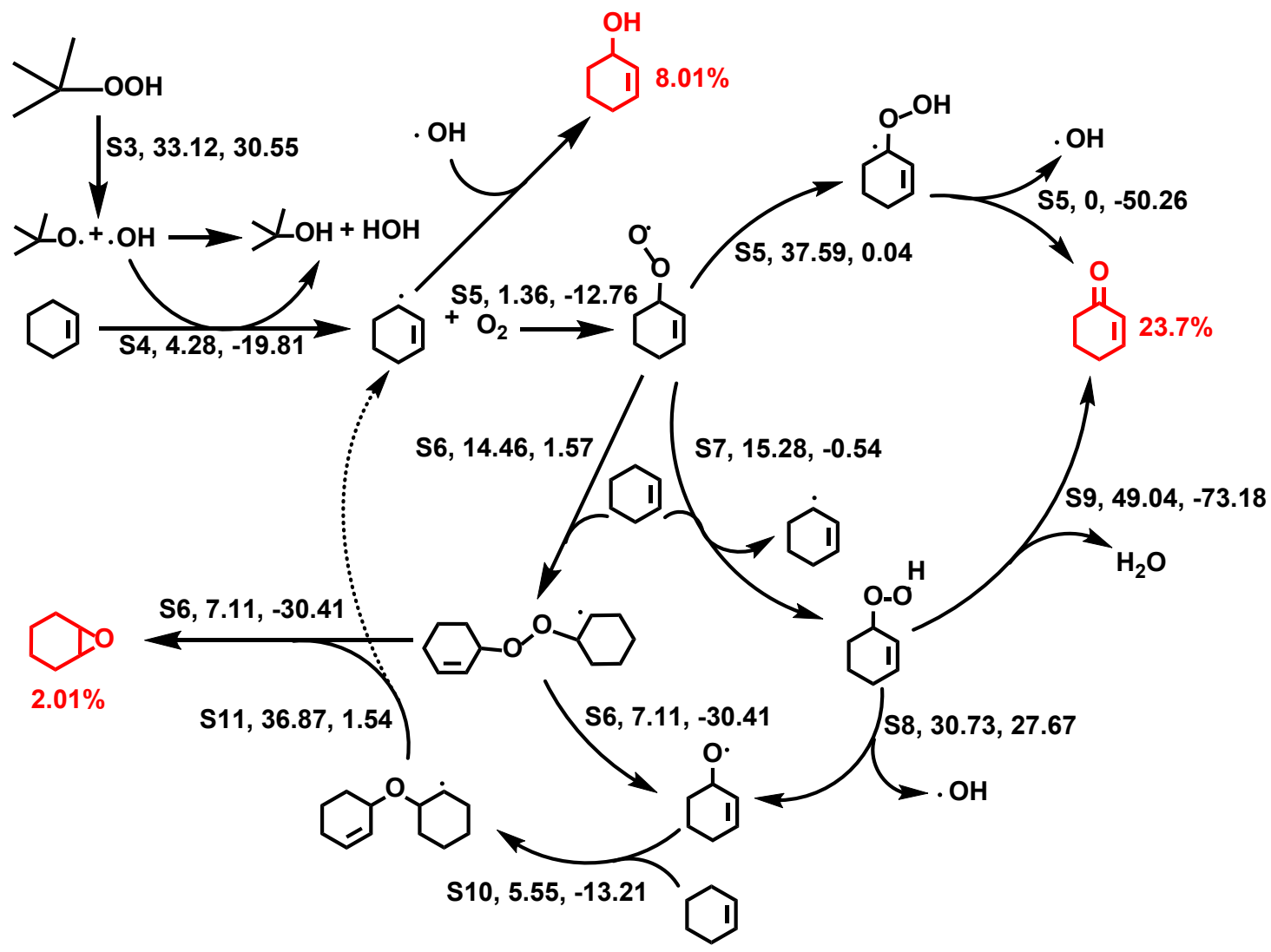

Scheme 6.1. Proposed mechanism for the free radical transformation of cyclohexene into the products observed. A potential energy plot for each transformation was calculated and the supplementary figure numbers, the activation energy and $\Delta H_{r}$ in $\mathrm{kcal} / \mathrm{mol}$ are indicated in that order.

exceeds the quantity of peroxide (i.e., $5 \%$ molar equivalents of peroxide to alkene) added to the reaction mixture. As can be seen on the top left in Scheme 6.1, the generation of a cyclohexene radical is accomplished at an activation energy of 4.28 $\mathrm{kcal} / \mathrm{mol}$ and the subsequent reaction with oxygen would then be almost instantaneous with an activation energy of $1.36 \mathrm{kcal} / \mathrm{mol}$. Both reactions are exothermic at -19.81 and $-12.76 \mathrm{kcal} / \mathrm{mol}$ respectively. These low values in the activation energies for the generation of the cyclohexene peroxy radical would suggest that the concentration of the cyclohexene peroxy radical is much greater than the concentration of the cyclohexene radical and subsequent reactions which have higher activation energy barriers would proceed at a slower rate. ${ }^{218}$ It is likely that cyclohex-2-en-1-ol is produced from the direct reaction of cyclohexene radical with an hydroxy radical as 
shown in the top center of Scheme 6.1 and, notably, this compound is obtained in 8.01 $\%$ yield.

The formation of 2-cyclohexen-1-one can proceed via two pathways. One of these, a unimolecular mechanism, involves a hydrogen atom 1-3 migration on the cyclohexene peroxy radical with subsequent rapid $\mathrm{O}-\mathrm{O}$ bond cleavage resulting in 2cyclohexen-1-one and a hydroxy radical with an activation energy of $37.59 \mathrm{kcal} / \mathrm{mol}$ as shown on the top right of Scheme 6.1 and Fig. S6.5. The other pathway involves a bimolecular reaction between the cyclohexene peroxy radical and cyclohexene resulting in hydrogen abstraction to form 1-hydroperoxycyclohex-2-ene and a cyclohexene radical with the subsequent generation of 2-cyclohexen-1-one and water at activation energies of 15.28 and $49.04 \mathrm{kcal} / \mathrm{mol}$ respectively. The $3-$ hydroperoxycyclohex-1-ene molecule can also undergo homolytic $\mathrm{O}-\mathrm{O}$ bond fissure resulting in 1-oxo-cyclohex-2-ene and hydroxy radicals as shown on the bottom right of Scheme 6.1.

The formation of cyclohexene epoxide (7-oxabicyclo[4.1.0]heptane) can be envisaged via two pathways as depicted in the center and bottom left of Scheme 6.1. The direct reaction between a cyclohexene peroxy radical and cyclohexene leads to a peroxide bridged radical species at an activation energy of $14.46 \mathrm{kcal} / \mathrm{mol}$, Fig. S6.6, with subsequent rearrangement to form the epoxide and the 1-oxo-cyclohex-2-ene radical. This radical which is also produced as a result of homolytic fission of the $\mathrm{O}-\mathrm{O}$ bond in 1-hydroperoxycyclohex-2-ene can also react with cyclohexene to form a oxobridged radical which can decompose into the epoxide and cyclohexene radical at activation energies of 5.55 and $36.87 \mathrm{kcal} / \mathrm{mol}$ respectively. Pictures of the LCAOs for the HOMOs in the oxo- and peroxo-bridged radicals, Fig. 1, indicate that the odd electron is mostly localized on the carbon atom indicated in Scheme 6.1. 


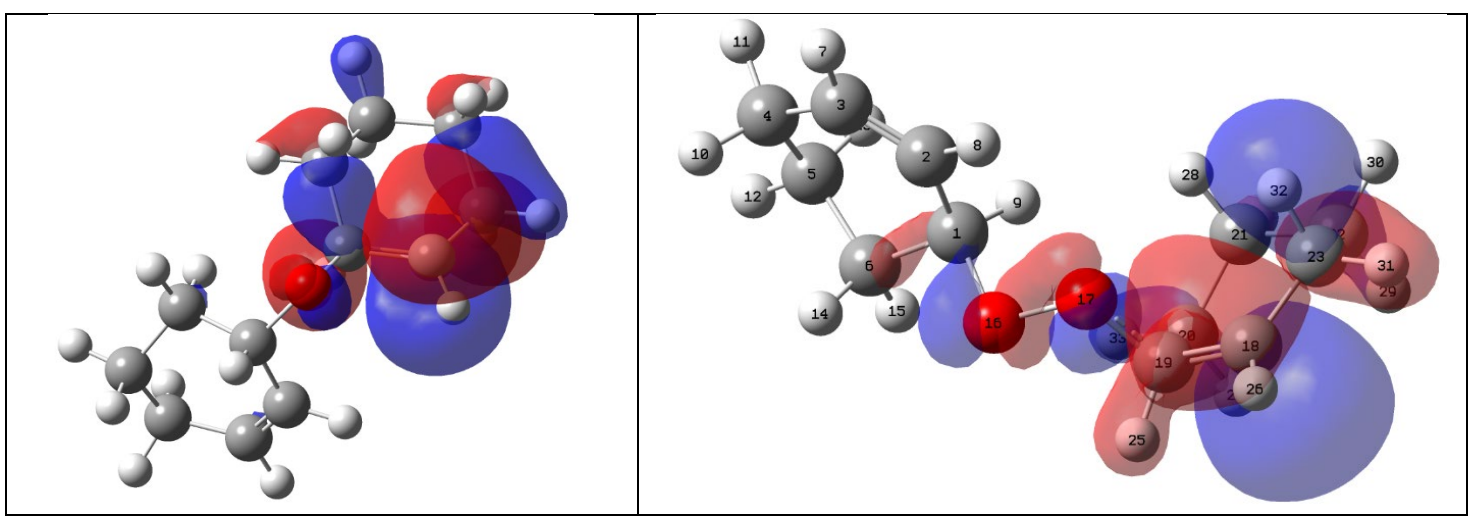

Figure 6.1. Drawings of the LCAOs for the HOMOs for the oxo- (left) and peroxobridged (right) species depicted in Scheme 6.1.

The yields of the compounds obtained, namely the $8.01 \%$ of alcohol, the $23.7 \%$ of the alkene ketone and the $2.01 \%$ of the epoxide would suggest that a unimolecular free radical pathway is favored as this would generate sufficient hydroxy radicals to yield the $8.01 \%$ of alcohol and the $23.7 \%$ of the ketone.

An examination of the heat of reaction as listed in Scheme 6.1 shows that breaking the $\mathrm{O}-\mathrm{O}$ bond in the peroxide structures is endothermic at $30.55 \mathrm{kcal} / \mathrm{mol}$ for ${ }^{t} \mathrm{BuOOH}$ and $27.67 \mathrm{kcal} / \mathrm{mol}$ for 3-hydroperoxycyclohex-1-ene. The most thermodynamically favored product is 2-cyclohexen-1-one which most likely results from the pathway on the top right of Scheme 6.1 .

With cyclooctene, similar activation energies are obtained for some of the proposed reactions, Scheme 6.2. The activation energies for the formation of cyclooctene radical and subsequent reaction with oxygen are calculated to be 2.22 and $0.80 \mathrm{kcal} / \mathrm{mol}$ respectively. Subsequent activation energies are much higher which would lead to an increased concentration of the cyclooctene peroxy radical depicted on the top of Scheme 6.2. The calculated activation energies for subsequent reactions for the bimolecular pathway (which lead to formation of epoxide) are much lower than that for the unimolecular step (depicted on the top of Scheme 6.2) and it is possible that this peroxy radical is more stable than that of cyclohexene and this allows the bimolecular pathway to proceed leading to the yield of cyclooctene epoxide (9oxabicyclo[6.1.0]nonane, $40.3 \%$ ) obtained. It is noteworthy that the calculated 
activation energy for the biscyclooctene peroxide bridged dimer at $5.73 \mathrm{kcal} / \mathrm{mol}$ is much lower than that for the equivalent step in the cyclohexene pathway at 7.11 $\mathrm{kcal} / \mathrm{mol}$ and this may also be contributing to the increase yield of epoxide product with cyclooctene. The reaction of the 1-oxo-cyclooct-2ene radical with cyclooctene to form an ether radical as shown on the bottom of Scheme 6.2 is calculated to have an activation energy of $23.77 \mathrm{kcal} / \mathrm{mol}$ which is much higher than that for the equivalent reaction with cyclohexene at $5.55 \mathrm{kcal} / \mathrm{mol}$. Subsequent decomposition of the ether radical affords the epoxide and more cyclooctene radical at an activation energy of $29.96 \mathrm{kcal} / \mathrm{mol}$ which is lower than the equivalent reaction in the case of cyclohexene at $36.87 \mathrm{kcal} / \mathrm{mol}$. It is interesting that this pathway with the formation of the ether radical yields the cyclooctene radical and as a substantial quantity of the cyclooctene radical must be produced to have a $40.3 \%$ yield of the epoxide, this pathway must be operative. We do not see any $(Z)$-cyclooct-2-en-1-ol under the conditions of the experiment so the 1-oxo-cyclooct-2-ene radical is not abstracting a hydrogen atom from cyclooctene and the ether radical is produced.

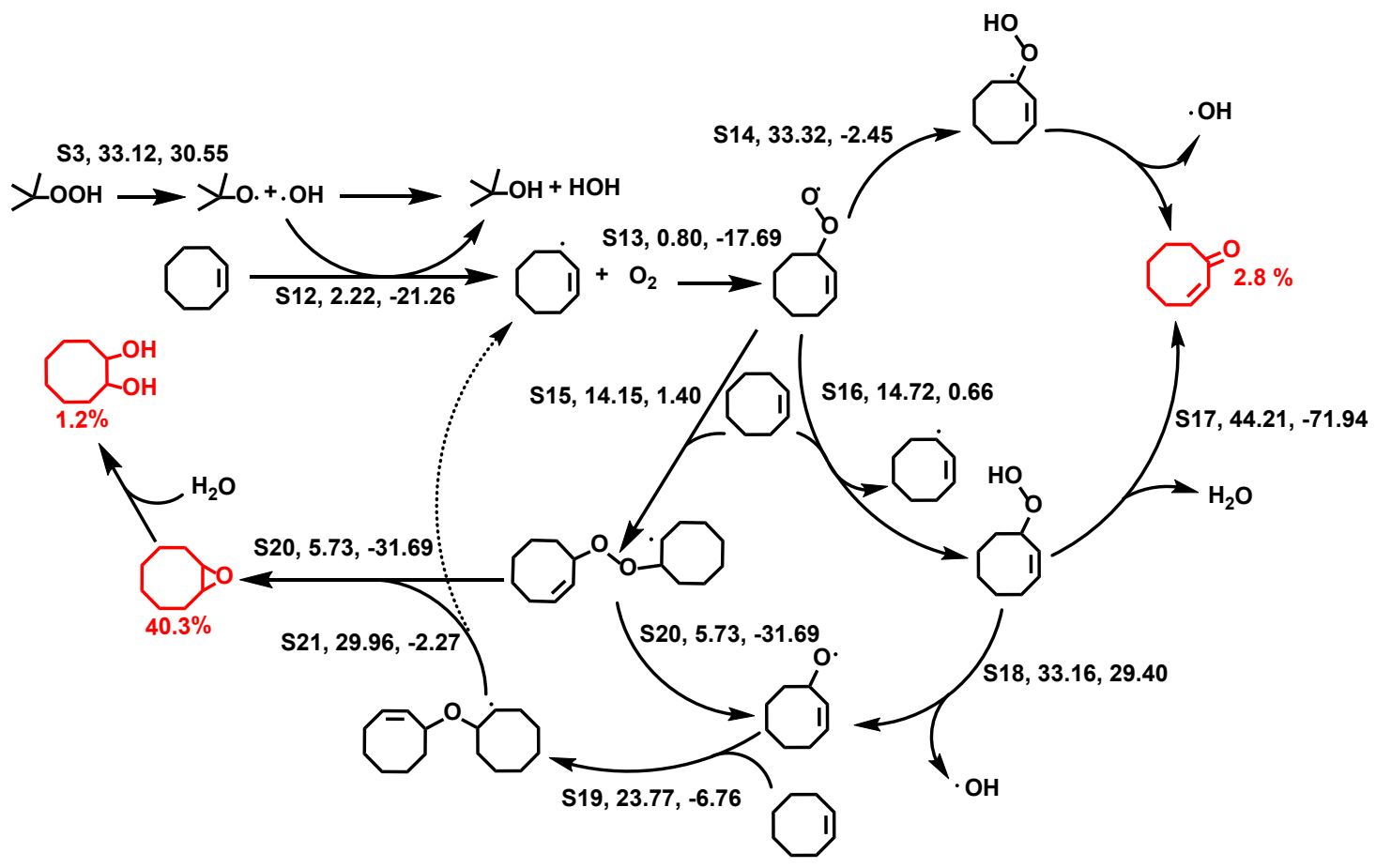


Scheme 6.2. Proposed mechanism for the free radical transformation of cyclooctene into the products observed. A potential energy plot for each transformation was calculated and the supplementary figure numbers, the activation energy and $\Delta H_{r}$ in $\mathrm{kcal} / \mathrm{mol}$ are indicated in that order.

Drawings of the LCAOs for the HOMOs in the oxo- and peroxy-bridged dimeric radicals, Fig. 6.2, situate the radical on the carbon atom depicted in Scheme 6.2.

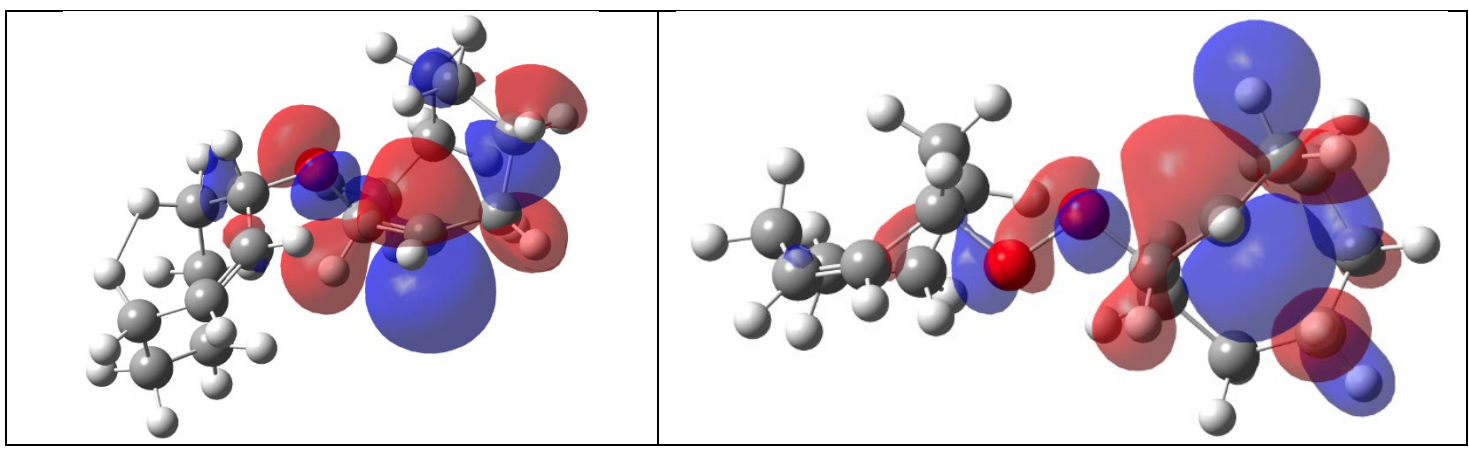

Figure 6.2. Drawings of the LCAOs for the HOMOs for the oxo- (left) and peroxobridged (right) species depicted in Scheme 6.2.

As was the case with cyclohexene, the most thermodynamic favored product appears to be (Z)-cyclooct-2-en-1-one, Scheme 6.2. Experimentally this compound is only obtained with a yield of $2.8 \%$ in contrast to the less thermodynamically favored epoxide product at $40.3 \%$.

\subsection{Discussion}

In most cases the reaction was allowed to go for $72 \mathrm{~h}$ and involved $5 \%$ of peroxide to cycloalkene substrate. A wide range of experiments were conducted to determine if oxygen was required.for the reaction. The data in Table 6.1 show that slightly more of the epoxide product is obtained under pure oxygen with less of the 2cyclohexe-1-one compound with similar conversion rates of around $32 \%$. For cyclooctene, more epoxide is produced under pure oxygen $(49.1(7) \%$ compared to 40(2) \% under air, Table 6.9. The results under nitrogen gas or in a sealed glass tube with a small quantity of oxygen were also similar at 1.76(2)5 and 2.7(1) \% respectively, suggesting that a direct reaction between the added peroxide agent at $5 \%$ 
molar equivalents was capable of producing some epoxide at a very lower yield. Under nitrogen and with $100 \%$ equivalent peroxide added, we find only $14.1(1) \%$ yield of the epoxide with some cyclooct-2-en-1-one, 5.3(2)\%, and 1,2-cyclooctanediol, 5.1(4)\%, also being produced. The reaction appears not to involve catalysis by the surface of the glass container. Experiments done using a Teflon container with a similar volume of trapped oxygen from the air above the mixture did not result in significant differences in yields as the data in Table 6.4 illustrate. Under these experimental conditions, many products were observed with styrene as substrate, none for 1-pentene and indene afforded 7(2)\% of indanone, Table 6.7. The reaction is based on free radicals as experiments conducted in the presence of the free radical trap BHT only resulted in very low yields of epoxide, i.e., 0.73(1) \% in the case of cyclooctene, Table 6.8 .

The nature of the oxidizing agent was also examined. The data in Table 6.10 show that an oxidizer is required with ammonium persulfate not affording any epoxide and cyclooctene oxide remaining unchanged. Five percent equivalents of $\mathrm{H}_{2} \mathrm{O}_{2}$ to substrate produced less epoxide at $31(2) \%$ compared to $5 \%$ and $100 \%$ equivalent ${ }^{t} \mathrm{BuOOH}$ where an identical yield was obtained at $40(2) \%$.

The reaction can be initiated with either ${ }^{\mathrm{t}} \mathrm{BuOOH}$ or $\mathrm{H}_{2} \mathrm{O}_{2}$ in the case of cyclohexene, Table 6.2, and similar conversions are obtained at 33.68 and $35.16 \%$ respectively. We had previously reported results for cyclooctene but at that time did not contemplate a free radical mechanism but had used catalysts such as $\mathrm{MCl}_{2}(\mathrm{O})_{2}\left(\mathrm{OPMePh}_{2}\right)_{2}, \mathrm{M}=\mathrm{Mo}$ or $\mathrm{W}$, where yields of the desired epoxide were $100 \%$ and $61 \%$ respectively after $24 \mathrm{~h} .{ }^{219}$ The fact that reactions without the catalysts involving just ${ }^{\mathrm{t}} \mathrm{BuOOH}$ and cycooctene resulted in significant quantities of epoxide at $26 \%$ at $90{ }^{\circ} \mathrm{C}$ and $6 \mathrm{~h}$ was also noted but this was with stoichiometric equivalence.

Given the nature of the products obtained in the oxidation of cyclohexene, measurements of the reaction mixture were determined after 24,48 and $72 \mathrm{~h}$ and these demonstrated that the quantities of alcohol and ketone increased with time, Table 6.3. However it is not clear from this experiment if the epoxide was initially produced and 
then transformed into the other products. Results of experiments to probe the stability of the products under reaction conditions in the case of cyclohexene are listed in Tables 6.5 and 6.6 for 2-cyclohexen-1-ol and cyclohexene oxide respectively. Both of these compounds are stable in the absence of $5 \%$ equivalents of peroxide but 2-cyclohexen1 -ol does result in 38.93(8)\% yield of 2-cyclohexen-1-one after 72 hours under air but only 5.8(2) \% under nitrogen which is slightly larger than the stock solution which had $3.1(1) \%$. In contrast there are no significant changes in the concentration of cyclohexene oxide and 2-cyclohexen-1-ol when subjected to $5 \%$ peroxide or heated in its absence, Table 6.6. Increasing the reaction temperature to $100^{\circ} \mathrm{C}$ in DMSO only resulted in 6.0(9)\% yield of epoxide. Interestingly, increasing the volume of solvent used from 5.5 to $11 \mathrm{~mL}$ resulted in a $9.22(9) \%$ yield of epoxide, much reduced from that obtained with $5.5 \mathrm{~mL}$ at $40(2) \%$.

These experimental results are in keeping with the proposed mechanisms shown in Schemes 6.1 and 6.2. The reaction temperature of $80^{\circ} \mathrm{C}$ is required for the homolysis of the peroxide $\mathrm{O}-\mathrm{O}$ bond with subsequent generation of the alkene peroxide radical. This can then essentially react with free cycloalkene to produce a peroxide bridged radical which can decompose to form the epoxide and an oxoradical which is the dominant reaction in the case of cyclooctene. The oxoradical can also react with cycloalkene to produce a bridging oxide radical which can decompose to produce an epoxide and a cycloalkene radical which can then react with oxygen initiating another cycle. This step is important in generating free cycloalkene radicals to obtain the experimental yields. Running the reaction under more dilute conditions resulted in a much lower yield of the epoxide in the case of cyclooctene providing experimental evidence of this bimolecular pathway. It is not obvious why under these conditions, the oxidation of cyclohexene results mostly in the ketone 2-cyclohexen-1one. The pathway suggested for the formation of this compound is via a unimolecular pathway, Scheme 6.1, and the transition state activation energy for this pathway is higher than that for the bimolecular pathway a circumstance which pertains for both cyclohexene and cyclooctene. While it is established that the lower transition state 
pathway may not be the one utilized in a unimolecular reaction, ${ }^{220,221}$ the fact that under more dilute conditions less of the epoxide was formed with cyclooctene, Table 6.8 , suggests that it is not useful to comparing transition states between unimolecular and bimolecular pathways as the route with the lower activation energy may not be the one chosen. For cyclooctene, the bimolecular pathway appears to function with more concentrated solutions but with cyclohexene, the unimolecular one may be operative.

Tables 6.11 and 6.12 lists a subsection of literature results using ${ }^{\mathrm{t}} \mathrm{BuOOH}, \mathrm{H}_{2} \mathrm{O}_{2}$ and $\mathrm{O}_{2}$ as the oxygen source (more comprehensive listings including reaction details are available as supplementary information, Table S6.1-S6.6) where, in some cases, a range of products are obtained for cyclohexene and cyclooctene respectively. This listing is compromised as different reaction conditions of temperature, solvent, ratio of peroxide to substrate are involved and these complicate direct comparison to the results reported here. However, it is likely that those listings in Table 6.11 closest to the products obtained herein or with mixtures of products are functioning not under catalytic conditions but via free radical mechanisms such as those depicted in Scheme 6.1. The yields of the products were calculated from the conversions listed together with the percentages of products obtained. One immediate conclusion from an examination of these listings is that with cyclohexene, Table 6.11, the major product in most cases is the alkene oxide, whereas with cyclooctene, Table 6.12, the epoxide is the major product.

It is important to note that nearly all the reactions listed were conducted with greater than $100 \%$ equivalence of peroxide to substrate as the idea was to directly transfer the $\mathrm{O}$ atom. This reason, together with the temperature at which the reaction was conducted, may account for some variation in the products obtained. For cyclohexene, Table 6.11 , the composition of the product changes from $100 \%$ epoxide to $100 \%$ cycloalkene ketone with a very rough correlation from homogeneous to heterogeneous catalysts as an examination of the column for catalyst in the table would reveal. This would suggest that the catalysts are forming peroxides which are more effective at transferring a more activated oxygen atom to the cycloalkene resulting in 
the epoxide whereas with a heterogeneous catalyst (or perhaps nanoparticles), it is more difficult for such a transfer to take place and the cycloalkene ketone results, perhaps from a unimolecular pathway. In all the listed cases for cyclohexene, the use of group 6 transition metal catalysts showed some of the highest yields for epoxide with the trend of $\mathrm{Mo}>\mathrm{W}>>\mathrm{Cr}$ with $\mathrm{Cr}$ resulting in 2-cyclohexen-1-one. Other transition metal catalysts such as Fe, $\mathrm{Au}, \mathrm{Ag}, \mathrm{Cu}, \mathrm{Rh}, \mathrm{Mn}, \mathrm{Co}, \mathrm{Zn}, \mathrm{Ti}, \mathrm{Ru}$, and V were used and produced a wide variety of products. Comparing Mn porphyrin cage (93\% epoxide) and $\mathrm{Mn}(\mathrm{Oac})_{2} \cdot 4 \mathrm{H}_{2} \mathrm{O}(85 \%$ ketone $)$ demonstrates that the transition metal may not be the determining factor as one produces mainly cyclohexene epoxide (presumably homogeneous) and the other produces 2-cyclohexen-1-one (perhaps nanoparticles). Of note is the reaction employing 0.05 eq of ${ }^{\mathrm{t}} \mathrm{BuOOH}$ with the catalyst $\mathrm{Au} / \mathrm{CNTs}$ $\mathrm{IM}^{222}$ where yields of $43.6 \%$ cyclohexene oxide, $7.48 \%$ 2-cyclohexen-1-ol and $6.38 \%$ 2-cyclohexen-1-one are obtained in contrast to that reported here at 2.01, 8.01 and $23.7 \%$ respectively. This may well be related to the fact that Au does not form multiple bonds with oxygen atoms $\mathrm{s}^{223}$ and hence a more facile transfer of $\mathrm{Au}$ bonded $\mathrm{O}$ atom to the double bond resulting in cyclohexene oxide is possible. It is curious that many of the listed reactions involved greater than $100 \%$ molar equivalents of peroxide to cycloalkene and this presumably compensates for catalytic decomposition of the peroxide on the metal surface.

Table 6.11. The yields of products from the oxidation of cyclohexene using $\mathrm{O}_{2}$, ${ }^{t} \mathrm{BuOOH}$ or $\mathrm{H}_{2} \mathrm{O}_{2}$ as the oxidizer. See references for other conditions of the reactions. A dash indicates that the yield for that product if present was not reported.

\begin{tabular}{|c|c|c|c|c|c|c|c|}
\hline Catalyst & Oxidant & Yield & Yield & Yiel & Yield & Others & Ref \\
\hline $\begin{array}{c}{\left[\mathrm{MoO}_{2} \mathrm{Cl}_{2}\left(\mathrm{H}_{2} \mathrm{O}\right)_{2}\right] \cdot\left(\mathrm{H}_{2} \text { dipy- }\right.} \\
\text { pra) } \mathrm{Cl}_{2}, \mathrm{NaHCO}_{3}\end{array}$ & 4 eq $\mathrm{H}_{2} \mathrm{O}_{2}$ & 99 & - & - & - & - & 224 \\
\hline $\mathrm{H}_{3} \mathrm{PW}_{12} \mathrm{O}_{40}$ & $2 \mathrm{eq} \mathrm{H}_{2} \mathrm{O}_{2}$ & 78.2 & - & - & - & - & 225 \\
\hline$\left[\mathrm{MoO}\left(\mathrm{O}_{2}\right)_{2} 4,4 \text {-bipy }\right]_{\mathrm{n}}$ & 2.5 eq $\mathrm{H}_{2} \mathrm{O}_{2}$ & 95 & - & - & - & - & 226 \\
\hline $\begin{array}{c}(4- \\
\mathrm{ddp})_{1.5} \mathrm{Na}_{5.5}\left[\mathrm{PTi}_{2} \mathrm{~W}_{10} \mathrm{O}_{40}\right] \cdot 5 \\
\mathrm{H}_{2} \mathrm{O}\end{array}$ & 2 eq $\mathrm{H}_{2} \mathrm{O}_{2}$ & 9.02 & - & - & 1.65 & - & 227 \\
\hline
\end{tabular}




\begin{tabular}{|c|c|c|c|c|c|c|c|}
\hline$\left(\mathrm{VOTPPCl}_{8}\right)$ & $2 \mathrm{eq} \mathrm{H}_{2} \mathrm{O}_{2}$ & 99 & - & - & - & - & 228 \\
\hline Co-salen-SBA15 & $2 \mathrm{eq}_{2} \mathrm{O}_{2}$ & 60 & - & - & - & - & 229 \\
\hline Mn porphyrin cage & $1 \mathrm{~atm} \mathrm{O} 2$ & 93 & - & - & - & - & 230 \\
\hline $\begin{array}{c}\text { NHPI, Co(OAc })_{2} \text {, and } \\
\mathrm{Mo}(\mathrm{CO})_{6}, 4 \AA \mathrm{MS}\end{array}$ & $1 \mathrm{~atm} \mathrm{O}_{2}$ & 59.2 & - & - & - & - & 231 \\
\hline $\mathrm{Fe}_{3} \mathrm{O}_{4} / \operatorname{tart} / \mathrm{Mn}(\mathrm{TCPP}) \mathrm{Cl}$ & $1 \mathrm{~atm} \mathrm{O}_{2}$ & 86 & 12 & - & - & - & 232 \\
\hline $\mathrm{Cu}-\mathrm{MOF}$ & $1 \mathrm{~atm} \mathrm{O}_{2}$ & 0.16 & 0.22 & 0.47 & - & $\underset{\mathrm{a}}{6.14 \mathrm{OOH}}$ & 233 \\
\hline $\begin{array}{c}\mathrm{TBA}_{5} \mathrm{Na}_{3}\left[(\mathrm{Cp} *) \mathrm{Rh} \cdot \mathrm{P}_{2} \mathrm{~W}_{15} \mathrm{~N}\right. \\
\left.\mathrm{b}_{3} \mathrm{O}_{62}\right] \\
\end{array}$ & $1 \mathrm{~atm} \mathrm{O}_{2}$ & - & 0.10 & 0.8 & - & - & 234 \\
\hline No Catalyst & 2 eq TBO & - & - & 1.12 & - & - & 235 \\
\hline$\left[\mathrm{LMn}(\mathrm{OAc})_{2}\right]$ & $2 \mathrm{eq} \mathrm{H}_{2} \mathrm{O}_{2}$ & 61.4 & 3.6 & 2.2 & - & - & 236 \\
\hline $\mathrm{VO}(\mathrm{acac})_{2}$ & $1 \mathrm{~atm} \mathrm{O}_{2}$ & 6.5 & 2.6 & 2.34 & - & $\begin{array}{c}\text { 14.6EPO } \\
\mathrm{H}^{\mathrm{a}}\end{array}$ & 237 \\
\hline$\left[\mathrm{Cu}-\right.$ Imace-H-H] $\left[\mathrm{BF}_{4}\right]$ & $1 \mathrm{~atm} \mathrm{O}_{2}$ & 50.4 & 1.8 & 5.4 & - & - & 238 \\
\hline $\begin{array}{l}\mathrm{Mo}(\mathrm{VI}) \mathrm{Cl}_{2} \mathrm{O}_{2} \mathrm{Bipy} / \mathrm{TiO}_{2} \mathrm{SC}- \\
150 \text { fresh (photocatalysis) }\end{array}$ & $1 \mathrm{~atm} \mathrm{O}_{2}$ & 45.4 & 3.82 & 5.47 & - & - & 239 \\
\hline $\mathrm{Au} / \mathrm{CNTs}-\mathrm{IM}$ & $0.05 \mathrm{eq}$ TBO & 43.6 & 7.48 & 6.38 & - & - & 222 \\
\hline $\mathrm{TBA}_{16}\left[\mathrm{Co}_{4}\left(\mathrm{P}_{2} \mathrm{~W}_{15} \mathrm{O}_{56}\right)_{2}\right]$ & 9 eq $\mathrm{H}_{2} \mathrm{O}_{2}$ & 3.23 & 5.7 & 10.1 & - & - & 240 \\
\hline $\begin{array}{c}\mathrm{TBA}_{5} \mathrm{Na}_{3}\left[(\mathrm{COD}) \mathrm{Ir} \cdot \mathrm{P}_{2} \mathrm{~W}\right. \\
\left.\mathrm{Nb}_{3} \mathrm{O}_{62}\right]\end{array}$ & $1 \mathrm{~atm} \mathrm{O}$ & 2 & 10 & 12 & - & - & 234 \\
\hline $\mathrm{Cu}\left(\mathrm{H}_{2}\right.$ btec $)$ (bipy) MOF & 1 eq TBO & 47.15 & - & $\begin{array}{c}12.3 \\
8\end{array}$ & - & $\begin{array}{c}4.97 \\
\text { ANONE }^{a}\end{array}$ & 241 \\
\hline$\left[\mathrm{LFe}(\mathrm{OAc})_{2}\right]$ & 0.5 eq $\mathrm{H}_{2} \mathrm{O}_{2}$ & 3.1 & 9.8 & 13.4 & - & - & 236 \\
\hline $\mathrm{TBA}_{16}\left[\mathrm{Ni}_{4}\left(\mathrm{P}_{2} \mathrm{~W}_{15} \mathrm{O}_{56}\right)_{2}\right]$ & 9 eq $\mathrm{H}_{2} \mathrm{O}_{2}$ & 3.24 & 8.1 & 15.7 & - & - & 240 \\
\hline $\begin{array}{c}\text { [NSP]@MWNTs Nickel } \\
\text { salophen nanotubes }\end{array}$ & $1 \mathrm{~atm} \mathrm{O}$ & - & 49.8 & 19.5 & - & - & 242 \\
\hline $\mathrm{TBA}_{16}\left[\mathrm{Mn}_{4}\left(\mathrm{P}_{2} \mathrm{~W}_{15} \mathrm{O}_{56}\right)_{2}\right]$ & 9 eq $\mathrm{H}_{2} \mathrm{O}_{2}$ & 10.0 & 7.03 & 20.0 & - & - & 240 \\
\hline None & $\begin{array}{c}0.05 \text { eq } \\
\mathrm{H}_{2} \mathrm{O}_{2}\end{array}$ & 2.14 & 9.44 & 23.6 & - & - & $\underset{\mathrm{b}}{\mathrm{TW}}$ \\
\hline None & $\begin{array}{c}0.05 \text { eq } \\
\text { TBO }\end{array}$ & 2.01 & 8.01 & 23.7 & - & - & $\begin{array}{c}\mathrm{TW} \\
\mathrm{b}\end{array}$ \\
\hline CFO-Ce $e_{0.3}$ & $1.5 \mathrm{eq} \mathrm{H}_{2} \mathrm{O}_{2}$ & 1.47 & 15.7 & 26.4 & - & - & 243 \\
\hline $\begin{array}{c}\mathrm{TBA}_{4.5} \mathrm{Na}_{2.5}\left[\left(\mathrm{be}^{\cdot}\right.\right. \\
\left.\text { nzene }) \mathrm{Ru} \cdot \mathrm{P}_{2} \mathrm{~W}_{15} \mathrm{Nb}_{3} \mathrm{O}_{62}\right]\end{array}$ & $1 \mathrm{~atm} \mathrm{O}_{2}$ & 8 & 20 & 28 & - & - & 234 \\
\hline $\begin{array}{c}\left(n \mathrm{Bu}_{4} \mathrm{~N}\right)_{4} \mathrm{~W}_{10} \mathrm{O}_{32} / \mathrm{SiO}_{2} / \\
\mathrm{Fe}(\mathrm{TDCPP}) \mathrm{Cl}+\mathrm{h} \nu+\text { Dark } 3 \\
\text { hrs }\end{array}$ & $1 \mathrm{~atm} \mathrm{O}_{2}$ & 1.4 & 20 & 29 & - & $\begin{array}{l}1.6 \mathrm{ETH}^{\mathrm{a}} \\
48 \mathrm{OOH}^{\mathrm{a}}\end{array}$ & 244 \\
\hline $\mathrm{TBA}_{8}\left[(\mathrm{CO})_{3} \mathrm{Re} \cdot \mathrm{P}_{2} \mathrm{~W}_{15} \mathrm{Nb}_{3} \mathrm{O}\right.$ & $1 \mathrm{~atm} \mathrm{O}_{2}$ & 7 & 20 & 30 & - & - & 234 \\
\hline $\mathrm{LFe}\left(\mathrm{NO}_{3}\right)$ & 1 eq $\mathrm{H}_{2} \mathrm{O}_{2}$ & 10.5 & 29.5 & 35.3 & 11.1 & - & 245 \\
\hline Cr-MCM-41 & 2 eq TBO & - & - & 39.0 & - & - & 235 \\
\hline Co-g- $\mathrm{C}_{3} \mathrm{~N}_{4}$ & $39.5 \mathrm{~atm} \mathrm{O}_{2}$ & - & 12.9 & 40.1 & 1.06 & - & 246 \\
\hline $\mathrm{TBA}_{12}\left[\mathrm{Fe}_{4}\left(\mathrm{P}_{2} \mathrm{~W}_{15} \mathrm{O}_{56}\right)_{2}\right]$ & 9 eq $\mathrm{H}_{2} \mathrm{O}_{2}$ & 23.6 & 9.88 & 42.6 & - & - & 240 \\
\hline $\mathrm{TBA}_{16}\left[\mathrm{Zn}_{4}\left(\mathrm{P}_{2} \mathrm{~W}_{15} \mathrm{O}_{56}\right)_{2}\right]$ & 9 eq $\mathrm{H}_{2} \mathrm{O}_{2}$ & 33.9 & 8.7 & 44.4 & - & - & 240 \\
\hline $\mathrm{BNO}_{2}-\mathrm{Cu}-\mathrm{TDCPP}$ & $3.95 \mathrm{~atm} \mathrm{O}_{2}$ & - & 13.8 & 45.5 & - & $\begin{array}{c}\text { 6.60OTH } \\
\text { ERS }\end{array}$ & 247 \\
\hline $\mathrm{LRuCl}$ & $1 \mathrm{eq} \mathrm{H}_{2} \mathrm{O}_{2}$ & 13.0 & 30.8 & 47.1 & 5.17 & - & 245 \\
\hline Cr-MCM-41 & 2 eq $\mathrm{H}_{2} \mathrm{O}_{2}$ & - & - & 47.3 & - & - & 248 \\
\hline $\mathrm{Fe}(\mathrm{TPP}) \mathrm{Cl}$ & $1 \mathrm{~atm} \mathrm{O}_{2}$ & - & - & 52 & - & - & 249 \\
\hline Calcined $\mathrm{CuO}$ catalyst & $3.95 \mathrm{~atm} \mathrm{O}_{2}$ & 4.41 & 31.1 & 54.4 & - & - & 250 \\
\hline
\end{tabular}




\begin{tabular}{|c|c|c|c|c|c|c|c|}
\hline Cr-MCM-48 & $2 \mathrm{eq}$ TBO & - & - & 55.6 & - & - & 235 \\
\hline $\begin{array}{c}\text { Diacetoxyiodobenzene } \\
\mathrm{K}_{2} \mathrm{CO}_{3}\end{array}$ & 4 eq TBO & - & - & 56 & - & - & 251 \\
\hline AgNP-MCM-41 & $\begin{array}{c}0.05 \text { eq } \\
\text { TBO }\end{array}$ & 0.69 & 18.0 & 59.4 & - & - & 252 \\
\hline $\mathrm{Rh}_{2}(\mathrm{cap})_{4}$ & 5 eq TBO & - & - & 60 & - & - & 253 \\
\hline $\mathrm{MgCl}_{2} / \mathrm{NHPI}$ & $3 \mathrm{~atm} \mathrm{O}_{2}$ & - & - & 60.3 & - & - & 254 \\
\hline $\mathrm{Cr}-\mathrm{mZrP}$ & 2 eq $\mathrm{H}_{2} \mathrm{O}_{2}$ & - & - & 63 & - & - & 255 \\
\hline $\mathrm{CoCl}_{2}$ & $1 \mathrm{~atm} \mathrm{O}_{2}$ & - & 4 & 71 & - & - & 256 \\
\hline g- $\mathrm{C}_{3} \mathrm{~N}_{4} / \mathrm{NHPI}$ & $1 \mathrm{~atm} \mathrm{O}_{2}$ & - & - & 71.6 & - & - & 257 \\
\hline $\mathrm{Cu}(\mathrm{II})$ salqu complex & 3 eq TBO & - & - & 74 & - & - & 258 \\
\hline $\mathrm{CoCr}-\mathrm{HTSi}_{2}$ & $1 \mathrm{eq} \mathrm{H}_{2} \mathrm{O}_{2}$ & - & 26 & 74 & - & - & 259 \\
\hline$\left[\mathrm{Cu}(\mathrm{Pht})(\mathrm{Im})_{2}\right] \cdot 1.5 \mathrm{H}_{2} \mathrm{O}_{\mathrm{n}}$ & 9 eq $\mathrm{H}_{2} \mathrm{O}_{2}$ & 11.3 & 11.5 & 75.2 & - & - & 260 \\
\hline $\begin{array}{l}{\left[\mathrm{Mn}\left(\mathrm{C}_{6} \mathrm{H}_{5} \mathrm{COO}\right)\left(\mathrm{H}_{2} \mathrm{O}\right)-\right.} \\
\left.(\mathrm{phen})_{2}\right]\left(\mathrm{ClO}_{4}\right)\left(\mathrm{CH}_{3} \mathrm{OH}\right)\end{array}$ & 8 eq TBO & 4.6 & 2.5 & 76 & 11.2 & - & 261 \\
\hline$\left[\mathrm{C}_{10} \mathrm{mim}\right]\left[\mathrm{Co}\left(\mathrm{F}_{6}-\mathrm{acac}\right)_{3}\right]$ & $1 \mathrm{~atm} \mathrm{O}_{2}$ & -- & - & 81 & - & - & 262 \\
\hline $\mathrm{Mn}(\mathrm{Oac})_{2} \cdot 4 \mathrm{H}_{2} \mathrm{O}$ & $2 \mathrm{eq}$ TBO & - & - & 85 & - & - & 263 \\
\hline $\mathrm{Ag}-\mathrm{VPO}$ & 3 eq TBO & - & - & 86.3 & - & - & 264 \\
\hline $\mathrm{Fe}_{3} \mathrm{O}_{4} \mathrm{MNPs}$ & 3 eq TBO & - & - & 87 & - & - & 265 \\
\hline$[(\mathrm{TAML}) \mathrm{Fe}(\mathrm{III})]^{-}$ & $1 \mathrm{~atm} \mathrm{O}_{2}$ & 11 & - & 89 & - & - & 266 \\
\hline Au-Silica & $8-13 \mathrm{~atm} \mathrm{O}_{2}$ & - & 2.76 & 89.2 & - & - & 267 \\
\hline CoEPS3 & 6 eq TBO & - & - & 90 & - & - & 268 \\
\hline
\end{tabular}

${ }^{\mathrm{a}}$ see Fig. S22. ${ }^{\mathrm{b}}$ This work.

We find that for cyclooctene, 5 mole $\%{ }^{\mathrm{t}} \mathrm{BuOOH}$ resulted in $40.3 \%$ epoxide, $0.35 \%$ of 1,2-cyclooctanediol, and $1.18 \%$ of 2-cycloocten-1-one suggesting that oxygen and free radicals must be involved in this reaction, Table 6.12. The use of group 6 transition metal catalysts also showed some of the highest yields for producing the epoxide with the trend of Mo $>\mathrm{W}$. This may be due to differences in $\mathrm{M}-\mathrm{O}$ bond strength as tungsten is reported to form very strong bonds with oxygen. ${ }^{269}$ Other transition metal catalysts such as Fe, Au, Ag, Cu, Rh, Mn, Co, Zn, Ti, Re, and V were also employed but produced a variety of products. Interestingly large tungsten oxide clusters, e.g., $\mathrm{TBA}_{16}\left[\mathrm{Ni}_{4}\left(\mathrm{P}_{2} \mathrm{~W}_{15} \mathrm{O}_{56}\right)_{2}\right], \mathrm{TBA}_{12}\left[\mathrm{Fe}_{4}\left(\mathrm{P}_{2} \mathrm{~W}_{15} \mathrm{O}_{56}\right)_{2}\right]$, $\mathrm{TBA}_{16}\left[\mathrm{Zn}_{4}\left(\mathrm{P}_{2} \mathrm{~W}_{15} \mathrm{O}_{56}\right)_{2}\right],{ }^{[32]}$ resulted in significant quantities of the ketone, 2cycloocten-1-one and 1,2-cyclooctanediol at 19.1, 47.8 and 43\% yield respectively. ${ }^{236}$ Due to the different conditions used (lower temperatures and 200 to 900 mole \% equivalents of peroxide) it is not reasonable to compare this work with the others listed in Table 6.12, but in these reactions, some decomposition of the peroxide may be occurring rending the possibility of free radical reactions. It was also found that the amount of ketone produced increased as the quantity of peroxide used in the 
reaction increased. ${ }^{270}$ It is possible that reactions affording less than $40 \%$ of epoxide product are occurring via free radical mechanisms but those greater than $50 \%$ may well involve metal atom catalyst.

Table 6.12. The yields of products from the oxidation of cyclooctene using $\mathrm{O}_{2}$, ${ }^{t} \mathrm{BuOOH}$ (TBO) or $\mathrm{H}_{2} \mathrm{O}_{2}$ as the oxidant. See references for other conditions of the reactions. A dash indicates that the yield for that product was not reported.

\begin{tabular}{|c|c|c|c|c|c|c|c|}
\hline Catalyst & Oxidant & Yiel & Yield & Yield & Yield & Yield & Ref. \\
\hline None $^{a}$ & $2 \mathrm{eq}_{2} \mathrm{O}_{2}$ & - & - & - & - & - & 240 \\
\hline$\left(n \mathrm{Bu}_{4} \mathrm{~N}\right)_{4} \mathrm{~W}_{10} \mathrm{O}_{32}+\mathrm{hv}$ & $1 \mathrm{~atm} \mathrm{O}_{2}$ & 1.9 & - & - & - & 5.8 & 244 \\
\hline $\mathrm{VO}(\mathrm{acac})_{2}$ & $1 \mathrm{~atm} \mathrm{O}$ & 2.97 & - & - & - & - & 237 \\
\hline $\mathrm{TBA}_{16}\left[\mathrm{Co}_{4}\left(\mathrm{P}_{2} \mathrm{~W}_{15} \mathrm{O}_{56}\right)_{2}\right]$ & 9 eq $\mathrm{H}_{2} \mathrm{O}_{2}$ & 4.51 & - & 4.4 & 2.09 & - & 240 \\
\hline $\mathrm{TBA}_{16}\left[\mathrm{Ni}_{4}\left(\mathrm{P}_{2} \mathrm{~W}_{15} \mathrm{O}_{56}\right)_{2}\right]$ & $9 \mathrm{eq} \mathrm{H}_{2} \mathrm{O}_{2}$ & 6.93 & - & 19.1 & 6.93 & - & 240 \\
\hline $\mathrm{Au}$ on $\mathrm{SiC}$ & $1.5 \mathrm{eq}$ TBO & 8.07 & - & - & - & - & 271 \\
\hline $\mathrm{TBA}_{16}\left[\mathrm{Mn}_{4}\left(\mathrm{P}_{2} \mathrm{~W}_{15} \mathrm{O}_{56}\right)_{2}\right]$ & $2 \mathrm{eq} \mathrm{H}_{2} \mathrm{O}_{2}$ & 10.7 & - & 12.2 & 3.12 & - & 240 \\
\hline$\left[\mathrm{LFe}(\mathrm{Oac})_{2}\right]$ & $0.5 \mathrm{eq} \mathrm{H}_{2} \mathrm{O}_{2}$ & 19.5 & - & - & - & - & 236 \\
\hline $\mathrm{Au} / \mathrm{CNTs}-\mathrm{IM}$ & $\begin{array}{c}0.05 \mathrm{eq} \\
\text { TBO }\end{array}$ & 24.0 & - & 4.59 & 4.26 & - & 222 \\
\hline $\mathrm{TBA}_{12}\left[\mathrm{Fe}_{4}\left(\mathrm{P}_{2} \mathrm{~W}_{15} \mathrm{O}_{56}\right)_{2}\right]$ & 9 eq $\mathrm{H}_{2} \mathrm{O}_{2}$ & 30 & - & 47.8 & 3.24 & - & 240 \\
\hline $\mathrm{TBA}_{16}\left[\mathrm{Zn}_{4}\left(\mathrm{P}_{2} \mathrm{~W}_{15} \mathrm{O}_{56}\right)_{2}\right]$ & 9 eq $\mathrm{H}_{2} \mathrm{O}_{2}$ & 31 & - & 43 & 12 & - & 240 \\
\hline None & $\begin{array}{c}0.05 \mathrm{eq} \\
\mathrm{H}_{2} \mathrm{O}_{2} \\
\end{array}$ & 31.0 & - & - & - & - & $\mathrm{TW}^{\mathrm{b}}$ \\
\hline $\mathrm{MoCl}_{2}(\mathrm{O})_{2}\left(\mathrm{OPMePh}_{2}\right)_{2}$ & $1.5 \mathrm{eq} \mathrm{H}_{2} \mathrm{O}_{2}$ & 35 & - & - & - & - & 219 \\
\hline None & $\begin{array}{c}0.05 \mathrm{eq} \\
\mathrm{TBO}\end{array}$ & 40.3 & 0.35 & 1.18 & - & - & $\mathrm{TW}^{\mathrm{b}}$ \\
\hline$\left[\mathrm{MoO}\left(\mathrm{O}_{2}\right)_{2} 4,4-\text { bipy }\right]_{\mathrm{n}}$ & $2.5 \mathrm{eq} \mathrm{H}_{2} \mathrm{O}_{2}$ & 41 & - & - & - & - & 226 \\
\hline $\mathrm{WCl}_{2}(\mathrm{O})_{2}\left(\mathrm{OPMePh}_{2}\right)_{2}$ & $1.5 \mathrm{eq}$ TBO & 61 & - & - & - & - & 219 \\
\hline$\left(\mathrm{LMnCl}_{2}\right)$ & $2 \mathrm{eq} \mathrm{H}_{2} \mathrm{O}_{2}$ & 64 & - & - & - & - & 236 \\
\hline $\mathrm{Fe}_{3} \mathrm{O}_{4} \mathrm{MNPs}$ & 3 eq TBO & 70 & - & - & - & - & 265 \\
\hline $\begin{array}{c}(4- \\
\text { ddp })_{1.5} \mathrm{Na}_{5.5}\left[\mathrm{PTi}_{2} \mathrm{~W}_{10} \mathrm{O}_{40}\right] \cdot 5 \\
\mathrm{H}_{2} \mathrm{O}\end{array}$ & 2 eq $\mathrm{H}_{2} \mathrm{O}_{2}$ & 70 & - & - & - & - & 227 \\
\hline Gold Clusters & $1 \mathrm{~atm} \mathrm{O}_{2}$ & 70 & - & - & - & - & 272 \\
\hline $\mathrm{WCl}_{2}(\mathrm{O})_{2}(\mathrm{OPMePh})_{2}$ & $1.5 \mathrm{eq} \mathrm{H}_{2} \mathrm{O}_{2}$ & 70 & - & - & - & - & 219 \\
\hline AgNP-MCM-41 & $\begin{array}{c}0.05 \mathrm{eq} \\
\mathrm{TBO}\end{array}$ & 72.4 & - & 2.02 & 0.22 & - & 252 \\
\hline $\begin{array}{c}\text { NHPI, } \mathrm{Co}(\mathrm{OAc})_{2}, \text { and } \\
\mathrm{Mo}(\mathrm{CO})_{6}, 4 \AA \mathrm{MS}\end{array}$ & $1 \mathrm{~atm} \mathrm{O}_{2}$ & 73.9 & - & - & - & 0.1 & 231 \\
\hline$\gamma-\mathrm{SiW}_{10} \mathrm{Fe}^{3+}\left(\mathrm{OH}_{2}\right)_{2} \mathrm{O}_{38^{6-}}$ & $1 \mathrm{~atm} \mathrm{O}$ & 80.4 & - & - & - & - & 273 \\
\hline Mn porphyrin cage & $1 \mathrm{~atm} \mathrm{O}_{2}$ & 89 & - & - & - & - & 230 \\
\hline $\mathrm{H}_{3} \mathrm{PW}_{12} \mathrm{O}_{40}$ & 2 eq $\mathrm{H}_{2} \mathrm{O}_{2}$ & 89.3 & - & - & - & - & 225 \\
\hline
\end{tabular}




\begin{tabular}{|c|c|c|c|c|c|c|c|}
\hline $\mathrm{Fe}_{3} \mathrm{O}_{4} / \mathrm{tart} / \mathrm{Mn}(\mathrm{TCPP}) \mathrm{Cl}$ & 1 atm $\mathrm{O}_{2}$ & 96 & - & - & - & - & ${ }^{232}$ \\
\hline $\begin{array}{c}{\left[\mathrm{MoO}_{2} \mathrm{Cl}_{2}\left(\mathrm{H}_{2} \mathrm{O}\right)_{2}\right] \cdot\left(\mathrm{H}_{2} \mathrm{dipy}-\right.} \\
\text { pra }) \mathrm{Cl}_{2},\end{array}$ & 4 eq H$_{2} \mathrm{O}_{2}$ & 99 & - & - & - & - & ${ }^{224}$ \\
\hline$\left[\mathrm{CH}_{3} \mathrm{ReO}_{3}\right]$ & 2 eq $\mathrm{H}_{2} \mathrm{O}_{2}$ & 100 & - & - & - & - & ${ }^{274}$ \\
\hline $\mathrm{MoCl}_{2}(\mathrm{O})_{2}\left(\mathrm{OPMePh}_{2}\right)_{2}$ & 1.5 eq TBO & 100 & - & - & - & - & ${ }^{219}$ \\
\hline
\end{tabular}

${ }^{\mathrm{a}}$ Reaction conducted at $50{ }^{\circ} \mathrm{C} .{ }^{\mathrm{b}} \mathrm{TW}=$ this work.

Of particular note are those reactions catalyzed in the presence of just oxygen. The catalyst labelled as Mn porphyrin cage (representing a supramolecular manganese porphyrin complex) requires an aldehyde reductant (i.e., 10 equivalents of isobutyraldehyde) and results in remarkable yields of epoxide in the case of cyclohexene (93\%, Table 6.11) and cyclooctene $(89 \%$, Table 6.12$) .{ }^{230}$ This reaction does not proceed in the presence of BHT suggesting that free radical species are involved. ${ }^{230}$ In contrast to the mechanisms suggested in Schemes 6.1 and 6.2, the proposed mechanism in this case involves the formation of an acyl radical from isobutyraldehyde with subsequent formation of a peroxide by reaction with oxygen which results in the formation of a manganese oxide that transfers the $\mathrm{O}$ atom to the alkene resulting in the epoxide. This shows that very complex mechanisms pertain to the systems listed in Tables 6.11 and 6.12.

\subsection{Conclusions}

A variety of experimental conditions including using a Teflon container to conduct the reaction, changing reaction concentration and temperature, using the free radical trap BHT, using different solvents and oxygen or nitrogen atmospheres permitted the conclusion that the oxidation of cyclohexene and cyclooctene in the presence of 0.05 equivalents of either $\mathrm{H}_{2} \mathrm{O}_{2}$ or ${ }^{\mathrm{t}} \mathrm{BuOOH}$ under oxygen occurs via the formation of free radicals. Under the stated reaction conditions 23.7\% 2-cyclohexen-1one, $8.0 \%$ 2-cyclohexen-1-ol and 2.0\% cyclohexene oxide were obtained for cyclohexene and $40.3 \%$ epoxide, $0.35 \%$ of 1,2 -cyclooctanediol, and $1.18 \%$ of 2 cycloocten-1-one for cyclooctene. Two Schemes were proposed which suggested that the formation of ketones required higher activation energies based on Gaussian calculations and occurred via a unimolecular pathway and that the formation of 
epoxide required lowed activation energies was bimolecular. The data suggests that some results in the literature may well be the result of free radical reactions.

\subsection{Supplementary Data for Chapter 6}

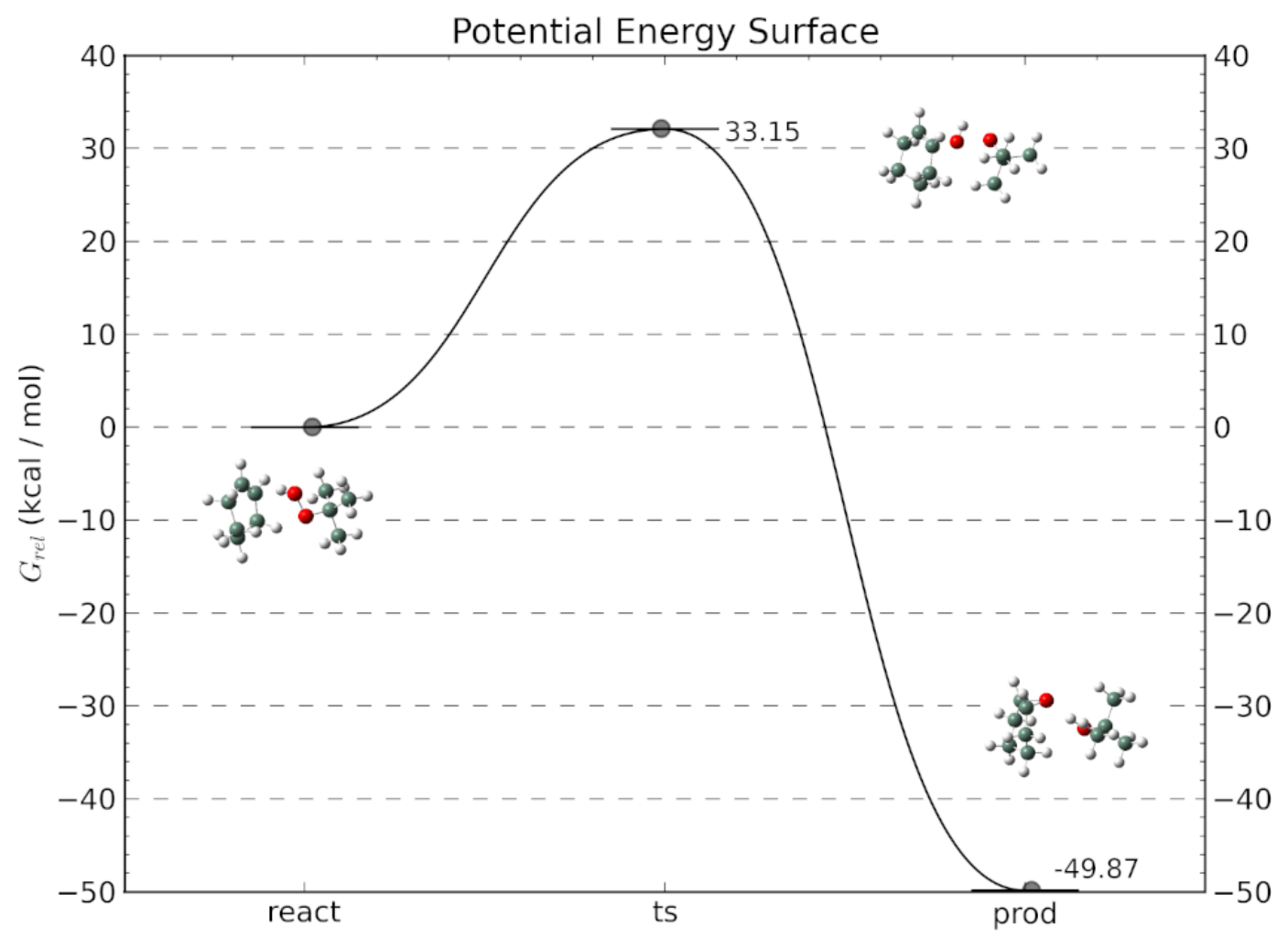

Figure S6.1. PE plot for the reaction between cyclohexene and ${ }^{\mathrm{t}} \mathrm{BuOOH}$. 


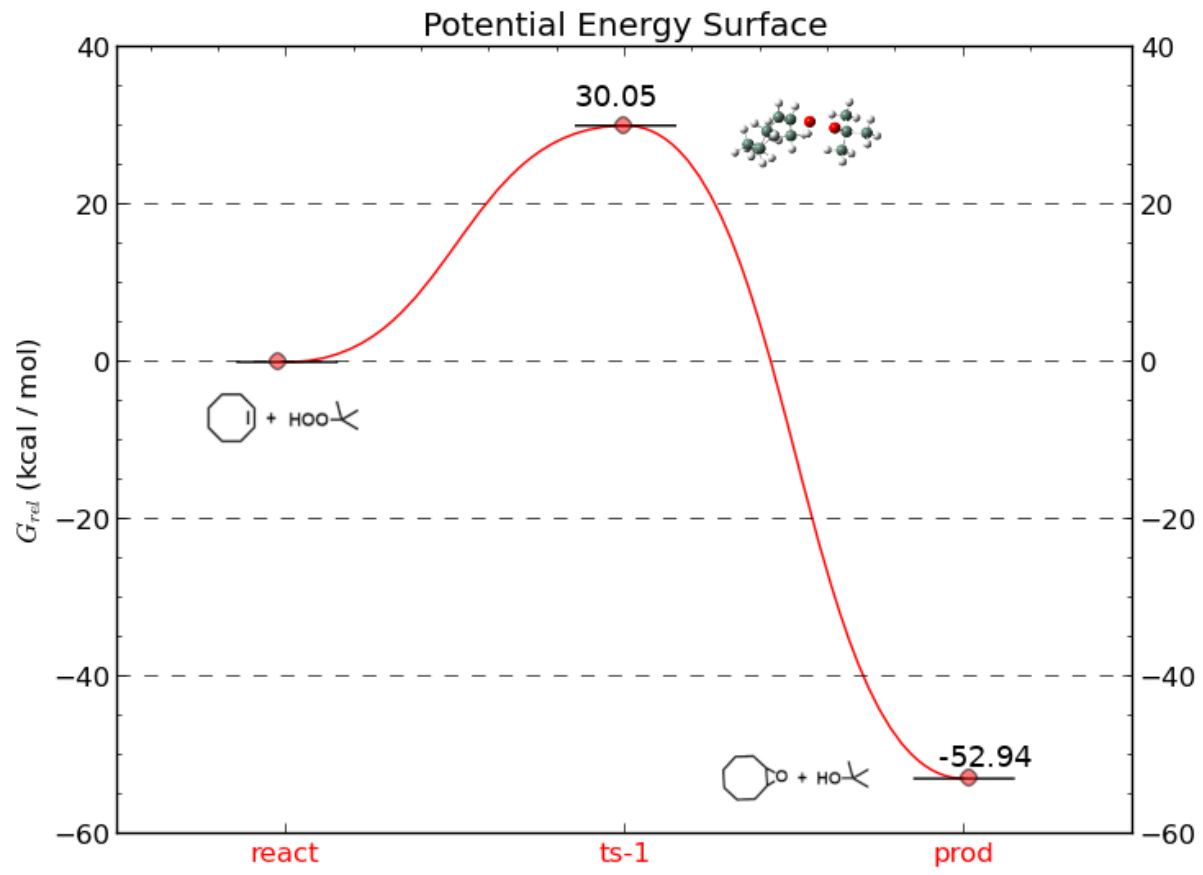

Figure S6.2. PE plot for the reaction between cyclooctene and ${ }^{t} \mathrm{BuOOH}$. 


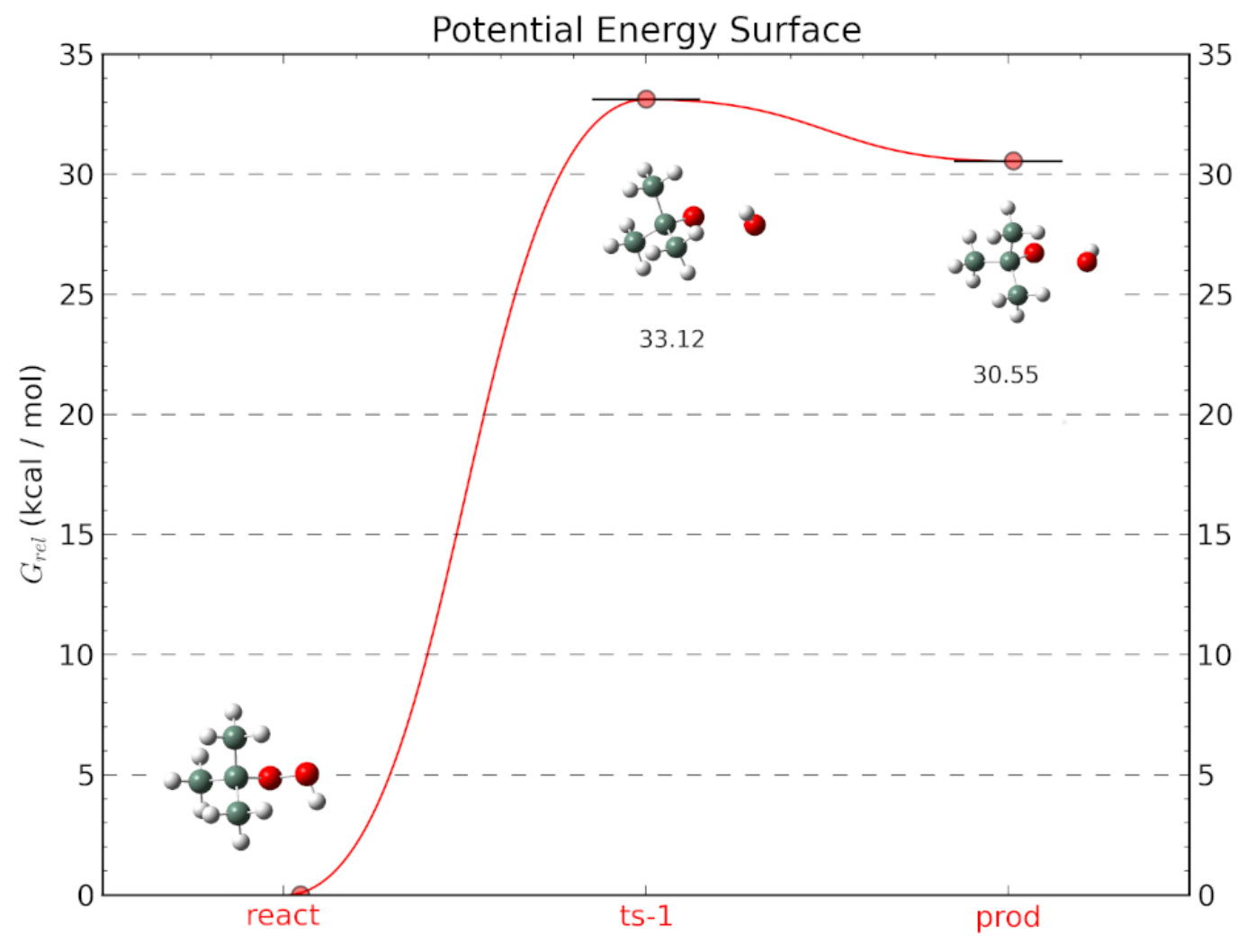

Figure S6.3. Rupture of the $\mathrm{O}-\mathrm{O}$ bond in ${ }^{\mathrm{t}} \mathrm{BuOOH}$. 


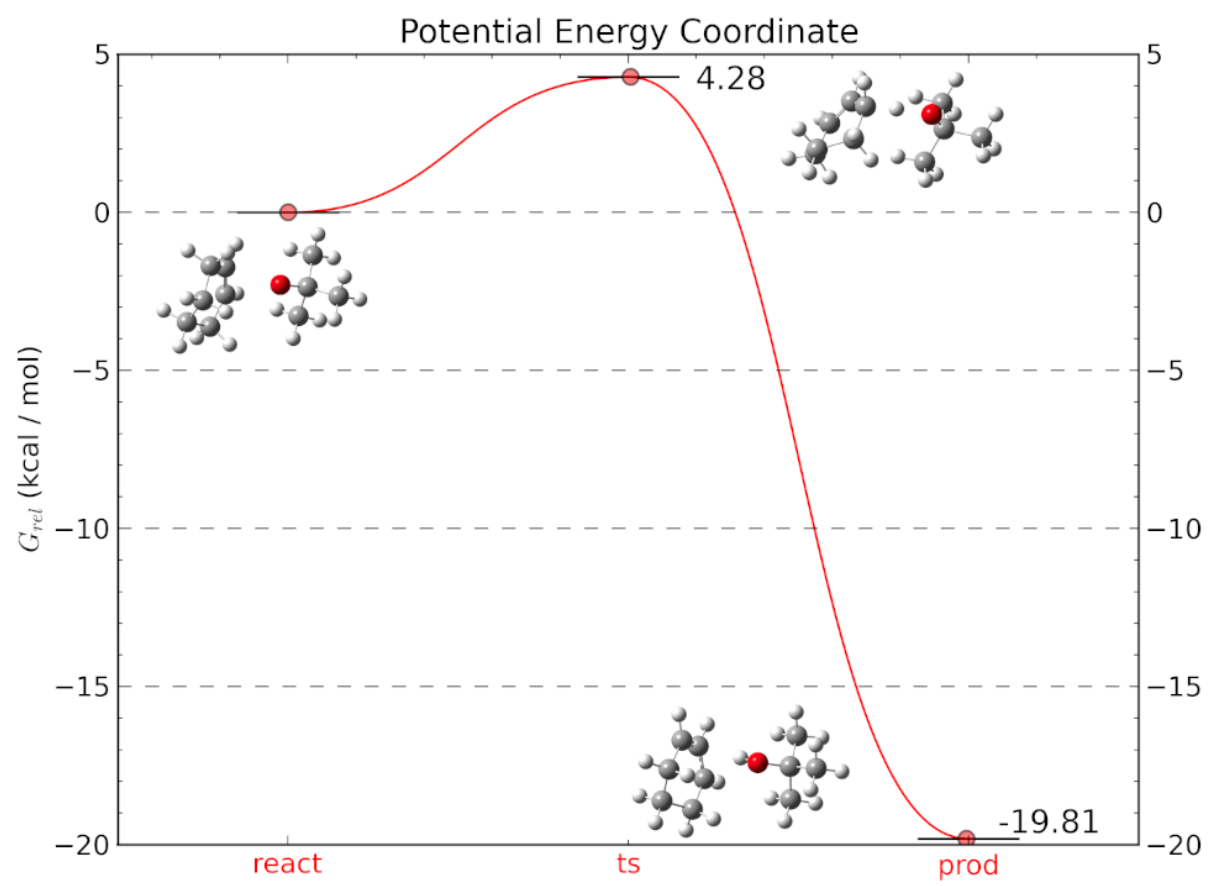

Figure S6.4. Abstracting a proton from cyclohexene by the ${ }^{\mathrm{t}} \mathrm{BuO} \cdot$ radical 

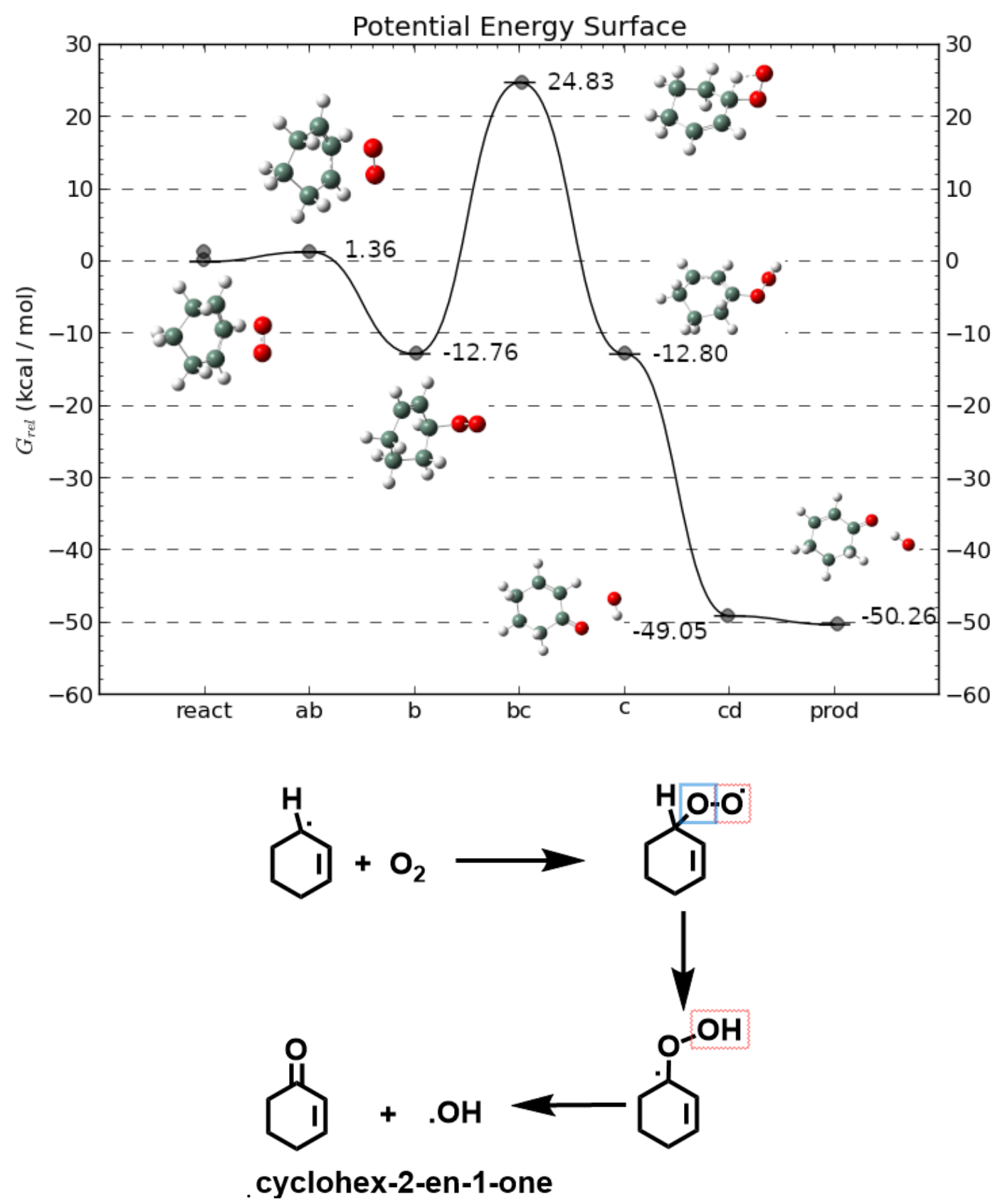

Figure S6.5. The formation of cyclohex-2-en-1-one as depicted in the PE plot for the scheme shown below. 

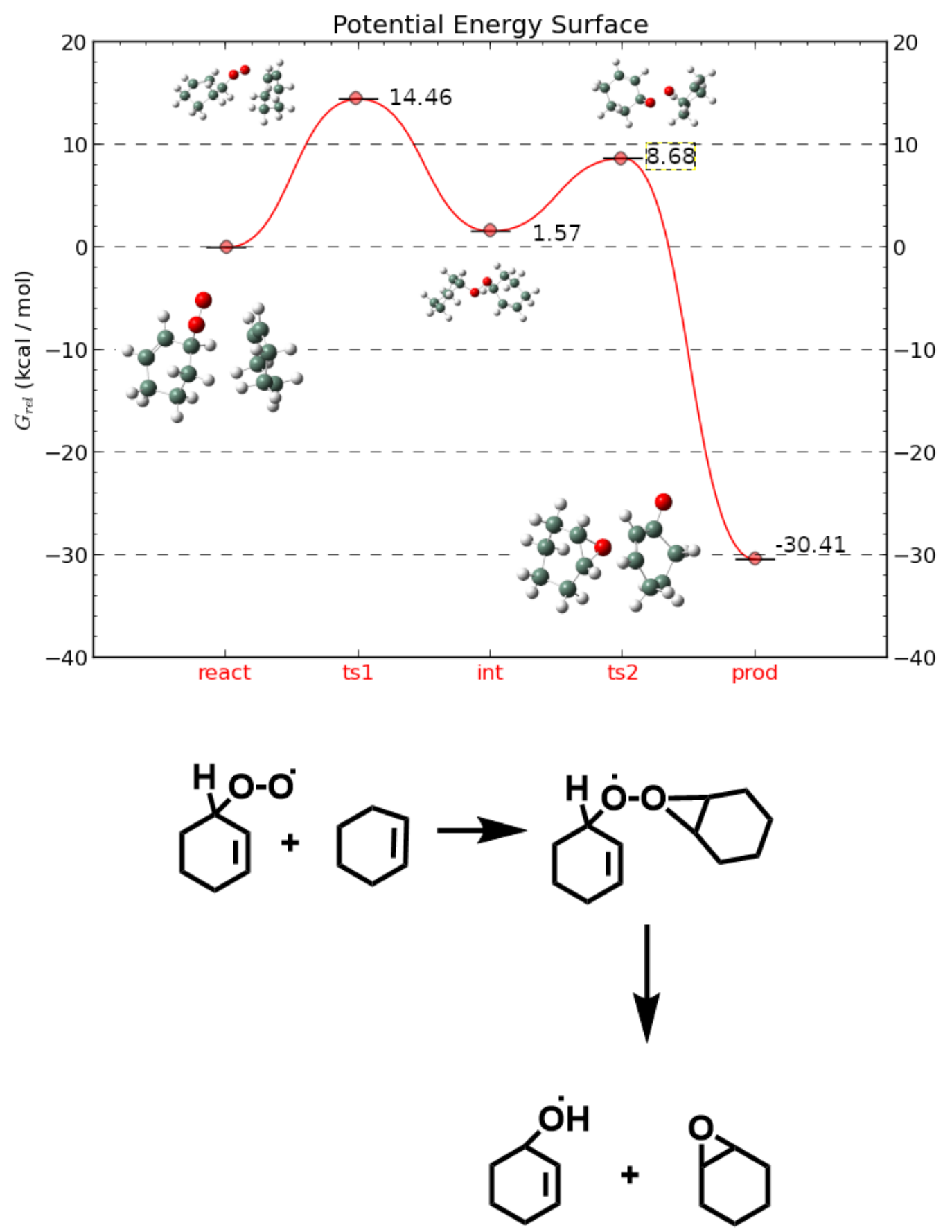

Figure S6.6. The formation of cyclohexene oxide as depicted in the PE plot for the scheme shown below. 

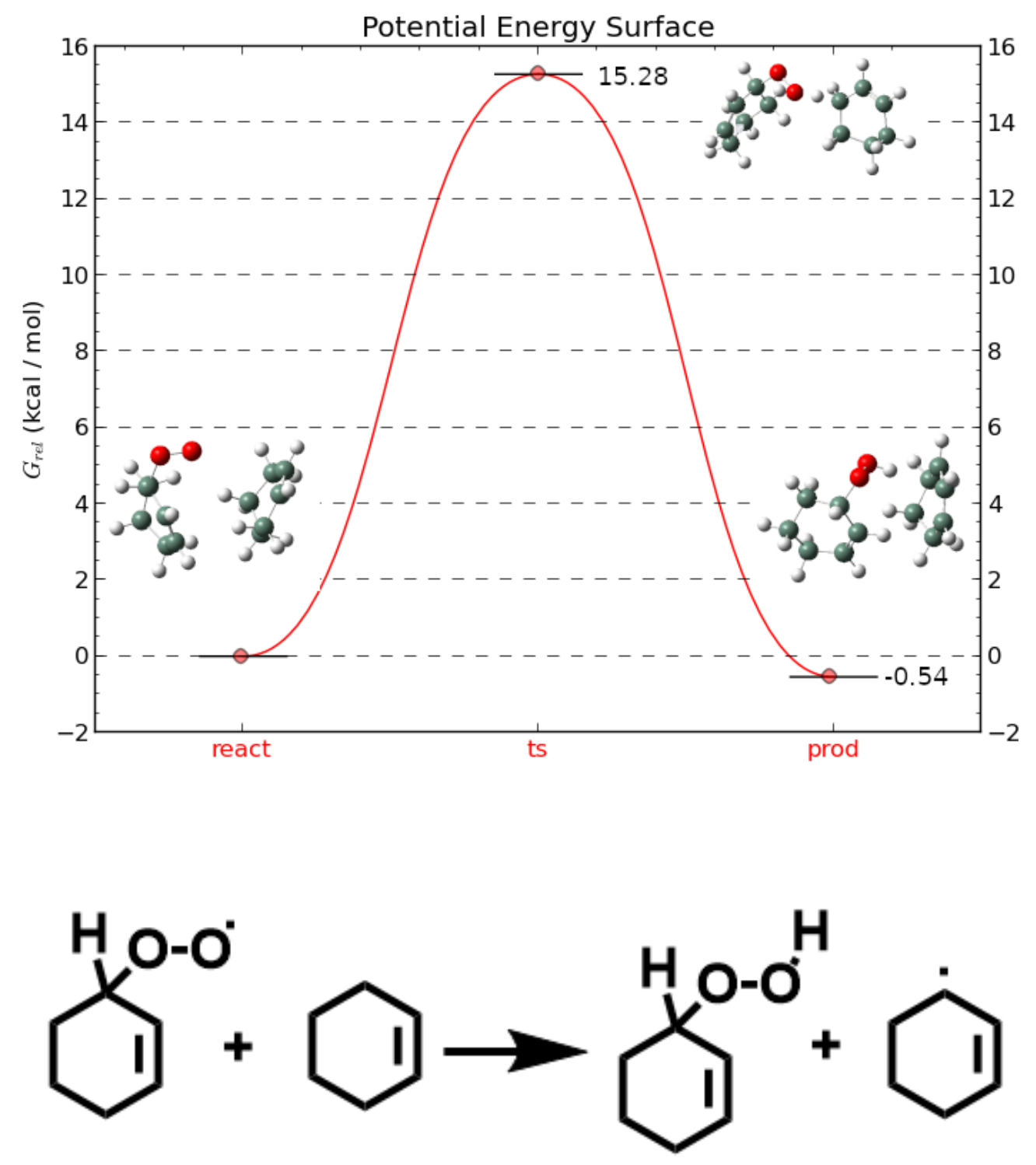

Figure S6.7. The formation of 3-hydroperoxycyclohex-1-ene as depicted in the PE plot for the scheme shown below the plot. 


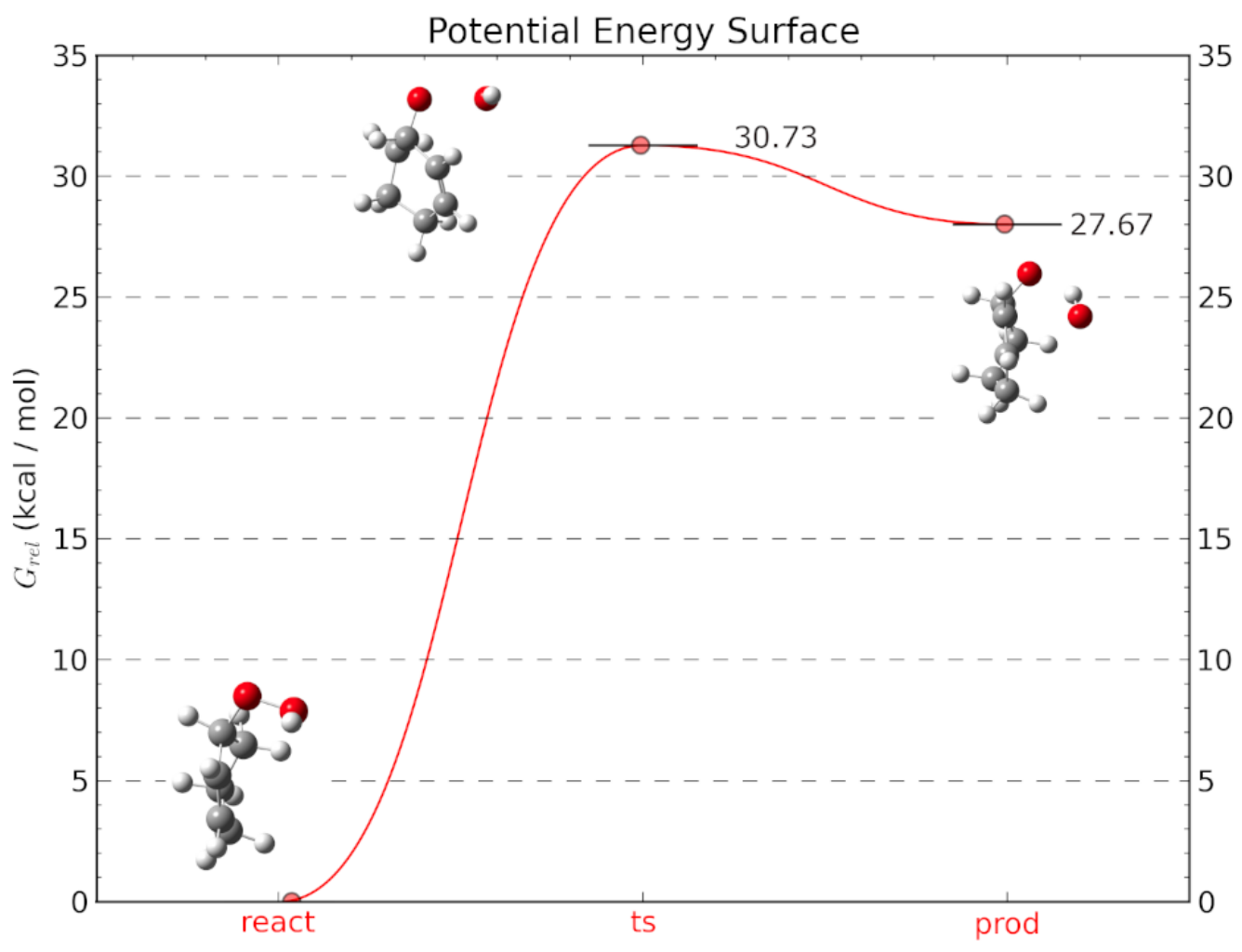

Figure S6.8. Rupture of the O-O bond in 3-hydroperoxycyclohex-1-ene to form 1-oxocyclohex-2-ene and hydroxide radicals. 

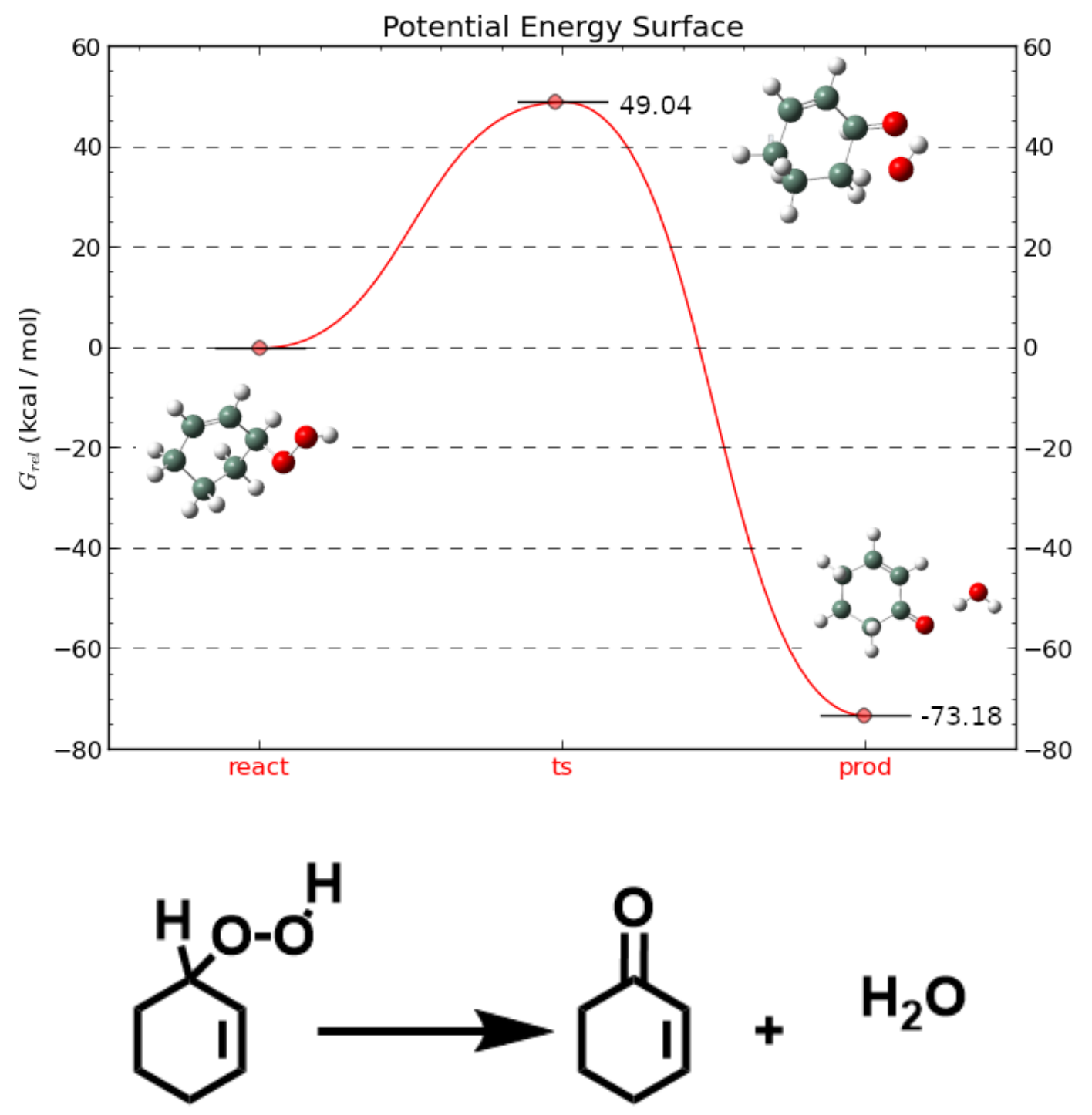

Figure S6.9. The formation of cyclohex-2-en-1-one as depicted in the PE plot for the scheme shown below the plot. 


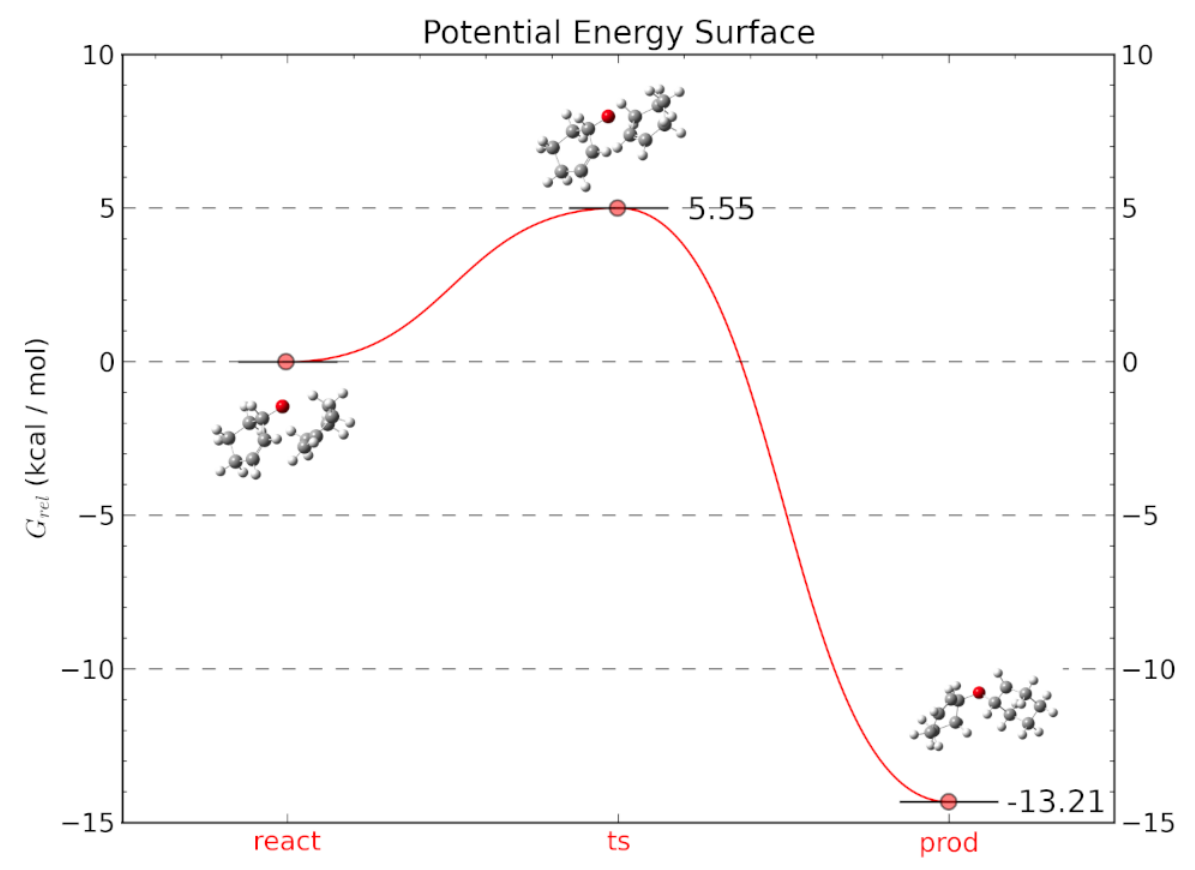

Figure S6.10. The reaction of the 1-oxo-cyclohex-2-ene radical with cyclohexene to form a dicyclohexene ether radical.

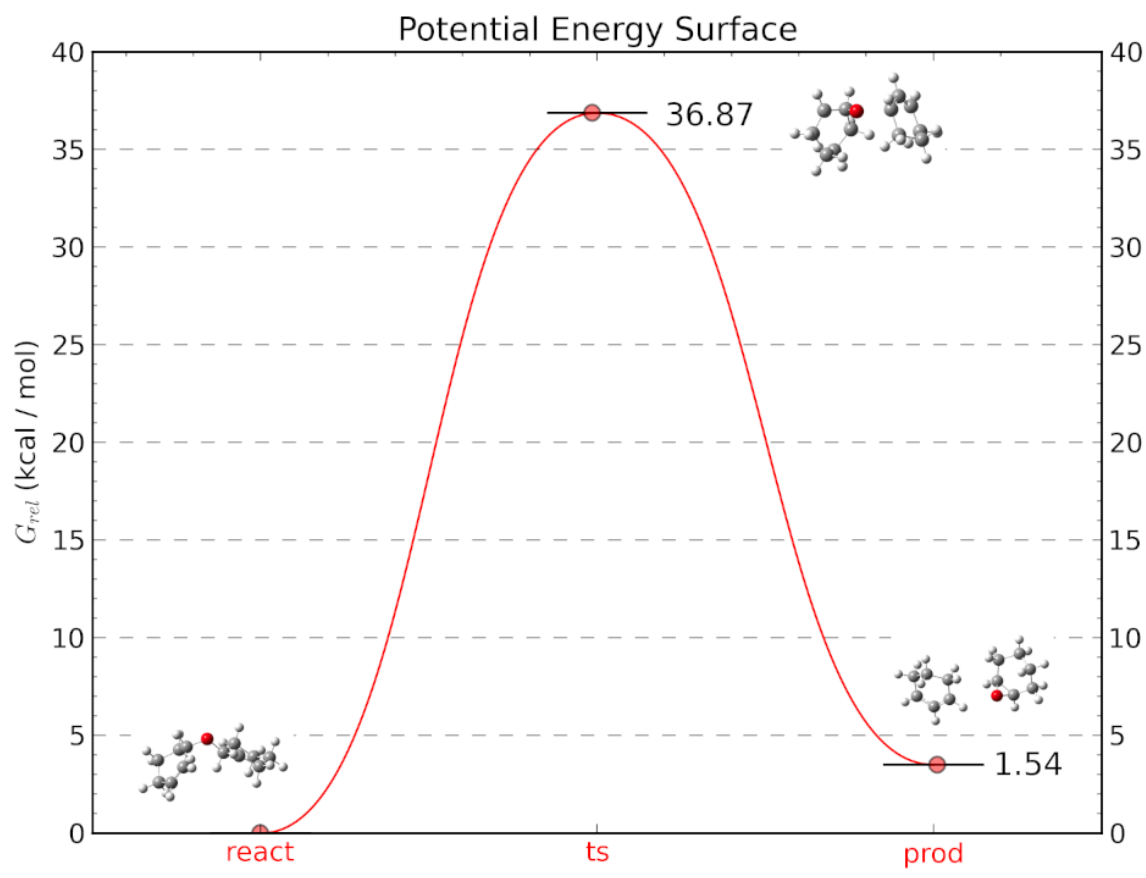

Figure S6.11. Dissociation of the dicyclohexene ether radical into cyclohexene epoxide and cyclohexene radical. 


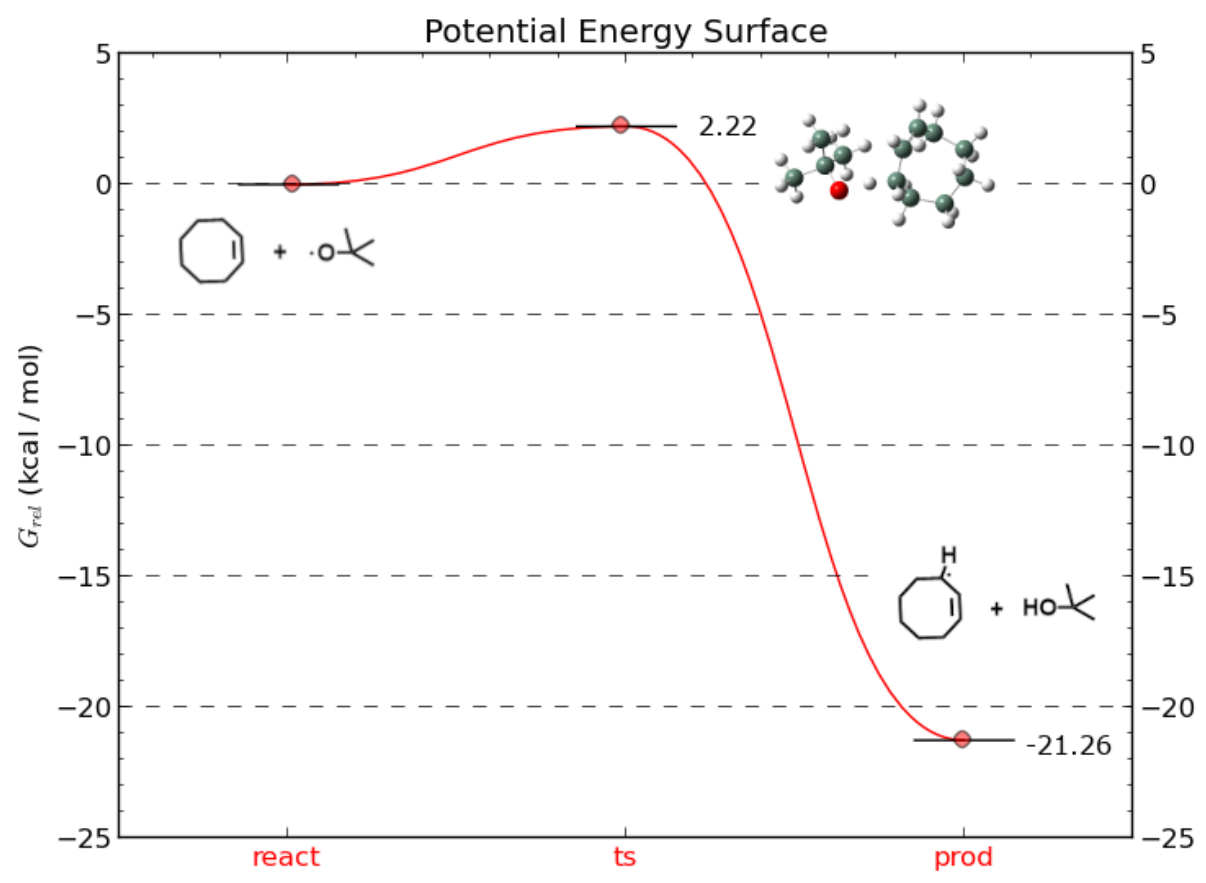

Figure S6.12. Abstraction of a proton from cyclooctene by the ${ }^{\mathrm{t}} \mathrm{BuO} \bullet$ radical.

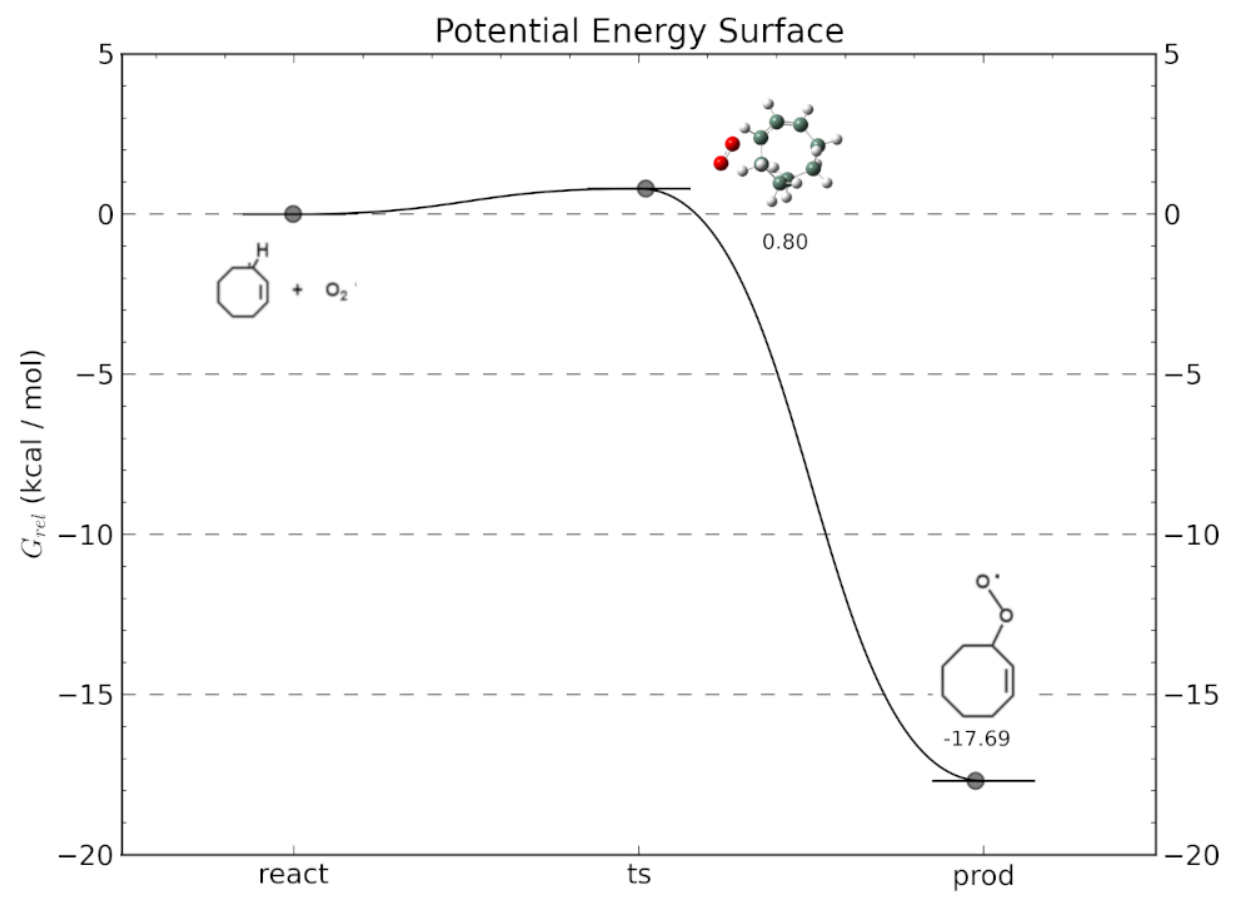

Figure S6.13. Reaction of $\mathrm{O}_{2}$ with the cyclooctene radical. 


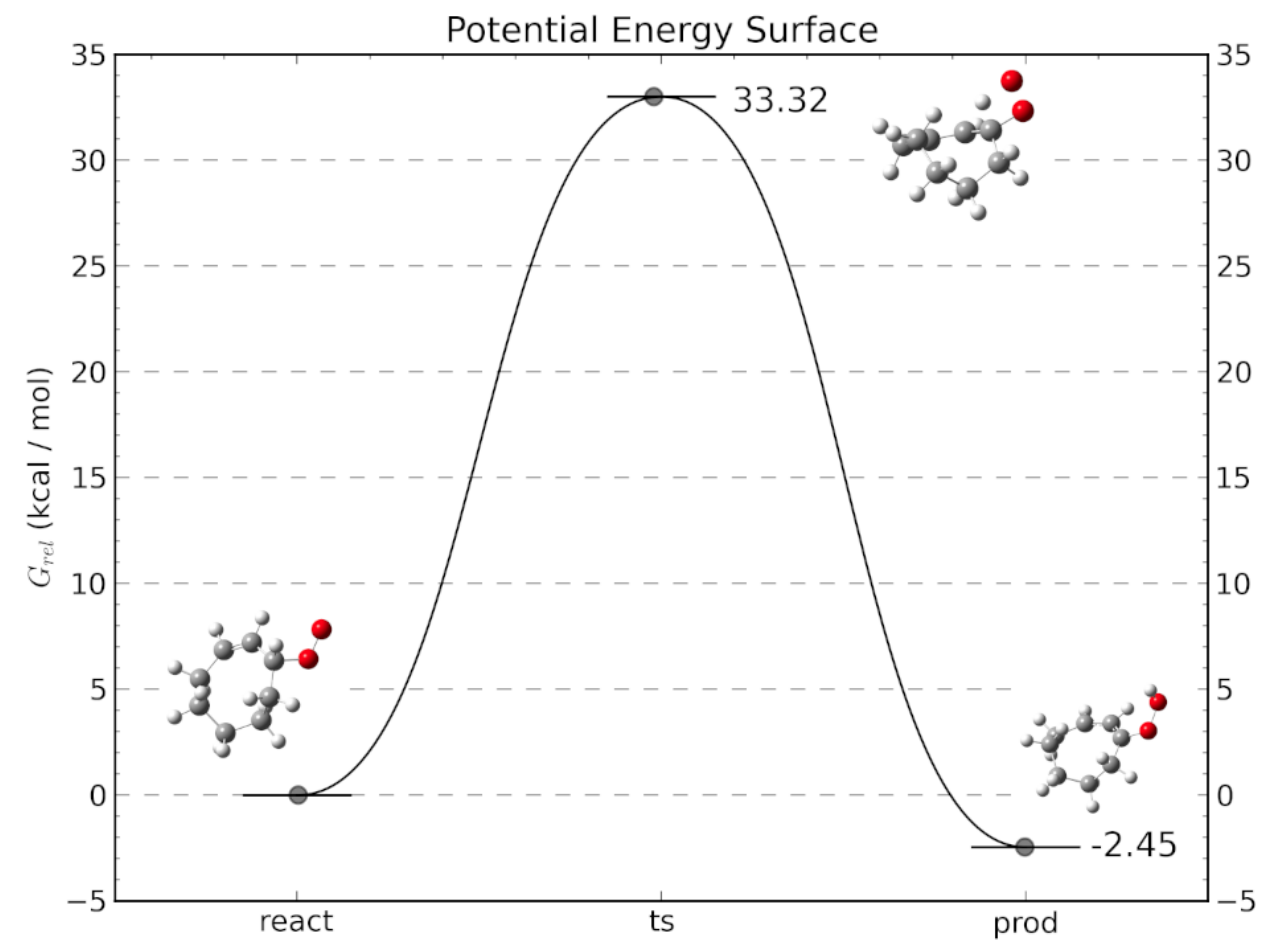

Figure S6.14. Hydrogen atom shift in the cyclooctene peroxy radical.

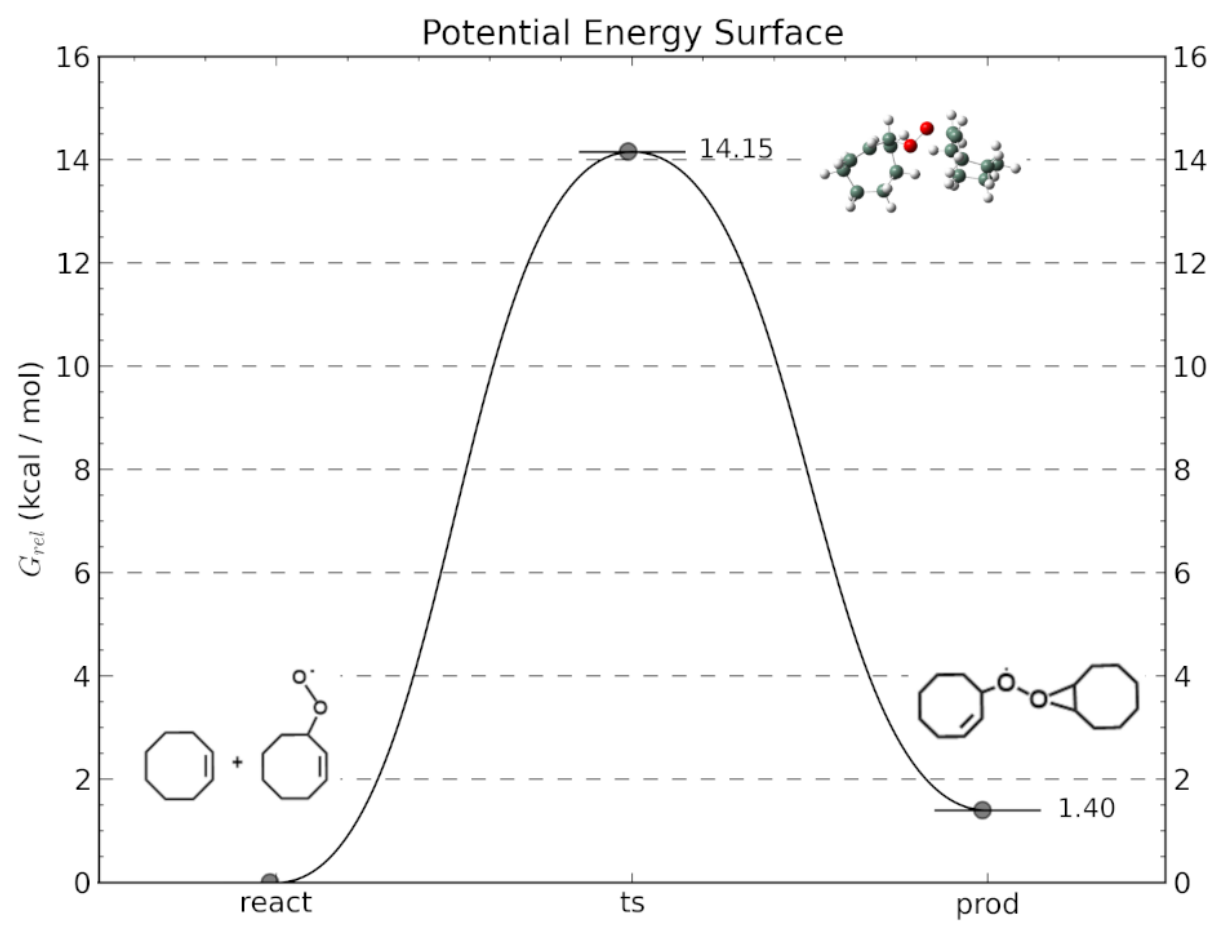

Figure S6.15. Reaction between cyclooctene and the cyclooctene peroxy radical to produce the peroxo-bridged radical dimer. 


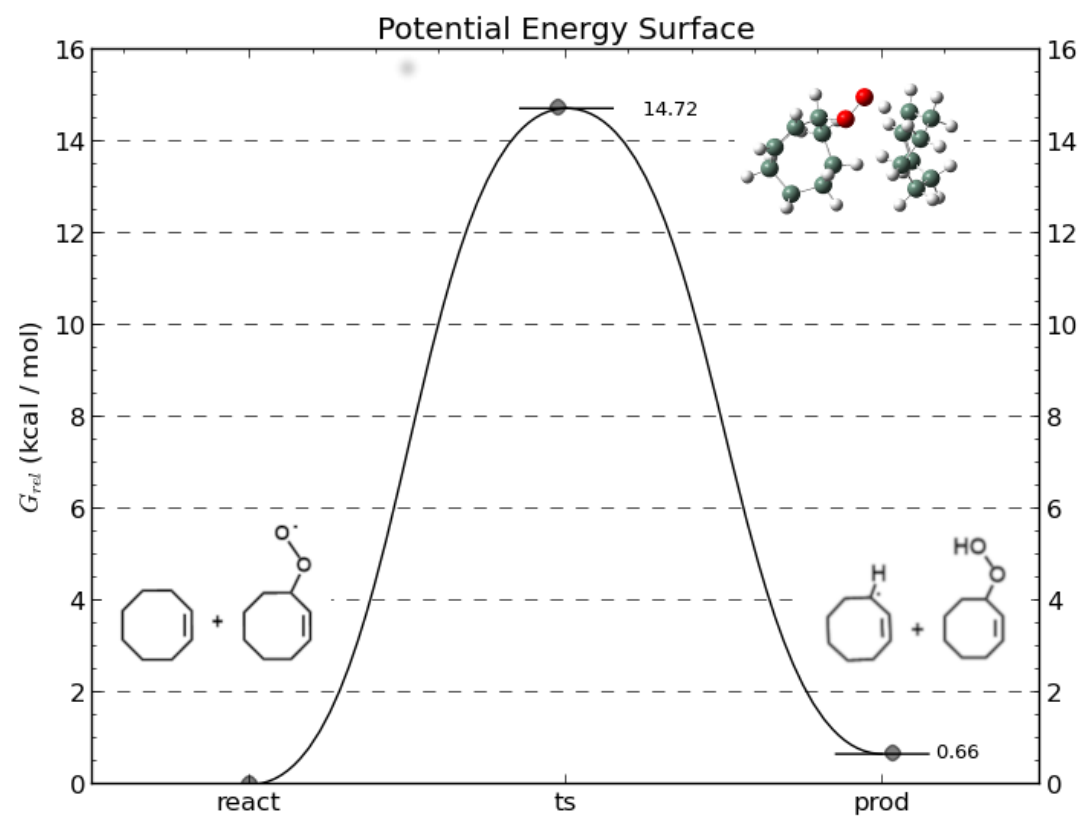

Figure S6.16. Formation of cyclooctene radical and (Z)-3-hydroperoxycyclooct-1-ene from the reaction between $(Z)-1$-peroxycyclooct-2-ene radical and cyclooctene.

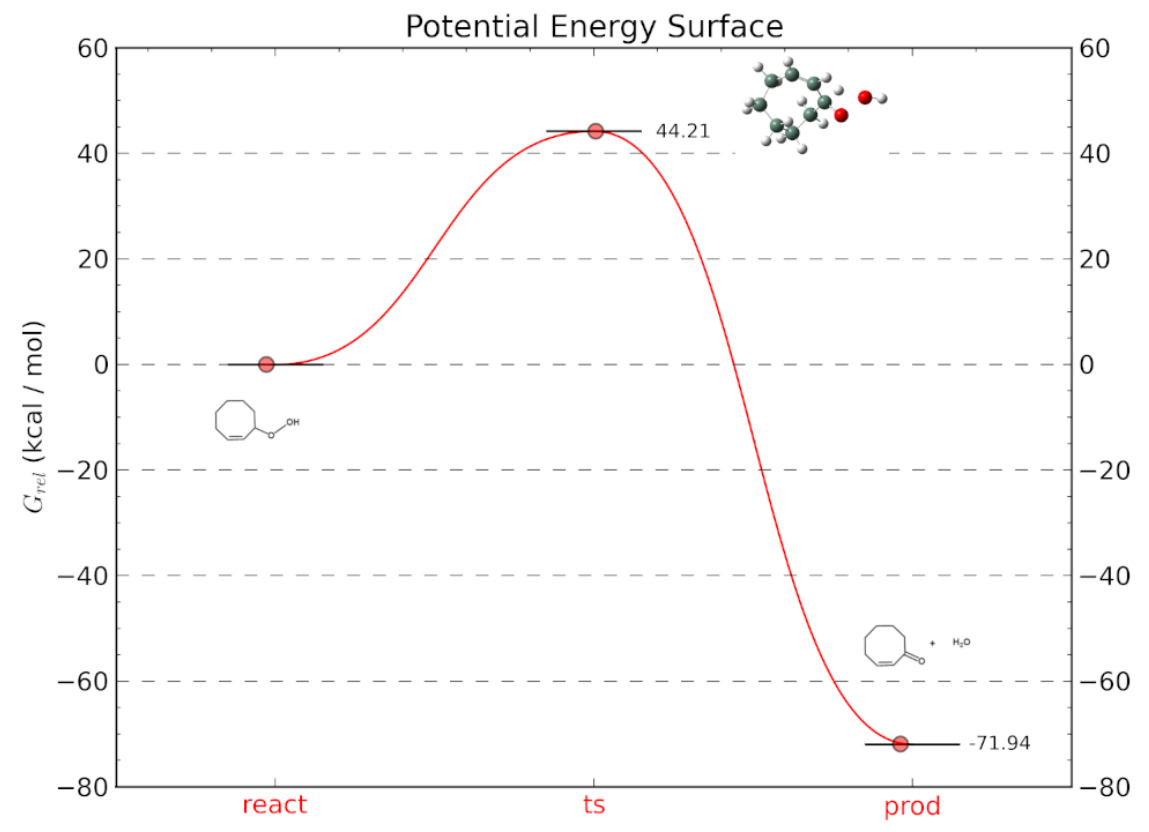

Figure S6.17. The formation of (Z)-cyclooct-2-en-1-one from (Z)-1-hydroperoxycyclooct-2ene. 


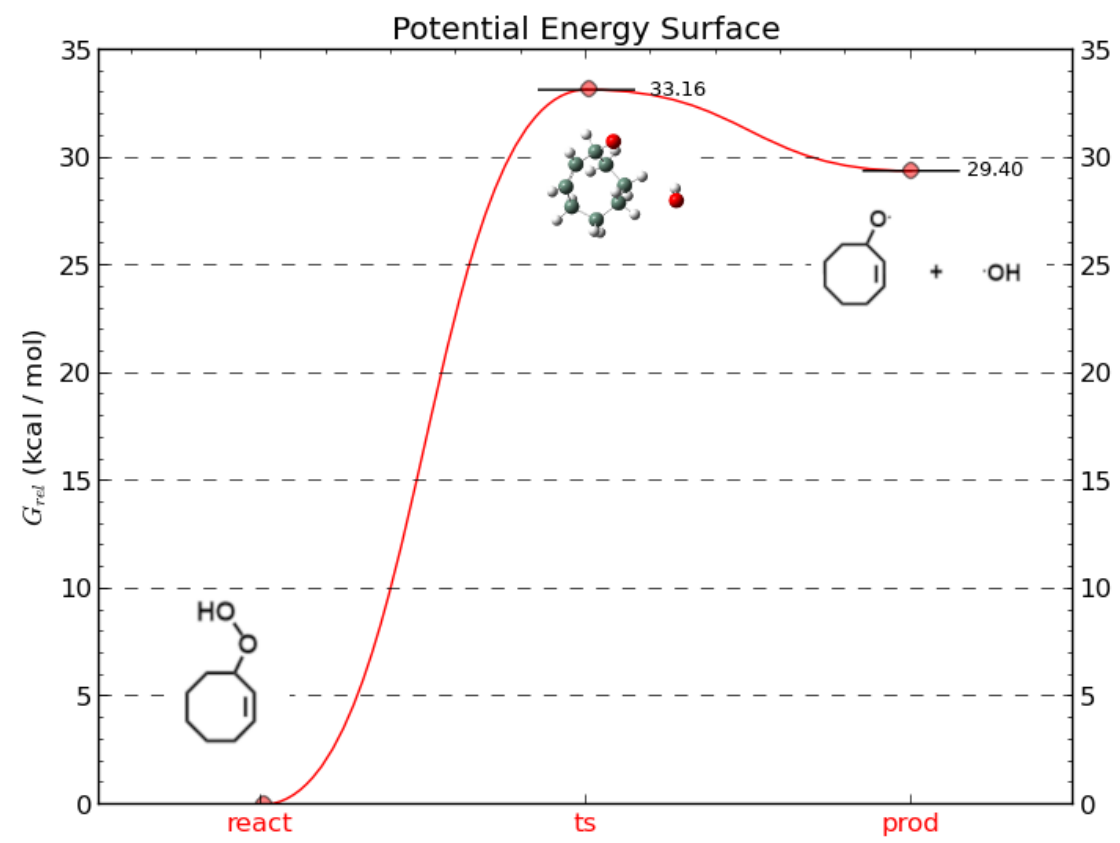

Figure S6.18. Homolytic rupture of the peroxide bond in (Z)-3-hydroperoxycyclooct-1-ene.

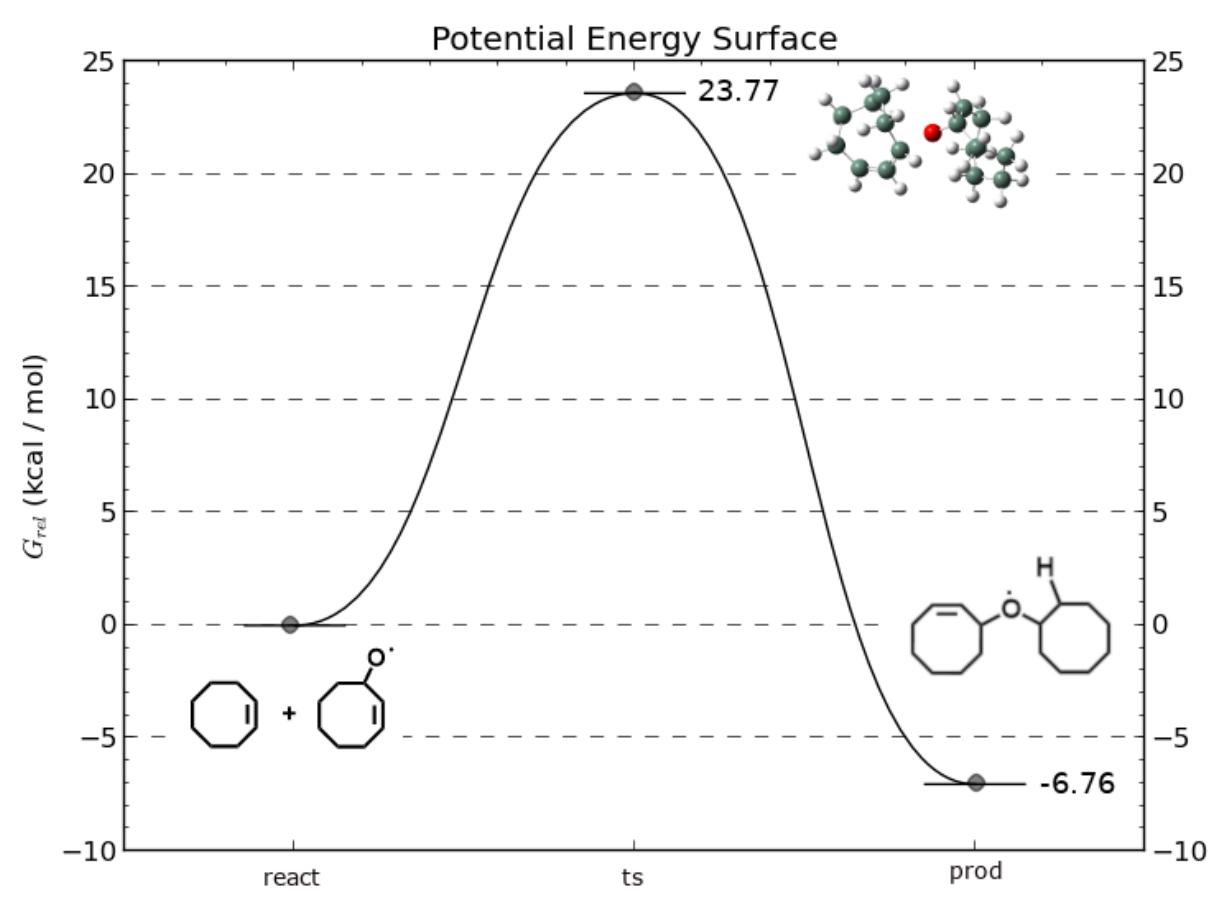

Figure S6.19. Formation of the oxo bridged radical from the 1-oxocyclooct-2-ene radical and and cyclooctene. 


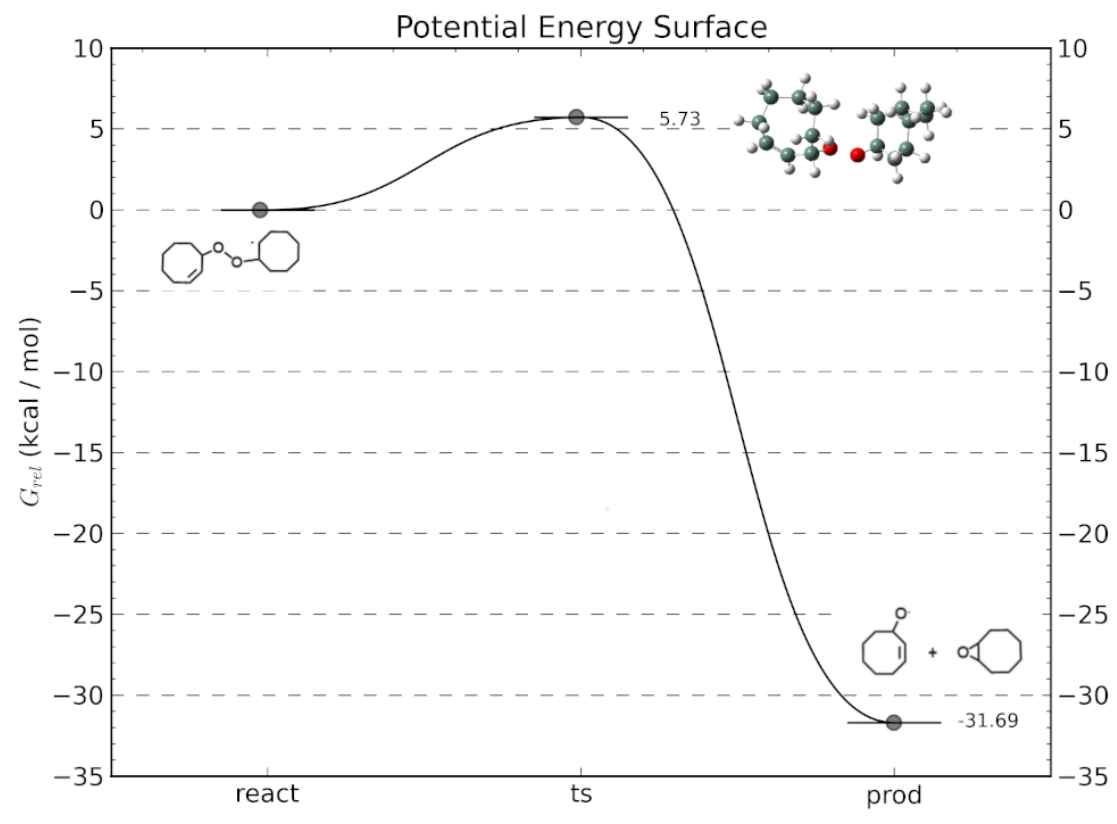

Figure S6.20. Formation of 9-oxabicyclo[6.1.0]nonane and an alkene oxo radical from the fragmentation of the (Z)-9-(cyclooct-2-en-1-yloxy)-9 $\square^{3}$-oxabicyclo[6.1.0]nonane radical.

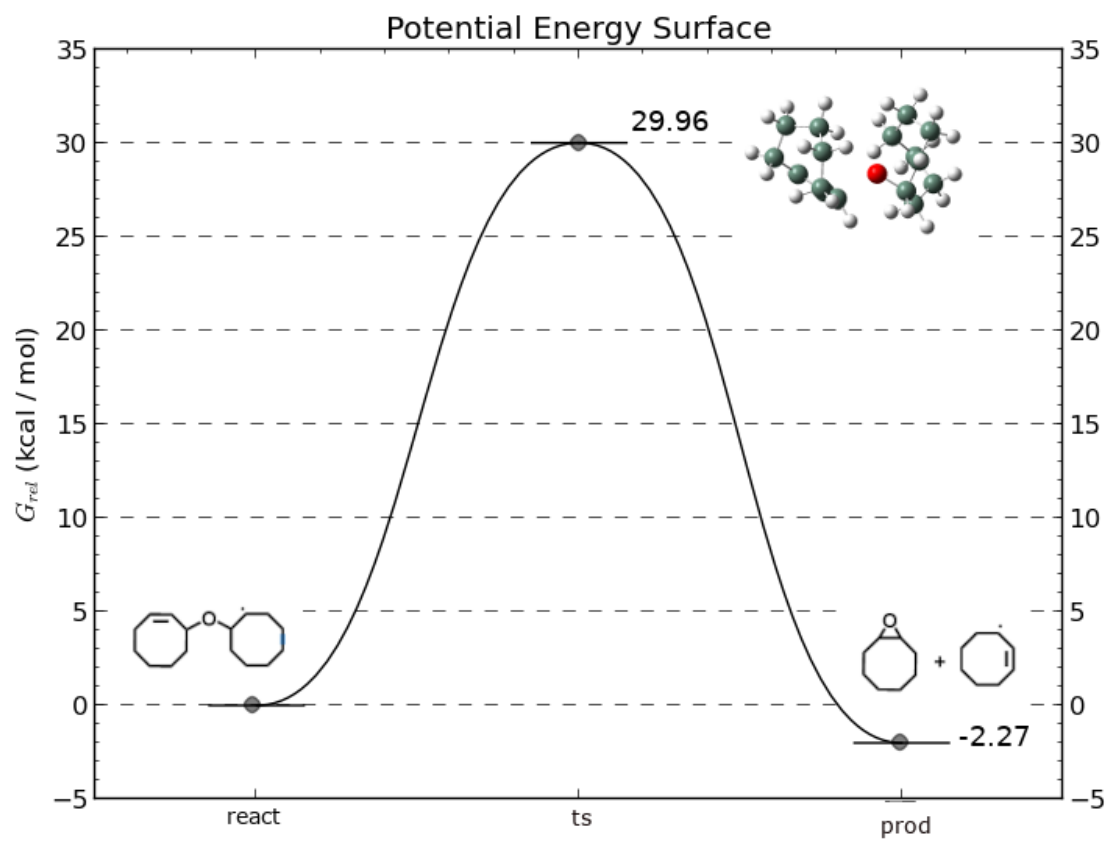

Figure S6.21. Formation of 9-oxabicyclo[6.1.0]nonane and cyclooctene radical from the decomposition of the biscyclooctene ether radical. 


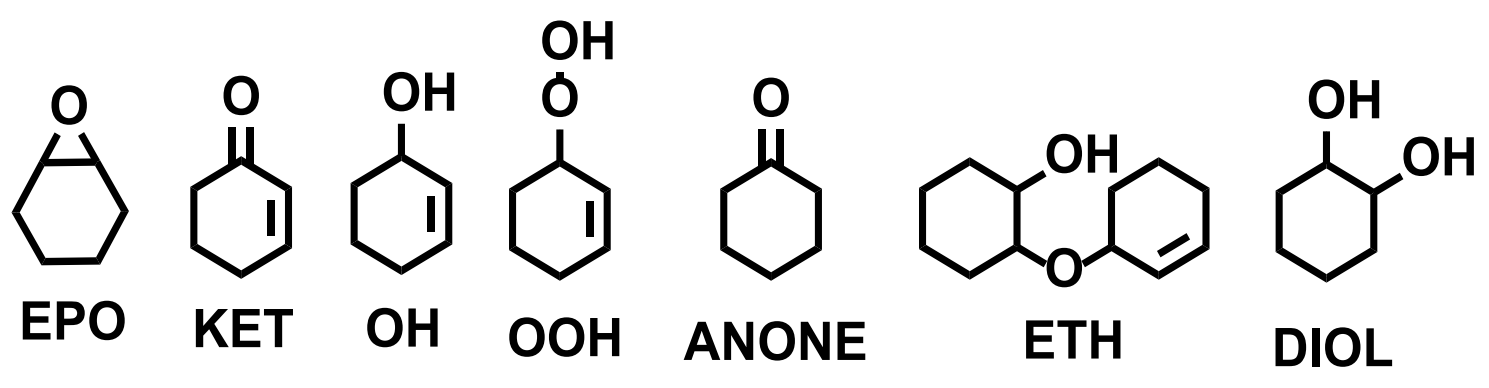

Figure S6.22. shows the structures that relate to the shorthand code for the molecules in Table S6.1, S6.2, and S6.3 below.

Table S6.1 contains the details of reactions from literature and this work of cyclohexene using t-butyl hydroperoxide as the oxidizer. Entries are listed in increasing order based on the yield of the 2-cyclohexen-1-one denoted as KET.

\begin{tabular}{|c|c|c|c|c|c|c|}
\hline Catalyst & $\begin{array}{l}\text { Tem } \\
\mathrm{p} \\
\left({ }^{\circ} \mathrm{C}\right)\end{array}$ & Oxidizer & Solvent & $\begin{array}{l}\text { Time } \\
\text { (Hour } \\
\text { s) }\end{array}$ & Yields & Ref. \\
\hline No Catalyst & 120 & $\begin{array}{l}2 \mathrm{eq} \\
\text { TbuOOH }\end{array}$ & chlorobenzene & 12 & $1.12 \% \mathrm{KET}$ & 235,275 \\
\hline MCM-41 & 120 & $\begin{array}{l}2 \mathrm{eq} \\
\text { TBuOOH }\end{array}$ & chlorobenzene & 12 & $1.46 \% \mathrm{KET}$ & 235 \\
\hline MCM-48 & 120 & $\begin{array}{l}2 \mathrm{eq} \\
\text { TBuOOH }\end{array}$ & chlorobenzene & 12 & $1.89 \% \mathrm{KET}$ & 235,276 \\
\hline $\begin{array}{l}\mathrm{Cu}\left(\mathrm{H}_{2} \text { btec }\right) \text { (bipy) } \\
\text { MOF }\end{array}$ & 30 & $\begin{array}{l}\text { leq } \\
\text { TBuOOH }\end{array}$ & DCE & 24 & $\begin{array}{l}18.44 \% \text { EP } \\
\text { O } \\
4.60 \% \text { ANO } \\
\text { NE } \\
4.32 \% \text { KET }\end{array}$ & 241 \\
\hline $\mathrm{Au} / \mathrm{CNT}_{\mathrm{s}} \mathrm{IM}$ & 85 & $\begin{array}{l}0.05 \mathrm{eq} \\
\text { TbuOOH }\end{array}$ & $\mathrm{ACN}$ & 6 & $\begin{array}{l}43.6 \% \mathrm{EPO} \\
7.48 \% \mathrm{OH} \\
6.38 \% \mathrm{KET}\end{array}$ & 277 \\
\hline $\begin{array}{l}\mathrm{Cu}\left(\mathrm{H}_{2} \text { btec }\right) \text { (bipy) } \\
\mathrm{MOF}\end{array}$ & 50 & $\begin{array}{l}\text { leq } \\
\text { TbuOOH }\end{array}$ & DCE & 24 & $\begin{array}{l}38.75 \% \mathrm{EP} \\
\mathrm{O} \\
4.85 \% \mathrm{ANO} \\
\mathrm{NE} \\
9.97 \% \mathrm{KET}\end{array}$ & 241 \\
\hline $\begin{array}{l}\mathrm{Cu}\left(\mathrm{H}_{2} \text { btec }\right)(\text { bipy }) \\
\text { MOF }\end{array}$ & 75 & $\begin{array}{l}\text { 1eq } \\
\text { TbuOOH }\end{array}$ & $\mathrm{DCE}$ & 24 & $\begin{array}{l}47.15 \% \mathrm{EP} \\
\mathrm{O} \\
4.97 \% \mathrm{ANO} \\
\mathrm{NE} \\
12.38 \% \mathrm{KE} \\
\mathrm{T}\end{array}$ & 241 \\
\hline None & 80 & $\begin{array}{l}0.05 \mathrm{eq} \\
\text { TBuOOH }\end{array}$ & $\mathrm{DCE} / \mathrm{ACN}$ & 72 & $\begin{array}{l}2.01 \% \mathrm{EPO} \\
8.01 \% \mathrm{OH}\end{array}$ & $\begin{array}{l}\text { This } \\
\text { Work }\end{array}$ \\
\hline
\end{tabular}




\begin{tabular}{|c|c|c|c|c|c|c|}
\hline & & & & & $23.7 \% \mathrm{KET}$ & \\
\hline Cr-MCM-41 & 120 & $\begin{array}{l}2 \mathrm{eq} \\
\text { TbuOOH }\end{array}$ & chlorobenzene & 12 & $39.0 \% \mathrm{KET}$ & 235 \\
\hline Cr-MCM-48 & 120 & $\begin{array}{l}2 \mathrm{eq} \\
\text { TbuOOH }\end{array}$ & chlorobenzene & 12 & $55.6 \% \mathrm{KET}$ & 235 \\
\hline $\begin{array}{l}\text { Diacetoxyiodobenz } \\
\text { ene } \mathrm{K}_{2} \mathrm{CO}_{3}\end{array}$ & -20 & $\begin{array}{l}4 \mathrm{eq} \\
\text { TbuOOH }\end{array}$ & $\mathrm{nPrCO} 2 \mathrm{nBu}$ & 12 & $56 \% \mathrm{KET}$ & 251 \\
\hline AgNP-MCM-41 & 80 & $\begin{array}{l}0.05 \mathrm{eq} \\
\mathrm{TBuOOH}\end{array}$ & $\mathrm{DCE} / \mathrm{ACN}$ & 72 & $\begin{array}{l}0.69 \% \text { EPO } \\
18.0 \% \mathrm{OH} \\
59.4 \% \text { KET }\end{array}$ & 252 \\
\hline $\mathrm{Rh}_{2}(\text { cap })_{4}$ & 40 & $\begin{array}{l}\text { eq } \\
\text { TbuOOH }\end{array}$ & DCE & 1 & $60 \% \mathrm{KET}$ & 253 \\
\hline $\begin{array}{l}\mathrm{Cu}(\mathrm{II}) \text { salqu } \\
\text { complex }\end{array}$ & 70 & $\begin{array}{l}3 \text { eq } \\
\text { TBuOOH }\end{array}$ & $\mathrm{ACN}$ & 1 & $74 \% \mathrm{KET}$ & 258 \\
\hline $\begin{array}{l}\mathrm{Mn}_{2}(\mu- \\
\left.\left.\mathrm{C}_{6} \mathrm{H}_{5} \mathrm{COO}\right)_{2}(\text { bipy })_{4}\right] \cdot \\
2\left(\mathrm{ClO}_{4}\right)\end{array}$ & 70 & $\begin{array}{l}\text { 8eq } \\
\text { TBuOOH }\end{array}$ & $\mathrm{ACN}$ & 1 & $\begin{array}{l}3.8 \% \mathrm{EPO} \\
2.8 \% \mathrm{OH} \\
75.1 \% \mathrm{KET} \\
11.8 \% \mathrm{DIO} \\
\mathrm{L}\end{array}$ & 261 \\
\hline $\begin{array}{l}{\left[\mathrm{Mn}\left(\mathrm{C}_{6} \mathrm{H}_{5} \mathrm{COO}\right)\left(\mathrm{H}_{2}\right.\right.} \\
\left.\mathrm{O})(\mathrm{phen})_{2}\right]\left(\mathrm{ClO}_{4}\right)(\mathrm{C} \\
\left.\mathrm{H}_{3} \mathrm{OH}\right)\end{array}$ & 70 & $\begin{array}{l}\text { eq } \\
\text { TBuOOH }\end{array}$ & $\mathrm{ACN}$ & 1.5 & $\begin{array}{l}4.6 \% \text { EPO } \\
2.5 \% \mathrm{OH} \\
76 \% \mathrm{KET} \\
11.2 \% \mathrm{DIO} \\
\mathrm{L}\end{array}$ & 261 \\
\hline $\mathrm{Mn}(\mathrm{Oac})_{2} \cdot 4 \mathrm{H}_{2} \mathrm{O}$ & 0 & $\begin{array}{l}2 \mathrm{eq} \\
\text { TbuOOH }\end{array}$ & DCM & 0.33 & $85 \% \mathrm{KET}$ & 263 \\
\hline Ag-VPO & 82 & $\begin{array}{l}3 \text { eq } \\
\text { TbuOOH }\end{array}$ & $\mathrm{ACN}$ & 6 & $86.3 \% \mathrm{KET}$ & 264 \\
\hline $\mathrm{Fe}_{3} \mathrm{O}_{4} \mathrm{MNPs}$ & 120 & $\begin{array}{l}3 \mathrm{eq} \\
\mathrm{TBuOOH}\end{array}$ & None & 6 & $87 \% \mathrm{KET}$ & 265 \\
\hline Co ESP3 & 70 & $\begin{array}{l}\text { 6eq } \\
\text { TbuOOH }\end{array}$ & Benzene & 16 & $90 \% \mathrm{KET}$ & 268 \\
\hline Co EPS3 & 50 & $\begin{array}{l}\text { 6eq } \\
\text { TbuOOH }\end{array}$ & $\mathrm{ACN}$ & 24 & $90 \% \mathrm{KET}$ & 268 \\
\hline
\end{tabular}


Table S6.2 contains the details of reactions from literature and this work of cyclohexene using hydrogen peroxide as the oxidizer. Entries are listed in increasing order based on the yield of the 2-cyclohexen-1-one denoted as KET. Following is the list based on the yield of cyclohexene oxide denoted as EPO.

\begin{tabular}{|c|c|c|c|c|c|c|}
\hline Catalyst & $\begin{array}{l}\text { Temp } \\
\left({ }^{\circ} \mathrm{C}\right)\end{array}$ & Oxidizer & Solvent & $\begin{array}{l}\text { Time } \\
\text { (Hours } \\
\text { ) }\end{array}$ & Yields & Ref \\
\hline$\left(\mathrm{LMnCl}_{2}\right)$ & 25 & 2eq $\mathrm{H}_{2} \mathrm{O}_{2}$ & $\mathrm{ACN}$ & 6 & $\begin{array}{l}53.3 \% \text { EP } \\
\mathrm{O} \\
21 . \% \mathrm{OH} \\
1.7 \% \mathrm{KET}\end{array}$ & 236 \\
\hline$\left[\mathrm{LMn}(\mathrm{OAc})_{2}\right]$ & 25 & 2eq $\mathrm{H}_{2} \mathrm{O}_{2}$ & $\mathrm{ACN}$ & 6 & $\begin{array}{l}61.4 \% \mathrm{EP} \\
\mathrm{O} \\
3.6 \% \mathrm{OH} \\
2.2 \% \mathrm{KET}\end{array}$ & 236 \\
\hline $\begin{array}{l}\mathrm{TBA}_{16}\left[\mathrm{Co}_{4}\left(\mathrm{P}_{2} \mathrm{~W}_{15} \mathrm{O}_{56}\right)\right. \\
2]\end{array}$ & 50 & 2eq $\mathrm{H}_{2} \mathrm{O}_{2}$ & $\mathrm{ACN}$ & 6 & $\begin{array}{l}4.4 \% \mathrm{EPO} \\
2.2 \% \mathrm{OH} \\
4.4 \% \mathrm{KET}\end{array}$ & 240 \\
\hline $\begin{array}{l}\mathrm{TBA}_{10}\left[\mathrm{Co}_{4}\left(\mathrm{PW}_{9} \mathrm{O}_{34}\right)_{2}\right. \\
]\end{array}$ & 50 & 2eq $\mathrm{H}_{2} \mathrm{O}_{2}$ & $\mathrm{ACN}$ & 6 & $\begin{array}{l}7.5 \% \mathrm{EPO} \\
2.7 \% \mathrm{OH} \\
4.8 \% \mathrm{KET} \\
\end{array}$ & 240 \\
\hline Fe Zeolite Y & 80 & 1eq $\mathrm{H}_{2} \mathrm{O}_{2}$ & $\mathrm{ACN}$ & 18 & $\begin{array}{l}7.3 \% \text { EPO } \\
5.0 \% \text { KET }\end{array}$ & 245 \\
\hline Ru Zeolite Y & 80 & 1eq $\mathrm{H}_{2} \mathrm{O}_{2}$ & $\mathrm{ACN}$ & 18 & $\begin{array}{l}6.1 \% \text { EPO } \\
5.7 \% \text { KET }\end{array}$ & 245 \\
\hline $\mathrm{TBA}_{10}\left[\mathrm{Mn}_{4}\left(\mathrm{PW}_{9} \mathrm{O}_{34}\right)_{2}\right.$ & 50 & 2eq $\mathrm{H}_{2} \mathrm{O}_{2}$ & $\mathrm{ACN}$ & 6 & $\begin{array}{l}19.6 \% \mathrm{EP} \\
\mathrm{O} \\
2.24 \% \mathrm{OH} \\
6.16 \% \mathrm{KE} \\
\mathrm{T}\end{array}$ & 240 \\
\hline $\begin{array}{l}\mathrm{TBA}_{16}\left[\mathrm{Mn}_{4}\left(\mathrm{P}_{2} \mathrm{~W}_{15} \mathrm{O}_{56}\right.\right. \\
\left.)_{2}\right]\end{array}$ & 50 & 2eq $\mathrm{H}_{2} \mathrm{O}_{2}$ & $\mathrm{ACN}$ & 6 & $\begin{array}{l}14.4 \% \mathrm{EP} \\
\mathrm{O} \\
2.64 \% \mathrm{OH} \\
6.96 \% \mathrm{KE} \\
\mathrm{T}\end{array}$ & 240 \\
\hline $\mathrm{LFeCl}_{2}$ & 25 & 0.5 eq $\mathrm{H}_{2} \mathrm{O}_{2}$ & $\mathrm{ACN}$ & 24 & $\begin{array}{l}2.66 \% \mathrm{EP} \\
\mathrm{O} \\
7.96 \% \mathrm{OH} \\
8.87 \% \mathrm{KE} \\
\mathrm{T}\end{array}$ & 236 \\
\hline $\begin{array}{l}\mathrm{TBA}_{16}\left[\mathrm{Co}_{4}\left(\mathrm{P}_{2} \mathrm{~W}_{15} \mathrm{O}_{56}\right)\right. \\
2]\end{array}$ & 50 & 9eq $\mathrm{H}_{2} \mathrm{O}_{2}$ & $\mathrm{ACN}$ & 6 & $\begin{array}{l}3.23 \% \mathrm{EP} \\
\mathrm{O} \\
5.7 \% \mathrm{OH} \\
10.1 \% \mathrm{KE} \\
\mathrm{T}\end{array}$ & 240 \\
\hline
\end{tabular}




\begin{tabular}{|c|c|c|c|c|c|c|}
\hline $\begin{array}{l}\mathrm{TBA}_{10}\left[\mathrm{Co}_{4}\left(\mathrm{PW}_{9} \mathrm{O}_{34}\right)_{2}\right. \\
]\end{array}$ & 50 & 9eq $\mathrm{H}_{2} \mathrm{O}_{2}$ & $\mathrm{ACN}$ & 6 & $\begin{array}{l}5.04 \% \mathrm{EP} \\
\mathrm{O} \\
5.67 \% \mathrm{OH} \\
10.3 \% \mathrm{KE} \\
\mathrm{T}\end{array}$ & 240 \\
\hline None & 70 & 1eq $\mathrm{H}_{2} \mathrm{O}_{2}$ & Methanol & 12 & $\begin{array}{l}8.84 \% \mathrm{EP} \\
\mathrm{O} / \mathrm{DIOL} \\
6.76 \% \mathrm{OH} \\
10.4 \% \mathrm{KE} \\
\mathrm{T}\end{array}$ & 259 \\
\hline $\begin{array}{l}\mathrm{TBA}_{16}\left[\mathrm{Ni}_{4}\left(\mathrm{P}_{2} \mathrm{~W}_{15} \mathrm{O}_{56}\right)\right. \\
2]\end{array}$ & 50 & 2eq $\mathrm{H}_{2} \mathrm{O}_{2}$ & $\mathrm{ACN}$ & 6 & $\begin{array}{l}6.93 \% \mathrm{EP} \\
\mathrm{O} \\
3.57 \% \mathrm{OH} \\
10.5 \% \mathrm{KE} \\
\mathrm{T}\end{array}$ & 240 \\
\hline $\mathrm{TBA}_{10}\left[\mathrm{Zn}\left(\mathrm{PW}_{9} \mathrm{O}_{34}\right)_{2}\right]$ & 50 & 2eq $\mathrm{H}_{2} \mathrm{O}_{2}$ & $\mathrm{ACN}$ & 6 & $\begin{array}{l}70.4 \% \mathrm{EP} \\
\mathrm{O} \\
4.4 \% \mathrm{OH} \\
13.2 \% \mathrm{KE} \\
\mathrm{T}\end{array}$ & 240 \\
\hline$\left[\mathrm{LFe}(\mathrm{OAc})_{2}\right]$ & 25 & 0.5 eq $\mathrm{H}_{2} \mathrm{O}_{2}$ & $\mathrm{ACN}$ & 24 & $\begin{array}{l}3.1 \% \mathrm{EPO} \\
9.8 \% \mathrm{OH} \\
13.4 \% \mathrm{KE} \\
\mathrm{T}\end{array}$ & 236 \\
\hline $\mathrm{TBA}_{10}\left[\mathrm{Ni}_{4}\left(\mathrm{PW}_{9} \mathrm{O}_{34}\right)_{2}\right]$ & 50 & 2eq $\mathrm{H}_{2} \mathrm{O}_{2}$ & $\mathrm{ACN}$ & 6 & $\begin{array}{l}11.2 \% \mathrm{EP} \\
\mathrm{O} \\
6.4 \% \mathrm{OH} \\
14.4 \% \mathrm{KE} \\
\mathrm{T}\end{array}$ & 240 \\
\hline $\begin{array}{l}\mathrm{TBA}_{16}\left[\mathrm{Zn}_{4}\left(\mathrm{P}_{2} \mathrm{~W}_{15} \mathrm{O}_{56}\right)\right. \\
2]\end{array}$ & 50 & 2eq $\mathrm{H}_{2} \mathrm{O}_{2}$ & $\mathrm{ACN}$ & 6 & $\begin{array}{l}49 \% \mathrm{EPO} \\
6.3 \% \mathrm{OH} \\
14.7 \% \mathrm{KE} \\
\mathrm{T}\end{array}$ & 240 \\
\hline $\mathrm{TBA}_{10}\left[\mathrm{Mn}_{4}\left(\mathrm{PW}_{9} \mathrm{O}_{34}\right)_{2}\right.$ & 50 & 9eq $\mathrm{H}_{2} \mathrm{O}_{2}$ & $\mathrm{ACN}$ & 6 & $\begin{array}{l}12.6 \% \mathrm{EP} \\
\mathrm{O} \\
6.12 \% \mathrm{OH} \\
15.2 \% \mathrm{KE} \\
\mathrm{T}\end{array}$ & 240 \\
\hline $\begin{array}{l}\mathrm{TBA}_{16}\left[\mathrm{Ni}_{4}\left(\mathrm{P}_{2} \mathrm{~W}_{15} \mathrm{O}_{56}\right)\right. \\
\text { 2] }\end{array}$ & 50 & 9eq $\mathrm{H}_{2} \mathrm{O}_{2}$ & $\mathrm{ACN}$ & 6 & $\begin{array}{l}3.24 \% \mathrm{EP} \\
\mathrm{O} \\
8.1 \% \mathrm{OH} \\
15.7 \% \mathrm{KE} \\
\mathrm{T}\end{array}$ & 240 \\
\hline $\begin{array}{l}\mathrm{TBA}_{12}\left[\mathrm{Fe}_{4}\left(\mathrm{P}_{2} \mathrm{~W}_{15} \mathrm{O}_{56}\right)\right. \\
2]\end{array}$ & 50 & 2eq $\mathrm{H}_{2} \mathrm{O}_{2}$ & $\mathrm{ACN}$ & 6 & $\begin{array}{l}42.9 \% \mathrm{EP} \\
\mathrm{O} \\
4.62 \% \mathrm{OH}\end{array}$ & 240 \\
\hline
\end{tabular}




\begin{tabular}{|c|c|c|c|c|c|c|}
\hline & & & & & $\begin{array}{l}18.5 \% \mathrm{KE} \\
\mathrm{T}\end{array}$ & \\
\hline $\mathrm{TBA}_{6}\left[\mathrm{Fe}_{4}\left(\mathrm{PW}_{9} \mathrm{O}_{34}\right)_{2}\right]$ & 50 & 2eq $\mathrm{H}_{2} \mathrm{O}_{2}$ & $\mathrm{ACN}$ & 6 & $\begin{array}{l}53.9 \% \mathrm{EP} \\
\mathrm{O} \\
3.85 \% \mathrm{OH} \\
19.3 \% \mathrm{KE} \\
\mathrm{T}\end{array}$ & 240 \\
\hline $\begin{array}{l}\mathrm{TBA}_{16}\left[\mathrm{Mn}_{4}\left(\mathrm{P}_{2} \mathrm{~W}_{15} \mathrm{O}_{56}\right.\right. \\
\left.)_{2}\right]\end{array}$ & 50 & 9eq $\mathrm{H}_{2} \mathrm{O}_{2}$ & $\mathrm{ACN}$ & 6 & $\begin{array}{l}10.0 \% \mathrm{EP} \\
\mathrm{O} \\
7.03 \% \mathrm{OH} \\
20.0 \% \mathrm{KE} \\
\mathrm{T}\end{array}$ & 240 \\
\hline None & 80 & 0.05 eq $\mathrm{H}_{2} \mathrm{O}_{2}$ & $\begin{array}{l}\text { DCE/AC } \\
\mathrm{N}\end{array}$ & 72 & $\begin{array}{l}2.14 \% \mathrm{EP} \\
\mathrm{O} \\
9.44 \% \mathrm{OH} \\
23.6 \% \mathrm{KE} \\
\mathrm{T}\end{array}$ & $\begin{array}{l}\text { Thi } \\
\text { s } \\
\text { wor } \\
\mathrm{k}\end{array}$ \\
\hline CFO-Ce $e_{0.3}$ & 90 & 1.5eq $\mathrm{H}_{2} \mathrm{O}_{2}$ & $\begin{array}{l}\text { 1,4- } \\
\text { dioxane }\end{array}$ & 9 & $\begin{array}{l}1.47 \% \mathrm{EP} \\
\mathrm{O} \\
15.7 \% \mathrm{OH} \\
26.4 \% \mathrm{KE} \\
\mathrm{T}\end{array}$ & 243 \\
\hline $\mathrm{TBA}_{10}\left[\mathrm{Ni}_{4}\left(\mathrm{PW}_{9} \mathrm{O}_{34}\right)_{2}\right]$ & 50 & $9 \mathrm{eq} \mathrm{H}_{2} \mathrm{O}_{2}$ & $\mathrm{ACN}$ & 6 & $\begin{array}{l}6.9 \% \text { EPO } \\
11.5 \% \mathrm{OH} \\
27.6 \% \mathrm{KE} \\
\mathrm{T}\end{array}$ & 240 \\
\hline $\mathrm{LFe}\left(\mathrm{NO}_{3}\right)$ & 80 & 1eq $\mathrm{H}_{2} \mathrm{O}_{2}$ & $\mathrm{ACN}$ & 18 & $\begin{array}{l}11.1 \% \mathrm{DI} \\
\mathrm{OL} \\
10.5 \% \mathrm{EP} \\
\mathrm{O} \\
29.5 \% \mathrm{OH} \\
35.3 \% \mathrm{KE} \\
\mathrm{T}\end{array}$ & 245 \\
\hline $\mathrm{TBA}_{6}\left[\mathrm{Fe}_{4}\left(\mathrm{PW}_{9} \mathrm{O}_{34}\right)_{2}\right]$ & 50 & 9eq $\mathrm{H}_{2} \mathrm{O}_{2}$ & $\mathrm{ACN}$ & 6 & $\begin{array}{l}30.3 \% \mathrm{EP} \\
\mathrm{O} \\
18.7 \% \mathrm{OH} \\
40.1 \% \mathrm{KE} \\
\mathrm{T}\end{array}$ & 240 \\
\hline$\left[\mathrm{Co}(\mathrm{Pht})(\mathrm{Im})_{2}\right] \mathrm{n}$ & 22 & 9eq $\mathrm{H}_{2} \mathrm{O}_{2}$ & Acetone & 1 & $\begin{array}{l}1.94 \% \mathrm{EP} \\
\mathrm{O} \\
18.7 \% \mathrm{OH} \\
40.6 \% \mathrm{KE} \\
\mathrm{T}\end{array}$ & 260 \\
\hline $\begin{array}{l}\mathrm{TBA}_{12}\left[\mathrm{Fe}_{4}\left(\mathrm{P}_{2} \mathrm{~W}_{15} \mathrm{O}_{56}\right)\right. \\
\text { 2] }\end{array}$ & 50 & $9 \mathrm{eq} \mathrm{H}_{2} \mathrm{O}_{2}$ & $\mathrm{ACN}$ & 6 & $\begin{array}{l}23.6 \% \mathrm{EP} \\
\mathrm{O} \\
9.88 \% \mathrm{OH}\end{array}$ & 240 \\
\hline
\end{tabular}




\begin{tabular}{|c|c|c|c|c|c|c|}
\hline & & & & & $\begin{array}{l}42.6 \% \mathrm{KE} \\
\mathrm{T}\end{array}$ & \\
\hline $\begin{array}{l}{\left[\mathrm{Cu}(\mathrm{Pht})(\mathrm{Im})_{2}\right] \cdot 1.5 \mathrm{H}_{2}} \\
\mathrm{O}_{\mathrm{n}}\end{array}$ & 22 & 4.5eq $\mathrm{H}_{2} \mathrm{O}_{2}$ & Acetone & 48 & $\begin{array}{l}4.67 \% \mathrm{EP} \\
\mathrm{O} \\
11.4 \% \mathrm{OH} \\
43.4 \% \mathrm{KE} \\
\mathrm{T}\end{array}$ & 260 \\
\hline $\begin{array}{l}\mathrm{TBA}_{16}\left[\mathrm{Zn}_{4}\left(\mathrm{P}_{2} \mathrm{~W}_{15} \mathrm{O}_{56}\right)\right. \\
2]\end{array}$ & 50 & 9eq $\mathrm{H}_{2} \mathrm{O}_{2}$ & $\mathrm{ACN}$ & 6 & $\begin{array}{l}33.9 \% \mathrm{EP} \\
\mathrm{O} \\
8.7 \% \mathrm{OH} \\
44.4 \% \mathrm{KE} \\
\mathrm{T}\end{array}$ & 240 \\
\hline $\mathrm{TBA}_{10}\left[\mathrm{Zn}_{4}\left(\mathrm{PW}_{9} \mathrm{O}_{34}\right)_{2}\right]$ & 50 & 9eq $\mathrm{H}_{2} \mathrm{O}_{2}$ & $\mathrm{ACN}$ & 6 & $\begin{array}{l}44.6 \% \mathrm{EP} \\
\mathrm{O} \\
9.9 \% \mathrm{OH} \\
44.6 \% \mathrm{KE} \\
\mathrm{T}\end{array}$ & 240 \\
\hline$(\mathrm{LRuCl})$ & 80 & 1eq $\mathrm{H}_{2} \mathrm{O}_{2}$ & $\mathrm{ACN}$ & 18 & $\begin{array}{l}5.17 \% \mathrm{DI} \\
\mathrm{OL} \\
13.0 \% \mathrm{EP} \\
\mathrm{O} \\
30.8 \% \mathrm{OH} \\
47.1 \% \mathrm{KE} \\
\mathrm{T}\end{array}$ & 245 \\
\hline Cr-MCM-41 & 80 & 2eq $\mathrm{H}_{2} \mathrm{O}_{2}$ & Methanol & 12 & $\begin{array}{l}47.3 \% \mathrm{KE} \\
\mathrm{T}\end{array}$ & 248 \\
\hline Cr-mZrP & 80 & 2eq $\mathrm{H}_{2} \mathrm{O}_{2}$ & None & 12 & $63 \% \mathrm{KET}$ & 255 \\
\hline $\mathrm{CoCr}-\mathrm{HTSi}_{2}$ & 70 & 1eq $\mathrm{H}_{2} \mathrm{O}_{2}$ & Methanol & 12 & $\begin{array}{l}26 \% \mathrm{OH} \\
74 \% \text { KET }\end{array}$ & 259 \\
\hline $\begin{array}{l}{\left[\mathrm{Cu}(\mathrm{Pht})(\mathrm{Im})_{2}\right] \cdot 1.5 \mathrm{H}_{2}} \\
\mathrm{O}_{\mathrm{n}}\end{array}$ & 22 & 9eq $\mathrm{H}_{2} \mathrm{O}_{2}$ & $\begin{array}{l}\text { Acetone } \\
\text { half }\end{array}$ & 1 & $\begin{array}{l}11.3 \% \mathrm{EP} \\
\mathrm{O} \\
11.5 \% \mathrm{OH} \\
75.2 \% \mathrm{KE} \\
\mathrm{T}\end{array}$ & 260 \\
\hline $\begin{array}{l}{\left[\mathrm{Cu}(\mathrm{Pht})(\mathrm{Im})_{2}\right] \cdot 1.5 \mathrm{H}_{2}} \\
\mathrm{O}_{\mathrm{n}}\end{array}$ & 22 & 9eq $\mathrm{H}_{2} \mathrm{O}_{2}$ & Acetone & 48 & $\begin{array}{l}1.49 \% \mathrm{EP} \\
\mathrm{O} \\
6.78 \% \mathrm{OH} \\
85.6 \% \mathrm{KE} \\
\mathrm{T}\end{array}$ & 260 \\
\hline $\begin{array}{l}{\left[\mathrm{Cu}(\mathrm{Pht})(\mathrm{Im})_{2}\right] \cdot 1.5 \mathrm{H}_{2}} \\
\mathrm{O}_{\mathrm{n}}\end{array}$ & 22 & 9eq $\mathrm{H}_{2} \mathrm{O}_{2}$ & Acetone & 1 & $\begin{array}{l}8.39 \% \mathrm{EP} \\
\mathrm{O} \\
3.06 \% \mathrm{OH} \\
87.7 \% \mathrm{KE} \\
\mathrm{T}\end{array}$ & 260 \\
\hline $\begin{array}{l}{\left[\mathrm{Cu}(\mathrm{Pht})(\mathrm{Im})_{2}\right] \cdot 1.5 \mathrm{H}_{2}} \\
\mathrm{O}_{\mathrm{n}}\end{array}$ & 22 & 12 eq $\mathrm{H}_{2} \mathrm{O}_{2}$ & Acetone & 48 & $\begin{array}{l}0.49 \% \mathrm{EP} \\
\mathrm{O} \\
5.32 \% \mathrm{OH}\end{array}$ & 260 \\
\hline
\end{tabular}




\begin{tabular}{|c|c|c|c|c|c|c|}
\hline & & & & & $\begin{array}{l}\text { 93.4\% KE } \\
\mathrm{T}\end{array}$ & \\
\hline $\begin{array}{l}(4- \\
\text { ddp })_{1.5} \mathrm{Na}_{5.5}\left[\mathrm{PTi}_{2} \mathrm{~W}_{10}\right. \\
\left.\mathrm{O}_{40}\right] \cdot 5 \mathrm{H}_{2} \mathrm{O}\end{array}$ & 50 & 2eq $\mathrm{H}_{2} \mathrm{O}_{2}$ & $\begin{array}{l}\mathrm{ACN} / \mathrm{DC} \\
\mathrm{E}\end{array}$ & 10 & $\begin{array}{l}9.02 \% \mathrm{EP} \\
\mathrm{O} \\
1.65 \% \mathrm{DI} \\
\mathrm{OL}\end{array}$ & 227 \\
\hline $\mathrm{H}_{3} \mathrm{PW}_{11} \mathrm{VO}_{40}$ & 65 & 2eq $\mathrm{H}_{2} \mathrm{O}_{2}$ & DCE & 7 & $\begin{array}{l}37.5 \% \mathrm{EP} \\
\mathrm{O}\end{array}$ & 225 \\
\hline $\mathrm{H}_{3} \mathrm{PW}_{9} \mathrm{Mo}_{3} \mathrm{O}_{40}$ & 65 & 2eq $\mathrm{H}_{2} \mathrm{O}_{2}$ & $\mathrm{DCE}$ & 7 & $\begin{array}{l}49.3 \% \text { EP } \\
\mathrm{O}\end{array}$ & 225 \\
\hline Co-salen-SBA15 & 90 & 2eq $\mathrm{H}_{2} \mathrm{O}_{2}$ & None & 0.033 & $60 \%$ EPO & 229 \\
\hline $\mathrm{H}_{3} \mathrm{PW}_{12} \mathrm{O}_{40}$ & 65 & 2eq $\mathrm{H}_{2} \mathrm{O}_{2}$ & $\mathrm{DCE}$ & 7 & $\begin{array}{l}78.2 \% \mathrm{EP} \\
\mathrm{O}\end{array}$ & 225 \\
\hline$\left[\mathrm{MoO}\left(\mathrm{O}_{2}\right)_{2} 4,4-\text { bipy }\right]_{\mathrm{n}}$ & 25 & $2.5 \mathrm{eq} \mathrm{H}_{2} \mathrm{O}_{2}$ & $\mathrm{DCE}$ & 6 & $95 \%$ EPO & 226 \\
\hline POSS-OIM $8-\mathrm{PW}$ & 70 & $1.2 \mathrm{eq} \mathrm{H}_{2} \mathrm{O}_{2}$ & $\mathrm{ACN}$ & 2 & $99 \%$ EPO & 278 \\
\hline $\begin{array}{l}{\left[\mathrm{MoO}_{2} \mathrm{Cl}_{2}\left(\mathrm{H}_{2} \mathrm{O}\right)_{2}\right] \cdot} \\
\left(\mathrm{H}_{2} \text { dipy-pra }\right) \mathrm{Cl}_{2}\end{array}$ & 25 & $4 \mathrm{eq}_{2} \mathrm{O}_{2}$ & $\mathrm{ACN}$ & 1.5 & $99 \%$ EPO & 224 \\
\hline $\begin{array}{l}{\left[\mathrm{MoO}_{2} \mathrm{Cl}_{2}\left(\mathrm{H}_{2} \mathrm{O}\right)_{2}\right] \cdot} \\
\left(\mathrm{H}_{2} \text { dipy-pra }\right) \mathrm{Cl}_{2}, \\
\mathrm{NaHCO}_{3}\end{array}$ & 25 & 4eq $\mathrm{H}_{2} \mathrm{O}_{2}$ & $\mathrm{ACN}$ & 1 & $99 \% \mathrm{EPO}$ & 224 \\
\hline$\left(\mathrm{VOTPPCl}_{8}\right)$ & 60 & 2eq $\mathrm{H}_{2} \mathrm{O}_{2}$ & $\begin{array}{l}\mathrm{ACN} / \mathrm{Wat} \\
\text { er }\end{array}$ & 0.5 & $99 \% \mathrm{EPO}$ & 228 \\
\hline
\end{tabular}

Table S6.3 contains the details of reactions from literature and this work of cyclohexene using oxygen as the oxidizer. Entries are listed in increasing order based on the yield of the 2cyclohexen-1-one denoted as KET. Following is the list based on the yield of cyclohexene oxide denoted as EPO.

\begin{tabular}{|l|l|l|l|l|l|l|}
\hline Catalyst & $\begin{array}{l}\text { Tem } \\
\text { p } \\
\left({ }^{\circ} \mathrm{C}\right)\end{array}$ & Oxidizer & Solvent & $\begin{array}{l}\text { Time } \\
(\text { Hour } \\
\text { s })\end{array}$ & Yields & Ref. \\
\hline $\mathrm{VO}(\text { acac })_{2}$ & 60 & $1 \mathrm{~atm} \mathrm{O}_{2}$ & None & - & None & 237 \\
\hline $\mathrm{VO}(\text { acac })_{2}$ & 60 & $1 \mathrm{~atm} \mathrm{O}_{2}$ & ACN & 40 & None & 237 \\
\hline $\mathrm{VO}(\mathrm{acac})_{2}$ & 60 & $1 \mathrm{~atm} \mathrm{O}_{2}$ & t-butanol & 40 & None & 237 \\
\hline $\mathrm{VO}(\mathrm{acac})_{2}$ & 60 & $1 \mathrm{~atm} \mathrm{O} \mathrm{O}_{2}$ & Aniline & 40 & None & 237 \\
\hline $\mathrm{VO}(\text { acac })_{2}$ & 60 & 1 atm $\mathrm{O}_{2}$ & n-hexane & 40 & None & 237 \\
\hline $\mathrm{None}$ & 45 & $\begin{array}{l}\text { Oxygen } \\
\text { balloon }\end{array}$ & None & 15 & None & 233 \\
\hline $\mathrm{Cu}\left(\mathrm{BF}_{4}\right)_{2} \mathrm{H}_{2} \mathrm{O}$ & 45 & $\begin{array}{l}\text { Oxygen } \\
\text { balloon }\end{array}$ & None & 15 & None & 233 \\
\hline $\mathrm{Cu}\left(\mathrm{BF}_{4}\right)_{2} \mathrm{H}_{2} \mathrm{O}+$ ppy & 45 & $\begin{array}{l}\text { Oxygen } \\
\text { Balloon }\end{array}$ & None & 15 & None & 233 \\
\hline $\mathrm{Cu}-\mathrm{MOF}$ & 25 & $\begin{array}{l}\text { Oxygen } \\
\text { balloon }\end{array}$ & None & 15 & None & 233 \\
\hline
\end{tabular}




\begin{tabular}{|c|c|c|c|c|c|c|}
\hline $\begin{array}{l}\mathrm{TBA}_{9} \mathrm{P}_{2} \mathrm{~W}_{15} \mathrm{Nb}_{3} \mathrm{O}_{62} \\
\text { (control reaction) }\end{array}$ & 38 & $1 \mathrm{~atm} \mathrm{O}_{2}$ & DCM & 24 & None & 234 \\
\hline $\begin{array}{l}(\mathrm{n}-\mathrm{Bu} 4 \mathrm{~N})_{5} \mathrm{Na}_{3}[(1,5- \\
\left.\mathrm{COD}) \mathrm{Ir} \cdot \mathrm{P}_{2} \mathrm{~W}_{15} \mathrm{Nb}_{3} \mathrm{O}_{62}\right]\end{array}$ & 38 & $1 \mathrm{~atm} \mathrm{O}_{2}$ & DMSO & 24 & None & 234 \\
\hline $\begin{array}{l}\text { Halloysite nanotubes } \\
\text { supported } \\
\text { PANI (PANI@HA/1 } \\
\text { M/2.04-HCl) }\end{array}$ & 70 & 2eq $\mathrm{H}_{2} \mathrm{O}_{2}$ & None & 24 & $\begin{array}{l}97.7 \% \mathrm{DI} \\
\mathrm{OL} \\
0.44 \% \mathrm{OH} \\
0.05 \% \mathrm{KE} \\
\mathrm{T}\end{array}$ & 279 \\
\hline $\mathrm{Cu}-\mathrm{MOF}$ & 35 & $\begin{array}{l}\text { Oxygen } \\
\text { Balloon }\end{array}$ & None & 15 & $\begin{array}{l}0.22 \% \mathrm{OO} \\
\mathrm{H} \\
0.02 \% \mathrm{OH} \\
0.06 \% \mathrm{KE} \\
\mathrm{T}\end{array}$ & 233 \\
\hline $\mathrm{Cu}-\mathrm{MOF}$ & 45 & $\begin{array}{l}\text { Oxygen } \\
\text { Balloon }\end{array}$ & None & 15 & $\begin{array}{l}4.29 \% \mathrm{OO} \\
\mathrm{H} \\
0.10 \% \mathrm{EP} \\
\mathrm{O} \\
0.14 \% \mathrm{OH} \\
0.28 \% \mathrm{KE} \\
\mathrm{T}\end{array}$ & 233 \\
\hline $\mathrm{Cu}-\mathrm{MOF}$ & 50 & $\begin{array}{l}\text { Oxygen } \\
\text { balloon }\end{array}$ & None & 15 & $\begin{array}{l}6.14 \% \mathrm{OO} \\
\mathrm{H} \\
0.16 \% \mathrm{EP} \\
\mathrm{O}, \\
0.22 \% \mathrm{OH} \\
, \\
0.47 \% \mathrm{KE} \\
\mathrm{T}\end{array}$ & 233 \\
\hline $\begin{array}{l}\mathrm{TBA}_{5} \mathrm{Na}_{3}\left[(\mathrm{Cp} *) \mathrm{Rh} \cdot \mathrm{P}_{2}\right. \\
\left.\mathrm{W}_{15} \mathrm{Nb}_{3} \mathrm{O}_{62}\right]\end{array}$ & 38 & $1 \mathrm{~atm} \mathrm{O}_{2}$ & DCM & 24 & $\begin{array}{l}0.10 \% \mathrm{OH} \\
0.8 \% \mathrm{KET}\end{array}$ & 234 \\
\hline $\mathrm{HA}$ & 75 & $\begin{array}{l}\mathrm{O}_{2} \text { bubbling } \\
10 \text { mins }\end{array}$ & None & 18 & $\begin{array}{l}0.09 \% \mathrm{DI} \\
\mathrm{OL} \\
0.57 \% \mathrm{OH} \\
0.97 \% \mathrm{KE} \\
\mathrm{T}\end{array}$ & 279 \\
\hline $\begin{array}{l}\left(\mathrm{n}-\mathrm{Bu}{ }_{4} \mathrm{~N}\right)_{5} \mathrm{Na}_{3}[(1,5- \\
\left.\mathrm{COD}) \mathrm{Ir} \cdot \mathrm{P}_{2} \mathrm{~W}_{15} \mathrm{Nb}_{3} \mathrm{O}_{62}\right]\end{array}$ & 38 & $1 \mathrm{~atm} \mathrm{O}_{2}$ & DMF & 24 & $\begin{array}{l}1 \% \mathrm{EPO} \\
2 \% \mathrm{OH} \\
1 \% \mathrm{KET} \\
\end{array}$ & 234 \\
\hline $\begin{array}{l}(\mathrm{n}-\mathrm{Bu} 4 \mathrm{~N})_{5} \mathrm{Na}_{3}[(1,5- \\
\left.\mathrm{COD}) \mathrm{Ir} \cdot \mathrm{P}_{2} \mathrm{~W}_{15} \mathrm{Nb}_{3} \mathrm{O}_{62}\right]\end{array}$ & 38 & $1 \mathrm{~atm} \mathrm{O}_{2}$ & Acetone & 24 & $\begin{array}{l}1 \% \mathrm{OH} \\
1 \% \text { KET }\end{array}$ & 234 \\
\hline None & 75 & $\begin{array}{l}\mathrm{O}_{2} \text { bubbled } 10 \\
\text { mins }\end{array}$ & None & 18 & $\begin{array}{l}0.42 \% \mathrm{EP} \\
\mathrm{O}, \\
2.42 \% \mathrm{OH} \\
1.19 \mathrm{KET}\end{array}$ & 279 \\
\hline
\end{tabular}




\begin{tabular}{|c|c|c|c|c|c|c|}
\hline $\mathrm{CpV}(\mathrm{CO})_{4}$ & 60 & $1 \mathrm{~atm} \mathrm{O}$ & None & 1.5 & $\begin{array}{l}3.96 \% \mathrm{EP} \\
\mathrm{OH} \\
3.63 \% \mathrm{EP} \\
\mathrm{O} \\
1.87 \% \mathrm{OH} \\
1.54 \% \mathrm{KE} \\
\mathrm{T}\end{array}$ & 237 \\
\hline $\mathrm{V}_{2} \mathrm{O}_{5}$ & 60 & $1 \mathrm{~atm} \mathrm{O}_{2}$ & None & 7.5 & $\begin{array}{l}3.28 \% \mathrm{EP} \\
\mathrm{OH} \\
1.92 \% \mathrm{EP} \\
\mathrm{O} \\
0.96 \% \mathrm{OH} \\
1.84 \% \mathrm{KE} \\
\mathrm{T}\end{array}$ & 237 \\
\hline $\begin{array}{l}\left(\mathrm{n}-\mathrm{Bu}{ }_{4} \mathrm{~N}\right)_{5} \mathrm{Na}_{3}[(1,5- \\
\left.\mathrm{COD}) \mathrm{Ir} \cdot \mathrm{P}_{2} \mathrm{~W}_{15} \mathrm{Nb}_{3} \mathrm{O}_{62}\right]\end{array}$ & 38 & $1 \mathrm{~atm} \mathrm{O}_{2}$ & Methanol & 24 & $\begin{array}{l}1 \% \mathrm{OH} \\
2 \% \mathrm{KET} \\
\end{array}$ & 234 \\
\hline $\begin{array}{l}(\mathrm{n}-\mathrm{Bu} 4 \mathrm{~N})_{5} \mathrm{Na}_{3}[(1,5- \\
\left.\mathrm{COD}) \mathrm{Ir} \cdot \mathrm{P}_{2} \mathrm{~W}_{15} \mathrm{Nb}_{3} \mathrm{O}_{62}\right]\end{array}$ & 38 & $1 \mathrm{~atm} \mathrm{O}_{2}$ & Ethanol & 24 & $\begin{array}{l}1 \% \mathrm{OH} \\
2 \% \mathrm{KET}\end{array}$ & 234 \\
\hline $\mathrm{VO}(\mathrm{acac})_{2}$ & 60 & $1 \mathrm{~atm} \mathrm{O}_{2}$ & Benzene & 22 & $\begin{array}{l}8.28 \% \mathrm{EP} \\
\mathrm{OH} \\
5.76 \% \mathrm{EP} \\
\mathrm{O} \\
1.8 \% \mathrm{OH} \\
2.16 \% \mathrm{KE} \\
\mathrm{T}\end{array}$ & 237 \\
\hline $\mathrm{VO}(\mathrm{acac})_{2}$ & 60 & $1 \mathrm{~atm} \mathrm{O}_{2}$ & DCE & 15 & $\begin{array}{l}14.6 \% \mathrm{EP} \\
\mathrm{OH} \\
6.5 \% \mathrm{EPO} \\
2.6 \% \mathrm{OH} \\
2.34 \% \mathrm{KE} \\
\mathrm{T}\end{array}$ & 237 \\
\hline $\mathrm{VO}(\mathrm{acac})_{2}$ & 60 & $1 \mathrm{~atm} \mathrm{O}_{2}$ & $\begin{array}{l}1,4- \\
\text { dioxane }\end{array}$ & 26 & $\begin{array}{l}9.03 \% \mathrm{EP} \\
\mathrm{OH} \\
6.72 \% \mathrm{EP} \\
\mathrm{O} \\
2.73 \% \mathrm{OH} \\
2.52 \% \mathrm{KE} \\
\mathrm{T}\end{array}$ & 237 \\
\hline None & 90 & $4 \mathrm{MPa} \mathrm{O}$ & Water & 5 & $\begin{array}{l}1.20 \% \mathrm{DI} \\
\mathrm{OL} \\
1.00 \% \mathrm{OH} \\
2.83 \% \mathrm{KE} \\
\mathrm{T}\end{array}$ & 246 \\
\hline $\mathrm{VO}(\mathrm{acac})_{2}+\mathrm{AIBN}$ & 60 & $1 \mathrm{~atm} \mathrm{O}_{2}$ & None & 2.5 & $\begin{array}{l}7.79 \% \mathrm{EP} \\
\mathrm{OH} \\
5.32 \% \mathrm{EP} \\
\mathrm{O} \\
2.85 \% \mathrm{OH}\end{array}$ & 237 \\
\hline
\end{tabular}




\begin{tabular}{|c|c|c|c|c|c|c|}
\hline & & & & & $\begin{array}{l}3.04 \% \mathrm{KE} \\
\mathrm{T}\end{array}$ & \\
\hline $\begin{array}{l}(\mathrm{n}-\mathrm{Bu} 4 \mathrm{~N})_{5} \mathrm{Na}_{3}[(1,5- \\
\left.\mathrm{COD}) \mathrm{Ir} \cdot \mathrm{P}_{2} \mathrm{~W}_{15} \mathrm{Nb}_{3} \mathrm{O}_{62}\right]\end{array}$ & 38 & $1 \mathrm{~atm} \mathrm{O}_{2}$ & $1-\mathrm{C}_{2} \mathrm{H}_{4} \mathrm{Cl}_{2}$ & 24 & $\begin{array}{l}1 \% \mathrm{EPO} \\
2 \% \mathrm{OH} \\
4 \% \mathrm{KET}\end{array}$ & 234 \\
\hline $\mathrm{HA} / \mathrm{Co}^{2+}-2: 1$ & 75 & $\begin{array}{l}\mathrm{O}_{2} \text { bubbling } \\
10 \text { mins }\end{array}$ & None & 18 & $\begin{array}{l}1.03 \% \mathrm{DI} \\
\mathrm{OL} \\
4.16 \% \mathrm{OH} \\
4.39 \% \mathrm{KE} \\
\mathrm{T}\end{array}$ & 279 \\
\hline$[\mathrm{Cu}-\mathrm{Imace}-\mathrm{H}-\mathrm{H}]\left[\mathrm{BF}_{4}\right]$ & 60 & $\mathrm{O}_{2}$ bubbling & $\mathrm{ACN}$ & 3 & $\begin{array}{l}50.4 \% \mathrm{EP} \\
\mathrm{O} \\
1.8 \% \mathrm{OH} \\
5.4 \% \mathrm{KET}\end{array}$ & 238 \\
\hline $\begin{array}{l}\mathrm{Mo}(\mathrm{VI}) \mathrm{Cl}_{2} \mathrm{O}_{2} \mathrm{Bipy} / \mathrm{TiO}_{2} \\
\mathrm{SC}-150 \text { fresh } \\
\text { (photocatalysis) }\end{array}$ & 19 & $\mathrm{O}_{2}$ & $\mathrm{ACN}$ & 56 & $\begin{array}{l}45.4 \% \mathrm{EP} \\
\mathrm{O} \\
3.82 \% \mathrm{OH} \\
5.47 \% \mathrm{KE} \\
\mathrm{T}\end{array}$ & 239 \\
\hline $\mathrm{HA} / \mathrm{HCl}-18 \mathrm{~h}$ & 75 & $\begin{array}{l}\mathrm{O}_{2} \text { bubbling } \\
10 \text { mins }\end{array}$ & None & 18 & $\begin{array}{l}0.14 \% \mathrm{EP} \\
\mathrm{O} \\
3.66 \% \mathrm{OH} \\
5.50 \% \mathrm{KE} \\
\mathrm{T}\end{array}$ & 279 \\
\hline $\begin{array}{l}(\mathrm{n}-\mathrm{Bu} 4 \mathrm{~N})_{5} \mathrm{Na}_{3}[(1,5- \\
\left.\mathrm{COD}) \mathrm{Ir} \cdot \mathrm{P}_{2} \mathrm{~W}_{15} \mathrm{Nb}_{3} \mathrm{O}_{62}\right]\end{array}$ & 38 & $1 \mathrm{~atm} \mathrm{O}_{2}$ & $\mathrm{ACN}$ & 24 & $\begin{array}{l}1 \% \text { EPO } \\
1 \% \text { EPO } \\
6 \% \text { KET }\end{array}$ & 234 \\
\hline $\begin{array}{l}\left(n \mathrm{Bu}_{4} \mathrm{~N}\right)_{4} \mathrm{~W}_{10} \mathrm{O}_{32} / \mathrm{SiO}_{2}+ \\
\mathrm{h} v\end{array}$ & 22 & 760 torr $\mathrm{O}_{2}$ & $\mathrm{ACN}$ & 2 & $\begin{array}{l}1.5 \% \text { ETH } \\
89 \% \mathrm{OOH} \\
1.2 \% \text { EPO } \\
1.9 \% \mathrm{OH} \\
6.4 \% \mathrm{KET}\end{array}$ & 244 \\
\hline $\mathrm{CpV}(\mathrm{CO})_{4}$ & 60 & $1 \mathrm{~atm} \mathrm{O}_{2}$ & None & 0.4 & $\begin{array}{l}0.96 \% \mathrm{EP} \\
\mathrm{OH} \\
2.72 \% \mathrm{EP} \\
\mathrm{O} \\
5.92 \% \mathrm{OH} \\
6.40 \% \mathrm{KE} \\
\mathrm{T}\end{array}$ & 237 \\
\hline $\mathrm{VO}(\mathrm{acac})_{2}$ & 60 & $1 \mathrm{~atm} \mathrm{O}_{2}$ & Ethanol & 4.5 & $\begin{array}{l}3.36 \% \mathrm{EP} \\
\mathrm{O} \\
3.78 \% \mathrm{OH} \\
6.86 \% \mathrm{KE} \\
\mathrm{T}\end{array}$ & 237 \\
\hline $\mathrm{HA} / \mathrm{HCl}-6 \mathrm{~h} / \mathrm{Co}^{2+}-2: 1$ & 75 & $\begin{array}{l}\mathrm{O}_{2} \text { bubbling } \\
10 \text { mins }\end{array}$ & None & 18 & $\begin{array}{l}0.53 \% \mathrm{DI} \\
\mathrm{OL} \\
2.71 \% \mathrm{OH}\end{array}$ & 279 \\
\hline
\end{tabular}




\begin{tabular}{|c|c|c|c|c|c|c|}
\hline & & & & & $\begin{array}{l}7.24 \% \mathrm{KE} \\
\mathrm{T}\end{array}$ & \\
\hline$\left(n \mathrm{Bu}_{4} \mathrm{~N}\right)_{4} \mathrm{~W}_{10} \mathrm{O}_{32}+\mathrm{h} v$ & 22 & 760 torr $\mathrm{O}_{2}$ & $\mathrm{ACN}$ & 2 & $\begin{array}{l}1 \% \mathrm{ETH} \\
89 \% \mathrm{OOH} \\
0.7 \% \mathrm{EPO} \\
1.8 \% \mathrm{OH}, \\
7.5 \% \mathrm{KET}\end{array}$ & 244 \\
\hline $\mathrm{Co}\left(\mathrm{NO}_{3}\right)_{2} \cdot 6 \mathrm{H}_{2} \mathrm{O}$ & 75 & $\begin{array}{l}\mathrm{O}_{2} \text { bubbling } \\
10 \text { mins }\end{array}$ & None & 18 & $\begin{array}{l}0.68 \% \mathrm{EP} \\
\mathrm{O} \\
0.48 \% \mathrm{DI} \\
\mathrm{OL} \\
4.10 \% \mathrm{OH} \\
8.27 \% \mathrm{KE} \\
\mathrm{T}\end{array}$ & 279 \\
\hline $\mathrm{Co}\left(\mathrm{NO}_{3}\right)_{2} \cdot 6 \mathrm{H}_{2} \mathrm{O}$ & 75 & $\begin{array}{l}\mathrm{O}_{2} \text { bubbled } 10 \\
\text { mins }\end{array}$ & None & 18 & $\begin{array}{l}0.73 \% \mathrm{EP} \\
\mathrm{O}, \\
4.10 \% \mathrm{OH} \\
, \\
8.27 \% \mathrm{KE} \\
\mathrm{T}\end{array}$ & 279 \\
\hline $\begin{array}{l}\mathrm{HA} / \mathrm{HCl}-7.5 \mathrm{~h} / \mathrm{Co}^{2+}-2: \\
1\end{array}$ & 75 & $\begin{array}{l}\mathrm{O}_{2} \text { bubbling } \\
10 \text { mins }\end{array}$ & None & 18 & $\begin{array}{l}1.51 \% \mathrm{DI} \\
\mathrm{OL} \\
6.33 \% \mathrm{OH} \\
8.98 \% \mathrm{KE} \\
\mathrm{T}\end{array}$ & 279 \\
\hline $\begin{array}{l}\mathrm{TBA}_{5} \mathrm{Na}_{3}\left[(\mathrm{COD}) \mathrm{Rh} \cdot \mathrm{P}_{2}\right. \\
\left.\mathrm{W}_{15} \mathrm{Nb}_{3} \mathrm{O}_{62}\right]\end{array}$ & 38 & $1 \mathrm{~atm} \mathrm{O}_{2}$ & $\overline{\mathrm{DCM}}$ & 24 & $\begin{array}{l}0 \% \mathrm{EPO}, \\
3 \% \mathrm{OH}, \\
9 \% \mathrm{KET}\end{array}$ & 234 \\
\hline $\begin{array}{l}\mathrm{HA} / \mathrm{NaOH}-18 \mathrm{~h} / \mathrm{Co}^{2+}-1 \\
: 1\end{array}$ & 75 & $\begin{array}{l}\mathrm{O}_{2} \text { bubbling } \\
10 \text { mins }\end{array}$ & None & 18 & $\begin{array}{l}0.21 \% \mathrm{EP} \\
\mathrm{O} \\
1.65 \% \mathrm{DI} \\
\mathrm{OL} \\
7.86 \% \mathrm{OH} \\
9.46 \% \mathrm{KE} \\
\mathrm{T}\end{array}$ & 279 \\
\hline $\begin{array}{l}\mathrm{HA} / \mathrm{HCl}-18 \mathrm{~h} / \mathrm{Co}^{2+}-0.5 \\
: 1\end{array}$ & 75 & $\begin{array}{l}\mathrm{O}_{2} \text { bubbling } \\
10 \text { mins }\end{array}$ & None & 18 & $\begin{array}{l}0.61 \% \mathrm{EP} \\
\mathrm{O} \\
0.20 \% \mathrm{DI} \\
\mathrm{OL} \\
8.03 \% \mathrm{OH} \\
9.48 \% \mathrm{KE} \\
\mathrm{T}\end{array}$ & 279 \\
\hline $\begin{array}{l}\left(\mathrm{n}-\mathrm{Bu}_{4} \mathrm{~N}\right)_{5} \mathrm{Na}_{3}[(1,5- \\
\left.\mathrm{COD}) \mathrm{Ir} \cdot \mathrm{P}_{2} \mathrm{~W}_{15} \mathrm{Nb}_{3} \mathrm{O}_{62}\right]\end{array}$ & 38 & $1 \mathrm{~atm} \mathrm{O}_{2}$ & DCM & 24 & $\begin{array}{l}2 \% \mathrm{EPO}, \\
12 \% \mathrm{OH}, \\
10 \% \mathrm{KET}\end{array}$ & 234 \\
\hline
\end{tabular}




\begin{tabular}{|c|c|c|c|c|c|c|}
\hline Co-C & 90 & $4 \mathrm{MPa} \mathrm{O}$ & Water & 5 & $\begin{array}{l}1.27 \% \mathrm{DI} \\
\mathrm{OL} \\
4.18 \% \mathrm{OH} \\
10.7 \% \mathrm{KE} \\
\mathrm{T}\end{array}$ & 246 \\
\hline $\begin{array}{l}\left(\mathrm{n}-\mathrm{Bu}{ }_{4} \mathrm{~N}\right)_{5} \mathrm{Na}_{3}[(1,5- \\
\left.\mathrm{COD}) \mathrm{Ir} \cdot \mathrm{P}_{2} \mathrm{~W}_{15} \mathrm{Nb}_{3} \mathrm{O}_{62}\right]\end{array}$ & 38 & $1 \mathrm{~atm} \mathrm{O}_{2}$ & $\begin{array}{l}1,1,2,2- \\
\mathrm{C}_{2} \mathrm{H}_{2} \mathrm{Cl}_{4}\end{array}$ & 24 & $\begin{array}{l}2 \% \text { EPO } \\
1 \% \mathrm{OH} \\
11 \% \mathrm{KET}\end{array}$ & 234 \\
\hline $\begin{array}{l}\mathrm{TBA}_{5} \mathrm{Na}_{3}\left[(\mathrm{COD}) \mathrm{Ir} \cdot \mathrm{P}_{2}\right. \\
\left.\mathrm{W} \quad \mathrm{Nb}_{3} \mathrm{O}_{62}\right]\end{array}$ & 38 & $1 \mathrm{~atm} \mathrm{O}_{2}$ & DCM & 24 & $\begin{array}{l}2 \% \mathrm{EPO}, \\
10 \% \mathrm{OH}, \\
12 \% \mathrm{KET}\end{array}$ & 234 \\
\hline $\mathrm{VO}(\mathrm{acac})_{2}$ & 60 & $1 \mathrm{~atm} \mathrm{O}_{2}$ & DMF & 2.5 & $\begin{array}{l}4.32 \% \mathrm{EP} \\
\mathrm{O} \\
6.72 \% \mathrm{OH} \\
12.9 \% \mathrm{KE} \\
\mathrm{T}\end{array}$ & 237 \\
\hline $\mathrm{Co}-\mathrm{SiO}_{2}$ & 90 & $4 \mathrm{MPa} \mathrm{O}_{2}$ & Water & 5 & $\begin{array}{l}1.03 \% \mathrm{DI} \\
\mathrm{OL} \\
5.09 \% \mathrm{OH} \\
12.9 \% \mathrm{KE} \\
\mathrm{T}\end{array}$ & 246 \\
\hline $\begin{array}{l}\mathrm{HA} / \mathrm{HCl}-18 \mathrm{~h} / \mathrm{Co}^{2+}-1: \\
1\end{array}$ & 75 & $\begin{array}{l}\mathrm{O}_{2} \text { bubbling } \\
10 \text { mins }\end{array}$ & None & 18 & $\begin{array}{l}0.93 \% \mathrm{EP} \\
\mathrm{O} \\
1.30 \% \mathrm{DI} \\
\mathrm{OL} \\
11.3 \% \mathrm{OH} \\
13.1 \% \mathrm{KE} \\
\mathrm{T}\end{array}$ & 279 \\
\hline $\begin{array}{l}\mathrm{HA} / \mathrm{NaOH}-18 \mathrm{~h} / \mathrm{Co}^{2+}-4 \\
: 1\end{array}$ & 75 & $\begin{array}{l}\mathrm{O}_{2} \text { bubbling } \\
10 \text { mins }\end{array}$ & None & 18 & $\begin{array}{l}0.18 \% \mathrm{EP} \\
\mathrm{O} \\
1.68 \% \mathrm{DI} \\
\mathrm{OL} \\
7.13 \% \mathrm{OH} \\
13.5 \% \mathrm{KE} \\
\mathrm{T} \\
\end{array}$ & 279 \\
\hline $\begin{array}{l}\mathrm{HA} / \mathrm{HCl}-11 \mathrm{~h} / \mathrm{Co}^{2+}-2: \\
1\end{array}$ & 75 & $\begin{array}{l}\mathrm{O}_{2} \text { bubbling } \\
10 \text { mins }\end{array}$ & None & 18 & $\begin{array}{l}0.11 \% \mathrm{EP} \\
\mathrm{O} \\
1.23 \% \mathrm{DI} \\
\mathrm{OL} \\
6.90 \% \mathrm{OH} \\
15.7 \% \mathrm{KE} \\
\mathrm{T}\end{array}$ & 279 \\
\hline $\begin{array}{l}\mathrm{HA} / \mathrm{NaOH}-18 \mathrm{~h} / \mathrm{Co}^{2+}-2 \\
: 1\end{array}$ & 75 & $\begin{array}{l}\mathrm{O}_{2} \text { bubbling } \\
10 \text { mins }\end{array}$ & None & 18 & $\begin{array}{l}0.60 \% \mathrm{EP} \\
\mathrm{O} \\
5.22 \% \mathrm{DI} \\
\mathrm{OL} \\
7.49 \% \mathrm{OH} \\
\end{array}$ & 279 \\
\hline
\end{tabular}




\begin{tabular}{|c|c|c|c|c|c|c|}
\hline & & & & & $\begin{array}{l}15.8 \% \mathrm{KE} \\
\mathrm{T}\end{array}$ & \\
\hline $\begin{array}{l}\left(n \mathrm{Bu}_{4} \mathrm{~N}\right)_{4} \mathrm{~W}_{10} \mathrm{O}_{32} / \mathrm{SiO}_{2} / \\
\mathrm{Fe}(\mathrm{TDCPP}) \mathrm{Cl}+\mathrm{h} v\end{array}$ & 22 & 760 torr $\mathrm{O}_{2}$ & $\mathrm{ACN}$ & 2 & $\begin{array}{l}1.2 \% \text { ETH } \\
73 \% \mathrm{OOH} \\
0.8 \% \text { EPO } \\
9.0 \% \mathrm{OH} \\
16 \% \mathrm{KET}\end{array}$ & 244 \\
\hline $\mathrm{Co}^{-\mathrm{TiO}_{2}}$ & 90 & $4 \mathrm{MPa} \mathrm{O}$ & Water & 5 & $\begin{array}{l}1.28 \% \mathrm{DI} \\
\mathrm{OL} \\
4.58 \% \mathrm{OH} \\
16.6 \% \mathrm{KE} \\
\mathrm{T}\end{array}$ & 246 \\
\hline $\begin{array}{l}\text { Co(II)-containing } \\
\text { metal-organic } \\
\text { frameworks }\end{array}$ & 80 & $\begin{array}{l}\text { Oxygen } \\
\text { Balloon }\end{array}$ & None & 20 & $\begin{array}{l}0.98 \% \mathrm{EP} \\
\mathrm{O} \\
12.9 \% \mathrm{OH} \\
16.8 \% \mathrm{KE} \\
\mathrm{T}\end{array}$ & 279 \\
\hline $\begin{array}{l}\text { Co(II)-containing } \\
\text { metal-organic } \\
\text { frameworks }\end{array}$ & 80 & $\begin{array}{l}\text { Oxygen } \\
\text { Balloon }\end{array}$ & None & 24 & $\begin{array}{l}1.00 \% \mathrm{EP} \\
\mathrm{O}, \\
12.90 \% \mathrm{O} \\
\mathrm{H}, \\
16.81 \% \mathrm{~K} \\
\mathrm{ET}\end{array}$ & 279 \\
\hline PVA stabilized CuNP & 100 & 4 bar $\mathrm{O}_{2}$ & None & 6 & $\begin{array}{l}2.18 \% \mathrm{EP} \\
\mathrm{O} \\
14.2 \% \mathrm{OH} \\
17.3 \% \mathrm{KE} \\
\mathrm{T}\end{array}$ & 250 \\
\hline $\begin{array}{l}\mathrm{HA} / \mathrm{HCl}-18 \mathrm{~h} / \mathrm{Co}^{2+}-4: \\
1\end{array}$ & 75 & $\begin{array}{l}\mathrm{O}_{2} \text { bubbling } \\
10 \text { mins }\end{array}$ & None & 18 & $\begin{array}{l}0.32 \% \mathrm{EP} \\
\mathrm{O} \\
1.17 \% \mathrm{DI} \\
\mathrm{OL} \\
9.81 \% \mathrm{OH} \\
17.8 \% \mathrm{KE} \\
\mathrm{T}\end{array}$ & 279 \\
\hline $\begin{array}{l}\text { [NSP]@MWNTs } \\
\text { Nickel salophen } \\
\text { nanotubes }\end{array}$ & 70 & $1 \mathrm{~atm} \mathrm{O}_{2}$ & None & 10 & $\begin{array}{l}49.8 \% \mathrm{OH} \\
19.5 \% \mathrm{KE} \\
\mathrm{T}\end{array}$ & 242 \\
\hline $\begin{array}{l}\mathrm{TBA}_{4.5} \mathrm{Na}_{2.5}[(\mathrm{be} \cdot \\
\text { nzene }) \mathrm{Ru} \cdot \mathrm{P}_{2} \mathrm{~W}_{15} \mathrm{Nb}_{3} \mathrm{O}_{62} \\
\text { ] }\end{array}$ & 38 & $1 \mathrm{~atm} \mathrm{O}_{2}$ & DCM & 24 & $\begin{array}{l}8 \% \text { EPO, } \\
20 \% \mathrm{OH}, \\
28 \% \mathrm{KET}\end{array}$ & 234 \\
\hline $\begin{array}{l}\left(n \mathrm{Bu}_{4} \mathrm{~N}\right)_{4} \mathrm{~W}_{10} \mathrm{O}_{32} / \mathrm{SiO}_{2} / \\
\mathrm{Fe}(\mathrm{TDCPP}) \mathrm{Cl}+\mathrm{h} v+\text { dark } \\
3 \text { hours }\end{array}$ & 22 & 760 torr $\mathrm{O}_{2}$ & $\mathrm{ACN}$ & 2 & $\begin{array}{l}1.1 \% \text { ETH } \\
59 \% \text { OOH } \\
1.4 \% \text { EPO } \\
20 \% \mathrm{OH} \\
29 \% \text { KET }\end{array}$ & 244 \\
\hline
\end{tabular}




\begin{tabular}{|c|c|c|c|c|c|c|}
\hline $\begin{array}{l}\left(n \mathrm{Bu}_{4} \mathrm{~N}\right)_{4} \mathrm{~W}_{10} \mathrm{O}_{32} / \mathrm{SiO}_{2} / \\
\mathrm{Fe}(\mathrm{TDCPP}) \mathrm{Cl}+\mathrm{h} v+\mathrm{Dar} \\
\mathrm{k} 3 \text { hours }\end{array}$ & 22 & 760 torr $\mathrm{O}_{2}$ & $\mathrm{ACN}$ & 2 & $\begin{array}{l}1.6 \% \text { ETH } \\
48 \% \text { OOH } \\
1.4 \% \text { EPO } \\
20 \% \mathrm{OH} \\
29 \% \text { KET }\end{array}$ & 244 \\
\hline $\begin{array}{l}\mathrm{TBA}_{8}\left[(\mathrm{CO})_{3} \mathrm{Re} \cdot \mathrm{P}_{2} \mathrm{~W}_{15} \mathrm{~N}\right. \\
\left.\mathrm{b}_{3} \mathrm{O}_{62}\right]\end{array}$ & 38 & $1 \mathrm{~atm} \mathrm{O}_{2}$ & DCM & 24 & $\begin{array}{l}7 \% \text { EPO, } \\
20 \% \mathrm{OH}, \\
30 \% \mathrm{KET}\end{array}$ & 234 \\
\hline $\begin{array}{l}\mathrm{HA} / \mathrm{HCl}-18 \mathrm{~h} / \mathrm{Co}^{2+}-2: \\
1\end{array}$ & 75 & $\begin{array}{l}\mathrm{O}_{2} \text { bubbling } \\
10 \text { mins }\end{array}$ & None & 18 & $\begin{array}{l}0.15 \% \mathrm{EP} \\
\mathrm{O} \\
3.32 \% \mathrm{DI} \\
\mathrm{OL} \\
23.0 \% \mathrm{OH} \\
31.8 \% \mathrm{KE} \\
\mathrm{T}\end{array}$ & 279 \\
\hline Au-Bentonite & 80 & $8-13$ bar $\mathrm{O}_{2}$ & None & 18 & $\begin{array}{l}18.0 \% \mathrm{OH} \\
33.4 \% \mathrm{KE} \\
\mathrm{T} \\
1.59 \% \mathrm{OT} \\
\mathrm{H}\end{array}$ & 267 \\
\hline $\mathrm{Co}-\mathrm{g}-\mathrm{C}_{3} \mathrm{~N}_{4}$ & 90 & $4 \mathrm{MPa} \mathrm{O} 2$ & Water & 5 & $\begin{array}{l}1.06 \% \mathrm{DI} \\
\mathrm{OL} \\
12.9 \% \mathrm{OH} \\
40.1 \% \mathrm{KE} \\
\mathrm{T}\end{array}$ & 246 \\
\hline $\mathrm{BNO}_{2}-\mathrm{Cu}-\mathrm{TDCPP}$ & 100 & $400 \mathrm{KPa} \mathrm{O}_{2}$ & None & 4 & $\begin{array}{l}13.8 \% \mathrm{OH} \\
45.5 \% \mathrm{KE} \\
\mathrm{T} \\
6.60 \% \mathrm{OT} \\
\text { HERS }\end{array}$ & 247 \\
\hline $\mathrm{Fe}(\mathrm{TPP}) \mathrm{Cl}$ & 25 & $1 \mathrm{~atm} \mathrm{O}$ & $\mathrm{ACN}$ & 24 & $52 \% \mathrm{KET}$ & 249 \\
\hline Calcined $\mathrm{CuO}$ catalyst & 100 & 4 bar $\mathrm{O}_{2}$ & None & 6 & $\begin{array}{l}4.41 \% \mathrm{EP} \\
\mathrm{O} \\
31.1 \% \mathrm{OH} \\
54.4 \% \mathrm{KE} \\
\mathrm{T}\end{array}$ & 250 \\
\hline $\mathrm{MgCl}_{2} / \mathrm{NHPI}$ & 80 & $0.3 \mathrm{MPa} \mathrm{O}_{2}$ & $\mathrm{ACN}$ & 4 & $\begin{array}{l}60.3 \% \mathrm{KE} \\
\mathrm{T}\end{array}$ & 254 \\
\hline $\mathrm{CoCl}_{2}$ & 45 & $1 \mathrm{~atm} \mathrm{O}_{2}$ & NMP & 19 & $\begin{array}{l}4 \% \mathrm{OH} \\
71 \% \mathrm{KET}\end{array}$ & 256 \\
\hline $\mathrm{g}-\mathrm{C}_{3} \mathrm{~N}_{4} / \mathrm{NHPI}$ & 60 & $1 \mathrm{~atm} \mathrm{O}_{2}$ & $\mathrm{ACN}$ & 8 & $\begin{array}{l}71.6 \% \mathrm{KE} \\
\mathrm{T}\end{array}$ & 257 \\
\hline $\begin{array}{l}{\left[\mathrm{C}_{10} \mathrm{mim}\right]\left[\mathrm{Co}\left(\mathrm{F}_{6^{-}}\right.\right.} \\
\left.\text {acac })_{3}\right]\end{array}$ & 60 & $1 \mathrm{~atm} \mathrm{O}_{2}$ & None & 6 & $81 \%$ KET & 262 \\
\hline${\text { [(TAML)Fe(III) }]^{-}}^{-}$ & 25 & Bubbling $\mathrm{O}_{2}$ & $\mathrm{ACN}$ & 4 & $\begin{array}{l}11 \% \text { EPO } \\
89 \% \text { KET }\end{array}$ & 266 \\
\hline Au-Silica & 80 & $8-13$ bar $\mathrm{O}_{2}$ & None & 18 & $2.76 \% \mathrm{OH}$ & 267 \\
\hline
\end{tabular}




\begin{tabular}{|l|l|l|l|l|l|l|}
\hline & & & & & $\begin{array}{l}89.2 \% \mathrm{KE} \\
\mathrm{T}\end{array}$ & \\
\hline None & 23 & $\begin{array}{l}\text { Oxygen } \\
\text { Balloon }\end{array}$ & DCM & 4 & $15 \% \mathrm{EPO}$ & 230 \\
\hline $\begin{array}{l}\mathrm{NHPI}, \mathrm{Co}(\mathrm{OAc})_{2} \text {, and } \\
\mathrm{Mo}(\mathrm{CO})_{6}, 4 \AA \mathrm{MS}\end{array}$ & 60 & 1 atm $\mathrm{O}_{2}$ & None & 14 & $\begin{array}{l}59.2 \% \mathrm{EP} \\
\mathrm{O}\end{array}$ & 231 \\
\hline $\mathrm{Fe}_{3} \mathrm{O}_{4} / \mathrm{tart} / \mathrm{Mn}(\mathrm{TCPP}) \mathrm{Cl}$ & 25 & $\begin{array}{l}\text { Oxygen } \\
\text { balloon }\end{array}$ & ACN & 8 & $\begin{array}{l}86 \% \mathrm{EPO} \\
12 \% \mathrm{OH}\end{array}$ & 232 \\
\hline $\mathrm{Mn}(\mathrm{TPP}) \mathrm{Cl}$ & 23 & $\begin{array}{l}\text { Oxygen } \\
\text { Balloon }\end{array}$ & DCE & 4 & $91 \% \mathrm{EPO}$ & 230 \\
\hline $\begin{array}{l}\mathrm{Mn} \text { porphyrin cage } 0.5 \\
\text { mol\% }\end{array}$ & 23 & $\begin{array}{l}\text { Oxygen } \\
\text { Balloon }\end{array}$ & DCE & 4 & $92 \% \mathrm{EPO}$ & 230 \\
\hline $\begin{array}{l}\text { Mn porphyrin cage } \\
\text { Oxygen } \\
\text { Balloon }\end{array}$ & 23 & DCM & 4 & $93 \% \mathrm{EPO}$ & 230 \\
\hline
\end{tabular}

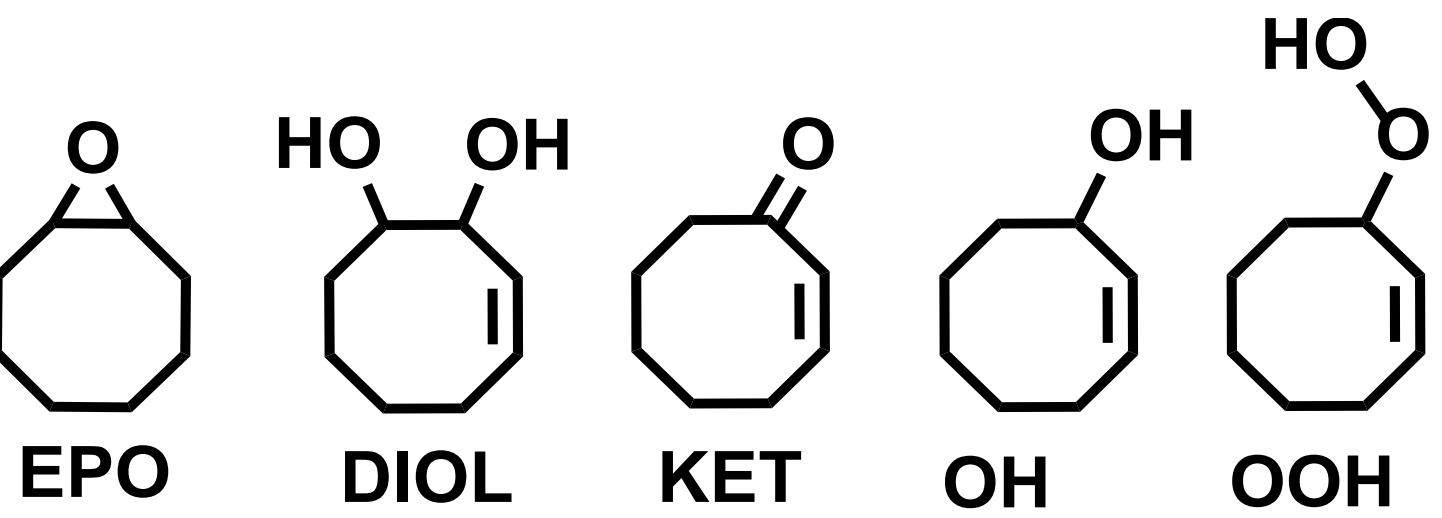

Figure S6.23. contains the structures that are associated with the shorthand codes that relate to the codes in tables S6.4, S6.5, and S6.6.

Table S6.4 contains the details of reactions from literature and this work of cyclooctene using t-butyl hydroperoxide as the oxidizer. Entries are listed in increasing order based on the yield of the cyclooctene oxide denoted as EPO.

\begin{tabular}{|c|c|c|c|c|c|c|}
\hline Catalyst & $\begin{array}{l}\text { Temp } \\
\left({ }^{\circ} \mathrm{C}\right)\end{array}$ & Oxidizer & $\begin{array}{l}\text { Solven } \\
\mathrm{t}\end{array}$ & $\begin{array}{l}\text { Time } \\
\text { (hours } \\
\text { ) }\end{array}$ & Yields & Ref. \\
\hline $\mathrm{HAuCl}_{4} \cdot 3 \mathrm{H}_{2} \mathrm{O}$ & 85 & $\begin{array}{l}0.05 \mathrm{eq} \\
\text { TBuOOH }\end{array}$ & $\mathrm{ACN}$ & 6 & $\begin{array}{l}2.25 \% \mathrm{EP} \\
\mathrm{O} \\
0.49 \% \mathrm{O} \\
\mathrm{H} \\
0.37 \% \mathrm{~K} \\
\mathrm{ET}\end{array}$ & 277 \\
\hline
\end{tabular}




\begin{tabular}{|c|c|c|c|c|c|c|}
\hline $\mathrm{Al}_{2} \mathrm{O}_{3}$ & 80 & $\begin{array}{l}1.5 \mathrm{eq} \\
\text { TbuOOH }\end{array}$ & None & 24 & $\begin{array}{l}3.14 \% \mathrm{EP} \\
\mathrm{O}\end{array}$ & 271 \\
\hline None & 80 & $\begin{array}{l}1.5 \mathrm{eq} \\
\text { TbuOOH }\end{array}$ & None & 24 & $\begin{array}{l}3.31 \% \mathrm{EP} \\
\mathrm{O}\end{array}$ & 271 \\
\hline $1 \% \mathrm{Au}$ on $\mathrm{Al}_{2} \mathrm{O}_{3}$ & 80 & $\begin{array}{l}1.5 \mathrm{eq} \\
\text { TbuOOH }\end{array}$ & None & 24 & $\begin{array}{l}4.57 \% \mathrm{EP} \\
\mathrm{O}\end{array}$ & 271 \\
\hline $\mathrm{SiC}$ & 80 & $\begin{array}{l}1.5 \mathrm{eq} \\
\text { TbuOOH }\end{array}$ & None & 24 & $\begin{array}{l}5.25 \% \mathrm{EP} \\
\mathrm{O}\end{array}$ & 271 \\
\hline $1 \% \mathrm{Au}$ on $\mathrm{SiC}$ & 80 & $\begin{array}{l}1.5 \mathrm{eq} \\
\text { TbuOOH }\end{array}$ & None & 24 & $\begin{array}{l}8.07 \% \mathrm{EP} \\
\mathrm{O}\end{array}$ & 271 \\
\hline $\mathrm{Au} / \mathrm{GA}-\mathrm{IM}$ & 85 & $\begin{array}{l}0.05 \mathrm{eq} \\
\text { TBuOOH }\end{array}$ & $\mathrm{ACN}$ & 6 & $\begin{array}{l}10.1 \% \mathrm{EP} \\
\mathrm{O} \\
3.36 \% \mathrm{O} \\
\mathrm{H} \\
2.50 \% \mathrm{~K} \\
\mathrm{ET}\end{array}$ & 277 \\
\hline $\mathrm{Au} / \mathrm{TiO}_{2}-\mathrm{IM}$ & 85 & $\begin{array}{l}0.05 \text { eq } \\
\text { TBuOOH }\end{array}$ & $\mathrm{ACN}$ & 6 & $\begin{array}{l}11.5 \% \mathrm{EP} \\
\mathrm{O} \\
2.93 \% \mathrm{O} \\
\mathrm{H} \\
1.26 \% \mathrm{~K} \\
\mathrm{ET}\end{array}$ & 277 \\
\hline $\mathrm{Au} / \mathrm{AC}-\mathrm{IM}$ & 85 & $\begin{array}{l}0.05 \text { eq } \\
\text { TBuOOH }\end{array}$ & $\mathrm{ACN}$ & 6 & $\begin{array}{l}12.4 \% \mathrm{EP} \\
\mathrm{O} \\
1.07 \% \mathrm{O} \\
\mathrm{H} \\
1.43 \% \mathrm{~K} \\
\mathrm{ET}\end{array}$ & 277 \\
\hline $\mathrm{Au} / \mathrm{SiO}_{2}$-IM & 85 & $\begin{array}{l}0.05 \text { eq } \\
\text { TBuOOH }\end{array}$ & $\mathrm{ACN}$ & 6 & $\begin{array}{l}17.7 \% \mathrm{EP} \\
\mathrm{O} \\
3.35 \% \mathrm{O} \\
\mathrm{H} \\
1.32 \% \mathrm{~K} \\
\mathrm{ET}\end{array}$ & 277 \\
\hline $\mathrm{Au} / \mathrm{Al}_{2} \mathrm{O}_{3}-\mathrm{IM}$ & 85 & $\begin{array}{l}0.05 \mathrm{eq} \\
\text { TBuOOH }\end{array}$ & $\mathrm{ACN}$ & 6 & $\begin{array}{l}18.9 \% \mathrm{EP} \\
\mathrm{O} \\
3.68 \% \mathrm{O} \\
\mathrm{H} \\
3.52 \% \mathrm{~K} \\
\mathrm{ET}\end{array}$ & 277 \\
\hline $\mathrm{Au} / \mathrm{CNTs}$-IM & 85 & $\begin{array}{l}0.05 \text { eq } \\
\text { TBuOOH }\end{array}$ & $\mathrm{ACN}$ & 6 & $\begin{array}{l}24.0 \% \mathrm{EP} \\
\mathrm{O}\end{array}$ & 277 \\
\hline
\end{tabular}




\begin{tabular}{|c|c|c|c|c|c|c|}
\hline & & & & & $\begin{array}{l}4.26 \% \mathrm{O} \\
\mathrm{H} \\
4.59 \% \mathrm{~K} \\
\mathrm{ET}\end{array}$ & \\
\hline None & 80 & $\begin{array}{l}0.05 \mathrm{eq} \\
\text { TBuOOH }\end{array}$ & $\begin{array}{l}\mathrm{DCE} / \mathrm{A} \\
\mathrm{CN}\end{array}$ & 72 & $\begin{array}{l}40.3 \% \mathrm{EP} \\
\mathrm{O} \\
0.35 \% \mathrm{O} \\
\mathrm{H} \\
1.18 \% \mathrm{~K} \\
\mathrm{ET}\end{array}$ & $\begin{array}{l}\text { This } \\
\text { Wor } \\
\mathrm{k}\end{array}$ \\
\hline $\mathrm{Fe}_{3} \mathrm{O}_{4} \mathrm{MNPs}$ & 120 & 3eq TBuOOH & None & 4 & $70 \% \mathrm{EPO}$ & 265 \\
\hline AgNP-MCM-41 & 80 & $\begin{array}{l}0.05 \mathrm{eq} \\
\text { TBuOOH }\end{array}$ & $\begin{array}{l}\mathrm{DCE} / \mathrm{A} \\
\mathrm{CN}\end{array}$ & 72 & $\begin{array}{l}72.4 \% \mathrm{EP} \\
\mathrm{O} \\
0.22 \% \mathrm{O} \\
\mathrm{H} \\
2.02 \% \mathrm{~K} \\
\mathrm{ET}\end{array}$ & 252 \\
\hline
\end{tabular}

Table S6.5 contains the details of reactions from literature and this work of cyclooctene using hydrogen peroxide as the oxidizer. Entries are listed in increasing order based on the yield of the cyclooctene oxide denoted as EPO.

\begin{tabular}{|c|c|c|c|c|c|c|}
\hline Catalyst & $\begin{array}{l}\text { Tem } \\
\mathrm{p} \\
\left({ }^{\circ} \mathrm{C}\right)\end{array}$ & Oxidizer & Solvent & $\begin{array}{l}\text { Time } \\
\text { (Hour } \\
\text { s) }\end{array}$ & Yields & Ref. \\
\hline None & 50 & $2 \mathrm{eq} \mathrm{H}_{2} \mathrm{O}_{2}$ & $\mathrm{ACN}$ & 6 & None & 240 \\
\hline None & 50 & 9eq $\mathrm{H}_{2} \mathrm{O}_{2}$ & $\mathrm{ACN}$ & 6 & None & 240 \\
\hline $\mathrm{TBA}_{16}\left[\mathrm{Co}_{4}\left(\mathrm{P}_{2} \mathrm{~W}_{15} \mathrm{O}_{56}\right)_{2}\right]$ & 50 & 9eq $\mathrm{H}_{2} \mathrm{O}_{2}$ & $\mathrm{ACN}$ & 6 & $\begin{array}{l}4.51 \% \mathrm{EPO} \\
2.09 \% \mathrm{OH} \\
4.4 \% \mathrm{KET}\end{array}$ & 240 \\
\hline $\mathrm{TBA}_{16}\left[\mathrm{Co}_{4}\left(\mathrm{P}_{2} \mathrm{~W}_{15} \mathrm{O}_{56}\right)_{2}\right]$ & 50 & $2 \mathrm{eq} \mathrm{H}_{2} \mathrm{O}_{2}$ & $\mathrm{ACN}$ & 6 & $\begin{array}{l}4.62 \% \text { EPO } \\
0.7 \% \mathrm{OH} \\
1.68 \% \mathrm{KET}\end{array}$ & 240 \\
\hline $\mathrm{TBA}_{16}\left[\mathrm{Ni}_{4}\left(\mathrm{P}_{2} \mathrm{~W}_{15} \mathrm{O}_{56}\right)_{2}\right]$ & 50 & 9eq $\mathrm{H}_{2} \mathrm{O}_{2}$ & $\mathrm{ACN}$ & 6 & $\begin{array}{l}6.93 \% \mathrm{EPO} \\
6.93 \% \mathrm{OH} \\
19.1 \% \mathrm{KET}\end{array}$ & 240 \\
\hline $\mathrm{TBA}_{10}\left[\mathrm{Co}_{4}\left(\mathrm{PW}_{9} \mathrm{O}_{34}\right)_{2}\right]$ & 50 & $2 \mathrm{eq} \mathrm{H}_{2} \mathrm{O}_{2}$ & $\mathrm{ACN}$ & 6 & $\begin{array}{l}\% \text { EPO } \\
1 \% \mathrm{OH} \\
2 \% \text { KET }\end{array}$ & 240 \\
\hline $\mathrm{TBA}_{10}\left[\mathrm{Co}_{4}\left(\mathrm{PW}_{9} \mathrm{O}_{34}\right)_{2}\right]$ & 50 & 9eq $\mathrm{H}_{2} \mathrm{O}_{2}$ & $\mathrm{ACN}$ & 6 & $\begin{array}{l}7.2 \% \text { EPO } \\
2.56 \% \mathrm{OH} \\
6.24 \% \mathrm{KET} \\
\end{array}$ & 240 \\
\hline
\end{tabular}




\begin{tabular}{|c|c|c|c|c|c|c|}
\hline $\begin{array}{l}\mathrm{H}_{3}\left[\mathrm{PW}_{12} \mathrm{O}_{40}\right] \cdot 6 \mathrm{H}_{2} \mathrm{O} \\
+ \text { cetylpyridinium chloride }\end{array}$ & 50 & 2eq $\mathrm{H}_{2} \mathrm{O}_{2}$ & $\begin{array}{l}\mathrm{ACN} / \mathrm{DC} \\
\mathrm{E}\end{array}$ & 10 & $9 \%$ EPO & 227 \\
\hline $\mathrm{TBA}_{16}\left[\mathrm{Mn}_{4}\left(\mathrm{P}_{2} \mathrm{~W}_{15} \mathrm{O}_{56}\right)_{2}\right]$ & 50 & 9eq $\mathrm{H}_{2} \mathrm{O}_{2}$ & $\mathrm{ACN}$ & 6 & $\begin{array}{l}10.7 \% \mathrm{EPO} \\
3.12 \% \mathrm{OH} \\
12.2 \% \mathrm{KET} \\
\end{array}$ & 240 \\
\hline $\mathrm{TBA}_{16}\left[\mathrm{Ni}_{4}\left(\mathrm{P}_{2} \mathrm{~W}_{15} \mathrm{O}_{56}\right)_{2}\right]$ & 50 & 2eq $\mathrm{H}_{2} \mathrm{O}_{2}$ & $\mathrm{ACN}$ & 6 & $\begin{array}{l}10.8 \% \mathrm{EPO} \\
3.6 \% \mathrm{OH} \\
8 \% \mathrm{KET}\end{array}$ & 240 \\
\hline$\left[\mathrm{NBu}_{4}\right]_{3}\left[\mathrm{PW}_{12} \mathrm{O}_{40}\right]$ & 50 & 2eq $\mathrm{H}_{2} \mathrm{O}_{2}$ & $\begin{array}{l}\mathrm{ACN} / \mathrm{DC} \\
\mathrm{E}\end{array}$ & 10 & $11 \% \mathrm{EPO}$ & 227 \\
\hline $4-\mathrm{dea}_{3}\left[\mathrm{PW}_{12} \mathrm{O}_{40}\right]$ & 50 & 2eq $\mathrm{H}_{2} \mathrm{O}_{2}$ & $\begin{array}{l}\mathrm{ACN} / \mathrm{DC} \\
\mathrm{E}\end{array}$ & 10 & $11 \% \mathrm{EPO}$ & 227 \\
\hline $\mathrm{TBA}_{10}\left[\mathrm{Ni}_{4}\left(\mathrm{PW}_{9} \mathrm{O}_{34}\right)_{2}\right]$ & 50 & 9eq $\mathrm{H}_{2} \mathrm{O}_{2}$ & $\mathrm{ACN}$ & 6 & $\begin{array}{l}11 \% \mathrm{EPO} \\
9.24 \% \mathrm{OH} \\
23.8 \% \mathrm{KET}\end{array}$ & 240 \\
\hline $\mathrm{H}_{3}\left[\mathrm{PW}_{12} \mathrm{O}_{40}\right] \cdot 6 \mathrm{H}_{2} \mathrm{O}$ & 50 & 2eq $\mathrm{H}_{2} \mathrm{O}_{2}$ & $\begin{array}{l}\mathrm{ACN} / \mathrm{DC} \\
\mathrm{E}\end{array}$ & 10 & $12 \%$ EPO & 227 \\
\hline 4-ddp $3\left[\mathrm{PW}_{12} \mathrm{O}_{40}\right]$ & 50 & 2eq $\mathrm{H}_{2} \mathrm{O}_{2}$ & $\begin{array}{l}\mathrm{ACN} / \mathrm{DC} \\
\mathrm{E}\end{array}$ & 10 & $14 \%$ EPO & 227 \\
\hline $\mathrm{TBA}_{16}\left[\mathrm{Mn}_{4}\left(\mathrm{P}_{2} \mathrm{~W}_{15} \mathrm{O}_{56}\right)_{2}\right]$ & 50 & $2 \mathrm{eq} \mathrm{H}_{2} \mathrm{O}_{2}$ & $\mathrm{ACN}$ & 6 & $\begin{array}{l}16.2 \% \text { EPO } \\
0.36 \% \mathrm{OH} \\
1.44 \% \mathrm{KET}\end{array}$ & 240 \\
\hline$\left(\mathrm{LFeCl}_{2}\right)$ & 25 & $\begin{array}{l}0.5 \text { eq } \\
\mathrm{H}_{2} \mathrm{O}_{2}\end{array}$ & ACN & 24 & $16.5 \% \mathrm{EPO}$ & 236 \\
\hline $\mathrm{TBA}_{10}\left[\mathrm{Ni}_{4}\left(\mathrm{PW}_{9} \mathrm{O}_{34}\right)_{2}\right]$ & 50 & 2eq $\mathrm{H}_{2} \mathrm{O}_{2}$ & $\mathrm{ACN}$ & 6 & $\begin{array}{l}17.5 \% \mathrm{EPO} \\
5.25 \% \mathrm{OH} \\
12.3 \% \mathrm{KET}\end{array}$ & 240 \\
\hline $\mathrm{TBA}_{10}\left[\mathrm{Mn}_{4}\left(\mathrm{PW}_{9} \mathrm{O}_{34}\right)_{2}\right]$ & 50 & 9eq $\mathrm{H}_{2} \mathrm{O}_{2}$ & ACN & 6 & $\begin{array}{l}18.8 \% \mathrm{EPO} \\
3.63 \% \mathrm{OH} \\
10.6 \% \mathrm{KET} \\
\end{array}$ & 240 \\
\hline$\left[\mathrm{LFe}(\mathrm{Oac})_{2}\right]$ & 25 & $\begin{array}{l}0.5 \text { eq } \\
\mathrm{H}_{2} \mathrm{O}_{2}\end{array}$ & $\mathrm{ACN}$ & 24 & $19.5 \% \mathrm{EPO}$ & 236 \\
\hline $\begin{array}{l}(4- \\
\text { dea })_{4.5} \mathrm{Li}_{0.5}\left[\mathrm{PTiW}_{11} \mathrm{O}_{40}\right] \cdot 4 \mathrm{H}_{2} \mathrm{O}\end{array}$ & 50 & 2eq $\mathrm{H}_{2} \mathrm{O}_{2}$ & $\begin{array}{l}\mathrm{ACN} / \mathrm{DC} \\
\mathrm{E}\end{array}$ & 10 & $21 \% \mathrm{EPO}$ & 227 \\
\hline $\mathrm{TBA}_{10}\left[\mathrm{Mn}_{4}\left(\mathrm{PW}_{9} \mathrm{O}_{34}\right)_{2}\right]$ & 50 & 2eq $\mathrm{H}_{2} \mathrm{O}_{2}$ & $\mathrm{ACN}$ & 6 & $\begin{array}{l}23.5 \% \mathrm{EPO} \\
0.25 \% \mathrm{OH} \\
1.25 \% \mathrm{KET}\end{array}$ & 240 \\
\hline $\begin{array}{l}\text { (4- } \\
\text { ddp })_{4.5} \mathrm{Li}_{0.5}\left[\mathrm{PTiW}_{11} \mathrm{O}_{40}\right] \cdot 14 \mathrm{H}_{2} \\
\mathrm{O}\end{array}$ & 50 & 2eq $\mathrm{H}_{2} \mathrm{O}_{2}$ & $\begin{array}{l}\mathrm{ACN} / \mathrm{DC} \\
\mathrm{E}\end{array}$ & 10 & $26 \%$ EPO & 227 \\
\hline $\mathrm{TBA}_{12}\left[\mathrm{Fe}_{4}\left(\mathrm{P}_{2} \mathrm{~W}_{15} \mathrm{O}_{56}\right)_{2}\right]$ & 50 & 9eq $\mathrm{H}_{2} \mathrm{O}_{2}$ & ACN & 6 & $\begin{array}{l}30 \% \mathrm{EPO} \\
3.24 \% \mathrm{OH} \\
47.8 \% \mathrm{KET}\end{array}$ & 240 \\
\hline $\mathrm{TBA}_{16}\left[\mathrm{Zn}_{4}\left(\mathrm{P}_{2} \mathrm{~W}_{15} \mathrm{O}_{56}\right)_{2}\right]$ & 50 & 9eq $\mathrm{H}_{2} \mathrm{O}_{2}$ & $\mathrm{ACN}$ & 6 & $\begin{array}{l}31 \% \text { EPO } \\
12 \% \mathrm{OH} \\
43 \% \mathrm{KET}\end{array}$ & 240 \\
\hline
\end{tabular}




\begin{tabular}{|c|c|c|c|c|c|c|}
\hline None & 80 & $\begin{array}{l}0.05 \text { eq } \\
\mathrm{H}_{2} \mathrm{O}_{2}\end{array}$ & $\begin{array}{l}\mathrm{DCE} / \mathrm{AC} \\
\mathrm{N}\end{array}$ & 72 & $\begin{array}{l}31.02 \% \mathrm{EP} \\
\mathrm{O}\end{array}$ & $\begin{array}{l}\text { This } \\
\text { Work }\end{array}$ \\
\hline $\begin{array}{l}(4- \\
\text { dea })_{3} \mathrm{Na}_{4}\left[\mathrm{PTi}_{2} \mathrm{~W}_{10} \mathrm{O}_{40}\right] \cdot 9 \mathrm{H}_{2} \mathrm{O}\end{array}$ & 69 & 2eq $\mathrm{H}_{2} \mathrm{O}_{2}$ & $\mathrm{ACN}$ & 10 & $38 \%$ EPO & 227 \\
\hline$\left[\mathrm{MoO}\left(\mathrm{O}_{2}\right)_{2} 4,4-\text {-bipy }\right]_{\mathrm{n}}$ & 25 & $\begin{array}{l}2.5 \mathrm{eq} \\
\mathrm{H}_{2} \mathrm{O}_{2}\end{array}$ & DCE & 6 & $41 \% \mathrm{EPO}$ & 226 \\
\hline $\begin{array}{l}(4- \\
\text { dea })_{3} \mathrm{Na}_{4}\left[\mathrm{PTi}_{2} \mathrm{~W}_{10} \mathrm{O}_{40}\right] \cdot 9 \mathrm{H}_{2} \mathrm{O}\end{array}$ & 64 & 2eq $\mathrm{H}_{2} \mathrm{O}_{2}$ & $\begin{array}{l}\mathrm{ACN} / \mathrm{Be} \\
\text { nzene }\end{array}$ & 10 & $46 \%$ EPO & 227 \\
\hline $\mathrm{TBA}_{6}\left[\mathrm{Fe}_{4}\left(\mathrm{PW}_{9} \mathrm{O}_{34}\right)_{2}\right]$ & 50 & 9eq $\mathrm{H}_{2} \mathrm{O}_{2}$ & $\mathrm{ACN}$ & 6 & $\begin{array}{l}47.3 \% \mathrm{EPO} \\
8.19 \% \mathrm{OH} \\
35.5 \% \mathrm{KET}\end{array}$ & 240 \\
\hline $\begin{array}{l}(4- \\
\text { ddp })_{1.5} \mathrm{Na}_{5.5}\left[\mathrm{PTi}_{2} \mathrm{~W}_{10} \mathrm{O}_{40}\right] \cdot 5 \mathrm{H}_{2} \\
\mathrm{O}\end{array}$ & 64 & 2eq $\mathrm{H}_{2} \mathrm{O}_{2}$ & $\begin{array}{l}\mathrm{ACN} / \mathrm{Be} \\
\text { nzene }\end{array}$ & 10 & $48 \%$ EPO & 227 \\
\hline $\mathrm{TBA}_{12}\left[\mathrm{Fe}_{4}\left(\mathrm{P}_{2} \mathrm{~W}_{15} \mathrm{O}_{56}\right)_{2}\right]$ & 50 & 2eq $\mathrm{H}_{2} \mathrm{O}_{2}$ & $\mathrm{ACN}$ & 6 & $\begin{array}{l}54 \% \mathrm{EPO} \\
0.6 \% \mathrm{OH} \\
5.4 \% \mathrm{KET}\end{array}$ & 240 \\
\hline$\left[\mathrm{LMn}(\mathrm{OAc})_{2}\right]$ & 25 & $2 \mathrm{eq} \mathrm{H}_{2} \mathrm{O}_{2}$ & $\mathrm{ACN}$ & 6 & $54 \%$ EPO & 236 \\
\hline$\left[\mathrm{NBu}_{4}\right]_{5}\left[\mathrm{PTiW}_{11} \mathrm{O}_{40}\right] \cdot \mathrm{H}_{2} \mathrm{O}$ & 50 & $2 \mathrm{eq} \mathrm{H}_{2} \mathrm{O}_{2}$ & $\begin{array}{l}\mathrm{ACN} / \mathrm{DC} \\
\mathrm{E}\end{array}$ & 10 & $54 \%$ EPO & 227 \\
\hline $\begin{array}{l}(4- \\
\text { ddp) })_{1.5} \mathrm{Na}_{5.5}\left[\mathrm{PTi}_{2} \mathrm{~W}_{10} \mathrm{O}_{40}\right] \cdot 5 \mathrm{H}_{2} \\
\mathrm{O}\end{array}$ & 50 & 2eq $\mathrm{H}_{2} \mathrm{O}_{2}$ & $\begin{array}{l}\mathrm{ACN} / \mathrm{DC} \\
\mathrm{E}\end{array}$ & 10 & $55 \% \mathrm{EPO}$ & 227 \\
\hline $\begin{array}{l}{\left[\mathrm{NBu}_{4}\right]_{5} \mathrm{~K}_{2}\left[\mathrm{PTi}_{2} \mathrm{~W}_{10} \mathrm{O}_{40}\right] \cdot 6 \mathrm{H}_{2}} \\
\mathrm{O}\end{array}$ & 50 & 2eq $\mathrm{H}_{2} \mathrm{O}_{2}$ & $\begin{array}{l}\mathrm{ACN} / \mathrm{DC} \\
\mathrm{E}\end{array}$ & 10 & $56 \%$ EPO & 227 \\
\hline $\begin{array}{l}(4-\mathrm{dea})_{3} \mathrm{Na}_{4}\left[\mathrm{PTi}_{2} \mathrm{~W}_{10} \mathrm{O}_{40}\right] \\
9 \mathrm{H}_{2} \mathrm{O}\end{array}$ & 50 & 2eq $\mathrm{H}_{2} \mathrm{O}_{2}$ & $\begin{array}{l}\mathrm{ACN} / \mathrm{DC} \\
\mathrm{E}\end{array}$ & 10 & $58 \% \mathrm{EPO}$ & 227 \\
\hline $\mathrm{TBA}_{16}\left[\mathrm{Zn}_{4}\left(\mathrm{P}_{2} \mathrm{~W}_{15} \mathrm{O}_{56}\right)_{2}\right]$ & 50 & 2eq $\mathrm{H}_{2} \mathrm{O}_{2}$ & $\mathrm{ACN}$ & 6 & $\begin{array}{l}59.2 \% \mathrm{EPO} \\
0.65 \% \mathrm{OH} \\
5.2 \% \mathrm{KET} \\
\end{array}$ & 240 \\
\hline $\mathrm{TBA}_{10}\left[\mathrm{Zn}_{4}\left(\mathrm{PW}_{9} \mathrm{O}_{34}\right)_{2}\right]$ & 50 & 9eq $\mathrm{H}_{2} \mathrm{O}_{2}$ & $\mathrm{ACN}$ & 6 & $\begin{array}{l}61.4 \% \mathrm{EPO} \\
5.94 \% \mathrm{OH} \\
31.7 \% \mathrm{KET}\end{array}$ & 240 \\
\hline $\mathrm{TBA}_{6}\left[\mathrm{Fe}_{4}\left(\mathrm{PW}_{9} \mathrm{O}_{34}\right)_{2}\right]$ & 50 & 2eq $\mathrm{H}_{2} \mathrm{O}_{2}$ & $\mathrm{ACN}$ & 6 & $\begin{array}{l}63.8 \% \mathrm{EPO} \\
3.75 \% \mathrm{OH} \\
7.5 \% \mathrm{KET}\end{array}$ & 240 \\
\hline$\left(\mathrm{LMnCl}_{2}\right)$ & 25 & $2 \mathrm{eq} \mathrm{H}_{2} \mathrm{O}_{2}$ & $\mathrm{ACN}$ & 6 & $64 \%$ EPO & 236 \\
\hline $\begin{array}{l}(4- \\
\mathrm{ddp})_{1.5} \mathrm{Na}_{5.5}\left[\mathrm{PTi}_{2} \mathrm{~W}_{10} \mathrm{O}_{40}\right] \cdot 5 \mathrm{H}_{2} \\
\mathrm{O}\end{array}$ & 69 & 2eq $\mathrm{H}_{2} \mathrm{O}_{2}$ & $\mathrm{ACN}$ & 10 & $70 \%$ EPO & 227 \\
\hline $\mathrm{TBA}_{10}\left[\mathrm{Zn}_{4}\left(\mathrm{PW}_{9} \mathrm{O}_{34}\right)_{2}\right]$ & 50 & 2eq $\mathrm{H}_{2} \mathrm{O}_{2}$ & $\mathrm{ACN}$ & 6 & $\begin{array}{l}84.2 \% \mathrm{EPO} \\
0.85 \% \mathrm{KET}\end{array}$ & 240 \\
\hline $\mathrm{H}_{3} \mathrm{PW}_{12} \mathrm{O}_{40}$ & 65 & 2eq $\mathrm{H}_{2} \mathrm{O}_{2}$ & DCE & 0.15 & $89.3 \% \mathrm{EPO}$ & 225 \\
\hline $\begin{array}{l}{\left[\mathrm{MoO}_{2} \mathrm{Cl}_{2}\left(\mathrm{H}_{2} \mathrm{O}\right)_{2}\right] \cdot\left(\mathrm{H}_{2} \text { dipy- }\right.} \\
\text { pra) } \mathrm{Cl}_{2},\end{array}$ & 25 & $4 \mathrm{eq}_{2} \mathrm{O}_{2}$ & $\mathrm{ACN}$ & 1 & $99 \%$ EPO & 224 \\
\hline$\left[\mathrm{CH}_{3} \mathrm{ReO}_{3}\right]$ & 0 & 2eq $\mathrm{H}_{2} \mathrm{O}_{2}$ & $\mathrm{C}_{3} \mathrm{H}_{2} \mathrm{~F}_{6} \mathrm{O}$ & 3 & $100 \%$ EPO & 274 \\
\hline
\end{tabular}


Table S6.6 contains the details of reactions from literature and this work of cyclooctene using oxygen as the oxidizer. Entries are listed in increasing order based on the yield of the cyclooctene oxide denoted as EPO.

\begin{tabular}{|c|c|c|c|c|c|c|}
\hline Catalyst & $\begin{array}{l}\text { Tem } \\
\mathrm{p} \\
\left({ }^{\circ} \mathrm{C}\right)\end{array}$ & Oxidizer & Solvent & $\begin{array}{l}\text { Time } \\
\text { (Hours } \\
\text { ) }\end{array}$ & Yields & $\begin{array}{l}\text { Ref } \\
\text {. }\end{array}$ \\
\hline$\left(n \mathrm{Bu}_{4} \mathrm{~N}\right)_{4} \mathrm{~W}_{10} \mathrm{O}_{32}+\mathrm{h} v$ & 22 & 760 torr $\mathrm{O}_{2}$ & $\mathrm{ACN}$ & 2 & $\begin{array}{l}5.8 \% \mathrm{OOH} \\
1.9 \% \mathrm{EPO}\end{array}$ & 244 \\
\hline $\begin{array}{l}\left(n \mathrm{Bu}_{4} \mathrm{~N}\right)_{4} \mathrm{~W}_{10} \mathrm{O}_{32} / \mathrm{SiO}_{2}+ \\
\mathrm{h} v\end{array}$ & 22 & 760 torr $\mathrm{O}_{2}$ & $\mathrm{ACN}$ & 2 & $\begin{array}{l}1 \% \mathrm{OOH} \\
2.3 \% \mathrm{EPO}\end{array}$ & 244 \\
\hline $\mathrm{VO}(\text { acac })_{2}$ & 60 & $1 \mathrm{~atm} \mathrm{O}_{2}$ & None & 8 & $2.97 \% \mathrm{EPO}$ & 237 \\
\hline $\begin{array}{l}\left(n \mathrm{Bu}_{4} \mathrm{~N}\right)_{4} \mathrm{~W}_{10} \mathrm{O}_{32} / \mathrm{SiO}_{2} / \\
\mathrm{Fe}(\mathrm{TDCPP}) \mathrm{Cl}+\mathrm{h} v\end{array}$ & 22 & 760 torr $\mathrm{O}_{2}$ & $\mathrm{ACN}$ & 2 & $\begin{array}{l}0.1 \% \mathrm{OOH} \\
4.0 \% \mathrm{EPO}\end{array}$ & 244 \\
\hline $\begin{array}{l}\left(n \mathrm{Bu}_{4} \mathrm{~N}\right)_{4} \mathrm{~W}_{10} \mathrm{O}_{32} / \mathrm{SiO}_{2} / \\
\mathrm{Fe}(\mathrm{TDCPP}) \mathrm{Cl}+\mathrm{h} v+\mathrm{Dar} \\
\mathrm{k} 3 \text { hours }\end{array}$ & 22 & 760 torr $\mathrm{O}_{2}$ & $\mathrm{ACN}$ & 2 & $4.2 \% \mathrm{EPO}$ & 244 \\
\hline $\begin{array}{l}\left(n \mathrm{Bu}_{4} \mathrm{~N}\right)_{4} \mathrm{~W}_{10} \mathrm{O}_{32} / \\
\mathrm{Fe}(\mathrm{TDCPP}) \mathrm{Cl}+\mathrm{h} v\end{array}$ & 22 & 760 torr $\mathrm{O}_{2}$ & $\mathrm{ACN}$ & 2 & $\begin{array}{l}3.0 \% \mathrm{OOH} \\
4.9 \% \mathrm{EPO}\end{array}$ & 244 \\
\hline $\begin{array}{l}\left(n \mathrm{Bu}_{4} \mathrm{~N}\right)_{4} \mathrm{~W}_{10} \mathrm{O}_{32} / \\
\mathrm{Fe}(\mathrm{TDCPP}) \mathrm{Cl}+\mathrm{h} v+\text { Dar } \\
\text { k } 3 \text { hours }\end{array}$ & 22 & 760 torr $\mathrm{O}_{2}$ & $\mathrm{ACN}$ & 2 & $\begin{array}{l}1.0 \% \mathrm{OOH} \\
8.1 \% \mathrm{EPO}\end{array}$ & 244 \\
\hline Mn porphyrin cage & 23 & $\begin{array}{l}\text { Oxygen } \\
\text { balloon }\end{array}$ & DCE & 24 & $48 \%$ EPO & 230 \\
\hline Gold clusters & 100 & $\begin{array}{l}\text { Oxygen } \\
\text { Bubbling }\end{array}$ & None & 14 & $70 \% \mathrm{EPO}$ & 272 \\
\hline $\begin{array}{l}\text { NHPI, } \mathrm{Co}(\mathrm{OAc})_{2} \text {, and } \\
\mathrm{Mo}(\mathrm{CO})_{6}, 4 \AA \mathrm{MS}\end{array}$ & 60 & $1 \mathrm{~atm} \mathrm{O}_{2}$ & None & 14 & $\begin{array}{l}0.1 \% \mathrm{OOH} \\
73.9 \% \mathrm{EPO}\end{array}$ & 231 \\
\hline $\begin{array}{l}\gamma- \\
\mathrm{SiW}_{10} \mathrm{Fe}^{3+}\left(\mathrm{OH}_{2}\right)_{2} \mathrm{O}_{38^{6-}}\end{array}$ & 83 & $1 \mathrm{~atm} \mathrm{O}_{2}$ & $\begin{array}{l}\mathrm{DCE} / \mathrm{AC} \\
\mathrm{N}\end{array}$ & 385 & $80.4 \% \mathrm{EPO}$ & 273 \\
\hline Mn porphyrin cage & 23 & $\begin{array}{l}\text { Oxygen } \\
\text { balloon }\end{array}$ & DCE & 8 & $89 \%$ EPO & 230 \\
\hline $\begin{array}{l}\mathrm{Fe}_{3} \mathrm{O}_{4} / \operatorname{tart} / \mathrm{Mn}(\mathrm{TCPP}) \mathrm{C} \\
1\end{array}$ & 25 & $\begin{array}{l}\text { Oxygen } \\
\text { Balloon }\end{array}$ & $\mathrm{ACN}$ & 8 & $96 \% \mathrm{EPO}$ & 232 \\
\hline
\end{tabular}

Abbreviations: $\mathrm{EPO}=$ Epoxide, $\mathrm{OH}=\mathrm{Alcohol}, \mathrm{KET}=$ Ketone, $\mathrm{ACN}=$ Acetonitrile, $\mathrm{DCE}=1,2-$ dichloroethane, $\mathrm{DCM}=$ dichloromethane, $\mathrm{DMSO}=$ dimethylsulfoxide, $\mathrm{TbuOOH}=$ tert-butyl hydroperoxide, $\mathrm{SiC}=$ silicon carbide, $\mathrm{BHT}=$ butylated hydroxy toluene, $\mathrm{NMP}=\mathrm{n}$ methylpyrrolidinone 


\section{Dissertation Summary}

In Chapter 2, a bidentate ligand containing phosphorus and nitrogen that was previously synthesized was reacted with molybdenum and cobalt to create two new metal complexes, $\left[\mathrm{Co}\left(\left(\mathrm{C}_{6} \mathrm{H}_{5}\right)_{2} \mathrm{POCH}_{2}\left(\mathrm{C}_{3} \mathrm{~N}_{2} \mathrm{H}_{2}\right)\left(\mathrm{C}_{6} \mathrm{H}_{5}\right)\right)_{2}\left(\mathrm{C}_{4} \mathrm{H}_{8} \mathrm{O}\right)_{2}\right]\left[\mathrm{ClO}_{4}\right]_{2}$, and $\mathrm{Mo}_{2} \mathrm{O}_{4} \mathrm{Cl}_{2}\left(\left(\mathrm{C}_{6} \mathrm{H}_{5}\right)_{2} \mathrm{POCH}_{2}\left(\mathrm{C}_{3} \mathrm{~N}_{2} \mathrm{H}_{2}\right)\left(\mathrm{C}_{6} \mathrm{H}_{5}\right)\right)(\mathrm{THF})$. These complexes were analyzed via magnetic susceptibility, X-ray crystallography, FTIR, ${ }^{1} \mathrm{HNMR}, \mathrm{UV}-\mathrm{Vis}$, TGA, DFT, and Fluorescence spectroscopy. The ligand showed properties of fluorescence by itself, and a previous study showed that the terbium complex using the ligand was highly fluorescent. But in the case of this study, it appeared that there was no new fluorescence when attached to molybdenum or cobalt.

In Chapter 3, a mistake in a routine inorganic chemistry teaching laboratory on the synthesis of macrocyclic nickel complexes led to the discovery of a new complex with a unique stereochemistry. While trying to synthesize $\left[\mathrm{Ni}(\mathrm{II})^{\mathrm{SSRR}} \mathrm{L}\right]\left(\mathrm{PF}_{6}\right)_{2}$, the $\mathrm{pH}$ was adjusted to a $\mathrm{pH}$ of 1 rather than 3 , and $\left[\mathrm{Ni}(\mathrm{II})^{\mathrm{SRSR}} \mathrm{L}\right](\mathrm{Cl})\left(\mathrm{PF}_{6}\right)$ was the dominant product. The complex was characterized via X-ray crystallography, FTIR, ${ }^{1}$ HNMR, Cyclic Voltammetry, and DFT.

In Chapter 4, double-shell lignin nanocapsules were synthesized to transport antifungal medications with the goal of protecting them from the harsh environment of the body. This would enable the controlled release of the medication and could prevent the medicine from being destroyed by the harsh environment of the body. The double-shell lignin nanocapsules were analyzed using FTIR, UV-Vis, Confocal Microscopy, BET, and TEM. The double-shell lignin nanocapsules had the stability of 8 months in water at room temperature. The average hydrodynamic size of the double-shell lignin nanocapsules was $241.8(33.3) \mathrm{nm}$, and entrapment efficiency of $56.1 \%$ for propiconazole.

In Chapter 5, four natural zeolites from the United States were studied for their ability to adsorb/absorb lead ions from a simulated contaminated water source. Then the zeolites were modified using hydrochloric acid in an attempt to increase 
the surface area and porosity in an attempt to increase lead adsorption/absorption. The zeolites were also charged with potassium ions in an attempt to make the zeolite better at the ion exchange with lead ions, with no success in increasing the adsorption of lead. However, the increase in surface area of the natural zeolites was successful, which may be helpful for other purposes. The zeolites were analyzed using FTIR, ${ }^{29}$ Si MAS NMR, ${ }^{27}$ Al MAS NMR, BET, SEM, XRF, XRD, and the lead adsorption was studied using AA.

In Chapter 6, the reaction of cyclohexene using 5 mole $\%$ oxidizer resulted in $23.7 \%$ 2-cyclohexen-1-one, $8.0 \%$ 2-cyclohexen-1-ol and $2.0 \%$. The reaction of cyclooctene with 5 mole $\%$ oxidizer resulted in $40.3 \%$ epoxide, $0.35 \%$ of 1,2 cyclooctanediol, and $1.18 \%$ of 2 -cycloocten-1-one for cyclooctene. Since the yield is higher than $5 \%$, this indicates that oxygen from the atmosphere is heavily involved. The distribution of products suggests a free radical mechanism. A mechanism was proposed for the epoxidation of cyclohexene and cyclooctene. In the case of cyclooctene, the epoxide is the major product, and in the case of cyclohexene, 2-cyclohexen-1-one is the major product. Gaussian calculations suggest that cyclohexene proceeds through a unimolecular pathway and cyclooctene proceeds through a bimolecular pathway based on the lowest energy for the pathways. This is theorized to be the reason for the difference in products between cyclohexene and cyclooctene. Reactions were quantified using GCFID. 


\section{Future Work}

In Chapter 2, future work would include using the molybdenum and cobalt complexes as catalysts to double-check that they will not do any ultraviolet-induced catalysis as is the prediction based on the results from Fluorescence spectroscopy. Then a ligand re-design may be the proper way to approach this project.

For Chapter 3, future work would include using the complex as a catalyst to determine what reactions could be improved using the catalyst. Also, what would be helpful is the stereochemistry directing ability of the complexes due to their unique stereochemistry in the complexes themselves.

For Chapter 4, future work would include using the lignin nanocapsules containing the antifungal medications in vitro and then in vivo.

For Chapter 5, Future work would include using the modified zeolites as catalysts. Many zeolites are used in the cracking and reforming of hydrocarbons in the petroleum industry. The increased surface area zeolites would likely be more useful for this application rather than the adsorption/absorption of lead ions. Also, the natural zeolites could be used as a support for nanoparticles in nanoparticle catalysis; that way, the nanoparticles can be easily collected with the support and re-used in another reaction.

For Chapter 6, Future work would include trying to do more computational chemistry in an attempt to understand better the mechanism through which the reaction progresses. An understanding of why cyclooctene makes cyclooctene oxide and why cyclohexene makes 2-cyclohexen-1-one could provide very valuable insight into free radical chemistry and epoxidation reactions. The formation of aziridines from alkynes and nitric oxide could also provide some insight into free radical chemistry related to alkenes and alkynes. 


\section{Reference List}

1. Michael T. Madigan, J. M. M., Kelly S. Bender, Daniel H. Buckley, David A. Stahl, Brock Biology of Microorganisms. . 14th ed.; Pearson: 2015.

2. Shriver, D. F. W. M. T. O. T. R. J. A. F. A., Inorganic chemistry. 2014.

3. Directorate., S. M. Ultraviolet Waves.

https://science.nasa.gov/ems/10 ultravioletwaves (accessed 09/23/).

4. Driggers, E. M.; Hale, S. P.; Lee, J.; Terrett, N. K., The exploration of macrocycles for drug discovery - an underexploited structural class. Nature Reviews Drug Discovery 2008, 7 (7), 608-624.

5. Curtis, N. F., Macrocyclic coordination compounds formed by condensation of metal-amine complexes with aliphatic carbonyl compounds. Coordination Chemistry Reviews 1968, 3 (1), 3-47.

6. Woollins, J. D., Inorganic experiments. John Wiley \& Sons: 2010.

7. Britannica Lignin. https://www.britannica.com/science/lignin (accessed 9/28/21).

8. Zhang, Y.; Naebe, M., Lignin: A Review on Structure, Properties, and Applications as a Light-Colored UV Absorber. ACS Sustainable Chemistry \& Engineering 2021, 9 (4), 1427-1442.

9. Freudenberg, K.; Neish, A. C., Constitution and biosynthesis of lignin. Constitution and biosynthesis of lignin. 1968.

10. Smolarski, N., High-value opportunities for lignin: unlocking its potential. Frost \& Sullivan 2012, 1, 1-15.

11. Ramesh, K.; Reddy, D. D., Chapter Four - Zeolites and Their Potential Uses in Agriculture. In Advances in Agronomy, Sparks, D. L., Ed. Academic Press: 2011; Vol. 113, pp 219-241.

12. Sherman, J. D., Synthetic zeolites and other microporous oxide molecular sieves. Proceedings of the National Academy of Sciences 1999, 96 (7), 3471-3478.

13. Valtchev, V.; Mintova, S., Hierarchical zeolites. MRS Bulletin 2016, 41 (9), 689-693. 
14. Yu, W.; Yuan, P.; Liu, D.; Deng, L.; Yuan, W.; Tao, B.; Cheng, H.; Chen, F., Facile preparation of hierarchically porous diatomite/MFI-type zeolite composites and their performance of benzene adsorption: The effects of $\mathrm{NaOH}$ etching pretreatment. Journal of Hazardous Materials 2015, 285, 173-181.

15. Synthesis of Epoxides.

16. 11.3.6 Epoxidation of Alkenes.

17. J.S. Maass, R. K. W., R.L. Luck, M. Zeller., Inorg. Chim. Acta 2018, 471, 481.

18. Allen, F., The Cambridge Structural Database: a quarter of a million crystal structures and rising. Acta Crystallographica Section B 2002, 58 (3 Part 1), 380-388.

19. B. Z_urowska, J. M. s., Z. Ciunik, J. Ochocki., J. Mol. Struct. 2006, 791, 98.

20. B. Zurowska, A. B. n., J. Ochocki., Mater. Sci. 2009, 27, 987.

21. Yeh, C.-W.; Chen, J.-D., Role of ligand conformation in the structural diversity of divalent complexes containing phosphinic amide ligand. Inorganic Chemistry Communications 2011, 14 (8), 1212-1216.

22. C.-W. Yeh, K.-H. C., C.-Y. Hu, W. Hsu, J.-D. Chen., Polyhedron 2012, 31, 657.

23. Feng, L.; Maass, J. S.; Luck, R. L., Synthesis and characterization of four cubical molybdenum(V) tetramers and their catalytic properties for the epoxidation of cis-cyclooctene using H2O2. Inorganica Chimica Acta 2011, 373 (1), 85-92.

24. L. Feng, E. U., R.L. Luck. , J. Organomet. Chem. 2008, 693, 1564.

25. Yi, L.; Ge, W.; L., L. R.; Mu, Y.; Xiao, H., Oxidation of Alcohols with Hydrogen Peroxide Catalyzed by Molybdenum(VI)-Peroxo Complex under Solventfree Conditions. Chemistry Letters 2007, 36 (10), 1236-1237.

26. Jimtaisong, A.; Luck, R. L., Synthesis and catalytic epoxidation activity with TBHP and $\mathrm{H} 2 \mathrm{O} 2$ of dioxo-, oxoperoxo-, and oxodiperoxo molybdenum(VI) and tungsten(VI) compounds containing monodentate or bidentate phosphine oxide ligands: crystal structures of $\mathrm{WCl} 2(\mathrm{O}) 2(\mathrm{OPMePh} 2) 2, \mathrm{WCl} 2(\mathrm{O})(\mathrm{O} 2)(\mathrm{OPMePh} 2) 2$, $\mathrm{MoCl} 2(\mathrm{O}) 2 \mathrm{dppmO2.C4H10O}, \mathrm{WCl} 2(\mathrm{O}) 2 \mathrm{dppmO}$, $\mathrm{Mo}(\mathrm{O})(\mathrm{O} 2) 2 \mathrm{dppmO}$, and $\mathrm{W}(\mathrm{O})(\mathrm{O} 2) 2 \mathrm{dppmO}$. Inorg Chem 2006, 45 (25), 10391-402. 
27. Fronczek, F. R.; Luck, R. L.; Wang, G., Packing and compositional disorder with $\mathrm{MoO} 2 \mathrm{Cl} 2(\mathrm{OPMePh}) 2, \mathrm{MoOCl} 3(\mathrm{OPMePh} 2) 2$ and $\mathrm{MoCl}(\mathrm{OPMePh} 2) 2$ as assessed by single crystal X-ray diffraction. Inorganica Chimica Acta 2003, 342, 247 254.

28. Bruker, Apex2 v2.1-4. Madison, WI, USA 2007.

29. Sheldrick, G., SHELXT - Integrated space-group and crystal-structure determination. Acta Crystallographica Section A 2015, 71 (1), 3-8.

30. Spek., A. L., Acta Crystallogr. D Biol. Crystallogr. 2009, D65, 148.

31. Persistence of Vision Pty. Ltd., 3.7,. http://www.povray.org/download/.

32. Frisch, M. J.; Trucks, G. W.; Schlegel, H. B.; Scuseria, G. E.; Robb, M. A.; Cheeseman, J. R.; Scalmani, G.; Barone, V.; Petersson, G. A.; Nakatsuji, H.; Li, X.; Caricato, M.; Marenich, A. V.; Bloino, J.; Janesko, B. G.; Gomperts, R.; Mennucci, B.; Hratchian, H. P.; Ortiz, J. V.; Izmaylov, A. F.; Sonnenberg, J. L.; Williams; Ding, F.; Lipparini, F.; Egidi, F.; Goings, J.; Peng, B.; Petrone, A.; Henderson, T.; Ranasinghe, D.; Zakrzewski, V. G.; Gao, J.; Rega, N.; Zheng, G.; Liang, W.; Hada, M.; Ehara, M.; Toyota, K.; Fukuda, R.; Hasegawa, J.; Ishida, M.; Nakajima, T.; Honda, Y.; Kitao, O.; Nakai, H.; Vreven, T.; Throssell, K.; Montgomery Jr., J. A.; Peralta, J. E.; Ogliaro, F.; Bearpark, M. J.; Heyd, J. J.; Brothers, E. N.; Kudin, K. N.; Staroverov, V. N.; Keith, T. A.; Kobayashi, R.; Normand, J.; Raghavachari, K.; Rendell, A. P.; Burant, J. C.; Iyengar, S. S.; Tomasi, J.; Cossi, M.; Millam, J. M.; Klene, M.; Adamo, C.; Cammi, R.; Ochterski, J. W.; Martin, R. L.; Morokuma, K.; Farkas, O.; Foresman, J. B.; Fox, D. J. Gaussian 16 Rev. C.01, Wallingford, CT, 2016. 33. Hanwell, M. D.; Curtis, D. E.; Lonie, D. C.; Vandermeersch, T.; Zurek, E.; Hutchison, G. R., Avogadro: an advanced semantic chemical editor, visualization, and analysis platform. Journal of Cheminformatics 2012, 4 (1), 17.

34. Becke., A. D., J. Chem. Phys. 1993, 98, 5648.

35. Lee, C.; Yang, W.; Parr, R. G., Development of the Colle-Salvetti correlationenergy formula into a functional of the electron density. Physical Review B 1988, 37 (2), 785-789. 
36. Austin, A.; Petersson, G. A.; Frisch, M. J.; Dobek, F. J.; Scalmani, G.; Throssell, K., A Density Functional with Spherical Atom Dispersion Terms. Journal of Chemical Theory and Computation 2012, 8 (12), 4989-5007.

37. Macrae, C. F.; Bruno, I. J.; Chisholm, J. A.; Edgington, P. R.; McCabe, P.; Pidcock, E.; Rodriguez-Monge, L.; Taylor, R.; van de Streek, J.; Wood, P. A., Mercury CSD 2.0 - new features for the visualization and investigation of crystal structures. Journal of Applied Crystallography 2008, 41 (2), 466-470.

38. Raghavachari, K.; Trucks, G. W., Highly correlated systems. Excitation energies of first row transition metals Sc-Cu. The Journal of Chemical Physics 1989, $91(2), 1062-1065$.

39. Binning Jr., R. C.; Curtiss, L. A., Compact contracted basis sets for third-row atoms: Ga-Kr. Journal of Computational Chemistry 1990, 11 (10), 1206-1216.

40. Hay, P. J.; Wadt, W. R., Ab initio effective core potentials for molecular calculations. Potentials for $\mathrm{K}$ to Au including the outermost core orbitals. The Journal of Chemical Physics 1985, 82 (1), 299-310.

41. O'Boyle, N. M.; Tenderholt, A. L.; Langner, K. M., cclib: a library for package-independent computational chemistry algorithms. J Comput Chem 2008, 29 (5), 839-45.

42. Jin, L.-N.; Liu, Q.; Sun, W.-Y., Shape-controlled synthesis of Co 3 O 4 nanostructures derived from coordination polymer precursors and their application to the thermal decomposition of ammonium perchlorate. CrystEngComm 2012, 14 (22), 7721-7726.

43. Rapko, B. M.; McNamara, B. K.; Rogers, R. D.; Broker, G. A.; Lumetta, G. J.; Hay, B. P., Coordination of Lanthanide Triflates and Perchlorates with N, N, N ', N '-Tetramethylsuccinamide. Inorganic chemistry 2000, 39 (21), 4858-4867.

44. F.A. Cotton, G. W., M. Bochmann, C. Murillo., Advanced Inorganic Chemistry,. 6th ed.; 821, Wiley, United States of America (1998). 1998.

45. Dean, J. A., Lange's handbook of chemistry. Material and manufacturing process 1990, 5 (4), 687-688. 
46. Canty, A. J.; Lee, C. V., Interaction of methylmercury (II) with N-substituted pyrazoles.. sigma.-Donor ability of pyridines, imidazoles, and pyrazoles.

Organometallics 1982, 1 (8), 1063-1066.

47. Fulmer, G. R.; Miller, A. J.; Sherden, N. H.; Gottlieb, H. E.; Nudelman, A.; Stoltz, B. M.; Bercaw, J. E.; Goldberg, K. I., NMR chemical shifts of trace impurities: common laboratory solvents, organics, and gases in deuterated solvents relevant to the organometallic chemist. Organometallics 2010, 29 (9), 2176-2179.

48. Vener, M. V.; Shishkina, A. V.; Rykounov, A. A.; Tsirelson, V. G., Cl $\cdots$ Cl interactions in molecular crystals: Insights from the theoretical charge density analysis. The Journal of Physical Chemistry A 2013, 117 (35), 8459-8467.

49. Liu, J. F.; Li, N. B.; Luo, H. Q., Resonance Rayleigh scattering, second-order scattering and frequency doubling scattering spectra for studying the interaction of erythrosine with Fe (phen) $32+$ and its analytical application. Spectrochimica Acta Part A: Molecular and Biomolecular Spectroscopy 2011, 79 (3), 631-637.

50. Jacquemin, D.; Wathelet, V.; Perpete, E. A.; Adamo, C., Extensive TD-DFT benchmark: singlet-excited states of organic molecules. Journal of Chemical Theory and Computation 2009, 5 (9), 2420-2435.

51. Adamo, C.; Jacquemin, D., The calculations of excited-state properties with Time-Dependent Density Functional Theory. Chemical Society Reviews 2013, 42 (3), 845-856.

52. R. Dennington, T. A. K., J.M. Millam GaussView, V. 6.; Semichem Inc: Shawnee

Mission, KS, 2016.

53. Curtis, N. F., 855. Transition-metal complexes with aliphatic Schiff bases. Part I. Nickel(II) complexes with $\mathrm{N}$-isopropylidene-ethylenediamine schiff bases. Journal of the Chemical Society (Resumed) 1960, (0), 4409-4413.

54. Curtis, N. F., Chem. N.Z. 2002, 2 (66), 41. 
55. Curtis, N. F., Configurational isomerism of 2,5,5,7,9,12,12,14-octamethyl1,4,8,11-tetraazacyclotetradecane and its compounds. Coordination Chemistry Reviews 2012, $256(9), 878-895$.

56. Curtis, N. F., Syntheses and structures of compounds with acyclic imine ligands formed by reactions of coordinated amines with carbonyl compounds. Inorganica Chimica Acta 2019, 498, 118843.

57. Curtis, N. F. H., D. A., Chem. Ind. 1961, (1708).

58. 43 CSD REFCODES: AJITAQ, A., AQIXEE01, AVAROG, AVOJIE, CEQRUO, CEQRUO01, CEQSEZ, CEQSID, CIXQUW, CIXRAD, DARPAN, DEHTIT, FOTSUD, GOJRAA, HIMWAB, HMACNI, ITEKIB, KINNOK, KUGNEF, KUGNEF01, KUGNEF02, KUGNEF03, KUGNEF04, MAZTNI02, MAZTNI10, MAZTNI11, MELFUE, MUCBIW, OMACNI10, QAHMAP, RIGYAK, RUVSAD, SIBCIQ, SUVZAL, UWUDUM, VUYKUW, VUYKUW01, XAZLEQ, XONPEX, XONPIB, YENLIM, NOLGUT.

59. Groom, C. R.; Bruno, I. J.; Lightfoot, M. P.; Ward, S. C., The Cambridge Structural Database. Acta Crystallographica Section B 2016, 72 (2), 171-179.

60. Curtis, N. F.; Swann, D. A.; Waters, T. N., Structural studies on co-ordinated macrocyclic ligands. Part III. Preparations and crystal structure analyses of salts of the nickel(II) complex C-rac-5,5,7,12,12,14-hexamethyl-1,4,8,11-tetraazacyclotetradecane, $[\mathrm{Ni}($ tetb) $] 2+$, in the $\alpha-, \beta$-, and $\gamma$-configurations. Journal of the Chemical Society, Dalton Transactions 1973, (19), 1963-1974.

61. 79 CSD REFCODES: JIVBAU, A., AJITOE01, AJITUK, AJIVAS, AJIVEW, ANEMUD, ANEMUD01, ANENAK, ANENAK01, ANENEO, ANENEO01, ANENIS, ANENIS01, BADSAA, BADSAA10, BADSEE, BIYZIT, BURZUL, BUSBIC, BUSBIC01, BUSBOI, BUSBUO, CAPVUL, CERVIF, EBAJOJ, EBAJOJ01, EBAKUQ, EBAKUQ01, ECUREA, FIBHED, IDIKOY, IVUYON, KOHSUX, LIFYEG, MAZNIA, MEAZNI, MEAZNI01, MEAZNI02, MONKUW, MUVYIL, NIATET, NIATET01, NIATET02, NIATET03, NIBTET, NIGTET, NIGTET01, OBOPEC, OCAREP, OCMENH, OCMENH01, OCMENH02, 
OCMENH03, OCMENH04, OCMENI, PIMHAU, QADSIA, QADSIA01, QADSIA02, QADSOG, QAFVIF, QQQFMG, QQQFMJ, QUBCAS, RABWIC, RABWOI, RAJLOE, RAPXOW, UDUPOY, UQOREY, VURRAC, WACKUJ, WACLAQ, WUFQOF, XALQUZ, XEHKEB, YOWNON, NOLHAA.

62. Curtis, N. F. W., J.; Butcher, R., Inorg. Chim. Acta. 2015, (436), 103.

63. Curtis, N. F.; Coles, M. P.; Wikaira, J., Preparations and structures of nickel(II) compounds of 2,9-rac-2,5,5,7,9,12,12,14-octamethyl-1,4,8,11-tetraazacyclotetradecane. Polyhedron 2016, 110, 282-290.

64. Lin, Y.-C.; Misra, T. K.; Lu, T.-H.; Joseph, M. S.; Chung, C.-S., Reassignment, Isolation, Spectral and X-ray Characterization of Diastereoisomers of the Macrocyclic Ligand 3,10-meso-3,5,7,7,10,12,14,14-Octamethyl-1,4,8,11tetraazacyclotetradecane and their NiII and CuII Complexes. European Journal of Inorganic Chemistry 2006, 2006 (5), 994-1005.

65. Curtis, N. F. W., J.; Robinson, W. T., CCDC 773392. CSD Communication 2010.

66. Ou, G.-C. Y., X.-Y.; Li, Z.-Z., Jiegou Huaxue (Chin.) (Chin. J. Struct. Chem.) 2013, 32, 375 .

67. Jiang, L.; Feng, X.-L.; Lu, T.-B., Supramolecular Architectures of Macrocyclic Nickel(II) Complexes with Defined Structures of Cis and Trans Configurations.

Crystal Growth \& Design 2005, 5 (4), 1469-1475.

68. Ou, G.; Jiang, L.; Feng, X.; Lu, T., Synthesis and structures of two supramolecular complexes constructed via hydrogen bond linking. Science in China Series B: Chemistry 2009, 52 (4), 465-470.

69. Ito, T. I., H.; Toriumi, K., Acta Crystallogr., Sect. B: Struct. Crystallogr. Cryst. Chem. Geol. 1981, 37, 1412.

70. Curtis, N. F.; Butcher, R. J.; Coles, M. P.; Wikaira, J., Preparation and structures of nickel(II) compounds of 2,9-meso-7,14-rac-2,5,5,7,9,12,12,14octamethyl-1,4,8,11-tetraazacyclotetradecane. Polyhedron 2017, 132, 130-143. 
71. Thuéry, P.; Atoini, Y.; Harrowfield, J., Chiral Discrete and Polymeric Uranyl Ion Complexes with (1R,3S)-(+)-Camphorate Ligands: Counterion-Dependent Formation of a Hexanuclear Cage. Inorganic Chemistry 2019, 58 (1), 870-880. 72. Ou, G.-C.; Wang, Z.-Z.; Yang, L.-Z.; Zhao, C.-Y.; Lu, T.-B., Chiral resolution of a racemic macrocyclic complex by recognition of one enantiomer over the other: structures and DFT calculations. Dalton Transactions 2010, 39 (18), 4274-4279. 73. Brookhart, M.; Green, M. L. H.; Parkin, G., Agostic interactions in transition metal compounds. Proceedings of the National Academy of Sciences 2007, 104 (17), 6908-6914.

74. Huynh, H. V.; Wong, L. R.; Ng, P. S., Anagostic Interactions and Catalytic Activities of Sterically Bulky Benzannulated N-Heterocyclic Carbene Complexes of Nickel(II). Organometallics 2008, 27 (10), 2231-2237.

75. Curtis, N. F., 169. Borohydride derivatives of some complex nickel(II) amine cations. Journal of the Chemical Society (Resumed) 1965, (0), 924-931.

76. Farrugia, L., WinGX and ORTEP for Windows: an update. Journal of Applied Crystallography 2012, 45 (4), 849-854.

77. Enraf-Nonius., CAD-4 EXPRESS. The Netherlands, , 1994.

78. North, A. C. T.; Phillips, D. C.; Mathews, F. S., A semi-empirical method of absorption correction. Acta Crystallographica Section A 1968, 24 (3), 351-359.

79. Burla, M. C.; Caliandro, R.; Carrozzini, B.; Cascarano, G. L.; Cuocci, C.; Giacovazzo, C.; Mallamo, M.; Mazzone, A.; Polidori, G., Crystal structure determination and refinement via SIR2014. Journal of Applied Crystallography 2015, 48 (1), 306-309.

80. Farrugia, L., WinGX suite for small-molecule single-crystal crystallography. Journal of Applied Crystallography 1999, 32 (4), 837-838.

81. Frisch, M. J. T., G. W.; Schlegel, H. B.; Scuseria, G. E.; Robb, M. A.; Cheeseman, J. R.; Scalmani, G.; Barone, V.; Petersson, G. A.; Nakatsuji, H., et al., Gaussian 16, Revision A.03. Wallingford, CT, 2016. 
82. Leininger, T.; Nicklass, A.; Stoll, H.; Dolg, M.; Schwerdtfeger, P., The accuracy of the pseudopotential approximation. II. A comparison of various core sizes for indium pseudopotentials in calculations for spectroscopic constants of $\mathrm{InH}$, InF, and InCl. The Journal of Chemical Physics 1996, 105 (3), 1052-1059.

83. Adamo, C.; Barone, V., Exchange functionals with improved long-range behavior and adiabatic connection methods without adjustable parameters: The $\mathrm{mPW}$ and mPW1PW models. The Journal of Chemical Physics 1998, 108 (2), 664-675. 84. Escudero, D. L., A. D.; Jacquemin, D. Time-dependent density functional theory: a tool to explore excited states. In: Leszczynski, J.; Kaczmarek-Kedziera, A.; Puzyn, T.; G. Papadopoulos, M.; Reis, H.; K. Shukla, M., Editors., Handbook of Computational Chemistry. Springer International Publishing: 2017.

85. Warner, L. G.; Rose, N. J.; Busch, D. H., Proton magnetic resonance study of the stereochemistry of a macrocyclic Schiff base-amine complex of nickel(II). Journal of the American Chemical Society 1968, 90 (25), 6938-6946.

86. Karplus, M., Vicinal Proton Coupling in Nuclear Magnetic Resonance. Journal of the American Chemical Society 1963, 85 (18), 2870-2871.

87. Gu, N. X.; Oyala, P. H.; Peters, J. C., H2 Evolution from a Thiolate-Bound Ni(III) Hydride. Journal of the American Chemical Society 2020, 142 (17), 7827-7835.

88. Tyler, S. F.; Natoli, S. N.; Vlaisavljevich, B.; Fanwick, P. E.; Ren, T., Turning a New Leaf on Metal-TMC Chemistry: NiII(TMC) Acetylides. Inorganic Chemistry 2015, 54 (20), 10058-10064.

89. Zhang, Y.; Lewis, J. C.; Bergman, R. G.; Ellman, J. A.; Oldfield, E., NMR Shifts, Orbitals, and $\mathrm{M} \cdots \mathrm{H}-\mathrm{X}$ Bonding in $\mathrm{d} 8$ Square Planar Metal Complexes.

Organometallics 2006, 25 (14), 3515-3519.

90. Zhang, Y.; Guo, Z.; You, X.-Z., Hydrolysis Theory for Cisplatin and Its Analogues Based on Density Functional Studies. Journal of the American Chemical Society 2001, 123 (38), 9378-9387.

91. Keith, T. A., AIMAll (Version 19.10.12). . Overland Park KS, USA, 2019. 
92. Bader, R. F. W., A Bond Path: A Universal Indicator of Bonded Interactions. The Journal of Physical Chemistry A 1998, 102 (37), 7314-7323.

93. Bader, R. F. W., Atoms in molecules-a quantum theory. Oxford University Press: Oxford, 1990.

94. Palusiak, M.; Grabowski, S. J., Characteristics of ring critical point as descriptors of H-bond strength. Journal of Chemical Research 2004, 2004 (7), 492493.

95. Richter, A. P.; Bharti, B.; Armstrong, H. B.; Brown, J. S.; Plemmons, D.; Paunov, V. N.; Stoyanov, S. D.; Velev, O. D., Synthesis and Characterization of Biodegradable Lignin Nanoparticles with Tunable Surface Properties. Langmuir 2016, 32 (25), 6468-6477.

96. Wallmo, H.; Theliander, H.; Richards, T. In Lignin precipitation from kraft black liquors : kinetics and carbon dioxide absorption, 2007.

97. Zhang, H.; Liu, X.; Fu, S.; Chen, Y., High-value utilization of kraft lignin: Color reduction and evaluation as sunscreen ingredient. International Journal of Biological Macromolecules 2019, 133, 86-92.

98. Mahmood, N.; Yuan, Z.; Schmidt, J.; Xu, C., Depolymerization of lignins and their applications for the preparation of polyols and rigid polyurethane foams: A review. Renewable and Sustainable Energy Reviews 2016, 60, 317-329.

99. Liu, H.; Dai, Z.; Cao, Q.; Shi, X.; Wang, X.; Li, H.; Han, Y.; Li, Y.; Zhou, J., Lignin/Polyacrylonitrile Carbon Fibers: The Effect of Fractionation and Purification on Properties of Derived Carbon Fibers. ACS Sustainable Chemistry \& Engineering 2018, 6 (7), 8554-8562.

100. Gan, D.; Xing, W.; Jiang, L.; Fang, J.; Zhao, C.; Ren, F.; Fang, L.; Wang, K.; Lu, X., Plant-inspired adhesive and tough hydrogel based on Ag-Lignin nanoparticles-triggered dynamic redox catechol chemistry. Nature Communications 2019, $10(1), 1487$. 
101. Dai, L.; Liu, R.; Hu, L.-Q.; Zou, Z.-F.; Si, C.-L., Lignin Nanoparticle as a Novel Green Carrier for the Efficient Delivery of Resveratrol. ACS Sustainable Chemistry \& Engineering 2017, 5 (9), 8241-8249.

102. Zhang, H.; Fu, S.; Chen, Y., Basic understanding of the color distinction of lignin and the proper selection of lignin in color-depended utilizations. International Journal of Biological Macromolecules 2020, 147, 607-615.

103. Chen, L.; Zhou, X.; Shi, Y.; Gao, B.; Wu, J.; Kirk, T. B.; Xu, J.; Xue, W., Green synthesis of lignin nanoparticle in aqueous hydrotropic solution toward broadening the window for its processing and application. Chemical Engineering Journal 2018, 346, 217-225.

104. Garcia Gonzalez, M. N.; Levi, M.; Turri, S.; Griffini, G., Lignin nanoparticles by ultrasonication and their incorporation in waterborne polymer nanocomposites. Journal of Applied Polymer Science 2017, 134 (38), 45318.

105. Lievonen, M.; Valle-Delgado, J. J.; Mattinen, M.-L.; Hult, E.-L.; Lintinen, K.; Kostiainen, M. A.; Paananen, A.; Szilvay, G. R.; Setälä, H.; Österberg, M., A simple process for lignin nanoparticle preparation. Green Chemistry 2016, 18 (5), 1416-1422.

106. Qian, Y.; Deng, Y.; Qiu, X.; Li, H.; Yang, D., Formation of uniform colloidal spheres from lignin, a renewable resource recovered from pulping spent liquor. Green Chemistry 2014, 16 (4), 2156-2163.

107. Li, H.; Deng, Y.; Liang, J.; Dai, Y.; Li, B.; Ren, Y.; Qiu, X.; Li, C., Direct Preparation of Hollow Nanospheres with Kraft Lignin: A Facile Strategy for Effective Utilization of Biomass Waste. Bioresources 2016, 11, 3073-3083.

108. Li, H.; Deng, Y.; Liu, B.; Ren, Y.; Liang, J.; Qian, Y.; Qiu, X.; Li, C.; Zheng, D., Preparation of Nanocapsules via the Self-Assembly of Kraft Lignin: A Totally Green Process with Renewable Resources. ACS Sustainable Chemistry \& Engineering 2016, 4 (4), 1946-1953.

109. Chauhan, P. S., Lignin nanoparticles: Eco-friendly and versatile tool for new era. Bioresource Technology Reports 2020, 9, 100374. 
110. Zhou, Y.; Han, Y.; Li, G.; Chu, F., Effects of Lignin-Based Hollow Nanoparticle Structure on the Loading and Release Behavior of Doxorubicin. Materials 2019, 12 (10), 1694.

111. LaBauve, A. E.; Rinker, T. E.; Noureddine, A.; Serda, R. E.; Howe, J. Y.; Sherman, M. B.; Rasley, A.; Brinker, C. J.; Sasaki, D. Y.; Negrete, O. A., LipidCoated Mesoporous Silica Nanoparticles for the Delivery of the ML336 Antiviral to Inhibit Encephalitic Alphavirus Infection. Sci Rep 2018, 8 (1), 13990.

112. Li, Y.; Yang, D.; Lu, S.; Lao, S.; Qiu, X., Modified Lignin with Anionic Surfactant and Its Application in Controlled Release of Avermectin. Journal of Agricultural and Food Chemistry 2018, 66 (13), 3457-3464.

113. Yiamsawas, D.; Beckers, S. J.; Lu, H.; Landfester, K.; Wurm, F. R., Morphology-Controlled Synthesis of Lignin Nanocarriers for Drug Delivery and Carbon Materials. ACS Biomaterials Science \& Engineering 2017, 3 (10), 2375-2383.

114. Andeme Ela, R. C.; Spahn, L.; Safaie, N.; Ferrier, R. C.; Ong, R. G., Understanding the Effect of Precipitation Process Variables on Hardwood Lignin Characteristics and Recovery from Black Liquor. ACS Sustainable Chemistry \& Engineering 2020, 8 (37), 13997-14005.

115. Li, Y.; Fu, Q.; Yu, S.; Yan, M.; Berglund, L., Optically Transparent Wood from a Nanoporous Cellulosic Template: Combining Functional and Structural Performance. Biomacromolecules 2016, 17 (4), 1358-1364.

116. Zhou, Y.; Han, Y.; Li, G.; Yang, S.; Xiong, F.; Chu, F., Preparation of Targeted Lignin-Based Hollow Nanoparticles for the Delivery of Doxorubicin. Nanomaterials 2019, 9 (2), 188.

117. Rao, X.; Liu, Y.; Zhang, Q.; Chen, W.; Liu, Y.; Yu, H., Assembly of Organosolv Lignin Residues into Submicron Spheres: The Effects of Granulating in Ethanol/Water Mixtures and Homogenization. ACS Omega 2017, 2 (6), 2858-2865. 118. Mishra, P. K.; Ekielski, A., The Self-Assembly of Lignin and Its Application in Nanoparticle Synthesis: A Short Review. Nanomaterials 2019, 9 (2), 243. 
119. Cui, C.; Sun, R.; Argyropoulos, D. S., Fractional Precipitation of Softwood Kraft Lignin: Isolation of Narrow Fractions Common to a Variety of Lignins. ACS Sustainable Chemistry \& Engineering 2014, 2 (4), 959-968.

120. Nair, S. S.; Sharma, S.; Pu, Y.; Sun, Q.; Pan, S.; Zhu, J. Y.; Deng, Y.; Ragauskas, A. J., High shear homogenization of lignin to nanolignin and thermal stability of nanolignin-polyvinyl alcohol blends. ChemSusChem 2014, 7 (12), 3513-20. 121. Ház, A.; Jablonský, M.; Šurina, I.; Kačík, F.; Bubeníková, T.; Ďurkovič, J., Chemical Composition and Thermal Behavior of Kraft Lignins. Forests 2019, 10 (6), 483.

122. Hu, J.; Xiao, R.; Shen, D.; Zhang, H., Structural analysis of lignin residue from black liquor and its thermal performance in thermogravimetric-Fourier transform infrared spectroscopy. Bioresour Technol 2013, 128, 633-9.

123. Matsakas, L.; Karnaouri, A.; Cwirzen, A.; Rova, U.; Christakopoulos, P., Formation of Lignin Nanoparticles by Combining Organosolv Pretreatment of Birch Biomass and Homogenization Processes. Molecules 2018, 23 (7), 1822.

124. Wang, J.; Qian, Y.; Li, L.; Qiu, X., Atomic Force Microscopy and Molecular Dynamics Simulations for Study of Lignin Solution Self-Assembly Mechanisms in Organic-Aqueous Solvent Mixtures. ChemSusChem 2020, 13 (17), 4420-4427.

125. Brinker, C. J.; Lu, Y.; Sellinger, A.; Fan, H., Evaporation-Induced SelfAssembly: Nanostructures Made Easy. Advanced Materials 1999, 11 (7), 579-585. 126. Wang, H.; Chen, W.; Zhang, X.; Wei, Y.; Zhang, A.; Liu, S.; Wang, X.; Liu, C., Structural Changes of Bagasse dusring the Homogeneous Esterification with Maleic Anhydride in Ionic Liquid 1-Allyl-3-methylimidazolium Chloride. Polymers 2018, $10(4), 433$.

127. Li, Z; Ge, Y., Antioxidant activities of lignin extracted from sugarcane bagasse via different chemical procedures. International Journal of Biological Macromolecules 2012, 51 (5), 1116-1120.

128. Zhang, Y.; Mustapha, A. N.; Zhang, X.; Baiocco, D.; Wellio, G.; Davies, T.; Zhang, Z.; Li, Y., Improved volatile cargo retention and mechanical properties of 
capsules via sediment-free in situ polymerization with cross-linked poly(vinyl alcohol) as an emulsifier. Journal of Colloid and Interface Science 2020, 568, 155-164.

129. Chen, N.; Dempere, L. A.; Tong, Z., Synthesis of pH-Responsive LigninBased Nanocapsules for Controlled Release of Hydrophobic Molecules. ACS Sustainable Chemistry \& Engineering 2016, 4 (10), 5204-5211.

130. Li, Y.; Wu, M.; Wang, B.; Wu, Y.; Ma, M.; Zhang, X., Synthesis of Magnetic Lignin-Based Hollow Microspheres: A Highly Adsorptive and Reusable Adsorbent Derived from Renewable Resources. ACS Sustainable Chemistry \& Engineering 2016, 4 (10), 5523-5532.

131. Clogston, J. D. P., A. K., Zeta potential measurement. Methods Mol. Biol. 2011, 697, 63-70.

132. Hasan, A.; Fatehi, P., Flocculation of kaolin particles with cationic lignin polymers. Scientific Reports 2019, 9 (1), 2672.

133. Ammar, M. M., N.; Slimi, H.; Elaloui, E. , Isolation and purification of alfa grass kraft lignin from industrial waste. Curr. Trends Biomedical Eng. \& Biosci. 2017, $6(2), 31-35$.

134. Luo, S. P. C., J. Z.; McDonald, A. G. , Cross-linking of technical lignin via esterification and thermally initiated free radical reaction. . Ind. Crops Prod. 2018, 121, 169-179.

135. Xing, Q.; Buono, P.; Ruch, D.; Dubois, P.; Wu, L.; Wang, W.-J., Biodegradable UV-Blocking Films through Core-Shell Lignin-Melanin Nanoparticles in Poly(butylene adipate-co-terephthalate). ACS Sustainable Chemistry \& Engineering 2019, 7 (4), 4147-4157.

136. Espinoza-Acosta, J. L. T.-C., P. I.; Ramirez-Wong, B.; Lopez-Saiz, C. M.; Montaño-Leyva, B. , Antioxidant, antimicrobial, and antimutagenic properties of technical lignins and their applications. BioResources 2016, 11 (2), 5452-5481. 137. Qi, G.; Yang, W.; Puglia, D.; Wang, H.; Xu, P.; Dong, W.; Zheng, T.; Ma, P., Hydrophobic, UV resistant and dielectric polyurethane-nanolignin composites with good reprocessability. Materials \& Design 2020, 196, 109150. 
138. Gilca, I. A.; Popa, V. I.; Crestini, C., Obtaining lignin nanoparticles by sonication. Ultrason Sonochem 2015, 23, 369-75.

139. Danaei, M.; Dehghankhold, M.; Ataei, S.; Hasanzadeh Davarani, F.;

Javanmard, R.; Dokhani, A.; Khorasani, S.; Mozafari, M. R., Impact of Particle Size and Polydispersity Index on the Clinical Applications of Lipidic Nanocarrier Systems. Pharmaceutics 2018, 10 (2), 57.

140. Chemistry, D. o. Introduction to IR Spectra. https://webspectra.chem.ucla. (accessed 08/20/2020).

141. Zoia, L. S., A.; Frigerio, P.; Orlandi, M., Exploring allylation and claisen rearrangement as a novel chemical modification of lignin. Bioresources 2014, 9 (4), 6540-6561.

142. Argyropoulos, D. S., Quantitative Phosphorus-31 NMR Analysis of Lignins, a New Tool for the Lignin Chemist. Journal of Wood Chemistry and Technology 1994, $14(1), 45-63$.

143. Sluiter, A. H. B. R., R.; Scarlata, C.; Sluiter, J.; Templeton, D.; Crocker, D., Determination of structural carbohydrate and lignin in biomass. 2019.

144. https://www.lumiprobe.com/p/cy5-

alkyne?gclid=EAlalQobChMI8dX7tYDT6wIVRr7ACh251gpFEAAYASAAEgL7LvD BwE

145. Virta, R. L., United States Government, Department of the Interior. U.S.

Geological Survey Minerals Yearbook 2001, 1-5.

146. J.V., S., Origin and structure of zeolites. ACS Monogr. 1976, 171, 3-79.

147. Funada, S. O., T.; Nakamura, K.; Sasagawa, S.; Tanaka, M.; Igarashi, K.; Abe, T.; Obata, K.; Sasaki, S. Fired Zeolites Useful for Construction Materials, Direct-Heat Cooking Utensils, and Warm Rock Bathtubs. 2007.

148. Yorukogullari, E. A Novel Ecological and Biological Organomineral Fertilizer. 2019.

149. Song, H. G., W.; Liu, J. Compound Fertilizer and Its Preparation Method. CN108083950, 2018. 
150. Zhu, J. Z., X. Functional Soil Conditioning Agent and Preparation Method Thereof. 2017.

151. Meng, F. Y., L. Fertilizer Containing Seaweed Extract and Preparation Method Thereof. 2017.

152. Jin, Z. Z., Y.; Xu, W.; Lai, N. Special Slow Release Water-Soluble Fertilizer Used for Grape. 2017.

153. Chen, Q. Z., J. Controlled-Release Phosphorus Fertilizer Using ph Sensitive Material and Preparation Method Thereof. 2015.

154. Jin, W. M., X. Zeolite Sustained-Release Fertilizer and Its Manufacturing Method. 2013.

155. Merchant, R. J. C., P.L.S.; Ashenden, P.J. Improvements in or relating to cleaning or cosmetic compositions comprising natural zeolites. 2010.

156. Herzog, C. H., J.; Lelas, A. Use of zeolites for reducing the proportion of lactates and ammonium in human and animal organisms. 2003.

157. Barloková, D.; Ilavsky, J., Natural Zeolites with a Surface MnO2 Layer in Water Treatment. Chemicke Listy 2014, 108, 1153-1157.

158. Mumpton, F. A., Uses of natural zeolites in agriculture and industry.

Proceedings of the National Academy of Sciences 1999, 96 (7), 3463.

159. Szerement, J.; Szatanik-Kloc, A.; Jarosz, R.; Bajda, T.; Mierzwa-Hersztek, M., Contemporary applications of natural and synthetic zeolites from fly ash in agriculture and environmental protection. Journal of Cleaner Production 2021, 311, 127461 .

160. Wen, J. D., H.; Zeng, G. , Application of zeolite in removing salinity/sodicity from wastewater: A review of mechanisms, challenges and opportunities. J. Clean. Prod. 2018, 197, 1435-1446.

161. Krstj, V.; Urpaevj, T.; Pfaovski, B. D., A review on adsorbents for treatment of water and wastewaters containing copper ions. Chemical Engineering Science 2018, $192,273-287$. 
162. Chojnacka, M. S., P.; Petrus, R.; Warchol, Cr(vi) sorption on surface-modified natural zeolites. J. Przem. Chem. 2017, 96, 332-337.

163. Ates, A.; Akgül, G., Modification of natural zeolite with $\mathrm{NaOH}$ for removal of manganese in drinking water. Powder Technology 2016, 287, 285-291.

164. Yuna, Z., Review of the Natural, Modified, and Synthetic Zeolites for Heavy Metals Removal from Wastewater. Environmental Engineering Science 2016, 33 (7), 443-454.

165. Wang, K., Method and regeneration of sodium modified zeolites for treatment of ammonia-nitrogen wastewater. Shuichuli Jishu 2016, 42, 118-120.

166. Shi, H. W., L.; Yan, C.; Li, X., Research progress of phosphorus removal by zeolite in wastewater. Guangdong Huagong 2014, 41, 165, 169.

167. Regmi, U. B., T.H. , Ammonium and potassium removal from undiluted and diluted hydrolyzed urine using natural zeolites. Chemosphere 2021, 268, 128849.

168. Zwain, H. M.; Vakili, M.; Dahlan, I., Waste Material Adsorbents for Zinc Removal from Wastewater: A Comprehensive Review. International Journal of Chemical Engineering 2014, 2014, 347912.

169. Suhartana; Sukmasari, E.; Azmiyawati, C., Modification of Natural Zeolite with Fe(III) and Its Application as Adsorbent Chloride and Carbonate ions. IOP Conference Series: Materials Science and Engineering 2018, 349, 012075.

170. Armbruster, T.; Gunter, M. E., Crystal Structures of Natural Zeolites. Reviews in Mineralogy and Geochemistry 2001, 45 (1), 1-67.

171. Ambrozova, P.; Kynicky, J.; Urubek, T.; Nguyen, V. D., Synthesis and Modification of Clinoptilolite. Molecules 2017, 22 (7), 1107.

172. Ruíz-Baltazar, A.; Esparza, R.; Gonzalez, M.; Rosas, G.; Pérez, R., Preparation and Characterization of Natural Zeolite Modified with Iron Nanoparticles. Journal of Nanomaterials 2015, 2015, 364763.

173. Wani, A. L.; Ara, A.; Usmani, J. A., Lead toxicity: a review. Interdiscip Toxicol 2015, 8 (2), 55-64. 
174. Coombs, D. S. A., A.; Armbruster, T.; Artioli, G.; Colella, C.; Galli, E.; Grice, J.D.; Liebau, F.; Mandarino, J.A.; Minato, H.; et al. , Recommended nomenclature for zeolite minerals: Report of the subcommittee on zeolites of the international mineralogical association, commission on new minerals and mineral names. . Can. Miner. 1997, 35, 1571-1606.

175. Company, S. C. M. https://www.stcloudmining.com/sales/data-sheetsapplications/.

176. Thrush, K. A.; Kuznicki, S. M., Characterization of chabazite and chabazitelike zeolites of unusual composition. Journal of the Chemical Society, Faraday Transactions 1991, 87 (7), 1031-1035.

177. Kuznicki, S. M.; Lin, C. C. H.; Bian, J.; Anson, A., Chemical upgrading of sedimentary Na-chabazite from Bowie, Arizona. Clays and Clay Minerals 2007, 55 (3), 235-238.

178. Yazdanbakhsh, F. A., M.; Sawada, J.A.; Kuznicki, S.M. , A clinoptilolite-pdms mixed-matrix membrane for high temperature water softening. Water Sci. Technol. 2016, $73,1409-1417$.

179. An, W.; Zhou, X.; Liu, X.; Chai, P. W.; Kuznicki, T.; Kuznicki, S. M., Natural zeolite clinoptilolite-phosphate composite Membranes for water desalination by pervaporation. Journal of Membrane Science 2014, 470, 431-438.

180. Adamaref, S. A., W.; Jarligo, M.O.; Kuznicki, T.; Kuznicki, S.M., Natural clinoptilolite composite membranes on tubular stainless steel supports for water softening. Water Sci. Technol. 2014, 70, 1412-1418.

181. Kesraoui-Ouki, S.; Cheeseman, C.; Perry, R., Effects of conditioning and treatment of chabazite and clinoptilolite prior to lead and cadmium removal.

Environmental Science \& Technology 1993, 27 (6), 1108-1116.

182. Jang, H. K.; Chung, Y.-D.; Whangbo, S. W.; Lyo, I. W.; Whang, C. N.; Lee, S. J.; Lee, S., Effects of chemical etching with hydrochloric acid on a glass surface. Journal of Vacuum Science \& Technology A: Vacuum, Surfaces, and Films 2000, 18, 2563-2567. 
183. Brunauer, S.; Emmett, P. H.; Teller, E., Adsorption of Gases in Multimolecular Layers. Journal of the American Chemical Society 1938, 60 (2), 309-319.

184. Altomare, A.; Corriero, N.; Cuocci, C.; Falcicchio, A.; Moliterni, A.; Rizzi, R., QUALX2.0: a qualitative phase analysis software using the freely available database POW_COD. Journal of Applied Crystallography 2015, 48 (2), 598-603. 185. O'Neill, L., ICDD Annual Spring Meetings. Powder Diffraction 2013, 28 (2), 137-148.

186. Ali, A. A.-H.; El-Bishtawi, R., Removal of Lead and Nickel Ions Using Zeolite Tuff. Journal of Chemical Technology \& Biotechnology 1997, 69 (1), 27-34.

187. Higgins, M. M. J. T. a. J. B., Collection of Simulated Xrd Powder Patterns for Zeolites. Amsterdam, The Netherlands, 2001.

188. Keller, E. B.; Meier, W. M.; Kirchner, R. M., Synthesis, structures of AlPO4-C and AlPO4-D, and their topotactic transformation. Solid State Ionics 1990, 43, 93-102. 189. Galli, E.; Gottardi, G.; Mayer, H.; Preisinger, A.; Passaglia, E., The structure of potassium-exchanged heulandite at 293, 373 and 593 K. Acta Crystallographica Section B 1983, 39 (2), 189-197.

190. Koyama, K. T., Y., Clinoptilolite: The distribution of potassium atoms and its role in thermal stability. Z. Kristallogr. Cryst. Mater. 1977, 145, 216-239.

191. Levien, L. P., C.T.; Weidner, D.J., Structure and elastic properties of quartz at pressure. Am. Miner. 1980, 65, 920-930.

192. Arletti, R.; Quartieri, S.; Vezzalini, G., Elastic behavior of zeolite boggsite in silicon oil and aqueous medium: A case of high-pressure-induced over-hydration. American Mineralogist 2010, 95, 1247-1256.

193. Lippmaa, E.; Samoson, A.; Magi, M., High-resolution aluminum-27 NMR of aluminosilicates. Journal of the American Chemical Society 1986, 108 (8), 1730-1735. 194. Garcia-Basabe, Y. R.-I., I.; de Menorval, L.-C.; Llewellyn, P.; Maurin, G.; Lewis, D.W.; Binions, R.; Autie, M.; Ruiz-Salvador, A.R. , Step-wise dealumination of natural clinoptilolite: Structural and physicochemical characterization. . Microporous Mesoporous Mater. 2010, 135, 187-196. 
195. Holzinger, J.; Nielsen, M.; Beato, P.; Brogaard, R. Y.; Buono, C.; Dyballa, M.; Falsig, H.; Skibsted, J.; Svelle, S., Identification of Distinct Framework Aluminum Sites in Zeolite ZSM-23: A Combined Computational and Experimental 27Al NMR Study. The Journal of Physical Chemistry C 2019, 123 (13), 7831-7844. 196. Lippmaa, E.; Maegi, M.; Samoson, A.; Tarmak, M.; Engelhardt, G., Investigation of the structure of zeolites by solid-state high-resolution silicon-29 NMR spectroscopy. Journal of the American Chemical Society 1981, 103 (17), 4992-4996. 197. Khodabandeh, S.; Davis, M. E., Synthesis of a heulandite-type zeolite by hydrothermal conversion of zeolite P1. Chemical Communications 1996, (10), 1205 1206.

198. Malfait, W. J. H., W.E.; Verel, R., 29si nmr spectroscopy of silica glass: T1 relaxation and constraints on the $\mathrm{si}-\mathrm{O}-\mathrm{si}$ bond angle

distribution. Chem. Geol. 2008, 256, 269-277.

199. Minceva, M.; Fajgar, R.; Markovska, L.; Meshko, V., Comparative Study of $\mathrm{Zn} 2+, \mathrm{Cd} 2+$, and $\mathrm{Pb} 2+$ Removal From Water Solution Using Natural Clinoptilolitic Zeolite and Commercial Granulated Activated Carbon. Equilibrium of Adsorption. Separation Science and Technology 2008, 43 (8), 2117-2143.

200. Zendelska, A.; Golomeova, M.; Jakupi, Š.; Lisichkov, K.; Kuvendziev, S.; Marinkovski, M., CHARACTERIZATION AND APPLICATION OF CLINOPTILOLITE FOR REMOVAL OF HEAVY METAL IONS FROM WATER RESOURCES. 2018, 32.

201. Shahack-Gross, R.; Bar-Yosef, O.; Weiner, S., Black-Coloured Bones in Hayonim Cave, Israel: Differentiating Between Burning and Oxide Staining. Journal of Archaeological Science 1997, 24 (5), 439-446.

202. Akdeniz, Y.; Ülkü, S., Thermal stability of Ag-exchanged clinoptilolite rich mineral. Journal of Thermal Analysis and Calorimetry 2008, 94 (3), 703-710.

203. Oter, O.; Akcay, H., Use of natural clinoptilolite to improve water quality: sorption and selectivity studies of lead(II), copper(II), zinc(II), and nickel(II). Water Environ Res 2007, 79 (3), 329-35. 
204. Inglezakis, V. J.; Loizidou, M. D.; Grigoropoulou, H. P., Equilibrium and kinetic ion exchange studies of $\mathrm{Pb} 2+, \mathrm{Cr} 3+, \mathrm{Fe} 3+$ and $\mathrm{Cu} 2+$ on natural clinoptilolite. Water Res 2002, 36 (11), 2784-92.

205. Shannon, R., Revised effective ionic radii and systematic studies of interatomic distances in halides and chalcogenides. Acta Crystallographica Section A 1976, 32 (5), 751-767.

206. Santiago, O.; Walsh, K.; Kele, B.; Gardner, E.; Chapman, J., Novel pretreatment of zeolite materials for the removal of sodium ions: potential materials for coal seam gas co-produced wastewater. SpringerPlus 2016, 5 (1), 571.

207. Hamilton, D. E.; Drago, R. S.; Zombeck, A., Mechanistic studies on the cobalt(II) Schiff base catalyzed oxidation of olefins by O2. Journal of the American Chemical Society 1987, 109 (2), 374-379.

208. Cao, H.; Zhu, B.; Yang, Y.; Xu, L.; Yu, L.; Xu, Q., Recent advances on controllable and selective catalytic oxidation of cyclohexene. Chinese Journal of Catalysis 2018, 39 (5), 899-907.

209. Cánepa, A. L.; Chanquía, C. M.; Eimer, G. A.; Casuscelli, S. G., Oxidation of olefins employing mesoporous molecular sieves modified with copper. Appl. Catal., A 2013, 462-463, 8-14.

210. Hoffmann, R.; Minkin, V. I.; Carpenter, B. K., Ockham's Razor and chemistry. HYLE 1998, 3.

211. Bainbridge, P. C.; Luck, R. L.; Newberry, N. K., Syntheses, theoretical studies, and crystal structures of [Ni(II)SSRRL](PF6)2 and [Ni(II)SRSRL](Cl)(PF6) that contains anagostic interactions. Can. J. Chem. 2020, Ahead of Print.

212. ChemBio3D ChemBio3D http://www.cambridgesoft.com/software/chembio3d, 2012.

213. Frisch, M. J.; Trucks, G. W.; Schlegel, H. B.; Scuseria, G. E.; Robb, M. A.; Cheeseman, J. R.; Scalmani, G.; Barone, V.; Petersson, G. A.; Nakatsuji, H.; Li, X.; Caricato, M.; Marenich, A. V.; Bloino, J.; Janesko, B. G.; Gomperts, R.; Mennucci, B.; Hratchian, H. P.; Ortiz, J. V.; Izmaylov, A. F.; Sonnenberg, J. L.; Williams- 
Young, D.; Ding, F.; Lipparini, F.; Egidi, F.; Goings, J.; Peng, B.; Petrone, A.; Henderson, T.; Ranasinghe, D.; Zakrzewski, V. G.; Gao, J.; Rega, N.; Zheng, G.; Liang, W.; Hada, M.; Ehara, M.; Toyota, K.; Fukuda, R.; Hasegawa, J.; Ishida, M.; Nakajima, T.; Honda, Y.; Kitao, O.; Nakai, H.; Vreven, T.; Throssell, K.; Montgomery, J. A., Jr; Peralta, J. E.; Ogliaro, F.; Bearpark, M. J.; Heyd, J. J.; Brothers, E. N.; Kudin, K. N.; Staroverov, V. N.; Keith, T. A.; Kobayashi, R.; Normand, J.; Raghavachari, K.; Rendell, A. P.; Burant, J. C.; Iyengar, S. S.; Tomasi, J.; Cossi, M.; Millam, J. M.; Klene, M.; Adamo, C.; Cammi, R.; Ochterski, J. W.; Martin, R. L.; Morokuma, K.; Farkas, O.; Foresman, J. B.; Fox, D. J. Gaussian 16, Revision A.03, Gaussian, Inc.: Wallingford CT, 2016.

214. Scalmani, G.; Frisch, M. J., Continuous surface charge polarizable continuum models of solvation. I. General formalism. The Journal of Chemical Physics 2010, 132 (11), 114110.

215. Dennington, R.; Keith, T. A.; Millam, J. M. GaussView, Version 6.0.16, 6.0.16; GaussView, Version 6.0.16. Semichem Inc.: Shawnee Mission, KS., Gauss View, Version 6.0.16. Semichem Inc. 2016.

216. Luchini, G.; Alegre-Requena, J.; Funes-Ardoiz, I.; Paton, R., GoodVibes: automated thermochemistry for heterogeneous computational chemistry data [version 1; peer review: 2 approved with reservations]. F1000Research 2020, 9 (291).

217. Bach, R. D.; Ayala, P. Y.; Schlegel, H. B., A Reassessment of the Bond Dissociation Energies of Peroxides. An ab Initio Study. Journal of the American Chemical Society 1996, 118 (50), 12758-12765.

218. Ingold, K. U.; Pratt, D. A., Advances in Radical-Trapping Antioxidant Chemistry in the 21st Century: A Kinetics and Mechanisms Perspective. Chem Rev 2014, 114 (18), 9022-9046.

219. Jimtaisong, A.; Luck, R. L., Synthesis and Catalytic Epoxidation Activity with TBHP and H2O2 of Dioxo-, Oxoperoxo-, and Oxodiperoxo Molybdenum(VI) and Tungsten(VI) Compounds Containing Monodentate or Bidentate Phosphine Oxide Ligands: Crystal Structures of WCl2(O)2(OPMePh2)2, WCl2(O) $(\mathrm{O} 2)(\mathrm{OPMePh} 2) 2$, 
$\mathrm{MoCl} 2(\mathrm{O}) 2 \mathrm{dppmO} 2 \cdot \mathrm{C} 4 \mathrm{H} 10 \mathrm{O}, \mathrm{WCl} 2(\mathrm{O}) 2 \mathrm{dppmO} 2, \mathrm{Mo}(\mathrm{O})(\mathrm{O} 2) 2 \mathrm{dppmO}$, and $\mathrm{W}(\mathrm{O})(\mathrm{O} 2) 2$ dppmO2. Inorg. Chem. 2006, 45 (25), 10391-10402.

220. Carpenter, B. K., Taking the high road and getting there before you. Science (Washington, DC, U. S.) 2011, 332 (6035), 1269-1270.

221. Schreiner, P. R.; Reisenauer, H. P.; Ley, D.; Gerbig, D.; Wu, C.-H.; Allen, W. D., Methylhydroxycarbene: Tunneling Control of a Chemical Reaction. Science 2011, 332 (6035), 1300-1303.

222. Li, B.; He, P.; Yi, G.; Lin, H.; Yuan, Y., Performance of Gold Nanoparticles Supported on Carbon Nanotubes for Selective Oxidation of Cyclooctene with Use of O2 and TBHP. Catal. Lett. 2009, 133 (1), 33.

223. O'Halloran, K. P.; Zhao, C.; Ando, N. S.; Schultz, A. J.; Koetzle, T. F.; Piccoli, P. M. B.; Hedman, B.; Hodgson, K. O.; Bobyr, E.; Kirk, M. L.; Knottenbelt, S.; Depperman, E. C.; Stein, B.; Anderson, T. M.; Cao, R.; Geletii, Y. V.;

Hardcastle, K. I.; Musaev, D. G.; Neiwert, W. A.; Fang, X.; Morokuma, K.; Wu, S.; Kögerler, P.; Hill, C. L., Revisiting the polyoxometalate-based late-transition-metaloxo complexes: the "oxo wall" stands. Inorganic chemistry 2012, 51 (13), 7025-7031. 224. Luan, Y.; Wang, G.; Luck, R. L.; Yang, M., A Two-Dimensional, HydrogenBond-Cross-Linked Molybdenum (VI) Network Polymer with Catalytic Activity. Wiley Online Library: 2007.

225. Timofeeva, M.; Pai, Z.; Tolstikov, A.; Kustova, G.; Selivanova, N.; Berdnikova, P.; Brylyakov, K.; Shangina, A.; Utkin, V., Epoxidation of cycloolefins with hydrogen peroxide in the presence of heteropoly acids combined with phase transfer catalyst. Russian chemical bulletin 2003, 52 (2), 480-486.

226. Afsharpour, M.; Mahjoub, A.; Amini, M., Synthesis, characterization and catalytic activity of a new peroxomolybdenum (VI) complex-based coordination polymer. Applied Catalysis A: General 2007, 327 (2), 205-210.

227. Yamase, T.; Ishikawa, E.; Asai, Y.; Kanai, S., Alkene epoxidation by hydrogen peroxide in the presence of titanium-substituted Keggin-type polyoxotungstates [PTixW12- xO40](3+2x)- and [PTixW12- xO40- $\mathrm{x}(\mathrm{O} 2) \mathrm{x}](3+$ 
$2 \mathrm{x})-(\mathrm{x}=1$ and 2). Journal of Molecular Catalysis A: Chemical 1996, 114 (1-3), 237245.

228. Kumar, R.; Chaudhary, N.; Sankar, M.; Maurya, M. R., Electron deficient nonplanar $\beta$-octachlorovanadylporphyrin as a highly efficient and selective epoxidation catalyst for olefins. Dalton Transactions 2015, 44 (40), 17720-17729.

229. Luque, R.; Badamali, S. K.; Clark, J. H.; Fleming, M.; Macquarrie, D. J., Controlling selectivity in catalysis: Selective greener oxidation of cyclohexene under microwave conditions. Applied Catalysis A: General 2008, 341 (1-2), 154-159.

230. Bernar, I.; Rutjes, F. P.; Elemans, J. A.; Nolte, R. J., Aerobic epoxidation of low-molecular-weight and polymeric olefins by a supramolecular manganese porphyrin catalyst. Catalysts 2019, 9 (2), 195.

231. Iwahama, T.; Hatta, G.; Sakaguchi, S.; Ishii, Y., Epoxidation of alkenes using alkyl hydroperoxides generated in situ by catalytic autoxidation of hydrocarbons with dioxygen. Chemical Communications 2000, (2), 163-164.

232. Farokhi, A.; Hosseini-Monfared, H., A recyclable Mn-porphyrin catalyst for enantioselective epoxidation of unfunctionalized olefins using molecular dioxygen. New Journal of Chemistry 2016, 40 (6), 5032-5043.

233. Jiang, D.; Mallat, T.; Meier, D. M.; Urakawa, A.; Baiker, A., Copper metalorganic framework: Structure and activity in the allylic oxidation of cyclohexene with molecular oxygen. Journal of Catalysis 2010, 270 (1), 26-33.

234. Weiner, H.; Trovarelli, A.; Finke, R. G., Expanded product, plus kinetic and mechanistic, studies of polyoxoanion-based cyclohexene oxidation catalysis: the detection of $\sim 70$ products at higher conversion leading to a simple, product-based test for the presence of olefin autoxidation. Journal of Molecular Catalysis A: Chemical 2003, 191 (2), 217-252.

235. Dapurkar, S. E.; Sakthivel, A.; Selvam, P., Novel mesoporous (Cr)MCM-48 molecular sieves: Promising heterogeneous catalysts for selective oxidation reactions. New Journal of Chemistry 2003, 27 (8), 1184-1190. 
236. Papastergiou, M.; Stathi, P.; Milaeva, E.; Deligiannakis, Y.; Louloudi, M., Comparative study of the catalytic thermodynamic barriers for two homologous Mnand Fe-non-heme oxidation catalysts. Journal of Catalysis 2016, 341, 104-115. 237. Kaneda, K.; Jitsukawa, K.; Itoh, T.; Teranishi, S., Direct epoxy alcohol synthesis from cyclic olefins using molecular oxygen and VO (acac) 2-AIBN catalyst system. The Journal of Organic Chemistry 1980, 45 (15), 3004-3009.

238. Yang, G.; Du, H.; Liu, J.; Zhou, Z.; Hu, X.; Zhang, Z., Oxidation of olefins using molecular oxygen catalyzed by a part per million level of recyclable copper catalyst under mild conditions. Green Chemistry 2017, 19 (3), 675-681.

239. Martínez, H.; Cáceres, M. F.; Martínez, F.; Páez-Mozo, E. A.; Valange, S.; Castellanos, N. J.; Molina, D.; Barrault, J.; Arzoumanian, H., Photo-epoxidation of cyclohexene, cyclooctene and 1-octene with molecular oxygen catalyzed by dichloro dioxo-(4, 4'-dicarboxylato-2, 2'-bipyridine) molybdenum (VI) grafted on mesoporous TiO2. Journal of Molecular Catalysis A: Chemical 2016, 423, 248-255.

240. Riahi Farsani, M.; Jalilian, F.; Yadollahi, B.; Amiri Rudbari, H., Comparison between various Keggin and Wells-Dawson sandwich-type polyoxometalates in catalytic oxidation of cyclooctene and cyclohexene with hydrogen peroxide. Applied Organometallic Chemistry 2015, 29 (1), 7-11.

241. Brown, K.; Zolezzi, S.; Aguirre, P.; Venegas-Yazigi, D.; Paredes-García, V.; Baggio, R.; Novak, M. A.; Spodine, E., [Cu(H2btec)(bipy)]ळ: a novel metal organic framework (MOF) as heterogeneous catalyst for the oxidation of olefins. Dalton Transactions 2009, (8), 1422-1427.

242. Bazarganipour, M.; Salavati-Niasari, M., Synthesis, characterization and chemical binding of a Ni (II) Schiff base complex on functionalized MWNTs; Catalytic oxidation of cyclohexene with molecular oxygen. Chemical Engineering Journal 2016, 286, 259-265.

243. Tong, J.; Li, W.; Bo, L.; Wang, H.; Hu, Y.; Zhang, Z.; Mahboob, A., Selective oxidation of styrene catalyzed by cerium-doped cobalt ferrite nanocrystals with greatly enhanced catalytic performance. Journal of Catalysis 2016, 344, 474-481. 
244. Molinari, A.; Amadelli, R.; Carassiti, V.; Maldotti, A., Photocatalyzed Oxidation of Cyclohexene and Cyclooctene with (nBu4N) 4W10O32 and (nBu4N) 4W10O32/FeIII [meso-Tetrakis (2, 6-dichlorophenyl) porphyrin] in Homogeneous and Heterogeneous Systems. European Journal of Inorganic Chemistry 2000, 2000 (1), 9196.

245. Godhani, D. R.; Nakum, H. D.; Parmar, D. K.; Mehta, J. P.; Desai, N. C., Zeolite Y encaged Ru (III) and Fe (III) complexes for oxidation of styrene, cyclohexene, limonene, and $\alpha$-pinene: An eye-catching impact of $\mathrm{H} 2 \mathrm{SO} 4$ on product selectivity. Journal of Molecular Catalysis A: Chemical 2017, 426, 223-237.

246. Yang, D.; Jiang, T.; Wu, T.; Zhang, P.; Han, H.; Han, B., Highly selective oxidation of cyclohexene to 2-cyclohexene-1-one in water using molecular oxygen over Fe-Co-gC 3 N 4. Catalysis Science \& Technology 2016, 6 (1), 193-200.

247. Henriques, C. A.; Fernandes, A.; Rossi, L. M.; Ribeiro, M. F.; Calvete, M. J.; Pereira, M. M., Biologically inspired and magnetically recoverable copper porphyrinic catalysts: A greener approach for oxidation of hydrocarbons with molecular oxygen. Advanced Functional Materials 2016, 26 (19), 3359-3368.

248. Mohapatra, S.; Selvam, P., A highly selective, heterogeneous route to enones from allylic and benzylic compounds over mesoporous CrMCM-41 molecular sieves. Journal of Catalysis 2007, 249 (2), 394-396.

249. Li, S.-J.; Wang, Y.-G., A novel and selective catalytic oxidation of hydrocarbons to ketones using chloramine-T/O2/Fe (TPP) $\mathrm{Cl}$ system. Tetrahedron letters 2005, 46 (46), 8013-8015.

250. da Silva, F. P.; Gonçalves, R. V.; Rossi, L. M., Magnetically recoverable copper oxide catalysts for aerobic allylic oxidation of cyclohexene. Journal of Molecular Catalysis A: Chemical 2017, 426, 534-541.

251. Zhao, Y.; Yeung, Y.-Y., An Unprecedented Method for the Generation of tertButylperoxy Radical Using DIB/TBHP Protocol: Solvent Effect and Application on Allylic Oxidation. Organic Letters 2010, 12 (9), 2128-2131. 
252. Chen, Z.; Luck, R. L., Oxidation of olefins using atmospheric oxygen atoms initiated by tert-butylhydroperoxide or hydrogen peroxide with silver nanoparticles deposited on MCM-41 as catalysts. Green Chemistry 2016, 18 (11), 3354-3359.

253. Catino, A. J.; Forslund, R. E.; Doyle, M. P., Dirhodium (II) caprolactamate: An exceptional catalyst for allylic oxidation. Journal of the American Chemical Society 2004, 126 (42), 13622-13623.

254. Yang, X.; Zhou, L.; Chen, Y.; Chen, C.; Su, Y.; Miao, H.; Xu, J., A promotion effect of alkaline-earth chloride on N-hydroxyphthalimide-catalyzed aerobic oxidation of hydrocarbons. Catalysis Communications 2009, 11 (3), 171-174.

255. Sinhamahapatra, A.; Sutradhar, N.; Pahari, S. K.; Pal, P.; Bajaj, H. C.; Jayachandran, M.; Panda, A. B., Allylic and Benzylic Oxidation over CrIIIIncorporated Mesoporous Zirconium Phosphate with 100\% Selectivity. ChemCatChem 2011, 3 (9), 1447-1450.

256. Alper, H.; Harustiak, M., Allylic oxidation of olefins catalyzed by cobalt chloride. The beneficial effect of N-methylpyrrolidinone. Journal of molecular catalysis 1993, 84 (1), 87-92.

257. Zhang, P.; Wang, Y.; Yao, J.; Wang, C.; Yan, C.; Antonietti, M.; Li, H., Visible-light-induced metal-free allylic oxidation utilizing a coupled photocatalytic system of g-C3N4 and N-hydroxy compounds. Advanced Synthesis \& Catalysis 2011, 353 (9), 1447-1451.

258. Li, Y.; Lee, T. B.; Wang, T.; Gamble, A. V.; Gorden, A. E., Allylic C-H Activations Using $\mathrm{Cu}$ (II) 2-Quinoxalinol Salen and tert-Butyl Hydroperoxide. The Journal of organic chemistry 2012, 77 (10), 4628-4633.

259. Thangaraj, B.; Jayaraj, C.; Ganesh, V.; Ayyamperumal, S., Silicate intercalated cobalt chromium-hydrotalcite (CoCr-HTSi): An environment-friendly recyclable catalyst for organic transformations. Catalysis Communications 2016, 74, 85-90.

260. Baca, S. G.; Reetz, M. T.; Goddard, R.; Filippova, I. G.; Simonov, Y. A.; Gdaniec, M.; Gerbeleu, N., Coordination polymers constructed from o-phthalic acid 
and diamines: syntheses and crystal structures of the phthalate-imidazole complexes $\{[\mathrm{Cu}(\mathrm{Pht})(\mathrm{Im}) 2] \cdot 1.5 \mathrm{H} 2 \mathrm{O}\} \mathrm{n}$ and $[\mathrm{Co}(\mathrm{Pht})(\mathrm{Im}) 2] \mathrm{n}$ and their application in oxidation catalysis. Polyhedron 2006, 25 (5), 1215-1222.

261. Kani, I.; Bolat, S., Effective catalytic oxidation of alcohols and alkenes with monomeric versus dimeric manganese (II) catalysts and t-BuOOH. Applied Organometallic Chemistry 2016, 30 (8), 713-721.

262. Zhang, P.; Gong, Y.; Lv, Y.; Guo, Y.; Wang, Y.; Wang, C.; Li, H., Ionic liquids with metal chelate anions. Chemical Communications 2012, 48 (17), 23342336.

263. Pan, J.-F.; Chen, K., A facile catalytic oxidation of activated hydrocarbons to the carbonyl functionality mediated by Mn (II) complexes. Journal of Molecular Catalysis A: Chemical 2001, 176 (1-2), 19-22.

264. Liu, J.; Wang, F.; Ma, Z.; Lin, J.; Gu, Z., Vanadium phosphorus oxide modified by silver doping: A highly effective catalyst for allylic oxidation of cycloolefins. Catalysis Communications 2011, 15 (1), 103-107.

265. Zarghani, M.; Akhlaghinia, B., Fe 3 O 4 magnetic nanoparticles (MNPs) as an efficient catalyst for selective oxidation of benzylic and allylic $\mathrm{C}-\mathrm{H}$ bonds to carbonyl compounds with tert-butyl hydroperoxide. RSC advances 2016, 6 (45), 38592-38601.

266. Sankaralingam, M.; Lee, Y.-M.; Nam, W.; Fukuzumi, S., Selective oxygenation of cyclohexene by dioxygen via an iron (V)-oxo complex-autocatalyzed reaction. Inorganic chemistry 2017, 56 (9), 5096-5104.

267. Ghasemi, G.; Martínez-Huerta, M.; Ghiaci, M., Synthesis and characterization of Au nanocatalyst on modifed bentonite and silica and their applications for solvent free oxidation of cyclohexene with molecular oxygen. Journal of Molecular Catalysis A: Chemical 2015, 406, 118-126.

268. Jurado-Gonzalez, M.; Sullivan, A. C.; Wilson, J. R., Allylic and benzylic oxidation using cobalt (II) alkyl phosphonate modified silica. Tetrahedron letters 2003, 44 (22), 4283-4286. 
269. Crevier, T. J.; Mayer, J. M., C-O Bond Homolysis in a Tungsten Alkoxide: The Mechanism of Alcohol Deoxygenation by WC12(PMe3)4 and WH2Cl2(PMe3)4. Journal of the American Chemical Society 1997, 119 (36), 8485-8491.

270. Farsani, M. R.; Jalilian, F.; Yadollahi, B.; Rudbari, H. A., A comparative study on Keggin and Wells-Dawson sandwich type polyoxometallates in the oxidation of alcohols with 30\% hydrogen peroxide. Polyhedron 2014, 76, 102-107.

271. Bawaked, S.; Dummer, N. F.; Bethell, D.; Knight, D. W.; Hutchings, G. J., Solvent-free selective epoxidation of cyclooctene using supported gold catalysts: an investigation of catalyst re-use. Green Chemistry 2011, 13 (1), 127-134.

272. Qian, L.; Wang, Z.; Beletskiy, E. V.; Liu, J.; Dos Santos, H. J.; Li, T.;

Rangel, M. d. C.; Kung, M. C.; Kung, H. H., Stable and solubilized active Au atom clusters for selective epoxidation of cis-cyclooctene with molecular oxygen. Nature communications 2017, 8 (1), 1-9.

273. Nishiyama, Y.; Nakagawa, Y.; Mizuno, N., High turnover numbers for the catalytic selective epoxidation of alkenes with $1 \mathrm{~atm}$ of molecular oxygen. Angewandte Chemie 2001, 113 (19), 3751-3753.

274. Altmann, P.; Cokoja, M.; Kühn, F. E., Fluorinated Solvents in Methyltrioxorhenium-Catalyzed Olefin Epoxidations. European Journal of Inorganic Chemistry 2012, 2012 (19), 3235-3239.

275. Jin, F.; Chang, C.-C.; Yang, C.-W.; Lee, J.-F.; Jang, L.-Y.; Cheng, S., New mesoporous titanosilicate MCM-36 material synthesized by pillaring layered ERB-1 precursor. Journal of Materials Chemistry A 2015, 3 (16), 8715-8724.

276. Jin, F.; Huang, S.; Cheng, S.; Wu, Y.; Chang, C.-C.; Huang, Y.-W., The influences of $\mathrm{Al}$ species and Ti species on the catalytic epoxidation over Si/Ti-pillared MCM-36 synthesized from MCM-22. Catalysis Science \& Technology 2015, 5 (5), 3007-3016.

277. Li, B.; He, P.; Yi, G.; Lin, H.; Yuan, Y., Performance of gold nanoparticles supported on carbon nanotubes for selective oxidation of cyclooctene with use of $\mathrm{O} 2$ and TBHP. Catalysis letters 2009, 133 (1), 33-40. 
278. Zhao, J.; Leng, Y.; Jiang, P.; Wang, J.; Zhang, C., POSS-derived mesoporous ionic copolymer-polyoxometalate catalysts with a surfactant function for epoxidation reactions. New Journal of Chemistry 2016, 40 (2), 1022-1028.

279. Li, C.; Zhao, Y.; Zhu, T.; Ruan, J.; Li, G., Effective solvent-free oxidation of cyclohexene to allylic products with oxygen by mesoporous etched halloysite nanotube supported Co 2+. RSC advances 2018, 8 (27), 14870-14878. 


\section{Copyright Documentation}

\subsection{Copyright Documentation for Chapter 3 Journal of Coordination Chemistry (Taylor and Francis)}

Copied from https://authorservices.taylorandfrancis.com/publishing-yourresearch/moving-through-production/copyright-for-journal-authors/

After assigning copyright, you will still retain the right to:

- Be credited as the author of the article.

- Make printed copies of your article to use for a lecture or class that you are leading on a non-commercial basis.

- Share your article using your free eprints with friends, colleagues and influential people you would like to read your work.

- Include your article Author's Original Manuscript (AOM) or Accepted Manuscript(AM), depending on the embargo period in your thesis or dissertation. The Version of Record cannot be used. For more information about manuscript versions and how you can use them, please see our guide to sharing your work.

- Present your article at a meeting or conference and distribute printed copies of the article on a non-commercial basis.

- Post the AOM/AM on a departmental, personal website or institutional repositories depending on embargo period. To find the embargo period for any Taylor \& Francis journal, please use the Open Access Options Finder. 


\title{
11.2 Copyright Documentation for Chapter 4 Can. J. Chem. (NRC Research Press)
}

\author{
Canadian Science Publishing license to publish agreement \\ Date of agreement: 30-Apr-2020 \\ Article: "Syntheses, theoretical studies and crystal structures of [Ni(II $\left.)^{S_{S R R}}{ }_{\mathbf{L}} \mathbf{P F}_{\mathbf{6}}\right)_{\mathbf{2}}$ and

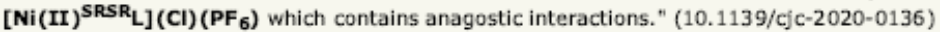 \\ Authors: Bainbridge, Peyton C; Luck, Rudy Lin; Newberry, Nick K \\ Journal: Canadian Journal of Chemistry
}

To allow the Article in the Journal to be distributed as widely as possible, the copyright holder (the Owner) grants Canadian Science Publishing (the Publisher) a licence to publish the above Article. The Article is deemed to include all material submitted for publication, including, but not limited to, title, abstract, text, figures, tables, supplementary material, and author-supplied promotional material. Unless otherwise specified, the Article is deemed to include the Submitted Article, the Accepted Article, and the Article Version of Record.

Definitions for different versions of the Article

Submitted Article $=$ the version of the Article submitted to the Journal for peer review

Accepted Article $=$ the version of the Article revised by authors to incorporate suggestions by pee reviewers and subsequently accepted for publication in the Journal

Article Version of Record $=$ the official version of the Article that has been prepared by the Publisher, and appears in either the e-First section of a Journal's website or with in an issue of the Journal

req What license is being granted

req Please select which license the copyright holder (Owner) is granting to the Publisher. License terms and conditions are described under the signatures area. Authors who plan to pay for open access publication of the Article must select CC BY.

(1) Standard license to publish: terms and conditions $1.1-1.10$ apply

Who is the copyright holder

req Please identify the Owner of your copyright interests in the Article by selecting from options A-D.

(A) I am an Author whose employer does not hold copyright. I am an Owner and hold all or some of the copyright.

Signature for:

Mr. Nick Newberry

Houghton Michigan United States

If you selected option A above, sign here 
Author signature:

\section{If you selected option B, C, or D, complete the section below}

Owner name and address:

Name and address of government institution or company

Name and title of signing officer:

The signing officer is a representative of the Owner with

the authority to sign legal documents on its behalf

Signature of signing officer:

Email signature to cjc@cdnsciencepub.com. If you have the authority to sign legal documents on behalf of your employer, type your own name at right. Otherwise, you may:

- use a print-out of this online form, $O R$ - use our PDF standard or $O A$ form, $O R$ - forward an email from your signing officer declaring their agreement to publication of the Article in Canadian Journal of Chemistry under the terms of the CSP license to publish agreement.

Names of Author(s) who are employed by the Owner: The Publisher requires only one copy of the form on behalf of Authors fisted at right

Owner's copyright statement to be published with the article:

Provide only if Owner requires specific text in the

copyright statement

By checking the box and clicking the SUBMIT button below the License terms, the Owner confirms that they have read and agree to the terms and conditions of this license agreement.

License terms

\section{Standard license to publish}

Publisher rights

1.1. In consideration of the Publisher publishing the Article, the Owner grants to the Publisher for the full term of copyright and any extensions thereto an irrevocable, royalty-free, exclusive licence to edit,

publish, reproduce, distribute, transmit, display, store, translate, adapt, create derivative works from, and use the Article in any language and in any form, manner, format, or medium now known or hereafter developed, throughout the world; to license others to do any or all of the above; and to assign this license. 1.2. In consideration of the Publisher publishing the Article, the Owner also grants to the Publisher for the full term of copyright and any extensions thereto all the same rights provided for in clause 1.1 , for any supplementary material and author-supplied promotional material submitted with the Article, but on a non-exclusive basis. 
1.3. The Owner authorizes the Publisher to take such steps as it considers necessary, at its own discretion and expense, in the Author(s)' name and on their behalf, if it believes that a third party is infringing or is likely to infringe copyright in the Article, including but not limited to taking legal proceedings.

Author and Owner rights

1.4. The Author(s) retain their moral rights to attribution, association, and integrity of their work in the Article.

1.5. Ownership of the copyright in all versions of the Article remains with the Owner. The Owner retains the following non-exclusive rights:

(a) To post an electronic copy of the Submitted Article (pre-print) and/or the Accepted Article (post-print) on their own website, an institutional repository, or their funding body's designated archive, provided that posted versions of the Accepted Article include a hyperlink to the Article Version of Record.

(b) Subject to the Owner's permission, the Author(s) and any academic institution where they work at the time may reproduce the Article for the purpose of teaching.

(c) To reuse all or part of any version of the Article in other works created by the Author(s), provided the Article Version of Record is acknowledged with a note or citation that includes author, year of publication, article title, journal title, digital object identifier (DOI), and a hyperlink to the Article version of Record on the Journal website.

Warranties

1.6. Publisher and Journal branding, and Article identifiers - including but not limited to copyright notices, unique digital object identifiers (DOIs), Publisher and Journal logos, references, hyperlinks, and any other notices that are included in the Article or that are provided by the Publisher with instructions that such must accompany display of the Article - shall not be removed or tampered with in any way.

1.7. The Owner(s) warrant and represent that:

(a) The Author(s) qualify for authorship and are the only contributors who qualify for authorship of the Article.

(b) The Article represents original work, is not under consideration for publication elsewhere, and has not been previously published in any way, except as listed below:

- an un-refereed, preliminary version of the Article may be posted to a preprint server, institutional repository, Author website, or funder archive;

- the work underpinning the Article may be presented at a conference as an abstract, poster,

lecture, or paper; and

- the Article may comprise the Author's thesis or dissertation (in full or in part).

(c) The Article accepted for publication by the Publisher, or its equivalent, will not be submitted for publication elsewhere.

(d) All of the facts contained in the Article are true and accurate.

(e) Nothing in the Article is obscene, defamatory, libellous, violates any right of privacy, or infringes any intellectual property rights or human rights.

(f) Nothing in the Article infringes any duty of confidentiality that any of the Author(s) may owe to anyone else or violates any contract, express or implied, of any of the Author(s), and all the institutions in which work recorded in the Article was carried out have authorized publication of the Article.

(g) If the Article includes material from other copyrighted work, the Author(s) have obtained permission from the copyright owners of such materials to enable the Authors to grant the rights contained herein. Any copyrighted material has been appropriately acknowled ged in the Article. Copies of all such permissions have been sent to the Publisher.

(h) The Owner(s) have communicated the terms and conditions of this license with the Authors, and the Authors her eby acknowledge and agree to abide by said terms and conditions.

General

1.8. If after acceptance the Article is withdrawn, rejected, or not published within 2 years, the license is revoked.

1.9. The terms and conditions of this license may not be modified without the express written consent of 
both parties.

1.10. This Agreement shall endure to the ben efit of and be binding on the Publisher and the Owner, and their respective heirs, legal representatives, successors, and assigns.

\section{Open access license (CC BY)}

Open access: Publisher responsibilities

2.1. The Publisher will enable unrestricted access to the Article on the Journal website under the terms of the Creative Commons Attribution 4.0 International license (CC BY 4.0),

https://creativecommons.org/licenses/by/4.0\%. This license allows others to share (copy, distribute, and transmit the work), remix (to adapt the work), and to make commercial use of the work under the condition that they acknowledged the original publication with a credit line that includes author, year of publication, article title, journal title, and digital object identifier (DOI).

Open access: non-exclusive license

2.2. License terms and conditions 1.1-1.10 apply with the following mod ifications:

(a) Replace Clause 1.1 with 2.2(a). In consideration of the Publisher publishing the Article, the Owner grants to the Publisher for the full term of copyright and any extensions thereto an irrevocable, royaltyfree, non-exclusive license to edit, publish, reproduce, distribute, transmit, display, store, translate, adapt, create derivative works from and use the Article in any language and in any form, manner, format, or medium now known or her eafter developed, throughout the world; to license others to do any or all of the above; and to assign this license.

(b) Replace Clause 1.5(a) with 2.2(b). To post any version of the Article on their own website, an institutional repository, or their funding body's designated archive, provided they include a hyperlink to the Article Version of Record on the Journal website. 


\subsection{Copyright Documentation for Chapter 5 ACS Sustainable}

\section{Chem. Eng.}

Reprinted with permission from [Andeme Ela, R. C., et al. (2020). "Double-Shell

Lignin Nanocapsules Are a Stable Vehicle for Fungicide Encapsulation and Release." ACS Sustainable Chemistry \& Engineering 8(46): 17299-17306]. Copyright [2020] American Chemical Society.

Copied from: https://pubs.acs.org/pb-assets/acspubs/Migrated/dissertation.pdf American Chemical Society's Policy on Theses and Dissertations This policy addresses permission to include your article(s) or portions of text from your article(s) in your thesis. Reuse/Republication of the Entire Work in Theses or Collections: Authors may reuse all or part of the Submitted, Accepted or Published Work in a thesis or dissertation that the author writes and is required to submit to satisfy the criteria of degree-granting institutions. Such reuse is permitted subject to the ACS' "Ethical Guidelines to Publication of Chemical Research". Appropriate citation of the Published Work must be made as follows "Reprinted with permission from [COMPLETE REFERENCE CITATION]. Copyright [YEAR] American Chemical Society." Insert the appropriate wording in place of the capitalized words. Citation information may be found after the "Cite this:" heading below the title of the online version and at the bottom of the first page of the pdf or print version of your ACS journal article. If the thesis or dissertation to be published is in electronic format, a direct link to the Published Work must also be included using the ACS Articles on Request authordirected link. If your university requires written permission and your manuscript has not yet received a DOI (published ASAP), send a request to copyright@acs.org that includes the manuscript number, the name of the ACS journal, and the date that you need to receive our reply. If your university requires you to obtain permission for manuscripts in ASAP status or final published articles, you must use the RightsLink permission system. See RightsLink instructions at http://pubs.acs.org/page/copyright/permissions.html and make requests at the "Rights 
\& Permissions" link under the title of the online version of the article. Submission to a Dissertation Distributor: If you plan to submit your thesis to UMI or to another dissertation distributor, you should not include the unpublished ACS paper in your thesis if the thesis will be disseminated electronically, until ACS has published your paper. After publication of the paper by ACS, you may release the entire thesis (not the individual ACS article by itself) for electronic dissemination through the distributor; ACS's copyright credit line should be printed on the first page of the ACS paper.

\subsection{Copyright Documentation for Chapter 6 MDPI Processes}

Copied from

https://www.mdpi.com/authors/rights\#: :text=For\%20all\%20articles\%20publish ed $\% 20$ in,read $\% 20$ the $\% 20$ paper $\% 20$ for $\% 20$ free.

For all articles published in MDPI journals, copyright is retained by the authors. Articles are licensed under an open access Creative Commons CC BY 4.0 license, meaning that anyone may download and read the paper for free. In addition, the article may be reused and quoted provided that the original published version is cited. These conditions allow for maximum use and exposure of the work, while ensuring that the authors receive proper credit.

In exceptional circumstances articles may be licensed differently. If you have specific condition (such as one linked to funding) that does not allow this license, please mention this to the editorial office of the journal at submission. Exceptions will be granted at the discretion of the publisher.

\subsection{Copyright Documentation for Chapter 7}

Not yet published. 
A Appendix

\section{A1 Fourier Transform Infrared (FTIR)}

\section{A1.1 Theory}

Fourier Transform Infrared, used in Chapters 2, 3, 4, and 6, works by emitting infrared radiation from a source. This radiation is passed through a sample, and some of the radiation is absorbed. Some of the radiation that passes through the sample loses some of its energy in the excitation of the material due to the vibrations and stretches of the bonds in the molecule. The radiation that makes it through is measured by the detector, and a percent transmittance is given for each wavelength or energy. This spectrum is converted mathematically using the Fourier Transform of intensity as a function of the radiation's energy. The spectrum produced shows a signature of the molecule based on the specific wavelength of energy that was absorbed that can be deciphered to determine the functional groups contained in the material.

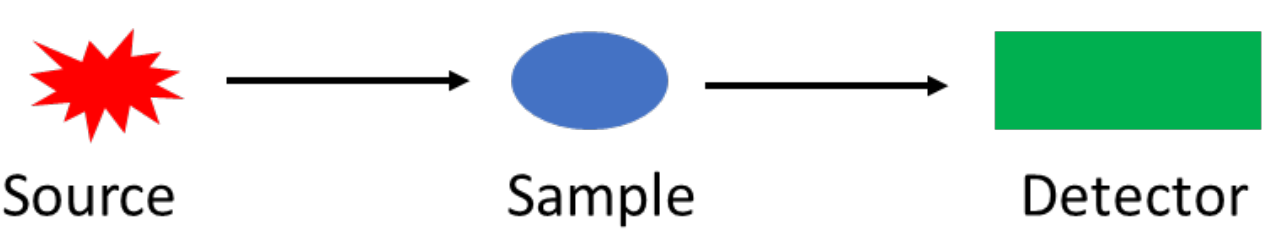

Figure A1 shows a simplified version of a typical FTIR instrument.

When looking at an FTIR spectrum, a peak at a specific wavenumber (energy), each peak can be designated to a symmetric stretch, asymmetric stretch, or vibration of certain functional groups of the molecule. These signature peaks at these wavelengths can be used to determine the functional groups contained in the molecule and the characteristics of the bonds of the substance.

\section{A1.2 Sampling}

No matter the sample, the air inside the machine can interact with the radiation and absorb energy. Thus, a background spectrum needs to be obtained. This adjusts for the composition of the air in the room, assuming all of the air is made of the same 
mixture of compounds such as $\mathrm{CO}_{2}, \mathrm{CO}, \mathrm{N}_{2}, \mathrm{O}_{2}, \mathrm{H}_{2} \mathrm{O}$, etc. Samples for FTIR can be gas, liquid, or solid phase.

For the analysis of gas-phase samples, a sample chamber is used to contain them and placed into the beam. For liquid samples, a common technique is to put a drop of the liquid on a salt plate made of $\mathrm{NaCl}$ and sandwich the drop with another plate; however, the sample cannot contain water as it would dissolve the $\mathrm{NaCl}$ salt plate. For solid, a pellet can be made by mixing the sample with $\mathrm{KBr}$ and compressing it into a pellet where the $\mathrm{KBr}$ acts to dilute the solid so it does not completely absorb the radiation resulting in no detection of the signal. Another technique for solids is making a nujol mull. This is done by finely grinding the powder with a few drops of mineral oil in a mortar and pestle or between two ground glass joints. The drawback of a nujol mull is that the peaks pertaining to mineral oil will also be present in the spectra.

A more common technique is called attenuated total reflectance (ATR); this works by a slightly different method. Instead of passing the beam of radiation through the sample, it is reflected off the sample at an angle. This can eliminate the need to make a "mull" or dissolve the product and can also be used with aqueous samples, unlike the $\mathrm{NaCl}$ and $\mathrm{KBr}$ plates that would be dissolved by the water in the sample. This technique is preferred due to the low amount of sample prep that needs to be done and the non-destructive nature of the analysis of the sample.

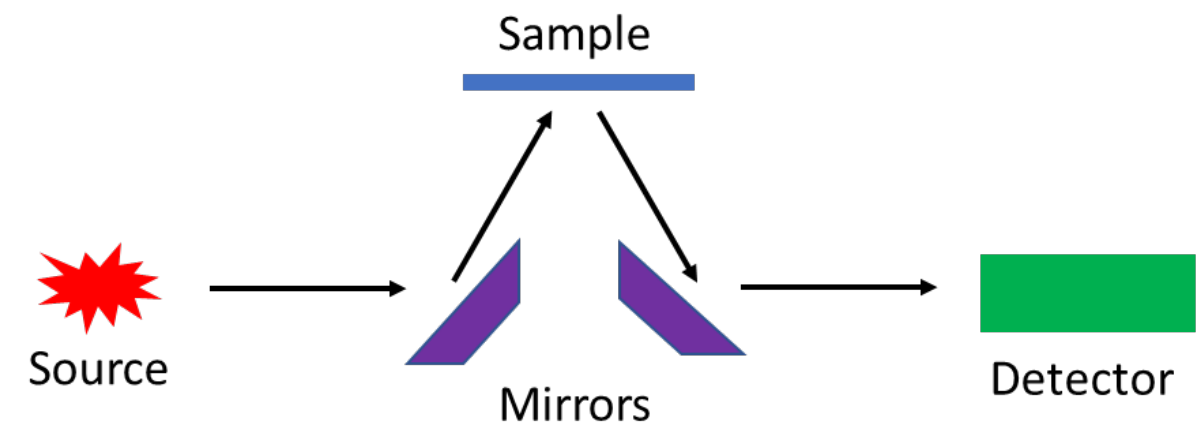

Figure A.2 shows a simplified version of an FTIR/ATR instrument. 


\section{A2 Nuclear Magnetic Resonance (NMR)}

\section{A2.1 Theory}

NMR used in Chapters 2, 3, and 6 is performed by inserting a sample into a very strong magnetic field. When an atom with a spin state is inserted into an external magnetic field, it aligns its magnetic field with the external magnetic field. The sample is then irradiated with radio waves of a certain energy. This energy causes the atom to go from a low spin state to a high spin state, thus reversing the direction of its magnetic field to be opposite of the external magnetic field. When the atom returns from the high spin state to the lower spin state, the energy is emitted as a radio wave. This energy is going to be very specific to the atom and its environment, which through interpretation, can be used to help determine the structure of the molecules in the sample.

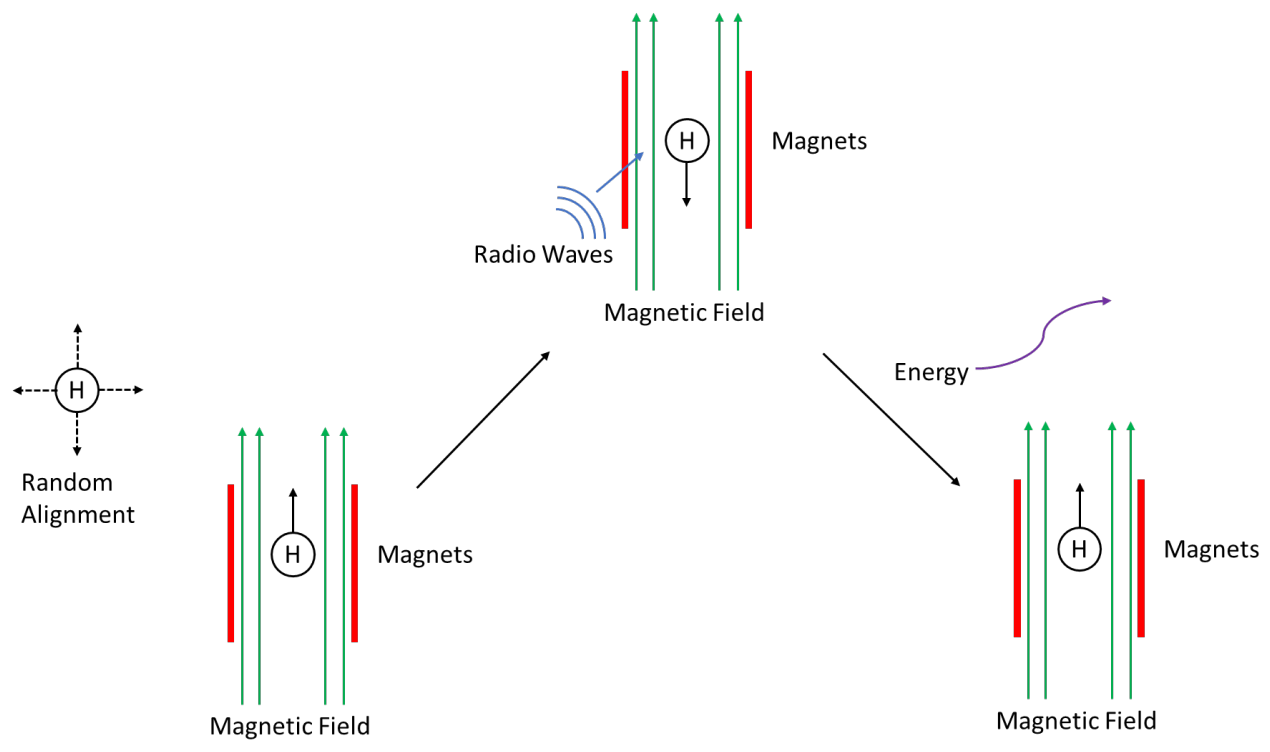

Figure $\mathbf{A 3}$ shows a simplified diagram of how NMR works based on a simple ${ }^{1} \mathrm{H}$ nucleus. 


\section{A2.2 Samples}

Typical nuclei analyzed via NMR spectroscopy are ${ }^{1} \mathrm{H},{ }^{13} \mathrm{C},{ }^{19} \mathrm{~F},{ }^{31} \mathrm{P}$, and less common ${ }^{27} \mathrm{Al}$, and ${ }^{29} \mathrm{Si}$. Samples can be solid or liquid, with liquid being the most common.

\section{A3 Magnetic Susceptibility}

\section{A3.1 Theory}

Magnetic susceptibility used in Chapter 2 is used to measure the magnetic moment of substances. When all electrons in a substance are paired, the substance is diamagnetic, or it repels a magnet. When there are unpaired electrons, then the substance is paramagnetic, or it is attracted to a magnet. To measure magnetic susceptibility, the sample is weighed and packed into a tube. The volume of the tube is taken, and then the sample is weighed on a balance with an applied magnetic field. The measurement can then be used to determine the number of unpaired electrons for a substance. This technique is typically used for metal complexes to determine whether the complex is high spin or low spin and can also help with the determination of the oxidation state of the metal. 


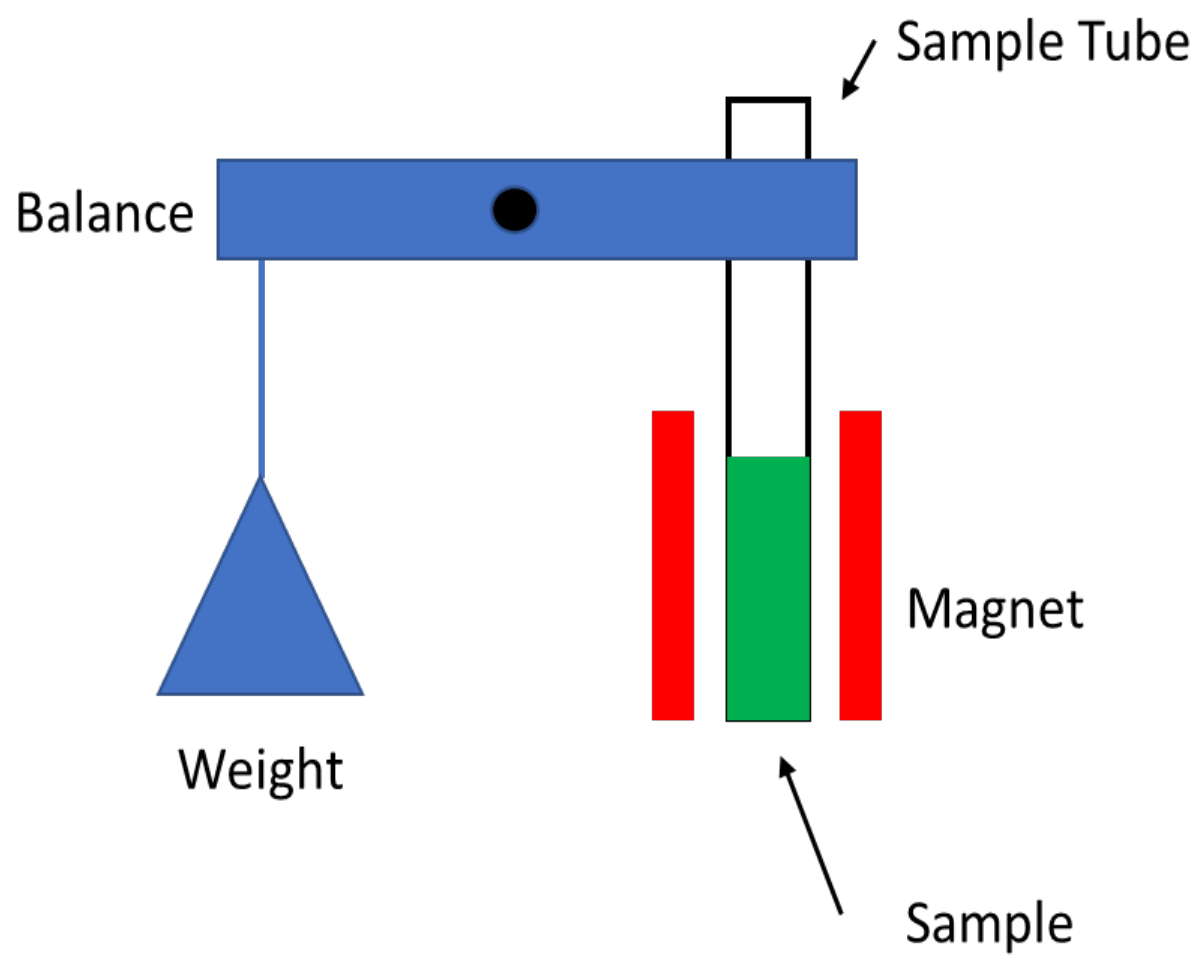

Figure A4 contains the diagram showing how a Guoy balance works to determine the magnetic susceptibility of a sample.

\section{A5 Thermogravimetric Analysis (TGA)}

\section{A5.1 Theory}

Thermogravimetric Analysis (TGA) used in Chapter 2 works by measuring the mass of a sample while heating the sample under a flow of nitrogen. As the sample is heated and decomposes, the mass loss can be analyzed, and the path of decomposition can be found. TGA can be very useful to determine the lability of ligands and the stability of metal-organic complexes. 


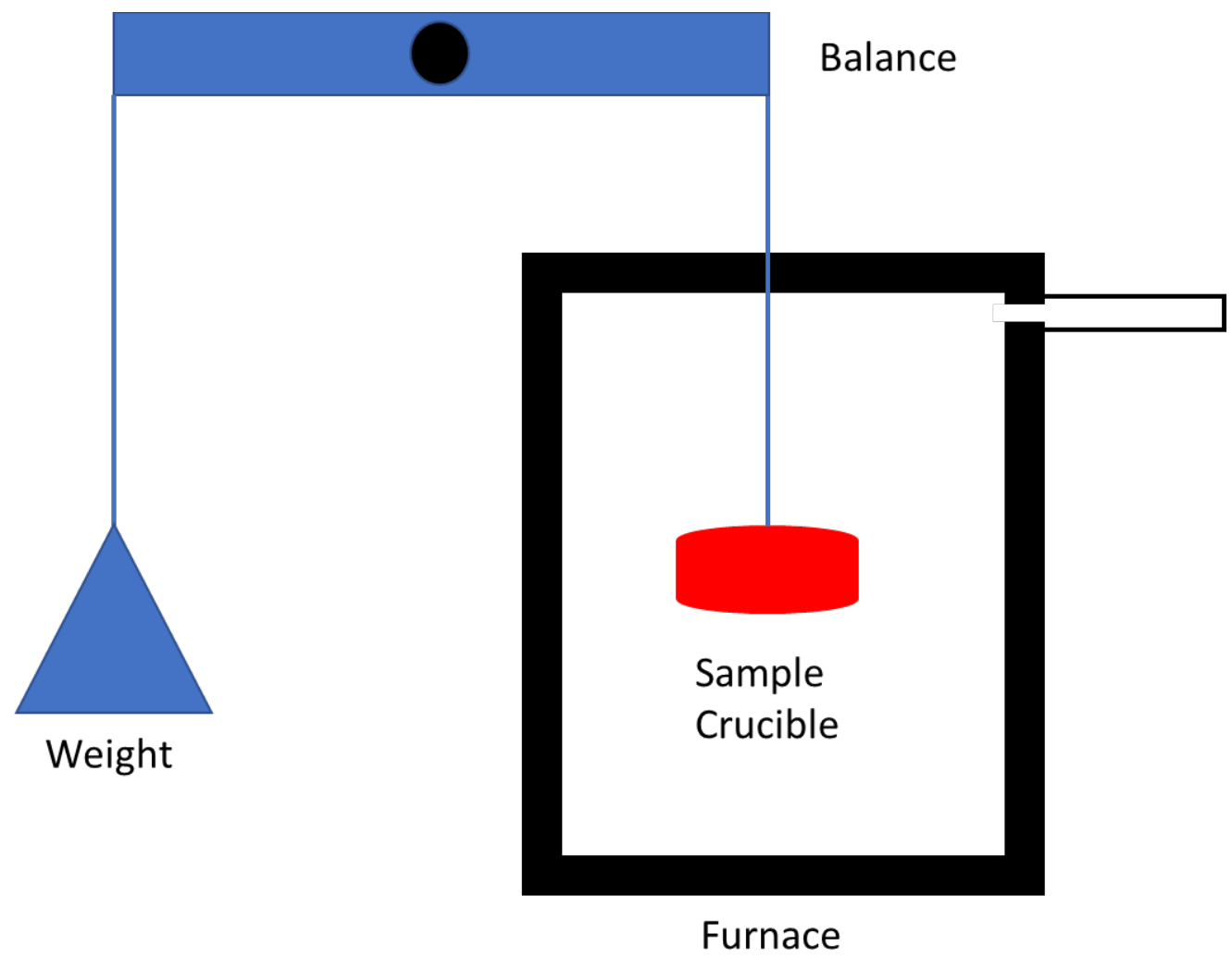

Figure A5 shows a simplified version of how a TGA machine works.

\section{A6 Ultraviolet-Visible Absorbance Spectroscopy (UV- vis)}

\section{A6.1 Theory}

Ultraviolet-visible spectroscopy (UV-Vis Spectroscopy) used in Chapter 2

works by using a source to generate radiation in the energy corresponding to ultraviolet or visible wavelength energy. This radiation is then passed through a sample, and then the energy that passes through the sample is detected. If all of the light passes through, then the sample did not absorb any energy, also referred toknown as the sample has no absorbance, but if not all of the light passes through, then the sample absorbed the radiation.

Molecules can absorb radiation in the form of energy by going from a low spin state to a higher spin state. This energy is then released when the high spin state relaxes to a lower spin state as vibration. The wavelength that a chemical absorbs the radiation 
energy at is specific to the amount of energy that it takes to promote an electron in the molecule from a low spin state to a high spin state.

When using a simple UV-Vis spectrometer, a single wavelength is selected and used on the samples. This single wavelength technique is typically used for quantification work when the absorbance wavelength of a substance is known.

When using a more complex UV-Vis spectrometer, a scan of wavelength is typically used first. This determines the absorbance over a specified range of the ultraviolet-visible spectrum. This multiple wavelength scan is typically used when trying to determine the absorbance of new compounds or studying the shift in absorbance of compounds. The more complex UV-Vis spectrometer can also be set to a specific wavelength to use in the same way as the simple UV-Vis spectrometer.

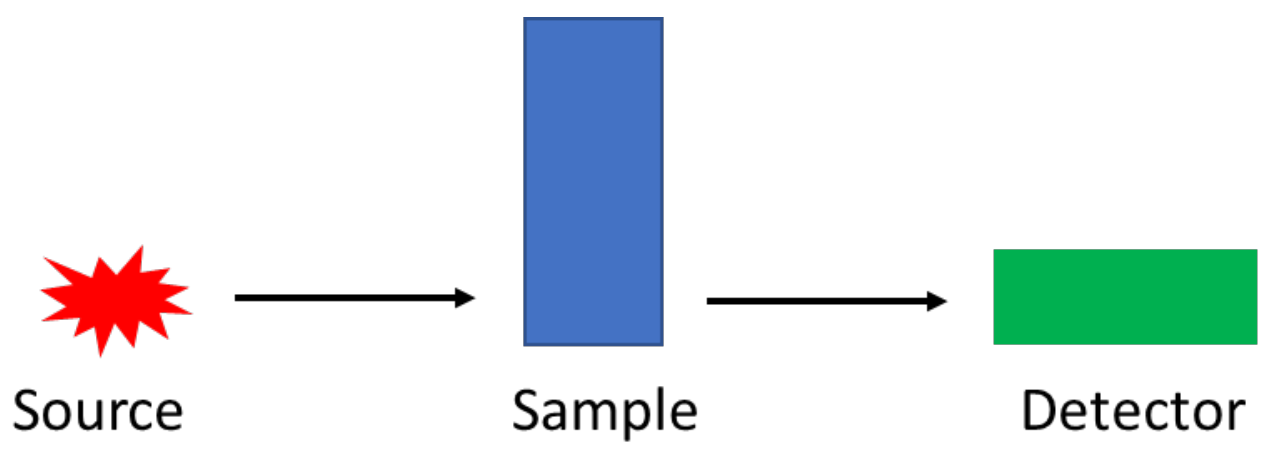

Figure A6 shows a simplified view of a UV-Vis machine

\section{A6.2 Samples}

Samples for UV-Vis are typically a liquid as solids are too dense for the ultravioletvisible radiation to pass through; thus, they absorb all of the radiation. Samples are usually placed in a glass or quartz cuvette. When analyzing a sample via UV-vis spectroscopy, glass cuvettes can be used for a wavelength above $300 \mathrm{~nm}$, but a quartz cuvette must be used for a wavelength less than $300 \mathrm{~nm}$ because glass absorbs radiation less than $300 \mathrm{~nm}$ in energy. Quartz cuvettes can be used for all samples but aren't typically used unless the desired wavelength is less than $300 \mathrm{~nm}$ due to the high price of quartz cuvettes. 


\section{A7 Fluorescence Spectroscopy}

\section{A7.1 Theory}

Fluorescence spectroscopy used in Chapter 2 works by emitting energy at a sample at a specified wavelength termed the excitation energy. A detector is positioned at a right angle to the incident beam; that way, any radiation made by the incident beam is not hitting the detector. When this energy hits the sample, the result is that it promotes an electron from a lower energy level to a higher energy level. If that promoted electron comes back to the previous level very quickly, then the energy of that electron moving to the lower level is emitted in the form of vibrational energy, and no fluorescence is observed. However, if the promoted electron loses a small amount of energy and slowly returns to the lower energy level, then the energy is emitted in the form of visible light and fluorescence is observed.

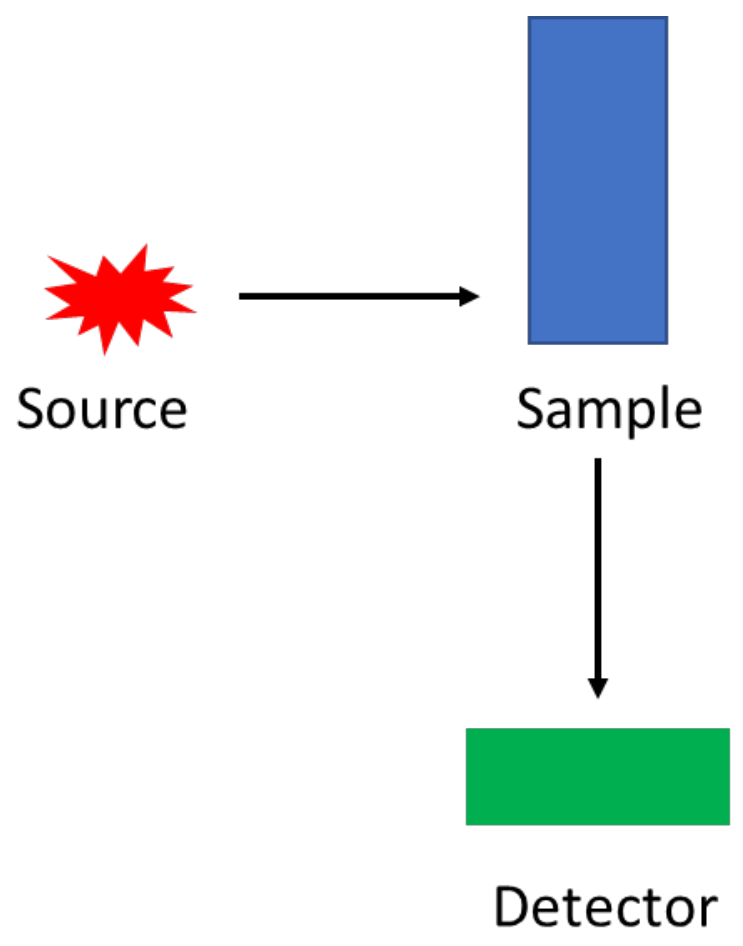

Figure A7 shows a simplified example of a fluorescence spectroscopy machine. 


\section{A8 X-Ray Diffraction (Single Crystal)}

\section{A8.1 Theory}

X-ray diffraction (Single Crystal) used in Chapters 2 and 3 works by generating an X-ray beam, and this beam is passed through a crystal. The crystal is a uniform structure that diffracts the X-ray beam, which makes it scatter at a unique angle, producing an X-ray diffraction pattern. Only X-rays that are diffracted at an angle in accordance with Bragg's law $(\mathrm{n} \lambda=2 \mathrm{~d} \sin \theta)$ will produce signals that have constructive interference meaning the signals do not cancel each other. When Bragg's law is not obeyed, a phenomenon known as destructive interference can happen, which cancels out the signal of the diffracted beam resulting in no signal at the detector, which results in no diffraction pattern. Since the crystal is uniform, the scattering of the beams by the electrons is uniform by rotating the crystal and changing the angle between the detector and the X-ray source; the collection of the diffracted beams that obey Bragg's law for different values of $\theta$ is completed. Once the diffraction patterns are collected at all of the different crystal planes or d spacings, a Fourier transform can be performed to give the coordinates of the density of electrons within the crystal. A model can be built using computer software based on the number of electrons at each location in the model. 


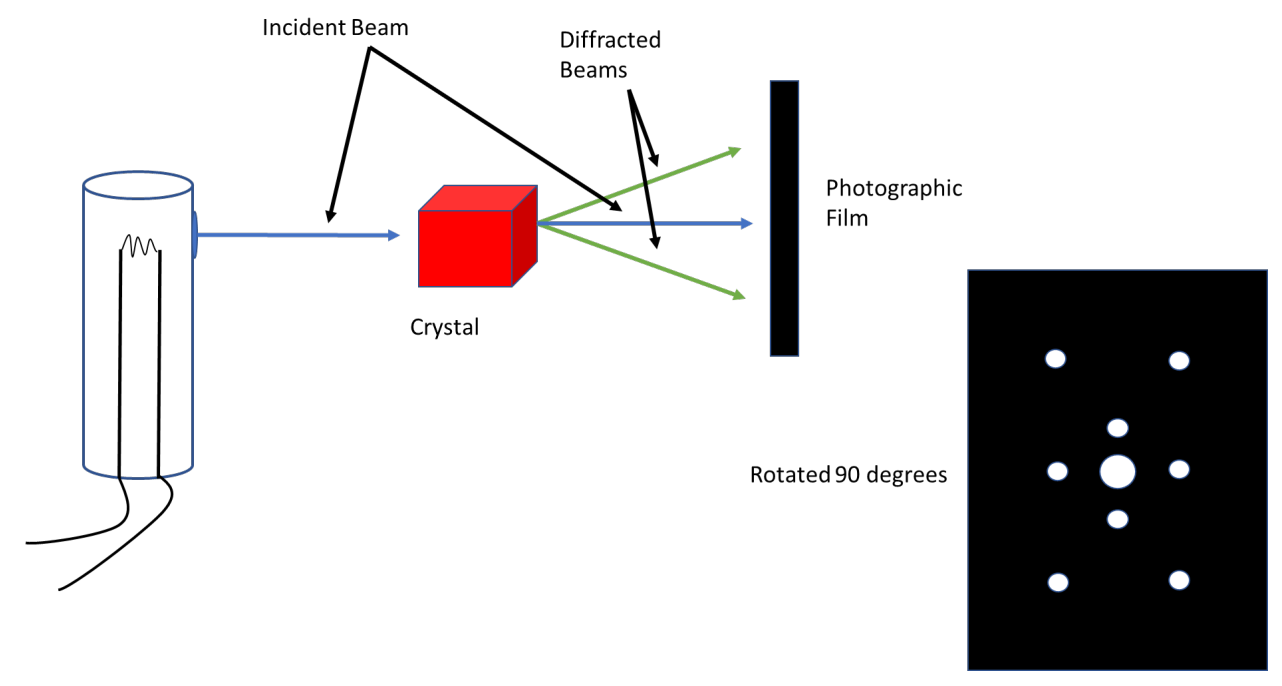

Figure A8 shows a typical example of single-crystal x-ray diffraction. The black rectangle on the right shows a typical example of a diffraction pattern that is made by the crystal diffracting the X-ray beam.

\section{A9 Cyclic Voltammetry}

\section{A9.1 Theory}

Cyclic voltammetry used in Chapter 3 works by applying a voltage or potential to a solution containing the sample along with an electrolyte. This potential causes the oxidation of the material, which is seen as a change in the potential between the reference and the working electrode. The sample can also go through a reduction which can be seen as a change in the potential between the reference and the working electrode. This technique is most commonly used to determine the oxidation/reduction potential for metal complexes to estimate their likelihood of being a good oxidation/reduction catalyst. 


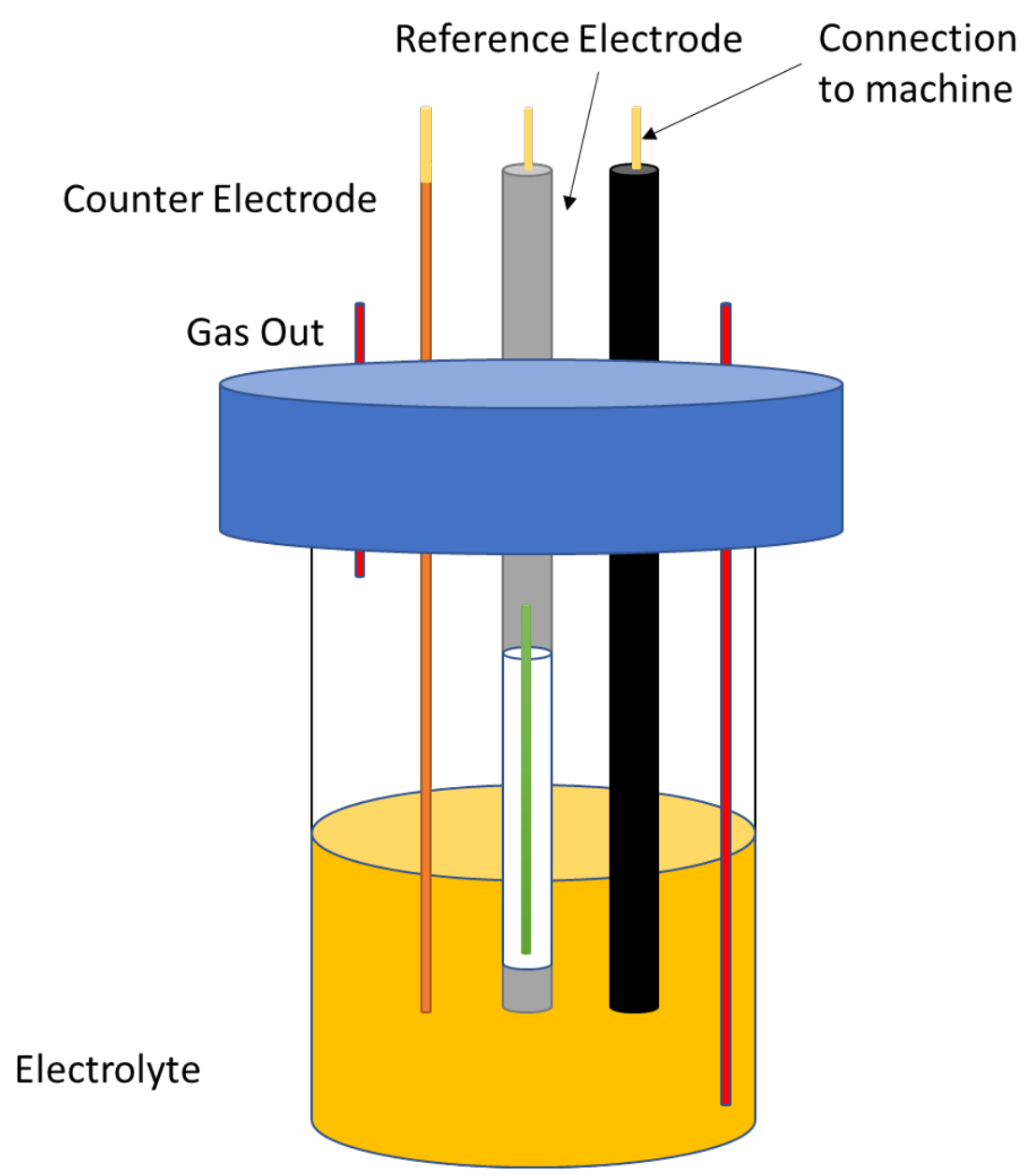

Figure A9 shows the typical setup for cyclic voltammetry.

\section{A10 Scanning Transmission Electron Microscope (STEM)}

\section{A10.1 Theory}

Scanning Transmission Electron Microscopy used in Chapter 4 works by shooting a beam of electrons at a sample, and an image is made by collecting the electrons that pass through the sample. It is typically known as Transmission Electron Microscopy (TEM), and Scanning just means that it collects an average picture of the area by moving the beam to different areas of the material. 


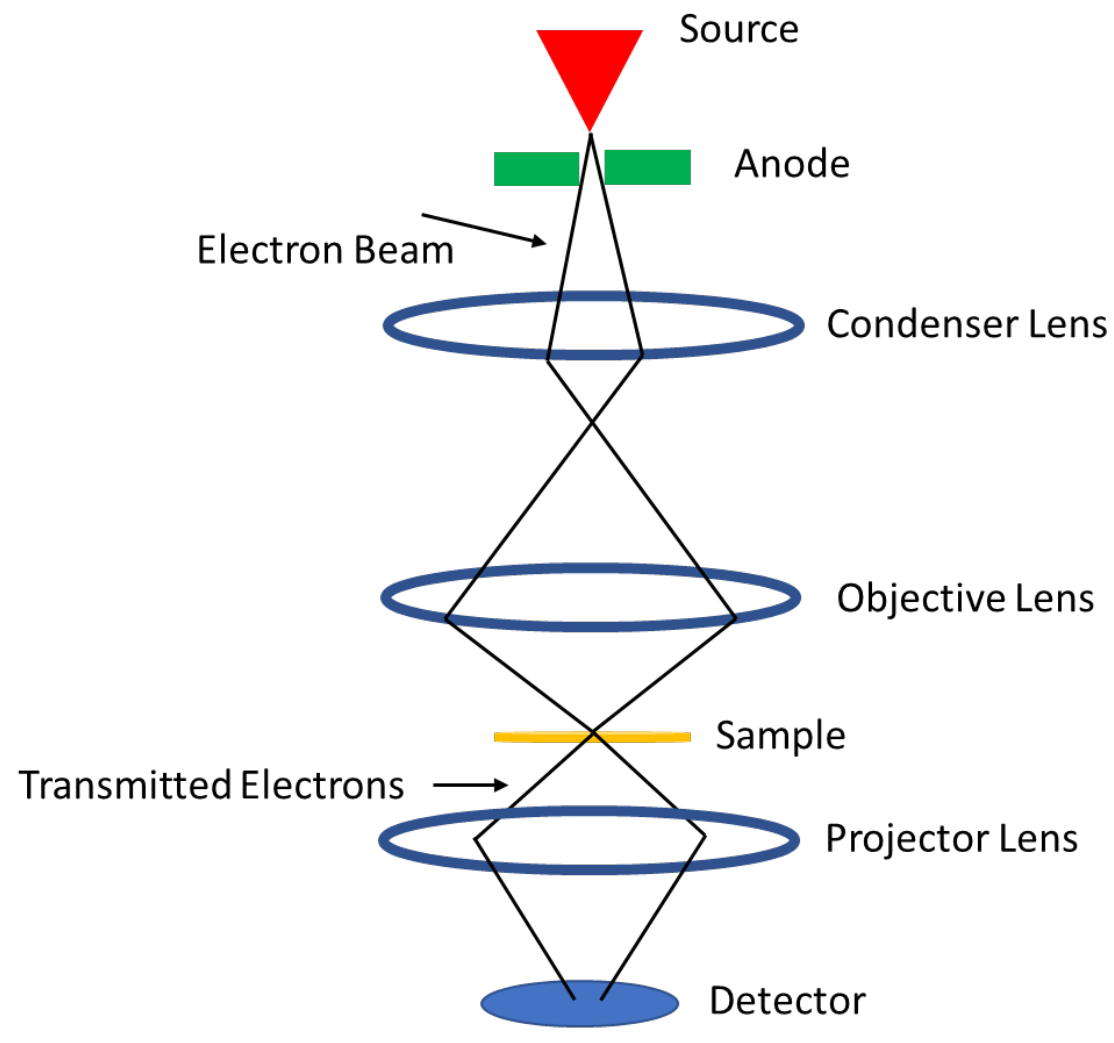

Figure A101 Shows an example of how a TEM machine works. To make a STEM image, the beam is scanned over an area of the sample, and the images are compiled together.

\section{A11 Brunauer-Emmett-Teller Surface Area (BET)}

\section{A11.1 Theory}

BET used in Chapters 4 and 6 is used to measure the surface area of very small materials. BET works by dosing a chamber with a certain volume of nitrogen gas. This chamber is dipped into liquid nitrogen, which then causes the nitrogen gas to condense in a single layer onto the surface of the material. This change in pressure due to the nitrogen condensing can then be calculated as how many molecules of $\mathrm{N}_{2}$ condensed on the surface, and this can be calculated as the surface area. The volume of the pores can also be measured by increasing the pressure in the sample chamber which will force the nitrogen into the pores when it condenses on the surface of the material. The difference in amount of 
nitrogen absorbed/adsorbed vs how much was simply adsorbed is the volume of the pores.
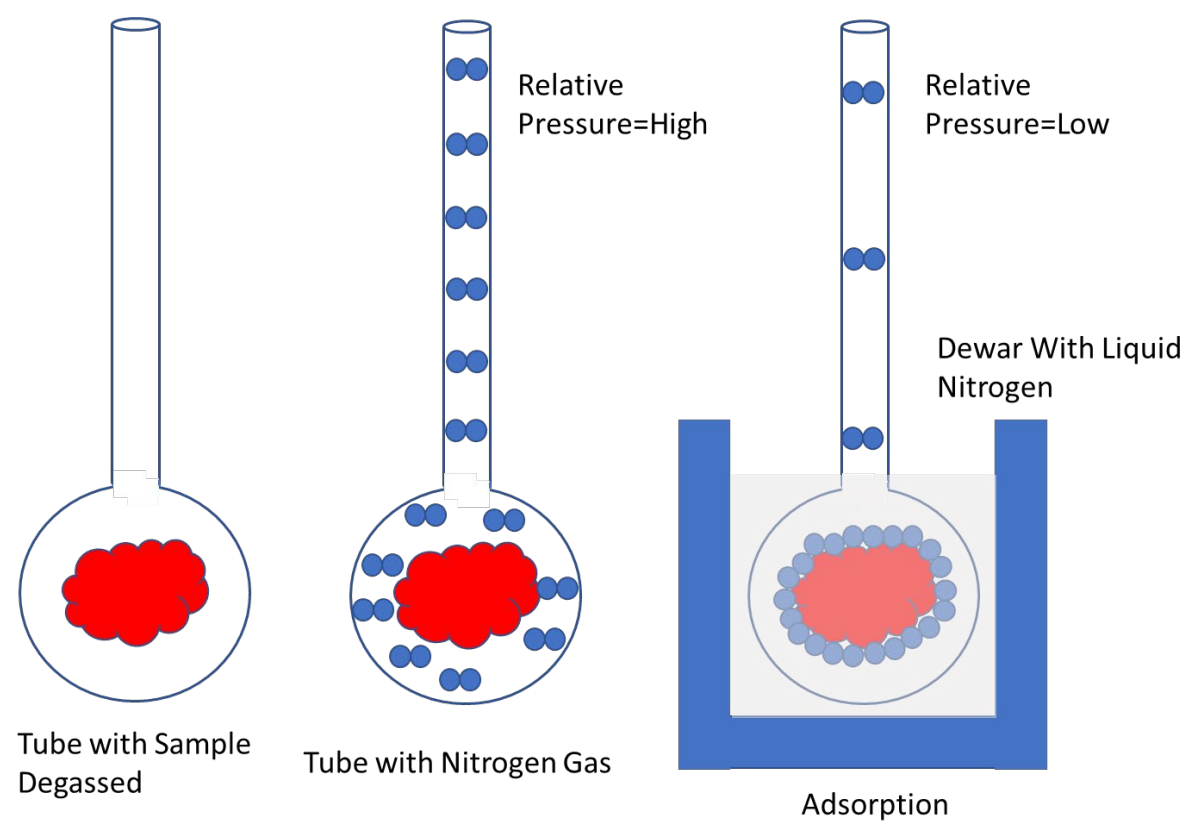

Figure A11 shows a simplified diagram to explain how BET surface area is measured.

\section{A12 Confocal Fluorescence Microscopy}

\section{A12.1 Theory}

Confocal Microscopy used in Chapter 4 is a technique that uses the combination of fluorescence and microscopy. It works by shining a laser at the sample to supply the energy needed to make the sample fluoresce. Then it uses a camera under high magnification to take a picture of the sample. This is commonly used for the imaging of cells and other biological structures. 


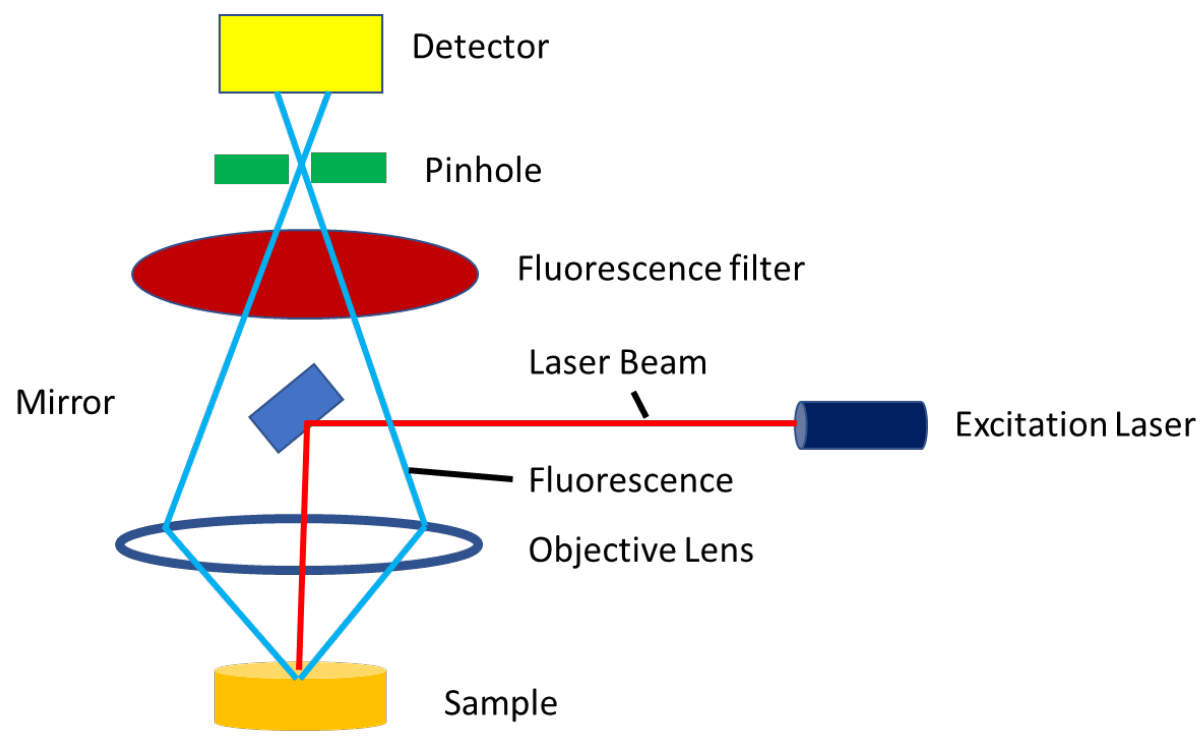

Figure A12 shows a diagram of a confocal fluorescence microscope.

\section{A13 X-Ray Diffraction (Powder)}

\section{A13.1 Theory}

$\mathrm{X}$-ray diffraction (powder) used in Chapter 6 is the same technique as X-Ray

Diffraction (Crystal), but the difference is the sample that is being X-rayed.

When using a crystal, the crystal is oriented in the beam to collect the desired data. In the case of a powder, the sample is still crystalline, but each crystal is not ordered in the same direction. Instead, the crystals are ordered in random directions, but naturally, a portion of the crystals are ordered in the proper orientation to be analyzed with the X-ray beam. Crystals that are oriented properly will diffract the X-ray beam at a specific angle that can be detected. All other X-rays that are diffracted by crystals that are not in the correct orientation miss the detector. Only X-rays that are diffracted at an angle in accordance with Bragg's law $(\mathrm{n} \lambda=2 \mathrm{~d} \sin \theta)$ will produce signals that have constructive interference meaning the signals do not cancel each other. When Bragg's law is not obeyed, a phenomenon known as destructive interference can happen, which cancels out the signal of the diffracted beam resulting in no signal at the detector. When using XRD (powder), the angle between the 
incident beam and the detector is changed, and the data is collected as a graph of intensity vs. angle. The position of the signal based on $\theta$ can then be used to calculate the $d$ spacing for the crystal planes. These spacings are very specific in minerals and can be compared to databases to determine the phases present in the sample and possibly the identity of the sample. The determination of unknown crystal structures is not typically done using XRD (powder) Due to the difficulty involved with structure determination.

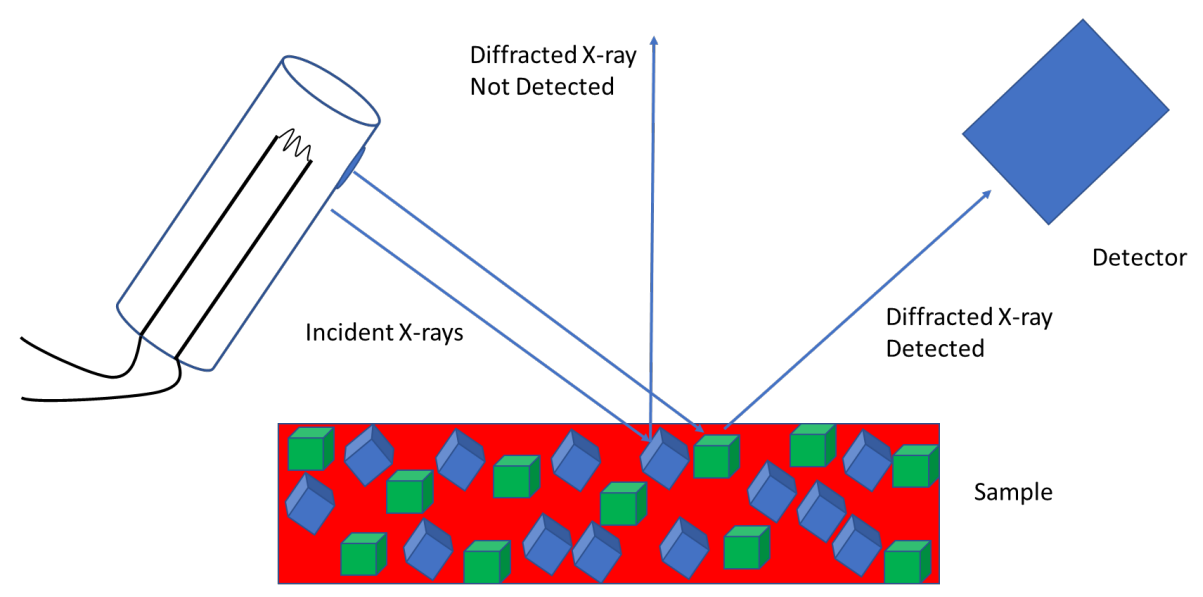

Figure A13 shows a typical setup for X-ray diffraction when using a powder sample. Only the crystals that are oriented in the proper orientation are responsible for producing the signal for the diffracted X-ray beam. The green cubes represent the crystals in the sample that are in the correct orientation for diffraction, and the blue cubes represent crystals that are not oriented correctly for diffraction.

\section{A14 Energy Dispersive Spectroscopy/ X-Ray Fluorescence (EDS/ERF)}

\section{A14.1 Theory}

EDS/XRF used in Chapter 6 works by bombarding the sample with an X-ray.

This causes an electron from an inner shell to be ejected. Once this electron is ejected, then an electron from an outer shell moves to fill the space of the electron that was ejected. This process of the electron moving from the outer shell to the inner shell emits energy in the form of an X-ray. The energy associated with this X-ray is specific to the element from which it comes from, 
thus when the energy is measured, the value can be compared with standard values to determine the elemental composition of the sample.

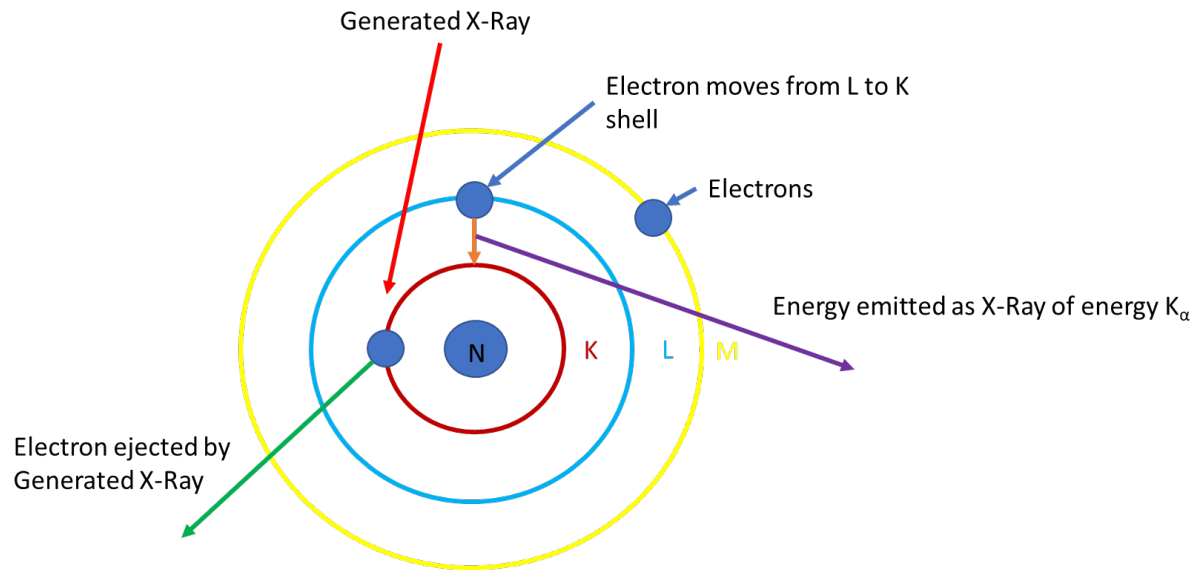

Figure A14 shows a diagram of how an X-ray can be generated by bombarding a sample with higher-energy X-rays.

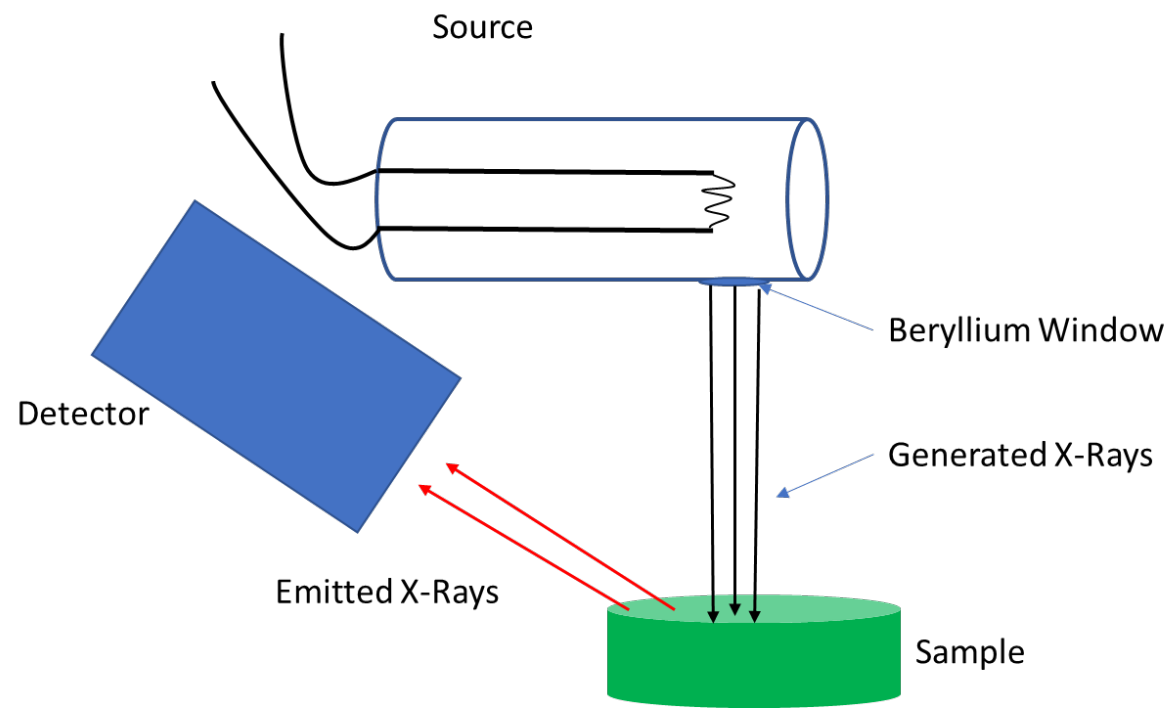

Figure A15 shows a diagram of the typical configuration of an EDS/XRF machine.

\section{A15 Atomic Absorption (AA)}

\section{A15.1 Theory}

Atomic absorption used in Chapter 6 works by using a source bulb that has a filament made from the element of interest, which is aimed at a detector that collects only a specific selected wavelength. Between the source and the 
detector is a flame that uses an aspirator to distribute the sample into the flame, where it is energized. When the sample is excited, it causes the absorption of some of the incident light coming from the source bulb, which is read by the detector as an absorption of the incident light. Using this value for absorption, the quantification is possible if a quantification graph made from standards of known concentration is made.

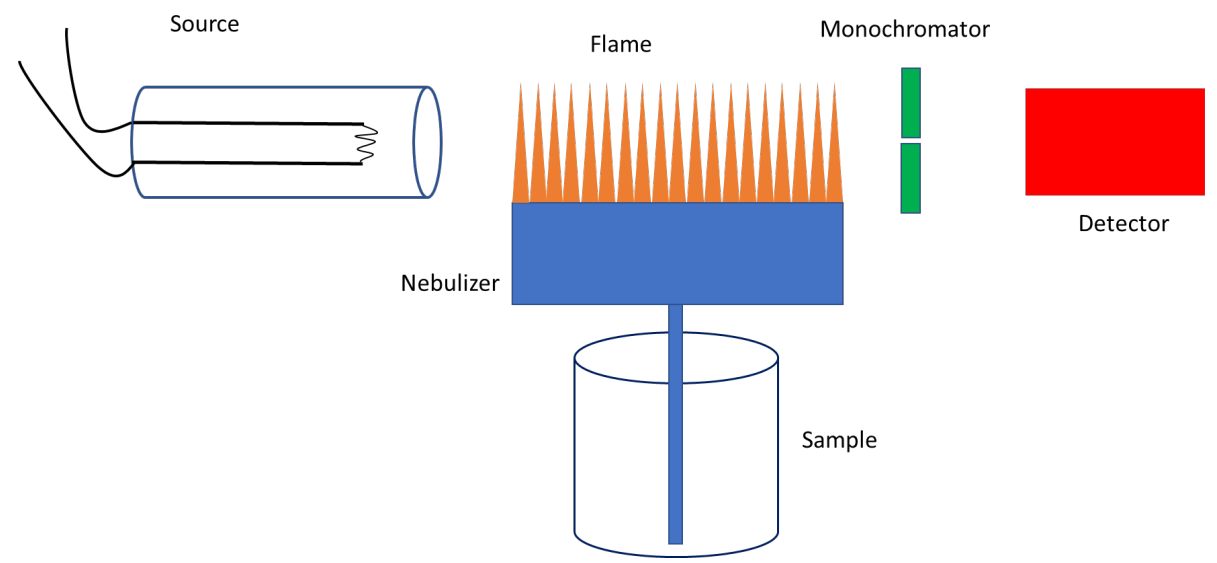

Figure A16 shows a diagram of an Atomic Absorption Spectrometer.

\section{A16 Scanning Electron Microscopy (SEM)}

\section{A16.1 Theory}

SEM used in Chapter 6 works by shooting a beam of electrons at a sample.

When this beam hits the sample, some of the electrons are absorbed, and others bounce off the sample. The ones that bounce off the sample are collected by a detector that is positioned on the peripheral of the machine. The machine collects a number of electrons over a certain area of the material by scanning across the material, which results in an image of the surface. 


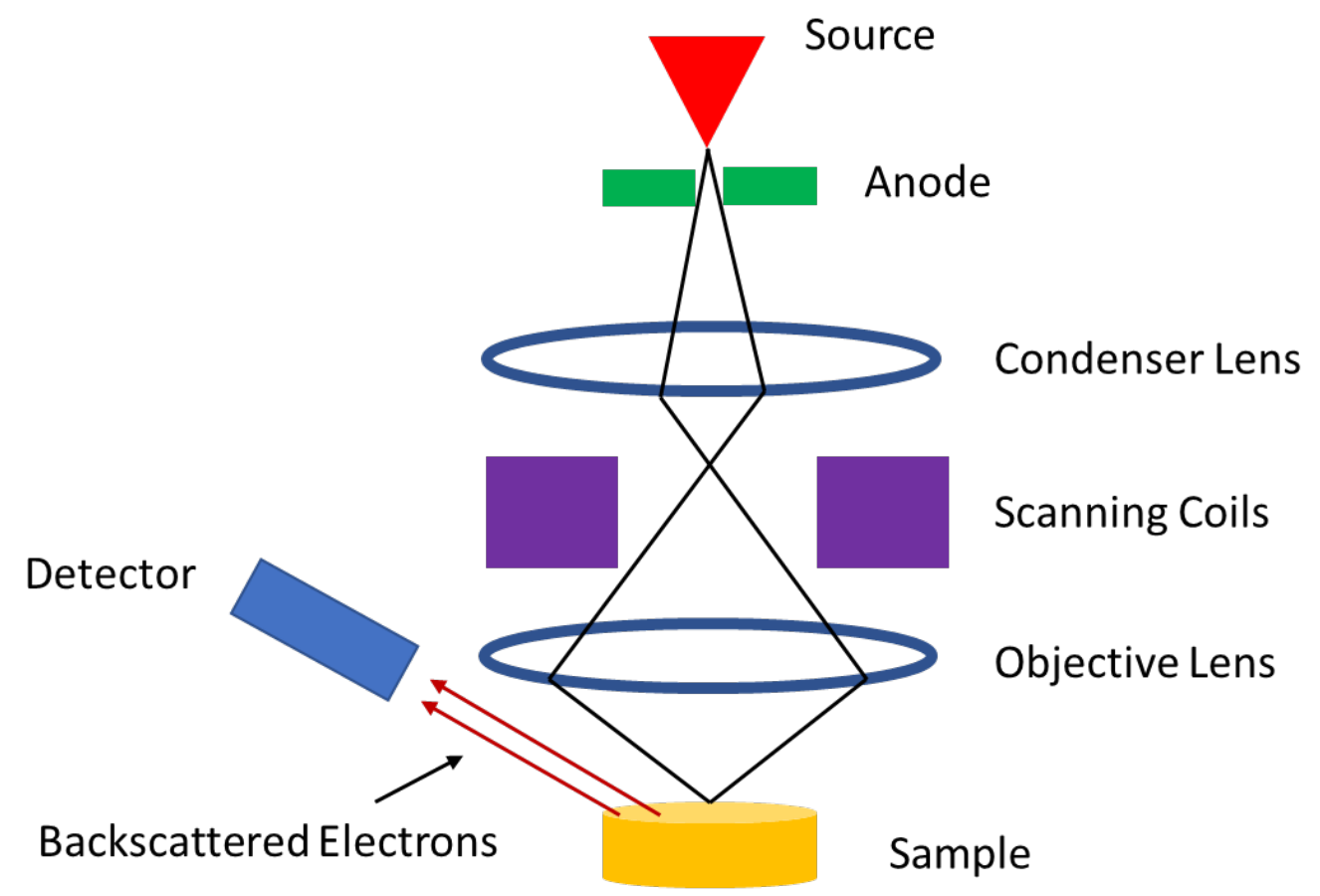

Figure A17 is a diagram of a SEM machine.

\section{A17 Theory of gas chromatography}

Gas chromatography used in Chapter 7 works by converting a sample into gas using high temperature inside the injection chamber and forcing it onto the column using helium. Once the sample is on the column, a combination of heating and helium carrier gas pushes it through the column. The coating on the inside of the column causes different substituents to interact with the coating, which causes them to move through the column at different rates. This causes the separation of the components of the mixture, which are then detected individually as they leave the column. 


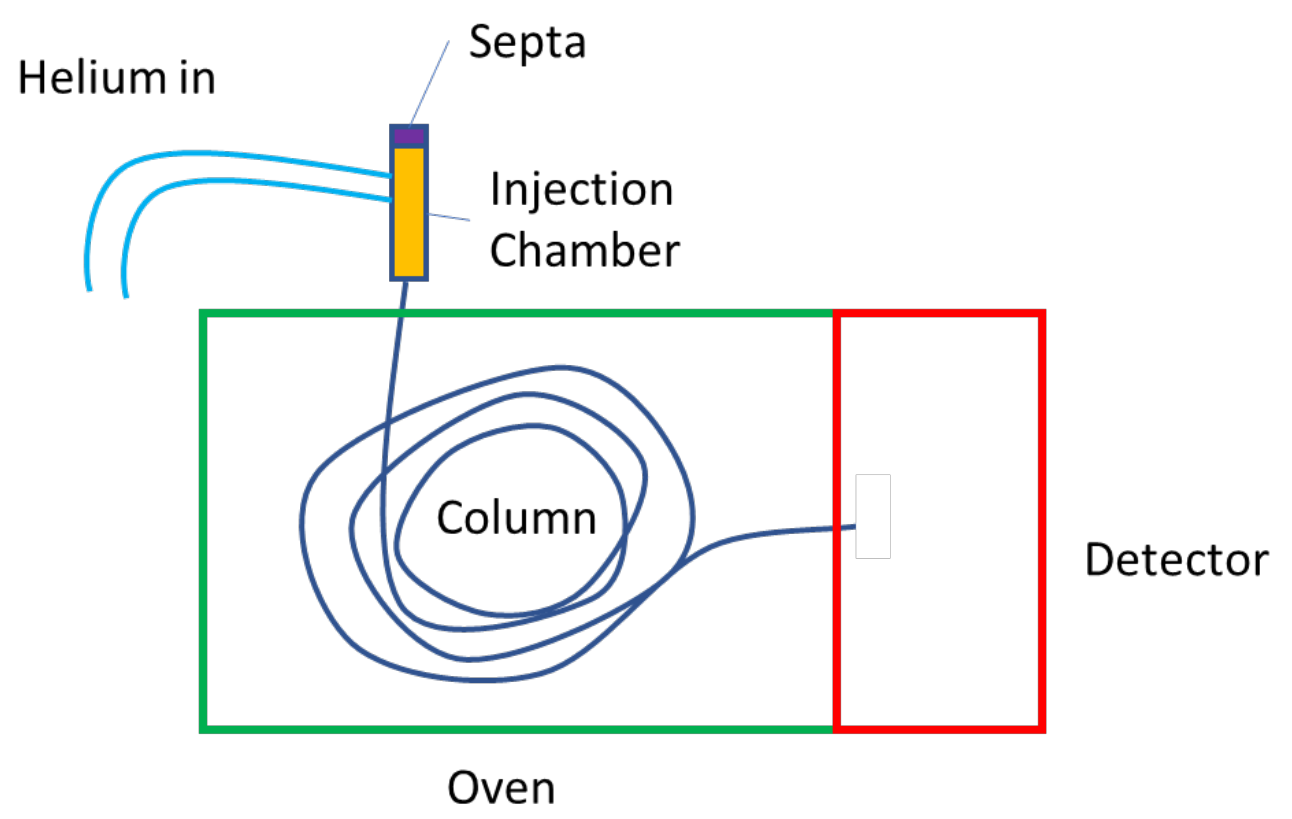

Figure A18 shows a representative setup of a gas chromatography machine.

\section{A17.1 Flame ionization Detector}

A flame ionization detector works by passing the substances that come out of the column into a flame. This causes ionization, and this is detected as a voltage from the detector. This detected signal forms a peak. The area of this peak can be used to determine how much of the substance was detected, but the amount is relative and needs to be used in conjunction with a quantification graph made using the same parameters and machine.

\section{A17.2 Mass Spectrometry Detector}

A mass spectrometry detector works by ionizing the materials that come out of the column. This causes the material to become charged. This can then be measured using a potential applied inside the machine based on the mass to charge ratio. 